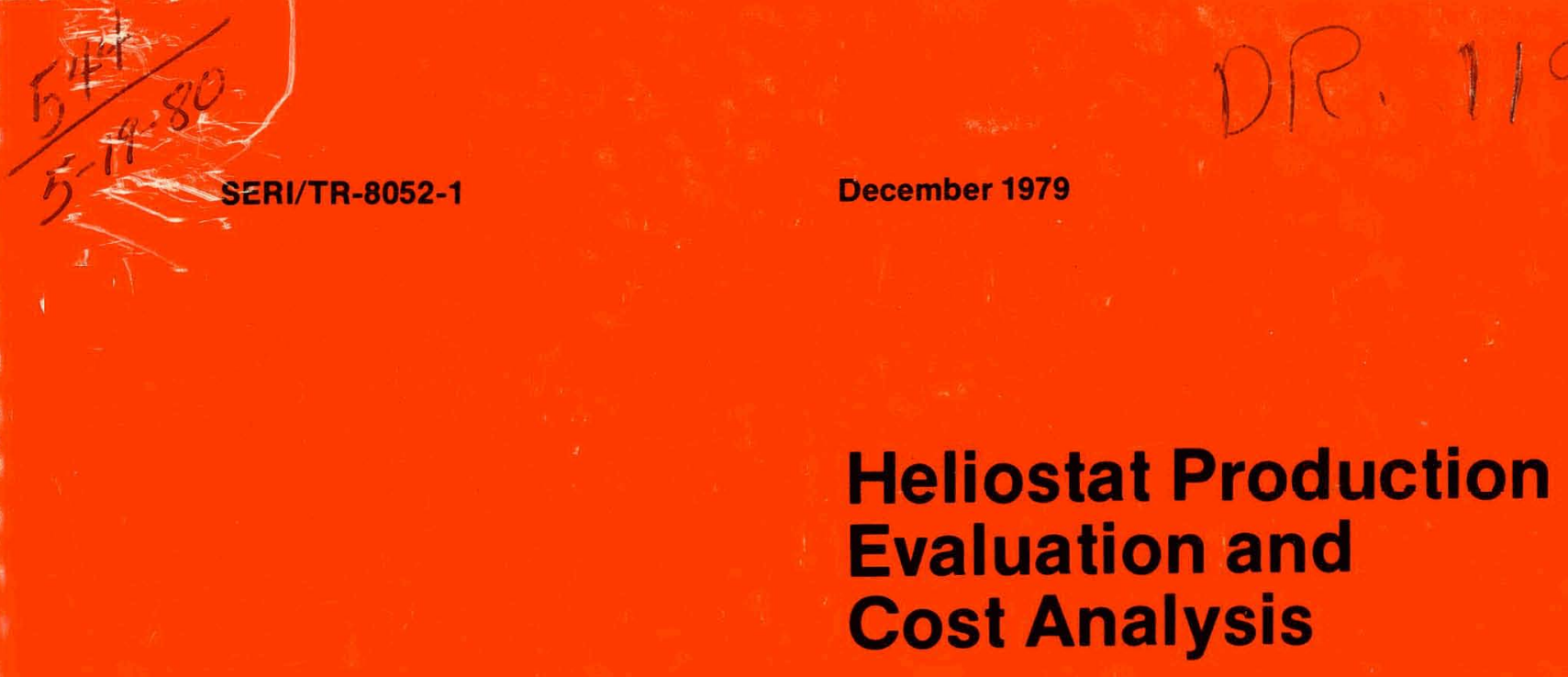

\title{
Heliostat Production Evaluation and Cost Analysis
}

\section{Prepared by}

General Motors Corporation

Warren, Michigan
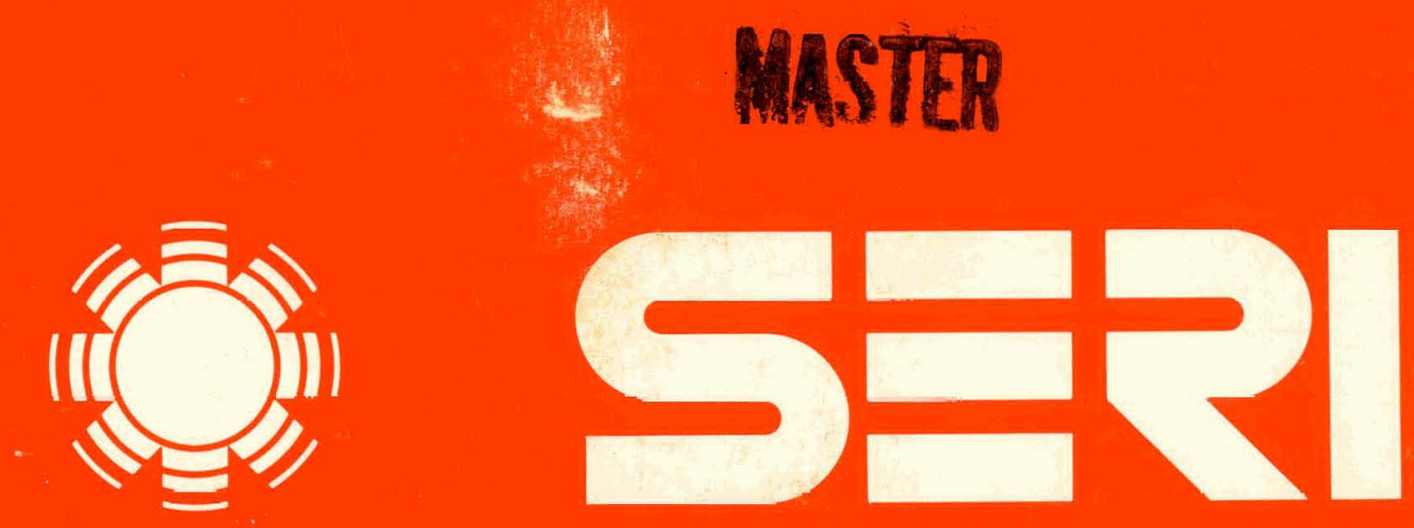

Solar Energy Research Institute

A Division of Midwest Research Institute

1617 Cole Boulevard

Golden, Colorado 80401

Operated for the

U.S. Department of Energy

under Contract No. EG-77-C-01-4042 


\section{DISCLAIMER}

This report was prepared as an account of work sponsored by an agency of the United States Government. Neither the United States Government nor any agency Thereof, nor any of their employees, makes any warranty, express or implied, or assumes any legal liability or responsibility for the accuracy, completeness, or usefulness of any information, apparatus, product, or process disclosed, or represents that its use would not infringe privately owned rights. Reference herein to any specific commercial product, process, or service by trade name, trademark, manufacturer, or otherwise does not necessarily constitute or imply its endorsement, recommendation, or favoring by the United States Government or any agency thereof. The views and opinions of authors expressed herein do not necessarily state or reflect those of the United States Government or any agency thereof. 


\section{DISCLAIMER}

Portions of this document may be illegible in electronic image products. Images are produced from the best available original document. 


\author{
Printed in the United States of America \\ Available from: \\ National Technical Information Service \\ U.S. Department of Commerce \\ 5285 Port Royal Road \\ Suringfield, VA 22161 \\ Price: \\ Microfiche $\$ 3.0^{\circ}$ \\ Printed Copy $\$ 12.50$ \\ 18,4
}

\begin{abstract}
NOTICE
This report was prepared as an account of work sponsored by the United States Government. Neither the United States nor the United States Department of Energy, nor any of their employees, nor any of their contractors, subcontractors, or their employees, makes any warranty, express or implied, or assumes any legal liability or responsibility for the accuracy, completeness or usefulness of any information, apparatus, product or process disclosed, or represents that its use would not infringe privately owned rights.
\end{abstract}


SERI/TR-8052-1

UC CATEGORY: UC-62C, 64C

HELIOSTAT PRODUCTION

EVALUATION AND

COST ANALYSIS

DECEMBER 1979
J. F. BRITT
C. W. SHULTE
H. L. DAVEY

27

GM TRANSPORTATION SYSTEMS CENTER

GENERAL MOTORS CORPJORATION

GENERAL MOTORS TECHNICAL CENTER

WARREN, MICHIGAN

PREPARED UNDER SUBCONTRACT

NO. $X L-9-8052-1$

FOR THE

SOLAR ENERGY RESEARCH INSTITUTE

A DIVISION OF MIDWEST RESEARCH INSTITUTE

OPERATED FOR THE

U.S. DFPARTMENT OF ENERGY

CONTRACT NO. EG-77-C-01-4042

PROJECT MANAGER

DENNIS HORGAN

Thit boot. wan nrenared as an account of work sponsores by an agency of the United States Government, Neither the United States Government nor any ogency thereot, nor any of dieii tmployces. makas any

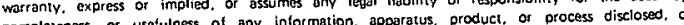

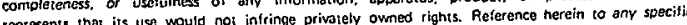

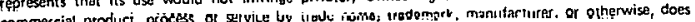




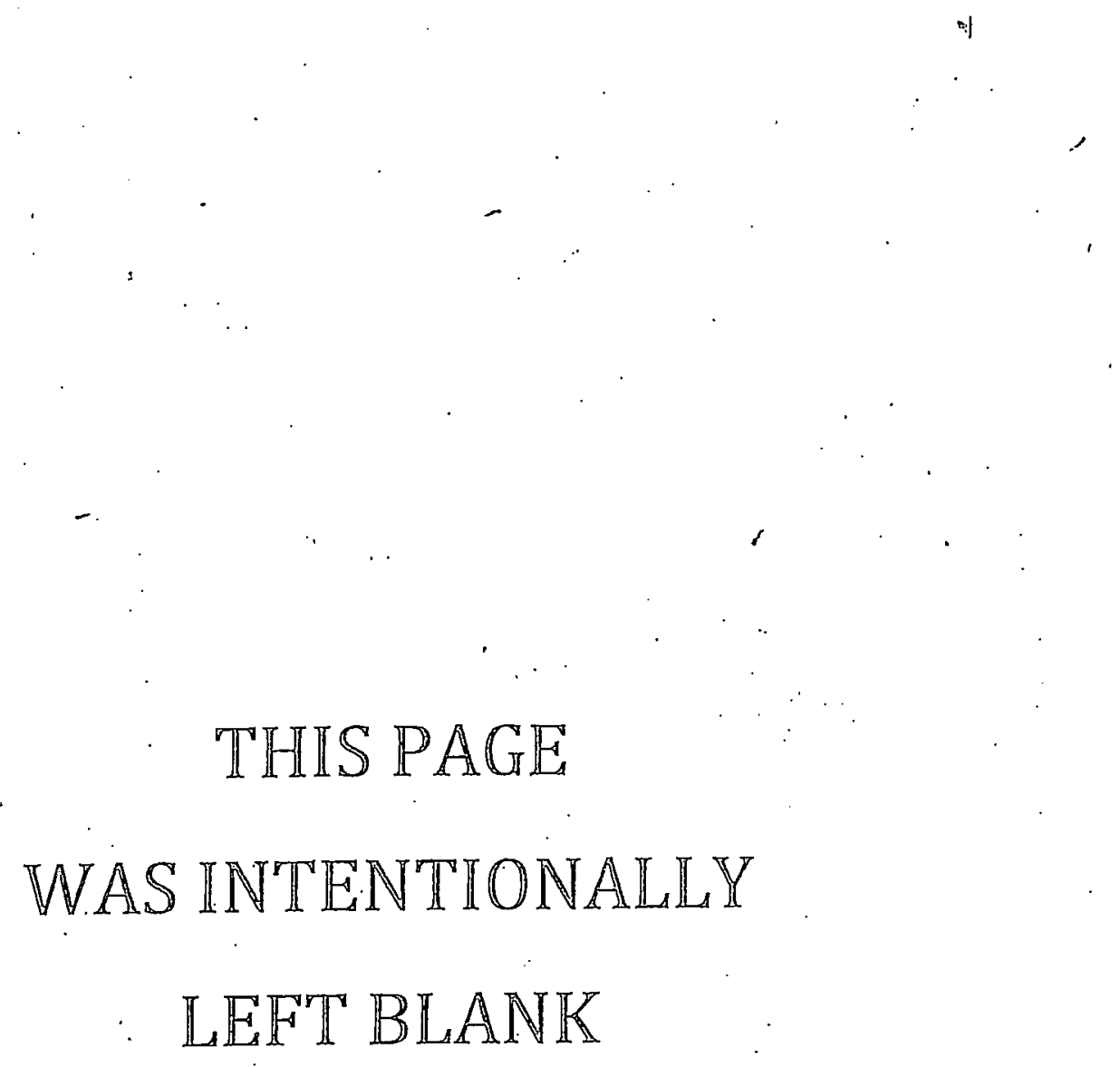


The retrofit of solar central receiver heat supply systems to existing steam-generating stations, an application known as "repowering," is being considered as a major programmatic effort by the Department of Energy's Large Solar Central Power Systems Program. Several promising features of repowering lead to this interest :

- Technical: Repowering offers a relatively low-risk technical path to large-scale test and demonstration of central receiver technology. Partial reliance on existing hardware places both cost and technical emphasis on the heat supply system, where the major uncertainties lie. However, the hybrid nature of repowered plants permits them to operate even when the solar heat supply system is not providing heat.

- Demand: The confinement of risk to the solar portion of the plant makes utility involvement more attractive and facilitates cost-sharing arrangements between the public and private sectors. Early involvement of the eventual user group promises to increase the market development value of the test and demonstration program in several important areas, including relevance, credibility, information dissemination, and response.

- Supply: The requirements for cost effectiveness of the solar heat supply system are possibly less stringent in repowering than in new capacity applications. If this is so, then the opportunity for early hardware sales for repowering may be an important advantage for the development of the supply industry.

- Energy Displacement: While the likely population of repowerable plants in the southwest is not large (roughly 4-6 GWe), it is heavily reliant on oil and gas. Thus the direct effects of repowering on energy displacement are in, the desired categories.

The determination of an appropriate government response to the opportunities of repowering is an important policy question and is the major reason the Department of Energy (DOE) has requested SERI to perform the Repowering strategy Analysis. The repowering study objective is to define a government role in repowering that constitutes an efficient program investment in pursuit of viable private markets for heliostat-based energy systems. In support of that objective, this study is designed to identify the scope and nature of the repowering opportunity within the larger context of its contributions to central receiver technology development and commercialization. 
FOREWORD

This final report was prepared under subcontract AH-9-8052-1 as a part of SERI Task 5121.11, the Supply Task of the Repowering strategy Analysis. The purpose of the supply Task is to determine the installed cost of solar systems and components in a repowering program and outline the manufacturing investment required to achieve those costs.

The objective of this production evaluation and cost analysis stuady is to estimate the factory cost of the current generation of helinstat iesigns at variouo production volumes. The methudulogy used to determine the factory cost was that of detailed production cost analysis. Processes were developed for the manufacture of each component of the heliostat down to the lowest level of purchased material. The tooling, labor, and facilities requirements were defined and costed for each of the processes, and vendor quotations were obtained to determine the cost of purchased material. Finally, indirect factory expenses were added to the direct costs to produce the factory cost.

The focus of this study was limited to factory cost and does not include the cost of installation nor does the study provide for a return on capital. However, several interesting results do emerge from this study. The first result is that the factory cost of the McDonnell-Douglas Prototype Heliostat is estimated to be less than $\$ 96 /$ meter $^{2}$ at a production rate of 25,000 units per year. This sost is between one-half and one-third of the cost estimates for the same product in custom production and clearly shows the benefits of mass production. However, the favorable factory cost estimate is dependent on a projected $\$ 89$ million investment in facilities and tooling. A second result of the study is that 81 percent of the factory cost is purchased material. This result implies that heliostat manufacture can be a relatively low value added industry, which is a necessary condition for meeting the program cost goals. The high materials fraction also implies that the estimated cost is relatively insensitive to the cost of processing and that the most important area of heliostat development will be the reduction of materials cost.

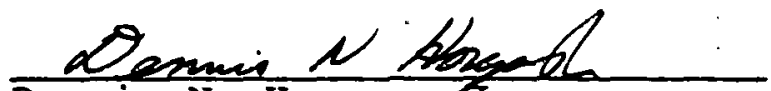

Dennis N. Horgan, Jr. Project Manager 
The U.S. Department of Energy has asked the Solar Energy Research Institute (SERI) to perform a Repowering strategy Analysis. The supply task of that analysis requires the definition of price-quantity relationships for heliostats in order that existing heliostat designs may be assessed for their suitability for mass production and to determine at what level of production unit costs will reach an acceptable level. In addition, the technical obstacles that present heliostat designs offer to mass production, and the capital investment required for mass production to be initiated, are of considerable importance.

The GM Transportation systems Center has conducted a production evaluation and manufacturing cost analysis of the McDonnell Douglas Astronautics Company (MDAC) Solar Central Receiver Prototype Heliostat design for SERI and the results of that study are contained in the report of which this summary is a part.

In the study, design and engineering data were collected on the MDAC heliostat design, manufacturing processes defined, a manufacturing plant configured, manufacturing labor developed and finally, a factory cost established for two different production volumes. The production volumes considered were chosen by SERI as 25,000 heliostats per year and 250,000 heliostats per year. To provide some insight to the variability of manufacturing costs as a function of percent changes in production level, heliostat costs were also developed at 75 percent and 125 percent of plant capacity for both the 25,000 and the 250,000, volumes. These percent changes were accomplished by adjusting labor levels and material flow rates for the two plants configured.

Consideration was given to the location for the heliostat plant and Tucson, Arizona was the selected site. Availability of local labor, land, associated supply industry, taxes and transportation to possible central receiver system sites were factors in this selection.

This study developed a "factory cost" for the manufacture of heliostats and it is very important that the definition of this term is clear and explicit. Factory cost is the sum of all costs necessary to place a finished product on the factory dock ready to ship. Factory cost does not include shipping, field installation, profit, return on investment, distributed general and administrative expenses, state or local product or inventory taxes, general commercial expense, sales and advertising costs, public relations costs, or any other profit and loss items. A summary of the cost analysis is given on the next page. 
Annual heliostat production rate Plant size in square feet

Investment required

Factory cost per heliostat

Factory cost per square meter

$$
25,000
$$$$
304,384
$$$$
\$ 87,330,250
$$$$
250,000
$$$$
682,240
$$

$\$ 392,805,000$

$$
\begin{array}{lrrr}
\$ & 4,699.07 & \$ & 3,301.87 \\
\$ & 95.80 & \$ & 67.31
\end{array}
$$

Due to the speculative nature of the heliostat production scenario, certain suppliers were reluctant to include their investment and/or tooling costs in their material and part quotations. These are real costs that must be considered if heliostat production is begun at mass production levels. The investments required are given below.

Annual heliostat production rate Investment required

The Policy Analysis Branch of the Solar Energy Research Institute has developed a profit figure and used an installation cost from a study done for SERI by Battelle Northwest Laboratory to allow a comparison to be made of heliostat installed costs. The results are given below.

Annual heliostat production rate Factory cost

Profit

Factory price F.O.B.

Instaliation cost per unit

Installed cost per unit

Installed cost per square meter

$\begin{array}{crrr} & 25,000 & & 250,000 \\ \$ & 4,699.07 & \$ & 3,301.87 \\ \$ & 350.86 & \$ & 207.96 \\ \$ & 5,049.31 & \$ & 3,509.83 \\ \$ & 940.38 & \$ & 879.52 \\ \$ & 5,990.31 & \$ & 4,389.35 \\ \$ & 122.12 & \$ & 89.48\end{array}$

The Battelle installed costs are:

Installed cost per unit Installed cost per square meter

$\begin{array}{rrrr}\$ & 4,507.01 & \$ & 3,948.35 \\ \$ & 91.88 & \$ & 80.49\end{array}$


1.0 Introduction $\ldots \ldots \ldots \ldots \ldots \ldots \ldots \ldots \ldots \ldots \ldots \ldots \ldots \ldots \ldots \ldots$

1.1 Scope of work ........................ 1

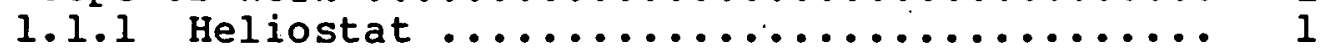

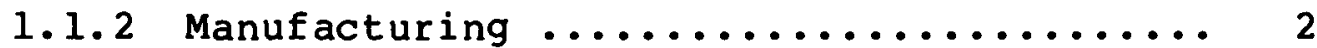

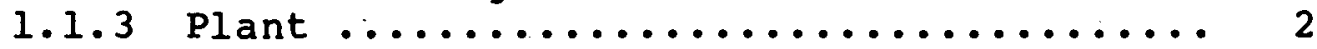

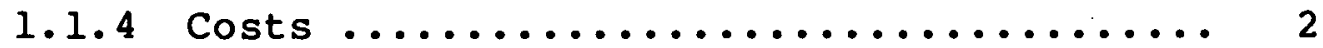

1.2 Study Approach ........................ 3

1.2 .1 Cost Breakdown Structure .............. 3

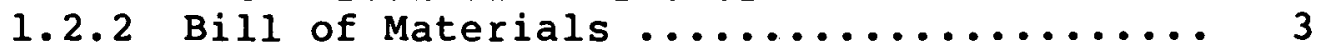

1.2.3 Manufacturing Analysis ............... 3

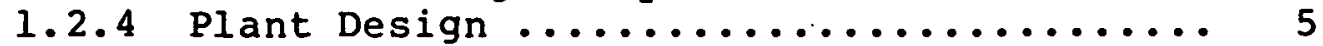

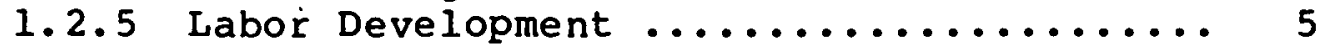

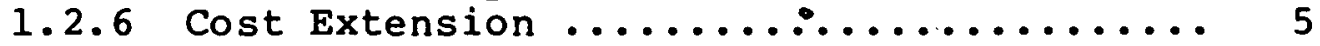

1.2 .7 Factory Cost ....................... 5

2.0 Costing Ground Rules ..................... 7

2.1 Production Volumes ..................... 7

2.2 Design Data Sources ................... 8

2.3 site selection ....................... 9

2.4 Costing Procedures ...................... 13

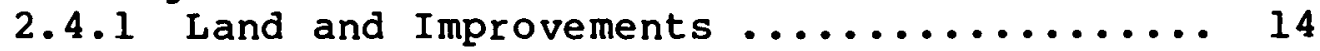

2.4.2 Plant Structure and Equipment .......... 14

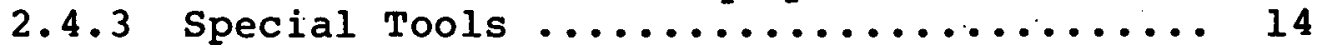

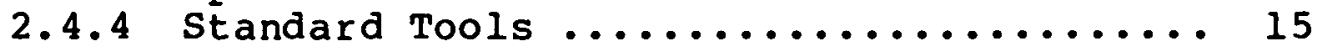

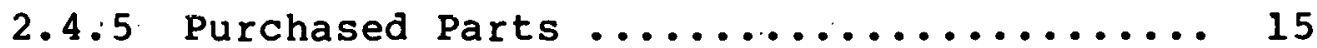

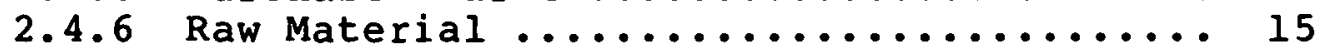

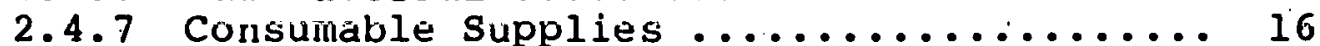

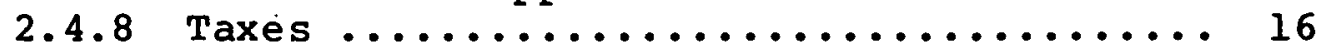

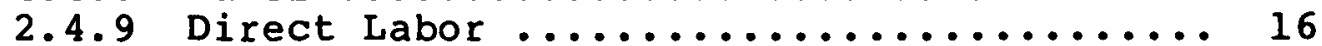

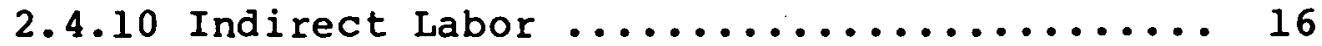

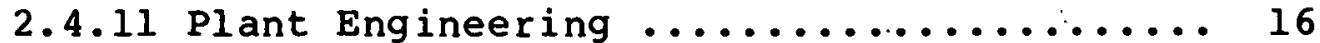

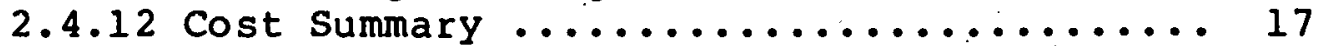

3.0 Heliostat Design .............................. 19

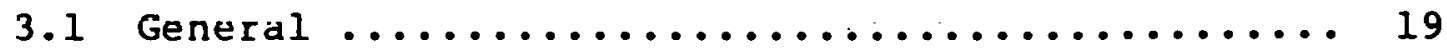

3.2 Design Description .................... 19 


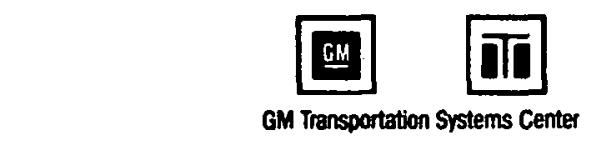

TABLE OF CONTENTS (continued)

3.3 Heliostat Specifications ................. $\frac{\text { Page }}{19}$

3.3.1 Reflective Surface .................. 22

3.3.2 Support structure .................. 22

3.3 .3 Reflective Unit .................... 22

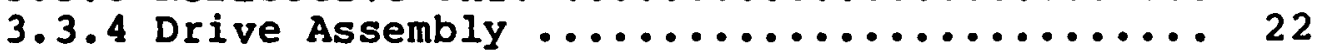

3.3.5 Azimuth Drive Housing - Welded ......... 27

3.3.6 Azimuth Drive ..................... 27

3.3.7 Drag Link Assembly ................ 30

3.3 .8 Torque Tube Assembly ................ 30

3.3 .9 Pedestal Assembly ................. 30

4.0 Processing Description ..................... 35

4.1 Production Flow ........................ 35

4.2 Make/Buy Decisions ..................... 38

4.2.1 Reflective Surface ................. 38

4.2 .2 Support structure ................. 38

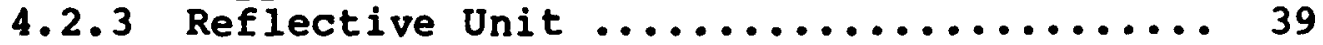

4.2 .4 Drive Assembly .................... 39

4.2.5 Electrical/Electronic Equipment ........ 41

4.3 Plant Processing and Equipment............. 43

4.3.1 Reflector Assembly ................ 43

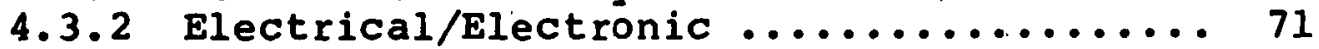

4.3.3 Drive Assembly .................... 83

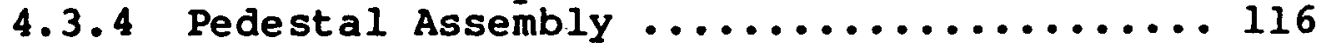

4.3 .5 Final Assembly ................... 121

4.4 Plant Layout ........................ 123

5. 0. Heliostat Production Costs .................. 131

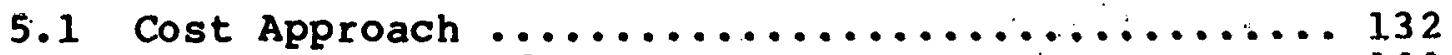

5.1 .1 Purchased Parts ................... 132

5.1 .2 Labor (direct $/$ indirect) .............. 133

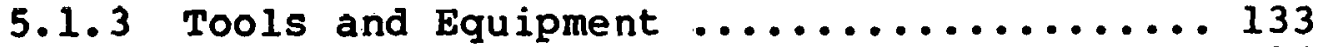

5.1.4 Production Plant Costs .............. 134

5.1 .5 Spare Parts ....................... 134

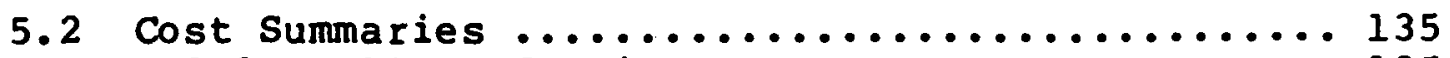

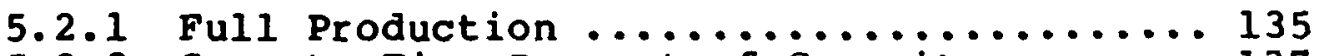

5.2 .2 Seventy-Five Percent of Capacity ....... 137

52.3 One Hundred Twenty-Five Percent of

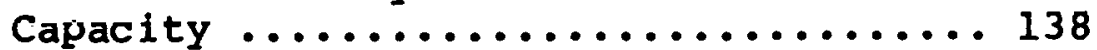

5.2.4 Material, Labor, and Burden Summaries ... 139

5.2.5 Burden Per Heliostat Unit ............. I4I

5.2.6 Non-Allied Tooling and Plant Costs ..... 141

5.2.7 Investment Per Heliostat Unit ......... 142

5.2.8 Installed Price (a SERI Mongraph) ...... 142 


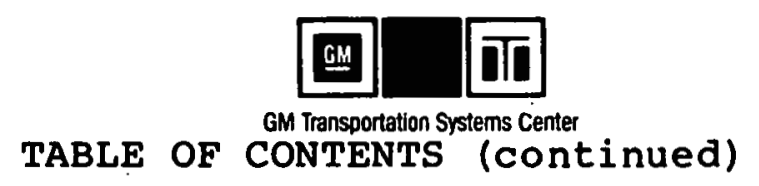

6.0 Technical Obstacles to Production $\ldots \ldots \ldots \ldots \ldots \ldots \ldots$ Page

6.1 Fusion Glass Plant Capacity .............. 145

6.2 Mirror Surface Protection ............... 146

6.3 Adhesive Cure Time $\ldots \ldots \ldots \ldots \ldots \ldots \ldots \ldots \ldots 146$

6.4 Mirror Line Capacity ................ 147

7.0 Design/Production Opportunities .............. 149

7.1 Support Structure Weldment ............. 149

7.2 Harmonic Drive $\ldots \ldots \ldots \ldots \ldots \ldots \ldots \ldots \ldots \ldots$

7.3 Fusion Glass Front Lite Size ................. 150

7.4 Flex Spline Shear Bolts ................ 150

7.5 Wire-Race Bearing $\ldots \ldots \ldots \ldots \ldots \ldots \ldots \ldots \ldots \ldots 151$

7.6 Fusion versus float $\ldots \ldots \ldots \ldots \ldots \ldots \ldots \ldots \ldots \ldots \ldots$

7.7 Fiber Optics versus Copper Cable .......... 151

7.8 Galvanizing .......................... 152

7.9 Existing Plant versus New Construction ....... 152

7.10 Weldment versus Casting Costs ............. 153

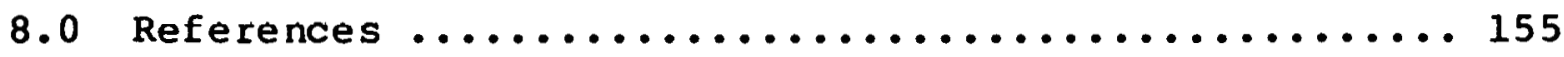

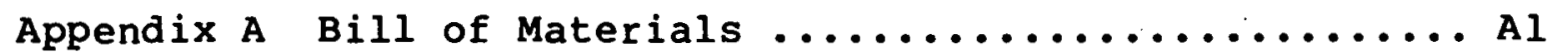

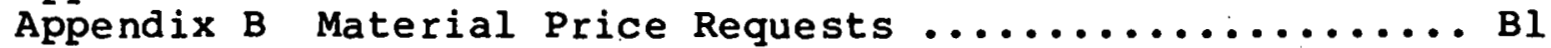

Appendix $C$ Tool and Labor Routings ................... Cl

Appendix D Product Cost Estimates ................. D1

Appendix E Typical Labor Development ................ El 
THIS PAGE

\section{WAS INTENTIONALLY LEFT BLANK}


1-1 Heliostat Unit Cost Breakdown Structure ........... $\frac{\text { Page }}{4}$

3-1 Baseline Prototype Heliostat .................. 20

3-2 Reflective surface......................... 23

3-3 support structure ......................... 24

3-4 Reflective Unit ........................... 25

$3-5$ Drive Assembly ........................... 26

3-6 Azimuth Drive Welded Housing .................. 28

3-7 Azimuth Drive ........................... 29

3-8 Drag Link Assembly ........................ 31

3-9 Torque Tube ............................ 32

$3-10$ Pedestal Assembly ....................... 33

4-1 25,000 Annual Volume Production Flow Diagram ....... 36

4-2 250,000 Annual Volume Production Flow Diagram ....... 37

4-3 Reflective Surface Line - 25,000 Annual Volume ......44

4-4 Glass Loader - 25,000 Annual Volume ............. 46

4-5 Mirror Module Rotator - 25,000 Volume ............ 48

4-6 Stringer Loader $-25,000$ Volume ............... 50

4-7 Stringer - Clinch Nut Subassembly - 25,000/250,000...

Unit Annual volume ..................... 51

4-8 Rollerized Pallet - 25,000 Annual volume ......... 52

4-9 Reflective Surface Line - 250,000 Annual Volume ..... 54

4-10 Inboard Beam Die Line ..................... 55

4-11 Diagonal Beam Die Line ................... 57

4-12 Mirror Support structure Welding Line ........... 58

4-13 Heliostat Support Structure station 1 ,

Load/Weld Doublers ....................... 59

4-14 Ḧeliostat support structure station 2,

Load/Weld Gussets ....................... 60

4-15 Heliostat Support Structure Station 3,

Manually Arc Weld Gussets/Auto Turn ............ 61

4-16 Heliostat Support Structure Station 4,

Load Outboard Beam ...................... 62 


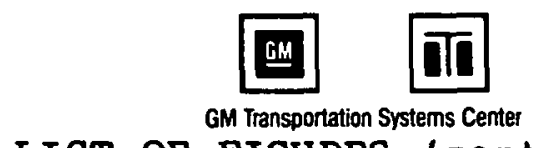

LIST. OF FIGURES (continued)

4-17 Heliostat Support Structure station 5,

Page

Load/Weld Diagonals ..................... 63

4-18 Heliostat Support Structure Station 6, Weld Diagonals. 64

4-19 Heliostat Support Structure station 7, 8, 9,

Weld Diagonals to Gussets .................. 66

4-20 Heliostat Support Structure Station 10,

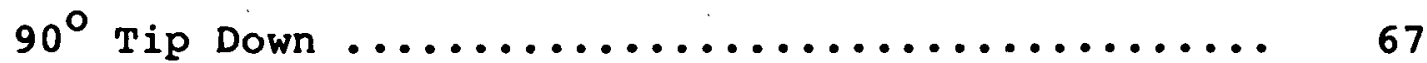

4-21 Heliustat support Structure Stations 11 and 12,

Counter-bore .........................68 68

4-22 Heliostat Mirror and Back Support Station 13, Unload . 69

4-23 Reflective Unit Assembly .................. 70

4-24 Electrical/Electronic Assembly and Test Area -

25,000 Annual volume $\ldots \ldots \ldots \ldots \ldots \ldots \ldots \ldots \ldots \ldots . \ldots \ldots$

4-25 Electrical/Electronic Assembly and Test Area -

250,000 volume ........................... 73

4-26 Azimuth Drive Housing Machining-\#1 -

25,000 Annual volume ...................... 85

4-27 Azimuth Drive Housing Machining-\#2 -

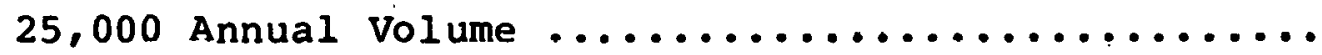

4-28 Azimuth Drive Housing Machining-\#3 -

25,000 Annual volume $\ldots \ldots \ldots \ldots \ldots \ldots \ldots \ldots \ldots, 88$

4-29 Azimuth Drive Housing Machining -

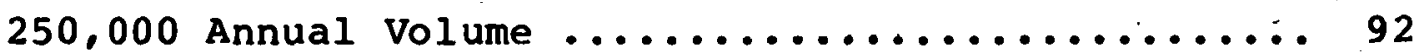

4-30 Drag Link Machining - 25,000 Annual Volume ......... 94

4-31 Drag Link Machining - 250,000 Annual Volume ........ 97

4-32 Torque Tube Machining-\#1 - 25,000 Annual volume ..... 99

4-33 Torque Tube Machining-\#2 - 25,000 Annual volume ..... 100

4-34 Torque Tube Machining - 250,000 volume ............ 102

4-35 Drive Unit Assembly Line - 25,000 Annual volume ..... 113

4-36 Drive Unit Assembly Line - 250,000 Annual Volume .... 114

4-37 Azimuth/Elevation Assembly Area -

25,000 Annual Volume $\ldots \ldots \ldots \ldots \ldots \ldots \ldots \ldots \ldots \ldots \ldots \ldots \ldots$ 


\section{LIST OF FIGURES (continued)}

$\underline{\text { Page }}$

4-38 Azimuth/Elevation Assembly Area 250,000 Annual Volume ...................... 118

4-39 Final Assembly Bench Pedestal Assembly - 25,000 Unit

Annual Volume ........................... 122

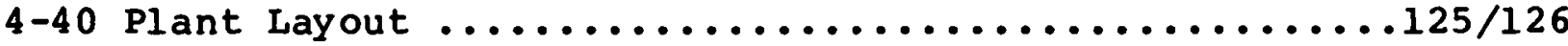

4-41 Plant Layout ...........................127/128

\section{LIST OF TABLES}

$\underline{\text { Page }}$

2-1 Heliostat Component Design and Source Requirements ... 10

2-2 Plant Location Data Comparison ................. 13

3-1 Heliostat Specifications ..................... 21

5-1. Spare Parts Requirements - Line Replaceable Units ... 135

5-2 Total Cost Per Heliostat Unit

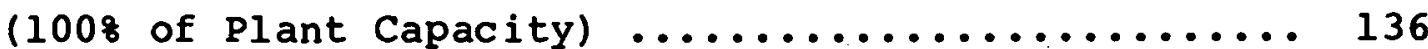

5-3 Total Cost Per Heliostat Unit

(758 of Plant Capacity) ................... 137

5-4 Total Cost Per Heliostat Unit

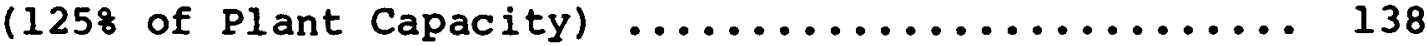

5-5 Heliostat Cost Summary - 25,000 Unit Annual Volume

(Material, Labor and Burden) ................. i 39

5-6 Heliostat Cost Summary - 250,000 Unit Annual Volume

(Material, Labor and Burden) .................. 140

5-7 Burden Costs Per Heliostat Unit ................. 141

5-8 Non-Allied Tooling and Plant Costs .............. 14l

5-9 Investment Per Heliostat Unit ................. 142

5-10 Heliostat Production Cost Per Unit -

25,000 Units/Year ........................ 144

5-11 Hellostat Production Cost Per Unit -

250,000 Units/Year $\ldots \ldots \ldots \ldots \ldots \ldots \ldots \ldots \ldots \ldots \ldots \ldots$

7-1 Weldment and Casting Cost Estimates ............. 153 


\section{THIS PAGE \\ WAS INTENTIONALLY \\ LEFT BLANK}

xiv 


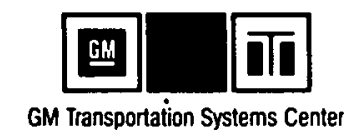

SECTION 1.0

INTRODUCTION

This final report is of a study conducted by GM Transportation Systems Center to develop a manufacturing cost estimate for a heliostat design. The Solar Central Receiver Prototype Heliostat of the McDonnell Douglas Astronautics Company (MDAC) was chosen by the Solar Energy Research Institute (SERI) for the design concept. The major subcontractor to GM Transportation Systems Center was the F. Jos. Lamb Company which developed the processing, tooling, machines, and plant layouts for manufacture of the heliostat. The Harrison Radiator Division, General Motors Corporation, provided substantial assistance in labor development and cost extension, and other General Motors Divisions and Staffs provided aid and consultation.

\subsection{SCOPE OF WORK}

Frequently cost studies are performed by parties interested in determining whether the developed cost lies above or below a target cost or "bogey." The results of such studies of ten are obtained by a "top down" evaluation starting with the cost bogie. In the study addressed by this document, a cost bogey was not established, and the effort was concentrated on developing a cost from the "bottom up." This meant that enough design and engineering data had to be acquired in order to develop manufacturing processes, configure a plant in which to build the heliostats, and then collect material and labor costs on a part-by-part basis. Current (1979) production technology was the basis for the production evaluation and cost results are expressed in 1979 dollars.

\subsubsection{Heliostat}

The background for the heliostat design is provided by the "low cost heliostat" project which was completed during 1978 under the direction of Sandia Livermore Laboratory. One of the four designs involved in this study was that of the McDonnell Douglas Astronautics Company. For the purpose of the current production evaluation and cost analysis study, the MDAC Solar Central Receiver Prototype Heliostat was chosen as the technological basis for the work to. be performed. Design data for this heliostat design was defined in a number of ways. First, information was developed to the extent possible from the MDAC Final Report on the low cost heliostat project. Second, data was obtained directly from drawings provided by MDAC and from MDAC personnel during meetings coordinated by SERI. Third, in at least one instance, the azimuth drive, data was developed from representative hardware by inspection and 


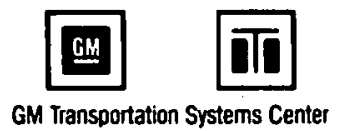

measurement as drawings with sufficient detail were unavailable; and fourth, design assumptions were made and documented in cooperation with the SERI Contracting officers Technical Representative (COTR) to fill any final data gaps.

\subsubsection{Manufacturing}

The ultimate objective of this task was to define the technical information on materials, methods, and labor as required to conduct a manufacturing cost analysis. Each step in the fabrication and assembly of the heliostat from the initial material (raw or purchased part) through the final assembly and packaging for shipment was addressed in accomplishing this objective.

The work defined under manufacturing was to provide the basis for developing a manufacturing cost per heliostat at two gelected production volumes, 25,000 helinstat.s per year and 250,000 heliostats per year. In addition, to provide some insight to the variability of manufacturing cost as a function of production level changes, manufacturing costs were to be developed for 75 percent and 125 percent of plant capacity at both the low and high standard volumes.

Manufacturing equipment, tooling, fixtures, and other devices required in processing and/or assembly operations were to be identified for each step in the manufacturing process. Labor hours were to be carefully developed for each step in the routing and allowances made for machine downtime, for repair and maintenance.

\section{1 .3 Plant}

For this study, a dedicated facility of new construction was chosen as the plant configuration for both the low and high volumes. Factors to be considered in defining the plant for cost analysis are geographic location, land requirements including allowance for possible expansion, available labor and supporting vendor industry, heliostat transportation requirements, material availability and the physical configuration of the building(s) necessary for an integrated manufacturing site.

\section{1 .4 Costs}

The objective of this task was to bring together the details of cost and cost related factors such that the total manufacturing cost for the production of heliostats at the low and high volumes could be estimated. Facility costs, fixed and variable production costs, material costs, burden costs, and all other allocated cost factors will be considered to develop the total factory cost on a per unit (heliostat) basis*.

*See Section 1.2.7, Factory Cost. 


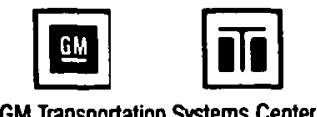

\subsection{STUDY APPROACH}

In order to understand how the production evaluation and cost analysis were performed, the following section lists the major elements of the work effort in the order in which they were accomplished.

\subsubsection{Cost Breakdown Structure}

A cost breakdown structure diagrams the categories into which the various costs of manufacturing a product are collected. The cost breakdown structure also effectively collects the work effort to be performed into categories which are product related and, thus, can be referred to as a work breakdown structure. Figure $1-1$ is the cost breakdown developed for the heliostat. The control or identification numbers, 4410 through 4480 , of the cost breakdown structure are in correspondence with those used in the McDonnell Douglas Final Report, Reference 1 of Section 8.0.

\subsubsection{Bill of Materials}

The basic document upon which any production or cost analysis of a manufactured product is based is called the "bill of materials."

The bill of materials lists every item, part, or raw material required to complete the manufacture and assembly of the heliostat. Primary reference for each item is the ERD code which refers to the cost breakdown structure. Where applicable, items are identified by a commercial part number or referenced to a drawing number. Unit quantities, material specification, form, shape, and weight are indicated, and finally the material source is shown.

The bill of materials for the heliostat analyzed in this study is Appendix A to this document.

\subsubsection{Manufacturing Analysis}

After completing a bill of materials, the next step in a manufacturing analysis is to provide initial information for tool and labor routing sheets and material purchase request sheets.

Each step of the manufacturing process must be listed on the tool and labor routing sheets. In order to accomplish this, all manufacturing processes and. tools required must be developed and/or defined. This was done and the results are shown in Section 4.0 . 

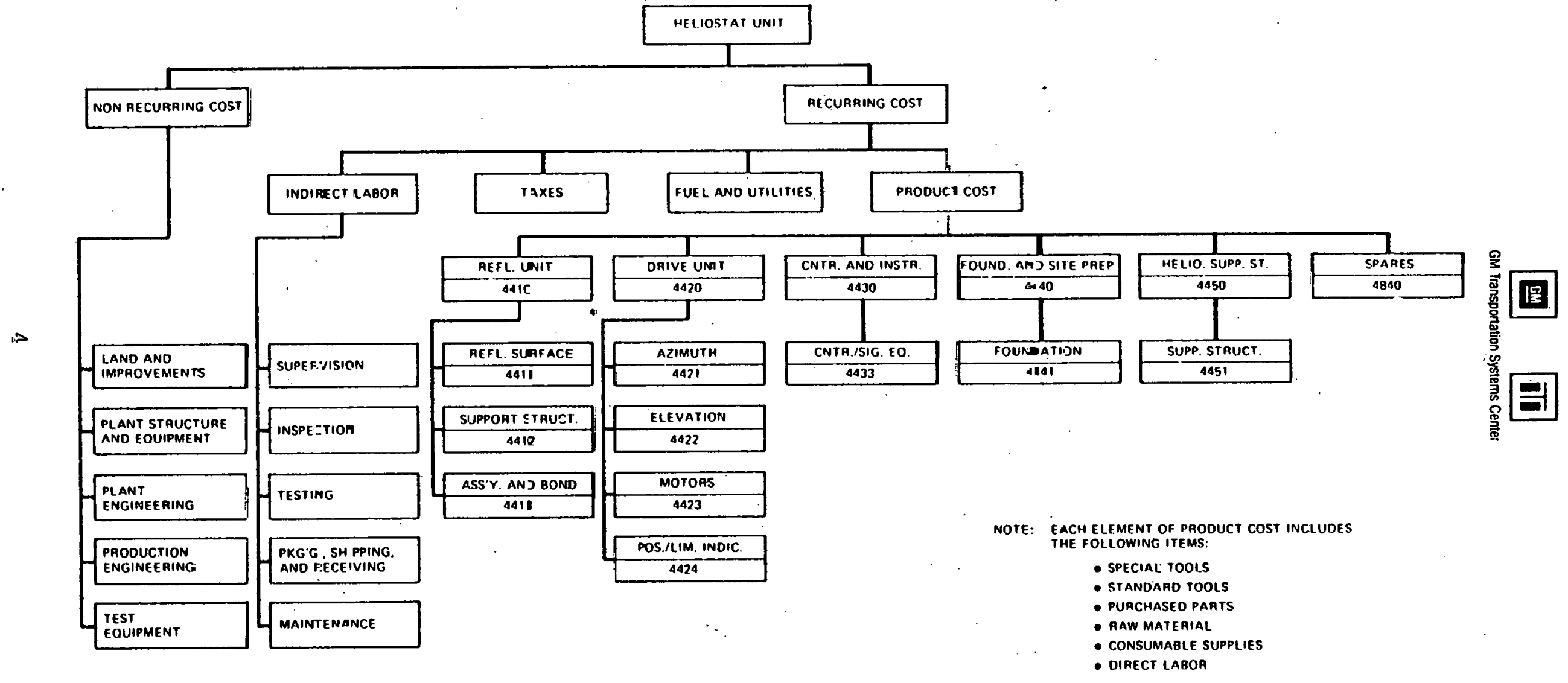

Figure 1-1. HELIOSTAT UNIT COST BREAXDOWN jTRUCTURE 


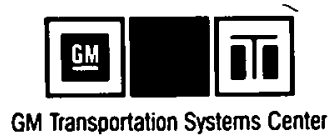

Equipment required in the manufacturing process is also defined and listed on tool and labor routing sheets.

\subsubsection{Plant Design}

In order to complete the production analysis and labor development, a plant configuration must be determined. Based on the production flow, processing, and equipment shown in section 4.4, plant layouts were completed for the low and the high volumes.

\subsubsection{Labor Development}

The development of the labor content of the manufacturing process is a complex, time-consuming procedure. This activity requires an effort similar to the depth of study required for processing development.

Appendix E, Typical Labor Development, shows the type of detail used to generate the labor content for the manufacturing process. The appendix is provided to show how the labor data that is included on the Tool and Labor Routing sheets was developed.

With the completion of the Tool and Labor Routing Sheets which are contained in Appendix $C$, burden costs can be developed and the cost extension completed.

\subsubsection{Cost Extension}

Material cost, labor hours, labor rate, labor cost, burden rate, and burden cost are collected on the product cost Estimate sheets to show the total manufacturing cost. The product cost Estimate' sheets are contained in Appendix $D$.

\subsubsection{Factory Cost}

It is important for the reader to understand that from its inception this study of heliostat.production costs intended to develop what is known in industry as "factory cost."

Factory cost is:

the sum of all costs necessary to place a finished product on the factory dock ready to ship.

Factory cost does not include:

shipping, field installation, profit, return on investment, distributed general and administrative expenses, state or local product or inventory taxes, general commercial expense, sales and advertising costs, public relations costs, or any other profit and loss items. 


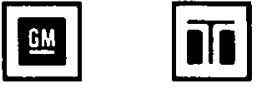

GM Transportation Systems Center

Outside tooling and plant costs were added to factory cost in order to provide a per square meter equivalent factory cost due to the extraordinary requirement for tools, precious metals, mirroring, glass making, gear making, and box making investments which vendor industries contacted during the study indicated they would not undertake. 


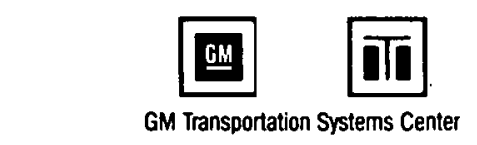

SECTION 2.0

COSTING GROUND RULES

The costs developed during this program are manufacturing costs incurred during the production of a single heliostat unit, produced at the manufacturing facility and prepared for shipment to the generation site. This analysis excludes shipping and site-related costs. The following elements from the MDAC cost breakdown of collector equipment have been considered:

\begin{tabular}{|c|c|c|}
\hline - & 4410 & $\begin{array}{l}\text { Reflective Unit } \\
\text { - } 4411 \text { Reflective Surface } \\
\text { - } 4412 \text { Mirror and Back Support } \\
\text { - } 4413 \text { Assembly and Bond }\end{array}$ \\
\hline$\bullet$ & 4420 & $\begin{array}{l}\text { Drive Unit } \\
\text { - } 4421 \text { Azimuth } \\
\text { - } 4422 \text { Elevation } \\
\text { - } 4423 \text { Motors } \\
\text { - } 4424 \text { Position/Limit Indicators } \\
\text { - } 4425 \text { Power Supply/Distribution }\end{array}$ \\
\hline •. & 4430 & $\begin{array}{l}\text { Control and Instrumentation } \\
-4433 \text { Control Signal Equipment }\end{array}$ \\
\hline • & 4440 & $\begin{array}{l}\text { Foundation and Site Preparation } \\
-4441 \text { Foundation (Tapered Pipe only) }\end{array}$ \\
\hline & 4450 & $\begin{array}{l}\text { Heliostat Support and Protection } \\
-4551 \text { Heliostat Support Structure }\end{array}$ \\
\hline
\end{tabular}

\subsection{PRODUCTION. VOLUMES}

Two production volumes have been selected for the manufacturing cost estimates of heliostat fabrication and assembly: a lowvolume case which represents the heliostat usage in two to four major repowering projects and a high-volume case which represents the achievement of higher DOE goals. The low-volume production capacity has been determined by SERI to be 25,000 heliostats per year. The high volume production capacity has been determined by SERI to be 250,000 heliostat units per year. This capacity represents possible future levels of demand and is intended to supply information on the cost sensitivity of heliostats to production volume.

Each production facility has been analyzed to determine the impact on heliostat cost for operations at full capacity (100 percent) as well as points at 75 and 125 percent of capacity. These capacity modifications are made through labor adjustments. At the 75 percent level, shift reductions will be 
utilized. For the 125 percent level, third shift and/or overtime operations are scheduled.

At the 25,000 unit annual volume, plant design is based on two shift operations in all areas with the exception of the reflector panels assembly area. This area operates on only one shift. All plant equipment is used with the assumption of 67 percent operating efficiency. This efficiency considers machine downtime, tool replacement and operating stoppages. Therefore, a particular machine, although designed for an operating speed at 100 percent efficiency will only produce at a 67 percent average rate. As an example, a single part of the heliostat which is to be produced at the rate of 25,000 pieces per year on a two shift basis will be made on a machine with a capacity of:

$$
25,000 \frac{\text { piece }}{\text { year }} \cdot \frac{\text { year }}{4000 \text { hours }} \cdot \frac{1}{0.67 \mathrm{eff} .}=9.3 \mathrm{pieces} / \mathrm{hour}
$$

At the 250,000 unit annual volume, the machine is designed to be capable of producing 93 pieces per hour.

\subsection{DESIGN DATA SOURCES}

The level of design detail available from MDAC falls into three general categories:

- Manufacturers' information on available components which are assembled into the heliostat

- Assembly and detail drawings of heliostat components together with engineering instruction sheets

- Functional descriptions of electronic and/or fiber optics hardware.

In addition to these data, information was made available by MDAC on mirror lamination and the harmonic drive.

Where a commercial component is used in the heliostat, the technical data used to define the part for cost analysis is the manufacturers' part number or specification. Cost quotations or engineering cost estimates from the manufacturer are used to generate cost data at the 25,000 and 250,000 unit per year volume levels.

The drawings provided by MDAC have been analyzed to define the processing and tooling required for fabrication. If component fabrication is to be completed through an outside supplier, a quotation or engineering cost estimate has been obtained. If the fabrication is to be completed in the heliostat plant, tooling and fabrication labor cost has been developed. 
Where design data do not exist, as is the case for the control signal equipment, commercially available hardware has been selected to meet the functional requirements defined by MDAC. This equipment, being generic in nature, may not be optimum for the heliostat application but is expected to provide reasonable cost data. For the harmonic drive, detail design and processing information were not available. In this case, a commercially available drive unit was analyzed and detail drawings generated to the proper scale for heliostat operation. These detail drawings were then used as the basis for the manufacturing analysis.

Based on the evaluation of the material supplied by MDAC, Table 2-l has been prepared to show the components which are part of the heliostat assembly. For each component, the type of design data available and the sourcing policy are listed. The sourcing policy is indicated for the 25,000 unit per year capacity level. Those items which are welded, machined and galvanized in the production facility at the 250,000 unit per year capacity are indicated by an asterisk. components manufactured complete in the plant at this volume are indicated by two asterisks.

\subsection{SITE SELECTION .}

The selection of a general area for the location of a heliostat production facility is influenced by the need to be close to a major potential market area for repowering sites. The selected area includes the states of Texas,. New Mexico, Colorado, Arizona, Utah, Nevada, and California. The need to be central to this area is influenced by the shipping costs for completed heliostat components. These components are of low density and shipping costs can be reduced if short-haul trucking can be used between the manufacturing plant and the repowering site. Central states in this general area include: Arizona, Colorado, New Mexico, and Utah. These four states were selected for a more detailed comparison of the following factors:

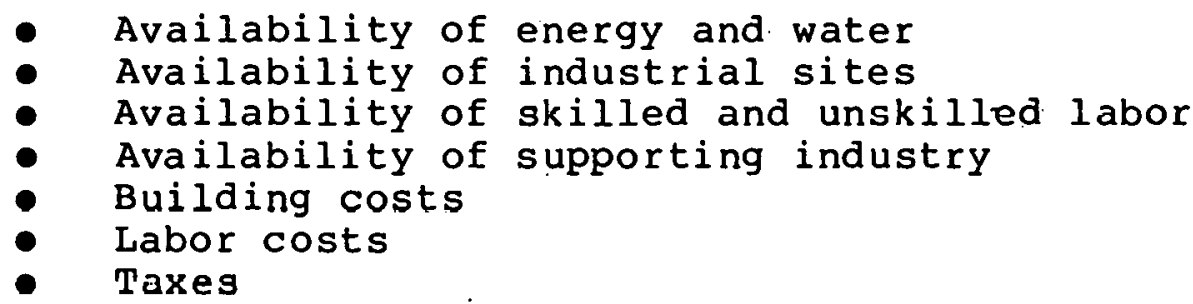

Land costs vary considerably; and have relatively little effect on total cost. Therefore, they are not included in the list of factors affecting site selection. In general the availability of the factors listed preclude the selection of smaller urban areas. This limitation and the consideration of a central 
Table $2-1$. HELIOSTAT COMPONENT DESIGN AND SOURCE REQUIREMENTS

Bill of Materials Reference Number

$$
\begin{aligned}
& 4411-0 C 0 \\
& 4411-0 C 1 \\
& 4411-002 \\
& 4411-004 \\
& 4411-0 C 6
\end{aligned}
$$

$4412-0 \mathrm{C} 0$

$4412-0 C 9$

$4412-010$

$4412-011$

$4412-012$

$4412-013$

$4412-0 \in 0$

$4412-065$

$44 \lambda 2-x>x$

$4413-000$

$4413-0 \mathrm{C} \cdot 7$

$4421-000$

$4421-06.6$

$4421-067$

4421-070

$4421-0 \div 1$

4421-073

$4421-0 \notin 0$

$4421-081$

$4421-082$

$4421-105$

$4421-16.6$

$4421-110$

$4421-115$

\section{Comfonent Identification}

Reflective Surface

Front Lite

Back Lite

Mirroring Chemicals

Adhesive

Mirror Support Structure

Diagonal Bean-LH

Diagonal Beam-RH

Inbaard Cross Beam

Dutboard Cross Beam

Stringer

Doutler

Gusset

Hardware

Assembly and Banc̄.

Adhesive

Azimuth Drive

Bearing Retainer

Eover

Hous ing

Oil Par:

Flexible spline

Duter Retainer

Helicon Gear

Plate

Drive Shaft

Tube

Circular spline

Wave Generator Plug

\section{Design Detail}

Assembly Drauing

Material Specification

Material Specification

Material Specification

Material Specification

Assembly Drawing

Detail Drawing

Detail Drawing

Detail Drawing

Detail Drawing

Detail Drawing

Detail Drawing

Detail Drawing

Material Specificalion

Process Spec-fication

Material Specification

Assembly Drawing

Detail Drawing

Detail Drawing

Detail Drawing

Detail Drawing

Parts Analys is

Detail Drawing

Material Specification

Detail Drawing

Detail Drawing

Detail Drawing

Parts Analysis

Parts Analys -5

\section{Source}

Plant Assembly

Supplier

Supplier

Supplier

Supplier

Plant Assembly

Plant Processing

Plant Processing

plant Processing

Supplier

plant Processing

Supplier

Supplier

Supplier

Plant Assembly

Supplier

Plant Assembly

Plant Machining

Supplier

Plant Machining

Supplier

Plant Fabrication

Plant Machining

Supplier

Supplier

Plant Machining

Plant Fabrication

Plant Fabrication

plant Fabrication 
Table 2-1. HELIOSTAT COMPONENT DESIGN AND SOURCE REQUIREMENTS (2 of 3 )

Bill of Materials Reference Number

$$
\begin{array}{r}
4421-120 \\
4421-130
\end{array}
$$$$
4421-x \times x
$$$$
4422-000
$$$$
\text { 4422-029 }
$$$$
\text { 4422-030 }
$$$$
4422-031
$$$$
4422-033
$$$$
4422-075
$$$$
44.22-074
$$$$
4422-121
$$$$
\text { 4422-122 }
$$$$
4422-.123
$$$$
4422-124
$$$$
4422-133
$$$$
4422-134
$$$$
\text { 4422-137 }
$$$$
4422-138
$$$$
4422-172
$$

$\$ 423-000$

4423-148

$4423-149$

4423-150

$4424-000$

4424-152

$4424-155$

4.424-180

$4424-181$

4424-182

$4424-x \times x$

\section{Component Identification}

Bushing

Wave Generator Bearing

Hardware

Elevation Drive

Pin

Spacer, Hinge

spacer, Hinge

Pin-Hinge

Torque Tube Assembly

Drag Link Assembly

Bushing - Clevis

Bushing - Trunnion

Bushing, Hinge - Drag Link

Bushing, Hinge - Torque Tube

Thrust Bearing - Clevis

Thrust Bearing - Trunnion

Shim-Clevis

Shim - Trunnion

Actuator Assembly

Motors, Total

Motor - Azimuth

Motor - Tracking

Motor - Stowage

Position/Limit Indicators

Printed Circuit Board

Vane Actuator

Sensor, Hall Effect

Line Driver

Dual Differential Line Receiver

Electronic Components

\section{Design Detail}

Material Specification. Material specification Material Specification

Assembly Drawing

Detail Drawing

Detail Drawing

Detail Drawing

Detail Drawing

Detail Drawing

Detail Drawing

Detail Drawing

Detail Drawing

Detail Drawing

Detail Drawing

Detail Drawing

Detail Drawing

Detail Drawing

Detail Drawing

Material Specification

Assembly Drawing

Material Specification

Material Specification

Material specification

Assembly Drawing

Functional Description Detail Drawing

Material Specification

Functional Description

Functional Description

Functional Description
Source

Supplier Supplier Supplier

Plant Assembly

Supplier

Supplier

Supplier

Supplier

Suppliex *

Supplier *

Supplier

Supplier

Supplier

Supplier

Supplier

Supplier

Supplier

Supplier

Supplier

Plant Assembly Supplier

Supplier

Supplier

Plant Assembly

Plant Assembly

Supplier

Supplier

Supplier

Supplier

Supplier 


Bill of Materials
Reference
Number

Component Identification

Fower Supplyidistribution

Fiber Cptic Cabie

Fower Cable

Control Cable

Circuit Breaker

Electrical Components

Control/signal Bquipment

Box

Optical Transceiver

Connector

Micro Computer

Quad Differential Line Driver

Quad Differential Line Receiver

HEX-D Flip Flop

Power Supply

Electronic Components

Heliostat Suppori Structure

Cover

Cap

Pedestai

Tapered Pipe

\section{Design Detail}

Functional Lescription Functional Eescription

Functional Description

Functional Description

Functional Description

Functional Description

Functional Description Functional Description Functional Description. Functional Description Functional Description Functional Description Functional Description. Functional Description Functional Description Functional Description

Assembly Drawing

Detail Drawing Detail. Drawing

Detail Drawing

Detail Drawing
Source

Plant Assembly Supplier Supplier Supplier Supplier Supplier

Plant Assembly Supplier Supplier Supplier Supplier Supplier supplier Supplier Supplier Supplier

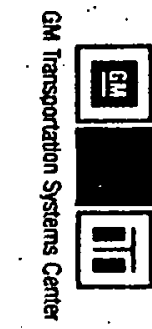

Plant Assembly Supplier Supplier Supplier * * Supplier * * 


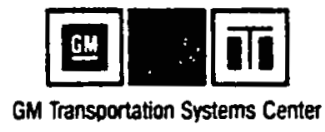

shipment point narrowed the selection process to the following cities:

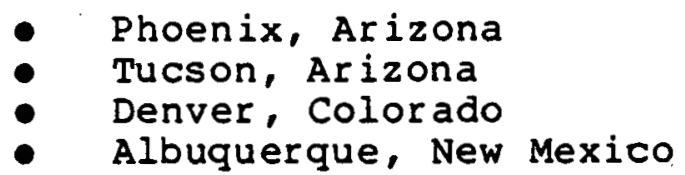

Data for these four cities are compared in Table 2-2. These data do not indicate significant. differences among the locations studied for a plant site. For the purpose of the manufacturing cost analysis, cost data will be developed using Tucson as the plant site.

Table 2-2. PLANT LOCATION DATA COMPARISON

\begin{tabular}{|l|c|c|c|c|}
\hline & $\begin{array}{c}\text { Total Labor } \\
\text { Availability } \\
\text { in Area } \\
\text { (Mfg. Related) }\end{array}$ & $\begin{array}{c}\text { Supporting } \\
\text { Industry }\end{array}$ & $\begin{array}{c}\text { Building } \\
\text { Costs } \\
\text { (Index) }\end{array}$ & $\begin{array}{c}\text { Labor } \\
\text { Costs } \\
\text { (Avg. Hourly } \\
\text { March 1979) }\end{array}$ \\
\hline Phoenix & 65,000 & yes & 102.6 & $\$ 6.44$ \\
Tucson & 12,000 & Yes & 101.0 & $\$ 6.05$ \\
Denver & 96,000 & yes & 100.5 & $\$ 6.61$ \\
Albuquerque & 14,000 & yes & 100.0 & $\$ 5.25$ \\
\hline
\end{tabular}

\subsection{COSTING PROCEDURES}

The costing ground rules govern the generation of the estimated cost for each heliostat unit as produced in the assembly plant and prepared for shipment to the site for installation. A heliostat unit, for this purpose, is defined in Paragraph 1.1.2. These ground rules cover the methods to be used in the generation of cost estimates for all elements pertinent to cost for a single heliostat unit. These elements include:

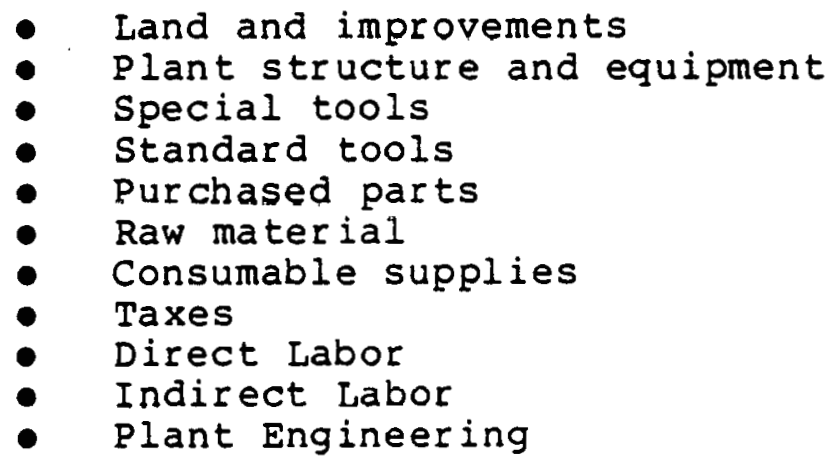


Costs have been collected for both the 25,000 and 250,000 unit per year production volumes and the required production facilities. These facilities will be located in Tuscon, Arizona.

In general, the costs associated with each subassembly are collected and identified with the specific subassembly. These costs include: tools, raw material, purchased parts, and direct labor. Those costs which cannot be directly identified with a particular subassembly are collected on a yearly basis, divided by the production volume and added to the total heliostat cost. These costs include: land, plant, consumables, taxes, indirect labor, and plant engineering. A cost breakdown structure to show the collection of hellostat costing is given in section 4.0 .

The following paragraphs give the detail costing methods which govern the generation of estimates for each cost element of the heliostat.

\subsubsection{Land and Improvements}

Based on the plant configuration and sizing for the two production volumes and the Tuscon, Arizona, site selection, typical plant sites have been developed and costed. Estimates of land and improvements costs are developed in current (1979) dollars.

\subsubsection{Plant Structure and Equipment}

plant layouts have been generated for the two production volumes. The plant layouts are shown in section 4.0 .

The plant and equipment cost estimates consider generally applicable building code requirements. The annual cost for the building and equipment is generated by amortizing the investment. This annual cost is uniformly applied over the yearly heliostat production volume.

\subsubsection{Spec1al 'l'ools}

Special tools are those units which have been designed and fabricated for heliostat production. These include: glass handling equipment, machine tool lines, automated welding lines, conveyors, hoists, adhesive application equipment., cleaning tanks, welding fixtures, zinc plating equipment,. bonding equipment and electronic assembly equipment.

Design definition for this equipment has been established and engineering costs generated or budgetary quotes obtained from vendors. The capital cost of this equipment is amortized to 
determine an annual cost. This annual cost is then divided by the heliostat volume and the piece cost applied to the corresponding element of the heliostat assembly.

\section{4 .4 standard Tools}

Standard tools are those items which are available from tool suppliers on a regular basis and may include modifications specific to heliostat production. These items include: flame cutters, vertical turret lathes, numerical control lathes, automatic lathes, hydrosize machines, punch presses, multiple drill stations, numerical control and standard mills, submerged arc and spot welders, saws, broaches and grinders.

Production machine tool catalogs have been consulted to select machines for heliostat production. For each machine, the vendors have submitted budgetary cost information. The capital cost of this equipment is amortized to determine an annual cost. The annual cost is divided by the heliostat volume and the piece cost will be applied to the corresponding element of the heliostat assembly.

\subsubsection{Purchased Parts}

Purchased parts include items which are in production at outside sources and special design items which are made to heliostat design requirements. These items include: glass, mirroring, rolled steel sections, weldments, steel stock, motors, gears, bearings, screw jacks, miscellaneous hardware, cable, electronic components, printed wiring boards and fiber optic devices.

Supplier quotes, catalog prices, or budgetary costs have been obtained for all purchased parts in the two production volumes. The piece cost, based on these data, is applied to the corresponding elements of the heliostat assembly.

\section{4 .6 Raw Material}

Raw material purchased for heliostat production operation includes: adhesives and chemicals for cleaning. Items which require further processing in the plant, other than assembiy, are also considered raw materials.

Supplier quotes or cost estimates have been obtained for raw material sufficient to meet the two production volumes. The piece cost, based on these costs, is applied to the corresponding elements of the heliostat assembly. 


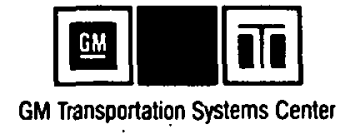

\subsubsection{Consumable Supplies}

Consumable supplies required for heliostat production include: energy (gas - oil - electric), water, welding supplies, grinding materials, machine tool bits, soldering supplies. Estimates for the annual consumption of these materials have been developed and costs generated for the two production volumes. These annual costs are divided by the production volume and the piece cost applied to the corresponding element of the heliostat assembly.

\section{4 .8 Taxes}

State, and local property taxes which are applicable to the production site, plant and equipment have been estimated for the area of the plant site in Tuscon, Arizona. The applicable tax rates are applied to the capital evaluation to determine an annual tax. The annual cost is divided by the production volume and added to piece cost for each heliostat assembly.

\subsubsection{Direct Labor}

Tooling and routing sheets are prepared for each component of the heliostat assembly to be processed in the assembly plant. The analysis of these sheets included developing the skill level. requirements for each labor operation. Based on the skill level requirements and the plant site location, average wage rates have been determined.

For each heliostat component, the labor hour content, multiplied by the skill rate, is added to the pioce cost.

\subsubsection{Indirect Labor}

Indirect labor requirements include: plant supervision, inspection, materials handling and maintenance. Based on the direct labor force in each plant, the indirect headcount has been estimated. Using the appropriate labor ratco, the annual cost of indirect labor has been computed. The annual cost is divided by the annual production volume to determine the cost for each heliostat unit.

\subsubsection{Plant Engineering}

The initial, one-time plant engineering activities represent a substantial investment. These costs have been estimated and amortized. Annual costs generated by the amortization schedule are divided by the production volume to achieve a unit heliostat cost. In addition, the cost of continuing annual plant engineering activities has been estimated, divided by the production volume, and a unit heliostat cost established. 


\section{4 .12 Cost Summary}

Piece, assembly, overhead and packaging costs have been summed for each heliostat unit. This cost, divided by the area of the reflective unit, is used to determine the estimated cost per square meter. (See Section 5.2.) 


\section{THIS PAGE \\ WAS INTENTIONALLY \\ LEFT BLANK}




\section{Gim \\ GM Transportation Systerns Center}

SECTION 3.0

HELIOSTAT DESIGN

\subsection{GENERAL}

The heliostat design considered in this report was developed by the McDonnell Douglas Astronautics Company. This design is a version of the baseline design which was selected by the DOE for the solar central receiver pilot plant competition. Design detail for this baseline heliostat is contained in the MDAC final report. For this project, design details were collected directly from MDAC in meetings held with the contractor. These meetings produced advanced design drawings which were current as of June 1979. Although the MDAC design continues to evolve, the design detail used in this study contains only information obtained from the contractor through July, 1979.

\subsection{DESIGN DESCRIPTION}

The design is characterized by reflective panels consisting of laminated glass sheets with bonded sheet metal stringers which stiffen the panel and are used to fasten it to the support structure as shown in Figure 3-1. The support structure is fabricated from roll-formed sheet metal sections which are spot-welded together to form the structure. The azimuth drive housing, drag link, torque tube, pedestal and tapered pipe are all fabricated through cutting, forming, and welding of steel material. The harmonic drive gearing in the azimuth drive is made up of fabricated steel elements which are machined. Drive motors, azimuth drive input gearing, and the elevation/stowage jacks are purchased components. Electrical and electronic elements of the signal and power circuits are fabricated in the assembly plant using the following purchased items: electronic components, printed circuit boards, electrical wire, connectors, and fiber optic cables.

\subsection{HELIOSTAT SPECIFICATIONS}

Specifications for heliostat performance have been extracted from the MDAC final report. These specifications are shown in Table 3-1. These specifications cover operating and design i ife requirements for the azimuth, tracking, and stowage actuators. Included with these specifications 15 a descivipioin of drive motor requirements. 


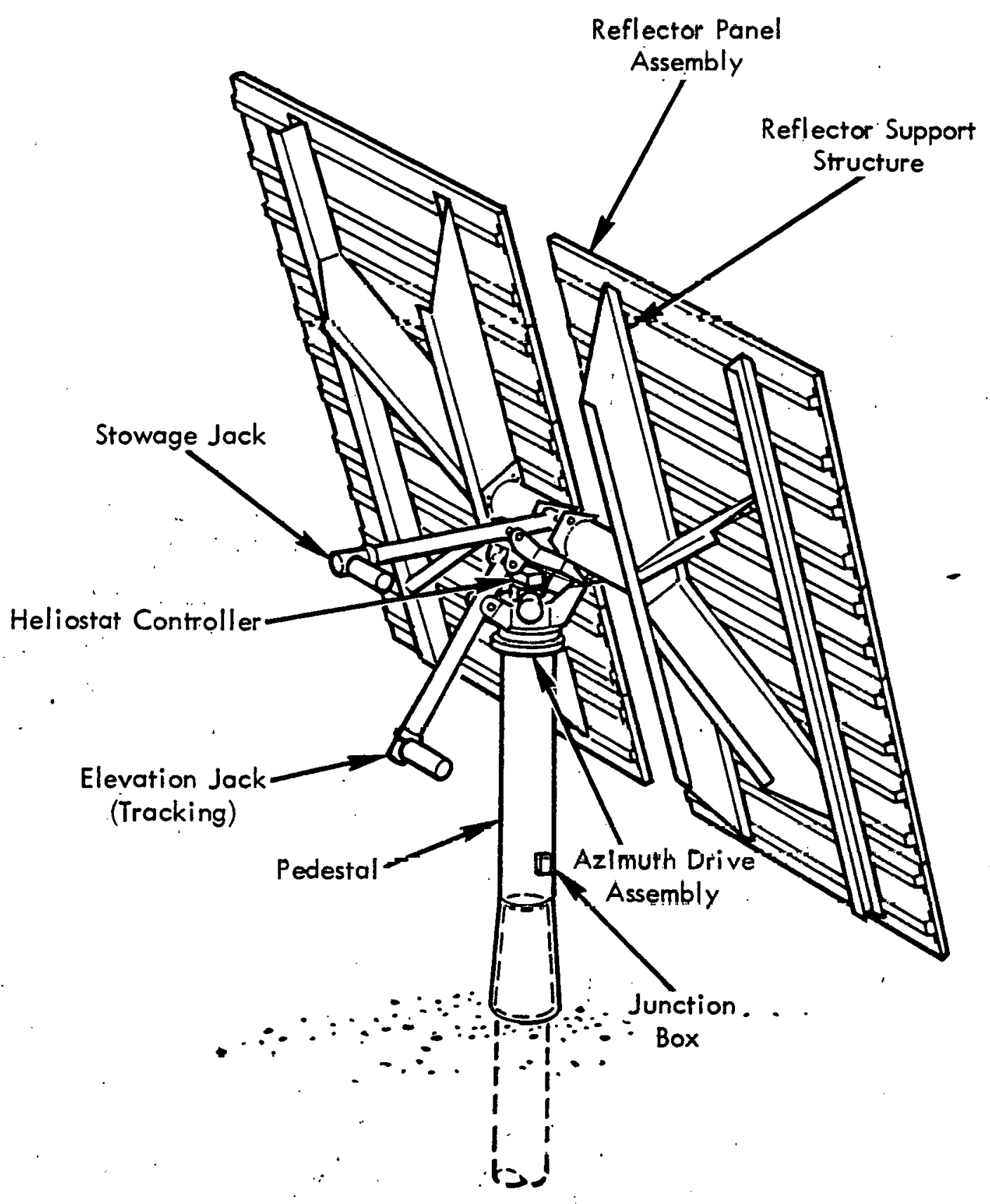

Figure 3-1. BASELINE PROTOTYFE HELIOSTAT 
Table 3-1. HELIOSTAT SPECIFICATIONS

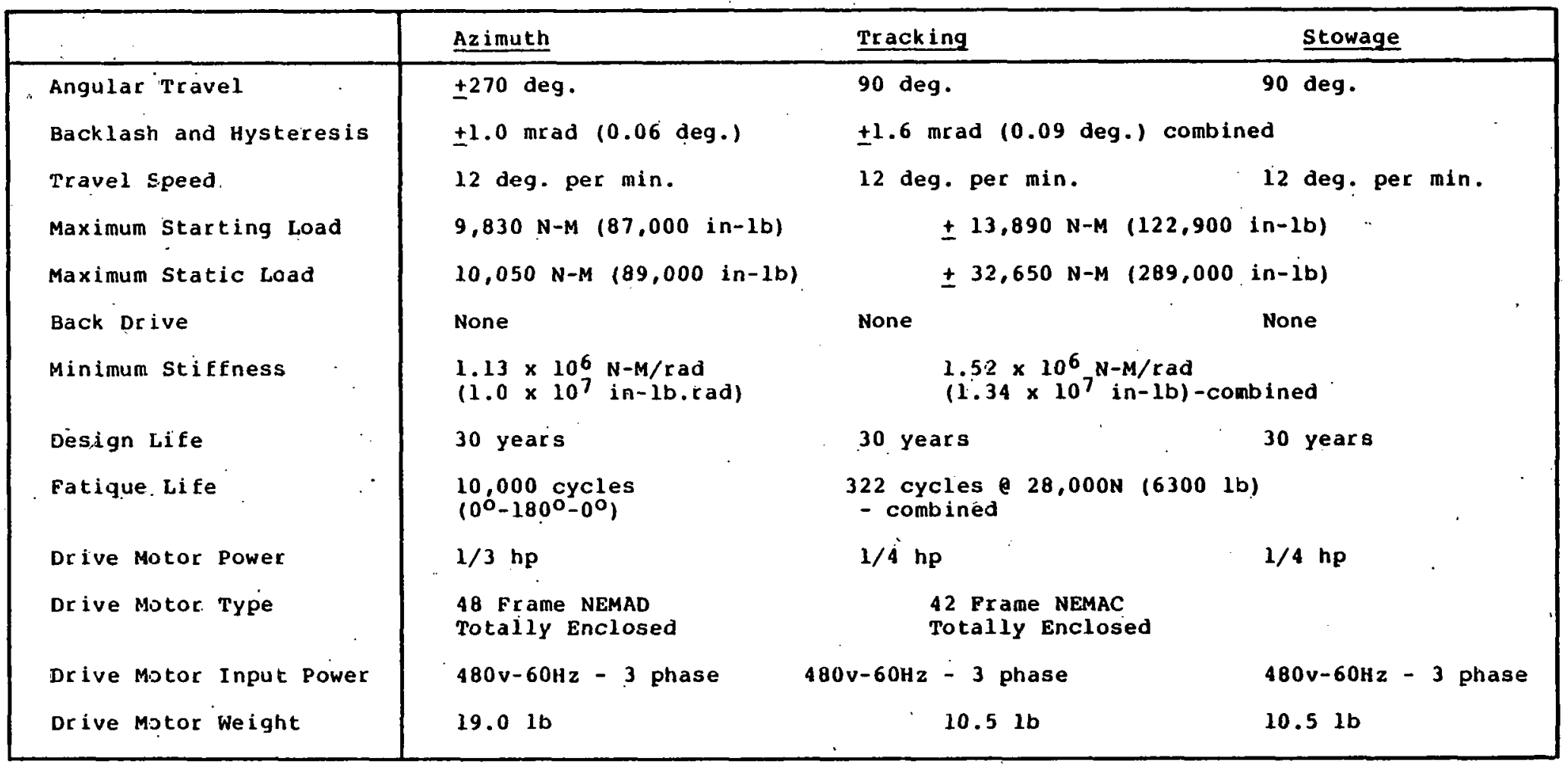




\subsubsection{Reflective Surface}

The reflective surface uses a laminated construction to stiffen the assembly and protect the back of the mirror surface. The construction of this lamination is shown in Figure 3-2. The front lite of the reflective surface consists of a 0.060 inch thick piece of low-iron fusion glass which has overall dimensions of $4 \mathrm{ft}$ by $11 \mathrm{ft}$. The back side of this glass is plated with pure silver and overplated with copper. At assembly, the back surface is sprayed with a two-part polyurethane adhesive that bonds the front and back lites of the reflector. The back lite is a 0.188 inch thick piece of window-grade float glass which also has dimensions of $4 \mathrm{ft}$ by $11 \mathrm{ft}$.

Two longitudinal, hat-shaped, sheet-metal stringers are bonded to the back of the reflective surface. Each stringer contains two clinch nuts which are used to attach the reflector to the back support structure. These stringers are roll formed from 0.063 inch thick steel and are bonded with a two-part urethane adhesive to the back of the reflective surface.

\subsubsection{Support Structure}

The support structure is assembled through spot welding of roll-formed sheet steel components. The assembly consists of an inboard cross beam, outboard cross beam, two diagonal beams, two gussets, and two backing plates. The assembly is shown in Figure 3-3. Fabrication of this assembly requires cutting and forming of the beams after shipment from the steel rolling mill. The beams are then welded together and reinforced with the gussets and backing plates. The assembly is finally precision drilled so it can be attached to the torque tube at the rield site.

\subsubsection{Reflective Unit}

The reflective unit is assembled by bolting six reflective surfaces to the support structure using the stringers which have already been. bonded to the reflective surface back. (See Figure 3-4.) At this point, the reflective unit is ready for shipment to the field where it will be assembled to the torque tube. Two reflective units are mounted on each heliostat.

\subsubsection{Drive Assembly}

The drive assembly contains the drive motors and mechanism for the azimuth, elevation and tracking functions. (See Figure 3.-5.) The azimuth drive is contained in the housing which provides support for the other units and in the mounting interface with the pedestal. The elevation and stowage 


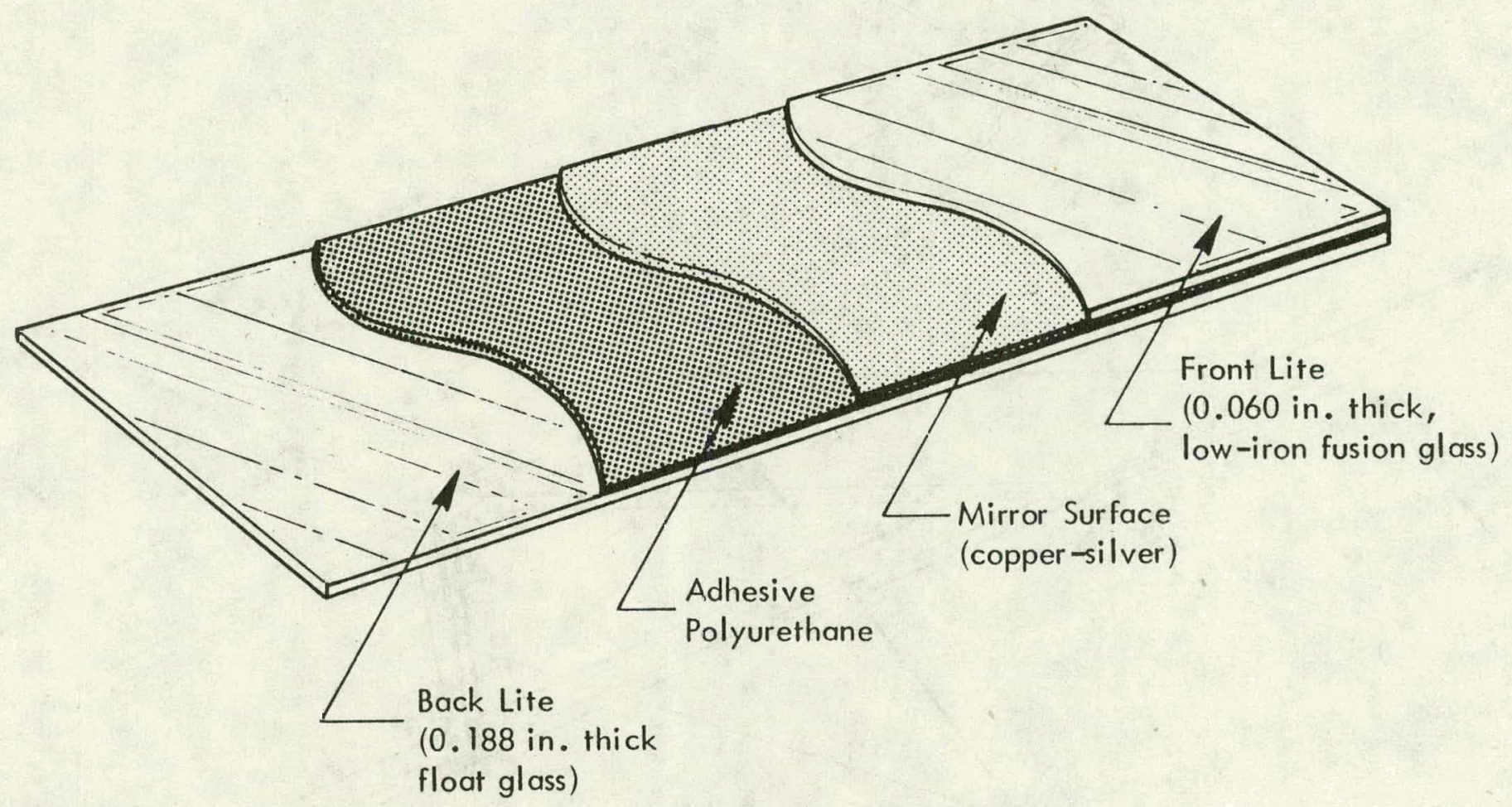

Figure 3-2. REFLECTIVE SURFACE 

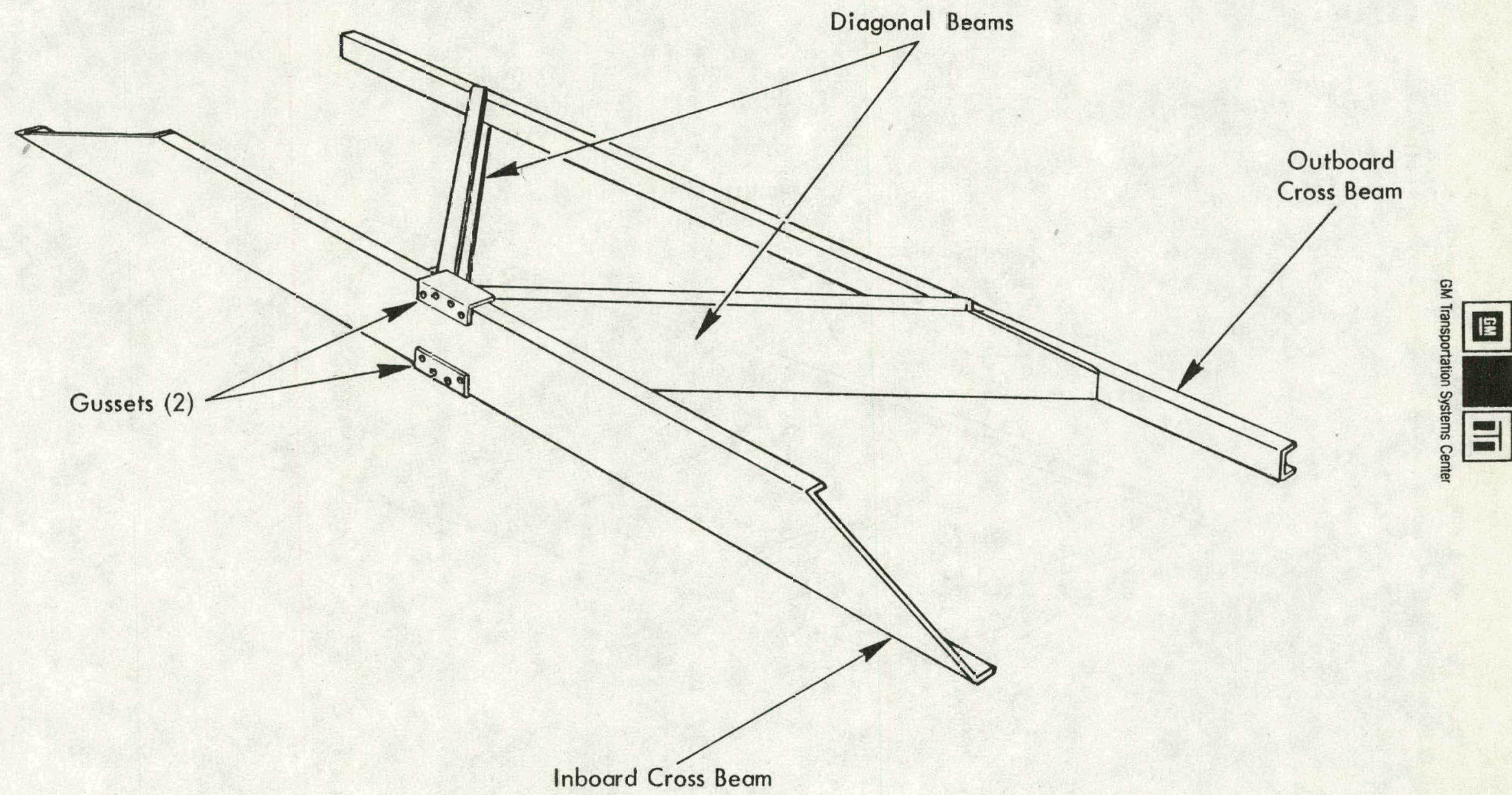

Figure 3-3. SUPPORT STRUCTURE 


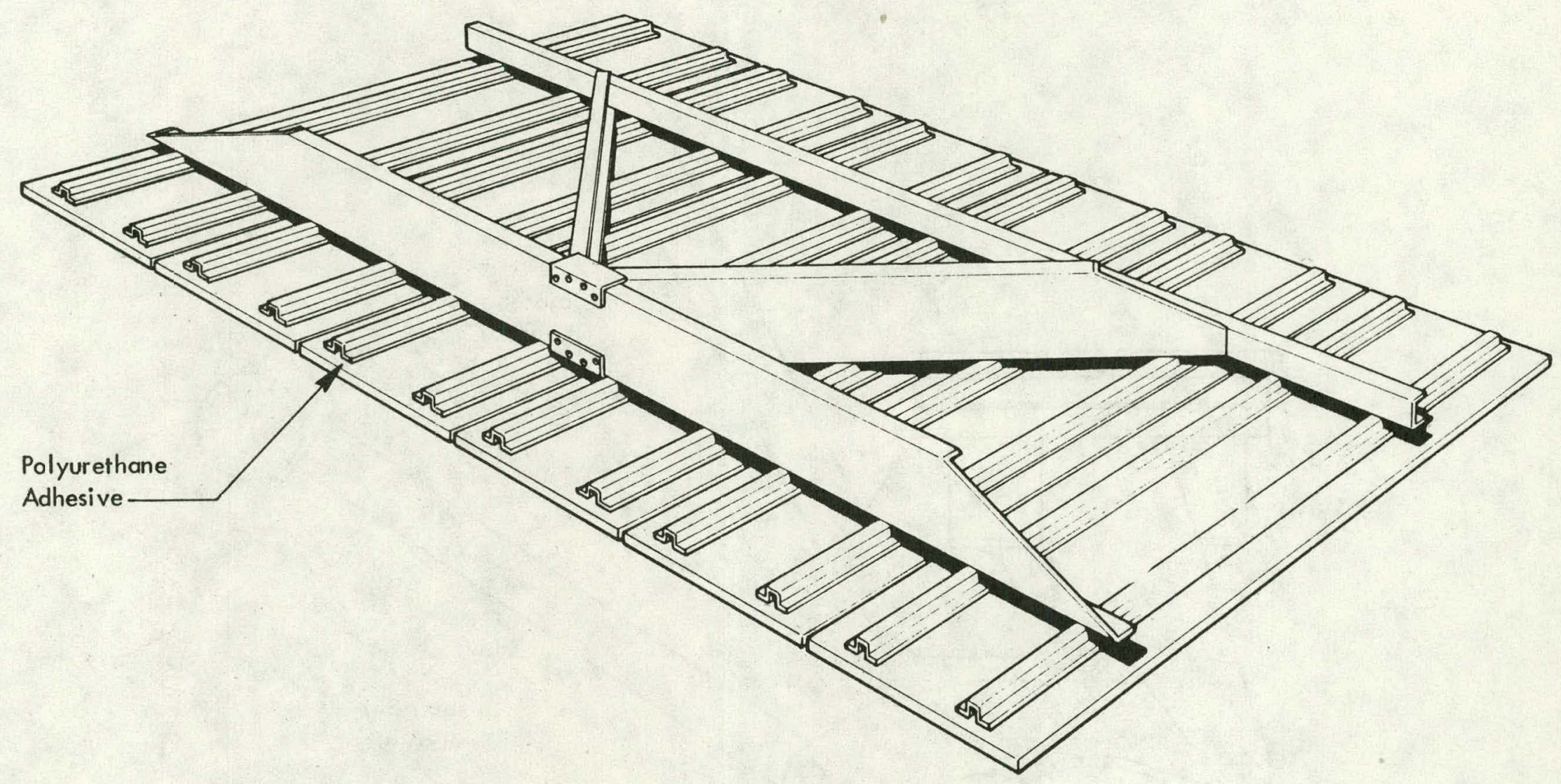




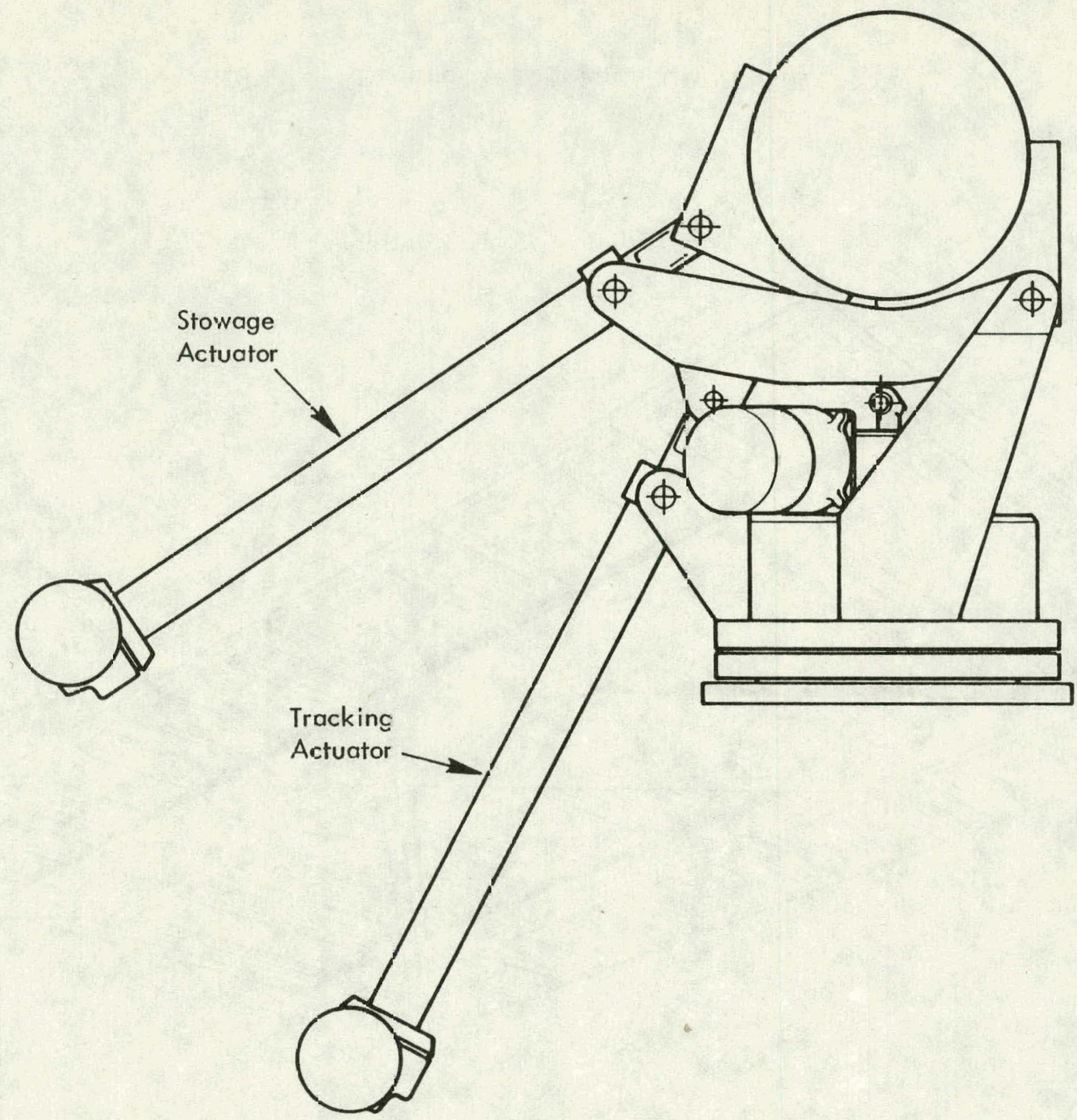

Figure 3-5. DRIVE ASSEMBLE 


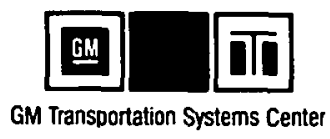

actuators are mounted on this unit and are used for rotation of the torque tube which supports the two reflective units. Elevation and stowage motions are accomplished through the drag link which shares a common pivot with the torque tube. Stowage motion occurs by extension of the actuator between the drag link and the torque tube. Elevation motion occurs by extension of the actuator between the drag link and the azimuth drive housing. This produces motion of the drag link, stowage actuator, and torque tube.

The drive assembly also contains the majority of the signal and control electronics associated with heliostat operation. The heliostat controller is mounted on top of the azimuth drive housing. This unit contains the conversion equipment for the fiber optic signal interface and the power controllers for the three drive motors. The input cable for the heliostat controller is fed down through the center of the drive housing where it connects to the junction box in the pedestal. Cables from the controller contain the power and signal wires for each of the drive motors.

\subsubsection{Azimuth Drive Housing - Welded}

A welded fabrication has been selected for the design of the azimuth drive housing. (See Figure 3-6.) The basic elements of this component are stock tubular and plate elements for the housing body, bearing flange, top cover, and gear case. The drive motor mount, tracking actuator brackets, and the drag link mounting brackets are welded to the basic assembly. The bearing flange is machined to accept the wire bearing race. The lower flange is also machined for a wire bearing race and is bolted to the bottom of the housing with 12 bolts. The bearing assembly is completed with the installation of the circular spline which is part of the azimuth drive. The welded housing is coated with a galvanized plating prior to machining of the mounting and bearing surfaces.

\subsubsection{Azimuth Drive}

The azimuth drive (Figure 3-7) provides two levels of reduction gearing between the drive motor and the circular spline. The input ratio is obtained through a purchased "Helicon" gear set with a ratio of $162: 1$. The output harmonic drive ratio is 242:1. The harmonic drive consists of a machined flexible spline, three-lobe wave generator, flexible bearing, and a circular spline and input shaft. The flexible spline is mounted to the top of the azimuth housing with 12 bolts. The wave generator is driven by the input shaft and produces distortion of the bearing and flexible spline at three points as it rotates. The circular spline contains gear teeth which mate with the flexible spline and bearing grooves for the wire race bearing which joins the circular spline and the azimuth 


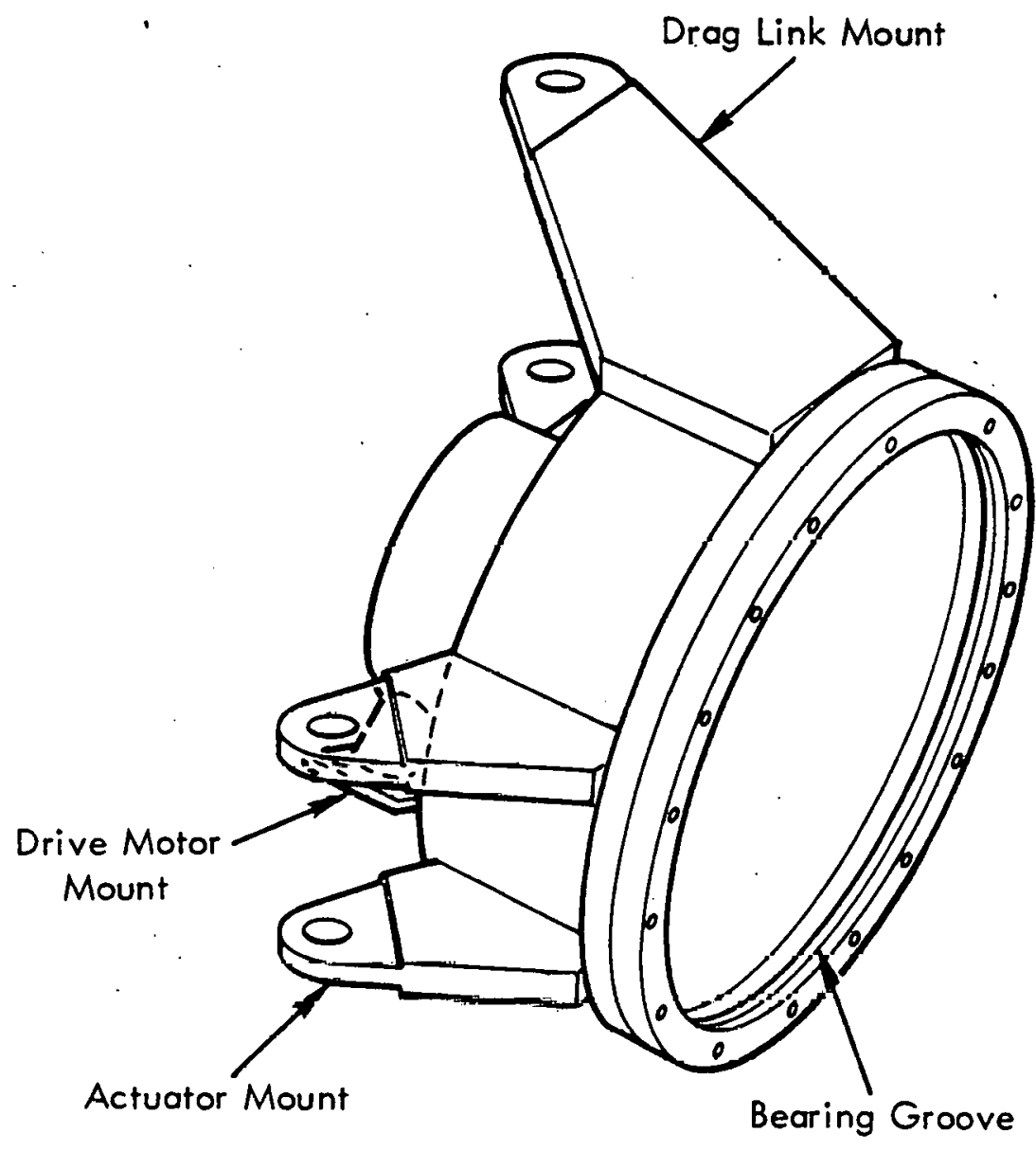

Figure 3-6. AZIMUTH DRIVE WELDED HOUSING 


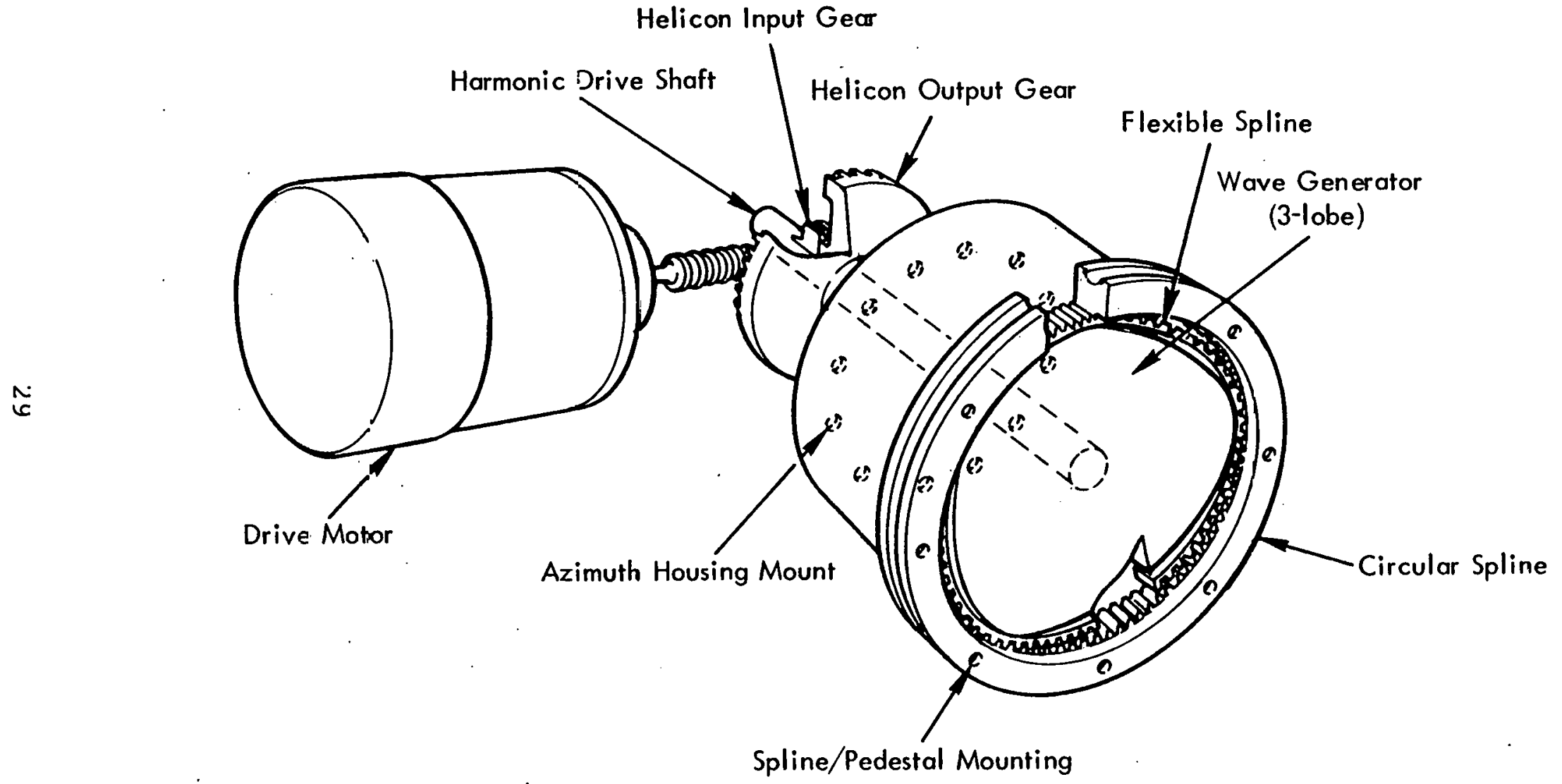


GM Transportation Systems Center

housing. The input shaft is machined and center-bored to allow the power and fiber optic cables to be routed from the pedestal junction box to the heliostat controller. The circular spline includes tapped holes for the mounting bolts which join the drive unit to the pedestal.

\subsubsection{Drag Link Assembly}

The drag link is fabricated from flame-cut steel plates which are welded into the assembly shown in Figure 3-8. After assembly, the weldment is galvanized. This weldment is then machined for mounting to the torque tube, stowage actuator trunnion, and tracking actuator clevis.

\subsubsection{Torque Tube Assembly}

The torque tube is assembled from standard steel tubing and flame-cut steel plates which are welded into the assembly shown in Figure 3-9. The flange plates which are welded to each end of the tube provide the mounting surface for the two reflective units. Tabs are provided for mounting at the drag link/azimuth housing joint and for the clevis mounting of the stowage actuator. After the support arms for the drag link have been attached to the torque tube, the weldment is galvanized. The weldment is then machined for the actuator mounting and the hinge joint. The end flanges are machined flat and precision drilled with eight holes each for the reflective unit mounting.

\subsubsection{Pedestal Assembly}

The pedestal assembly (Figure 3-10) consists of the pedestal and the tapered pipe which fits over the heliostat foundation. The tapered pipe is installed prior to pouring the concrete for the foundation and functions as a form for this operation. The tapered pipe is formed from sheet steel stock and seam welded. It is galvanized after fabrication.

The pedestal tube is also formed from steel plate and seam welded. After welding, the taper on the lower section is press-formed. The top cap is fabricated from steel plate stock and welded to the pedestal tube. An access area is provided for mounting the drive assembly, and a cutout is made for mounting the heliostat junction box. After assembly, the pedestal is galvanized. The assembly is then machined for the drive mounting surface and holes are drilled for the eight mounting bolts. 
Side Plate, Left Hand

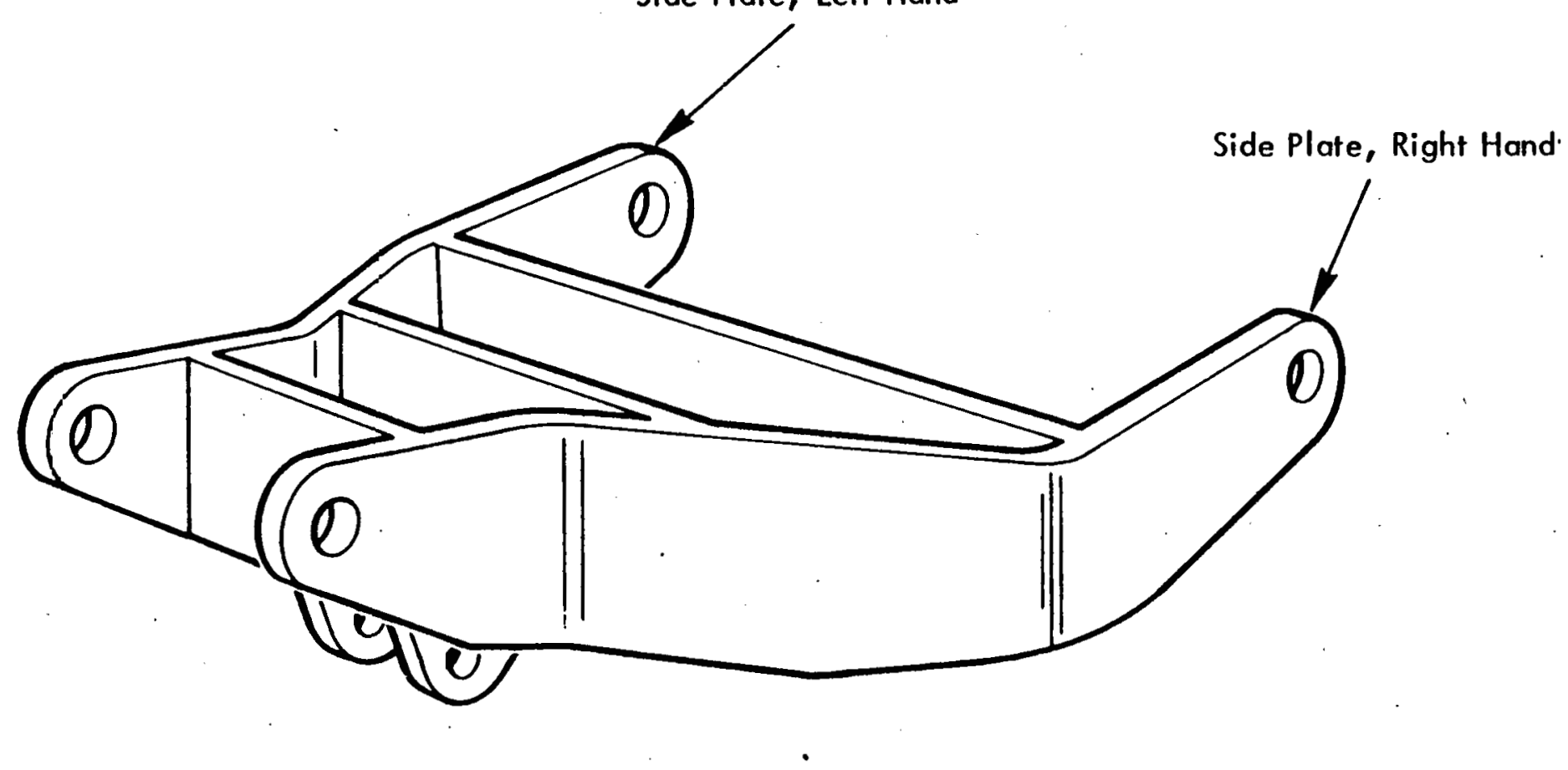




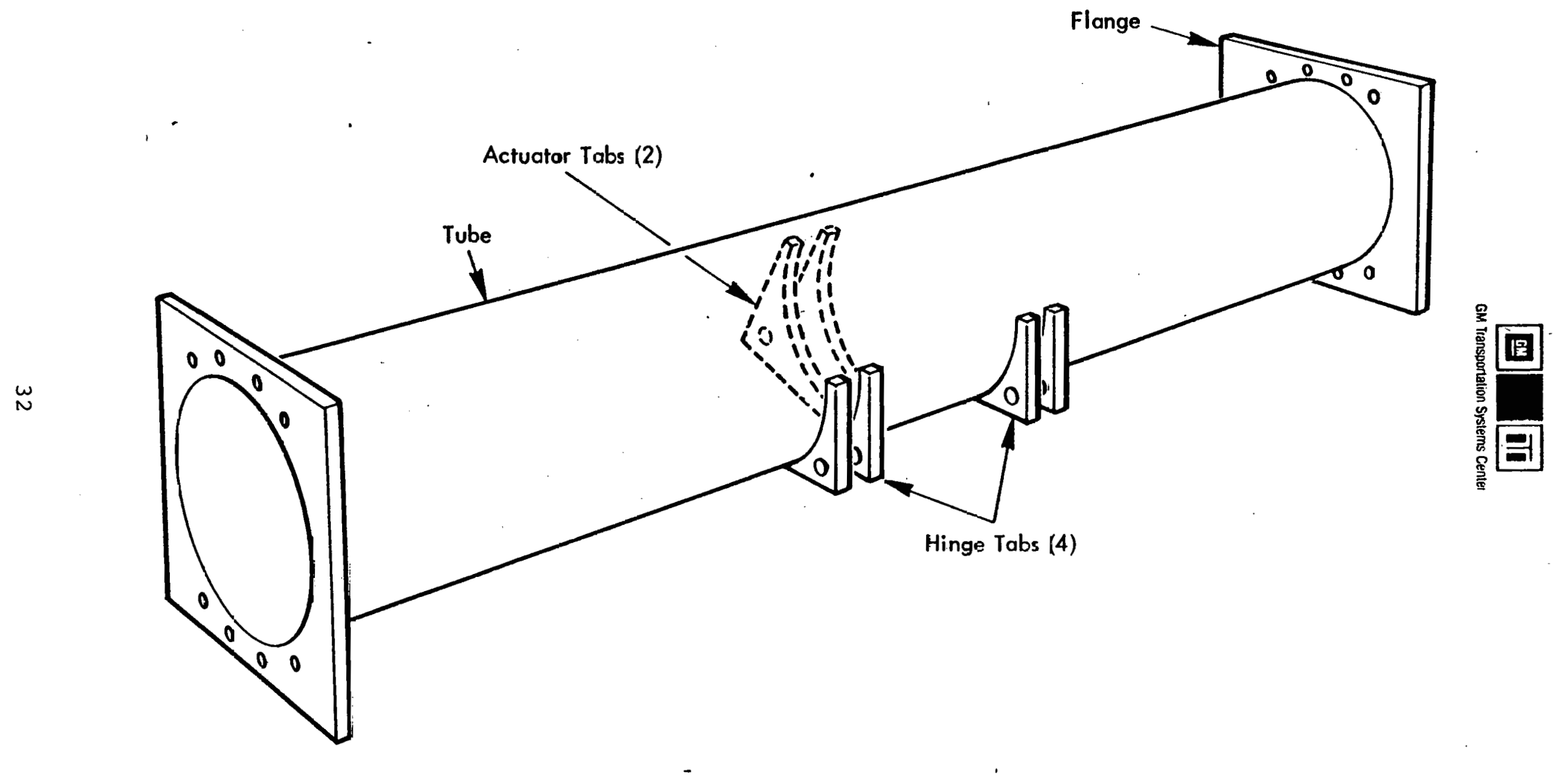

Figure 3-9. TORQUE: TUBE 


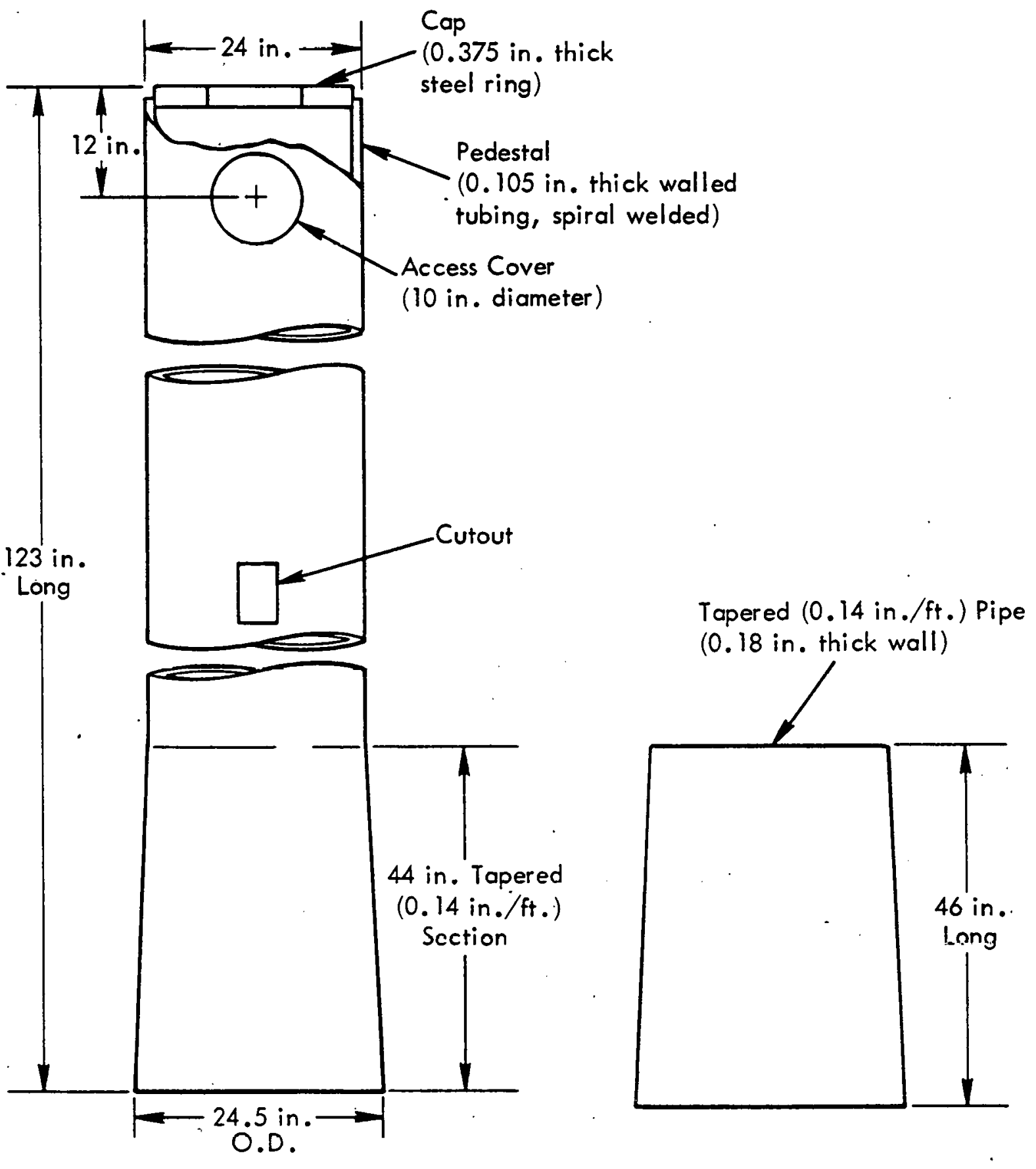

Figure 3-10. PEDESTAL ASSEMBLY 


\section{THIS PAGE \\ WAS INTENTIONALLY \\ LEFT BLANK}




\section{Gix \\ GM Transportation Systems Center \\ SECTION 4.0 \\ PROCESSING DESCRIPTION}

This section includes descriptions of the manufacturing process, equipment and plant for the two production volumes of 25,000 and 250,000 heliostats per year. Also discussed are the sourcing of heliostat components and the make/buy decisions which led up to the selection of the sources. Each major component of the heliostat processing is described in a section which contains information for both production volumes. The final section contains plant layouts for the heliostat plants for the two production volumes.

\subsection{PRODUCTION FLOW}

Pictorial representations of material and processing flow through the plants for the 25,000 and 250,000 annual volumes are shown in Figures 4-1 and 4-2.

For the lower production volume, major purchased items include:

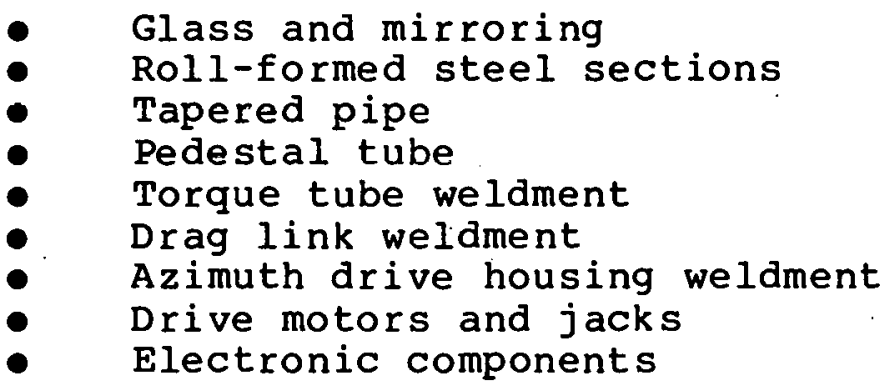

Plant.processing includes:

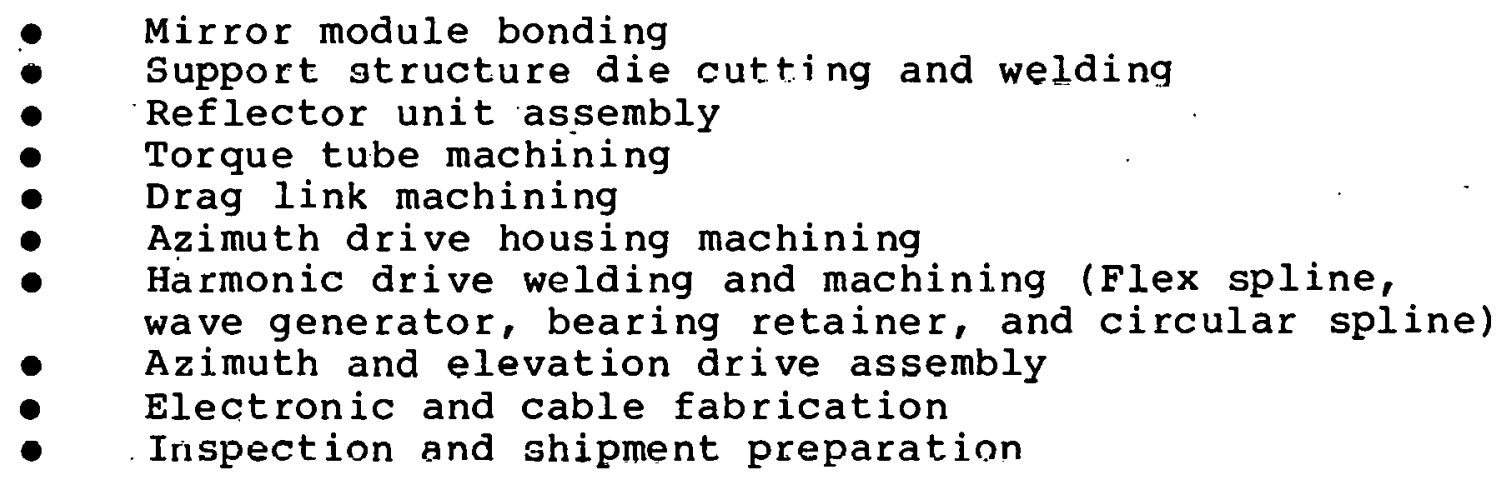

At the higher production volume, weldment preparation is performed in the heliostat plant. Operations performed include: tube tapering, welding and galvanizing. The items produced in this manner include the tapered pipe, pedestal tube, retainer, torque tube, drag link and azimuth drive housing. In addition, the higher production necessitates redesign of the machines and tooling for the higher flow rates. 

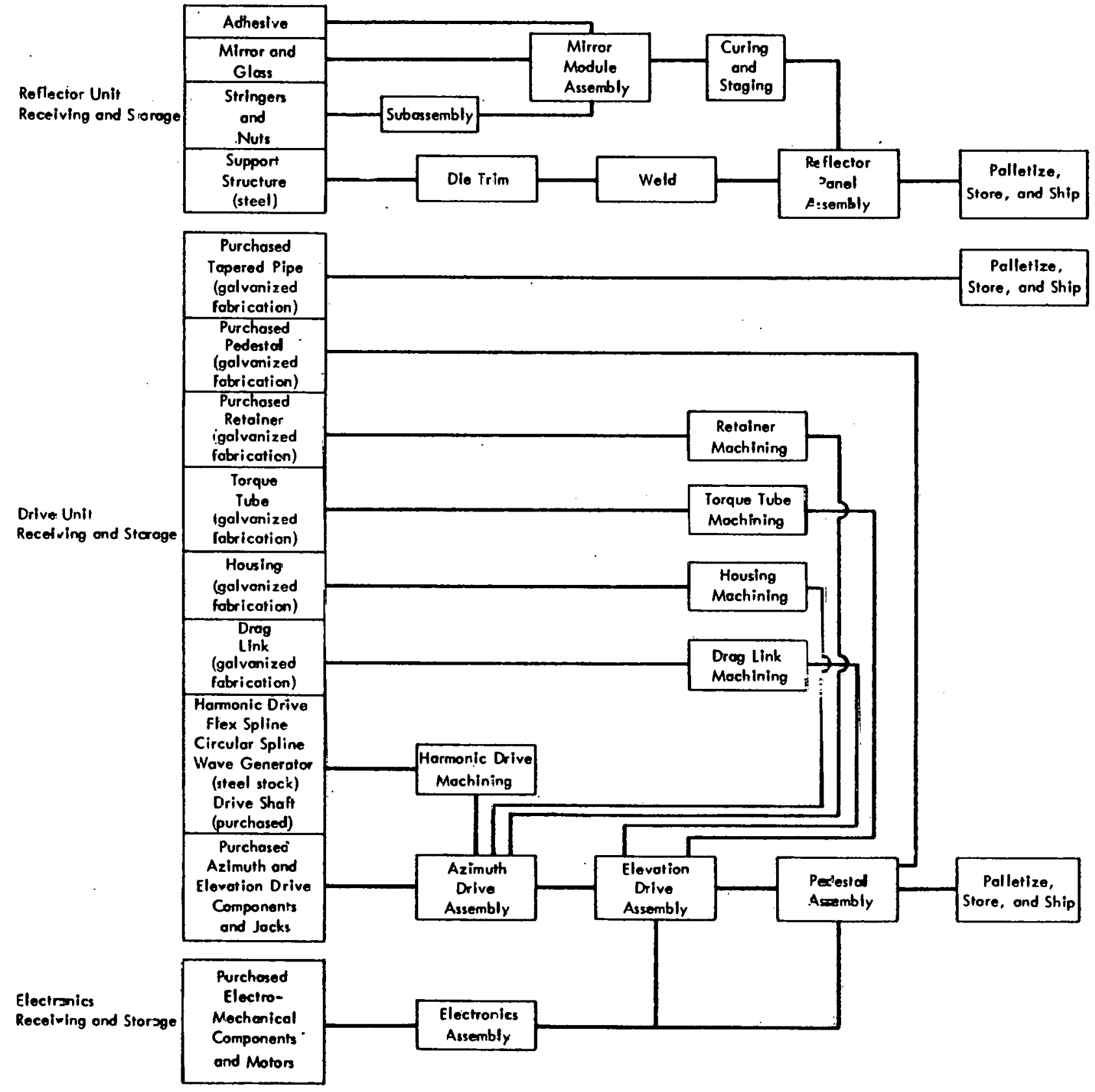

Figure 4-1. 25,0 00 ANNUAL VOLUME PRODUCTION FLON DIAGRAM. 


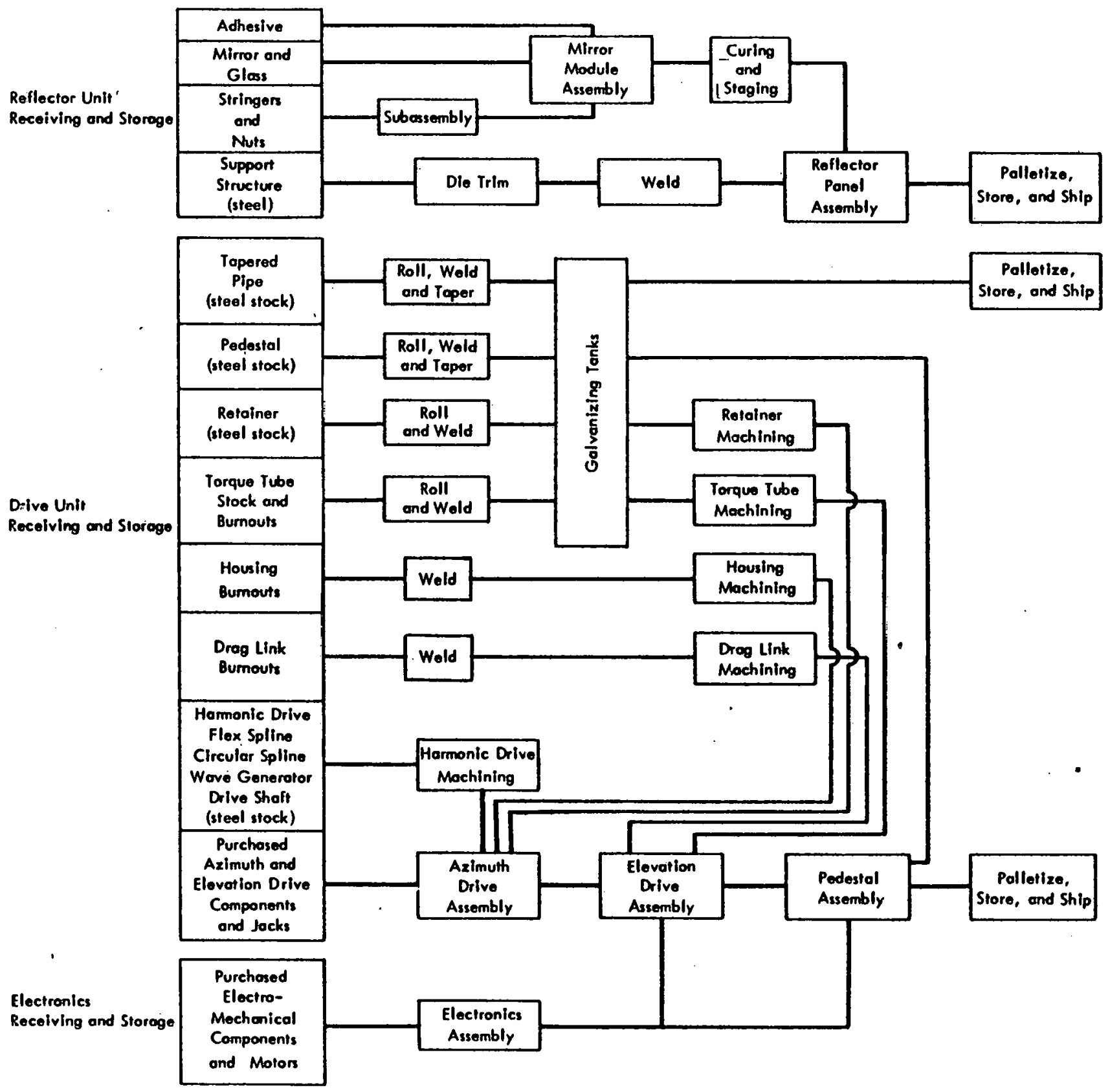

Figure 4-2. 250,000 ANNUAL VOLUME PRODUCTION FLOW DIAGRAM 


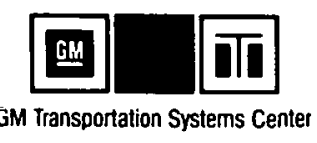

\subsection{MAKE/BUY DECISIONS}

\subsubsection{Reflective Surface}

Make/buy decisions for the 25,000 volume include the following:

- Purchase float glass - Commercial product with large tooling investment

- Purchase fusion glass - Proprietary process, Corning Glass Company

- Purchase adhesive - Special product, 3M

Purghacs ntringers - Cummerulal productioi lacillty designed for high volume; special tools are purchased for heliostat production. Clinch nut insertion is performed in the manufacturing plant.

- Purchase mirroring - Process in fusion glass plant reduces handling cost and breakage

- Make glass laminates and bond stringers - Unproven technology discourages vendor quotes for laminating and bonding. In-house facilities will be required for these operations.

All make/buy decisions for the 250,000 volume remain the same as the 25,000 volume. Additional investment capital is required for fusion glass, because the vendor may not risk capital to expand the facility. Expansion is required because the current plant does not have sufficient capacity.

\subsubsection{Support structure}

Make/buy decisions for the 25,000 volume include the following:

Purchase inboard beams, outboard beams, and diagonal beams - commercial production facility designed for very high volume. Special tools are purchased for heliostat production. Die cutting and shaping of the diagonal and inboard beams is performed in the manufacturing plant.

Make structure in-house - The welding is a risk item due to the structure design, and process control is best maintained in-house. Shipment of low density structure from supplier to assembly operation would increase costs. 
All make/buy decisions for the 250,000 volume remain the same as the 25,000 volume. Additional investment capital is required for the rolled beam sections. The vendor will not risk capital investment for these parts since there is no other usage for the increase in capacity generated by this special product. Therefore, tooling for the roll forming must be purchased by the heliostat producer.

\subsubsection{Reflective Unit}

Make/buy decisions for the 25,000 volume include the following:

- Assemble units in heliostat plant - shipping of parts to intermediate point increases cost. Quality control can be maintained at a higher level by in-plant assembly.

- Purchase fasteners - Commercial product

All make/buy decisions for the 250,000 volume remain the same as the 25,000 volume.

\subsubsection{Drive Assembly}

\subsubsection{Azimuth Drive Assembly}

Make/buy decisions for the 25,000 volume include the following:

- Purchase housing weldment - Specialized manual cutting and welding operations are available from local vendors at reasonable cost.

- In-house machining of housing weldment - Machining volume justifies special purpose machine line which is not available at veridor operations.

- Fabricate harmonic drive components - Proprietary vendor item made under license from USM. Supplier is not willing to fabricate special drive.

- Purchase gears and bearings - Commercial products

- Purchase mounting hardware - Commerical products

Make/buy decisions for the 250,000 volume include the following:

- Fabricate housing weldment in heliostat plant. specialized welding and plating facility is justified at this volume.

- Remaining decisions are the same at the higher volume. 
GM Transportation Systems Center

\subsubsection{Actuators}

Make/buy decisions for the 25,000 volume include the following:

- Purchase tracking and stowage actuators - Commercial products

- Purchase mounting hardware - Commercial products

All make/buy decisions for the 250,000 volume remain the same as the 25,000 volume.

\subsubsection{Drag L̄ink Assembly}

Make/buy decisions for the 25,000 volume include the following:

- Purchase drag link weldment - Specialized manual. cutting and welding operations are available from local vendors at reasonable cost.

- In-house machining - Machining volume justifies special purpose machine which is not available at vendor operations.

- Purchase mounting hardware - Commercial products

Most make/buy decisions for the 250,000 volume remain the same as the 25,000 volume with the following exception:

- Fabricate drag link weldment in heliostat plant. Specialized welding and plating facility is justified at this volume.

\subsubsection{Torque Tube Assembly}

Make/buy decisions for the 25,000 volume include the following:

- Purchase torque tube weldment - Specialized manual welding and cutting operations are available from local vendors at reaconable coat.

- In-house machining of torque tube - Machining volume justifies special purpose machine.

- Purchase mounting hardware - Commercial products 
GM Transportation Systems Center

Most make/buy decisions for the 250,000 volume remain the same as the 25,000 volume with the following exception:

- Fabricate torque tube weldment in heliostat plant. specialized welding and plating facility cost is justified at this volume.

\subsubsection{Pedestal Assembly}

Make/buy decisions for the 25,000 volume include the following:

- Purchase pedestal and tapered pipe, complete, from vendor - specialized fabricating and plating operations are available from local vendors at reasonable cost.

Make/buy decisions for the 250,000 volume include the following:

- Purchase pedestal end cap - Volume does not justify purchase of punching and piercing equipment to lower production costs.

- In-house fabrication 'of pedestal tube - Volume justifies purchase of roll- and taper-forming equipment to lower production costs.

- In-house fabrication of tapered pipe - Volume justifies purchase of roll- and taper-forming equipment to lower production costs. This is the same equipment used for pedestal tube processing.

- In-house welding of pedestal cap and tube - Volume justifies purchase of welding equipment.

- In-house galvanized plating - Volume justifies purchase of plating equipment. This equipment is also used for the plating operations on the azimuth drive housing, drag link, and torque tube.

\subsubsection{Electrical/Electronic Equipment}

\subsubsection{Control and Signal Electronics}

Make/buy decisions for the 25,000 volume include the following:

Purchase electrical cable and electronic components Commercial products readily available at this volume.

- Purchase printed wiring boards - Specialized operations are available from local vendors at a reasonable cost: 
GM Transportation Systems Center

- In-house cutting, trimming, and terminating of cables Capital equipment costs are low enough to justify fabrication in heliostat plant to lower production cost.

- In-house component insertion and flow soldering Capital equipment costs are low enough to justify fabrication in heliostat plant to lower production cost.

All make/buy decisions for the 250,000 volume remain the same as the 25,000 volume. Automatic equipment for component insertion and inspection is justified at this volume level to lower production labor costs.

\subsubsection{Motors (Position/Limit Indicator)}

Make/buy decisions for the 25,000 volume include the following:

- Purchase motors - Commercial product

- Purchase printed wiring boards - Specialized operations are available from local vendors at a reasonable cost

- In-house component insertion and flow soldering Capital equipment costs are low enough to justify fabrication in heliostat plant. Equipment is shared with control and signal electronics production.

All make/buy decisions for the 250,000 volume are the same as the 25,000 volume.

\subsubsection{Power Supply and Distribution System}

Make/buy decisions for the 25,000 volume include the following:

- Purchase electrical and fiber optic cables - Commercial products readily available at this volume at a reasonable cost.

- In-house cutting, trimming, and terminating of cables Capital equipment costs are low enough to justify fabrication in heliostat plant to lower production labor cost.

All make/buy decisions for the 250,000 volume are the same as the 25,000 volume. 


\subsection{PLANT PROCESSING AND EQUI PMENT}

This section contains a description of the plant processing for each major component of the heliostat for the production volumes of 25,000 and 250,000 units per year. In addition, the plant equipment used for each operation is shown along with the processing description.

\subsubsection{Reflector Assembly}

The reflector assembly is made up of the fusion/float glass laminated panel, with the reinforcing stringers bonded to it. Initially vendor supplied laminating and bonding operations were a consideration, but due to the new and unproven technology, firm quotations were not obtainable. Therefore, the decision was made to develop a concept design for a laminating and curing operation at both the low and high annual volumes. These lines together with the production equipment for the mirror support structure and reflector assembly are described in the following paragraphs.

\subsubsection{Reflective Surface}

Processing for the reflective surface involves handing of the float and fusion glass lites, bonding the glass lites together, bonding the hat section stringers to the back of the float glass, and curing of the assembly in an oven. The processing line is shown in Figure 4-3.

The processing for the reflective surface at the 25,000 unit annual volume follows:

(1) Float glass is loaded in shipping containers at the beginning of the line. The glass loader extracts the glass lites from the container and places them, " $t$ in" side down, on the conveyor. One loader handles all float glass fed to the line. The glass loader is described in a subsequent paragraph.

(2) The float glass is carried on a conveyor through a jet spray wash, deionized water rinse, warm air dry, and spray application of the urethane adhesive.

(3) Fusion glass is loaded from shipping containers onto the adhesive-coated surface of the float glass with the mirrored side down.

(4) The sandwich is conveyed through the pinch rollers which press the sandwich together to assure uniform bonding with the adhesive. 


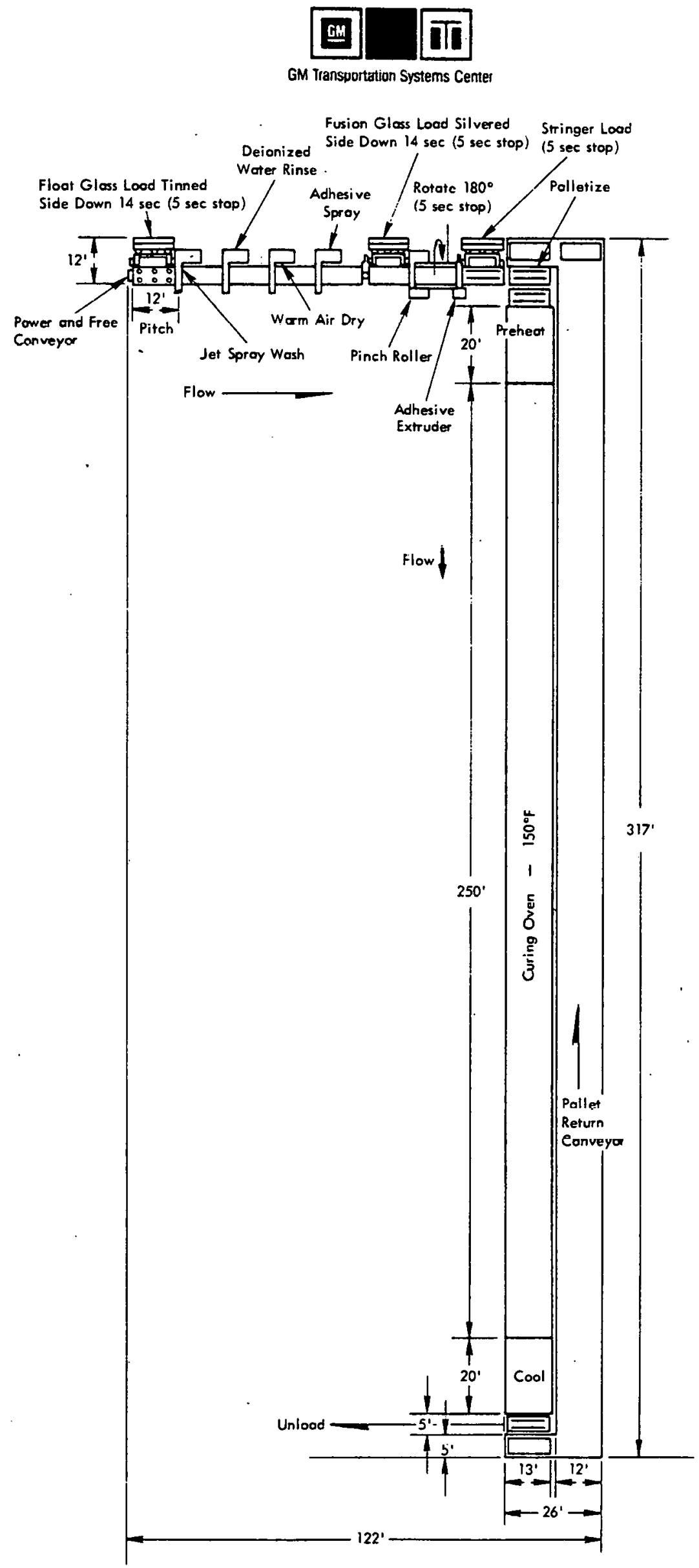

Figure 4-3. REFLECTIVE SURFACE LINE - 25,000 ANNUAL VOLUME 


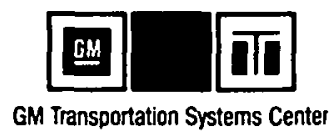

(5) The glass sandwich is rotated 180 degrees and moves through the extruder where adhesive is applied in the stringer section areas on the back of the float glass. The mirror module rotater is described in a subsequent paragraph.

(6) Two stringers are loaded on the back of each glass sandwich. The stringer loader is described below. Prior to loading, the stringer clinch nuts have been installed on the machine described in a subsequent paragraph.

(7) The sandwich and stringer assembly is conveyed into the rollerized pallets which clamp the stringers in place on the back of the float glass. The rollerized pallet is described in a subsequent paragraph:

(8) Pallets are conveyed into the curing ovens which operate at a temperature of 150 degrees $F$ and expose the reflector assemblies to a 10 minute curing cycle. Open type clamping fixtures, as opposed to platen-type devices, have been used to maximize the heat transfer into the adhesives.

(9) The exit area of the ovens includes a cooling area.

(10) After exiting the oven, the reflector assemblies are removed from the rollerized pallets and unloaded into racks for the completion of the curing cycle. Rack capacity in the plant is sufficient to allow a 3 hour cure before assembly of the reflectors onto the support structure.

(11) Rollerized pallets are conveyed back to the front of the oven to accept new assemblies for cycling through the oven.

Glass Loader - 25,000 Volume. The glass loader is used to load both the float and fusion-glass panels onto the assembly line. The arrangement and operation of the machine are shown in Figure 4-4. The following is a brief description of the machine operating cycles:

(1) Float/fusion glass arrives in shipping crates from the supply source.

(2) Shipping crates are loaded onto the glass loader with forklift trucks.

(3) Packaging is removed manually from the front side of the shipping crate. 

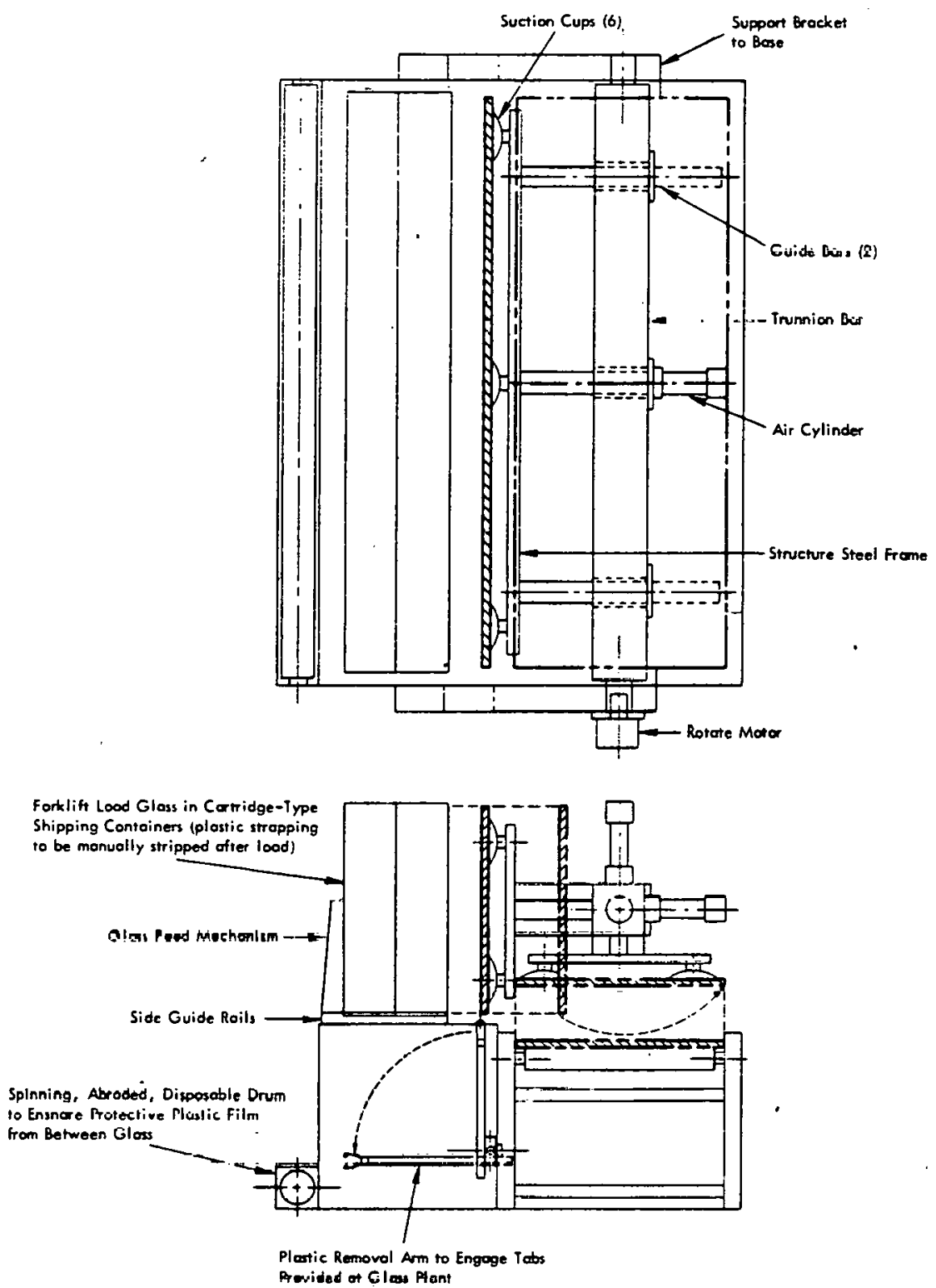

Scale $1 / 4^{\prime \prime}=l^{\prime}$

Figure 4-4. GLASS LOADER - 25,000 ANNUAL VOLUME 


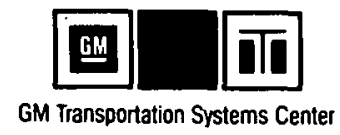

(4) A single glass lite is removed from the crate with a suction-cup rack mounted on the machine and positioned for rotation to point over the bed of the assembly line. In the case of mirrored fusion glass. This position is maintained while the protective film is engaged by the fingers on the machine.

(5) The glass lite is then rotated 90 degrees so that it is parallel with the bed of the assembly line. The protective film is removed from the mirrored glass during this motion.

(6) The glass Iite is then moved vertically downward to the bed of the machine and the vacuum is released in the suction cups. In the float glass case, the "tin" side of the glass is placed on the assembly line bed. For the mirrored fusion glass, the "mirror" side is placed on the adhesive-coated surface of the front glass.

Mirror Module Rotator $-25,000$ Volume. After the fusion/float glass sandwich has been bonded and passed through the pinch rolls, it is necessary to rotate it 180 degrees for application of the stringers to the back of the fusion glass. The mechanism for accomplishing this is shown in Figure 4-5. The device shown in this figure is capable of handling six sandwich sections simultaneously and is used on the line for the 250,000 unit annual volume. A single-sided version of this machine is used for the low-volume case.

The following is a brief description of the machine operating cycle:

(1) The glass sandwich is conveyed into the rotator and positioned after passing through the pinch rollers.

(2) Cam rollers then move to engage the end locating pins which locate the glass sandwich between the sets of large rollers on the machine.

(3) When clamped, the machine cycles to rotate the glass sandwich and clamp assembly 180 degrees.

(4) After rotation, the cam rollers release the locating pins and free the sandwich and allow it to be conveyed to the next station for application of adhesive and stringers.

Stringer Loader $-25,000$ Volume. The stringer loader is used to place the two stringers, with clinch nuts installed, on top of the adhesive strips which have been extruded on the back of the float glass. The arrangement and operations of this machine 


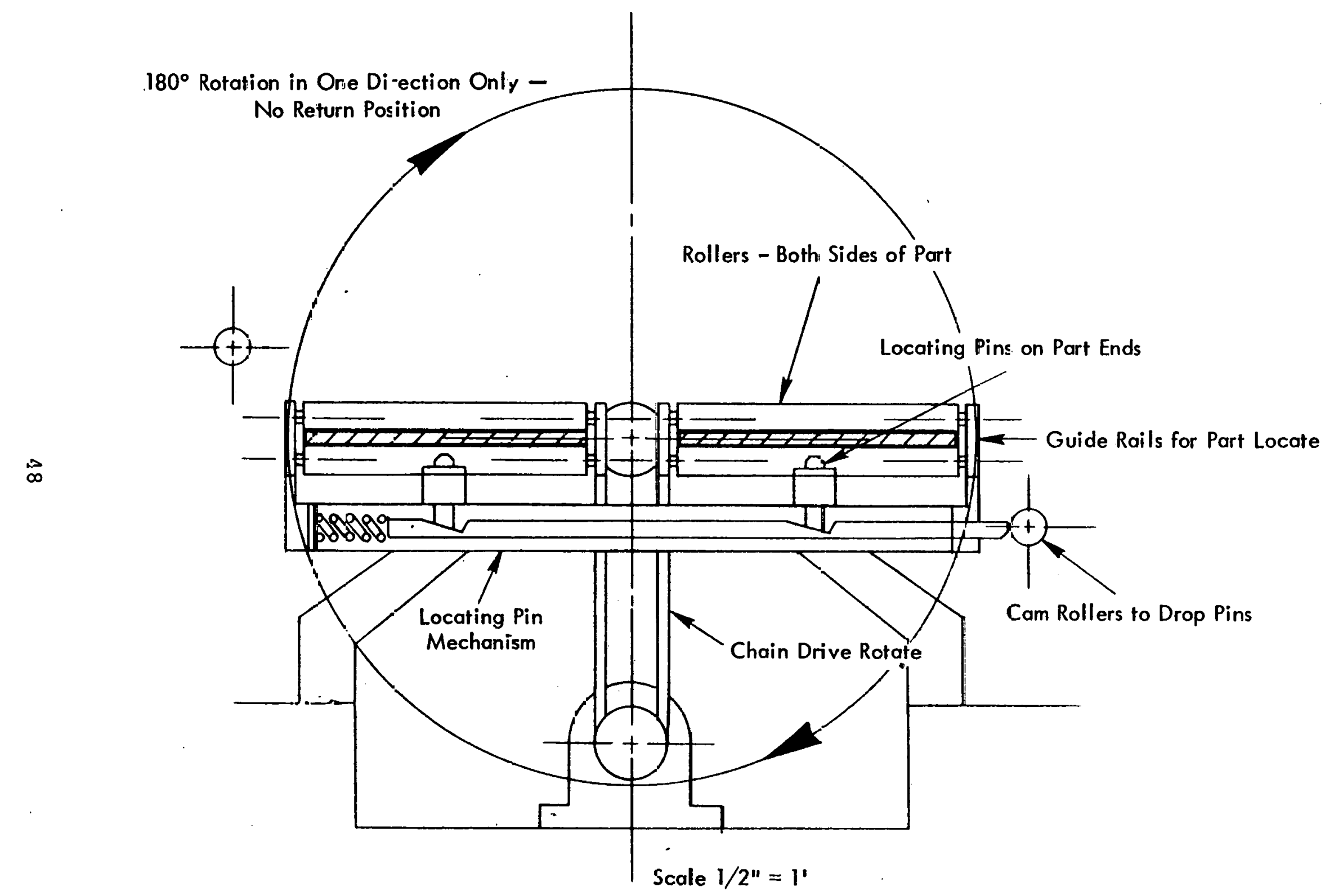

Figure 4-5. MIRROR MODULE ROTATOR - 25,000 ANNUAL VOLUME 


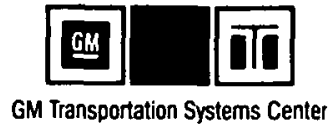

are shown in Figure 4-6. The following is a brief description of the machine operating cycles:

(1) The stringers are packaged in shipping containers which contain groups of 26 stringers in a cartridge.

(2) Cartridges are forklifted onto the loading machine in a vertical position with the top of the hat section facing the loading mechanism.

(3) The machine arms pick out a pair of stringers from the cartridge with magnetic clamps. The stringers are positioned with guide pins which engage the clinch nuts. The arm position spacing is equal to the stringer spacing required for the assembly.

(4) The arms translate out from the pallet to a position which allows rotation over the glass surface and rotates it 90 degrees.

(5) The arms move vertically downward and press the stringers into the extruded adhesive on the back of the float glass.

(6) The arms unclamp from the stringers and recycle to pick up the next pair of stringers from the cartridge (one position downward from the previous set).

(7) When the cartridge is emptied, it is removed with an overhead crane and the remaining cartridges move forward into the loading position.

Stringer - Clinch Nut Subassembly. Clinch nuts are installed, two per stringer, with the machine shown in Figure 4-7. The stringers, loaded in the shipping container, are loaded into the machine with an overhead crane. As the cartridge indexes through the mashine, clinch nuts are fed into position and pressed into each stringer.

At the low volume of 25,000 units, only one feeder and press are required. At the higher volume of 250,000 units, one feeder and four presses are used to increase the machine output.

Rollerized Pallets - 25,000 Volume. The rollerized pallet is used to hold the glass sandwich and stringers in position during the curing cycle in the line oven. This assures good alignment between the glass panels and the stringer assemblies. The arrangement and operation of the machine are shown in Figure 4-8. Following is a brief description of the machine operating cycle: 


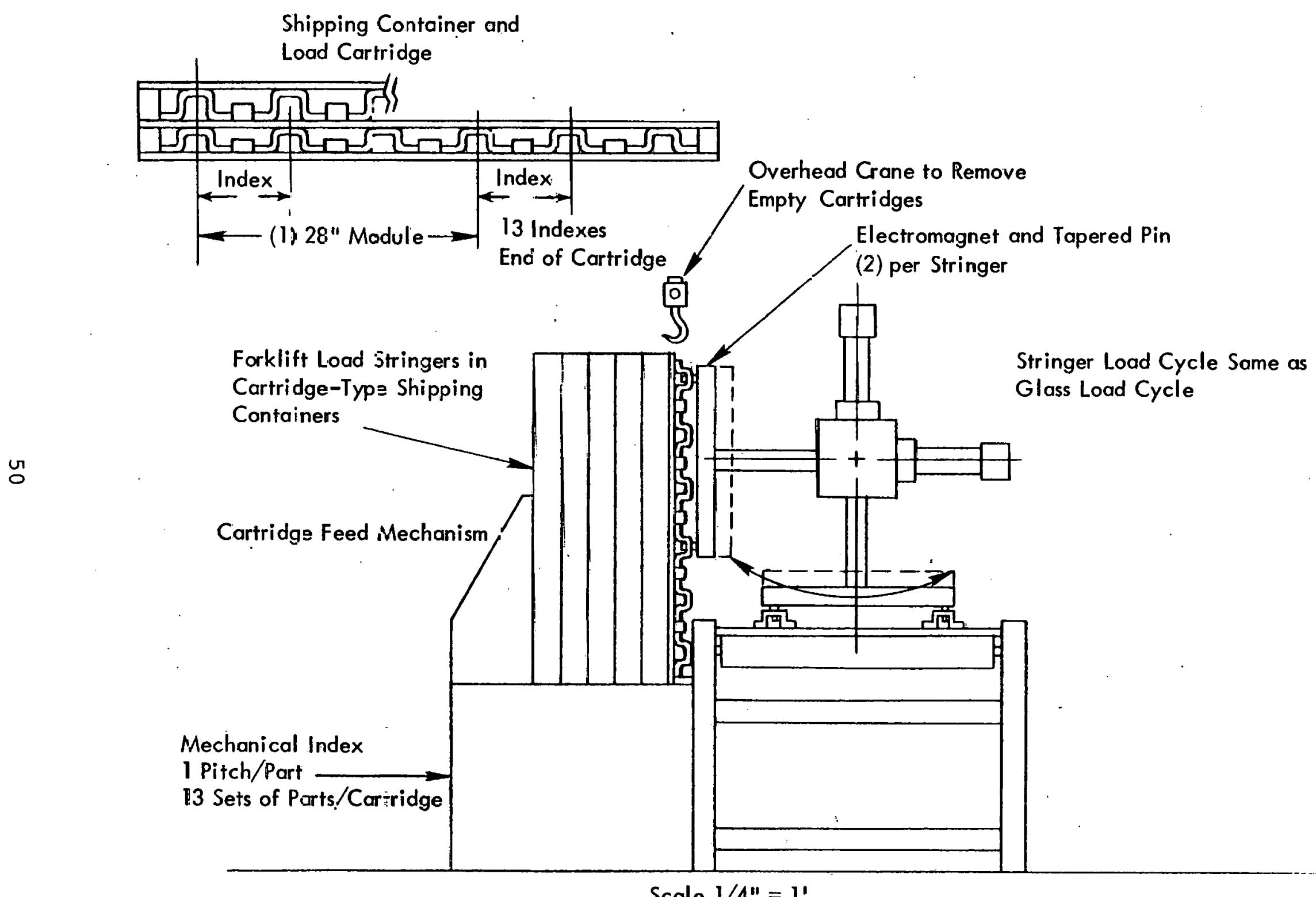

Scale $1 / 4^{\prime \prime}=l^{\prime}$

Figure 4-6. STRINGER LOADER - 25,000 ANNUAL VOLUME 


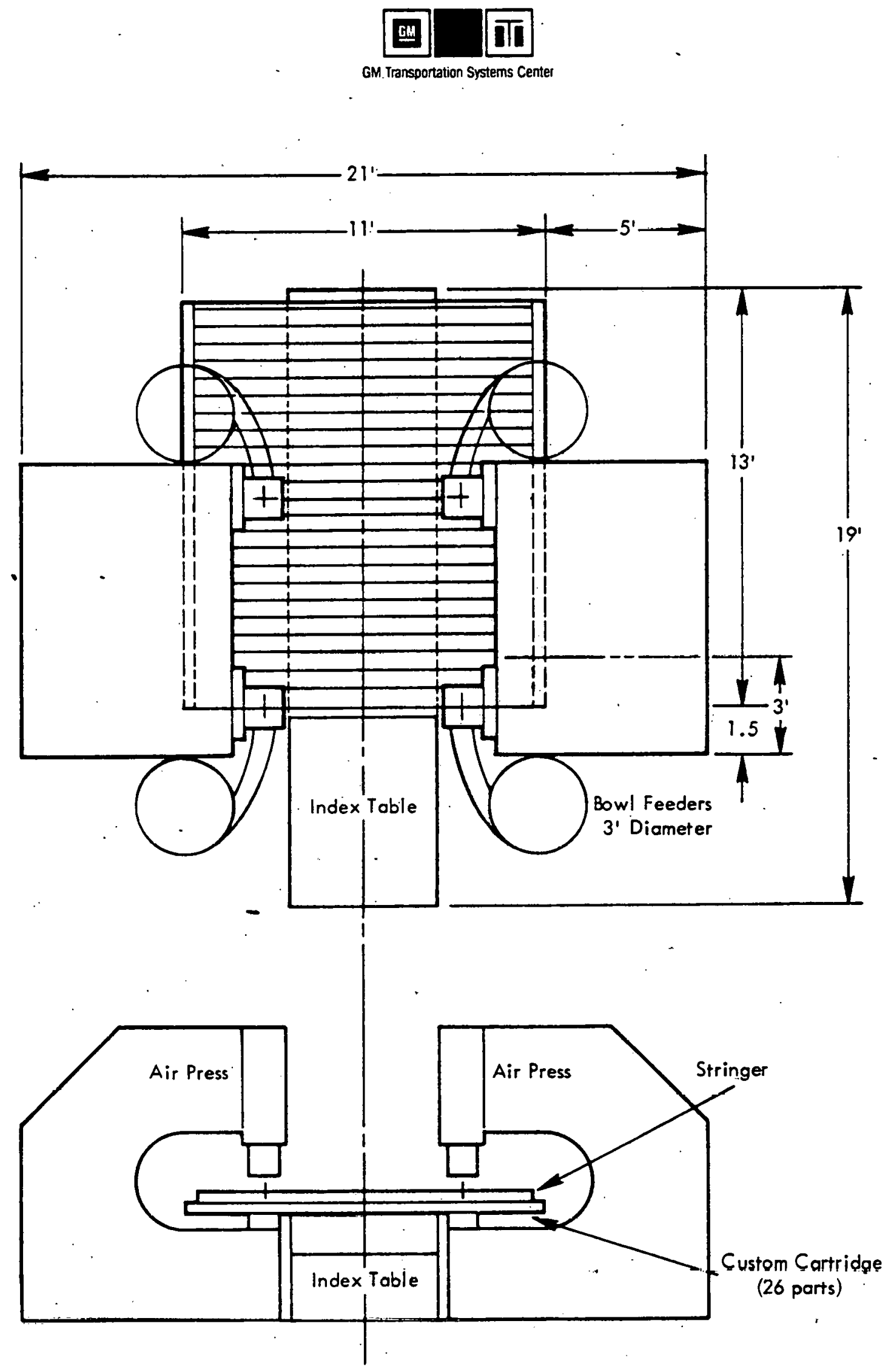

Figure 4-7. STRINGER - CLINCH NUT SUBASSEMBLY - 25,000/250,000 UNIT ANNUAL VOLUME 


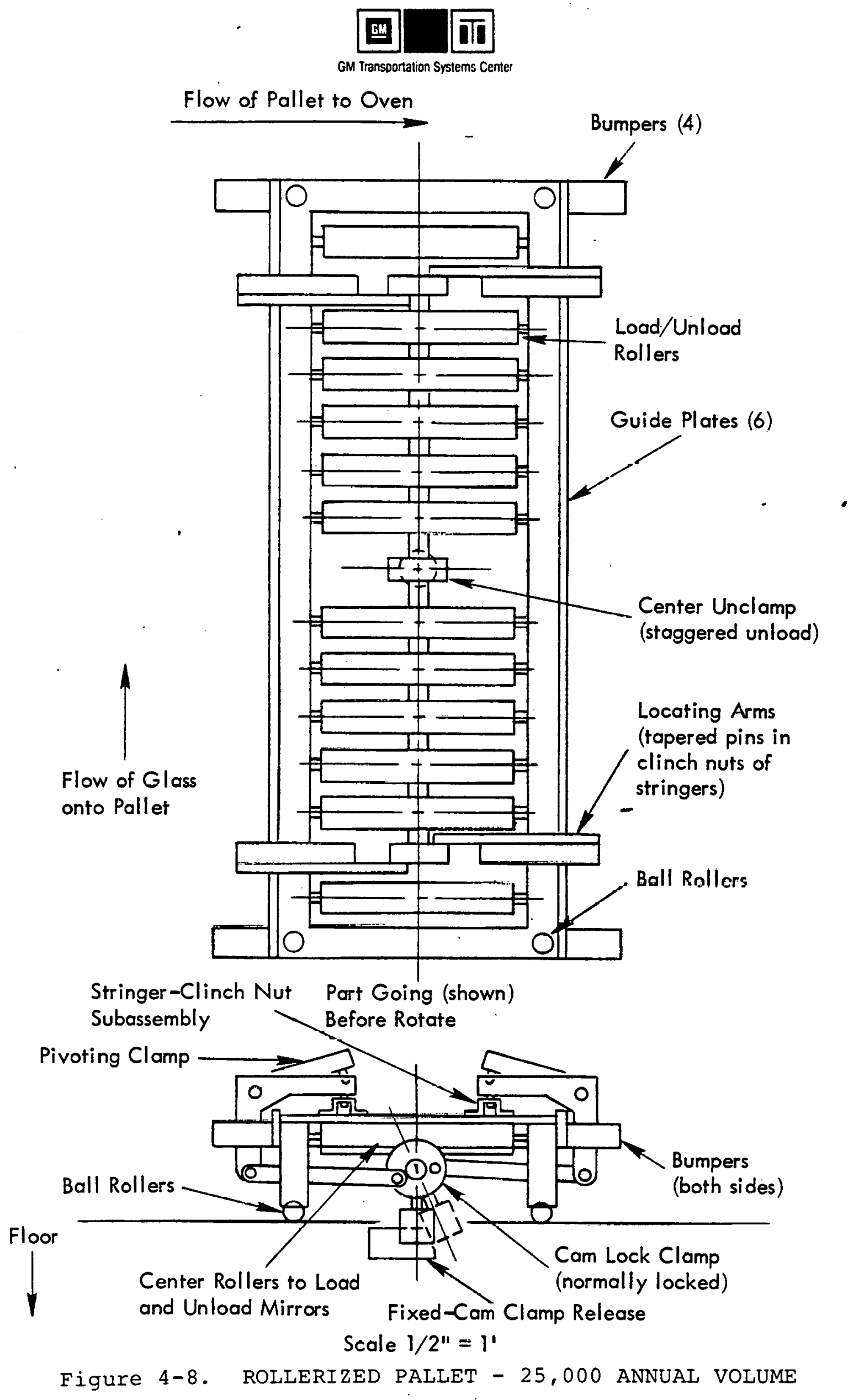


(1) The glass sandwich, with stringers attached, is conveyed into the rollerized pallet. At this point, the pallet is in a position with the cam lock held open. This frees the locating pins for the stringers.

(2) As the pallet moves from this position, the cam lock is released. This engages the edge and pin clamps.

(3) The pallet is conveyed through the curing oven with all clamps engaged.

(4) At the exit from the curing oven, the cam lock is released. This allows the cured reflective surface assembly to be conveyed out of the pallet and loaded into storage racks.

(5) Empty pallets are guided back to the assembly area for recycling through the oven.

There is no inspection at this point. Manual inspection operation is performed at this point for adhesive and stringer bonding.

\subsubsection{Reflective Surface - 250,000 Volume}

For the 250,000 volume a dual reflective surface line is employed (Figure 4-9) and the units are processed in groups of six. The processing of the reflective surface for the 250,000 volume is the same as the 25,000 volume, except that there are six each (three on each side) of the float glass and fusion glass loaders, rotators, and stringer loaders for the higher volume.

\subsubsection{Mirror Support structure}

The mirror support structure is fabricated from roll-formed sheet steel sections which are used for the inboard, diagonal and outboard beams. In addition, the mounting area between the torque tube and the structure is reinforced with formed doublers and gussets. Prior to welding of the beams, the ends of the diagonal and inboard beams are cut and formed in pressing operations. All components are then assembled into the welding machine for spot welding. This fixture provides good control of the structural alignment for later assembly. with the reflector panels. After welding the assembly is drilled and counter sunk for the beam mounting bolts and the frame is straightened. These operations are performed on the machines listed on the following pages.

Inboard Beam. The roll-formed sections for the inboard beam, received from the metal forming supplier, are loaded into the transfer press shown in Figure 4-10. After loading, the beams 


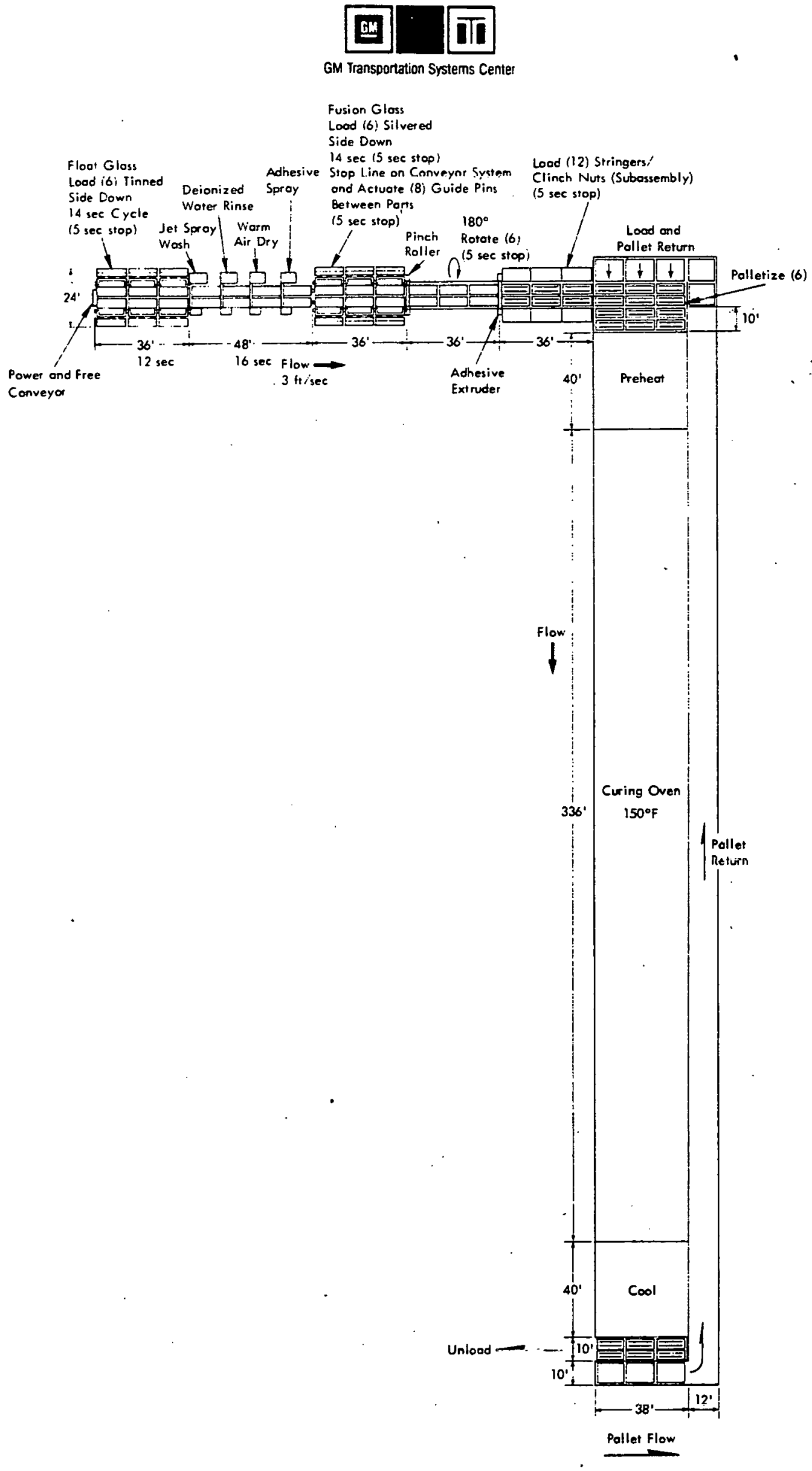

Figure 4-9. REFLECTIVE SURFACE LINE - 250,000 ANNUAL VOLUME 


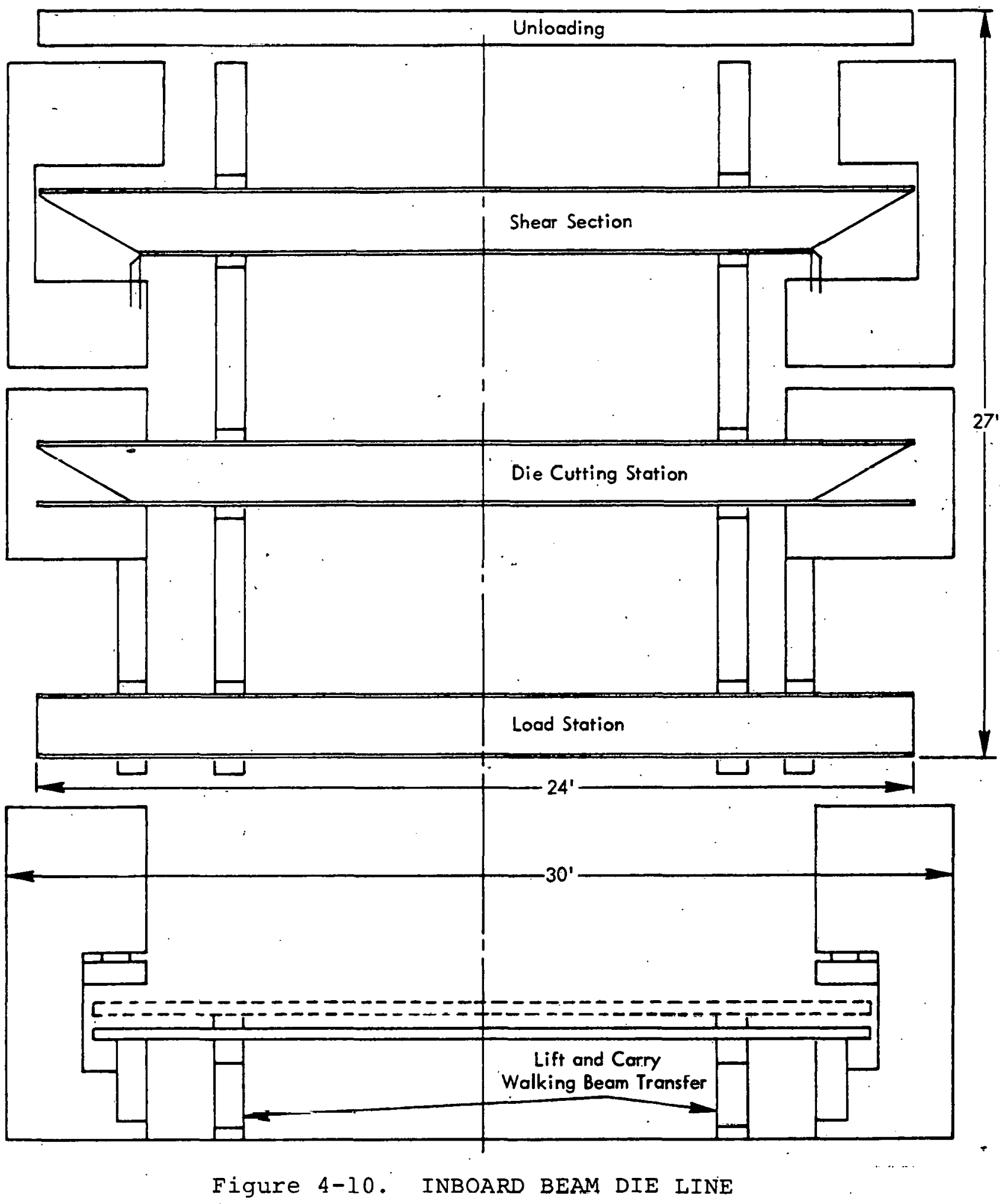




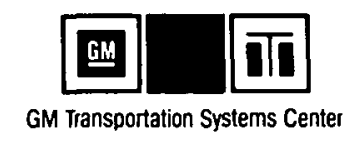

are automatically transferred through the two stations of the double-ended transfer press. The first stage of the press forms the taper cut in the beam and the second stage removes the flange section. The part is then transferred to the unloading station.

Diagonal Beam. The roll-formed sections for the diagonal beam, received from the metal forming supplier, are loaded into the transfer press shown in Figure 4-11. After loading, the beams are automatically transferred through the three stations of the double-ended transfer press. The first stage of the press forms the ends of the web section. The second stage of the press removes the flange sections of the beam. In the third section, flanges are bent up for the weld attachment to the inboard and outboard beams. The part is then transferred to the unloading section.

Outboard Beam. The outboard beam is received from the metal forming supplier pre-cut to length and punched for the mounting bolts. No die forming operations are required in this part.

Doublers and Gussets. These parts are formed by the supplier and do not require in-plant processing.

Welding. Process. The welding line for the assembly of the mirror support structure is shown in Figure 4-12. This 1 ine is fed by the die lines which form the inboard and diagonal beams. In addition the outboard beams, doublers and gussets are loaded into this line.

At Station 1 of this line, the doublers are manually loaded and spot welded to the inboard beam (see Figure 4-13).

At Station 2, the gussets are manually loaded and spot welded to the inboard beam (see Figure 4-14).

At station 3, gussets are manually arc-welded to inboard beam (see Figure 4-15).

At Station 4, outboard beams are manually loaded into the line (sed Figure 4-16).

At Station 5, the diagonal beams are loaded from the die line and six spot welds are completed at the joints between the diagonal beams and the inboard and outboard beams (see Figure 4-17).

At Station 6, the spot welding is completed between the diagonal and the inboard and outboard beams (see Figure 4-18). 


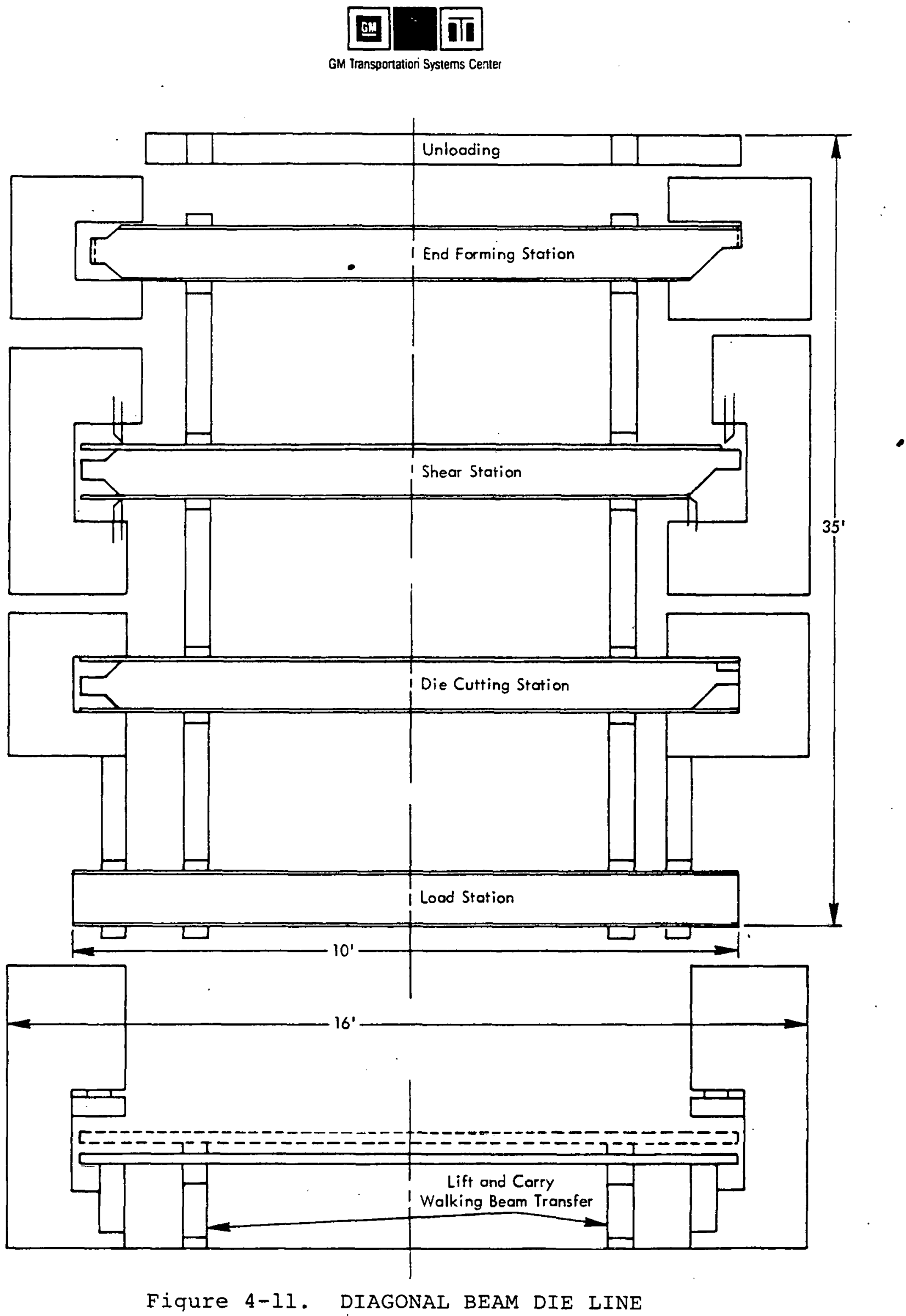




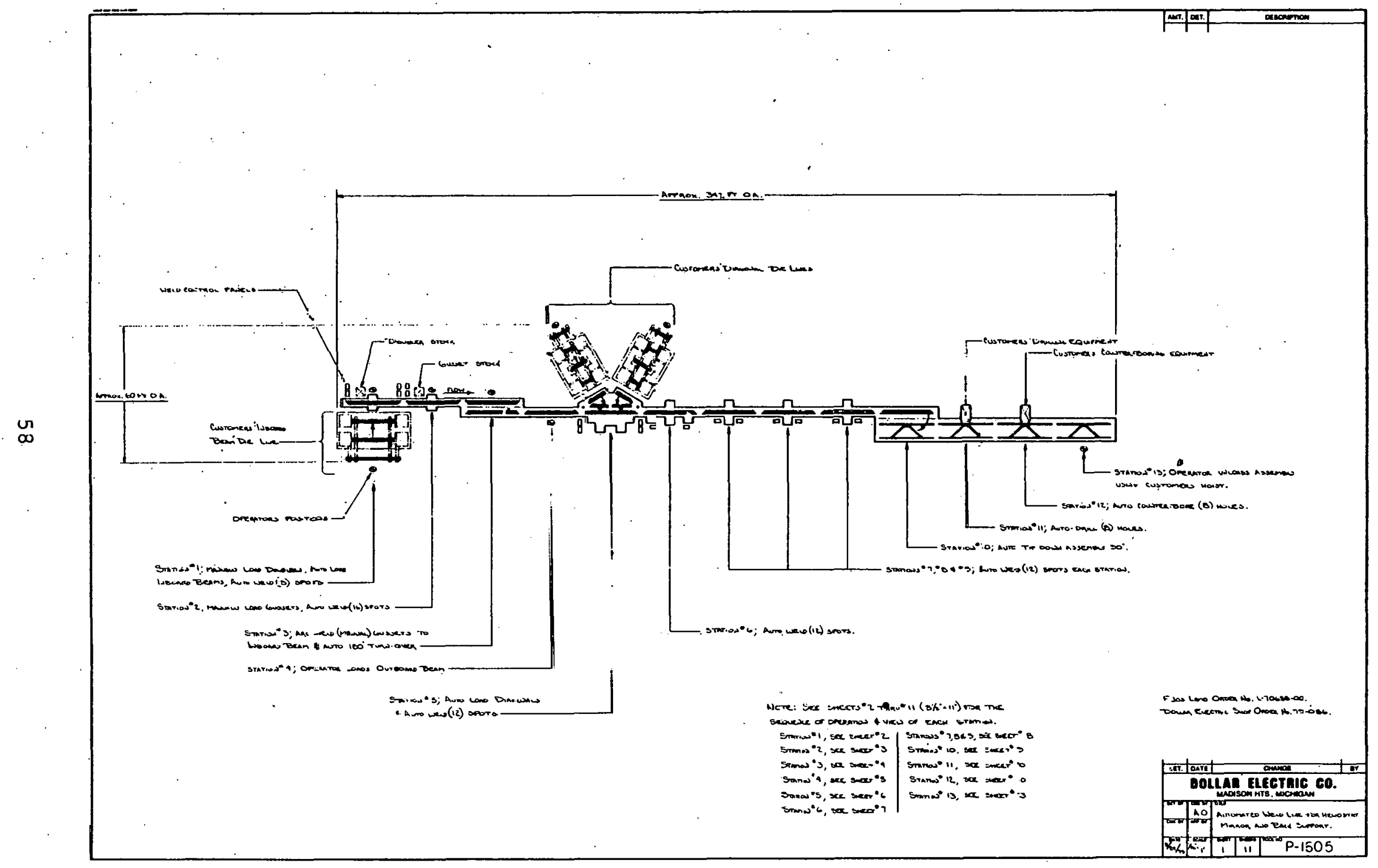

Figure 4-12. MIRRDR SUPPORT STRUCTURE WELDING LINE 
1. Auto index subassembly $26^{\prime}$

2. Manually load two doublers

3. Depress palm buttons

4. Lifter raises and beam end locator extends

5. Customer's lift and carry automation places inboard beam onto lifter

6. Lifter lowers beam onto doublers and into locators

7. Clamps close and eight equalizing weld guns pivot in

8. Weld eight spots

9. Clamps open, weld guns pivot out, and beam end locator retracts

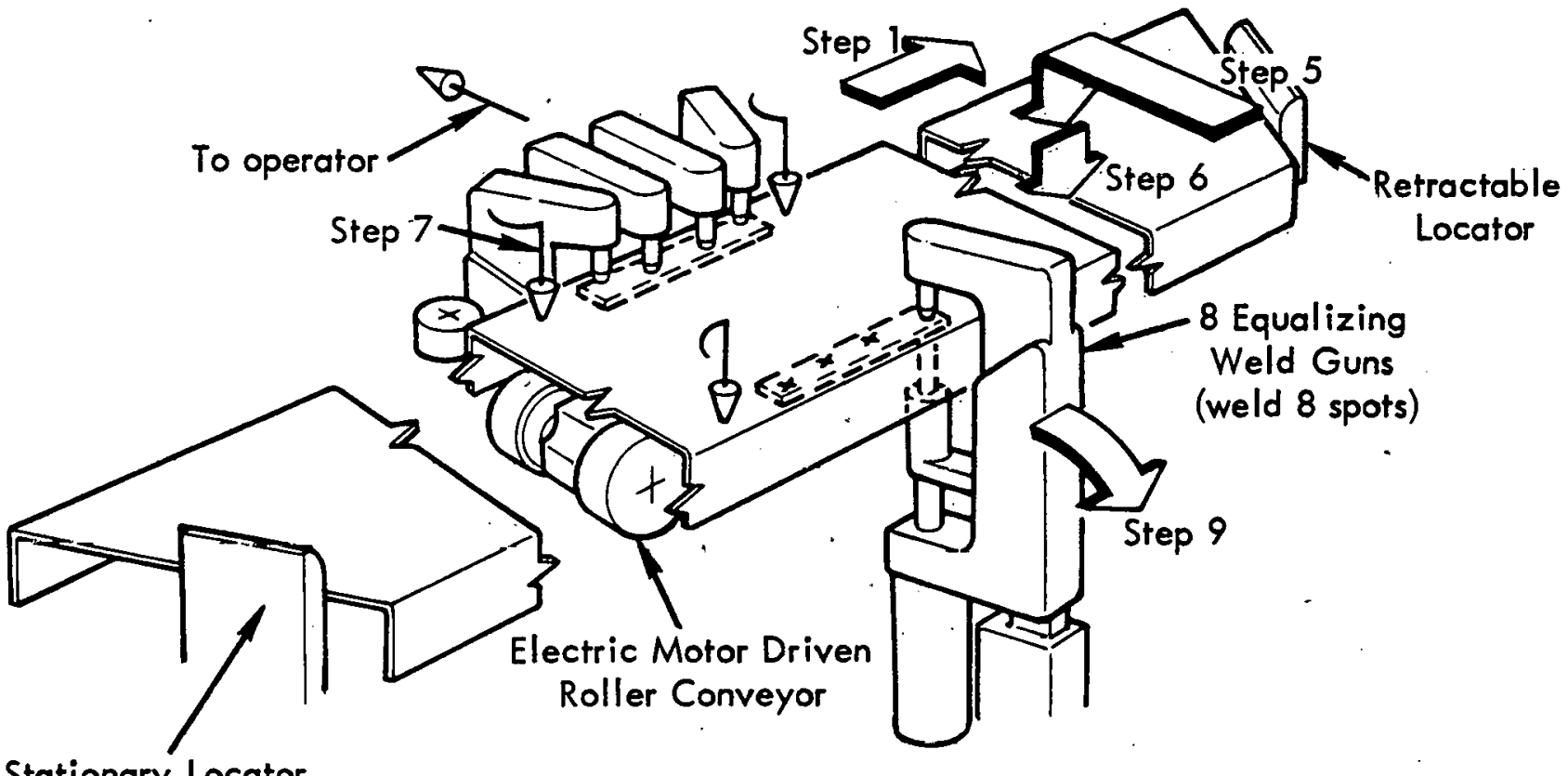
Stationary. Locator

at This End 
1. Auto index subassembly $26^{\prime}$

2. Manually load two gussets onto beam, into locator, as beam trailing end locator extends

3. Depress palm buttons

4. Clamps close on gussets

5. Weld four spots

6. Weld four spots

7. Index weld guns

8. Weld four spots

9. Weld four spots

10. Clamps open; beam end locators retract

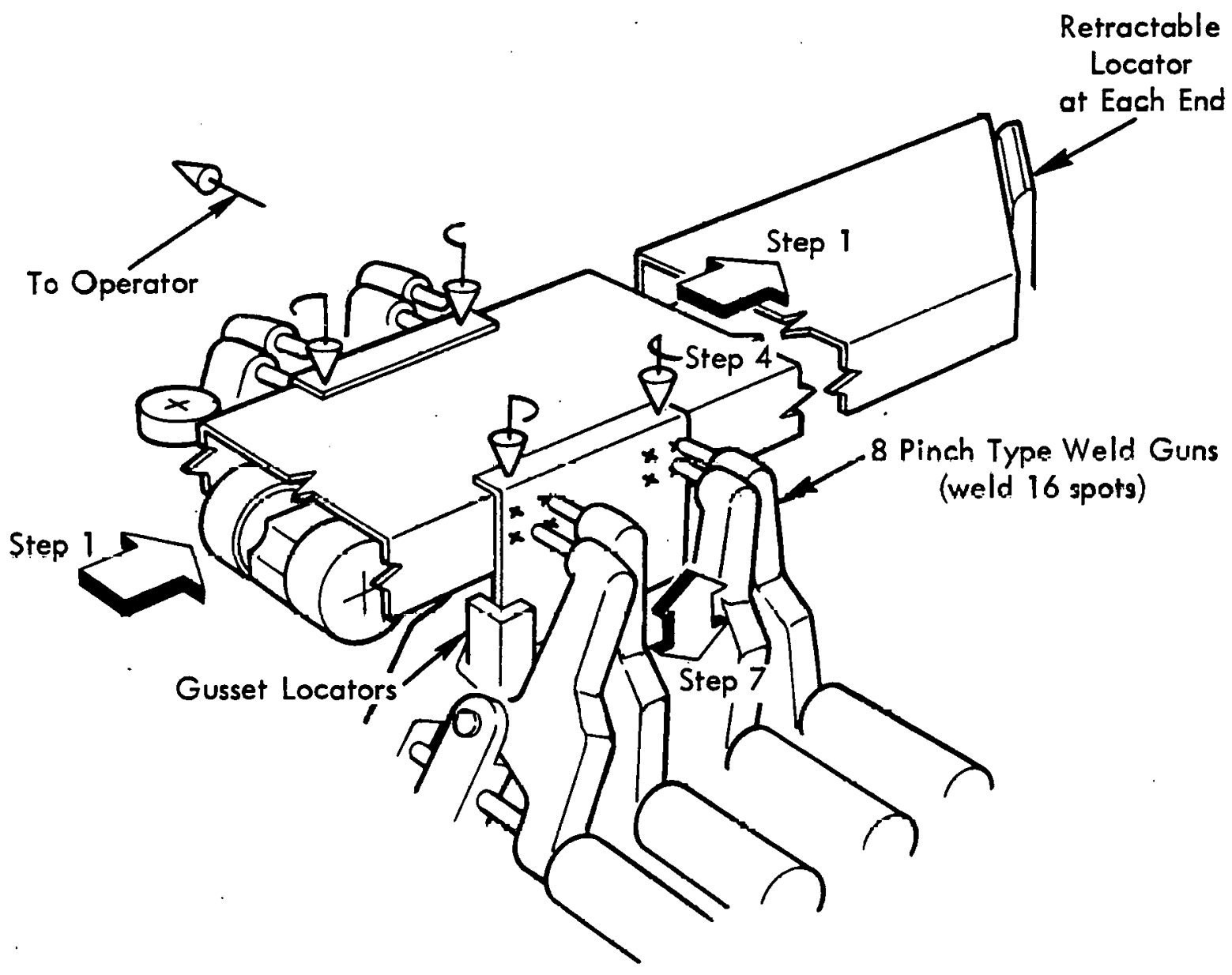

Figure 4-14. HELIOSTAT SUPPORT STRUCTURE STATION 2,
LOAD/WELD GUSSETS 
1. Auto index subassembly $26^{\prime}$

2. Depress palm buttons

3. Gusset clamps close

4. Manually arc weld using semi-automatic "squirt gun"

5. Depress palm buttons

6. Gusset clamps open

7. Turn over indexes $180^{\circ}$

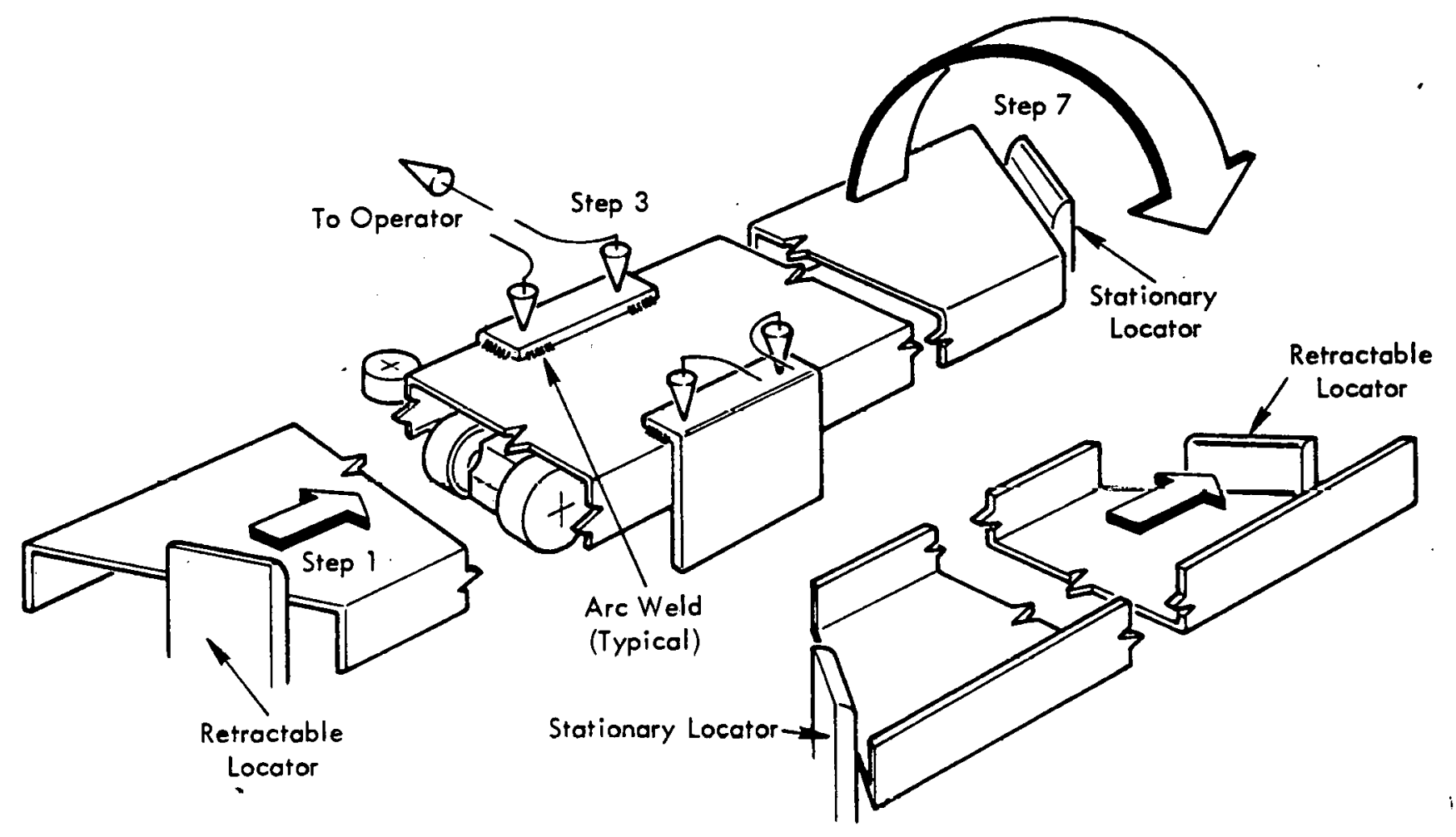

Figure 4-15. HELIOSTAT SURPORT STRUCTURE STATION 3, MANUALLY ARC WELD GUSSETS/AUTO TURN 
1. Auto index beams 26'

2. Loader lowers 4'

3. Manually load outboard beam into loader

4. Depress palm button

5. Looder raises $4^{\prime}$

\section{Electric Motor Driven Chain with} Pusher Dogs to Index Outboard Beam

Load Oytboard Beam onto Loader, within Idle Support/Guide Rollers

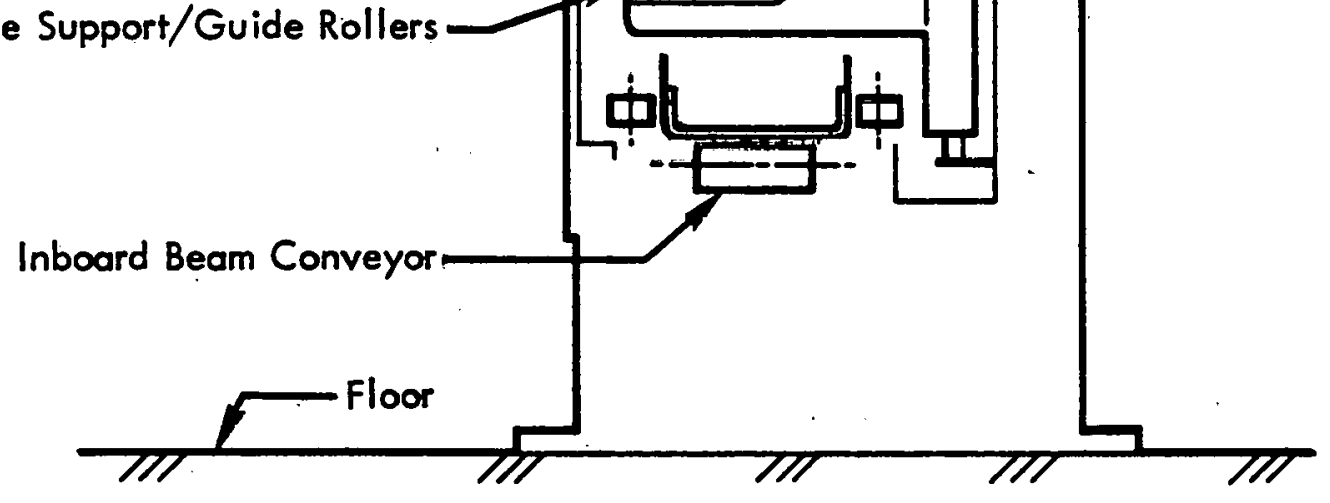

Front View - Part Coming Figure 4-16. HELIOSTAT SUPPORT STRUCTURE STATION 4,
LOAD OUTBOARD BEAM. 
1. Customer's lift and carry automation places diagonals into locators

2. Pivot-mounted locators index diagonals to load position

3. Diagonal loaders extend

4. Diagonal loaders grip diagonals

Note: Inboard and outboard beams outo index 26' during Steps 1 - 4.

5. Loaders index diagonals into station

6. Loaders rotate diagonals into position

7. Weld units advance 16" and shift down 5 "at center area. Weld units advance at outboard beam areas

8. Weld six spots

9. Index welding units

10. Weld six spots and diagonal loaders release

11. Weld units and diagonal loaders retract

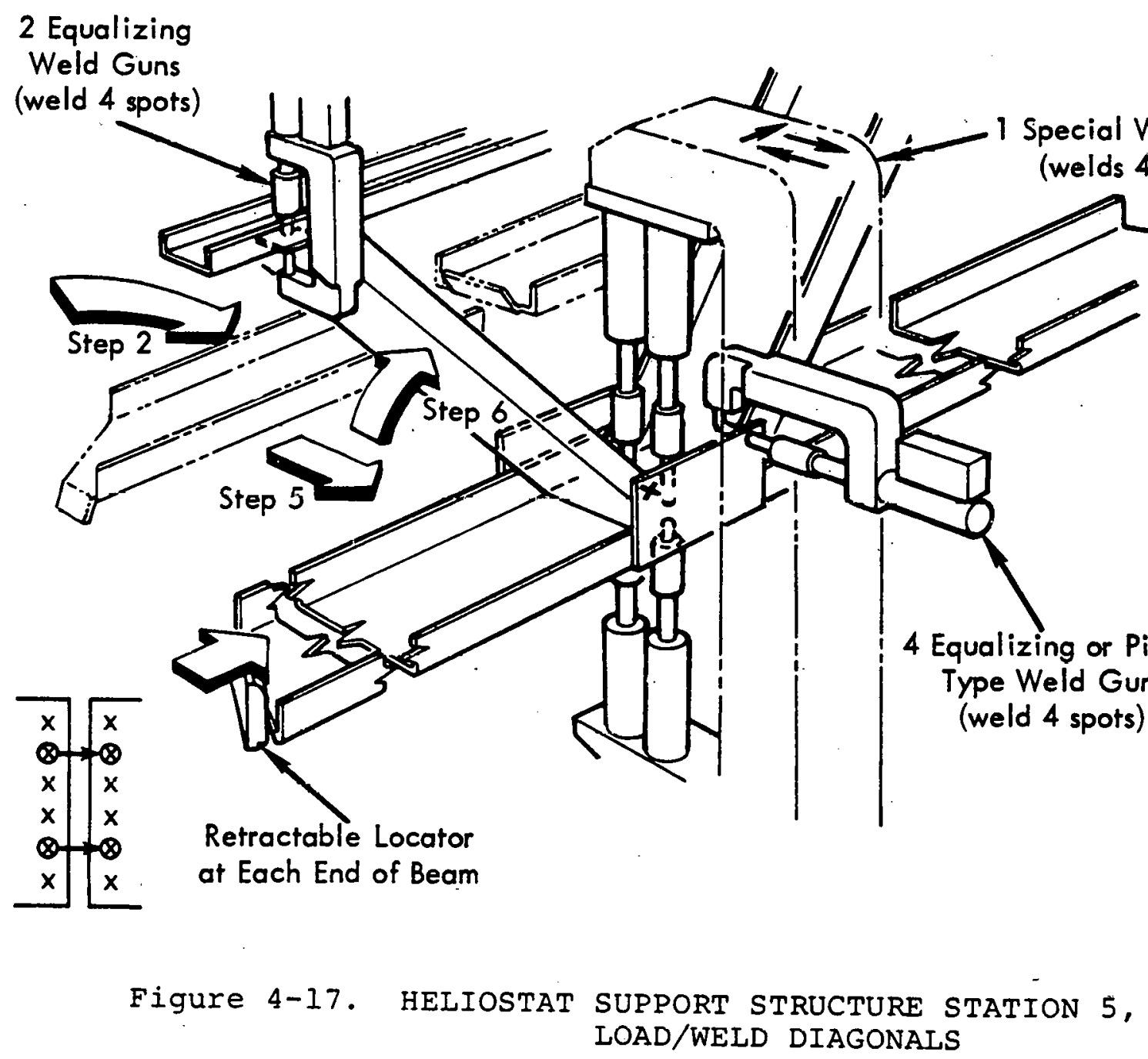


1. Auto index subassembly $26^{\prime}$

2. Weld units advance and shift down at center area. Weld units advance at outboard beam areas

3. Weld four spots

4. Index welding units

5. Weld four spots

6. Index welding units

7. Weld two spots

8. Index welding units

9. Weld two spots

10. Weld units retract

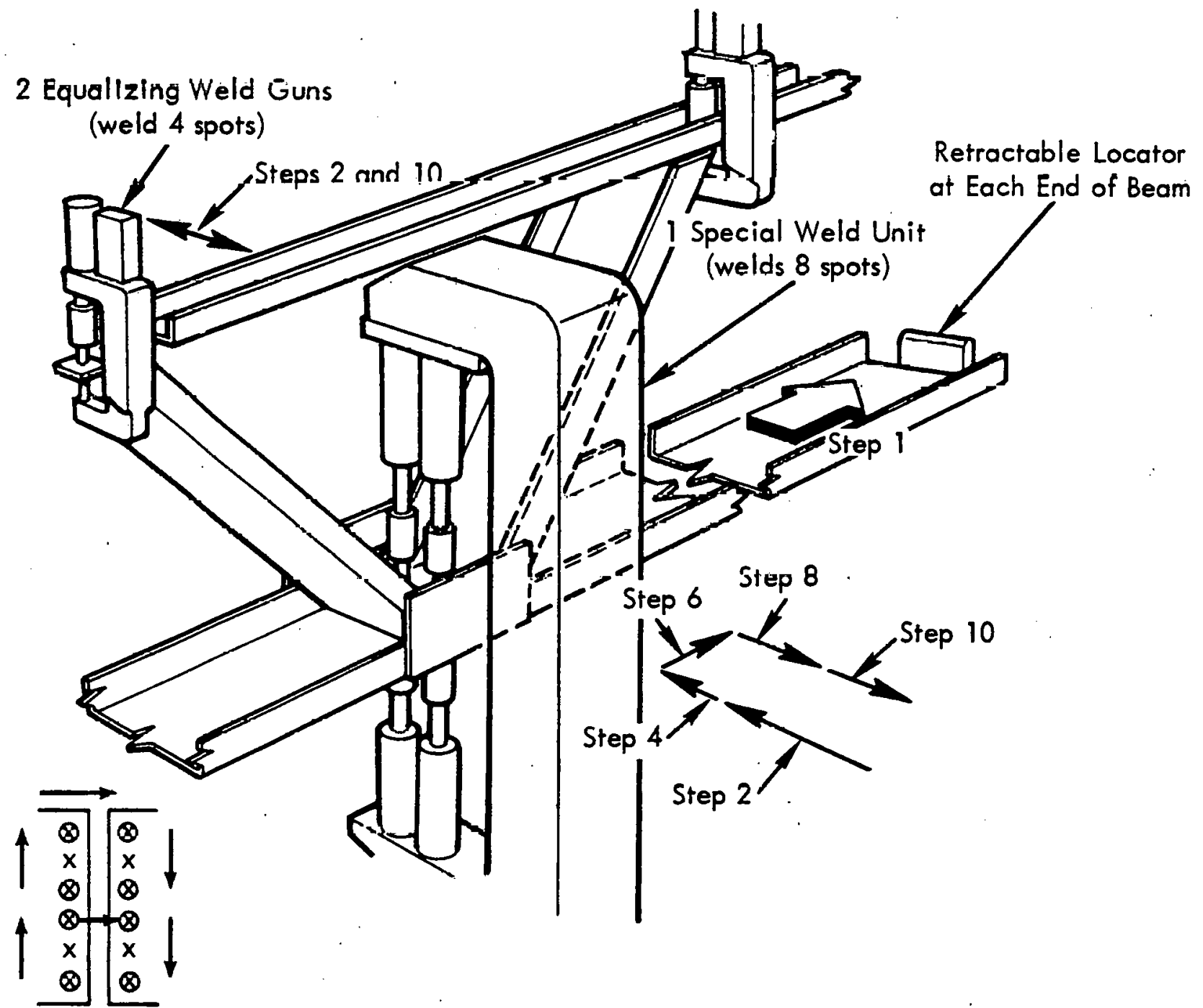




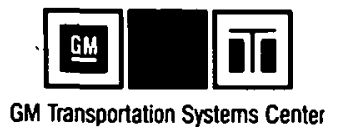

At Stations 7, 8, and 9, the spot welding is completed between the diagonal beams and the gussets (see Figure 4-19).

At Station 10, the assembly, which has been welded in the vertical position, is rotated downward 90 degrees to align it with the transfer table for movement to the next station (see Figure 4-20).

At Stations 11 and 12, the structure assembly is drilled and counterbored for the mounting bolts which are used for assembly to the torque tube (see Figure 4-21).

At station 13, the structure assembly is straightened and removed from the welding line with an overhead crane (see Figure 4-22).

\subsubsection{Reflector Assembly}

Assembly of the reflector unit consists of bolting the six mirror module units to the mirror support structure. Mirror module units are transported from the storage area to the reflector assembly area and loaded into an assembly fixture. The support structure is then lifted, with an overhead crane onto the assembly fixture. The 24 bolts which pass through the structure and engage the clinch nuts in the stringers are then installed and torqued manually with the assistance of air wrenches. These operations are performed. with the machine shown in Figure 4-23.

Six mirror module units are loaded onto the power and free conveyor unit which loads them onto the air table. The modules are positioned on the air table by the operators. The mirror support structure travels on the overhead crane and descends to the position over the air table. In this position, the operators feed and torque the attaching bolts between the structure and the mirror modules. At this station, the operators are positioned on an elevated platform which allows them to work over the inboard beam of the structure. After assembly, the reflector panels move down the conveyor to the inspection station. When inspection is complete, the reflector travels upward along the conveyor and travels to the shipping area. In the shipping area, the reflector is removed from the conveyor with an overhead crane and put into a shipping rack.

In the 25,000 unit annual volume, four operators and one assembly machine are required. At the 250,000 unit annual volume, twelve operators for each of the three assembly machines are required. 
1. Auto index subassembly $26^{\prime}$

2. Weld guns advance and lower

3. Weld four spots

4. Index guns

5. Weld four spots

6. Index guns

7. Weld four spots

8. Weld guns raise and retract

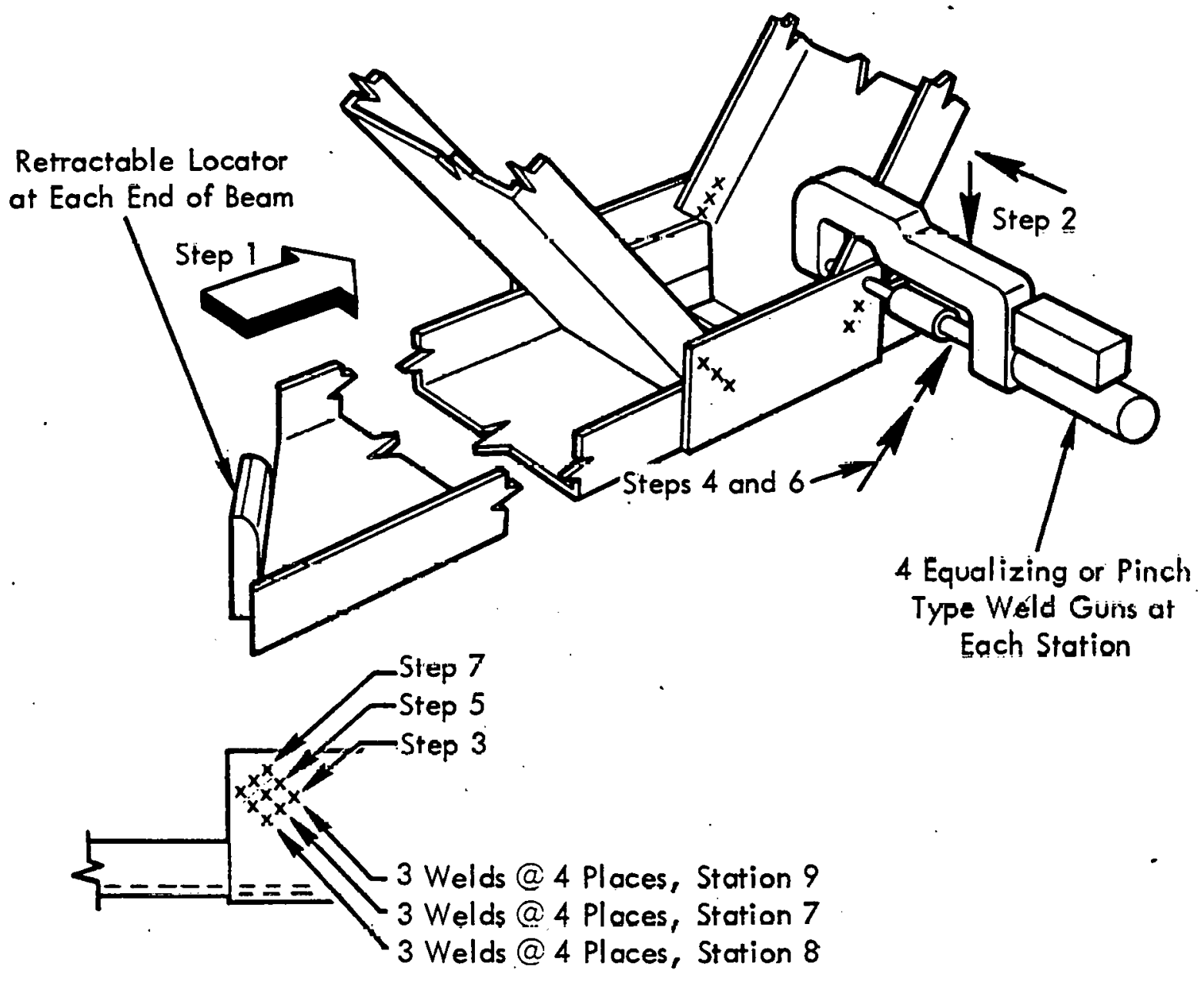

Figure 4-19. HELIOSTAT SUPPORT STRUCTURE STATION 7, 8, 9,
WELD DIAGONALS TO GUSSETS 
1. Auto Index (tipped-down) Assembly 26'

2. Empty Tipper Pivots Up $90^{\circ}$

3. Auto Index (up-right) Assembly 26'

4. Tipper Pivots down $90^{\circ}$

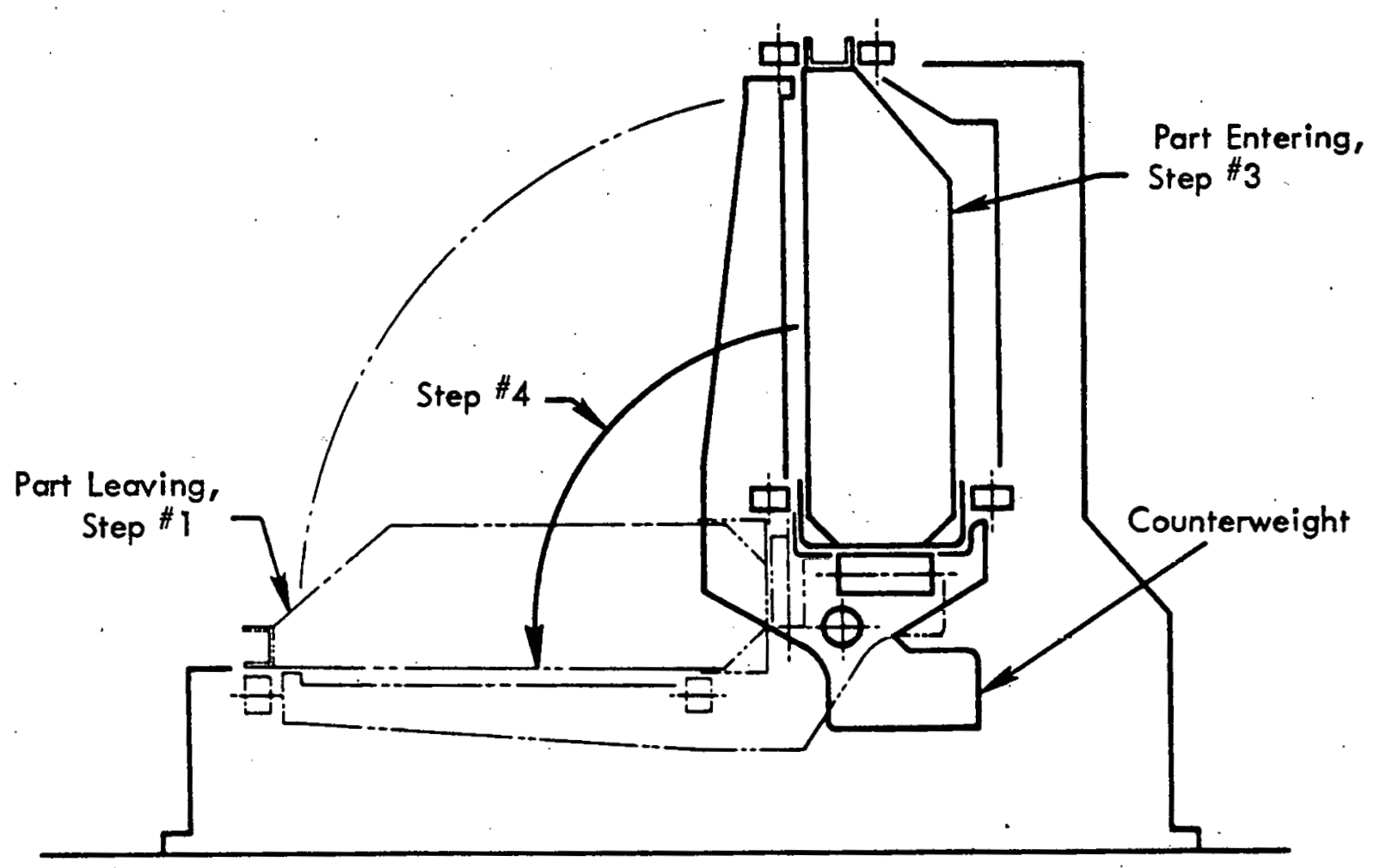

Figure 4-20. HELIOSTAT SUPPORT STRUCTURE STATION 10; $90^{\circ}$ TIP DOWN 
1. Auto index assembly 26', front locator extends

2. Rear locator extends

3. Drills advance, drill and retract

4. Front and rear locators retract

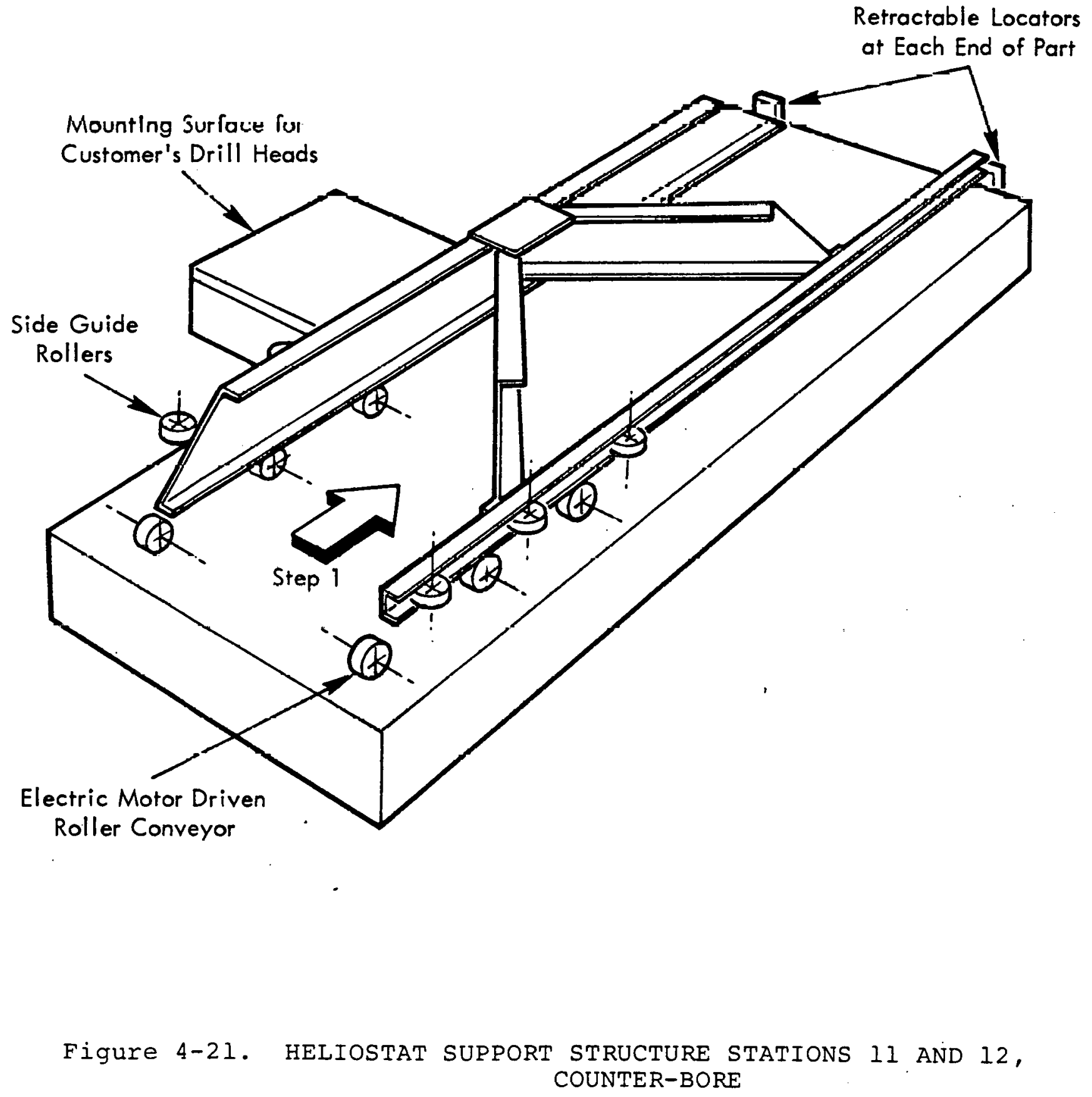


1. Auto index assembly $26^{\prime}$

2. Straighten

3. Manually unload assembly using customer's hoist

4. Depress palm buttons

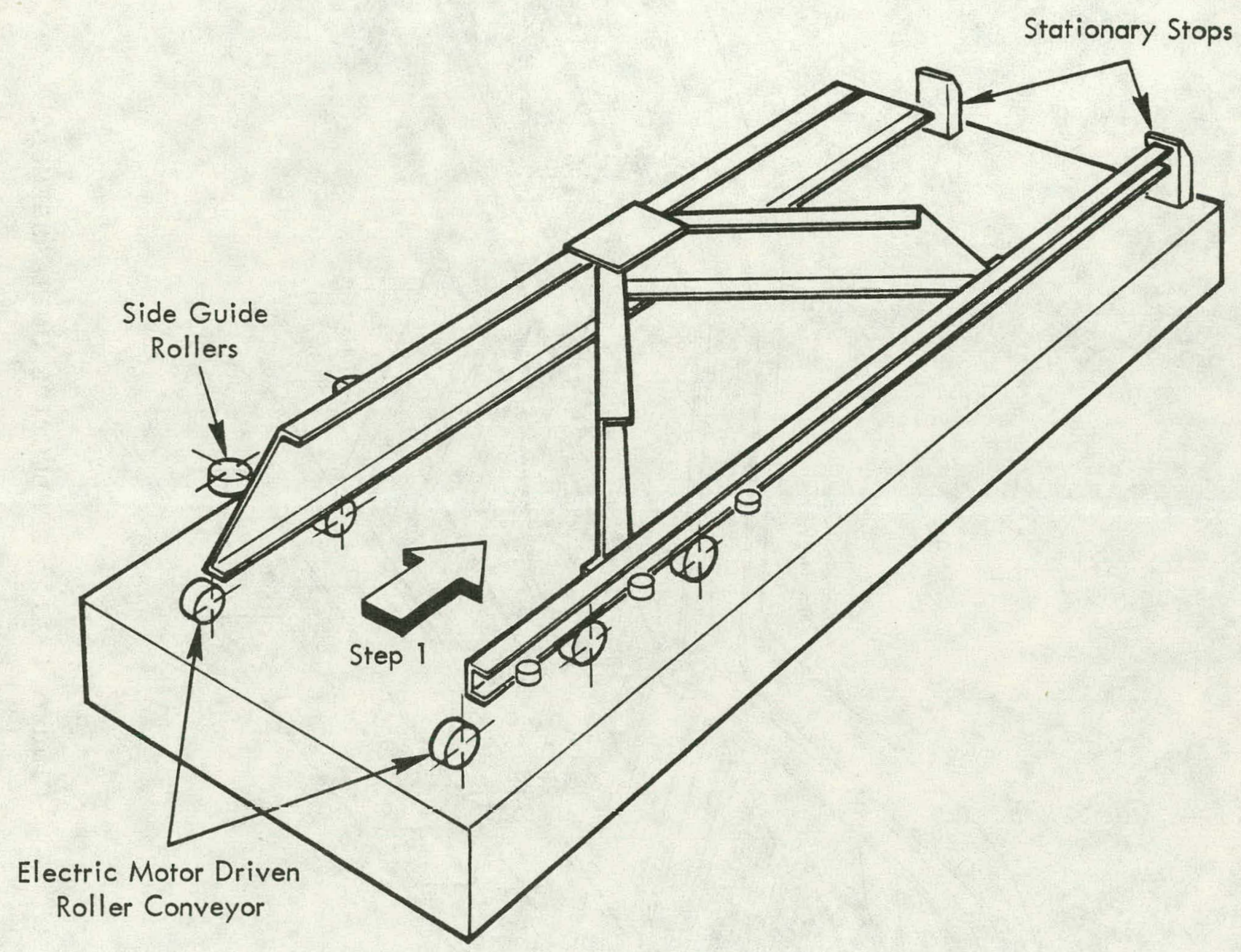

Figure 1-22. HELIOSTAT MTRROR AND BACK SUPPORT STATION 13, UNLOAD 


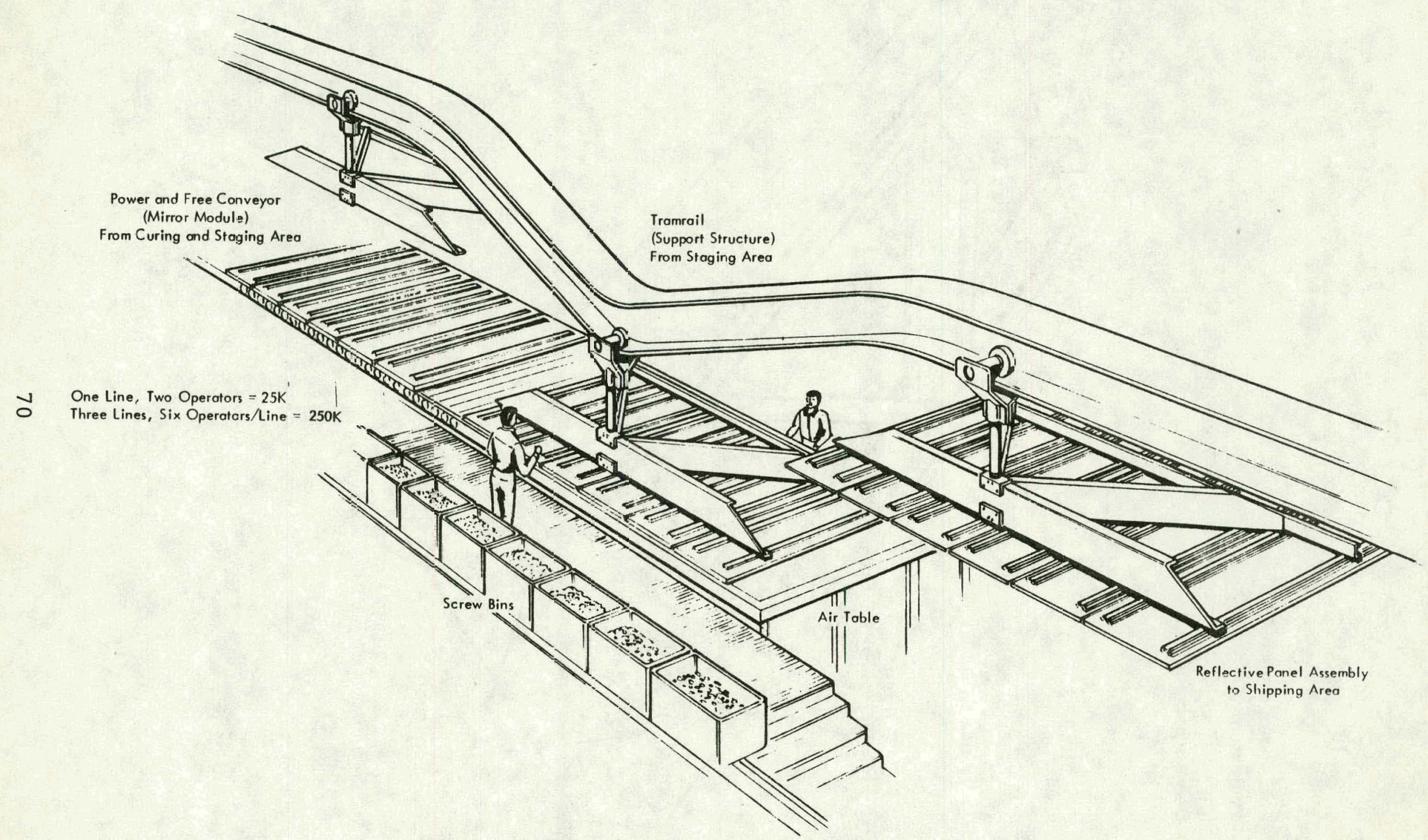

Figure 4-23. REFLECTIVE UNIT ASSEMELY 


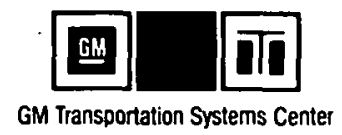

\subsubsection{Electrical/Electronic}

The plant layouts for the heliostat electrical and electronic components are shown in Figures 4-24 and 4-25 for the 25,000 and 250,000 unit annual volumes, respectively. At the 25,000 unit level of production automatic equipment is used for cable fabrication and termination and for component insertion and flow soldering of the printed wiring boards. At the 250,000 unit level of production, automatic equipment is added for the inspection of the printed wiring boards. Floor space requirements for two levels of production are 5400 and 19,800 square feet. The following paragraphs list the processing operations and production equipment used in the electronic/electrical assembly areas for the following heliostat components:

- Control and signal electronics
- Motors (position/limit indicator)
- Power supply and distribution.

\subsubsection{Control and Signal Electronics Fabrication}

The fabrication and processing of control and signal electronics for the annual volumes of 25,000 and 250,000 are given in the following pages. This equipment includes the heliostat controller, box enclosure, and cable connections. At the lower volume most operations are performed manually with the exception of small-component insertion, flow soldering, and environmental testing. At the higher volume, insertion and inspection is automated.

Completed controllers are fitted with the cable harness for later assembly to the drive unit.

Each process description is followed by a list of the production equipment used in the process.

The control and signal electronics process for the 25,000 volume is:

(1) Receive and inspect components, connectors, printed circuit boards, and plastic boxes and covers.

(2) Manually assemble large electronic components, microcomputer, and power supply to two-sided 4 -inch $x$ 5-inch printed circuit board.

(3) Manually load component tubes into automatic insertion machine.

(4) Automatically insert small components.

(5) Automatically trim, flow solder, clean, and dry printed circuit board assembly. 


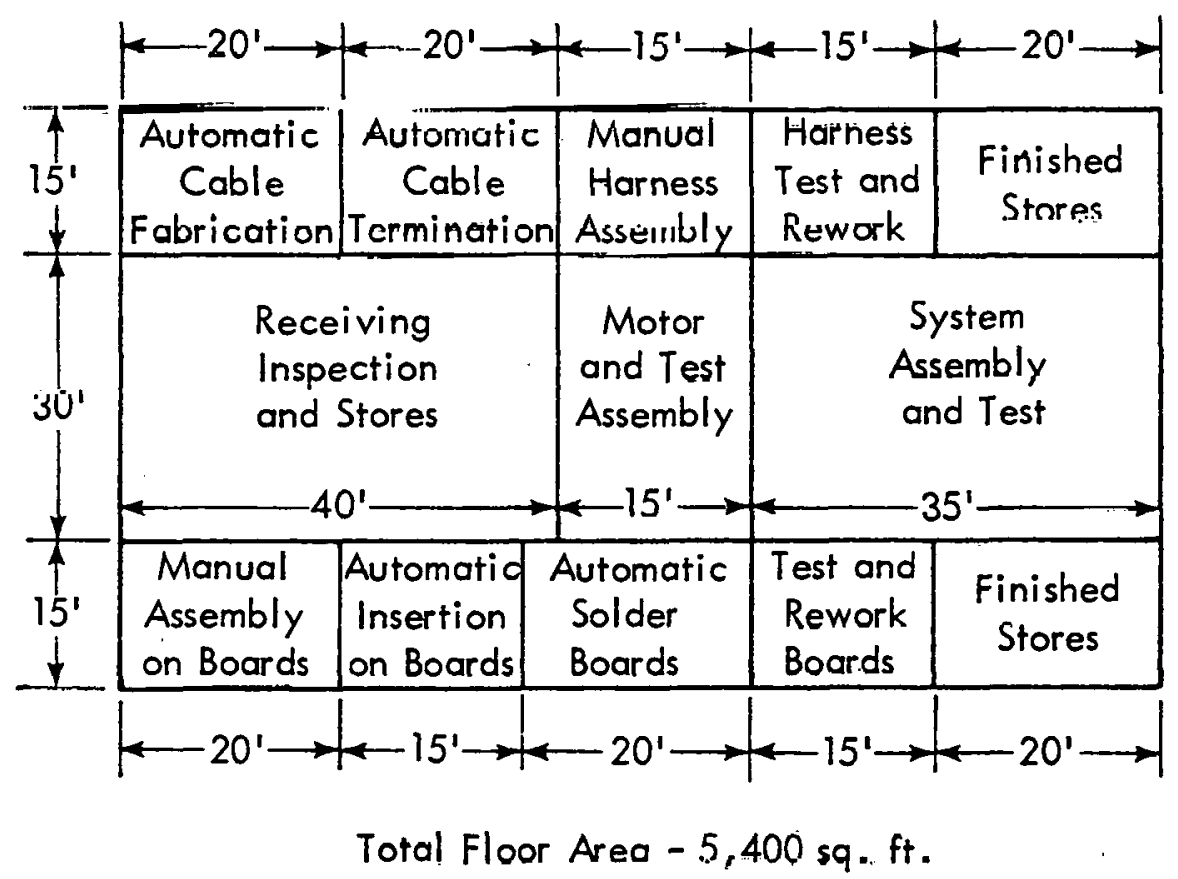

Figure 4-24. ELECTRICAL/ELECTRONIC ASSEMBLY AND TEST AREA 25,000 ANNUAL VOLUME 


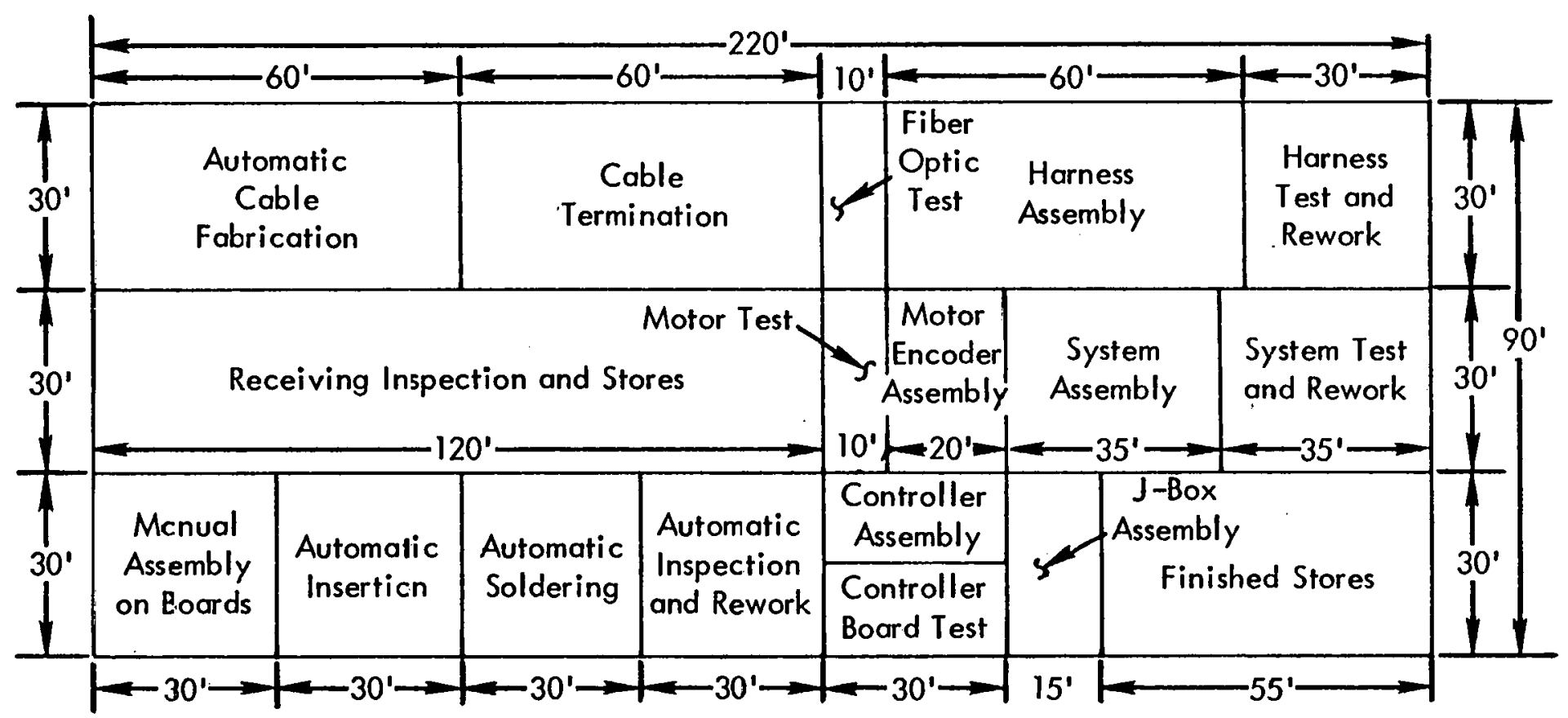

Total Floor Area - 19,800 sq. ft. 
(6) Visually inspect soldered board for voids, bridging, and inclusions.

(7) Rework soldered units (estimated to be less than 28).

(8) Load units (52) into fixture and environmentally test boards $\left(+165^{\circ} \mathrm{F}\right.$ for two hours).

(9) Functionally test 52 unit batch, less fallout.

(10) Recycle failed units (estimated to be less than 2\%).

(11) Manually assemble tested printed circuit boards to base with 6 screws.

(12) Assemble 4 cable fittings to base of box.

(13) Assemble elevation, stowage, and azimuth motors and junotion box aablco to heliostat eontroller box.

(14) Install cover.

(15) Transfer equipment to assembly area.

The control and signal electronics production equipment for the 25,000 volume includes:

- Universal Instruments Corp., automatic insertion machine with special fixtures (20)

- Hollis Engineering Co., automatic flow solder machine with special fixtures (20)

- Falcons Div., Universal Scjentific Corp.., oven with envi ronmental test fixtures and rack - 3 units

- Special DDI/H.C. functional test stand - 2 stands

- Special assembly fixture

- Handing fixtures (60) - inspection and test

- Work benches (6)

- Storage racks (2)

- Large tote bins (5)

- Small tote bins (15) 


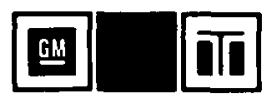

GM Transportation Systems Center

The control and signal electronics process for the 250,000 volume is:

(1) Receive and inspect components, connectors, printed circuit boards, and plastic boxes and covers.

(2) Manually assemble large electronic components, microcomputer, and power supply to two-sided 4-inch $x$ 5-inch printed circuit board.

(3) Manually load component tubes into automatic insertion machine.

(4) Automatically insert small components.

(5) Automatically trim, flow solder, clean, and dry printed circuit board assembly.

(6) Machine inspect printed circuit board for contents and visually inspect for voids or contamination (estimated to be less than 28 ).

(7) Rework soldered units (estimated to be less than 28).

(8) Environmentally test boards $\left(+165^{\circ} \mathrm{F}\right.$ for two hours). This test is performed on 28 of production.

(9) Functionally check printed circuit boards (110 units every half hour).

(10) Recycle failed units (estimated to be less than 28).

(11) Manually assemble tested printed circuit boards to base with 6 screws.

(12) Assemble 4 cable fittings to base of box.

(13) Assemble elevation, stowage, and azimuth motors and junction box cables to heliostat controller box.

(14) Install cover.

(15) Transfer equipment to assembly area.

The control and signal electronics production equipment for the 250,000 volume includes:

- Universal Instruments Corp., insertion machine, semi-automatic with special fixtures (120) and transfer machine for handling and metering work flow

Hollis Engineering Co., automatic flow soldering equipment with special fixtures (150) 
GM Transportation Systems Center

- Automatic inspection scanner

- Falcons Div., Universal Scientific Corp., oven with test fixture racks (3)

- Special DDI/H.C. with functional test stand - 9 stands

- Transfer equipment motors

- Work benches (17)

- Storage racks (10)

- Large tote hins (20)

- Small tote bins (45)

\subsubsection{Power Supply and Distribution Processing}

The fabrication and processing of the power supply and distribution equipment for the 25,000 and 250,000 annual volumes are given in the following pages. This equipment includes the junction box, circuit breaker, cables, and terminations for the heliostat assembly. At the low volume most operations are performed manually with the exception of wire cutting, stripping, and terminating. Fiber optic cable processing is performed manually. At the higher volume fiber optic cables are purchased complete with terminations.

The power and signal cable is connected to the heliostat controller for assembly on the azimuth drive. Cable connectors in this harness are mated with the drive motor connectors at the drive assembly point. The harness between the controller and the junction box is not connected until final assembly of the heliostat unit.

Each process description is followed by a list of the production equipment used in the process.

The power supply and distribution process for the 25,000 volume is:

(1) Receive and inspect the Eulluwing cumpunents:

- Junction box

- Terminal strip

- Circuit breaker

- Mounting panel

- Terminators

- Cable fitting

(2) Assemble terminal strip and circuit breaker on mounting panel. 
(3) Assemble 4 cable terminators and cable fitting into junction box.

(4) Install cover on junction box and transfer to assembly area.

(5) Receive and inspect the following components:

- 10-pin connectors

- 20-gauge power wire

- 24-gauge motor controller wire

- Wire terminals

(6) Automatically cut to length, strip, and terminate following lengths of 24 -gauge wire:

- $2-84$ inches

- 2 - 60 inches

- 2 - 12 inches

Mark wire ends.

(7) Automatically cut to length, strip, and terminate following lengths of 20-gauge wire:

- 1 - 84 inches

- 1 - 60 inches

- 1 - 12 inches

Mark wire ends.

(8) Assemble wire lengths into power cable harness and onto 10-pin connector per drawing.

(9) Receive and inspect fiber optic cable, cable terminators, and 25-pin connector.

(10) Manually cut fiber optic cable to length.

(11) Remove outer jacket of fiber optic cable (both ends), separate conductors, polish tips of fiber optic cable and install 4 terminators (both ends), and rewrap exposed fiber optic cable.

(12) Strip both ends of power cable, tin, and attach to 25-pin connector per drawing.

(13) Attach 3 motor power cables and motor control cable to 25-pin connector per drawing.

(14) Conduct continuity test on cable harness.

(15) Rework failed units (cstimated to be less than 28).

(16). Assemble heliostat controller, motors, and harness for system test, including optical test of fiber optics.

(17) Rework failed units (estimated to be less than 28).

(18) Transfer controller, harnesses, and mutors to azimuth/elevation assembly area. 


\section{GII}

GM Transportation Systems Center

The power supply and distribution production equipment for the 25,000 volume includes:

- Artos wire cutter, stripper, and terminator, Model CS-9-AT

- DITMCO Test Set

- DDI simulator with digital readout - 2 stations

- Adapter set

- Cutting fixture, special

- Cabling fixture, special

- Storage racks (6)

- Work benches (4)

- Large tote bins (4)

- Small tote bins (4)

The power supply and distribution process for the 250,000 volume is:

(1) Receive and inspect following components:

- Junction Box

- Terminal Strip

- Circuit Breaker

- Mounting Panel

- Terminators

- Cable Fitting

(2) Assemble terminal strip and circuit breaker on mounting panel.

(3) Assemble 4 cable terminators and cable fitting into junelion bux.

(4) Install cover on junction box and transfer to assembly a rea.

(5) Receive and inspect following components:

- 10-pin connectors

- 20-gauge power wire

- 24-gauge motor controller wire

- Wire terminals 


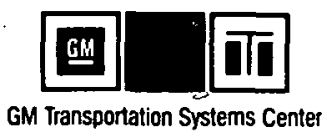

(6) Automatically cut to length, strip, and terminate following lengths of 24 gauge wire:

- 2 - 84 inch

- 2 - 60 inch

- 2 - 12 inch

Mark wire ends.

(7) Automatically cut to length, strip and terminate following lengths of 20 gauge wire:

- $1-84$ inch

- 1 - $60 \mathrm{inch}$

- 1 - 12 inch

Mark wire ends.

(8) Assemble wire lengths into harness and onto 10-pin connector per drawing.

(9) Receive and inspect fiber optic cable with terminators and 25-pin connector.

(10) Strip ends of power cables, tin and attach 25-pin connector to one end per drawing. Other end remains bare for assembly connection through hollow azimuth drive shaft and connection to pedestal junction box.

(11) Attach: 3 motor power cables and control cable to 25-pin connector per drawing.

(12) Conduct cable continuity test.

(13) Rework failed cable units (éstimated to be less than 28).

(14) Assemble heliostat controller, motors, harnesses, and fiber optics for system test.

(15) Conduct system test and optical check.

(16) Rework failed systems (estimated to be less than 28).

(17) Transfer controller, harness, and motors to azimuth/elevation assembly area.

The power supply and distribution production equipment of the 250,000 volume includes:

- Artos wire cutter, stripper, and terminator - Model CS-9-AT - 6 required

DITMCO Test Set with adaptors - 3 required

DDI simulator with digital readout - 10 required

Fab-Tec transfer line to storage 


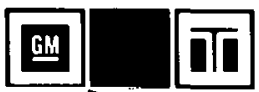

GM Transportation Systems Center

- Cabling fixture, special - 2 required

Storage racks (42)

Work Benches (28)

Large tote bins $(40)$

Small tote bins (8)

\subsubsection{Motors}

The processing of the drive motors for the 25,000 and 250,000 annual volume levels is given in the following pages. This equipment includes the drive motors and mounting hardware. Position/limit indicator hardware is mounted in a separate operation. At the lower volume, the motors are subjected to 100 percent receiving inspection. At the higher volume, motor testing is limited to a 5 percent sample.

Each processing description is followed by a list of the production equipment used in the process.

The motors process of the 25,000 volume is:

(1) Receive and inspect motors, bolts, and washers.

(2) Assemble and test each motor on motor test station.

(3) Return failed motors' to supplier (estimated to be less than 28).

(4) Transfer motors to stations for assembly of position/limit indicator.

The motors production equipment for the 25,000 volume is:

- Dynamometer with special test stand, $480 \mathrm{v}-3$ phase, with circuit breakers

The motors process for the 250,000 volume is:

(1) Receive and inspect motors, bolts, and washers from supplier.

(2) Assemble and test motors (58 sample) on motor test station.

(3) Return failed motors to supplier (estimated to be less than 0.58 ).

(4) Transfer motors to station for assembly of position/limit indicator. 


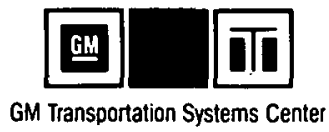

The motors production equipment for the 250,000 volume is:

- Dynamometer with special test stand, 480v - 3 phase, with circuit breakers - 2 required

\subsubsection{Position/Limit Indicator Processing}

The fabrication and processing instructions for the position/ limit indicator electronics for the annual volumes of 25,000 and 250,000 are given in the following pages. - This equipment includes the vane actuator and printed circuit board which are mounted on the drive motors. At the low volume components are automatically inserted on the circuit board and flow soldered. Mechanical components and the circuit board are manually assembled on the drive motors. At the higher volume printed circuit board inspection is accomplished automatically.

Each process description is followed by a list of the production equipment used in the process.

The position/limit indicator process for the 25,000 volume is:

(1) Receive, store, and issue electronic components in tubes as received from supplier. Issue tubes to automatic insertion equipment. Tubes contain (50 each) line drivers, line receivers, triacs, resistors, and capacitors. Issue 50 printed circuit boards.

(2) Manually load tubes for automatic insertion.

(3) Automatically insert components; transfer to flow solder equipment.

(4) Automatically flow solder, clean, and dry.

(5) Visually inspect for voids, bridging, inclusions, proper component pressure, and position.

(6) Rework soldered units (estimated to be less than 18).

(7) Transfer boards to encoder assembly station.

(8) Receive and inspect vane actuator and encoder mounting hardware.

(9) Assemble vane actuator and encoder on drive motor.

(10) Transfer completed motor assembly to drive assembly station. 


\section{回 园}

GM Transportation Systems Center

The position/limit indicator production equipment for the 25,000 volume is:

- Universal Instruments Corp., insertion machine with assembly fixtures (60)

- Storage racks (3)

- Tote boxes (19)

The position/limit indicator process for the 250,000 volume is:

(1) Receive, store, and issue electronic components in tubes as received from supplier. Issue tubes to automatic insertion equipment. Tubes contain (50 each) line drivers, line receivers, triacs, resistors, and capacitors. Issue 50 printed circuit boards.

(2) Manually load tubes for automatic insertion.

(3) Automatically insert components; transfer to flow solder equipment.

(4) Automatically flow solder, clean, and dry.

(5) Automatically transfer and inspect for proper component pressure and position. Inspect visually (28) for voids, bridging, and inclusions.

(6) Rework soldered units (estimated to be less than 18).

(7) Transfer boards to encoder assembly station.

(8). Receive and inspect vane actuators and encoder mounting hardware.

(9) Assemble vane actuators and encoders on drive motor.

(10) Transfer completed motor assemblies to drive assembly station.

The position/limit indicator production equipment for the 250,000 volume includes:

- Universal Instruments Corp., insertion machine with assembly fixtures (60)

- Fab-Tec transfer equipment with controls and meters and transfer fixtures (60)

- Hollis Engineering Co., automatic flow solder machine with flow fixtures (60)

- Fab-Tec transfer equipment with controls and meters 
- Automatic insertion scanner

- Fab-Tec transfer equipment with controls and meters (60) transfer fixtures

- Tote boxes (60)

- Fab-Tec transfer equipment with controls and meters and transfer fixtures (100)

- Work benches (4)

- Fab-Tec transfer equipment with controls and meters

- Storage racks (30)

\subsubsection{Drive Assembly}

The drive assembly comprises the drag link, the torque tube and the azimuth drive assembly. Processing instructions for these elements are included in the following pages.

\subsubsection{Azimuth Drive Housing}

The processing operations and equipment descriptions for the azimuth drive housing at the 25,000 and 250,000 annual volumes are listed on the following pages. For the low volume the housing is purchased as a completed weldment which is plated and ready for machining. At the high volume, welding and galvanizing are performed in the manufacturing plant. Machining is required for the drive motor mounting, input gear bearing, lower wire race bearing, and mountings for the torque tube, drag link, and tracking actuator. In each case, the machining is performed on automatic machines with transfer equipment. At the higher volume, shuttle transfer operations are replaced with noncumulative continuous cycling operations with assistance of a pallet return conveyor to reduce the cycle and match the required production rate, thus reducing labor requirements.

The azimuth drive housing - machining process for the 25,000 volume is:

(1) Receive and inspect galvanized housing weldment.

(2) Place housing on custom forklift pallets -- material handling with overhead crane -- qualify gage material handling on conveyor.

(3) Qualify locating diameter and face; rough turn, face, and bore. 
These operations are performed on a Bullard numerical control vertical turrent lathe. This machine is shown on the plant layout in section 4.4 .

(4) Perform part wash and in-process gaging -- material handling on conveyor.

(5) Bore, turn, face, contour, drill, chamfer, and tap.

These operations are performed on the Lamb 3-station shuttle machine shown in Figure 4-26. It requires one operator and occupies a floor area of $16 \mathrm{ft} x 20 \mathrm{ft}$. The operations performed at the three stations are described as follows:

Station

Number

1

2

3
Left Hand

Bore, face outside ring. Face and groove bearing bore

Tap drill (8), cover holes. Tap drill (4) retainer holes

Probe, tilt unit, tap (12) holes, tilt unit, probe

\section{Uperation}

Right Hand

Bore, face, turn, and plunge I.D. radius

Drill (12) holes through. Tap drill (16) holes

Probe, tilt unit, tap (16) holes, tilt unit, probe

(6) Perform part wash and in-process gaging -- material handling on conveyor.

(7) Mill, bore, and chamfer; drill and chamfer; tap motor mounting face. 


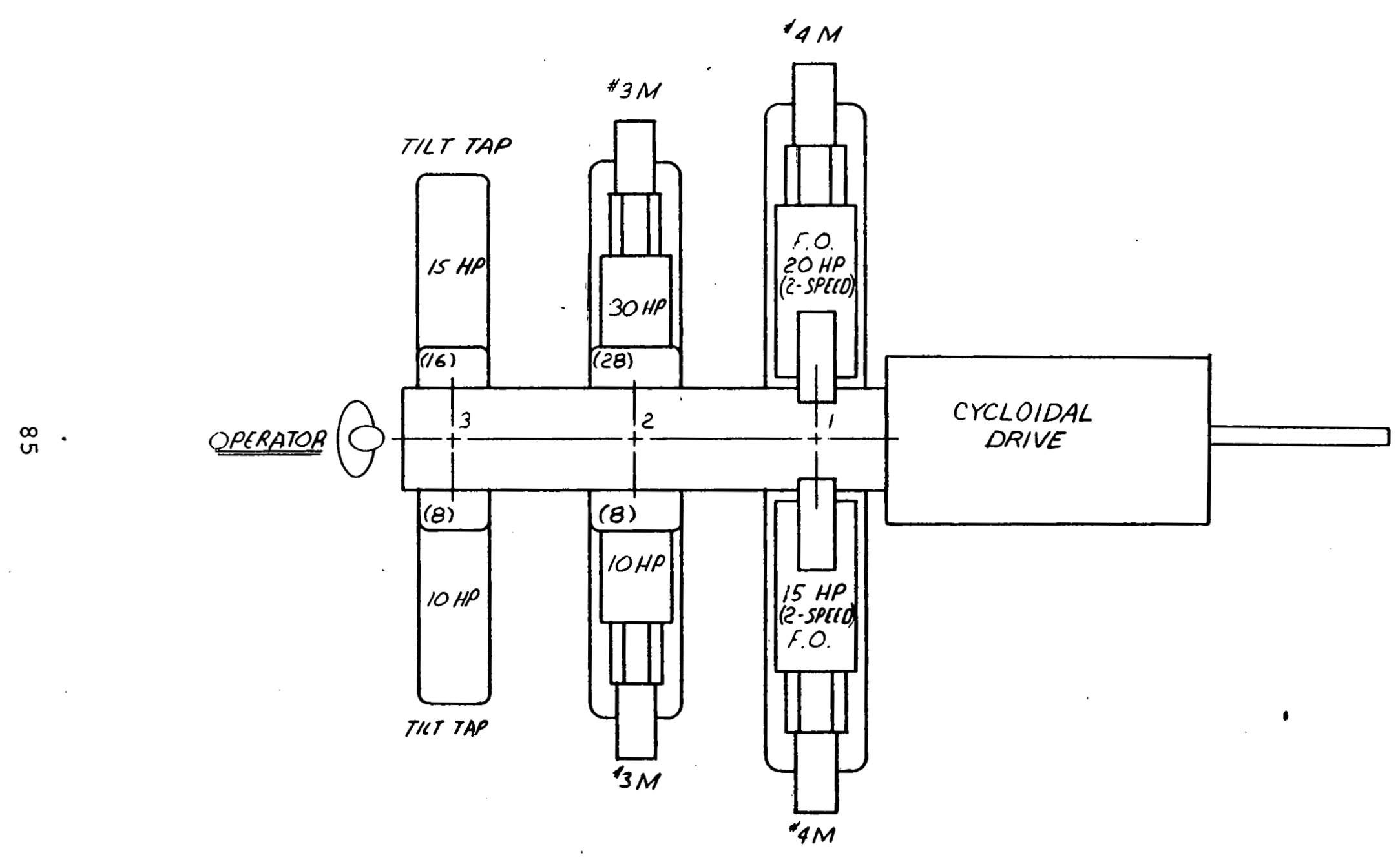

Scale $1 / 4^{\prime \prime}=1^{\prime}$

Figure 4-26. AgIMUTH DRIVE HOUSING MACHINING-\#1 - 25,000 ANNUAL VOLUME 
These operations are performed in the Lamb 5-station shuttle machine shown in Figure 4-27. It requires one operation and occupies a floor space of $37 \mathrm{ft} x 14 \mathrm{ft}$. The operations performed at the 5 stations are described as follows:

Station

Number

1

2

3

4

5
Left Hand

Operation

2 Generate face

Ream and chamfer (1) hole

Tap drill and chamfer

(4) holes

Tap (4) holes $\underline{\text { Right Hand }}$

Locate on O.D. and bottom face

Idle

Idle

Idle

Idle

(8) Perform part wash and in-process gaging -- material handling on conveyor.

(9) Mill, spot drill, drill, bore, and ream arms (4), and press-in 4 antifriction.bushings.

These operations are performed on the Lamb 6-station shuttle machine shown in Figure 4-28. It requires one operator and occupies a floor space of $53 \mathrm{ft} x 24 \mathrm{ft}$. The operations performed at the six stations are described as follows:

Station

Number

Operation

1

Load/unload

2

Straddle mill (4) arms

3

Spot drill to chamfer (2) holes (both sides)

4

Drill through (2) holes (both sides)

5

Ream (2) holes (both sides)

6

Press bushings (2) holes (both sides)

(10) Perform part wash, master gaging, and hand gaging -material handling with overhead crane. 


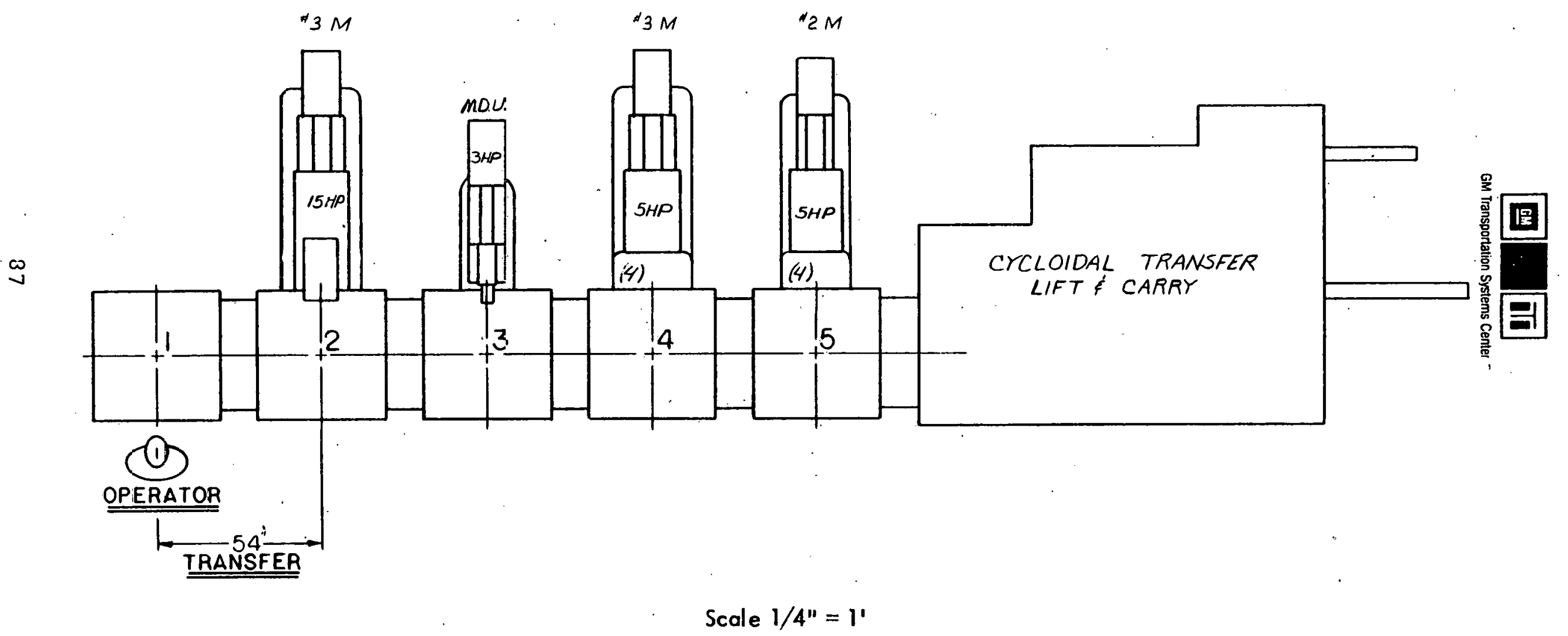

Figure 4-27. AZIMUTH DRIVE HOUSING MACHINING-\#2 - 25,000 ANNUAL VOLUME 


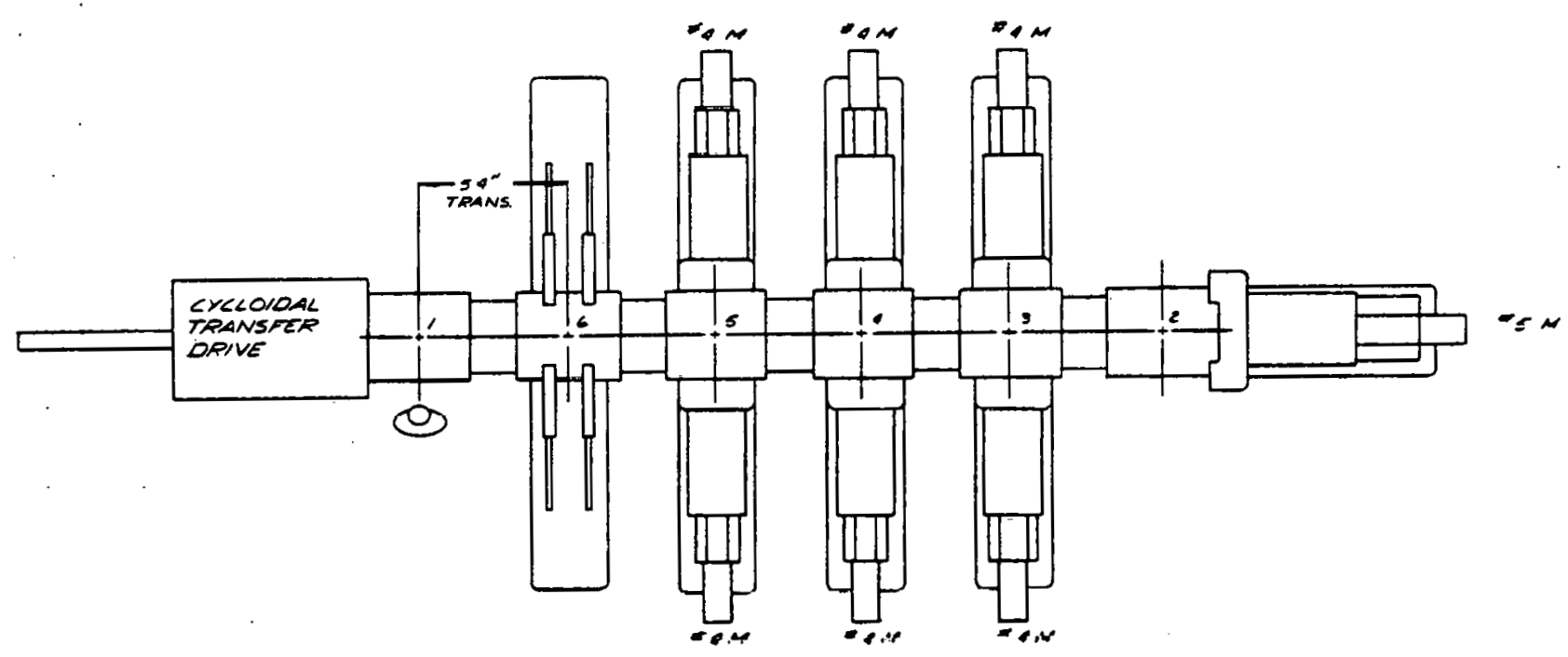

Scale $1 / 8^{n}=11$ 


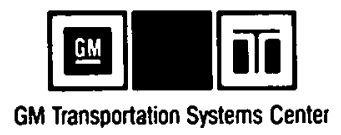

The welding process description, machine and operator requirements for the Azimuth drive housing at the 250,000 unit annual volume are as follows:

\section{Operation}

(1) Weld top plate to center hub

(2) Weld top plate to doubler

(3) Weld top plate subassembly to main tube

(4) Weld flange to large tube

(5) Weld motor tube to top tube

(6) Weld motor flange to motor tube

(7) Weld small tube subassembly to top plate

(8) Weld cross brace to large arms

(9) Weld large arms and cross brace to housing

(10) Weld short arms to subassembly housing

(11). Clean welded surfaces
Machine.

Ring welding machine

( 2 requi red)

Ring welding machine

(4 required)

Special welding machine ( 3 required)

Special welding machine 1.0 ( 3 required)

Manual welding operation $\quad 7.0$ with fixture ( 7 required)

Special welding machine 0.0 (1 required)

Ring welding machine 1.0

( 3 requi red)

3-station special welding 1.0 machine ( 2 required)

16-station special welding 1.0 machine ( 1 required)

4-station special welaing 1.0 machine ( 1 required)

Wheelabrator

1.0

The welding area and machine layout are shown on the plant layout in Section 4.4. This area of the plant is enclosed and is provided with special ventilation equipment. Welded housings are moved with overhead hoists to the staging area where they are stored on pallets. Housings are taken from the staging area to the galvanized plating area with fork-lift trucks. When they arrive at the plating area, housings are placed on the monorail loop for processing through the galvanizing area. 
GM Transportation Systems Center

The galvanizing line is also shown on the plant layout in Section 4.4. This line is also located in the enclosed area of the plant. The galvanizing process is described as follows:

\section{Processing step}

(1) Load housing on monorail

(2) Wash with highpressure water (30 micron filtration)

(3) Wash with alkaline solution - rinse with water - blow off with heated air

(4) Pickle in sulfuric acid

(5) Fresh water rinse with $\mathrm{pH}$ and temperature control - blow dry with heated air

(6) Flux dip

(7) Pre-heat housing to $250^{\circ} \mathrm{F}$

(8) Dip and travel in galvanizing tank

(9) Hot water rinse

(10) Hoist from monorail and store
Equipment

Fork-lift truck

( 1 requi red)

Mini-vac filter and

pump ( 1 required)

Rinse spray and heated blower ( 1 required) ..

Fiberglass tank, filter 0.0 and pump (1 required)

Heated water tank, blower and heater

(1 required)

Flux tank

Heater and blower

(1 required)

$20 \mathrm{ft}$. long hot-dip galvanizing tank

(1 required)

Rinse tank ( 1 required) 0.0

Fork-lift truck

(1 required).
0.0

0.0

0.0

0.0

Operators/

1.0

0.0

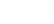

0.0

1.0

Operations which are shown without operator requirements are monitored and serviced by the five operators who man this line. 
GM Transportation Systems Center

The azimuth drive housing - machining process for the 250,000 volume is:

(1) Receive pre-cut material ready for welding and deliver to weld area.

(2) Weld per routing sheets.

(3) Galvanize.

(4) Place housing on custom forklift pallets -- material handling with overhead crane -- qualify. gage -material handling on conveyor.

(5) Qualify bottom and face.

These operations are performed on a Cincinnati horizontal broach. This machine is shown in the plant layout in section 4. 4 .

(4) Perform part wash and in-process gaging -- material handling on conveyor.

(5) Bore, turn, face, contour, drill, chamfer, and tap; mill, bore, and chamfer; drill and chamfer; tap motor mounting face; mill, spot drill, drill, bore, and ream arms (4), and press-in 4 antifriction bushings.

These operations are performed on the Lamb 18-station palletized transfer machine shown in Figure 4-29. It requires one operator and occupies a floor space of $80 \mathrm{ft} \times 50 \mathrm{ft}$. The operations performed on this machine are as follows:

Station Number
Left Hand

Load/unload

Rough contour, rough turn and face

3. Finish contour and finish turn

4 Gage contour and hub. Compensate station 3

5 Urill and chamfer (16)

holes

6 Probe, tap, probe (16)

7

8 Idle

\section{operation}

\section{Right Hand}

Rough bore, finish, plunge, face and chamfer Finish bore

Gage bore. Compensate Station 3

Drill and clidmfer (12)

holes

Probe, tap, probe (12)

holes

Straddle-mill (4) arms Mill motor mount face 


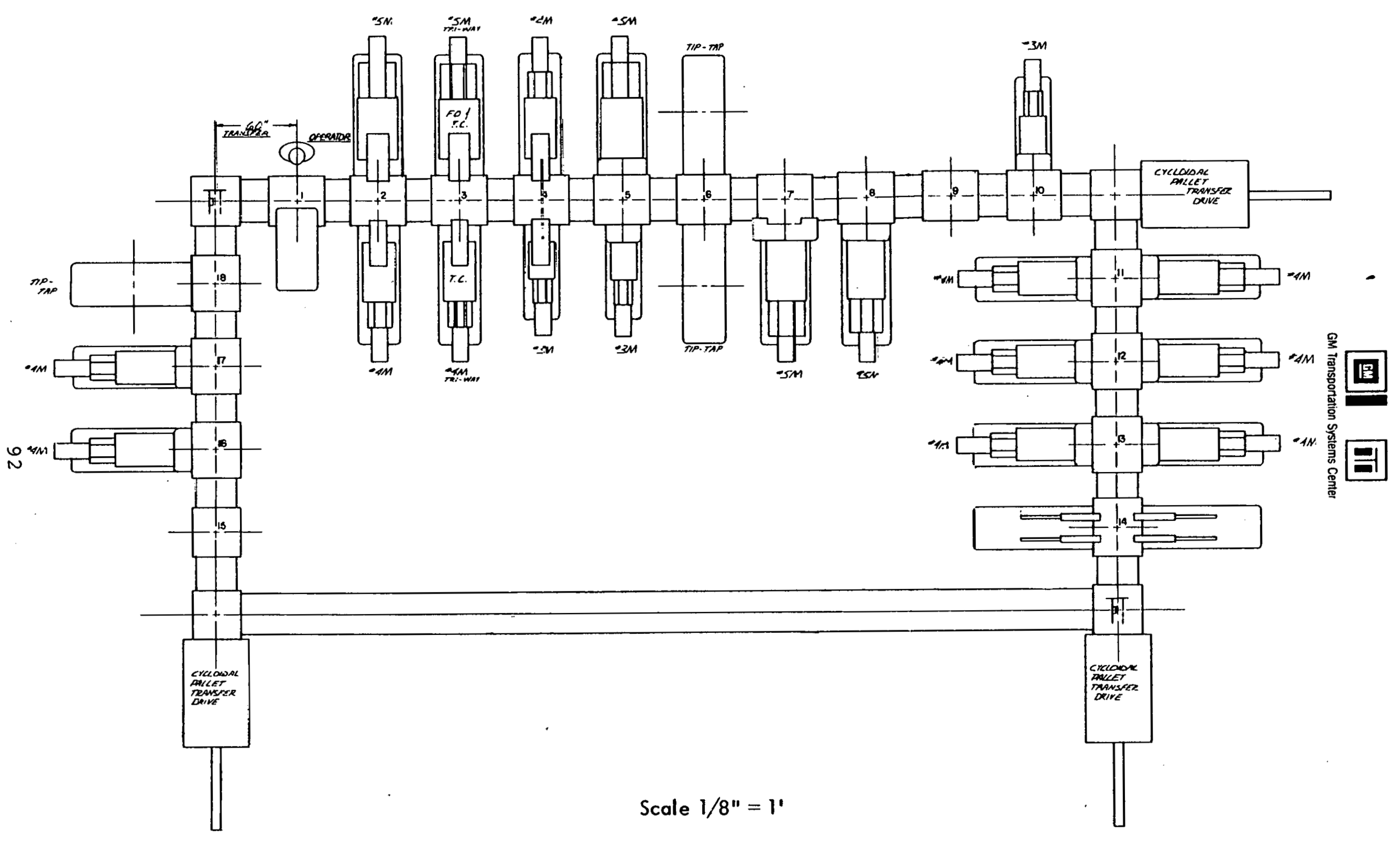

Figure 4-29. AZIMUTH DRIVE HOUSING MACHINING - 250,06D ANNUAL VOLUME 


$\begin{array}{lll} & \\ 9 & \text { Idle } & \text { Idle } \\ 10 & \text { Ream (12) holes } & \text { Idle } \\ 11 & \text { Spot drill to chamfer } & \text { Spot drill to chamfer } \\ 12 & \text { (2) holes holes } & \text { Drill through (2) holes } \\ 13 & \text { Drill through (2) holes } & \text { Ream (2) holes } \\ 14 & \text { Ream (2) holes } & \text { Press in bushings(2) } \\ 15 & \text { Press in bushings (2) } & \text { holes } \\ 16 & \text { holes } & \text { Idle } \\ 17 & \text { Future work } & \text { Idle } \\ 18 & \text { Ream (1) hole } & \text { Idle } \\ & \text { Drill, chamfer (4) holes } & \end{array}$

(6) Perform part wash, master gaging and hand gaging -material handing with overhead crane.

\subsubsection{Drag Link}

The machining and processing operations for the drag link at the 25,000 and 250,000 annual volumes are listed in the following pages. For the low volume, the drag link is purchased as a completed weldment which is plated and ready for machining., For the high volume, welding and galvanizing are completed in the manufacturing plant. Machining is required for the torque tube hinge mounting trunnion of the stowage jack, and clevis of the tracking actuator. This machining consists of facing the surfaces and boring the pin holes. In each case, the machining is performed on automatic machines with transfer equipment. At the higher volume, continuous cycling machining operations (noncumulative) are added by means of a pallet return system to improve cycle time and reduce labor requirements.

The drag link weldment - machining process for the 25,000 volume is:

(1) Receive and inspect drag link weldment with galvanized plating.

(2) spot drill, ream, mill, press-in bushings.

These operations are performed on the Lamb 6-station shuttle machine shown in Figure 4-30. It requires one operator and occuples a rluur space of 46 ft $x$ 20 ft. The operations performed on this machine are as follows: 
GM Transponation Systems Center

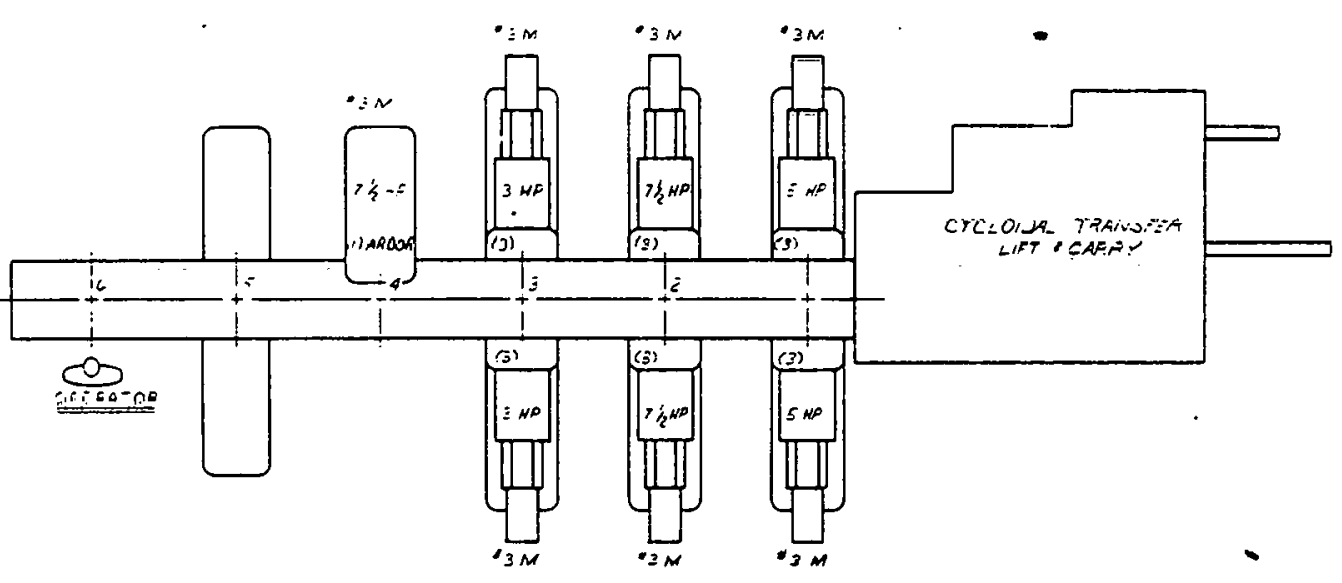

soalc $1,8^{\prime \prime}-1^{\prime}$

Figure 4-30. DRAG IINK MACHINING - 25,000 ANNUAL VOLUME 


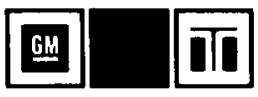

GM Transportation Systems Center

\begin{tabular}{cll}
$\begin{array}{c}\text { Station } \\
\text { Number }\end{array}$ & \multicolumn{1}{c}{ Left Hand } & Operation \\
1 & Spot drill (3) holes & Right Hand \\
2 & Drill (3) holes & Drill (3) holes \\
3 & Ream (3) holes & Ream (3) holes \\
4 & Idle & Mill lugs \\
5 & Press in (3) bushings & Press in (3) bushings \\
6 & Load/unload part &
\end{tabular}

(3) Perform part washing and master gaging.

(4) Transfer to forklift pallets with overhead crane.

At the higher volume, the drag link is assembled from purchased, pre-cut welding blanks. The welding process description, machine and operator requirements for the drag link at the 250,000 unit annual volume are as follows:

\section{- Operation}

(1) Weld ears to (2) braces

(2) Weld ear/brace subassembly and large brace to side links
Machine

4-station dial index welding machine (2 required)

6-station dial index welding machine

( 3 required)

(3) Clean welded surfaces Wheelabràtor

Operators/ Machine

1.0

1.0

1.0

The welding area and machine layout are shown on the plant layout in section 4:4. This area of the plant is enclosed and provided with special ventilation equipment. Welded drag links are placed on pallets for staging prior to the galvanizing operation. Drag links are processed. through the same galvanizing line with the azimuth drive housings. 'lhe process description for the galvanizing operation is contained in paragraph $4 \cdot 3 \cdot 3 \cdot 1$.

The drag link weldment - machining process for the 250,000 volume is:

(1) Receive and inspect pre-cut shapes ready for welding and deliver to weld area. 


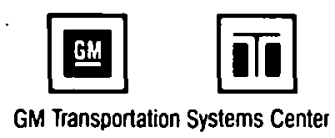

(2) Weld per routing sheets.

(3) Galvanize.

(4) Spot drill, ream, and mill in 4 places; press-in 4 bushings.

These operations are performed on the Lamb 6-station palletized transfer machine shown in Figure 4-31. It requires one operator and occupies a floor space of $53 \mathrm{ft}$ x $34 \mathrm{ft}$. The operations performed on this machine are as follows:

Station
Number

1

2 Spot drill (3) hỏles

3

4

5

6

\section{Left Hand}

Drill (3) holes

Ream (3) holes

Mill slots

Press (3) bushings

\section{Operation}

Right Hand

Load/unload part

spot arill (3) holes

Drill (3) holes

Ream (3) holes

Idle

Press (3) bushings

(5) Perform part washing and master gaging.

(6) Transfer to forklift pallets with overhead crane.

\subsubsection{Torque Tube}

The machining and processing operations for the torque tube assembly at the 25,000 and 250,000 annual volumes are listed in the following pages. For the low production volume the torque tube is purchased as a completed weldment which is plated and ready for machining. For the high volume, welding and galvanizing are performed in the manufacturing plant. Machining is required for the face of the mounting flanges and the tabs for mounting the azimuth drive housing and the clevis of the stowage actuator. Mounting and pin holes are bored and reamed. In each case, the machining is performed on automatic machines with transfer equipment. At the higher volume, continuous. cycling, noncumulative machining operations, utilizing a pallet return system, are added to improve cycle time and reduce labor requirements. 


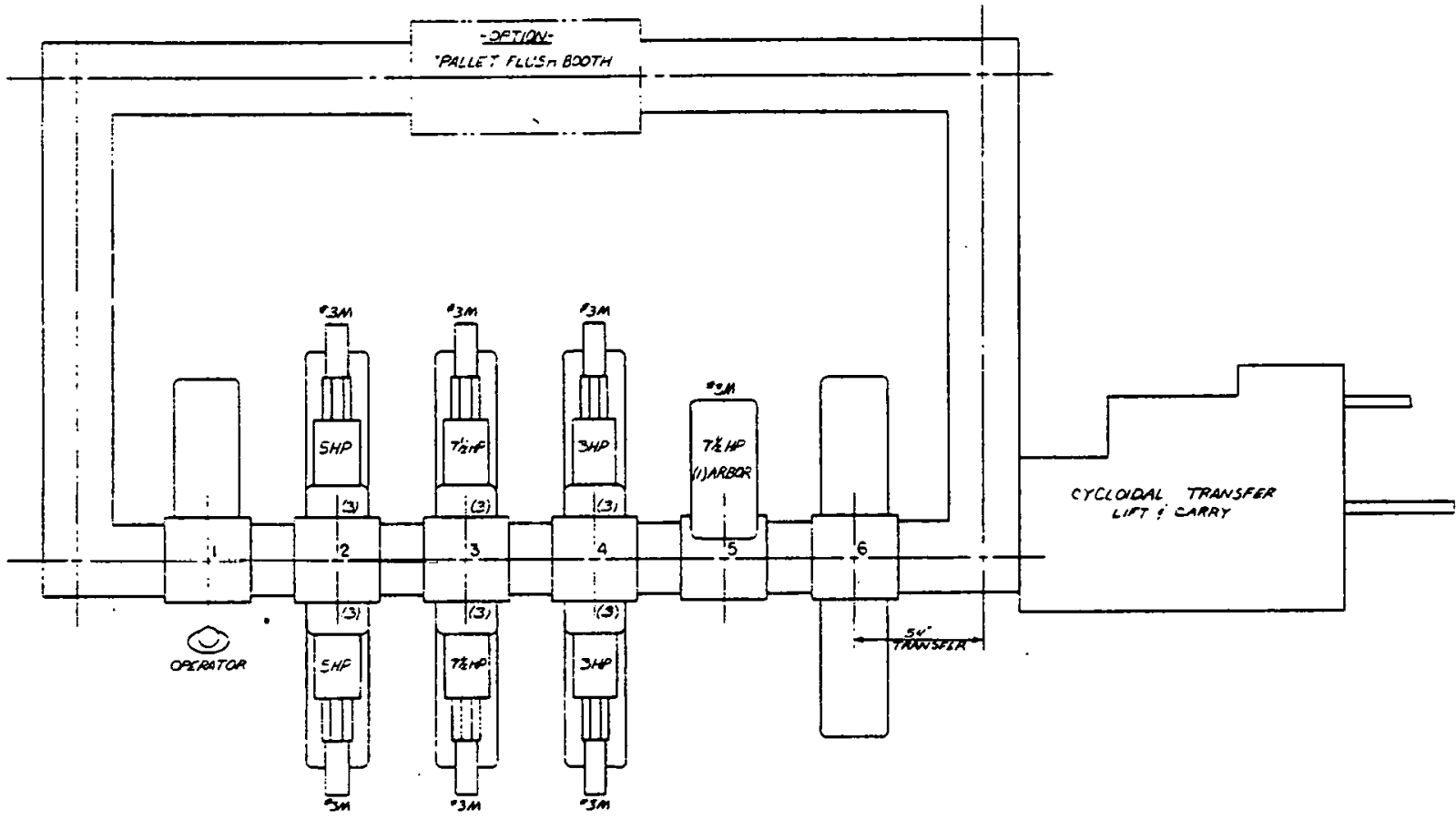

Scale $1 / 8^{\prime \prime}=1^{\prime}$

Figure 4-31. DRAG IINK MACHINING - 250,000 ANNUAL VOLUME 


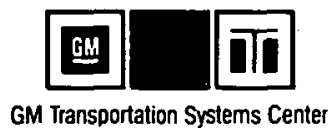

The torque tube weldment machining process for the 25,000 volume is:

(1) Receive and inspect torque tube weldment with galvanized plating.

(2) Mill ends; tap drill and tap 4 holes.

These operations are performed on the Lamb 4-station shuttle machine shown in Figure 4-32. It requires one operator and occupies a floor space of $29 \mathrm{ft} x 33 \mathrm{ft}$. The operations performed on this machine are as follows:

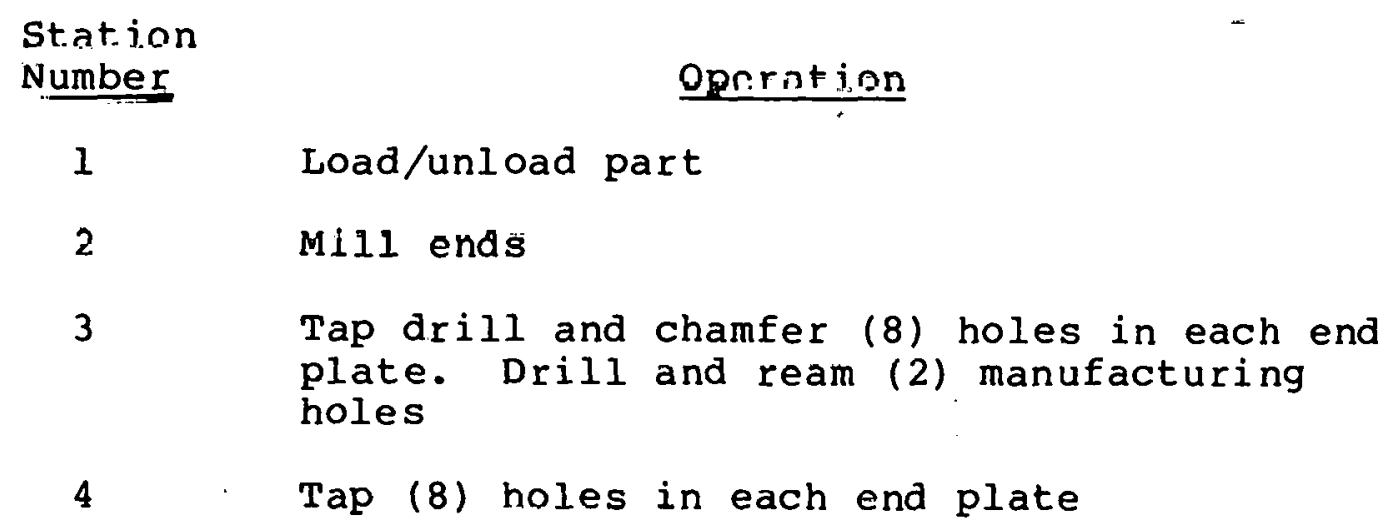

(3) Perform part washing and in-processing gaging.

(4) Drill, chamfer, ream, and mill 6 lugs.

These operations are performed on the Lamb 5-statinn shuttle machine sliown in Figure 4-33. It requires ne operator and occupies a floor space of $54 \mathrm{ft} x 16 \mathrm{ft}$. The operations performed on this machine are as follows:

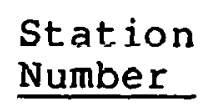

1

2

3

4

5

\section{Operation}

Load/unload part

Mill lug faces

Drill lug holes

Ream lug holes

Chamfer lug holes

(5) Perform part washing and master gaging.

(6) Transfer to forklift pallets with overhead crane. 


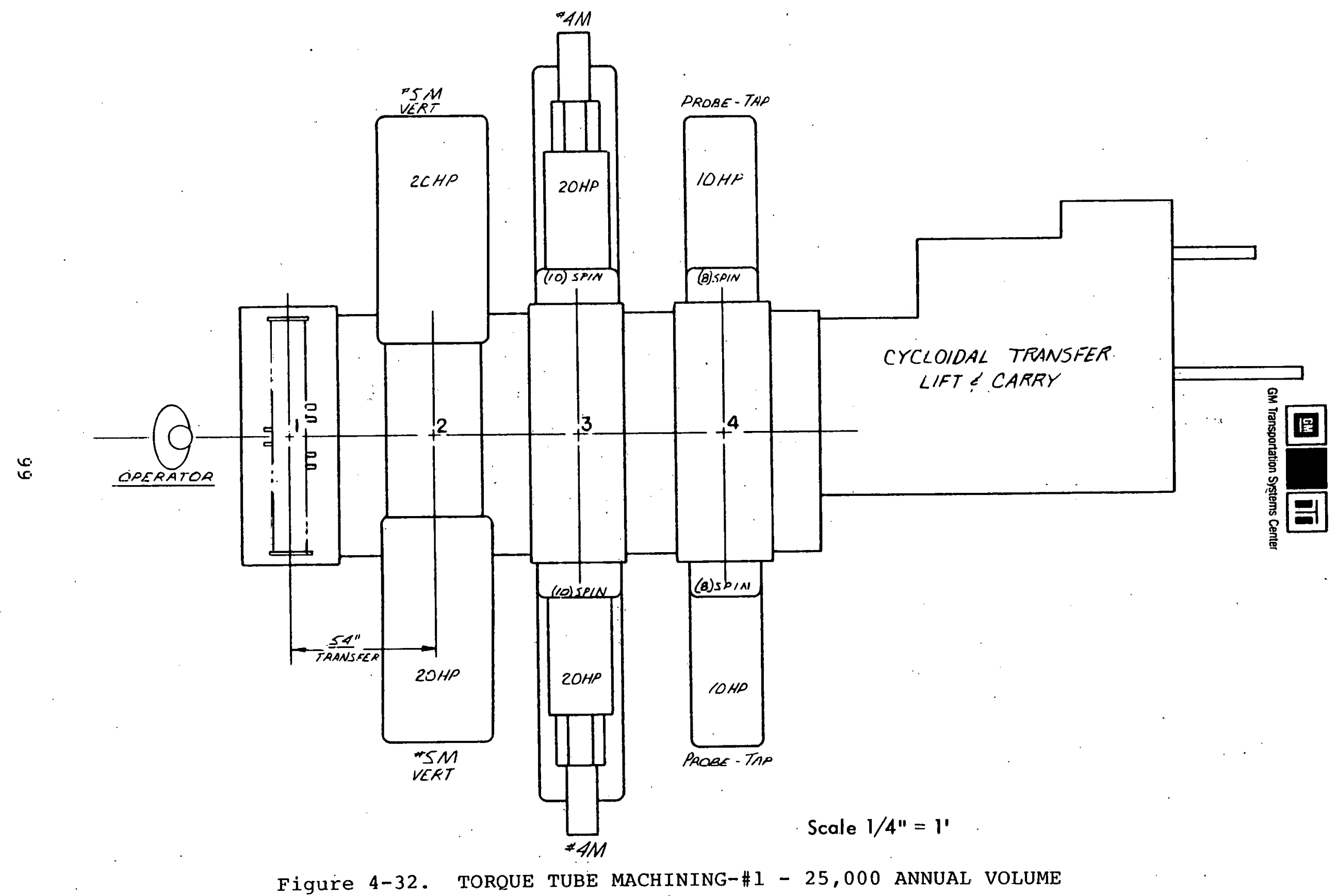




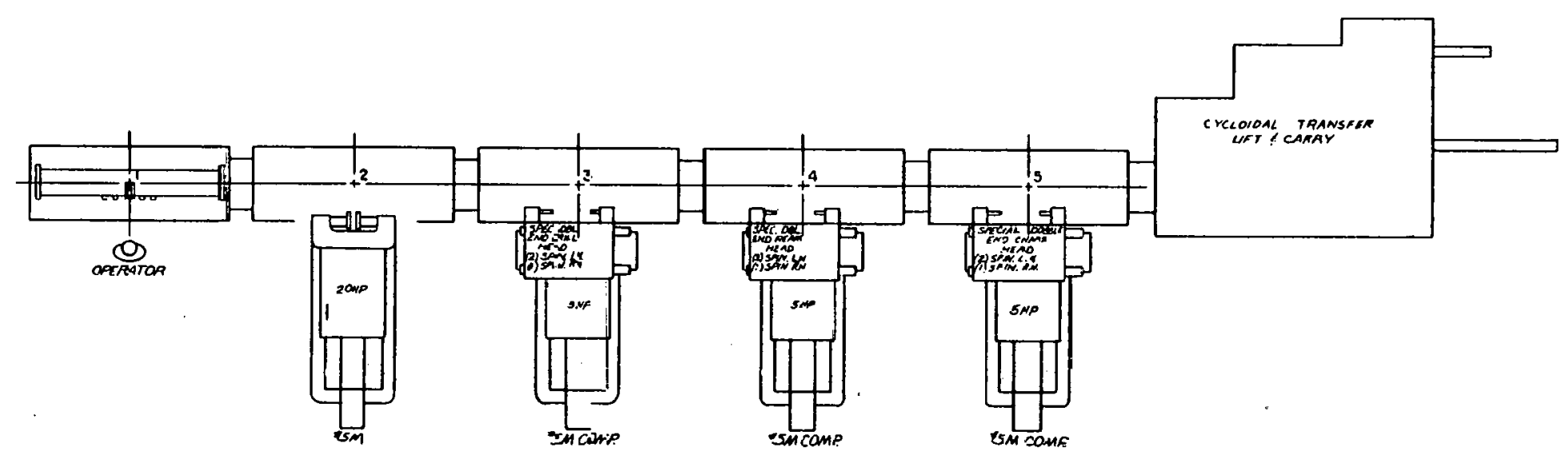

Scale $1 / 8^{\prime \prime}=11$

Figure 4-33. TORQJE TUBE MACHINING-\#2 - 25,000 INNUAL VOLUME 
At the higher volume, the torque tube is assembled from purchased, pre-cut welding blanks. The welding process description, machine and operator requirements for the torque tube at the 250,000 unit annual volume are as follows:

\section{Operation}

(1) Load pre-cut parts weld end flanges and actuator ears - one side only

Unload, invert, reload and weld remainingng side
Machine

Special purpose welding machine ( 4 required)
Operators/ Machine

1.0

Clean welded sufaces

Wheelabrator

1.0

The welding area and machine layout are shown on the plant layout in section 4.4. This area of the plant is enclosed and equipped with special ventilation equipment. Welded torque tubes are placed in pallets in the staging area prior to the galvanizing operation. Torque tubes are processed through the galvanizing area on a line that is separate from the one used for the azimuith housings and drag links. The galvanizing processing is the same as that discussed in paragraph 4.3.3.1, with the following exceptions; two operators are required for load/unload operations. Three operators are required for monitoring and servicing this line.

The torque tube weldment machining process for the 250,000 volume is:

(1) Receive and inspect pre-cut material and deliver to welding area.

(2) Weld per routing sheets.

(3) Galvanize.

(4) Mill ends; tap drill and tap 4 holes.

(5) Drill, chamfer, ream, and mill 6 lugs.

Operations in steps 2 and 3 are performed on the Lamb 8-station palletized transfer machine shown in Figure 4-34. It requires one operator and occupies a floor space of $74 \mathrm{ft} x 44 \mathrm{ft}$. The operations performed at the stations of this machine are as follows : 


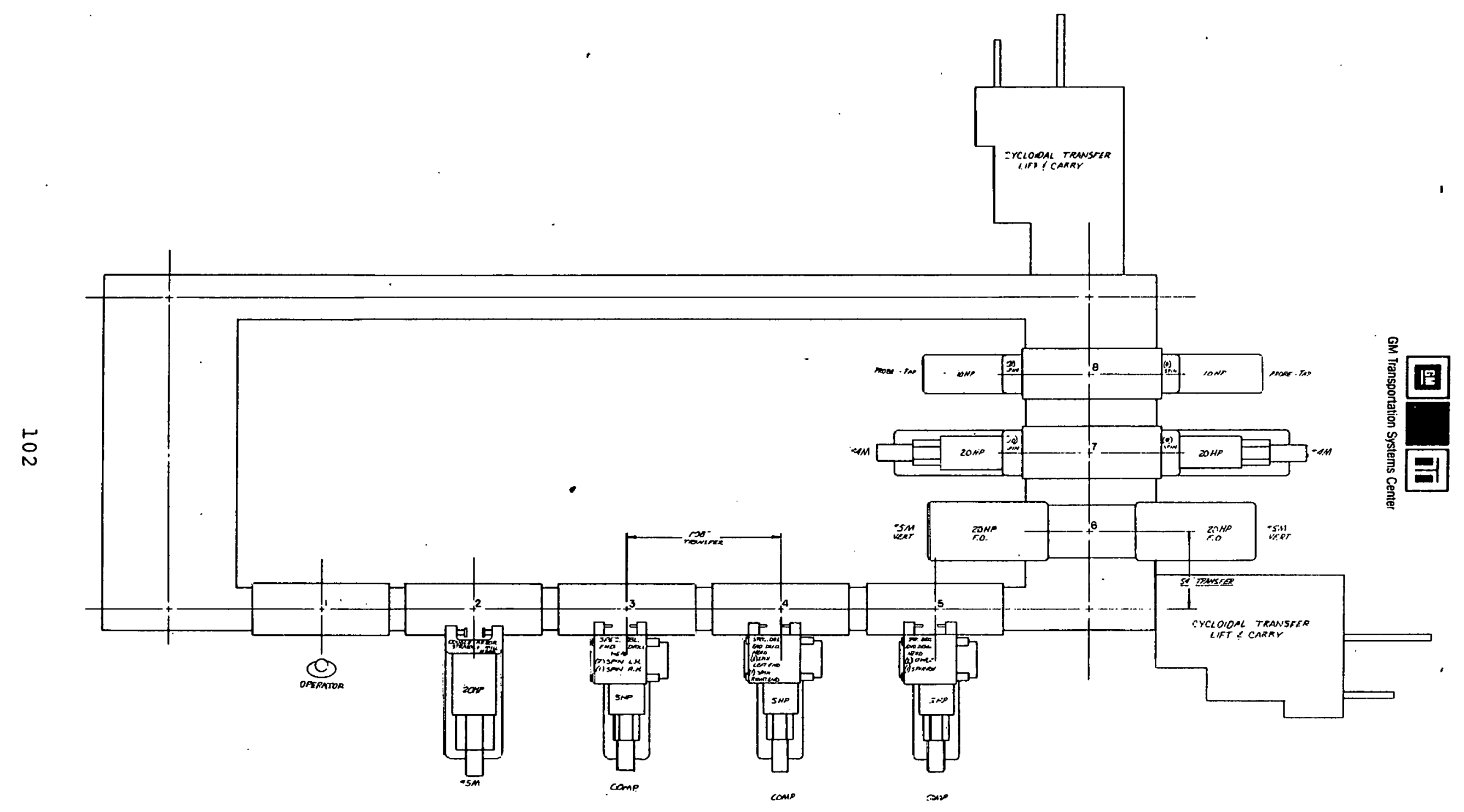

Scale $1 / 8^{\prime \prime}=I^{\prime}$

F-gure 4-34. TORQJE TUBE MACHINING - 250,0.J0 ANNUAL VOLUME 


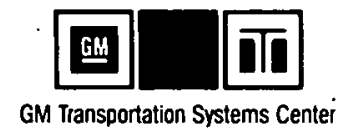

Station

Number

\section{Operation}

1 Load/unload part, locate

2 Mill lug faces

3. Drill lugs right and left of center

4 Chamfer both sides of lug holes

5 Ream lug holes right and left hand

$6 \quad$ Mill ends

7 Tap drill and chamfer (8) end plate holes

8 Probe (8) holes, tap (8) holes, and probe (8) holes

(4) Perform part washing and master gaging.

(5) Transfer to forklift pallets with overhead crane.

\subsubsection{Circular Spline}

The circular spline is machined from heavy-wall, seamless, sheet tubing. Spline parts are cut to length and the inner and outer diameters are machined. The cut-off face, outside diameter and bearing roll are ground. Mounting holes are drilled and tapped. The inside diameter spline teeth are shaped. The processing steps and machines used in the processing for the 25,000 and 250,000 unit annual volumes are described in the following pages.

The circular spline process for the 25,000 volume is:

Receive SAE 1018 seamless steel tubing heavy wall 15 inch O.D. $x$ 2-1/2 inch wall - nominal $16 \mathrm{ft}$ lengths.

(1) Load tube into cut-off machine.

(2) Turn O.D., bore, chamfer, and face.

(3) Lay faced surface on magnetic chuck and grind cutoff face to length.

(4) Demagnetize.

(5) Chuck on I.D., diamond roll form grind for O.D. and bearing contour to size. 


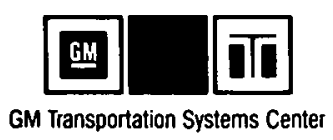

(6) Tap drill for eight 1/4-20 holes and eight 5/8-1l holes.

(7) Tap all holes from operation 6 .

(8) Chuck on finished O.D. and broach I.D. spline teeth.

(9) Wash.

(10) Final inspection.

These operations are performed on the following machines:

- Savage abrasive saw and Bullard temple turn vertical turret lathc

- Blanchard grinder (grind, cut off face)

- Landis grinder (grind O.D. and hearing raca)

- Buhr N.C. machine (drill and tap holes)

- Fellows gear shaper (shape I.D. spline teeth)

These machines are shown in the plant layout in Section 4.4 .

The circular spline process for the 250,000 volume is:

Receive SAE 1018 seamless steel tubing heavy wall 15 inch O.D. $x$ 2-1/2 inch wall - nominal $16 \mathrm{ft}$ lengths.

(1) Load tube into single spindle N.C. tubing machine.

(2) Turn O.D., bore and chamfer, face, and cut off.

(3) Lay faced surface on magnetic chuck and grind cutoff face to length.

(4) Demagnetize.

(5) Chuck on I.D., diamond roll form grind for O.D. and bearing contour to size.

(6) Tap drill for eight $1 / 4-20$ holes and eight 5/8-11 holes.

(7) Tap all holes from operation 6 .

(8) Chuck on finished O.D. and broach I.D. spline teeth.

(9) Wash.

(10) Final inspection. 


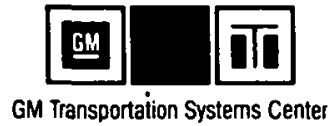

These operations are performed on the following machines:

- National Acme lathe (turn O.D., bore, chamfer, face, and cut off)

- Blanchard grinder (grind, cut off face)

- Landis grinder (grind O.D. and bearing race)

- Lamb 4-station dial machine

- Fellows gear shaper (broach I.O. spline teeth)

These machines are shown in the plant layout in section 4.4 .

\subsubsection{Flex Spline}

The flex spline is constructed from seamless steel tubing, a die-blanked steel diaphragm and a steel support doubler. The tubing is lathe-turned and hobbed to form the gear teeth. The diaphragm and the doubler are projection-welded together and the assembly is heli-arc welded to the machined tube. After welding the flex spline is drilled for the mounting holes and pilot diameter. A Tuff-tride treatment completes the processing.

The processing steps and machines used in the processing for the 25,000 and 250,000 unit annual volumes are described in the following pages.

The flex spline process for the 25,000 volume is:

Receive the following raw material:

- SAE seamless Rockrite tubing SAE 8620 steel - bearing quality, vacuum degassed, 10-1/4 inch $0 . D$. $x 3 / 8$ inch wall in $16 \mathrm{ft}$ minimum length

- Die blanked diaphragm - 9.625 \pm 0.0058620 steel $-3.1875^{-} \pm 0.005$ I.D. $x 1 / 8$ thick

- Support doubler SAE $1018-6.250 \pm 0.005$

$$
-3.1875^{-} \pm 0.005 \times 3 / 8 \text { thick }
$$


GM Transportation Systems Center

Plate to be embossed with projections suitable for projection resistance welding.

(1) Load tube into single spindle special purpose lathe chuck with collet on O.D.

(2) Rough bore I.D., turn and form O.D., face, and cut of $f$.

(3) Normalize heat treat for metallurgical grain size.

(4) Hone I.D.

(5) Finish tracer turn O.D.

(6) Họ spline tooth.

(7) Projection weld doubler to diaphragm.

(8) Expand the finished tube onto a mandrel.

(9) Rotate mandrel and tungsten-shielded arc (helium) weld diaphragm to tube.

(10) Load on full complement mandrel, bore chamfer pilot diameter, pre-drill and chamfer bolt holes, face doubler.

(11) Buff and clean.

(12) Tuff-tride.

(13) Wash.

(14) H'inal inspection.

These operations are performed on the following machines:

- National Acme lathe (tube machining)

- Normalizing furnace (vendor treatment)

- Micro-matic hone (hone, I.O.)

- Fellows gear shaper (hob spline teeth)

- Single station welding machine (projection welding)

- Single station welding machine (heli-arc welding)

- Buhr N.C. machine (drill and ream)

- Tuff-tride treatment (vendor process) 


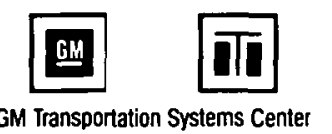

The in-plant machines on this list are shown on the plant layout in section 4.4 .

The flex spline process for the 250,000 volume is:

Receive the following raw material:

- SAE seamless Rockrite tubing SAE 8620 steel - bearing quality, vacuum begassed, 10-1/4 inch $0 . D . x 3 / 8$ inch wall in $16 \mathrm{ft}$ minimum length.

- Die blanked diaphragm - 9.625 \pm 0.0058620 steel

$$
-3.1875^{-} \pm .005 \text { I.D. } x 1 / 8 \text { thick }
$$

- Support doubler SAE $1018-6.25+0.005$.

$$
-3.187 \overline{5} \pm 0.005 \times 3 / 8 \text { thick }
$$

Plate to be embossed with projections suitable for projection resistance welding.

(1) Load tube into single spindle special purpose lathe chuck with collet on O.D.

(2) Rough bore I.D., turn and form O.D., face, and cut off.

(3) Normalize heat treat for metallurgical grain size and core hardness.

(4) Hone I.D.

(5) Finish tracer turn O.D.

(6) Hob spline teeth.

(7) Projection weld doubler to diaphragm.

(8) Expand the finished tube onto a mandrel.

(9) Rotate mandrel and tungsten-shielded arc (helium) weld diaphragm to tube.

(10) Load on full complement mandrel, bore chamfer pilot diameter, pre-drill and chamfer bolt holes, face doubler.

(11) Buff and̀ clean.

(12) Tuff-tride.

(13) Wash.

(14) Final inspection. 


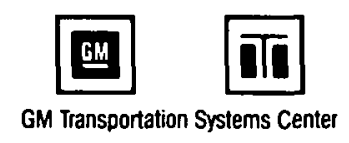

These operations are performed on the following machines:

- National Acme lathe (tube machining)

- Normalizing furnace (vendor treatment)

- Micro-matic hone (hone I.D.)

- Fellows gear shaper (hob spline teeth)

- Single station welding machine (projection welding)

- Single station welding machine (heli-arc welding)

- Lamb 4 station dial machine

- Tuff-tride treatment (vendor process)

The in-plant machines on this list are shown in the plant layout in Section 4.4 .

\subsubsection{Wave Generator Plug}

The wave generator for the harmonic drive is machined from steel bar stock which is lathe-cut to the proper thickness, ground on both sides, broached for the inside diameter, and countour-ground in a ganged setup.

The processing steps and the machines used in the processing for the 25,000 and 250,000 unit annual volumes are described in the following pages.

The wave generator plug process for the 25,000 volume is:

Receive SAE 1018 bar stock 7.250 O.D. in nominal $16 \mathrm{ft}$ lengths.

(1) Load into single spindle 2 AC Warner \& Swasey N.C. automatic lathe.

(2) Turn, face, bore, chamfer, and cut off.

(3) Blanchard grind both sides to length.

(4) Demagnetize.

(5) Key seat broach I.D.

(6) Gany luad un arbor; radial locate on key.

(7) Contour grind 3-lobe form on O.D. (polygon grinder).

(8) Wash.

(9) In spect. 


\section{國囯}

GM Transportation Systems Center

These operations are performed on the following machines:

- National Acme Lathe SST-10 5/8

- Blanchard grinder

- Mitts and Merrill broach

- Polygon grinder

These machines are shown in the plant layout in Section 4.4.

The wave generator plug process for the 250,000 volume is:

Receive SAE 1018 bar stock 7.250 O.D. in nominal $16 \mathrm{ft}$ lengths.

(1) Load into single spindle 2 AC Warner \& Swasey N.C. automatic lathe.

(2) Turn, face, bore, chamfer, and cut off.

(3) Blanchard grind both sides to length.

(4) Demagnetize

(5) Key seat broach I.D.

(6) Gang load on arbor; radial locate on key.

(7) Contour grind 3-lobe form on O..D. (polygon grinder)

(8) Wash.

(9) Inspect.

These operations are performed on the following machines:

- National Acme Lathe SST-10 5/8

- Blanchard grinder

- Mitts and Merrill broach

- Polygon grinder

These machines are shown on the plant layout in section 4.4. 


\subsubsection{Drive Shaft}

The drive shaft for the harmonic drive is machined from tubular steel stock. Machining is required to turn the outside diameter, thread the ends, mill (4) keyways and grind the bearing and cam diameters.

The machines used for this processing for the 25,000 and 250,000 unit annual volumes are listed below:

- 25,000 Volume

- Purchased from vendor

- 250,000.Volume

- 4 station trunnion machine (turn diameter and - thread ends)

- Single station double-ended mill (mill keyways)

- Landis grinder (grind bearing and cam diameter)

These machines are shown on the plant layout in section 4.4.

\subsubsection{Bearing Retainer}

The bearing retainer for the azimuth drive housing is machined from a purchased rolled-steel ring at the 25,000 volume level. This ring is then ground, lathe turned, drilled and galvanized. At the higher volume, the bearing retainer is fabricated from purchased steel bar. The bar is cut to length to form the retainer ring, heated, rnll formed and cxpanded. Finish machining at this volume is similar to that performed at the low volume level. After machining, the bearing retainer is galvanized.

The processing steps; machines and operator requirements for the 25,000 and 250,000 unit annual volumes are described on the following pages.

The processing for the bearing retainer at the 25,000 volume level is as follows:

\section{Operation}

(1) Grind sides of ring parallel and flat

(2) Turn inside diameter bearing race contour and "o"-ring grooves
Machine

Operators/ Machine
Blanchard grinder

(1 requi red)

Bullard Templaturn Vertical Turret Lathe (1 required)
0.5

1. 0 
Operation

(3)
Drive and counter bore (16) holes
Machine

Buhr N.C. Machine

(1 required)
Operators/

Machine

1.0

After machining, the bearing retainers are transported to the galvanizing area. The bearing retainers are processed and on the same line with the azimuth housings and drag links. The processing for these parts is described in paragraph 4.3.3.1. After galvanizing the bearing retainers are transported to the azimuth drive assembly area and stored in the staging area. The equipment and machining area for the bearing retainers is shown on the plant layout in Section 4.4 .

The processing for the bearing retainer at the 250,000 volume level is as follows:

\section{Operation}

(1) Cut purchased steel bar into retainer lengths

(2) Heat cut-off parts

(3) Transport and roll cut-off part into ring

(4) Expand ring to final size and round shape

(5) Transport and grind both sides parallel and flat

(6) Turn inside diameter contour and (2) "0" ring grooves

Drill (16) holes

\section{Machine}

W. J. Savage

abrasive saw

(1 required)

Oven ( 1 required)

Grotnes ring roller

(5 required)

Grotnes expander

(5 required)

Blanchard grinder

(2 required)

Bullard Templaturn

1.0

Vertical Turret Lathe

( 6 required)

Lamb 4-station dial index 1.0 machine ( 1 required)
Operators/ Machine

1. 0

1.0

1. 0

1.0 
GM Transportation Systems Center

\subsubsection{Azimuth Drive Unit Assembly Processing}

The processing steps for the assembly of the azimuth drive at the 25,000 and 250,000 annual volumes are listed in the following pages. For both production volumes, the housing moves along transfer equipment as the components are installed. These components include: drive gear set and bearings, drive shaft, flexible spline, flexible bearing, circular spline, and wave generator. At the lower volume most components are inserted manually and fasteners are torqued automatically. At the high volume, most component insertion, gaging, shim packing, and fastening are performed automatically. At this stage of assembly, the azimuth drive is complete, except for the installation of the drive motor. The input gcar oct io lubricated and the output gear case is oil filled. The completed subassemblies are then placed on pallets for transfer with forklift trucks to the final assembly area.

These operations are performed on an assembly line with manual loading. The machines required and operations for the azimuth drive components for the 25,000 and 250,000 unit annual volumes are given in the following pages.

The processing for the two annual volumes is similar. At the lower volume, a 29-station assembly line with 7 operators is required. This machine is shown in Figure 4-35.

At the higher volume, a 29-station assembly line with 12 operators is required. This machine is shown in Figure 4-36.

Following is a list of the processing steps required for both annual volumes.

'The drive unit assembly process for the 25,000 and 250,000 volume is:

(1) Using overhead crane, load machined azimuth drive housing on transfer line,

(2) Idlo

(3) Automatically load flex spline on mandrel and orient.

(4) Id le

(5) Advance mandrel and wedge flex spline into cavity.

(6) Press-in 6 bolts through top of housing.

(7) Install 6 torque nuts through mandrel and flex spline; torque-out nuts and bolts.

(8) Idle 


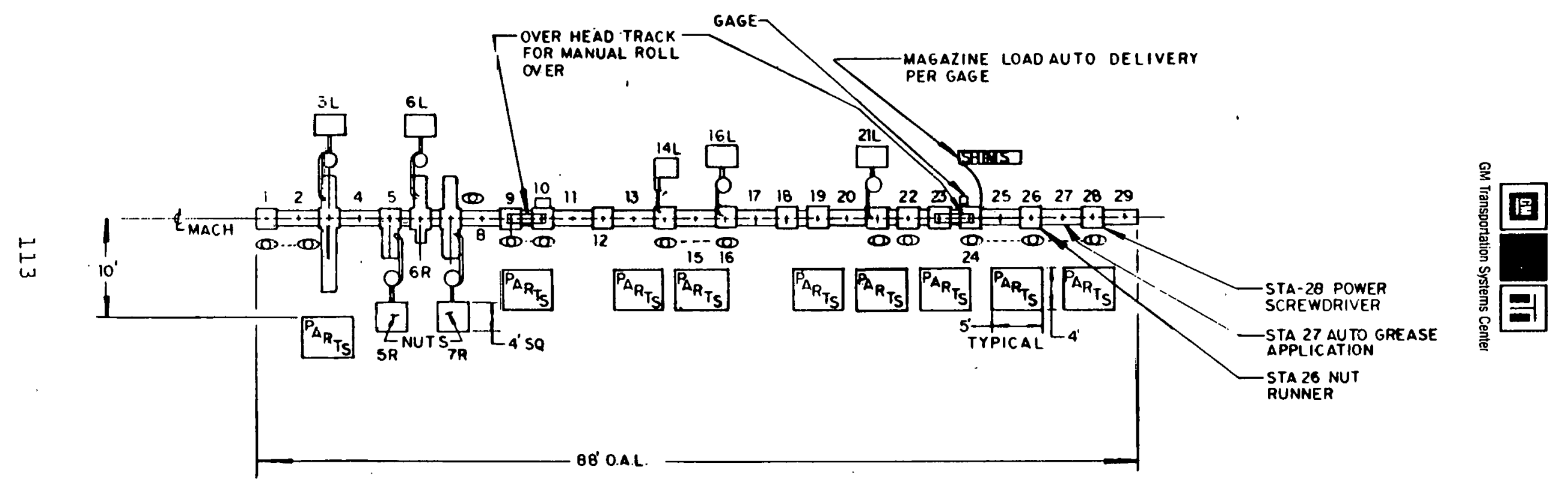

Figure 4-35. DRTVE UNIT ASSEMBLY LINE - 25,000 ANNUAL VOLUME 


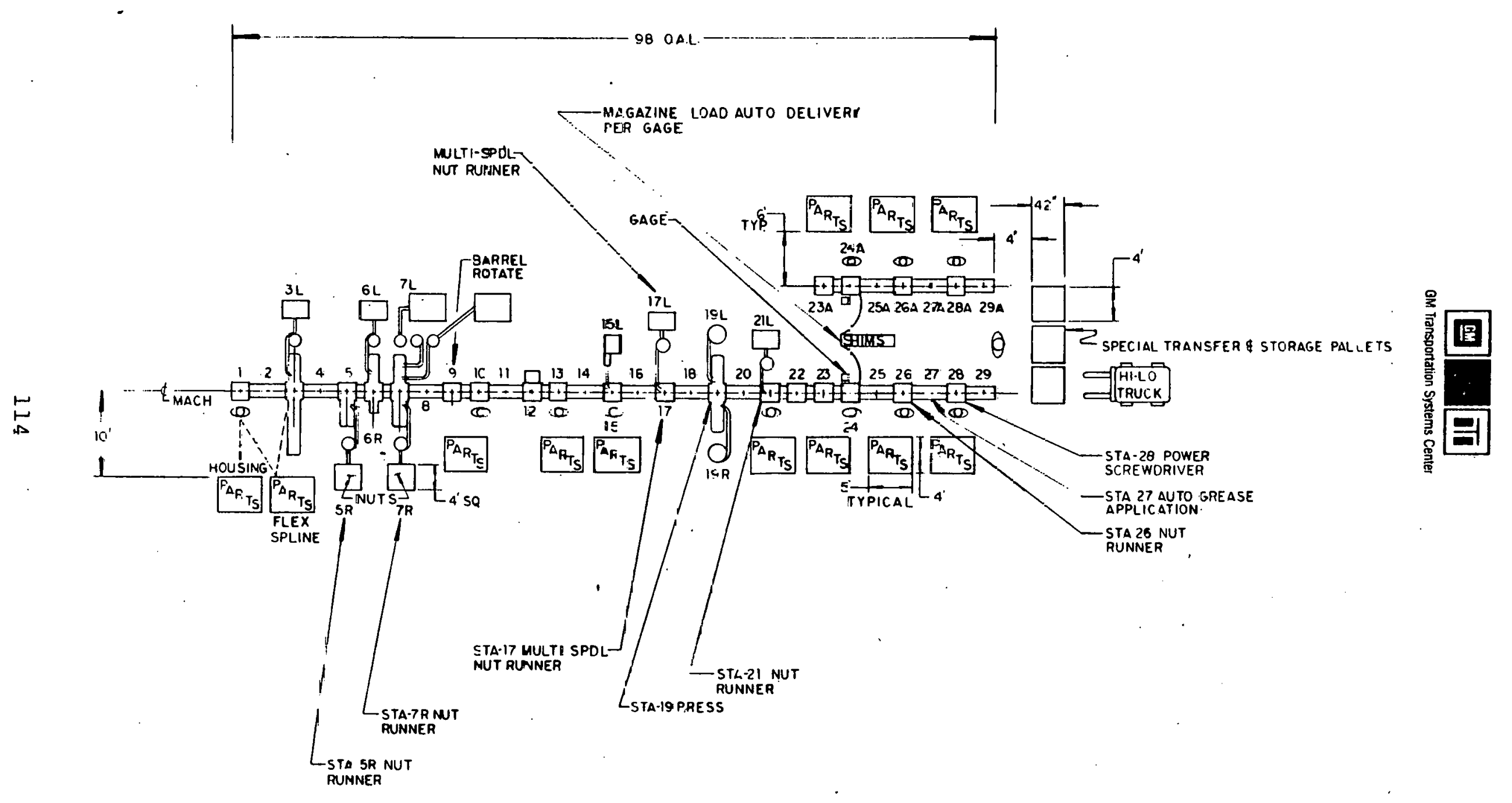

Figure 4-36. DRIVE UNIT ASSEMBLY LINE - 253,000 ANNUAL VOLUME 
GM Transportation Systems Center

(9) Press-in 6 bolts, alternate locations, through top of housing; remove mandrel and wedge.

(10) Install 6 torque nuts and torque-out nuts and bolts.

(11) Idle

(12) Press-in upper shaft bearing; install retainer and 4 bolts.

(13) Idle

(14) Hoist housing with rollover fixture and rotate 90 degrees.

(15) Idle

(16) Manually insert wave generator cam bearing and center shaft subassembly with key aligned and press in place -backup upper bearing.

(17) Idle

(18). Install circular spline ring with inner bearing races installed; install. upper outer bearing race; install bearing balls.

(19) Install 2 o-rings, -bearing retainer, subassembly with lower outer bearing race; install and torque bolts.

(20) Idle

(21) Press-in bushings for torque tube and tracking actuator.

(22) Oil fill housing cavity and install bottom cover (with sealant) and 8 bolts.

(23). Hoist housing assembly with rollover fixture and rotate 180 degrees.

(24) Install drive gear ${ }^{\circ}$ spacer and drive gear; perform automatic electronic shim selection; install shim and drive gear key.

(25) Idle

(26) Install drive gear lock washer and retaining nut and torque out; bend tab on washer.

(27) Idle

(28) Install top cover and cable elbow.

(29) Unload 
GM Transportation Systems Center

\subsubsection{Azimuth/Elevation Assembly Processing}

The azimuth/elevation assembly consists of the following components :

- Azimuth drive and motor

- Drag link

- Torque tube

- Tracking actuator and motor

- Storage actuator and motor

- Pins and shims

- Electronic controller and harness

At the 25,000 unit annual volume, these operations are performed manually on two assembly benches, each with two positions. This operating also requires two overhead rranes and four opcrators. A layout of the assembly station is shown in Figure 4-37.

The operations for the 250,000 volume are performed in a similar fashion to the 25,000 volume. These operations, however, are performed on a conveyor type transfer machine with 20 operators. The machine layout and processing are shown in Figure 4-38.

\subsubsection{Pedestal Assembly}

The pedestal assembly consists of the tapered pipe, the pedestal tube witt tapered end, and an end cap which is welded to the top of the pedestal tube. All of these components are galvanized for protection from corrosion. The process description for manufacturing the pedestal assembly for both production volumes is contained in the following pages.

\section{-}

4.3.4.1 Tapered Pipe Foundation Cap Process Description for the 25,000 volume

(1) Purchase zinc plated tapered pipe foundation cap complete from vendor.

(2) Inspect in plant.

(3) Deliver to site. 


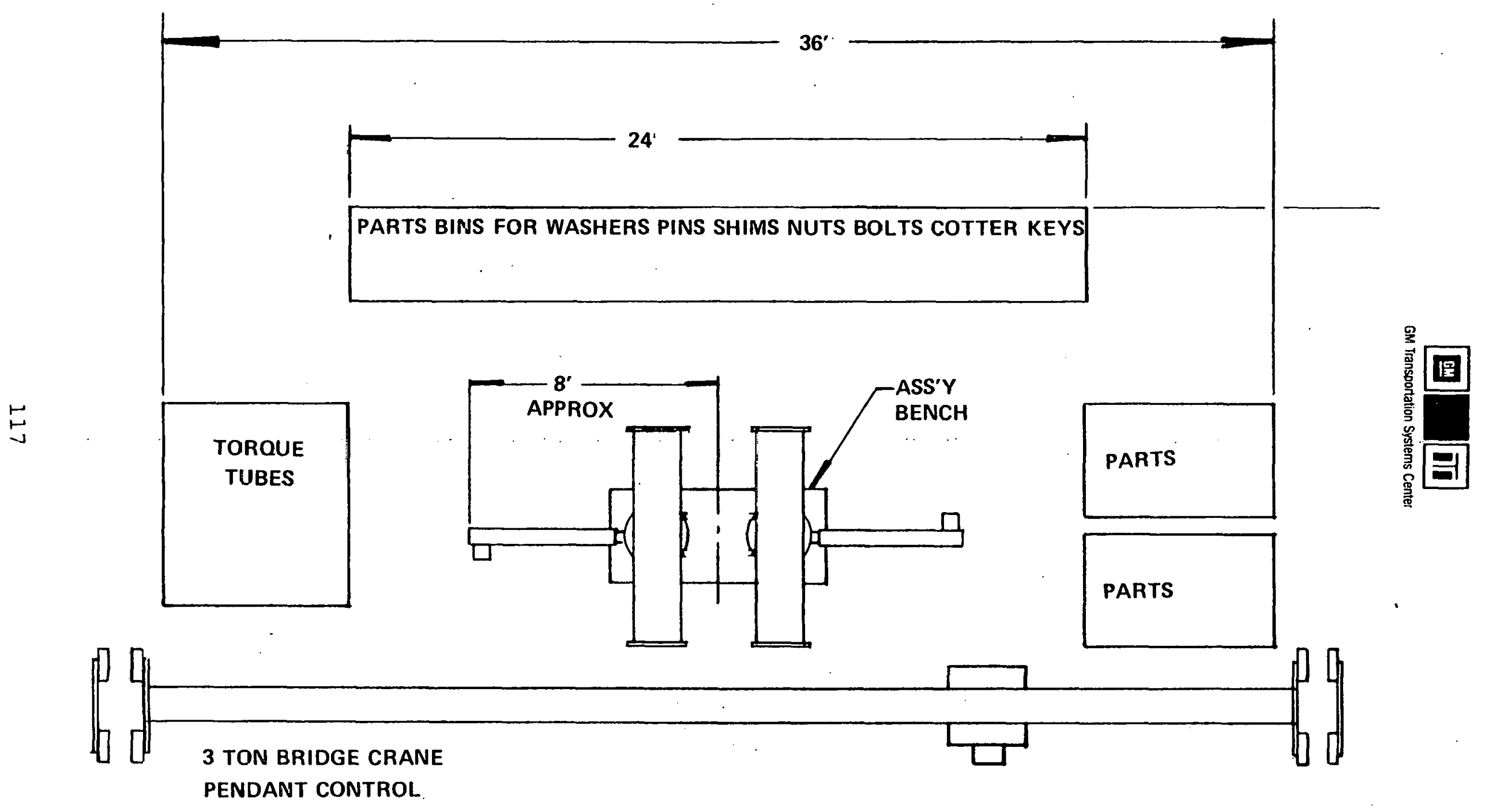

Figure 4-37. AZIMUTH/ELEVATION ASSEMBLy AREA - 25,000 ANNUAL VOLUME 
Load, Position Arm
Gage Tracking Actuator Ears
Position Tracking Actuator Shim
Install. Tracking Actuator Arm
Position Drag Link
Measure, Center and Install
Tracking Actuator Clevis Pin
Install Washers and Pins

Gage Housing and Drag Link Ears $\longrightarrow 0$

Position Torque Tube

Select and Position Hinge Pin__nstall Hinge Pin Cotter Pins

Position Stowage Actuator $\longrightarrow 0$.

Gage Between Actuator and Support
Ears and Select Shims

Insert Permanent Trunnion Pin

Press in Permanent Pins

Install Stowage Actuator Clevis Spacers $\longrightarrow 0$

Install Washers and Cotter Pins

Install Azimuth Drive Controller

Install Drive Motor's

$-0$

$\sqrt{ }$
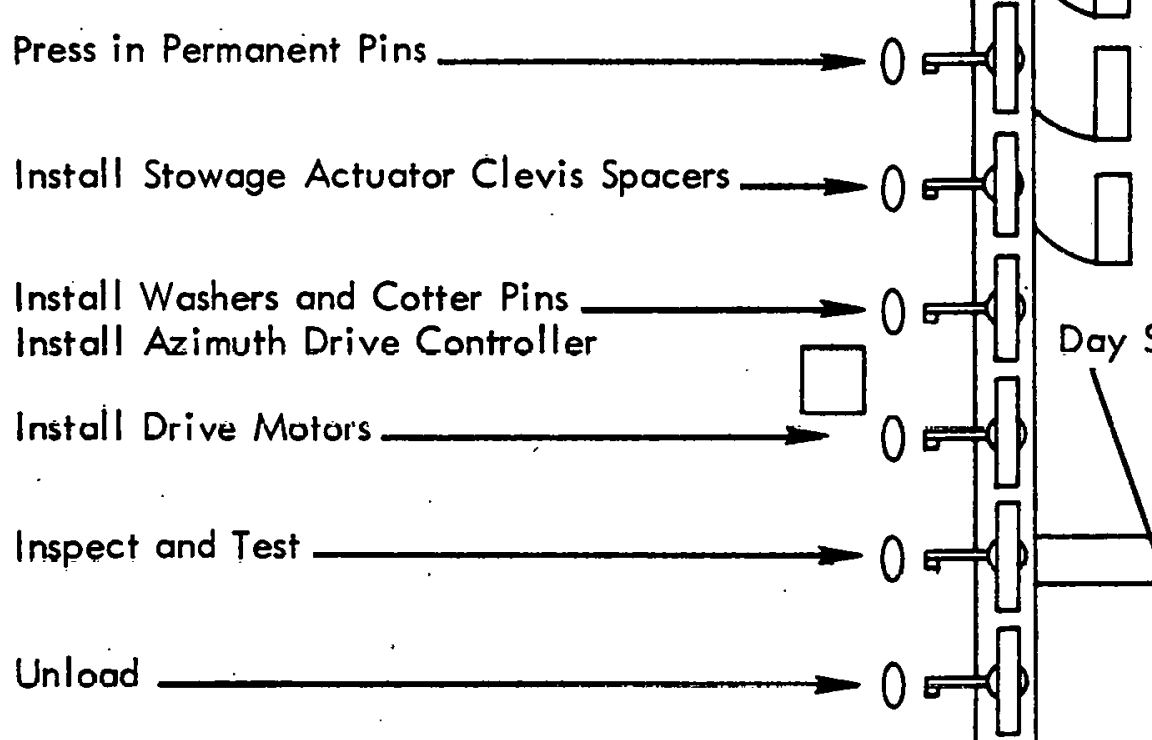

Day Shift Inspection

Night Shift Inspection Night Shift Inspection

-Figure 4-38. AZIMUTH/ELEVATION ASSEMBLY AREA - 250,000 ANNUAL VOLUME 


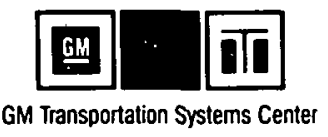

Tapered Pipe Foundation Cap Process Description for the 250,000 Volume

(1) Receive sheet steel from vendor slit to width.

(2) Manufacture welded tubing complete on tube mill, cut to length.

(3) Expand pipe over 46 inch length to 0.14 in./ft taper.

(4) Galvanizing of the tapered pipe is performed on a line that is separate from that used for the torque tube and azimuth drive components. The processing, however, is identical. This processing is described in paragraph 4.3.3.1, with the following exceptions: two operators are required for load/unload operations, three operators are required for monitoring and servicing of this line. The usage of this line is shared between the tapered pipe and the pedestal tube.

(5) Package for shipment to installation site.

These operations are performed on the following machines:

- Tube mill (roll forming and welding)

- Expanding mandrels (expanding taper)

- Galvanizing tank (galvanized plating)

Note: The tube mill and galvanizing tank are used for manufacture of the tapered pipe as well as the pedestal tube.

These machines are shown on the plant layout in Section 4.4. 


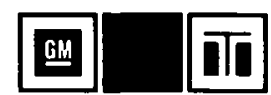

GM Transportation Systems Center

4.3.4.2 Pedestal Tube Process Description for the 25,000 Volume

(1) Purchase complete from vendor.

(2) Deliver tube to assembly area for buildup with azimuth drive components.

Pedestal Tube Process Description for the 250,000 Volume

(1) Receive sheet metal in rolls cut to width from vendor.

(2) Mánufacture welded tubing (0.105 wall) complete on tube mill with pipe cut to length at end of process.

(3) Nutomatioally aro wold oap to pedectal tubc.

(4) Expand one end of tube over 48 inches in length from 24 inches O.D. to 24.5 inches O.D. after cut-off.

(5) Flame cut round and square hole.

(6) Galvanizing of the pedestal tube is performed on a line that is shared with the tapered pipe operations. The processing is described in paragraph 4.3.3.1. Operator requirements for this shared line are given in paragraph 4.3 .4 .1 .

(7) Deliver tube to assembly area for buildup with azimuth drive components.

These operations are performed on the following machines:

- Tube mill (roll forming and welding)

- Pattern torch cutter

- Expandinq mandrels (expanding tapered section)

- Single station weld machines (end cap/tube welding)

- Galvanizing tanik (galvanized plating)

- Overhead cranes (3)

These machines are shown on the plant layout in Section 2.4.2.

4.3.4.3 End Cap Process Description for the 25,000 and 250,000 Volume

(1) Purchase end cap complete from vendor, including zinc plate. 


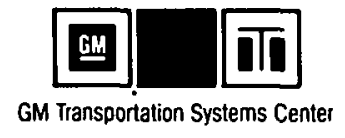

\subsubsection{Final Assembly}

For final assembly, completed azimuth/elevation assemblies and pedestal assemblies are transferred with fork-lift trucks on pallets to the final assembly area. The assembly operation requires the installation of mounting bolts between the drive assembly and the pedestal tube, routing of the cable harness, and connection to the junction box, and installation of the junction box.

4.3.5.1 Final Assembly for the 25,000 Volume

These operations are performed manually with the aid of an assembly fixture and overhead crane. Equipment required includes one bench and two overhead cranes. One operator is required. The following operations are performed at the final assembly station. (See Figure 4-39).

(1) Receive drive assembly and pedestal from staging areas.

(2) Crane load drive assembly on three-point cradle, supporting torque tube and housing flange. Crane load pedestal on two "V" block cradles, end cap against drive flange. Rotate pedestal to align holes.

(3) Through access opening in pedestal, manually insert and tighten with pneumatic wrench, eight 5/8-1l screws.

(4) Connect and install junction box.

(5) Electrical functional test of drive motors and electronics is performed at this point.

(6) Using overhead crane, unload final assembly and place in custom shipping containers at shipping dock.

\subsubsection{Final Assembly for the 250,000 Volume}

These operations for the 250,000 volume are performed in a manner similar to the 25,000 volume. The increased capacity requires 9 benches, each with 2 positions, and 18 overhead cranes. Forty nperators are required.

The processing description is the same as that for the lower volume and the assembly station is identical to that shown in Figure 4-39. 


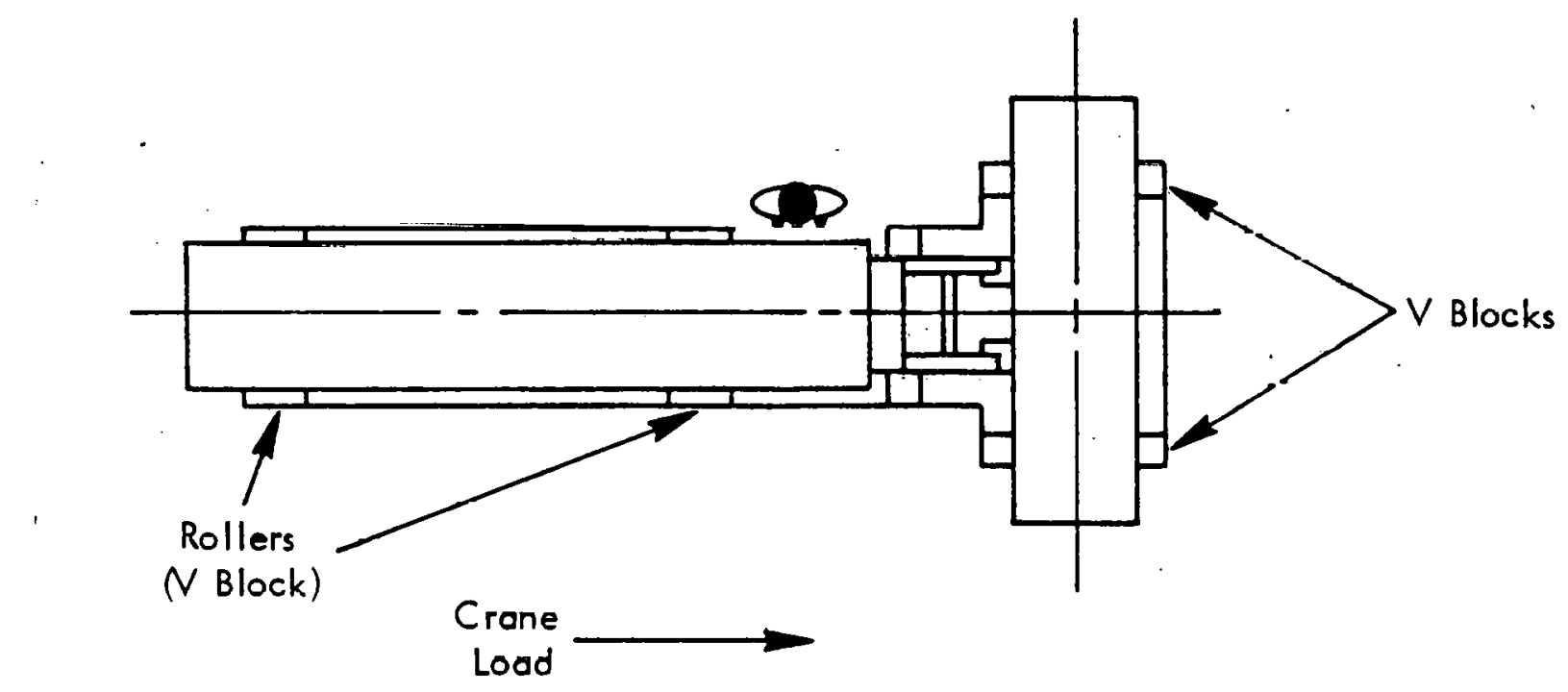

Figure 4-39. FINAL ASSEMBLY BENCH PEDESTAL ASSEMBIY - 25,000 UNIT ANNUAL VOLUME 


\subsection{Plant Layout}

The plant layouts for the 25,000 and 250,000 unit annual volume heliostat production are shown in Figures 4-40 and 4-4l, respectively. Both plant designs are single-story slab construction and of high-bay design. The low volume plant has floor area of approximately 300,000 square feet and the high volume plant occupies approximately 680,000 square feet.

The plant for the 25,000 unit annual volume, Figure 4-40, has facilities for the manufacture of the following operations:

- Mirror laminating

- Support structure pressing and welding

- Reflector panel assembly

- Azimuth drive housing machining

- Flex spline, wave generator, bearing retainer, and circular spline machining

- Drag link and torque tube machining

- Azimuth and elevation drive assembly

- Electronic/electrical component fabrication and assembly

- Final assembly

- Shipping

Major supplier items which are shipped into this plant include the following:

- Mirrored front lites

- Float glass back lites

- Roll formed sections for the support structure

- Azimuth drive, torque tube, drag link, pedestal and tapered pipe galvanized weldments

- Electronic parts, printed circuit boards and wiring

- Drive motors and linear actuators 


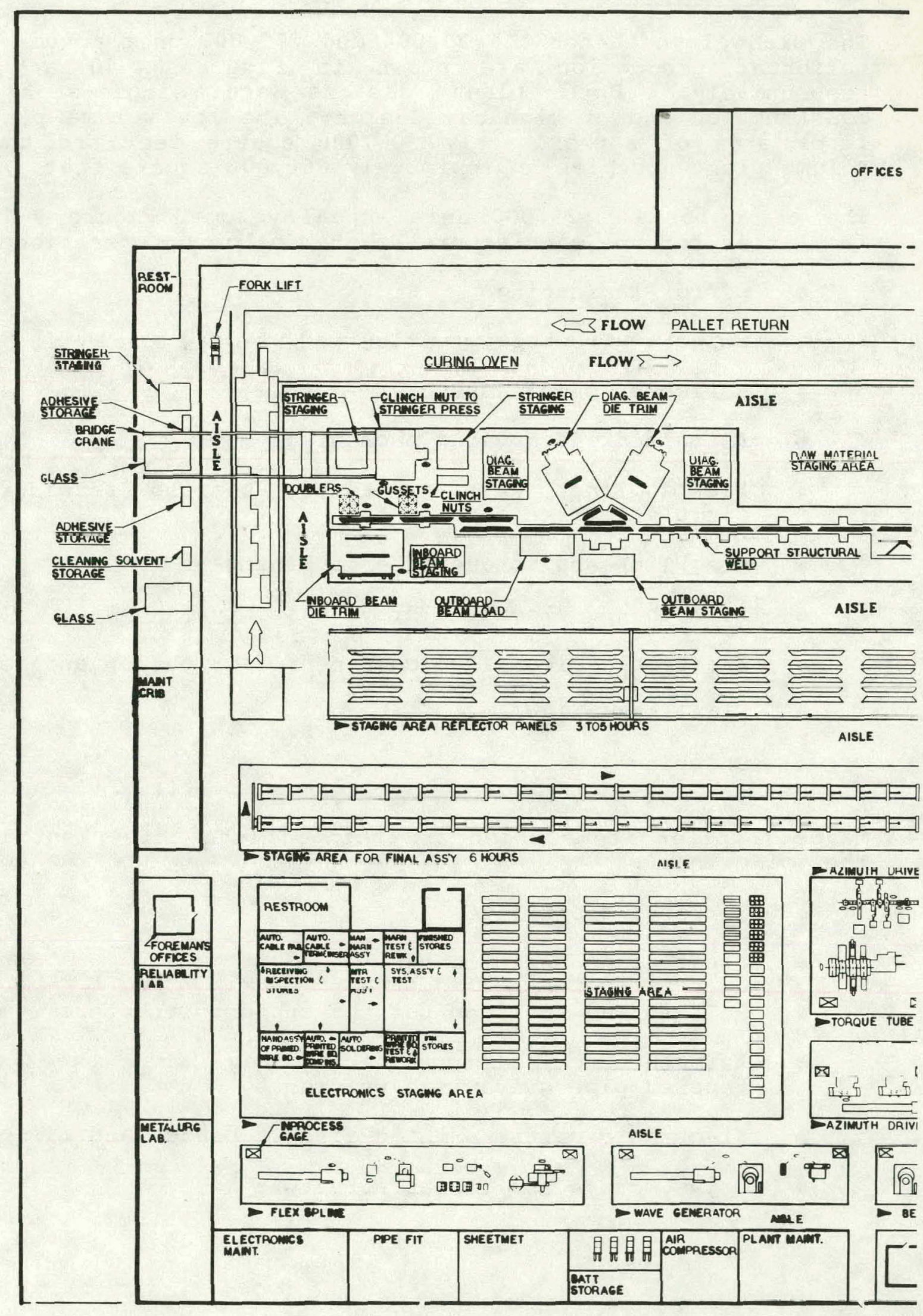




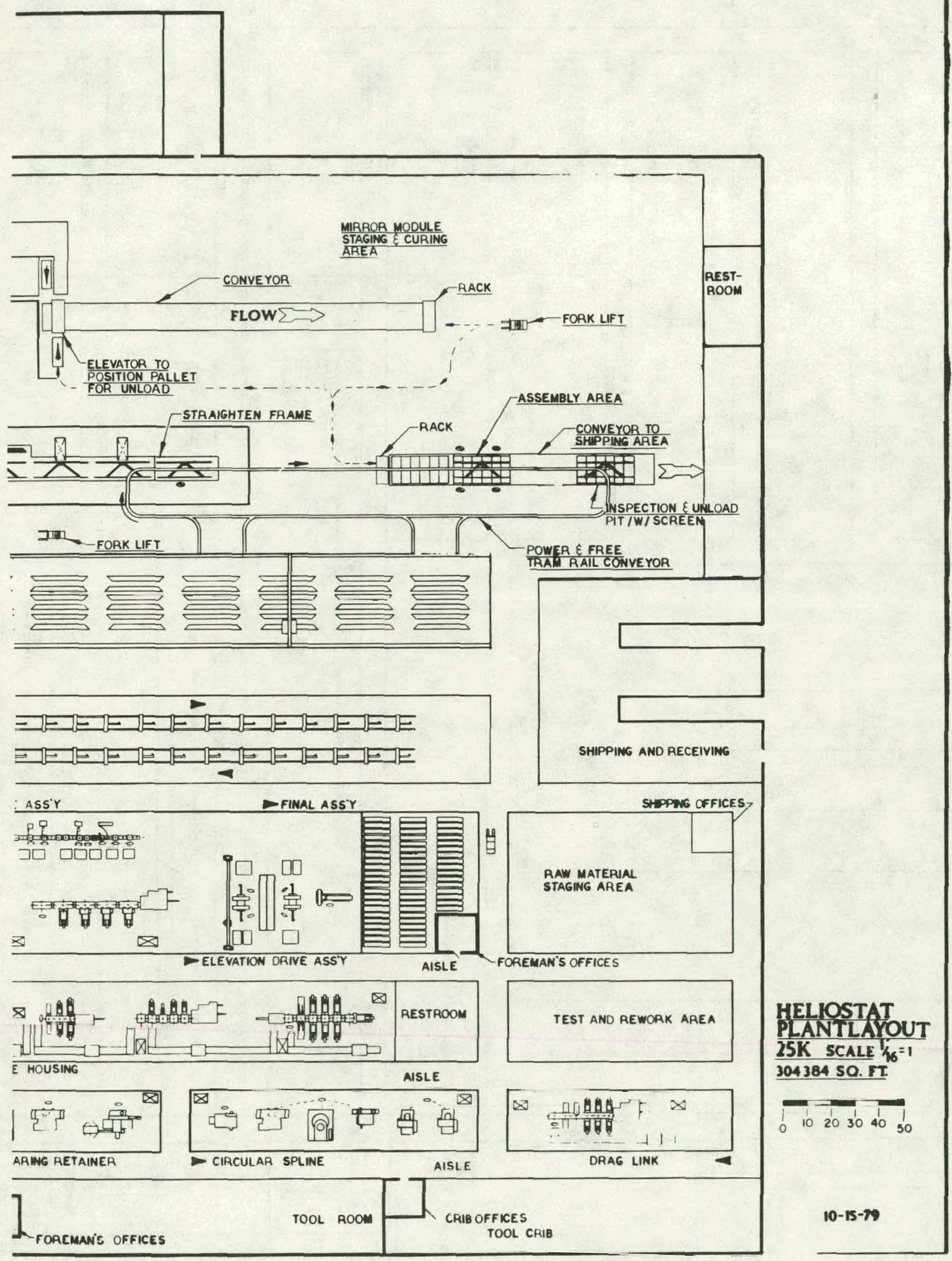

Figure 4-40. PLANT LAYOUT 2.5,ON0 UNIT ANNTAL VOLU:E 


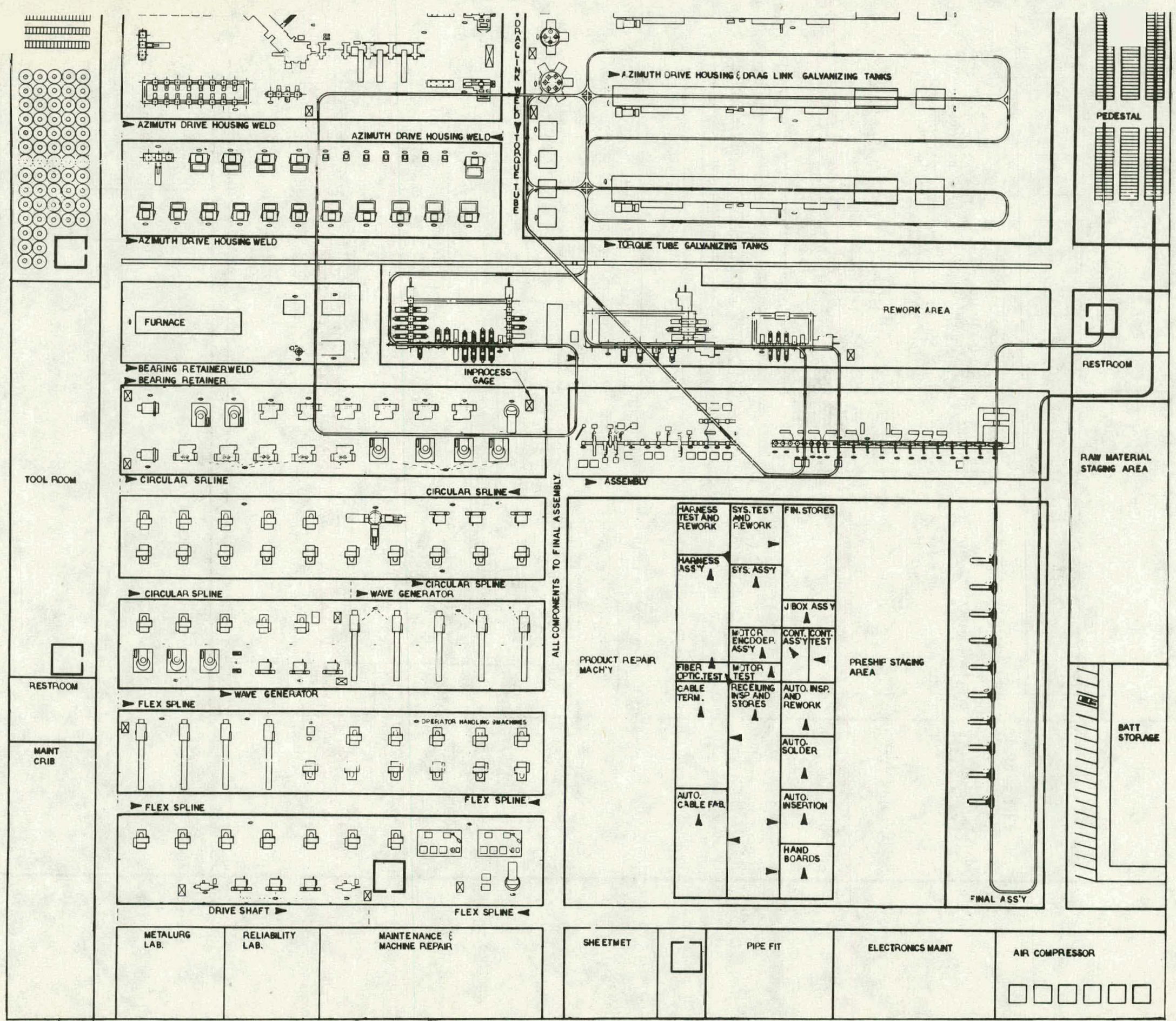




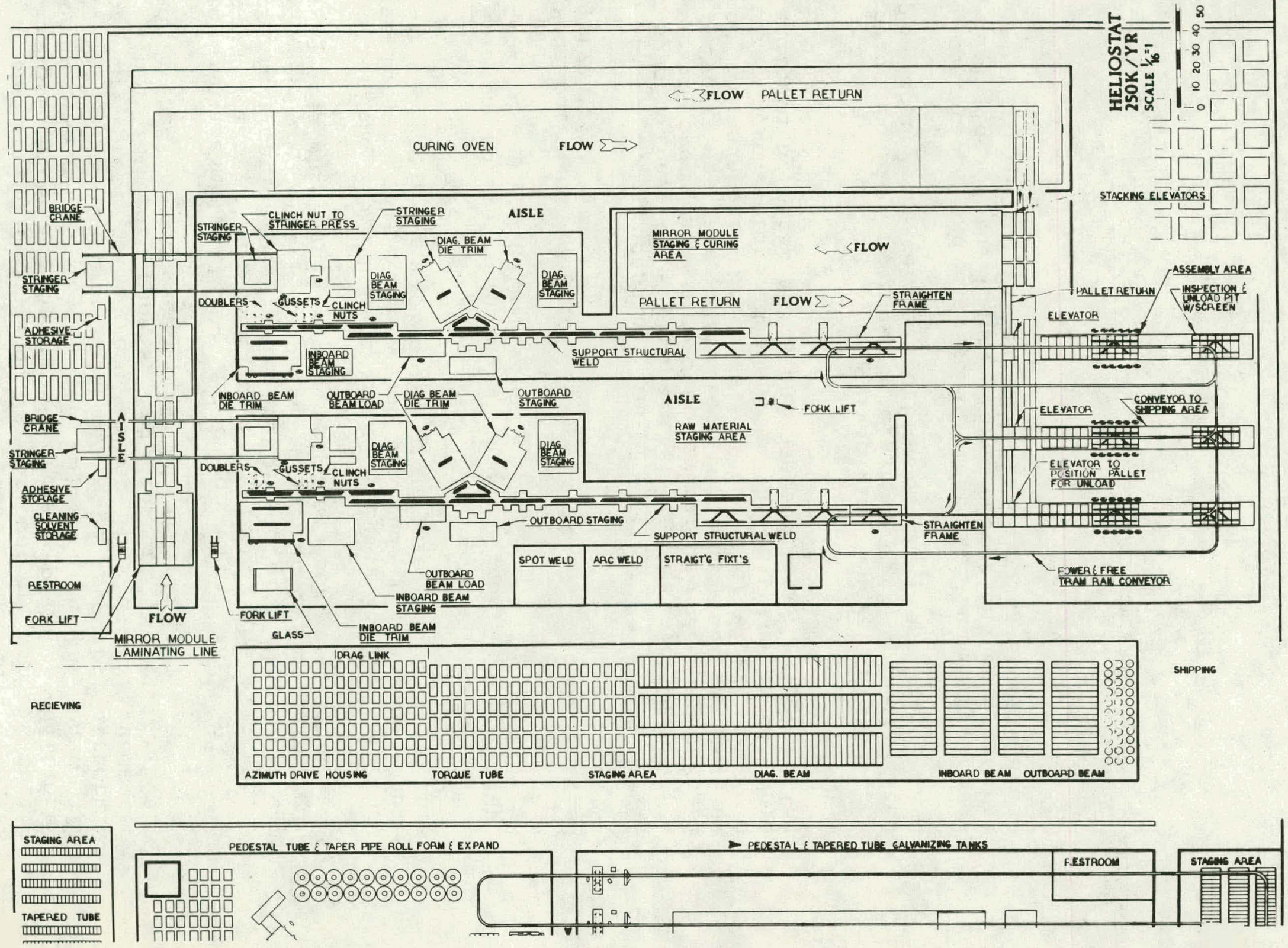


A major portion of the plant is occupied by the processing equipment for the reflective surface assembly. Glass laminating and stringer bonding are followed by partial curing in the oven located at the front of the plant. Additional curing occurs in the storage area adjacent to the oven. In parallel with the mirror assembly, the support structure components are press formed and welded in the semi-automated welding line. Mirror panels and support structures are assembled in the line adjacent to the shipping area.

Machining and assembly of the drive components take place in the various areas at the rear of the plant. The electronic/ electrical fabrication occurs in the closed area which is near the final assembly area. Completed drive units are stored in the staging area which ends at the shipping dock.

The plant for the 250,000 unit annual volume, Figure 4-41, has facilities for the same items which are made in the low-volume planl. In addition, the following itcms are produced in this plant:

- Azimuth drive housing, torque tube, drag link, fabricating and galvanizing

- Pedestal and tapered pipe forming, welding, and galvanizing

In this plant, the processing line for mirror laminating and stringer bonding handles six panels at a time and includes a larger curing oven and vertical tower for panel post-cure storage. Two lines are installed for the fabrication and welding of the support structure. These operations occupy a major portion of the plant adjacent to the shipping area. This area is enclosed by metal walls and has additional air handing equipment.

The fabrication, welding and galvanizing operation for the azimuth drive housing, torque tube, drag link, pedestal and tapered pipe occupy the central portion of the plant.

Machining operations and electronic/electrical assembly occupy the left-hand side of the plant. These operations all feed the drive assembly area which is near the pre-shipping storage area. 
THIS PAGE

\section{WAS INTENTIONALLY \\ LEFT BLANK}




\section{THIS PAGE}

\section{WAS INTENTIONALLY LEFT BLANK}




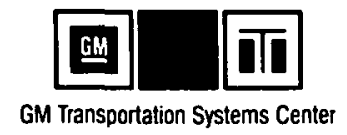

SECTION 5.0

\section{HELIOSTAT PRODUCTION COSTS}

Heliostat production costs have been developed from the processing, machines, and plant designs for the 25,000 and 250,000 unit annual volume of heliostat manufacture. Purchased parts and materials costs were developed from material price requests which were completed for each component of the heliostat. The actual forms used in this analysis are contained in Appendix B of this report. In all cases, material price quotes were obtained from vendors for each purchased heliostat component.

From the machine and plant designs, tooling and routing sheets were prepared. These forms indicate the operations to be performed, timing for manual and automatic operation, and prices for special tools and equipment. Copies of these forms are contained in Appendix $C$ of this report. All special machine designs were developed to the point of detailed concept sketches, and cost estimates were made by suppliers of similar equipment. Where standard machine tools are used, budgetary cost estimates or quotations were obtained from the vendors.

Average hourly labor rates for persons engaged in manufacturing in the southwestern area of the United States were used to establish the base hourly rate in the manufacturing plants. This rate, $\$ 6.30$ per hour, was adjusted for typical fringe benefits.

Plant costs were estimated for both the 25,000 and 250,000 volume units and reflect current rates for similar construction in the southwest.

Actual tax rate information for the selected site location of Tuscon, Arizona, was used in the determination of real estate and property taxes.

The factory cost totals for the two production volumes show the allocation of labor, material, burden, fringe benefits, special tools, and plant engineering for each unit of heliostat production at the 100 percent capacity level and provides a factory cost of $\$ 4,699.07$ at the low volume and $\$ 3,301.87$ at the high volume*. Outside tooling and plant costs which are required to meet supply at the two volumes are also indicated; when these costs are included the total per unit heliostat costs are $\$ 4,708.42$ at the 25,000 volume and $\$ 3,333.03$ at the 250,000 volume. The corresponding costs per square meter of heliostat surface area are $\$ 95.99$ and $\$ 67.95$.

*See Section 1.2.7, Factory Cost 


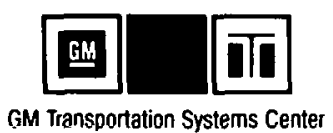

The heliostat costs for the two production volumes, adjusted to 75 percent of capacity the total per unit heliostat costs are $\$ 4,909.88$ at the 18,750 volume and $\$ 3,438.18$ at the 187,500 volume. The corresponding costs per square meter of heliostat surface area are $\$ 100.10$ and $\$ 70.10$.

The heliostat costs for the two production volumes, adjusted to 125 percent of capacity show that the total per unit heliostat costs are $\$ 4,587.58$ at the 31,250 volume and $\$ 3,269.94$ at the 312,500 volume. The corresponding costs per square meter of heliostat surface area are $\$ 93.53$ and $\$ 66.67$.

The breakdown of the burden cost, on a per unit basis for both fixed and variable burden have been indicated in section 5.2.5. The most significant portion of the burden account is for taxes and depreciation on the buildings and plant equipment.

The investment per unit heliostat at the two production volumes was also determined. The totals indicated have been depreciated to obtain the expense values shown in the burden account. Buildings depreciated over 40 years, equipment and machinery depreciated over 9.5 years, and special tools depreciated over 5 years.

Outside tooling and plant costs are summarized in section 5.2. Outside expenses result from rolling mill tools and buildings, mirroring equipment, glassmaking equipment, gear tooling, and junction box tooling. These outside costs add $\$ 0.19$ and $\$ 0.64$ per square meter to the heliostat cost at the two production volumes.

\subsection{COST APPROACH}

\subsubsection{Purchased Parts}

The Pitem labeled "Material" in subsequent cost tables includes all the raw materials and purchased parts required for the manufacture of the heliostat unit; examples are: glass, adhesive, steel, weldments, packaging, materials, etc. All indirect material costs are collected as a variable or fixed burden expense.

At both the high and low production volumes, your attention is drawn to the very high relative material cost, much of which can be associated with purchased parts (see the Bill of Materials). Material costs including purchased parts comprise 81 percent of the factory cost at the 25,000 units per year volume and 85 percent of the factory cost at 250,000 units per year. 


\subsubsection{Labor (direct/indirect)}

Direct labor includes all straight time wages of employes who perform manufacturing operations which enhance the value of the heliostat unit and/or who participate directly or indirectly in processing operations which enhance the value of raw materials and purchased parts. Direct labor includes inspectors, some material handlers, and machine attendants, as well as productive operators.

Indirect labor is a burden expense and comprises the following categories:

- Supervision

- Clerical

- Material handling

- $\quad$ Building and property attendants

- Machine, tool, and die setting

- Drafting and engineering

- Inspection
- Foremen, superintendents, and all other supervisory positions

- Factory clerks and checkers; office clerks and typists

Truckers, crane operators, and other material handlers not included in direct labor

\subsubsection{Tools and Equipment}

Expense tools and equipment costs are collected as a burden expense. These items include:

- Tools - cutters, drill bits, hand tools, etc.

- Equipment - special holding devices, bins, racks, etc.

- Office furniture and equipment.

Special tools are collected as a factory cost item and depreciated over a 5-year period. The double declining balance method is used with the first year convention. The second year's depreciation is then taken as the average annualized cost for estimating purposes. 


\subsubsection{Production Plant Costs}

The plants for heliostat manufacture at the 25,000 and 250,000 unit annual volume have floor areas of approximately 300,000 and 700,000 square feet, respectively. These plants feature concrete slab construction with a steel structure. The plants are air conditioned, fully sprinklered and have waste water treatment at the secondary level. Plant equipment is included for electric arc welding, compressed air, process water and battery charging for the materials handling equipment. Enclosed areas are provided for the welding and plating areas. These areas have metal walls and special air handling equipment.

Outside storage areas are provided for five days of heliostat production. 'These uncovered storage pads for heliostat components in shipping racks have areas of 50,000 and 500,000 square feet for the two production volumes. Plant sites are improved for access and storage and are completely fenced. The plant site sizes are 50 and 100 acres for the two production volumes. 'l'he site sizes have been selected to provide for possible future expansion.

For the 25,000 unit annual volume, the plant is estimated to cost $\$ 120$ per square foot and the land is estimated at $\$ 16,000$ per acre. The corresponding rates for the 250,000 unit annual volume plant are $\$ 110$ per square foot and $\$ 16,000$ per acre. The lower cost $r$ ate for the larger plant, approximately 10 percent, represents the cost/area relationship from the economy of scale.

Based on these rates, the total capital needed for the smaller plant is approximately $\$ 87,000,000$ of which $\$ 37,000,000$ is for the building and $\$ 800,000$ for land. The corresponding costs for the larger plant are approximately $\$ 393,000,000$ of which $\$ 75,000,000$ is for the building and $\$ 1,600,000$ for the land.

The buildings are depreciated over a period of 40 years and the land is not depreciated. Total annualized costs for the buildings and land, and investment per heliostat unit are in the sections that follow.

Building depreciation is performed by the double declining balance method with the first year convention. The second year's depreciation is then taken as the average annualized cost for estimating purposes.

\subsubsection{Spare Parts}

Spare parts requirements for the heliostat have been extracted from the MDAC final report. The component requirements are given in Table 5-1. The spare parts quantities given in this table represent the case for the 25,000 unit annual volume. At the 250,000 unit annual volume, spare part quantities are increased by a factor of ten. 
GM Transportation Systems Center

Since these parts requirements have a minimal effect on the production capacity of the two plants, machine and plant volumes have not been modified to reflect increased output required to produce the spare parts.

Table 5-1. SPARE PARTS REQUIREMENTS - LINE REPLACEABLE UNITS

\begin{tabular}{|l|c|c|c|}
\hline & $\begin{array}{c}\text { Initial } \\
\text { Spare Parts }\end{array}$ & $\begin{array}{c}\text { Total } \\
\text { Replacement } \\
\text { Spare Parts }\end{array}$ & $\begin{array}{c}\text { Sarts } \\
\text { Pare }\end{array}$ \\
\hline Drive Assembly, Azimuth & 25 & 13 & 38 \\
\hline Jack Assembly, Tracking & 24 & 11 & 35 \\
\hline Jack Assembly, Stowage & 3 & 1 & 42 \\
\hline Drive Motor, Azimuth & 28 & 14 & 42 \\
\hline Drive Motor, Elevation & 28 & 1 & 29 \\
\hline Drive Motor, Stowage & 3 & 7 & 206 \\
\hline Heliostat Control Electronics & 22 & 99 & 4 \\
\hline Reflector Panel & 107 & & 14 \\
\hline
\end{tabular}

The cost of the spare parts is less than 10 cents per square meter and has not been added to the total cost at the annual volumes.

\subsection{COST SUMMARIES}

This section includes all of the numbers derived from the study assembled in tabular form. In addition, a monograph provided by the Solar Energy Research Institute, Policy Analysis Branch, is included as section 5.2.8 where an installed price comparison is made to results of the Battelle Northwest Laboratory study.

\subsubsection{Full production}

This table reflects the estimated factory cost of heliostats produced at a mature facility operating at $100 \%$ of capacity where that design capacity includes allowances for machine, labor, and manufacturing efficiencies. 


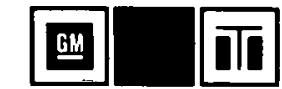

GM Transportatiun Systems Center

Table 5-2. TOTAL COST PER HELIOSTAT UNIT (100\% OF PLANT CAPACITY)

\begin{tabular}{|c|c|c|}
\hline & 25,000 Volume & 250,000 Volume \\
\hline $\begin{array}{l}\text { Direct Labor } \\
\text { Material } \\
\text { Variable Burden } \\
\text { Fixed Burden } \\
\text { Variable Fringe } \\
\text { Fixed Fringe } \\
\text { Overtime } \\
\text { Night Shift } \\
\text { C.O.L.A.** }\end{array}$ & $\begin{array}{r}63.18 \\
3,799.37 \\
178.82 \\
540.60 \\
40.29 \\
23.97 \\
3.35 \\
3.10 \\
7.74\end{array}$ & $\begin{array}{r}46.65 \\
2,798.67 \\
131.93 \\
261.44 \\
24.92 \\
14.83 \\
2.08 \\
1.92 \\
4.79\end{array}$ \\
\hline Subtotal & $4,660.42$ & $3,287.23$ \\
\hline $\begin{array}{l}\text { Special Tools } \\
\text { Plant Engineering }\end{array}$ & $\begin{array}{r}30.28 \\
8.37\end{array}$ & $\begin{array}{l}8.02 \\
6.62\end{array}$ \\
\hline *Total Factory Cost & $\$ 4,699.07$ & $\$ 3,301.87$ \\
\hline $\begin{array}{l}\text { Outside Tooling and } \\
\text { Plant Costs }\end{array}$ & 9.35 & 31.16 \\
\hline Grand Total & $\$ 4,708.42$ & $\$ 3,333.03$ \\
\hline$\$ / \mathrm{m}^{2}$ & $\$ \quad 95.99$ & 67.95 \\
\hline
\end{tabular}

* See Section 1.2.7, Factory Cost

** Cost of living allowance 


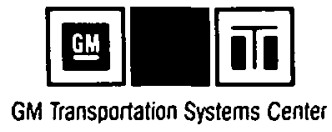

\subsubsection{Seventy-Five Percent of Capacity}

Table 5-3 reflects the estimated factory cost of a heliostat produced at a mature facility operating at $75 \%$ of capacity where total labor hours have been adjusted to accomplish a lower manufacturing rate.

Table 5-3. TOTAL COST PER HELIOSTAT UNIT (75\% OF PLANT CAPACITY)

\begin{tabular}{|c|c|c|}
\hline . & 18,750 Volume & 187,500 Volume \\
\hline $\begin{array}{l}\text { Direct Labor } \\
\text { Material } \\
\text { Variable Burden } \\
\text { Fixed Burden } \\
\text { Variable Fringe } \\
\text { Fixed Fringe } \\
\text { Overtime } \\
\text { Night Shift } \\
\text { C.O.L.A. }\end{array}$ & $\begin{array}{r}63.18 \\
3.799 .37 \\
178.82 \\
720.80 \\
40.29 \\
31.96 \\
3.35 \\
3.10 \\
7.74\end{array}$ & $\begin{array}{r}46.65 \\
2.798 .67 \\
131.93 \\
348.59 \\
24.92 \\
19.77 \\
2.08 \\
1.92 \\
4.79\end{array}$ \\
\hline Subtotal & $4,848.61$ & $3,379.32$ \\
\hline $\begin{array}{l}\text { Special Tools } \\
\text { Plant Engineering }\end{array}$ & $\begin{array}{r}40.37 \\
8.37\end{array}$ & $\begin{array}{r}10.69 \\
6.62\end{array}$ \\
\hline *Total Factory cost & $\$ 4,897.41$ & $\$ 3,396.63$ \\
\hline $\begin{array}{l}\text { Outside Tooling and } \\
\text { Plant Costs }\end{array}$ & 12.47 & 41.55 \\
\hline Grand Total & $\$ 4,909.88$ & $\$ 3,438.18$ \\
\hline$\$ / m^{2}$ & $\$ 100.10$ & 70.10 \\
\hline
\end{tabular}

* See Section 1.2.7, Factory Cost 


\subsubsection{One Hundred Twenty-Five Percent of Capacity}

Table 5-4 reflects the estimated factory cost of a heliostat produced at a mature facility operating at 1258 of capacity where total labor hours have been adjusted to accomplish a higher manufacturing rate.

Table 5-4. TOTAL COST PER HELIOSTAT UNIT (125\% OF PLANT CAPACITY)

\begin{tabular}{|c|c|c|}
\hline & 31,250 Volume & 312,500 Volume \\
\hline $\begin{array}{l}\text { Direct Labor } \\
\text { Material } \\
\text { Variable Burden } \\
\text { Fixed Burden } \\
\text { Variable Fringe } \\
\text { Fixed Fringe } \\
\text { Overtime } \\
\text { Night Shift } \\
\text { C.O.L.A. }\end{array}$ & $\begin{array}{r}63.18 \\
3,799.37 \\
178.82 \\
432.48 \\
40.29 \\
19.18 \\
3.35 \\
3.10 \\
7.74\end{array}$ & $\begin{array}{r}46.65 \\
2,798.67 \\
131.93 \\
209.15 \\
24.92 \\
11.86 \\
2.08 \\
1.92 \\
4.79\end{array}$ \\
\hline Subtotal & $4,547.51$ & $3,231.97$ \\
\hline $\begin{array}{l}\text { Special Tools } \\
\text { Plant Engineering }\end{array}$ & $\begin{array}{r}24.22 \\
8.37\end{array}$ & $\begin{array}{l}6.42 \\
6.62\end{array}$ \\
\hline *Total Factory Cost & $\$ 4,580.10$ & $\$ 3,245.01$ \\
\hline $\begin{array}{l}\text { Outside Tooling and } \\
\text { Plant costs }\end{array}$ & 7.48 & 24.93 \\
\hline Grand Total & $\$ 4,587.58$ & $\$ 3,269.94$ \\
\hline$\$ / \mathrm{m}^{2}$ & 93.53 & 66.67 \\
\hline
\end{tabular}

* See Section 1.2.7, Factory Cost 
5.2.4 Material, Labor, and Burden Summaries

Tables 5-5 and 5-6 comprise the detail of cost per heliostat identified by the cost breakdown structure code.

Table 5-5. HELIOSTAT COST SUMMARY - 25,000 UNIT ANNUAL VOLUME (MATERIAL, LABOR AND BURDEN)

\begin{tabular}{|c|c|c|c|c|c|}
\hline & & $\underset{\$}{\text { Material }}$ & $\begin{array}{c}\text { Labor } \\
\$ \$\end{array}$ & $\underset{\$}{\text { Burden }}$ & $\underset{\$}{\text { Total }}$ \\
\hline $\begin{array}{l}4411 \\
4412 \\
4413\end{array}$ & $\begin{array}{l}\text { - Reflective Surface } \\
\text { - Support Structure } \\
\text { - Assembly }\end{array}$ & $\begin{array}{r}1,065.17 \\
286.20 \\
1.13\end{array}$ & $\begin{array}{l}7.55 \\
2.40 \\
3.23\end{array}$ & $\begin{array}{l}95.35 \\
30.26 \\
40.81\end{array}$ & $\begin{array}{r}1,168.07 \\
318.86 \\
45.17\end{array}$ \\
\hline 4410 & - Reflective Unit & $1,352.50$ & 13.18 & 166.42 & $1,532.10$ \\
\hline $\begin{array}{l}4421 \\
4422 \\
4423 \\
4424 \\
4425\end{array}$ & $\begin{array}{l}\text { - Azimuth Drive } \\
\text { - Elevation Drive } \\
\text { - Motors } \\
\text { - P/L Indicator } \\
\text { - Power Sup./Dist. }\end{array}$ & $\begin{array}{r}766.38 \\
656.00 \\
145.65 \\
93.98 \\
162.56\end{array}$ & $\begin{array}{r}23.90 \\
8.74 \\
1.92 \\
1.79 \\
7.32\end{array}$ & $\begin{array}{r}301.80 \\
110.39 \\
24.28 \\
22.61 \\
92.40\end{array}$ & $\begin{array}{r}1.092 .08 \\
775.13 \\
171.86 \\
118.38 \\
262.27\end{array}$ \\
\hline 4420 & - Drive \& Controls & $1,824.57$ & 43.67 & 551.48 & $2,419.72$ \\
\hline 4433 & $\begin{array}{c}\text { - Control/sig. - } \\
\text { Equip. }\end{array}$ & 145.70 & 2.95 & 37.28 & 185.93 \\
\hline 4451 & $\begin{array}{r}\text { - Structure \& } \\
\text { Tapered Pipe }\end{array}$ & 358.00 & 0.08 & 0.99 & 359.07 \\
\hline & Materials Shipping & 116.93 & - & - & 116.93 \\
\hline & Final Assembly & 1.67 & 3.30 & 41.70 & 46.67 \\
\hline & Total & $3,799.37$ & 63.18 & 797.87 & $4,660.42$ \\
\hline
\end{tabular}


GM Transportation Systems Center

Table 5-6. HELIOSTAT COST SUMMARY - 250,000 UNIT ANNUAL VOLUME (MATERIAL, LABOR AND BURDEN)

\begin{tabular}{|c|c|c|c|c|c|}
\hline \multicolumn{2}{|r|}{. } & $\begin{array}{l}\text { Material } \\
\$ \$\end{array}$ & $\begin{array}{l}\text { Labor } \\
\quad \$\end{array}$ & $\underset{\$}{\text { Burden }}$ & $\begin{array}{l}\text { Total } \\
\$ \$\end{array}$ \\
\hline $\begin{array}{l}4411 \\
4412 \\
4413\end{array}$ & $\begin{array}{l}\text { - Reflective Surface } \\
\text { - Support Structure } \\
\text { - Assembly }\end{array}$ & $\begin{array}{r}681.77 \\
258.92 \\
1.04\end{array}$ & $\begin{array}{l}3.52 \\
2.25 \\
3.27\end{array}$ & $\begin{array}{l}33.30 \\
21.33 \\
30.98\end{array}$ & $\begin{array}{r}718.59 \\
282.50 \\
35.29\end{array}$ \\
\hline 4410 & - Reflective Unit & 941.73 & 9.04 & 85.61 & $1,036.38$ \\
\hline $\begin{array}{l}4421 \\
1422 \\
4423 \\
4424 \\
4425\end{array}$ & $\begin{array}{l}\text { - Azlmuth Drive } \\
\text { - Elevation Drive } \\
\text { - Motors } \\
\text { - P/L Indicator } \\
\text { - Power Sup./Dist. }\end{array}$ & $\begin{array}{r}496.97 \\
597.69 \\
138.38 \\
80.56 \\
153.89\end{array}$ & $\begin{array}{r}17.15 \\
4.81 \\
1.12 \\
1.48 \\
5.91\end{array}$ & $\begin{array}{r}162.47 \\
45.60 \\
10.63 \\
14.02 \\
56.00\end{array}$ & $\begin{array}{r}676.59 \\
648.10 \\
150.13 \\
96.06 \\
215.80\end{array}$ \\
\hline 4420 & - Drive \& Controls & $1,467.49$ & 30.47 & 288.72 & $1,786.68$ \\
\hline 4433 & $\begin{array}{c}\text { - Control/Sig.- } \\
\text { Equip. }\end{array}$ & 122.78 & 2.23 & 21.10 & 146.11 \\
\hline 4451 & $\begin{array}{l}\text { - Structure \& } \\
\text { Tapered Pipe }\end{array}$ & 148.07 & 1.86 & 17.64 & 167.57 \\
\hline & Materials Shipping & 116.93 & - & - & 116.93 \\
\hline & Final Assembly & 1.67 & 3.05 & 28.84 & 33.56 \\
\hline & Total & $2,798.67$ & 46.65 & 441.91 & $3,287.23$ \\
\hline
\end{tabular}




\subsubsection{Burden Per Heliostat Unit}

All indirect material, indirect labor, and other cost incurred by the factory in the course of performing the manufacturing operations are burden expense. These costs are summarized in Table 5-7.

Table 5-7. BURDEN COSTS PER HELIOSTAT UNIT

\begin{tabular}{|c|c|c|c|c|}
\hline \multirow[t]{2}{*}{ - } & 25,000 & Volume & 250,000 & Volume \\
\hline & Variable & Fixed & Variable & Fixed \\
\hline $\begin{array}{l}\text { Hourly } \\
\text { Salary } \\
\text { Supplies } \\
\text { Tools } \\
\text { Utilities } \\
\text { Maintenance } \\
\text { Scrap } \\
\text { Taxes and Depreciation } \\
\text { Sundry }\end{array}$ & $\begin{array}{r}5.34 \\
21.10 \\
8.33 \\
9.67 \\
12.25 \\
14.88 \\
98.01 \\
- \\
9.24\end{array}$ & $\begin{array}{r}1.26 \\
29.49 \\
- \\
24.79 \\
18.42 \\
1.53 \\
- \\
463.92 \\
1.19\end{array}$ & $\begin{array}{r}4.81 \\
6.87 \\
8.33 \\
4.88 \\
4.74 \\
12.70 \\
81.20 \\
8.40\end{array}$ & $\begin{array}{r}1.13 \\
9.60 \\
- \\
12.86 \\
7.14 \\
1.31 \\
- \\
228.21 \\
1.19\end{array}$ \\
\hline Total & $\$ 178.82$ & $\$ 540.60$ & $\$ 131.93$ & $\$ 261.44$ \\
\hline
\end{tabular}

\subsubsection{Non-Allied Tooling and Plant Costs}

Due to the speculative nature of the projected heliostat production scenario, certain vendor's were reluctant to include investment costs in their quotes. These costs are collected in Table 5-8.

Table 5-8. NON-ALLIED TOOLING AND PLANT COSTS

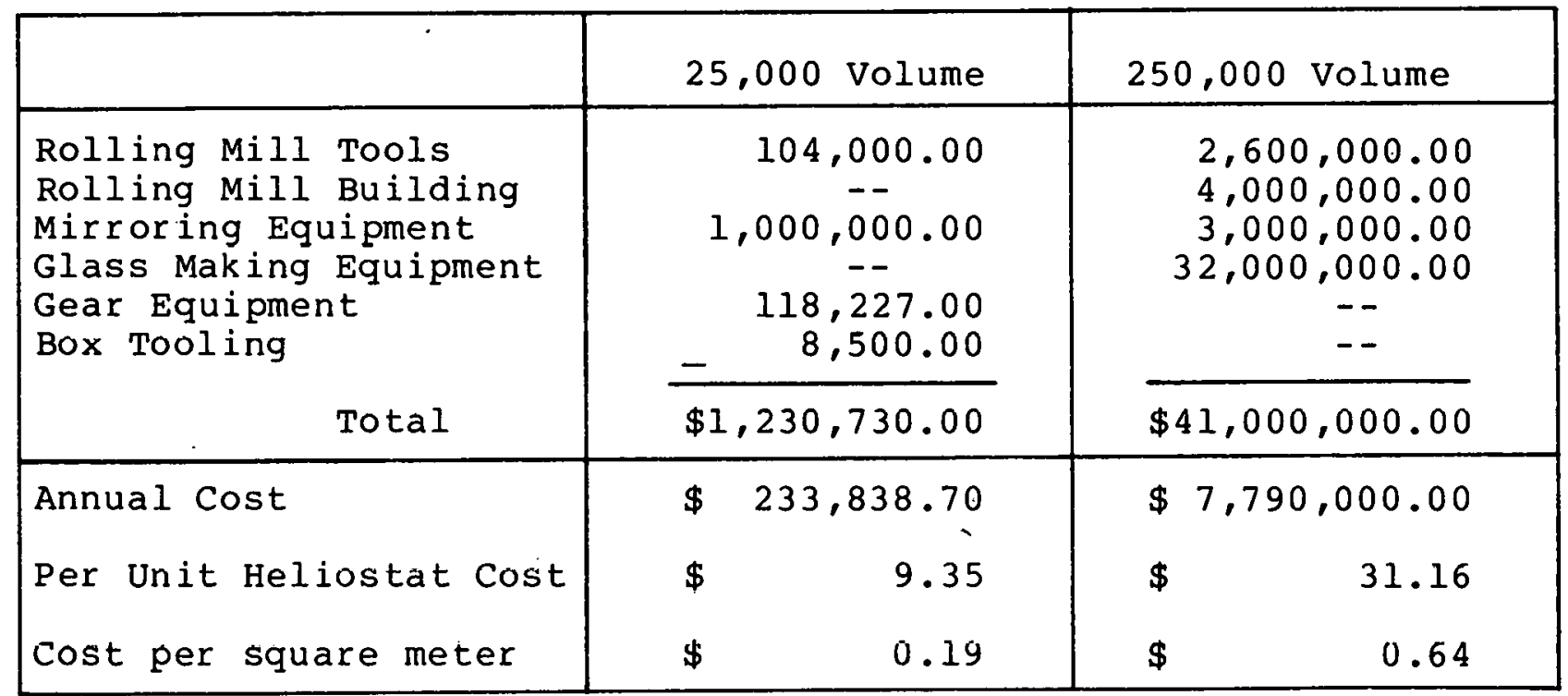




\subsubsection{Investment Per Heliostat Unit}

Total investment required for heliostat production are discussed in section 5.1.4. Table 5-9 provides a breakdown of the investment on a heliostat unit basis.

Table 5-9. INVESTMENT PER HELIOSTAT UNIT

\begin{tabular}{|l|r|r|}
\hline & 25,000 Volume & 250,000 Volume \\
\hline Building Improvements & $1,480.00$ & 300.00 \\
Land and Im & 35.20 & 6.40 \\
Machinery and Equipment & $1,732.75$ & $1,167.83$ \\
Tools & 151.39 & 40.10 \\
Uperations & 93.87 & 56.89 \\
Total Investment & $\$ 3,493.21$ & $\$ 1,571.22$ \\
\hline
\end{tabular}

5.2.8 Installed Price (a SERI Monograph)

The emphasis of this report is the development of the factory cost of producing the MDAC prototype heliostat. However, the factory cost should not be confused with the price of a heliostat which is delivered and ready to collect energy. That is, a potential customer should not expect to buy a heliostat for factory cost. This section will discuss the additional cost elements which must be added to factory cost to produce a selling price and will compare the cost estimates derived for this study with those produced by Battelle Pacific Northwest Labs.

The factory cost includes the cost of material, labor, burden, etc. (see Table 5-2). Burden includes engineering costs, tooling, various types of surpervisory labor, and an allocation of the depreciated capital for the heliostat factory. However, the factory cost does not include all of the costs required to operate a heliostat manufacturing company. It does not include all taxes, the cost of selling and distribution, or the cost of product research and development. Most significantly it does not provide for a return on capital investment. All of these costs must be added to the factory cost to produce a selling price.

The most difficult cost to determine is the return on investment (ROI). ROI is described as a cost because in private business it is the realization of a financial return that allows the capital stock to regenerate and the business to continue. In a mature business the ROI is determined to a great extent by market forces which determine the selling price and thus the allowable profit. However, in the absence of a mature market for heliostats, SERI is using a normative profit 


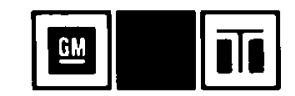

GM Transportation Systems Center

derived from the anticipated ROI which a heliostat company would need to attract private capital. This approach is part of the SAMICS methodology developed by the Jet propulsion Laboratory of Pasadena, California.

The target ROI selected by SERI for use on this project is 20 percent, and the cost of debt is 10 percent. (These financial parameters were selected in April 1979 and are intended to reflect long-term trends.) Assuming that a new heliostat corporation will be 80 percent equity financed (typical of many new ventures), the cost of capital will be 17.5 percent using these values. The expected profit is calculated to be $\$ 350.86$ per unit at the 25,000 production volume.

Values includes a return on equity for the book value of the initial $\$ 86$ million investment and an allowance for the working capital requirements of the facility estimated to be approximately $\$ 20.9$ million. Because of the higher capital requirements, this study requires a 6 percent profit on sales to achieve a 20 percent return on equity while the Battelle study requires a 4.2 percent profit on sales to achieve the same return on capital.

This study was not asked to consider to cost of installation or transportation for the heliostats. However, the Battelle study estimated those costs to be $\$ 940 /$ unit at 25,000 units/year and $\$ 880 /$ unit at 250,000 units/year. Using this estimate for installation the installed price may be projected. This information is summarized in Tables $5-10$ and 5-11.

The installed price of $\$ 122.12 / \mathrm{m}^{2}$ given here for the 25,000 units per year case is subject to one important assumption. The normative price calculation assumes that a 17.5 percent return on capital is sufficient to satisfy the investors, and at the same time that the market will support a selling price high enough to allow such a 17.5 percent return on capital. In this sense, the installed prices given here are not market price projections nor should this study be interpreted as a heliostat price forecast. 


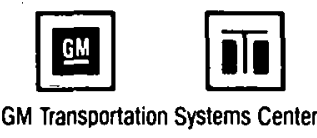

Table 5-10. HELIOSTAT PRODUCTION COST PER UNIT 25,000 UNITS/YEAR

\begin{tabular}{|l|r|r|}
\hline & $\begin{array}{c}\text { Battelle } \\
\$\end{array}$ & $\begin{array}{c}\text { GM } \\
\$\end{array}$ \\
\hline Material & $2,427.82$ & $3,799.37$ \\
\hline Direct Labor & 176.14 & 63.18 \\
\hline Overhead & 812.05 & 836.52 \\
\hline Eastery Cost & $3,416.01$ & $4,699.07$ \\
\hline Profit & 150.62 & 350.86 \\
\hline Factory Price F.O.B. & $3,566.63$ & $5,049.31$ \\
\hline Installation Cost & 940.38 & 940.38 \\
\hline Installed Cost $\$ /$ Unit & $4,507.01$ & $5,990.31$ \\
\hline Installed Cost $\$ / m^{2}$ & 91.88 & 122.12 \\
\hline
\end{tabular}

Table 5-11. HELIOSTAT PRODUCTION COST PER UNIT 250,000 UNITS/YEAR

\begin{tabular}{|l|c|c|}
\hline & $\begin{array}{c}\text { Battelle } \\
\$\end{array}$ & \begin{tabular}{c} 
GM \\
\hline
\end{tabular} \\
\hline Material & $2,242.35$ & $2,798.67$ \\
\hline Direct Labor & 98.82 & 46.65 \\
\hline Overhead & 613.33 & 456.55 \\
\hline Factory Cost & $2,954.50$ & $3,301.87$ \\
\hline Profit & 144.33 & 207.96 \\
\hline Factory Price F.O.B. & $3,068.83$ & $3,509.83$ \\
\hline Installation Cost & 879.52 & 879.52 \\
\hline Installed Cost $\$ /$ Unit & $3,948.35$ & $4,389.35$ \\
\hline Installed cost $\$ / m^{2}$ & 80.49 & 89.48 \\
\hline
\end{tabular}




\section{回 而 \\ GM Transportation Systems Center \\ SECTION 6.0}

TECHNICAL OBSTACLES TO PRODUCTION

Several obstacles have been identified which affect the cost and/or producibility of the components. used in the MDAC heliostat design. These obstacles include:

- Insufficient glass plant capacity to produce the fusion glass for the front lite at the 250,000 unit annual volume.

- Lack of corrosion protection for the mirror surfaces during shipment and service.

- Cure times for the adhesives used to bond the glass sandwich together and the steel stringers which are attached to the back Iite.

- Inadequate mirror line capacity in a single existing facility.

In this section, these obstacles are clarified and recommendations are made for plans to resolve the technical issues.

\subsection{FUSION GLASS PLANT CAPACITY}

The Corning Glass plant in Blacksburg, Virginia, is the sole source for the borosilicate fusion glass used in the front lite of the MDAC heliostat panels. This plant has sufficient capacity to supply the front lite requirements for the 25,000 unit annual volume. At the 250,000 unit level, additional melt and processing capacity would have to be added to this plant.

The estimated investment for this capacity would be approximately $\$ 32.5$ million. In addition 670,000 grams of precious metal, platinum, would be required to equip the new facility. The platinum need not be purchased since it is not consumed in the process. It has been assumed that the platimun would be made available from federal reserves at no cost.

The plant cost of $\$ 32.5$ million has been amortized over a period of $9-1 / 2$ years. This cost has been applied to the investment costs for the 250,000 unit production cost estimates. It contributes $\$ 0.50 / \mathrm{m}^{2}$ to the cost of a heliostat. 


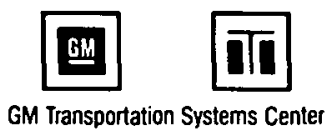

\subsection{MIRROR SURFACE PROTECTION}

In mirror production for normal field service, backing paints are applied over the silver/copper surface of the mirror to prevent corrosion of the metaliic components. In the MDAC design, application of the backing paint is eliminated and adhesive bonding is used in the assembly of the front and back lites, with the back lite providing mirror protection.

Since chemical attack may occur during shipment from the mirroring facility or storage at the heliostat manufacturing plant, the mirror supplier has recommended that a protective plastic film be applied after the mirroring process and removed prior to assembly of the reflector panels. This film adds a cost of approximately $\$ 0.32 / \mathrm{m}^{2}$ to the heliostat assembly and adds extra processing in the heliostat plant for removal and disposition.

The cost of this protective film is comparable to the cost of paint as a protective measure. In addition, recent investigations by MDAC show that an edge-sealing operation will be required to prevent corrosion of the mirror surface in spite of the adhesive used between the front and back lites.

It is recommended similar experiments and studies be conducted to determine if mirror backing paint will perform the protection function for shipment and field service. These investigations should be designed to determine the compatibility of the backing paint and the adhesives as well as the performance of the paint in simulated field testing. A cost comparison can then be made between the cost of the backing paint versus the protective film for shipment and the edge sealing operation for field service.

\subsection{ADHESIVE CURE TIME}

The long cure time for the polyurethane adhesives used in bonding the mirror to the back lite and the stringers to the back lite has necessitated the use of large and expensive ovens in the manufacturing plant. Data from the $3 \mathrm{M}$ Company, which produces both adhesives for this application, indicate that the adhesive will cure to shear strength of approximately 400 psi after 10 minutes at 150 degrees $F$. The oven designs are based on these data and the 250 psi minimum shear strength required for handling purposes.

Reductions in the cure time would have a significant effect on costs since the oven cost, energy requirements, and plant floor area would all be affected. 


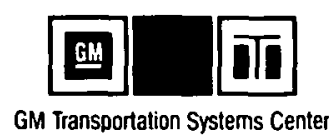

It is recommended, therefore, that two actions be taken in an attempt to reduce the cost of adhesive curing:

(1) Explore the possibility, with the $3 \mathrm{M}$ Company, of modifying the IXA 3504 and EC 3532 adhesives to reduce the cure time

(2) Perform experiments with actual glass, mirror and stringer samples to determine an acceptable minimum cure time that will allow handling between the oven and storage racks.

\subsection{MIRROR LINE CAPACITY}

A typical mirror line has the capacity to produce approximately 20 million square feet of mirrored surface per year, based on a 3-shift operation. The capacity required for heliostat production at the 25,000 unit annual volume level is approximately 13 million square feet per year. This requirement can be satisfied with a single mirror line of nominal size. At the higher level of 250,000 heliostats per year, approximately six lines would be required to meet the heliostat production requirements.

In order to more efficiently match the production capacity to heliostat requirements, it is recommended that a mirror line with greater capacity be used at both volume levels. A line designed for a capacity of 40 million square feet per year on a 3-shift basis would easily satisfy the mirroring requirements at the low volume if operated for only one shift. Three lines, with an improved speed capability, could then be used to satisfy the requirements for the higher volume of heliostat production.

To improve operating efficiency by reducing shipping and scrappage, the mirror line should be located in the fusion glass production facility. Corning Glass has agreed that this proposal is beneficial and is willing to consider the installation of mirroring equipment in the glass plant.

The estimated cost of a mirroring line designed for 40 million square feet per year is $\$ 1$ million. For the high volume case; three machines are required. The annual costs for these facilities are shown in Table 5-8. 


\section{THIS PAGE \\ WAS INTENTIONALLY LEFT BLANK}




\section{븐 \\ GM Transportation Systems Center \\ SECTION 7.0 \\ DESIGN/PRODUCTION OPPORTUNITIES}

While the technical obstacles presented in Section 6.0 have a direct impact on the producibility and cost of the MDAC heliostat, several other opportunities for design changes which may improve the cost results have been identified. These opportunities exist because the current design presents manufacturing difficulties that adversely affect the cost of the heliostat. These difficulties are stated so that appropriate design study can be made by the heliostat contractor. These difficulties include:

- Support structure welding in confined area

- Harmonic drive design requires extensive machining operations

- Fusion glass front lite size is not compatible with glass plant equipment

- Shear bolts in flex spline attachment are expensive, air-craft quality

- Wire bearing in the azimuth drive requires stringent quality control to meet required tolerances.

These items are discussed in greater detail in the following paragraphs.

\subsection{SUPPORT STRUCTURE WELDMENT}

The support structure weldment, which is a "K" frame design, required numerous spot welds to be located in the area where the diagonal beams join the inboard beam. This area is further complicated by the application of the doublers and gussets which reinforce the structure. As described in section 4.3.1.3, the fabrication and welding line designed to manufacture this part is quite complex and occupies a significant portion of the manufacturing plant. This equipment has high capital costs associated with it and requires significant labor for parts handling and manual arc welding. The concentration of welds in a single area of the structure has caused a significant increase in the cost of this equipment since additional weld stations have been required to allow the various welding heads access to the weld area.

Design changes should be considered which would reduce the number of components, and/or relieve the concentration of welding in the joint area. 


\subsection{HARMONIC DRIVE}

The harmonic drive contains the flex spline, the wave generator, and the circular spline which require extensive fabrication and machining operations. These operations are described in section 4.3. As an example, a rake angle in the flex spline gear teeth could preclude the use of gear hobbing equipment for this part. Instead, these teeth would be formed by shaping. The total number of components in the drive and the extensive tooling required adversely affect the heliostat cost.

Design changes should be considered which would substitute the harmonic drive gear reduction with other mechanisms which could be manufactured at lower cost.

\subsection{FUSION GLASS FRONT LITE SIZE}

The $4 \mathrm{ft} x \mathrm{xl} \mathrm{ft}$ size selected for the reflective surfaces has an adverse effect on the glass cost since it is not compatible with the facility used to produce the fusion glass. The facility is designed to produce glass panels which are 6 feet wide and 10 feet long. For the production of 4 foot wide panels, the throat of the weir will require modification.

The glass exits vertically from the throat in the molten state and solidifies as it drops through the cooling area. At the exit of the cooling area, the glass sheet is cut into lengths of up to 10 feet and is picked up and then transferred to the conveyor which transfers it to horizontal rolls. This mechanism will require modification in order to accommodate the 11 foot length required for the heliostat.

These modifications to the glass making facility increase the cost of the front lite. Selection of panel dimensions which are closer to the $6 \mathrm{ft} \times 10 \mathrm{ft}$ capacity of the facility would maintain the lower price for the front lite.

\section{4 FLEX SPLINE SHEAR BOLTS}

In the harmonic drive, the flex spline is attached to the azimuth drive housing with 12 aircraft-quality shear bolts. These bolts, manufactured by "Hi-Shear" represent a parts cost premium and may not be required for this application.

The supplier indicates that commercial grade fasteners are available for this application at a significant savings in cost. 


\subsection{WIRE-RACE BEARING}

The wire-race bearing which is installed between the azimuth drive housing and the circular spline, requires stringent manufacturing tolerances for proper operation. The manufacturer of this bearing indicates that special tooling will have to be developed in order to maintain the wire forming and welding tolerances. In addition, close tolerances have to be maintained in the azimuth housing, circular spline, and bearing retainer. These special operations increase the cost of the wire race bearing and the associated hardware.

Bearing designs of a more conventional nature should be investigated to determine if a more beneficial cost trade off can be achieved.

\subsection{FUSION VERSUS FLOAT}

For this study, design constraints dictated the use of .060 fusion glass for the mirrored front lite of the reflective surface. The use of .090 low iron float glass for the front lite may decrease the transmissivity and will increase the weight of the panel. However, it is suggested that a cost/performance trade-off be made between low iron float glass and the solar borosilicate fusion glass, since it may prove more cost effective to sacrifice some transmissivity, increase the field or collector size slightly, and use the float glass. In any event, the trade-off will provide a dollar-based evaluation of a possible decision to use fusion glass in the manufacture of heliostats.

\subsection{FIBER OPTICS VERSUS COPPER CABLE}

Fiber optic lines are presently in use with great success for communication links. Line costs per running foot for equivalent circuit performance are less for fiber optic transmission lines than for copper cable. However, for short distances, e.g., 20 feet, and multiple control interfaces the use of fiber optic signal systems may not be cost effective because of the cost of connector/interface elements. Signal converters and connectors for fiber optic signal systems become the driving cost function for systems covering short distances between signal interface points. Noise immunity may be a consideration, but again this aspect of fiber optic signal transmission lines is most advantageous for long line lengths. The problems of shielding signal converters for fiber optic systems are as bad if not worse than shielding for standard copper cable connectors.

If heliostats are to be evaluated for cost effectiveness in terms of 1980 construction, it is suggested that cost trade-off studies be conducted on the use of fiber optic signal systems versus conventional shielded copper cable signal systems. 
GM Transportation Systems Center

\subsection{GALVANIZING}

The heliostat design as specified for this study requires the galvanizing of the pedestal, tapered pipe, torque tube, azimuth housing, and drag link to provide a 4 to 5 mil protective coating for exterior corrosion resistance. The galvanizing process involves a sequence of surface treatment including a cleaning high pressure rinse, an alkaline rinse, a hot water rinse, hot blow-off dry, sulfuric acid pickle, followed by a hot water rinse, a flux dip, pre-heat, zinc dip, and finally, dry. Preliminary estimates indicate that approximately $\$ 9,000,000$ would be required to acquire and install tanks, drying chambers, monorails, dust and fume ducting, dust and fume scrubbers, waste treatment pipes and tanks, decking and drains for the high volume plant. The alkali, sulfuric acid, flux and zinc processes generate fumes which must be removed from the air by a series of scrubbers. The zinc galvanizing bath generates a dross which must be disposed of, and rinse watcr must bc treated to neutralize alkali and acid. The annual cost of $z$ inc make-up, including that lost in dross removal is about $\$ 6,000,000$. Local annual waste treatment is estimated at $\$ 750,000$. The cost of removal and disposition of waste has not been evaluated.

The high cost of galvanizing and consideration of the risk entailed in the disposition of waste material from the galvanizing process suggest the thorough investigation of other protective coatings. For example, acrylic resin paints can provide excellent exterior protection and although this application does involve fume and waste control, the problems may be substantially less than those associated with galvanizing. In addition, process energy for paint application should be less than that for galvanizing.

\subsection{EXISTING PLANT VERSUS NEW CONSTRUCTION}

Plant costs for this study were based on the construction of a dedicated facility on sufficient acreage to allow for normally expected business growth. The high volume plant of approximately 682,000 square feet is comprised of bays with 30 feet of vertical clearance to the bottom of the trusses. One half, or about 341,000 square feet, is made up of 40 ft by 60 $\mathrm{ft}$ hays with $12-1 / 2$ lbs of structural steel per square font with the remainder comprised of $60 \mathrm{ft}$ by $60 \mathrm{ft}$ bays requiring 18 los of structural steel per square foot. The floor is 8 inch concrete with 3 lbs of rebar steel per square foot. These requirements were dictated by the manufacturing sequence and plant as defined in this study.

A change in the plant layout or some redefinition of the manufacturing process might allow the use of an existing plant or facility for heliostat production at a lower investment cost than required for new construction. An investigation of 
available facilities should be conducted at the time heliostat production is contemplated and consideration given to the cost/manufacturing process trade-offs required in order to weigh the desirability of converting an existing plant versus constructing a new one.

\subsection{WELDMENT VERSUS CASTING COSTS}

Examination of the MDAC designs for the azimuth drive housing and drag link reveal that these parts may be constructed from either weldments (as designed) or by casting the units in a single piece. Manufacturing development personnel, familiar with the casting process and manufacturing costs, have made estimates of the casting cost based on internal processing. These costs, while not indicative of what an outside supplier might charge for the parts, show a cost savings for the cast parts. A cost comparison for the weldments and castings are shown below. These costs include the galvanized plating for the parts since they are puchased in this form at the low volume.

Table 7-1. WELDMENT AND CASTING COST ESTIMATES

\begin{tabular}{|l|c|c|c|c|}
\hline & \multicolumn{2}{|c|}{$\begin{array}{c}25,000 \text { Unit } \\
\text { Annual Volume }\end{array}$} & \multicolumn{2}{c|}{$\begin{array}{c}250,000 \text { Unit } \\
\text { Annual Volume }\end{array}$} \\
\cline { 2 - 5 } & $\begin{array}{c}\text { Purchased } \\
\text { Weldment }\end{array}$ & Casting & $\begin{array}{c}\text { Processed } \\
\text { Weldment }\end{array}$ & Casting \\
\hline $\begin{array}{l}\text { Azimuth Drive } \\
\text { Housing }\end{array}$ & $\$ 370.00$ & $\$ 180.48$ & $\$ 223.53$ & $\$ 180.48$ \\
\hline Drag Link & $\$ 72.00$ & $\$ 42.48$ & $\$ 59.52$ & $\$ 42.48$ \\
\hline
\end{tabular}

Although this limited study of weldment versus casting costs includes only gross estimates of comparataive costs, it does indicate generally lower costs for the cast parts. Therefore, it is recommended that investigations be pursued to determine if cost benefits can be achieved through substitution of castings for weldments in the MDAC heliostat design. 


\section{THIS PAGE}

\section{WAS INTENTIONALLY \\ LEFT BLANK}




\section{GM \\ GM Transportation Systems Center \\ SECTION 8.0}

REFERENCES

1. "Solar Central Receiver Prototype Heliostat," Final Technical Report, MDC G 7399, McDonnell Douglas Astronautics Company, August 1978.

2. "A Technical Proposal for: Heliostat production Evaluation. and Cost Analysis for Repowering Strategy Analysis," submitted to the Solar Energy Research Institute, EP-79034, GM Transportation Systems Center, February 1979.

3. "Heliostat Manufacturing Cost Analysis," K. Drumheller, et. al., SERI/TR-8043-1, Solar Energy Research Institute, Golden, Colorado, October 1979.

4. "A Normative Price for a Manufacturing product: The SAMICS Methodology," Robert Chamberlain, DOE/JPL-1012-79/5, Jet Propulsion Laboratory, Pasadena California, January 1979. 


\section{THIS PAGE \\ WAS INTENTIONALLY \\ LEFT BLANK}


APPENDIX A

BILL OF MATERIALS 
THIS PAGE

WAS INTENTIONALLY

LEFT BLANK 


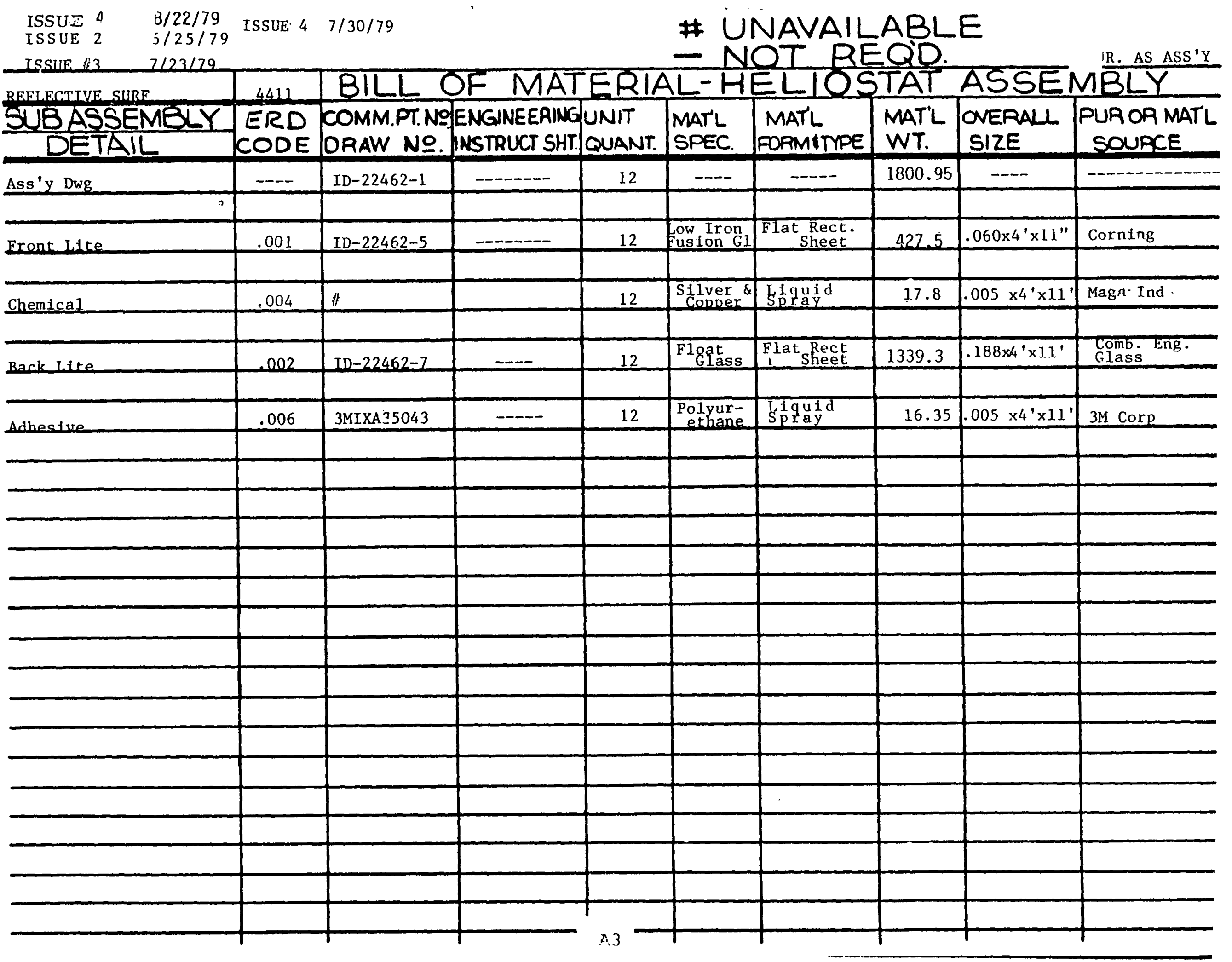




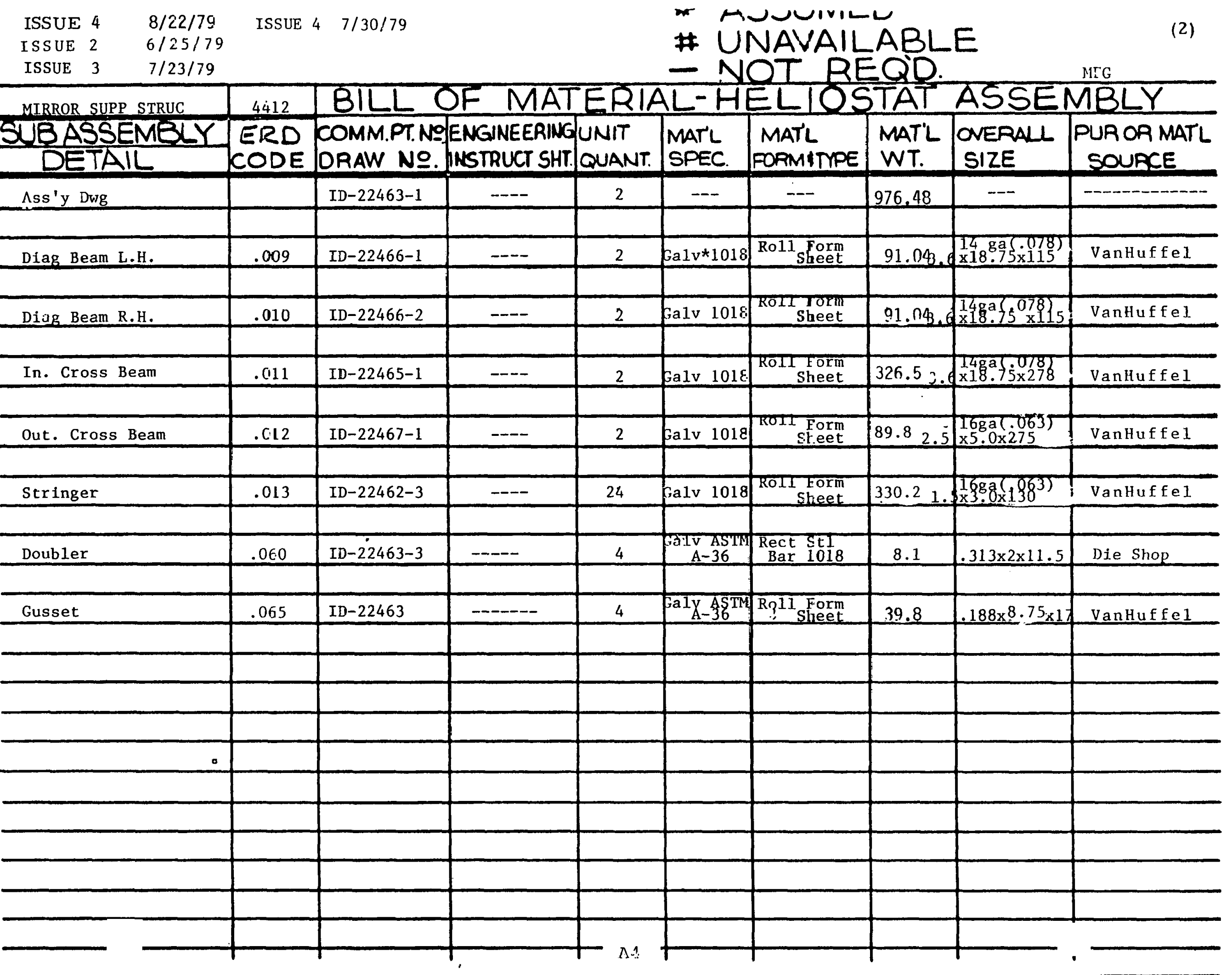




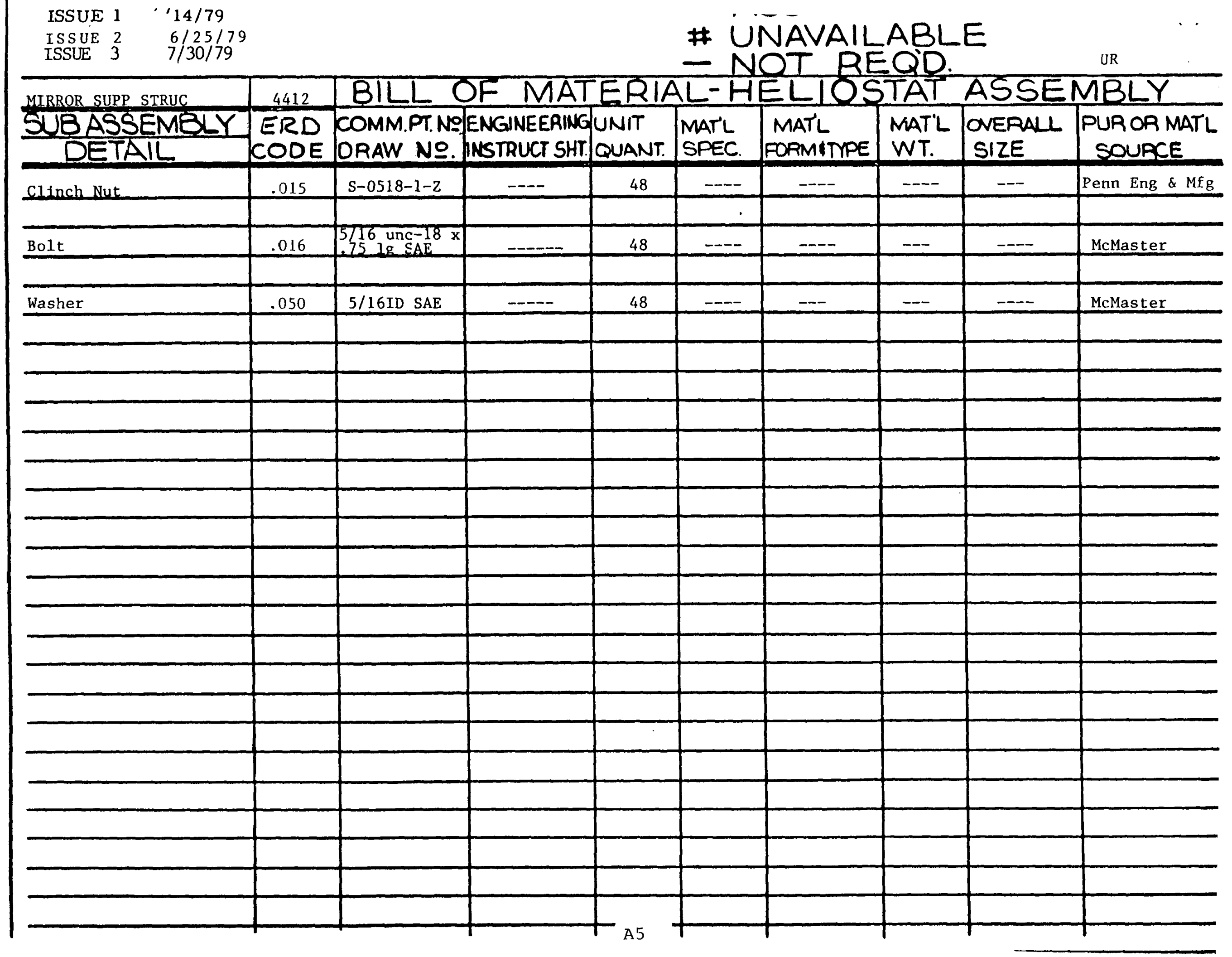




\section{ISSUE $1 / 14 / 79$ ISSUE $47 / 30 / 79$ \\ ח \\ - NOT REQD.}

ASS'Y \& BOND SUBASSEMELY DETAIL

4423 BILL OF MATERIA ERD COMM.PT. NO ENGINEERING UNIT CODE DRAW NO. IMSTRUCT SHT. QUANT.$$
\text { ADHESIVE }
$$

ADHESIVE

\begin{tabular}{|l|l|}
\hline .007 & 3MEC 3532 \\
\hline
\end{tabular}

-.-.

\begin{tabular}{l|l}
\hline & \\
\hline
\end{tabular}

MAT'L MATL

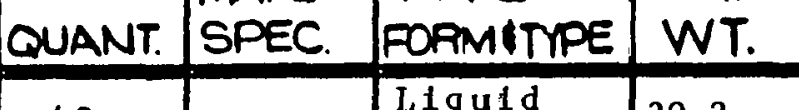

MAT'L OVERALL PUROR MATL SOURCE 


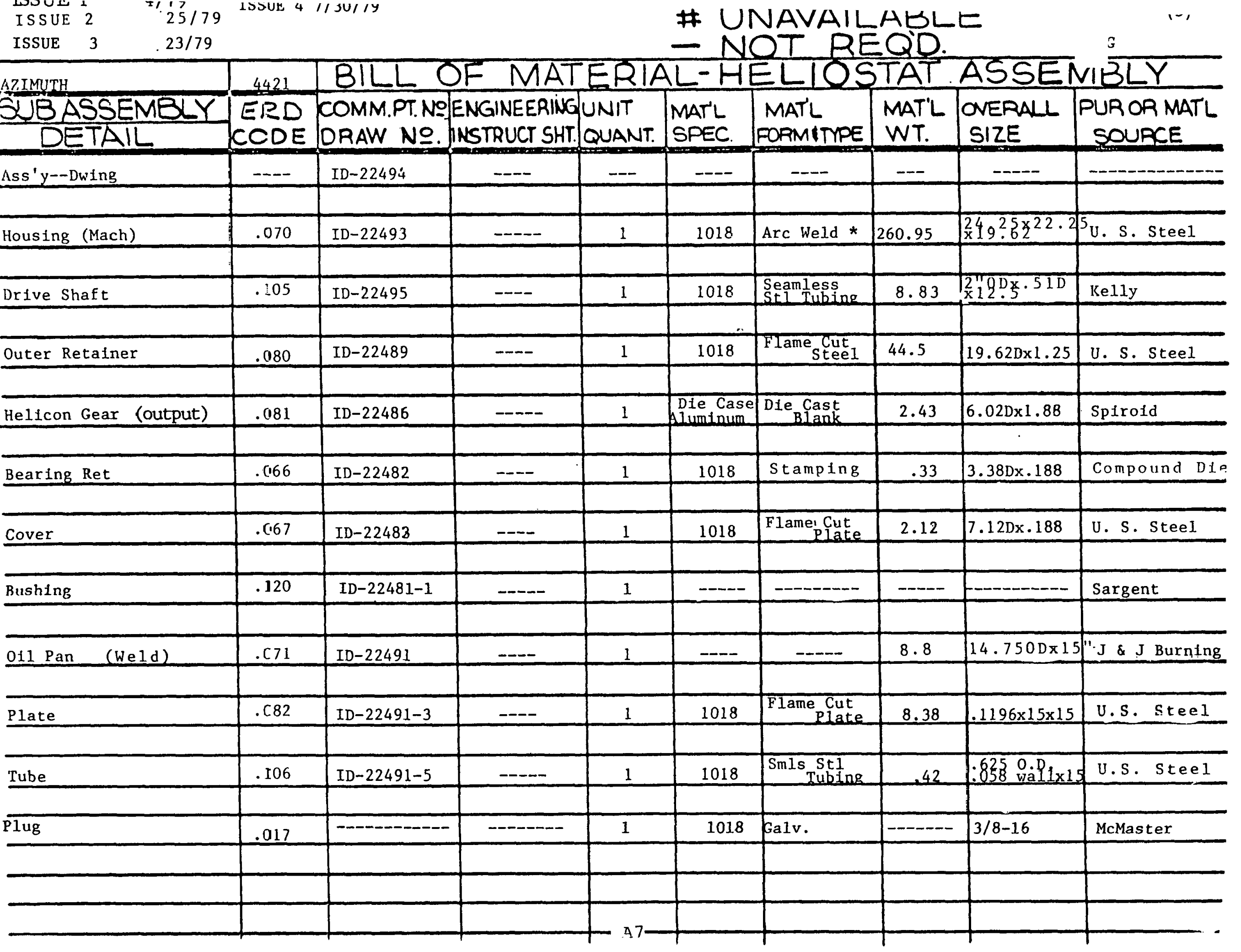




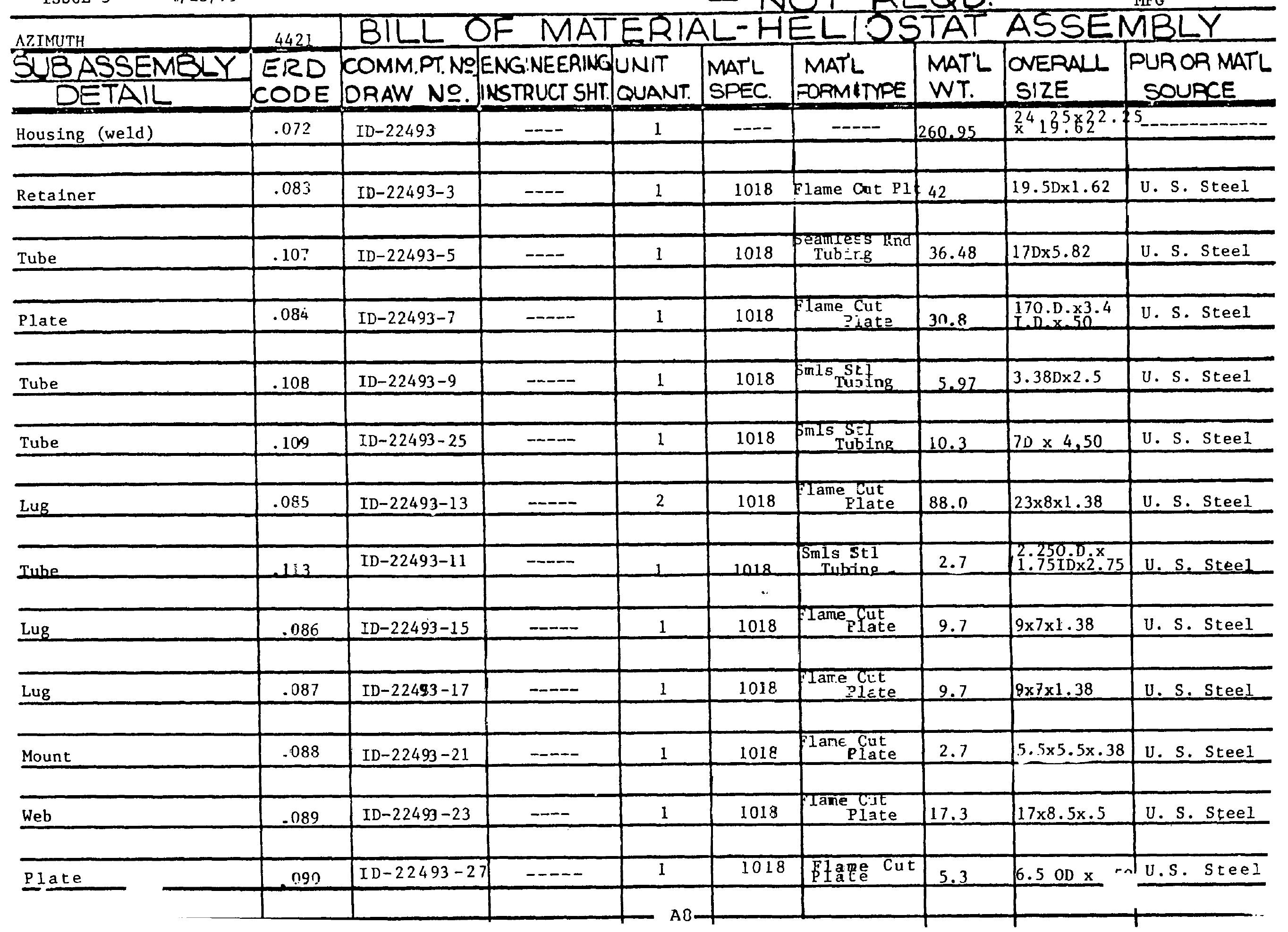


* UNAVAILABLE

ISSUE 3

$1 / 23 / 79$

- NOT REQD.

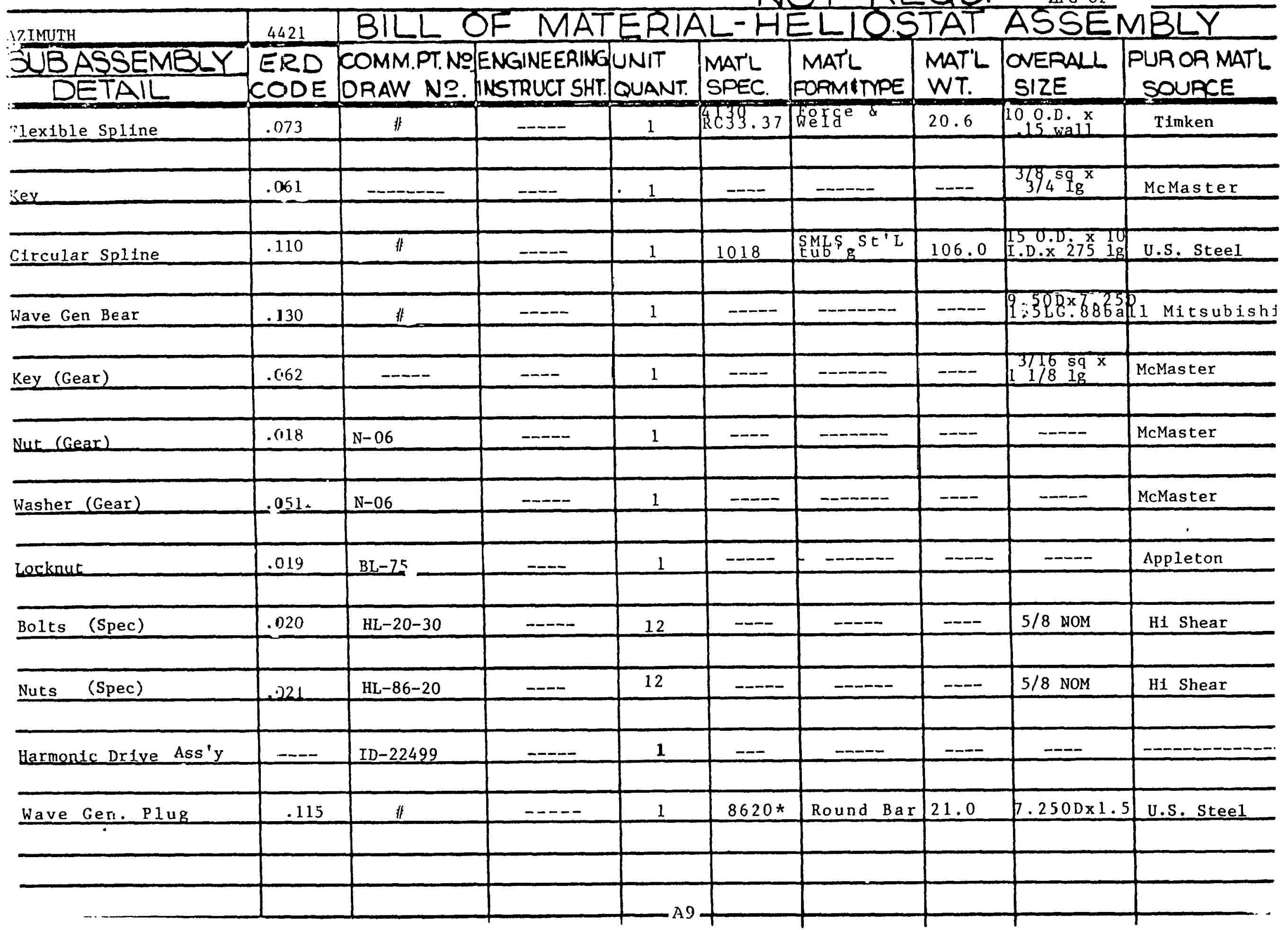




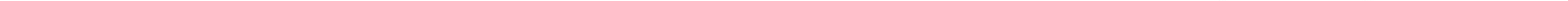




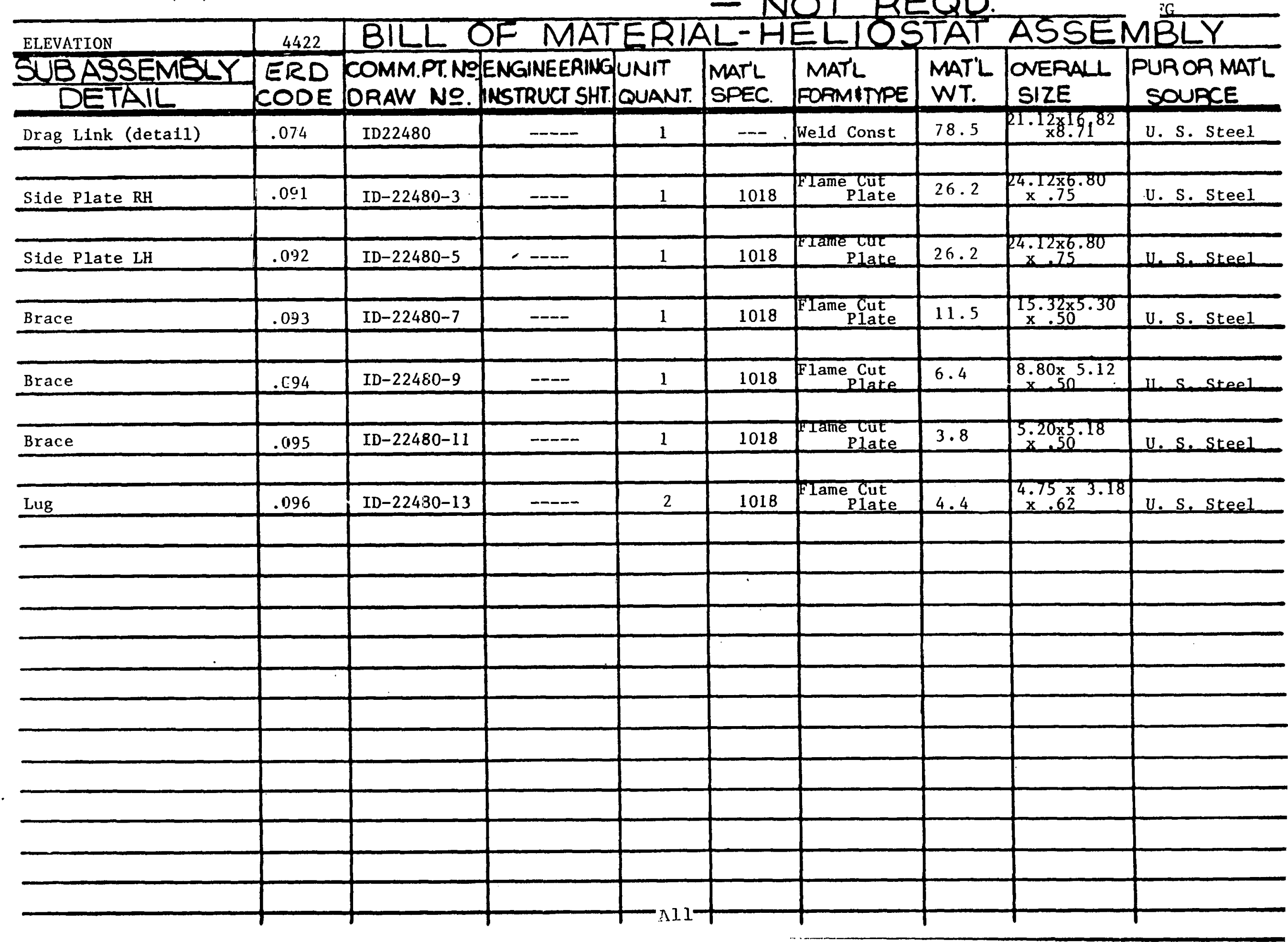




\section{ISSUE 1 ' $14 / 79$ ISSUE $47 / 30 / 79$ \\ ISSUE $2 \quad 6 / 25179$ \\ ISSUE $3 \quad 7 / 23 / 79$ \\ * UNAVAILABLE \\ - NOT REQ'D.}

\begin{tabular}{|c|c|c|c|c|c|c|c|c|c|}
\hline \multirow{2}{*}{$\begin{array}{l}\text { SUEVATION } \\
\text { DESASEMELYY } \\
\text { DETAIL }\end{array}$} & \multirow{3}{*}{$\begin{array}{r}4422 \\
\text { ERD } \\
\text { CODE }\end{array}$} & \multicolumn{8}{|c|}{ BILL OF MATERIAL-HELIOSTAT ASSEMBLY } \\
\hline & & $\begin{array}{l}\text { COMM.PT: № } \\
\text { ORAW NNO. }\end{array}$ & $\begin{array}{l}\text { ENGINEERING } \\
\text { INSTRUCT SHT. }\end{array}$ & $\begin{array}{l}\text { UNIT } \\
\text { QUANT. }\end{array}$ & $\begin{array}{l}\text { MATL } \\
\text { SPEC }\end{array}$ & $\begin{array}{l}\text { MATL } \\
\text { FORMITIPE }\end{array}$ & $\begin{array}{l}\text { MAT'L } \\
\text { WT. }\end{array}$ & $\begin{array}{l}\text { OVERALL } \\
\text { SIZE }\end{array}$ & $\begin{array}{l}\text { PUR OR MATL } \\
\text { SOURCE }\end{array}$ \\
\hline Torque Tube (Detail) & & ID-22464 & $\ldots$ & 1 & -- & Weld Canst & 325.5 & $\ldots$ & $J \&$ J Burning \\
\hline Tube & .111 & ID $-22464-3$ & $\ldots$ & 1 & 3018 & $\begin{array}{l}\text { seamless } \\
\text { st1 Tuting }\end{array}$ & 153 & $\begin{array}{l}16 \text { OPX.195 } \\
\text { wa11 } \times 81 \text { in } \\
\end{array}$ & Kelly Pipe \\
\hline & & & & & & & & & \\
\hline Flange & .097 & ID-22464-5 & $\cdots$ & 2 & $1018 *$ & Flame cut pute & 137.5 & $.75 \times 18 \times 18$ & U. S. Steel \\
\hline Lug & . 098 & ID $-22464-7$ & $\ldots$ & 6 & $1018 *$ & Flame put $_{\text {pute }}^{\text {cut }}$ & 35.0 & $62 \times 10 \times 10$ & u. 5. Steel \\
\hline & & & & & & & & & \\
\hline & & & & & & & & & \\
\hline & & & & & & & & & \\
\hline & & & & & & & & & \\
\hline & & & & & & & & & \\
\hline & & & & & & & & & \\
\hline & & & & & & & & & \\
\hline & & & & & & & & & \\
\hline & & & & & & & & & \\
\hline & & & & & & & & & \\
\hline & & & & & & & & & \\
\hline & & & & & & & & & \\
\hline & & & & & & & & & \\
\hline & & & & & & & & & \\
\hline & & & & & & & & & \\
\hline & & & & & & & & & \\
\hline & & & & & & & & & \\
\hline & & & & & & & & & \\
\hline
\end{tabular}

MFG 
ISSUE 2

ISSUE 3

\# UNAVAILABLE

\begin{tabular}{|c|c|c|c|c|c|c|c|c|c|}
\hline FLEVIATION & 4422 & BILL C & SF MAT & ERIA & $d L-H$ & ELIOS & A1 & ASSEI & $M \overline{B L Y}$ \\
\hline $\begin{array}{l}\text { ¿UASSEMELY } \\
\text { DETALL }\end{array}$ & $\begin{array}{l}\text { ERD } \\
\text { CODE }\end{array}$ & $\begin{array}{l}\text { COMM.PT. NO } \\
\text { ORAW NO․ }\end{array}$ & $\begin{array}{l}\text { ENGINEERING } \\
\text { INSTRUCT SHT. }\end{array}$ & $\begin{array}{l}\text { UNIT } \\
\text { QUANT. }\end{array}$ & $\begin{array}{l}\text { MATL } \\
\text { SPEC. }\end{array}$ & $\begin{array}{l}\text { MAT'L } \\
\text { FORMITIPE }\end{array}$ & $\begin{array}{l}\text { MAT'L } \\
\text { WT. }\end{array}$ & $\begin{array}{l}\text { OVERALL } \\
\text { SIZE }\end{array}$ & $\begin{array}{l}\text { PUR OR MATL } \\
\text { SOURCE }\end{array}$ \\
\hline Thrust Bear-Clevis & .133 & ID-22749-501 & $-\cdots$ & 4 & --- & $-\cdots$ & $\cdots$ & ---- & Sargent \\
\hline Shtm-Clevis & .157 & ID-22727-501 & --- & 4 & --- & $-\cdots$ & $-\cdots$ & $\ldots$ & McMaster \\
\hline P1n-Clevis & .029 & ID-22735-501 & $-\cdots$ & 2 & -- & $-\cdots$ & $-\cdots$ & $-\cdots$ & McMaster \\
\hline Shim - Trunnion & .138 & ID $-2272 i-1$ & $-\cdots-$ & 4 & $-\cdots$ & $-\cdots$ & $-\cdots$ & ---- & McMaster \\
\hline & & & & & & ST'L & & & \\
\hline Thrust Brg-Trunnion & .134 & ID- $22749-1$ & --- & 4 & --- & --- & $-\cdots$ & $-\cdots$ & Smrgent \\
\hline & & & & & & $9 T^{\prime} \mathrm{L}$ & & & \\
\hline & & & & & & & & & \\
\hline & & & & & & & & & \\
\hline & & & & & & & & & \\
\hline & & & & & & & & & \\
\hline & $=$ & & & & & & & & \\
\hline & & & & & & & & & \\
\hline & & & & & & & & & \\
\hline & & & & & & & & & \\
\hline & & & & & & & & & \\
\hline & & & & & & & & & \\
\hline & & & & & & & & & \\
\hline & & & & & & & & & \\
\hline & & & & & & & & & \\
\hline & & & & & & & & & \\
\hline & & & & & & & & & \\
\hline & & & & Al3 & & & & & \\
\hline
\end{tabular}


ISSUE 1

ISSUE 2

ISSUE 3
* UNavail able - NDT REQD.

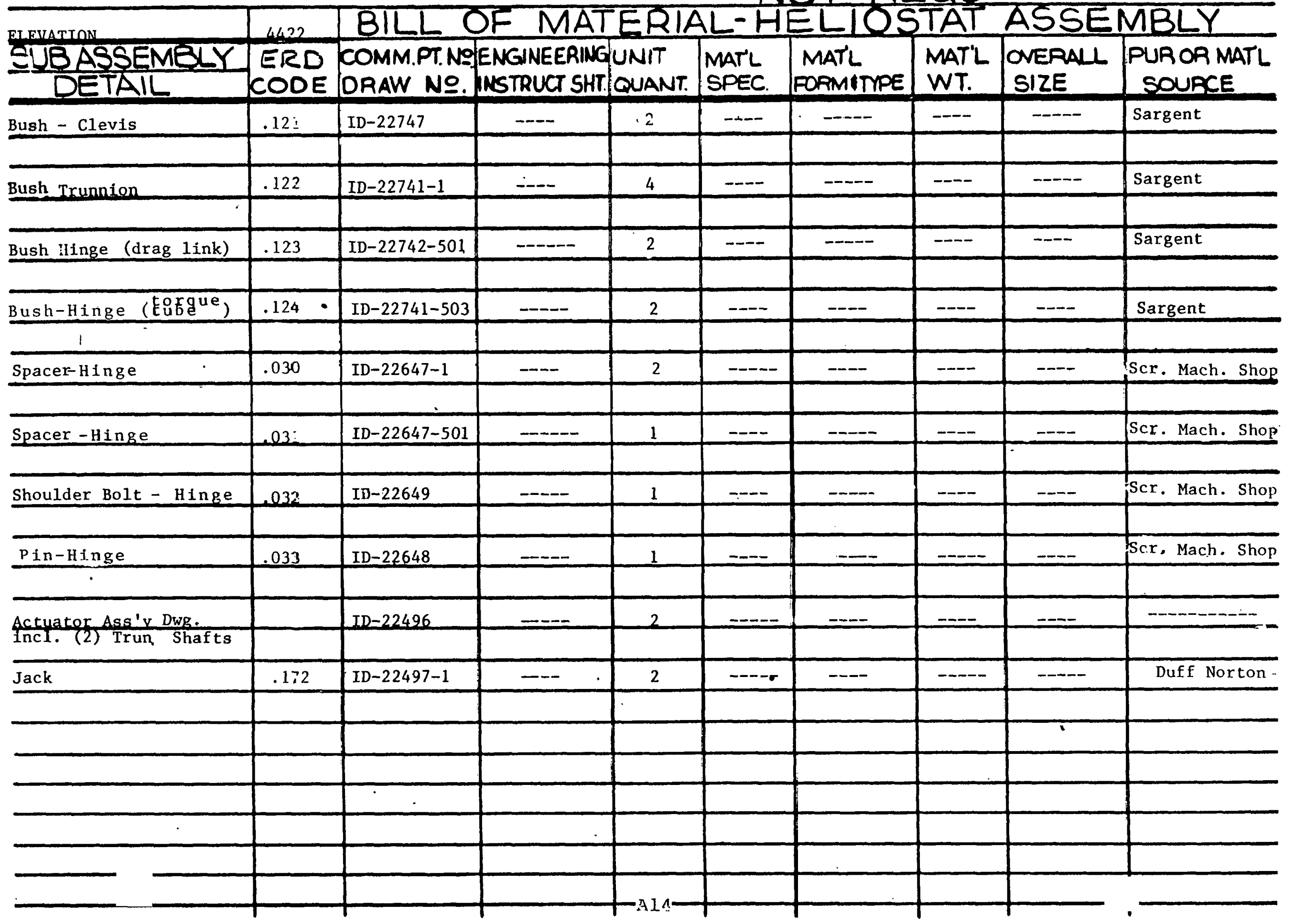




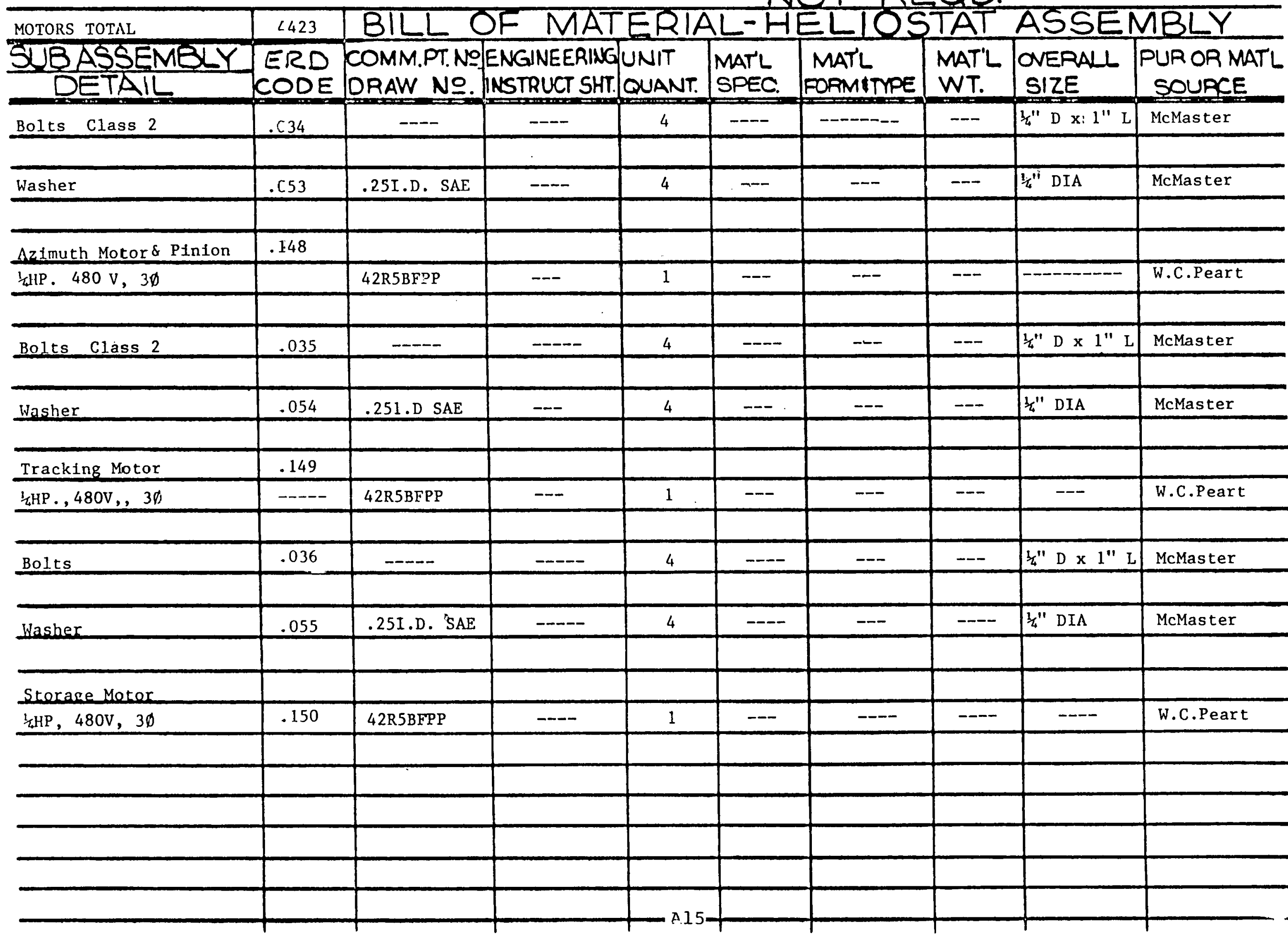


ISSUE 1 h/14/79 ISSUF $47 / 30 / 79$

ISSUE 2

$71,29,79$

\section{\# UNAVAILABLE - NOT REQD.}

\begin{tabular}{|c|c|c|c|c|c|c|c|c|c|}
\hline Pos/Limit/Ind & 4424 & & & & & & & & \\
\hline Hal] Eff Sensor & .180 & 1AY3A & --- & 6 & -- & $\rightarrow--$ & -- & --- & Micro Switch \\
\hline Line Drtver & $.18 \mathrm{~L}$ & 9614 & ----- & 3 & -- & -- & --- & --- & Fairchild \\
\hline Dua1 Diff. LIne Rec & .182 & 9615 or equal & --- & 3 & --- & -- & --- & --- & Fairchild \\
\hline Vane Actuator & $15 \equiv$ & ID $22739-3$ & ---- & 3 & 1018 & St]. Sht & $-\cdots--$ & $2.50 \times 04$ & MDAC \\
\hline Resistor $\frac{1}{2}$ watt & .183 & 11213 & --- & 12 & --- & ---- & $-r$ & ---- & R.C.A. \\
\hline Capacitor 0.I F l400V & $.18 \div$ & -ー-ー- & ---- & 12 & --- & $-\infty-$ & ---- & ---- & R.C.A. \\
\hline Connector & .185 & C09A09С3DBAA & -ーー-ー-ー & 3 & --- & ------ & ----- & ------ & ITT Cannon \\
\hline Printed Circult & .152 & $1022667-1$ & & 3 & epox sided & $-\cdots--$ & $-\infty$ & $1.10 \times 5.00$ & Hughe Connector \\
\hline Cylinder & .156 & ID $22479-3$ & $------n-$ & 3 & 1018 & Stl. Tube & ---- & $.25 \mathrm{w} 11 \times 3.6$ & MDAC \\
\hline Cover & $.15 ?$ & ID $22479-5$ & ---- & 3 & 1018 & St1. Sht & ---- & $.1345 \times 7 \times 7$ & MDAC \\
\hline Supp't. Bracket & .158 & ID 22739-5 & ----- & 3 & 1018 & StI. Sht & ---- & $5 \times 5 \times .0293$ & \\
\hline Drive Triacs /Opt. Isol. & .186 & $\mathrm{~T} 2850 \mathrm{D}$ & --- & 12 & ---- & ---- & ---- & $---\cdots$ & R.C.A./Motoro] \\
\hline Screw & .037 & --------- & MS51957-12 & 3 & & & & & \\
\hline Screw & .038 & ------- & MS51957-14 & 12 & & & & & \\
\hline Washer & .056 & -ーーーーーー- & AN960C3 & 15 & & & & & \\
\hline Nut & .039 & --ー- - - & NAS671C4 & 15 & & & & & \\
\hline Set Screw & .040 & -------- & NAS1081C06A2P & 6 & & & & & \\
\hline Screw & .041 & $-\infty----\infty$ & MS51958-61 & 9 & & & & & \\
\hline
\end{tabular}




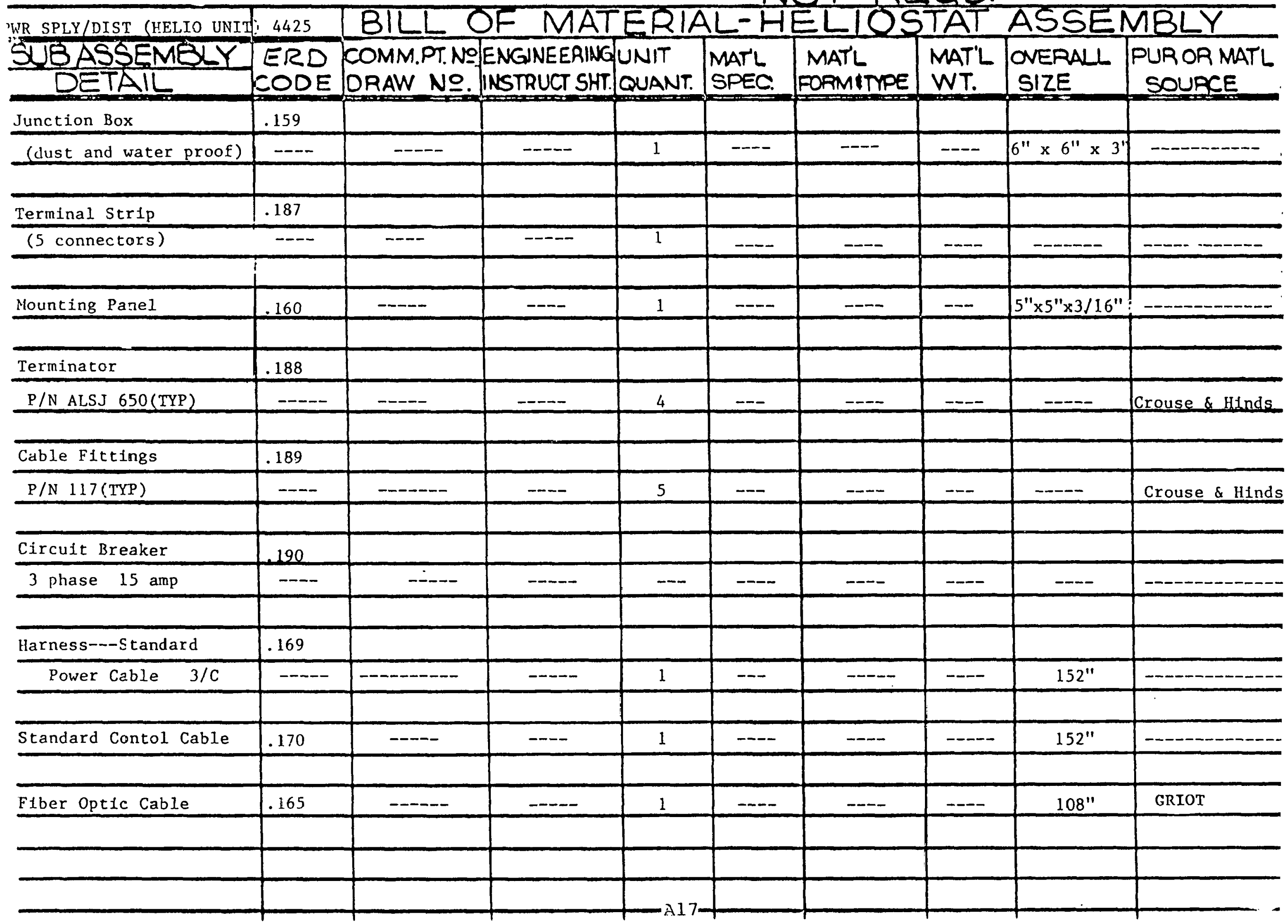


\# UNAVAILĀABLE

PWR SPLY/DIST (HELIO UNIF 4425 BILL OF MATERIAL-HELIOSTAT ASSEMBLY SUBASSEMBLY

\begin{tabular}{|c|c|c|c|}
\hline$\frac{\text { DUBASSEMBLY }}{\text { DETAIL }}$ & $\begin{array}{l}\text { ERD } \\
\text { CODE }\end{array}$ & $\begin{array}{l}\text { COMM.PT. No } \\
\text { ORAW NO. }\end{array}$ & $\begin{array}{l}\text { ENGINEERING] } \\
\text { INSTRUCT SHT. }\end{array}$ \\
\hline Connectors----Fiber & .166 & & \\
\hline Optic Terminators & --- & ----------- & ----- \\
\hline 25 Pin Connector & 191 & $\cdots$ & --- \\
\hline 10 Pin Connector & .192 & $\ldots$ & -.--- \\
\hline & & & \\
\hline & & & \\
\hline & & & \\
\hline & & & \\
\hline & & & \\
\hline & & & \\
\hline & & & \\
\hline & & & \\
\hline & & & \\
\hline & & & \\
\hline & & & \\
\hline & & & \\
\hline & & & \\
\hline & & & \\
\hline & & & \\
\hline & & & \\
\hline & & & \\
\hline
\end{tabular}

MATL

SPEC. MATL FORMITIPE MAT'L OVERALL WT. SIZE

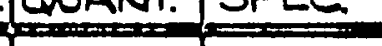

\section{intirme}

4

$---$

$---$
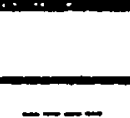

1

$---$

Alo SOURCE 
ISSUE 2 $1 / 23 / 79$ - NOT REQD.

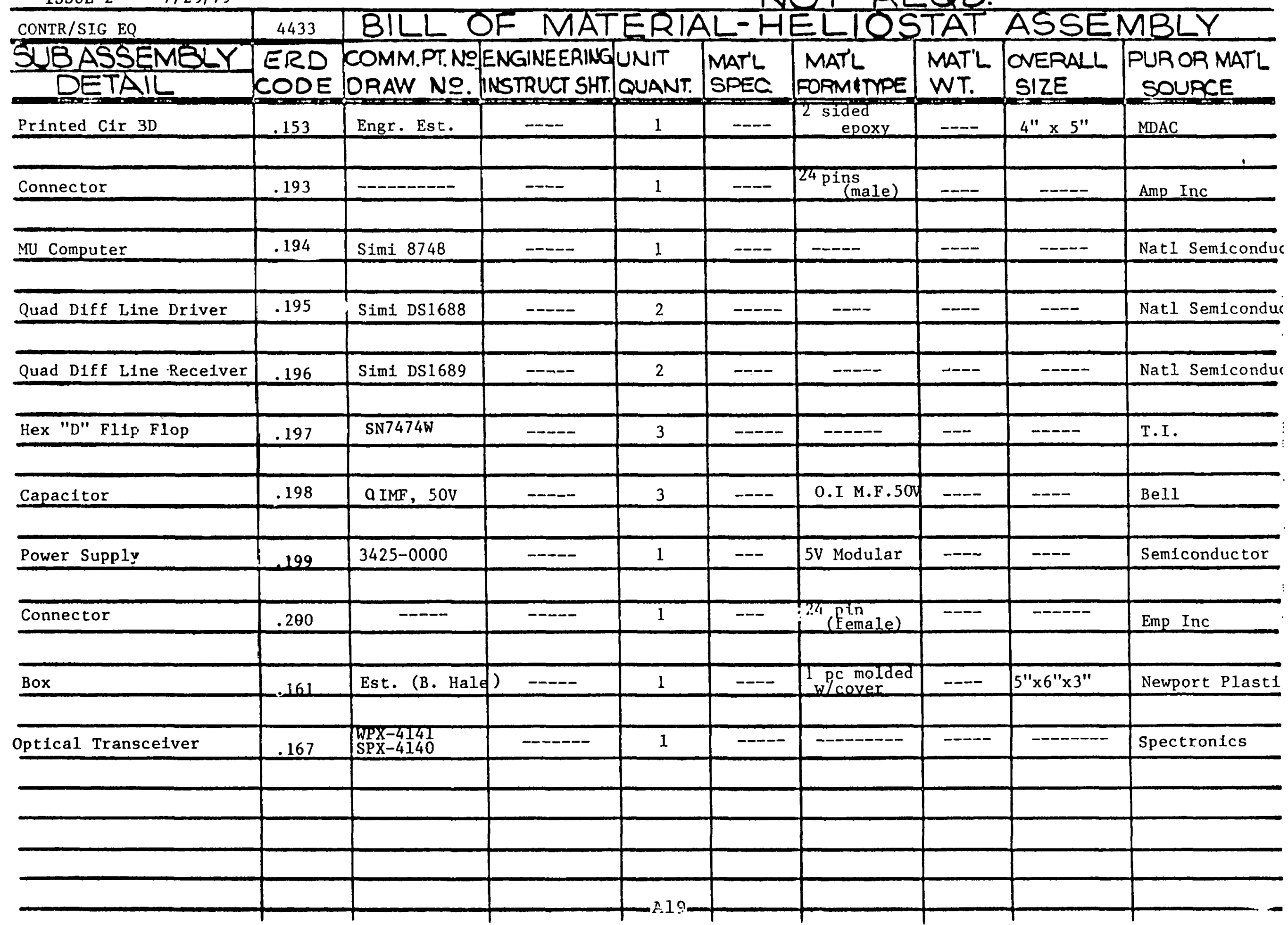




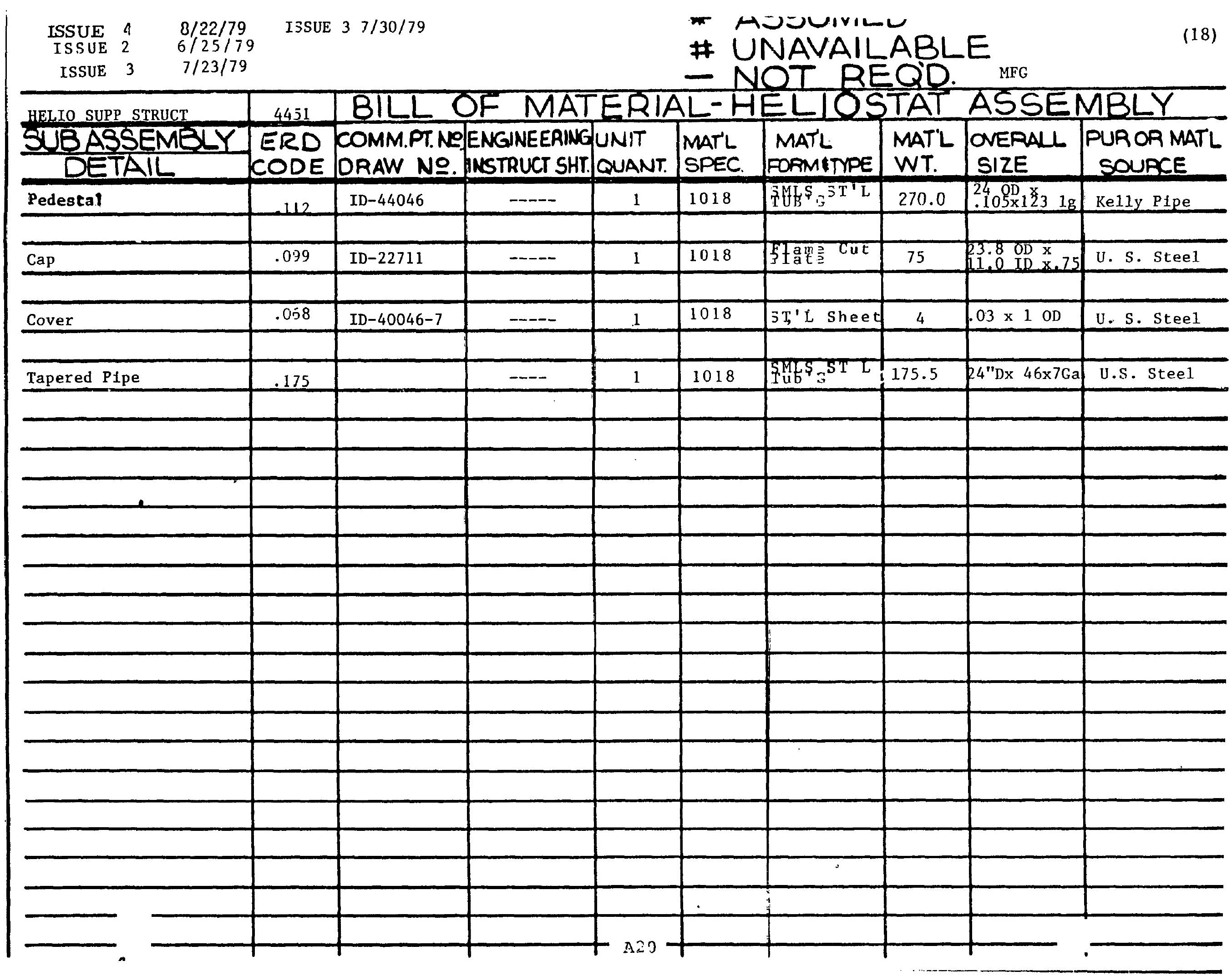


APPENDIX B

MATERIAL PRICE REQUESTS 
THIS PAGE WAS INTENTIONALLY

\author{
LEFT BLANK
}


MATERIAL PRICE REQUEST - 25,000 ANNUAL VOLUME HELIOSTAT

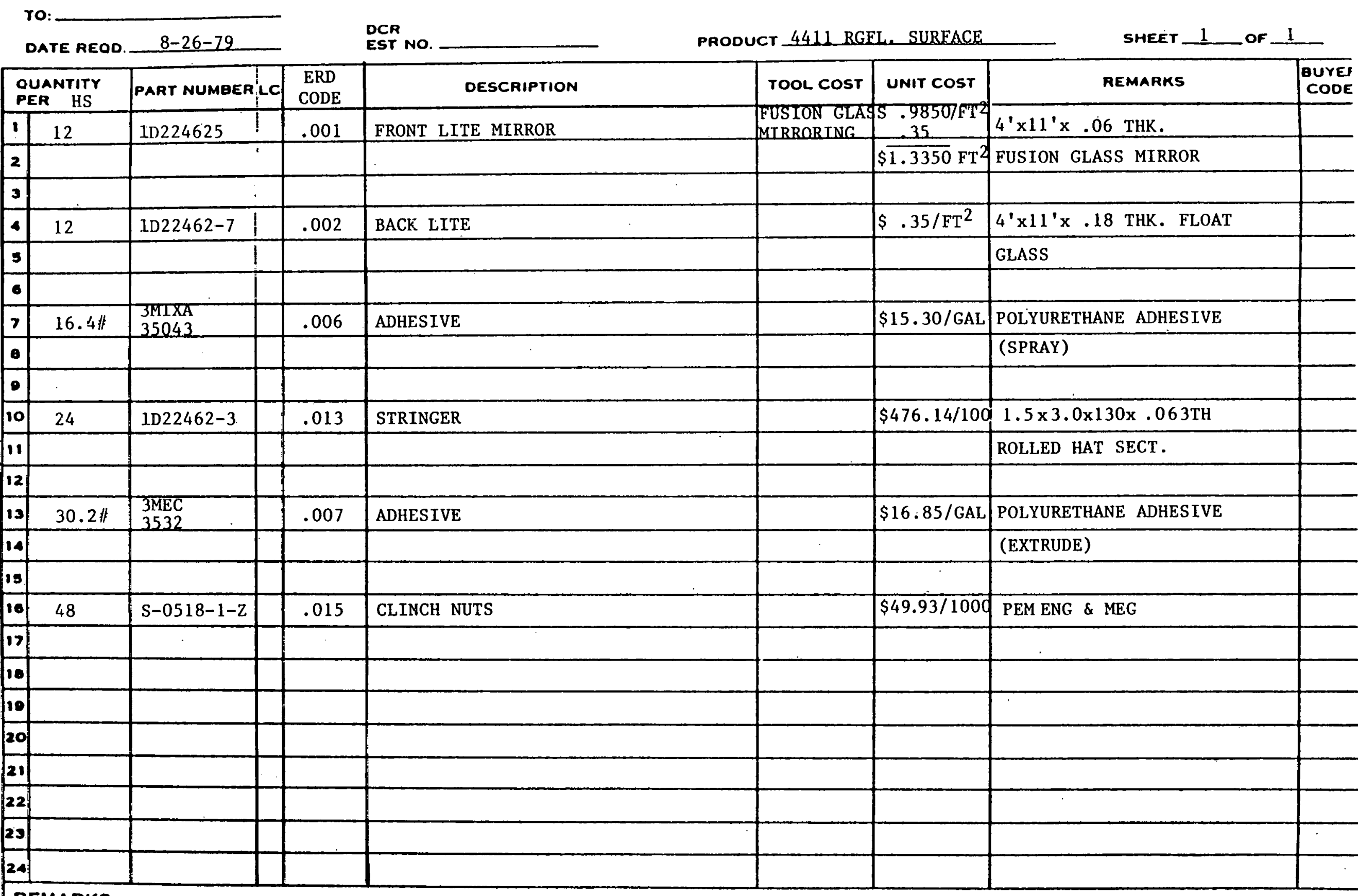

REMARKS: 
MATERIAL PRICE REQUEST - 25,000 ANNUAL VOLUME HELICSTAT

\begin{tabular}{|c|c|c|c|c|c|c|c|c|c|}
\hline \multicolumn{3}{|c|}{ DATE REOD. $8-26-79$} & \multicolumn{2}{|r|}{$\begin{array}{l}\text { DCR } \\
\text { EST NO. }\end{array}$} & \multicolumn{3}{|c|}{ PRODUCT 4412 MIRROR SUPP STRUCTURE } & \multicolumn{2}{|c|}{ SHEET 1 of 1} \\
\hline \multicolumn{2}{|c|}{$\begin{array}{l}\text { OUANTITY } \\
\text { PER HS } \\
\end{array}$} & \multirow{2}{*}{\begin{tabular}{|l} 
PART NUMBER \\
ID22463-1 \\
\end{tabular}} & \multirow[t]{2}{*}{$\begin{array}{c}\text { ERD } \\
\text { CODE } \\
\end{array}$} & \multicolumn{2}{|l|}{ DESCRIPTION } & \multirow[t]{2}{*}{ TOOL COST } & \multirow[t]{2}{*}{ UNIT COST } & \multirow[t]{2}{*}{ REMARKS } & \multirow[t]{2}{*}{$\begin{array}{l}\text { BUYEF } \\
\text { COOE }\end{array}$} \\
\hline 1 & 2 & & & ASS'Y DRAWING & & & & & \\
\hline \multicolumn{10}{|c|}{ 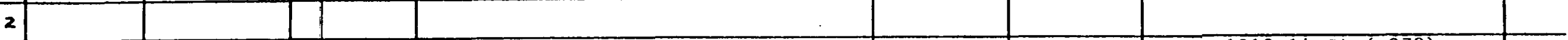 } \\
\hline 3 & 2 & ID22466-1 & .009 & DIAG BEAM L.H. & & & 47.06 & 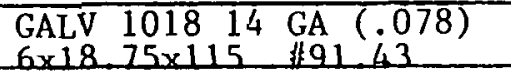 & \\
\hline \multicolumn{10}{|c|}{ (9) } \\
\hline $\mathbf{s}$ & 2 & ID22466-2 & .010 & DIAG BEAM R.H. & & & $4 ? .06$ & $\begin{array}{l}\text { GALV TO18 } 14 \text { GA (.078) } \\
6 \times 18.75 \times 115 \text { 非1.43 }\end{array}$ & \\
\hline \multicolumn{10}{|c|}{ 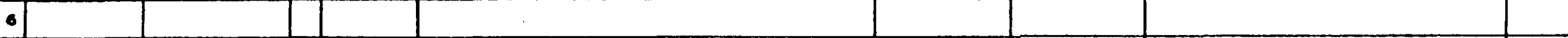 } \\
\hline 7 & 2 & ID22465-1 & .011 & IN. CROSS BE.MM & & & 125.80 & $\begin{array}{l}\text { GALV } 101814 \text { GA }(.078) \\
6 \times 18.75 \times 278\end{array}$ & \\
\hline \multicolumn{10}{|c|}{ मान } \\
\hline 9 & 2 & 1D22467-1 & .012 & OUT. CROSS BIAM & & & 42.14 & $\begin{array}{l}\text { GALV 1018 16 GA }(.063) \\
2.5 \times 5.0 \times 275 \quad \# 89.8 \\
\end{array}$ & \\
\hline \multicolumn{10}{|c|}{ 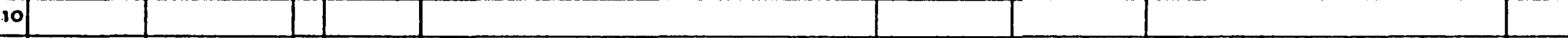 } \\
\hline 11 & 48 & & .016 & BOLT & & & $0 . \overline{79}$ & $5 / 16$ UNC. $18 \times .75$ LG SAE & \\
\hline \multicolumn{10}{|c|}{12} \\
\hline i3) & 4 & ID22463-3 & .060 & DOUBLER & & & 5.00 & $\begin{array}{l}\text { GALV ASTM A-36 } \\
313 \times 2 \times 11,5 \quad \$ 8,1\end{array}$ & \\
\hline \multicolumn{10}{|c|}{140} \\
\hline 15 & 4 & ID22 2463 & .065 & GUSSET & & & 18.00 & $\begin{array}{l}\text { GALV ASTM } A-36 \\
188 \times 8.75 \times 17 \quad \text { 非 } 39.8\end{array}$ & \\
\hline \multicolumn{10}{|c|}{ - } \\
\hline 27 & 48 & & .50 & WASHER & & & .34 & $5 / 16$ ID SAE & \\
\hline \multicolumn{10}{|c|}{10} \\
\hline \multicolumn{10}{|c|}{10} \\
\hline 20 & & & & & & & & . & \\
\hline \multicolumn{10}{|c|}{21} \\
\hline \multicolumn{10}{|l|}{22} \\
\hline \multicolumn{10}{|c|}{23} \\
\hline 24) & & & & & & & & & \\
\hline \multicolumn{10}{|c|}{ REMARKS: } \\
\hline & & & & & B4 & & & & \\
\hline
\end{tabular}


MATERIAL PRICE REQUEST - 25,000 ANNUAL VOLUME HELIOSTAT

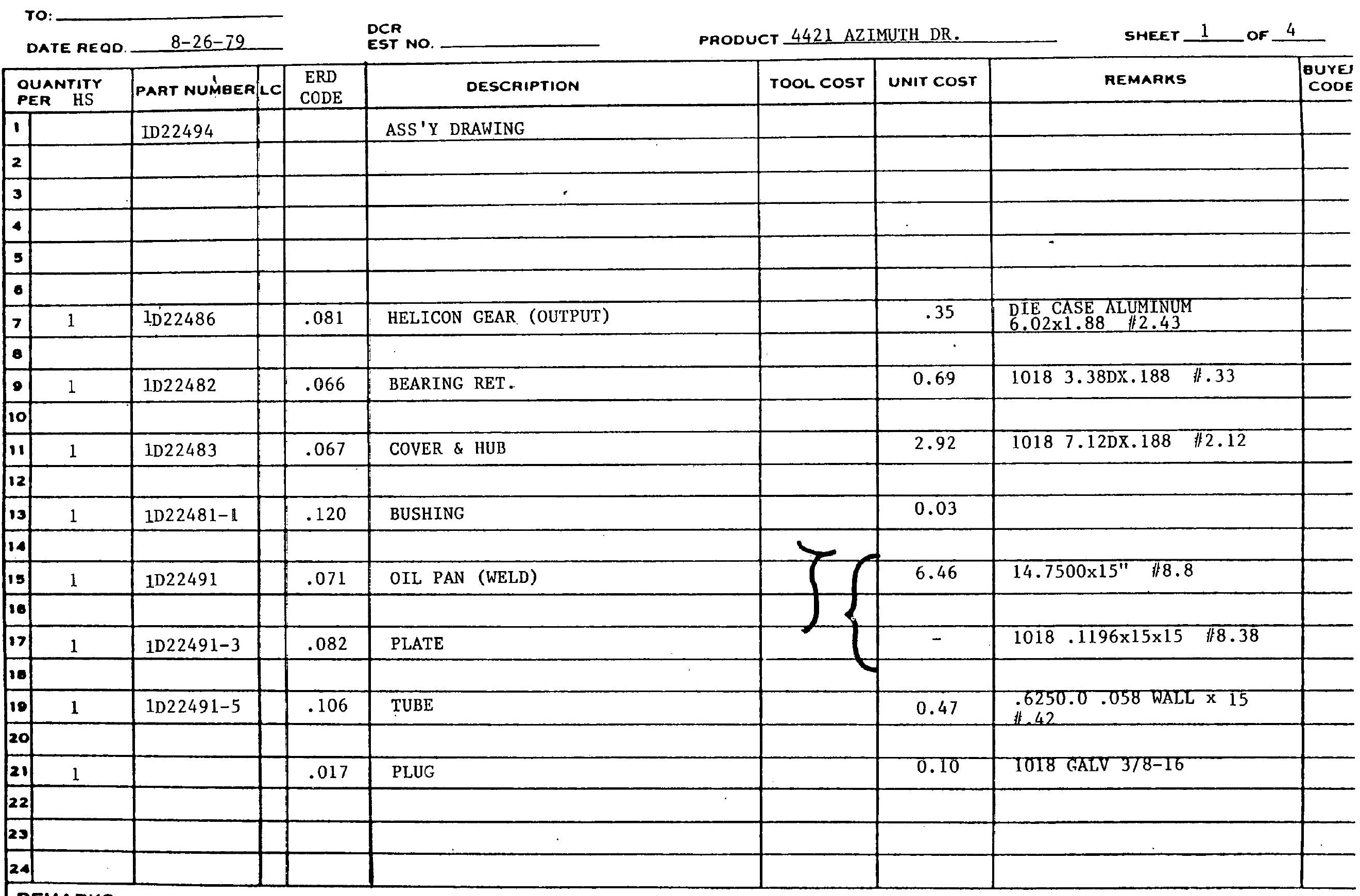

REMARKS: 
MATERIAL PRICE REQUEST - 25,000 ANNUAL VOLUME HELIOSTAT

\begin{tabular}{|c|c|c|c|c|c|c|c|c|c|}
\hline \multicolumn{3}{|c|}{ DATE REOD. $8-26-79$} & \multicolumn{2}{|r|}{$\begin{array}{l}\text { DCR } \\
\text { EST NO. }\end{array}$} & \multicolumn{3}{|c|}{ PRODUCT 4421 AZMUT: UR. } & \multicolumn{2}{|c|}{ SHEET 2 _ OF 4} \\
\hline \multicolumn{2}{|c|}{$\begin{array}{l}\text { OUANTITY } \\
\text { PER HS } \\
\end{array}$} & \multirow{2}{*}{\begin{tabular}{|l|} 
PART NUMBER \\
$2-466$ N398-7 \\
\end{tabular}} & \multirow{2}{*}{\begin{tabular}{|c|}
$\begin{array}{c}\text { ERD } \\
\text { CODE }\end{array}$ \\
.146 \\
\end{tabular}} & DESCRIPTION & \multirow{2}{*}{ TOOL COST } & \multirow{2}{*}{$\begin{array}{l}\text { UNIT COST } \\
3.49 \\
\end{array}$} & \multicolumn{2}{|r|}{ REMARKS } & \multirow[t]{2}{*}{$\begin{array}{l}\text { BUYEI } \\
\text { COOE }\end{array}$} \\
\hline 1 & 1 & & & PACKING & & & & & \\
\hline \multicolumn{10}{|l|}{2} \\
\hline 3 & 4 & 1D22485 & .136 & SHIM (GEAR) & & 3.16 & 1.500 .0 & $\mathrm{x} 1.125 \mathrm{I} . \mathrm{D}$ & \\
\hline \multicolumn{10}{|l|}{4} \\
\hline 5 & 1 & $\mathrm{~N}-08$ & .022 & LOCKNUT (WAVE GENERATOR) & & $\mathbf{1 . 6 5}$ & & & \\
\hline \multicolumn{10}{|l|}{6} \\
\hline 7 & 1 & $\mathrm{~W}-08$ & .052 & WASHER (WAVE GENERATOR) & & 9.12 & & & \\
\hline \multicolumn{10}{|l|}{8} \\
\hline$\cdot$ & 1 & $2-459 N-256-\$$ & .145 & PACKING & & 5.03 & & & \\
\hline \multicolumn{10}{|c|}{10} \\
\hline 11 & 1 & ALVANIA EPR & .140 & GREASE & & $\therefore .37$ & 1 PINT & (SHELL) & \\
\hline \multicolumn{10}{|c|}{12} \\
\hline 13 & 1 & $10 W 40$ & .141 & OIL & & 1.01 & $2 \mathrm{QT}$ & (SHELL) & \\
\hline \multicolumn{10}{|c|}{14} \\
\hline 13 & 1 & MF- -075 & .023 & PULL COR ELBOW & & 1.44 & & & \\
\hline 10 & & & & . & & & & & \\
\hline 17 & 8 & $1 / 4-20 \times .63$ & .024 & SCREW-FLT HD. & & 0.06 & - & & \\
\hline \multicolumn{10}{|c|}{10} \\
\hline 10 & 8 & $\| 8-32 x .56$ & .025 & BOLT L'WASHER & & $0 . \overline{05}$ & & & \\
\hline \multicolumn{10}{|c|}{20} \\
\hline 21 & 4 & $\# 10-24 \times .63$ & .026 & BOLT L'WASHER & & .02 & & & \\
\hline \multicolumn{10}{|l|}{22} \\
\hline 23 & 16 & $3 / 8-15-2$ & .027 & BOLT L'WASHER & & 0.73 & & & \\
\hline 24 & 8 & $5 / 8-1 \cdot 1 \times 4$ & .028 & BOLT L 'WASHER & & 2.56 & & & \\
\hline \multicolumn{10}{|c|}{ REMARKS: } \\
\hline & & & & & E6 & & & & \\
\hline
\end{tabular}


MATERIAL PRICE REQUEST - 25,000 ANNUAL VOLUME HELIOSTAT

\begin{tabular}{|c|c|c|c|c|c|c|c|c|c|}
\hline \multicolumn{3}{|c|}{ DATE REOO. $8-26-79$} & \multicolumn{2}{|r|}{$\begin{array}{l}\text { DCR } \\
\text { EST NO. }\end{array}$} & \multicolumn{3}{|c|}{ PRODUCT 4421 AZIMUTH DR. } & \multicolumn{2}{|c|}{ SHEET 3 OF 4} \\
\hline \multicolumn{2}{|c|}{$\begin{array}{l}\text { OUANTITY } \\
\text { PER HS } \\
\end{array}$} & PART NUMGER & \begin{tabular}{|l|c} 
LC & $\begin{array}{c}\text { CRD } \\
\text { CODE }\end{array}$ \\
\end{tabular} & DESCRIPTION & & TOOL COST & UNIT COST & REMARKS & \begin{tabular}{|l} 
BUYEA \\
CODE
\end{tabular} \\
\hline 1 & & & & & & & & & \\
\hline 2 & & & & & & & & & \\
\hline 3 & 1 & & .061 & KEY & & & 0.03 & $3 / 8 \mathrm{SQ} \times 3 / 4 \mathrm{LG}$ & \\
\hline 4 & & & & & & & & & \\
\hline 3 & 1 & & .130 & WAVE GEN BEAR & & & 75.62 & $\begin{array}{l}9.500 \times 7.250 \\
1.5 \text { JG . .88 BALL }\end{array}$ & \\
\hline 6 & & & & & & & & & \\
\hline 7 & 1 & & .62 & KEY (GEAR) & & & 0.01 & $3 / 16 \mathrm{SQ} \times 1 / 8 \mathrm{LG}$ & \\
\hline 8 & & & & & & & & & \\
\hline$\bullet$ & 1 & $\mathrm{~N}-06$ & .018 & NUT (GEAR) & & & 0.44 & & \\
\hline 10 & & & & & & & & & \\
\hline 11 & 1 & $\mathrm{~N}-06$ & .051 & WASHER (GEAR) & & & 0.10 & & \\
\hline 12 & & & & & & & & & \\
\hline 13 & 1 & $\mathrm{BL}-75$ & .019 & LOCKNUT & & & 0.06 & & \\
\hline 14 & & & & & & & & & \\
\hline 18) & 12 & $\mathrm{HL}-20-30$ & .020 & BOLTS (SPEC) & & & 31.80 & $5 / 8$ NOM & \\
\hline 16 & & & & & & & & & \\
\hline 17 & 12 & $\mathrm{HL}-86-20$ & .021 & NUTS (SPEC) & & & 21.57 & $5 / 8$ NOM & \\
\hline 10 & & & & & & & & & \\
\hline 18 & & & & & & & & & \\
\hline 20 & & & & & & & & & \\
\hline 21 & 1 & $106 \mathrm{~K} 5 \mathrm{ZZ}$ & .131 & BEARING (DRIVE SHAFT) & & & 3.31 & & \\
\hline 22 & & & & & & & & & \\
\hline 23 & & $1 \mathrm{D} 22490$ & .132 & BEARING KIT (TURRET) & & & 20.78 & & \\
\hline 24 & & & & & & & & & \\
\hline \multicolumn{5}{|c|}{ REMARKS: } & & & & & \\
\hline & & & & & B7 & & & & \\
\hline
\end{tabular}


MATERIAL PRICE REQUEST - 25,000 ANNUAL VOLUME HEL.IOSTAT

\begin{tabular}{|c|c|c|c|c|c|c|c|c|c|}
\hline \multicolumn{3}{|c|}{ DATE REOD. $\quad 8-7-79$} & \multicolumn{2}{|r|}{$\begin{array}{l}\text { DCR } \\
\text { EST NO. }\end{array}$} & \multicolumn{3}{|c|}{ PRODUCr 4421 AZIMUTH DR. } & \multicolumn{2}{|c|}{ SHEET 4 OF 4} \\
\hline \multicolumn{2}{|c|}{$\begin{array}{l}\text { OUANTITY } \\
\text { PER HS } \\
\end{array}$} & PART NUMBER & \begin{tabular}{|c|c} 
ERD \\
CODE \\
\end{tabular} & DESCAIPTION & & TOOL COST & UNIT COST & REMARKS & $\begin{array}{l}\text { BUYEI } \\
\text { COOE }\end{array}$ \\
\hline 1 & 1 & 1D22492 & .072 & HOUSING & & & & SAE 1018 - WELD CONST & \\
\hline 2 & & & & COST OF WELDMENT & & & 370.00 & 261\#PLATE \& TUBE & \\
\hline 3 & & & & & & & & & \\
\hline 4 & 1 & & .073 & FLEX SPLINE & & & 25.00 & SAE4320-BR'G QUAL. (TIMKEN) & \\
\hline 5 & & & & & & & & \#RD TUB'G \& PLAT'E & \\
\hline - & & & & & & & & & \\
\hline 7 & 1 & & .110 & CIRC. SELINE & & & 85.00 & SAE 1018 - RD.STJ. TUBE & \\
\hline - & & & & & & & & $\sharp$ & \\
\hline 8 & & & & & & & & & \\
\hline 10 & 1 & & .115 & WAVE GEN PLUG & & & 10.92 & SAE 1040 - RD BAR & \\
\hline 11 & & & & & & & & $\#$ & \\
\hline 12 & & & & & & . & & & \\
\hline 13 & 1 & $1 \mathrm{D} 22 \div 95$ & .105 & DRIVE SFAFT & & & 20.00 & SAE1018 - RD.STL. TUBE & \\
\hline 14 & & & & & & & & $9.58 \#$ & \\
\hline 15 & & & & & & & & $\cdot$ & \\
\hline 10 & 1 & $1 \mathrm{D} 22489$ & .080 & OUTER RETAINER & & & 77.00 & SAE 1018 FL. CUT PJATE & \\
\hline 77 & & & & & & & & $80.22 \#$ & \\
\hline 10) & & & & & & & & & \\
\hline is & & & & & & & & & \\
\hline 20 & & & & & & & & & \\
\hline \multirow[t]{2}{*}{21} & & & & & & & & & \\
\hline & & & & & & & & & \\
\hline \multirow[t]{2}{*}{23} & & & & & & & & & \\
\hline & & & & & & & & & \\
\hline \multicolumn{5}{|c|}{ REMARKS: } & & & & & \\
\hline & & & & & BE & & & & \\
\hline
\end{tabular}


MATERIAL PRICE REQUEST - 25,000 ANNUAL VOLUME HELIOSTAT

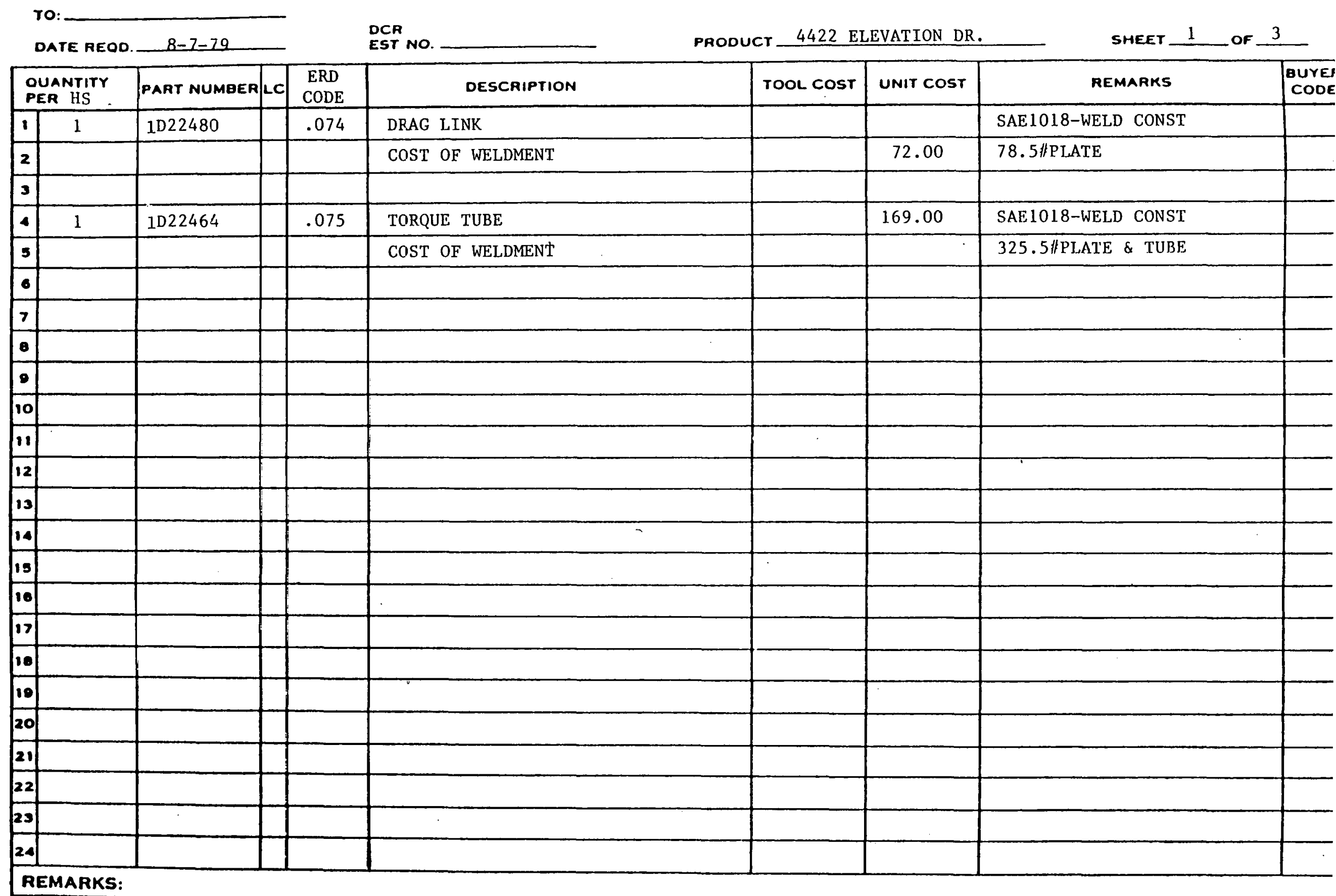


MATERIAL PRICE REQUEST - 25,000 ANNUAL VOLUME HELIOSTAT

\begin{tabular}{|c|c|c|c|c|c|c|c|c|c|}
\hline \multicolumn{3}{|c|}{ DATE REOD. $\quad 8-7-79$} & \multicolumn{2}{|r|}{$\begin{array}{l}\text { DCR } \\
\text { EST NO. }\end{array}$} & \multicolumn{3}{|c|}{ PROOUCT 4422 ELEVATION DR. } & \multicolumn{2}{|c|}{ SHEET 2 OF 3} \\
\hline \multicolumn{2}{|c|}{$\begin{array}{l}\text { OUANTITY } \\
\text { PEA HS }\end{array}$} & \multirow{2}{*}{$\begin{array}{l}\text { PART NUMEER } \\
\text { ID22747 }\end{array}$} & \multirow{2}{*}{\begin{tabular}{|c|} 
ERD \\
CODE \\
.121
\end{tabular}} & \multicolumn{2}{|l|}{ DESCRIPTION } & \multirow[t]{2}{*}{ TOOL COST } & \multirow{2}{*}{$\frac{\text { UNIT COST }}{1.40}$} & \multirow[t]{2}{*}{ REMARKS } & \multirow[t]{2}{*}{$\begin{array}{l}\text { BUYE } \\
\text { CODE }\end{array}$} \\
\hline 1 & 2 & & & BUSH-CIEVIS & & & & & \\
\hline \multicolumn{10}{|l|}{2} \\
\hline 3 & 4 & 1D22741-1 & .122 & BUSH-TZUNNION & & & 1.99 & & \\
\hline 4 & & & & ' & & & & & \\
\hline $\mathbf{5}$ & 2 & 1D22742-501 & .123 & BUSH HLNGE (DRAG LINK) & & & 1.00 & & \\
\hline \multicolumn{10}{|l|}{6} \\
\hline 7 & 2 & ID22741-503 & .124 & BUSH HLNGE (TORQUE TUBE) & & & 0.43 & & \\
\hline \multicolumn{10}{|l|}{ - } \\
\hline$\bullet$ & 2 & 1D22647-1 & .030 & SPACER-HINGE & & & 0.74 & & \\
\hline \multicolumn{10}{|c|}{10} \\
\hline 11 & 1 & $1022647-501$ & .031 & SPACER-HINGE & & & 0.47 & & \\
\hline \multicolumn{10}{|c|}{12} \\
\hline 13 & 1 & 1022649 & .032 & SHOULDER BOLT-HINGE & & & 2.47 & & \\
\hline \multicolumn{10}{|c|}{14} \\
\hline 18 & 1 & $1 D 22648$ & .033 & PIN-HINGE & & & 1.84 & & \\
\hline \multicolumn{10}{|c|}{10} \\
\hline 17 & 2 & $1 D 22496$ & & $\begin{array}{l}\text { ACTUATOR ASS'Y DWG. INCL. } \\
(2) \text { TRUN. SHAFTS }\end{array}$ & & & - & & \\
\hline \multicolumn{10}{|c|}{ 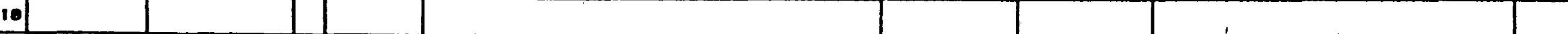 } \\
\hline 18 & 2 & 1D22497-1 & .172 & JACK & & & 400.00 & & \\
\hline \multicolumn{10}{|c|}{20} \\
\hline \multicolumn{10}{|c|}{21} \\
\hline \multicolumn{10}{|c|}{22} \\
\hline \multicolumn{10}{|c|}{ 23. } \\
\hline 24 & & & & & & & & & \\
\hline \multicolumn{10}{|c|}{ REMARKS: } \\
\hline & & & & & $\mathrm{B} 10$ & & & & \\
\hline
\end{tabular}


MATERIAL PRICE REQUEST - 25,000 ANNUAL VOLUME HELIOSTAT

\begin{tabular}{|c|c|c|c|c|c|c|c|c|}
\hline \multicolumn{3}{|c|}{ DATE REOD. $\quad 8-7-79$} & \multicolumn{2}{|r|}{$\begin{array}{l}\text { DCR } \\
\text { EST NO. }\end{array}$} & \multicolumn{2}{|c|}{ PRODUCT 4422 ELEVATION DR. } & \multicolumn{2}{|c|}{ SHEET 3 OF 3} \\
\hline \multicolumn{2}{|c|}{$\begin{array}{l}\text { OUANTITY } \\
\text { PER HS }\end{array}$} & \multirow{2}{*}{\begin{tabular}{|l|} 
PART NUMBER \\
1D22749-501 \\
\end{tabular}} & \multirow{2}{*}{\begin{tabular}{|c|}
$\begin{array}{c}\text { ERD } \\
\text { CODE }\end{array}$ \\
.133 \\
\end{tabular}} & DESCRIPTION & \multirow[t]{2}{*}{ TOOL COST } & \multirow{2}{*}{$\frac{\text { UNIT COST }}{0.42}$} & \multirow[t]{2}{*}{ REMARKS } & \multirow[t]{2}{*}{$\begin{array}{l}\text { BUYE } \\
\text { COOE }\end{array}$} \\
\hline 1 & 4 & & & THRUST BEAR-CLEVIS & & & & \\
\hline 2 & & & & $\cdots$ & & & & \\
\hline 3 & 4 & 1D22721-501 & .137 & SHIK-CLEVIS & . & 0.71 & & \\
\hline 4 & & & & & & & & \\
\hline 3 & 2 & $1 \mathrm{D} 22735-501$ & .029 & PIN-CLEVIS & & 2.62 & & \\
\hline - & & & & & & & & \\
\hline 7 & 4 & $1 \mathrm{D} 22727-1$ & .138 & SSHIY-TRUNNION & & 0.20 & & \\
\hline - & & & & & & & & \\
\hline - & 4 & $1 \mathrm{D} 22749-1$ & .134 & THRUST BRG. TRUNNION & & 0.71 & & \\
\hline 10 & & & & & & & & \\
\hline 11 & & & & & & & & \\
\hline 12 & & & & & & & & \\
\hline 13 & & & & & & & & \\
\hline 14 & & & & & & & & \\
\hline 15 & & - & & & & & & \\
\hline 10 & & & & & & & & \\
\hline 17 & & & & & & & & \\
\hline 10 & & & & & & & & \\
\hline 10 & & & & & & & & \\
\hline 20 & & & & & & & & \\
\hline 21 & & & & & & & & \\
\hline 22 & & & & & & & & \\
\hline 23 & $!$ & & & & & & & \\
\hline 24 & & & & & & & & \\
\hline
\end{tabular}

REMARKS: 
MATERIAL PRICE REQUEST - 25,000 ANNUAL VOLJME HELLOSTAT

\begin{tabular}{|c|c|c|c|c|c|c|c|}
\hline \multicolumn{3}{|c|}{ DATE REOD. $7-31-79$} & \multicolumn{5}{|c|}{ PRODUCT 4423 MOTCRS } \\
\hline \multicolumn{2}{|c|}{$\begin{array}{l}\text { OUANTITY } \\
\text { PER HS } \\
\end{array}$} & \multirow{2}{*}{\begin{tabular}{|l|} 
PART NUMBER \\
42R5BFPP \\
\end{tabular}} & DESCRIPTION & \multirow[t]{2}{*}{ TOOL COST } & \multirow{2}{*}{$\begin{array}{l}\text { UNIT COST } \\
48.50 \\
\end{array}$} & \multirow{2}{*}{$\begin{array}{l}\text { REMARKS } \\
\text { W.C. PEART } \\
\end{array}$} & \multirow[t]{2}{*}{$\begin{array}{l}\text { BUYEF } \\
\text { COOE }\end{array}$} \\
\hline 1 & 1 & & AZIMUTH MOTOR, $1 / 4$ H.P., $480 \mathrm{~V}$, & & & & \\
\hline 2 & & & $3 \emptyset, 1750$ R.P.M. & & & & \\
\hline 3 & 1 & 42R5BFPP & TRACKING MOTOR, $1 / 4 \mathrm{H.P.,} 480 \mathrm{v}$, & & 48.50 & W.C. PEART & \\
\hline 4 & & & $3 \emptyset, 1750$ R.P.M. & & & & \\
\hline 5 & 1 & 42R5BFPP & STOWAGE MOTOR, $1 / 4$ H.P., $480 \mathrm{~V}$, & & 48.50 & W.C. PEART & \\
\hline - & & & $3 \emptyset, 1750$ R.P.M. & & & 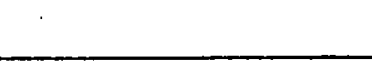 & \\
\hline 7 & 12 & & BOLTS, CLASS $2,1 / 4$ "DIA. $x 1$ " LONG & & .09 & MCMASTER & \\
\hline$\theta^{-}$ & & & & & & & \\
\hline 9 & & & & & & & \\
\hline 10 & & & & & & & \\
\hline י & 12 & & WASHERS, $1 / 4$ "DTAM. HOLE. & & .06 & MCMASTER & \\
\hline 12 & & & & & & & \\
\hline 13] & & & & & & & \\
\hline 14] & & & & & & & \\
\hline 15 & & & & & & & \\
\hline 10 & & & & & & & \\
\hline 17 & & & & & & & \\
\hline 18 & & & & & & & \\
\hline 10 & & & & & & . & \\
\hline 20 & & & & & & & \\
\hline 21 & & & & & & & \\
\hline 22 & & & & & & & \\
\hline 23 & & & & & & & \\
\hline 24 & & & & & & & \\
\hline
\end{tabular}


MATERIAL PRICE REQUEST - 25,000 ANNUAL VOLUME HELIOSTAT

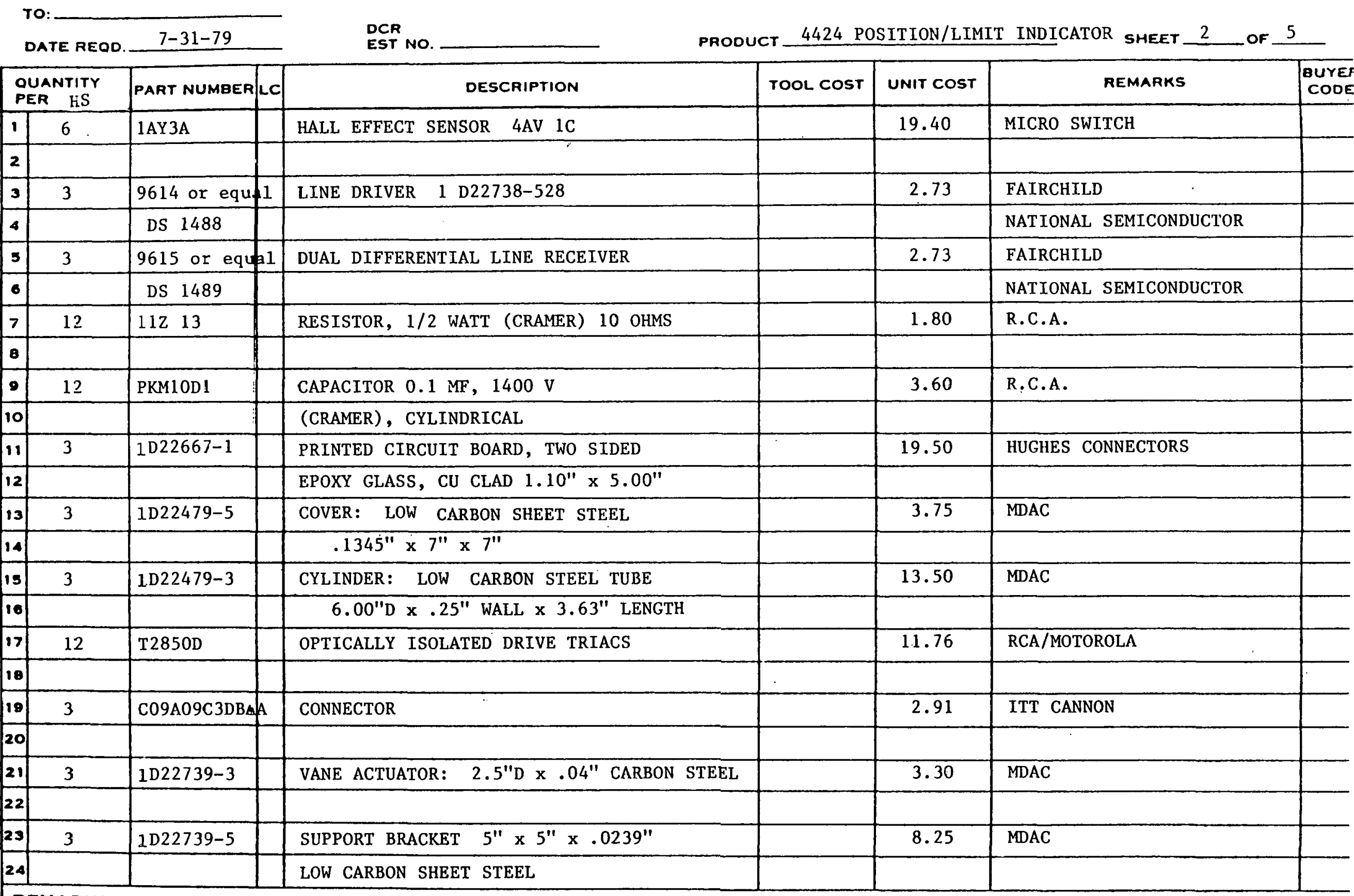

REMARKS: 
MATERIAL PRICE REQUEST - 25,000 ANMUAL VOLUME HELIGSTAT

\begin{tabular}{|c|c|c|c|c|c|c|c|c|}
\hline \multicolumn{3}{|c|}{ DATE REOD. $7-31-79$} & $\begin{array}{l}\text { DCA } \\
\text { EST NO. }\end{array}$ & \multicolumn{3}{|c|}{ PROCUCT 4424 POSITION/LIMIT INDICATOR } & \multicolumn{2}{|c|}{ SHEET 3 OF 5} \\
\hline \multicolumn{2}{|c|}{$\begin{array}{l}\text { OUANTITY } \\
\text { PER HS }\end{array}$} & \multirow{2}{*}{\begin{tabular}{|l|} 
PART NUMBER \\
MS5 $1957-12$ \\
\end{tabular}} & \multicolumn{2}{|l|}{ DESCAIPTION } & \multirow[t]{2}{*}{ TOOL COST } & \multirow{2}{*}{$\frac{\text { UNIT COST }}{.02}$} & \multirow[t]{2}{*}{ REMARKS } & \multirow[t]{2}{*}{$\begin{array}{c}\text { BUYER } \\
\text { CODE } \\
\end{array}$} \\
\hline 1 & 3 & & SCREW & & & & & \\
\hline 2 & $\cdot$ & & & & & & & \\
\hline 3 & 12 & MS5:957-14 & SCREW & & & .08 & & \\
\hline \multicolumn{9}{|c|}{ 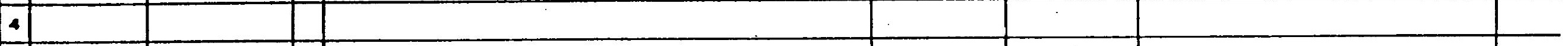 } \\
\hline 5 & 15 & AN960C3 & WASHER & & & .11 & & \\
\hline \multicolumn{9}{|c|}{6} \\
\hline 7 & 15 & NAS671C4 & NUT & & & .17 & & \\
\hline \multicolumn{9}{|c|}{ - } \\
\hline 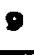 & 6 & NAS $1081 \mathrm{C} 06 \mathrm{~A}$ & SET SCREW & & & .19 & & \\
\hline \multicolumn{9}{|c|}{10} \\
\hline 11 & 9 & MS51958-61 & SCREW & & & .17 & & \\
\hline \multicolumn{9}{|c|}{12} \\
\hline \multicolumn{9}{|c|}{13} \\
\hline \multicolumn{9}{|c|}{14} \\
\hline \multicolumn{9}{|c|}{18} \\
\hline \multicolumn{9}{|c|}{10} \\
\hline \multicolumn{9}{|c|}{17} \\
\hline 10 & & & · & & & & & \\
\hline \multicolumn{9}{|c|}{10} \\
\hline \multicolumn{9}{|c|}{20} \\
\hline \multicolumn{9}{|c|}{21} \\
\hline \multicolumn{9}{|c|}{22} \\
\hline \multicolumn{9}{|c|}{23} \\
\hline \multicolumn{9}{|c|}{24} \\
\hline \multicolumn{9}{|c|}{ REMARKS: } \\
\hline & & & & B14 & & & & \\
\hline
\end{tabular}


MATERIAL PRICE REQUEST - 25,000 ANNUAL VOLUME HELIOSTAT

\begin{tabular}{|c|c|c|c|c|c|c|c|}
\hline \multicolumn{3}{|c|}{ DATE REOD. $7-31-79$} & \multicolumn{5}{|c|}{ PRODUCT 4425 POWER_SUPPLY/DISTRIBUTION } \\
\hline \multicolumn{2}{|c|}{$\begin{array}{l}\text { OUANTITY } \\
\text { PER HS }\end{array}$} & \multirow[t]{2}{*}{ PART NUMBER } & DESCRIPTION & \multirow[t]{2}{*}{ TOOL COST } & \multirow{2}{*}{$\begin{array}{l}\text { UNIT CosT } \\
14.97 \\
\end{array}$} & REMARKS & \multirow[t]{2}{*}{$\begin{array}{l}\text { BUYER } \\
\text { CODE }\end{array}$} \\
\hline 1 & 1 & & JUNCTION BOX $6^{\prime \prime} \times 6^{\prime \prime} \times 3^{\prime \prime}$ & & & . & \\
\hline 2 & & & (DUST AND WATER PROOF) & & & & \\
\hline 3 & 1 & & TERMINAL STRIP & & .65 & & \\
\hline 4 & & & & & & & \\
\hline $\mathbf{s}$ & 1 & & MOUNTING PANEL $5^{\prime \prime} \times 5^{\prime \prime} \times 3 / 16^{\prime \prime}$ & & 2.00 & & \\
\hline 6 & & & & & & & \\
\hline 7 & 4 & ALSJ650 & TERMINATOR & & 19.08 & CROUSE \& HINDS & \\
\hline - & & & & & & & \\
\hline$\bullet$ & 5 & CGFJ 513 & CABLE FITTINGS & & 71.30 & CROUSE \& HINDS & \\
\hline 10 & & & & & & & \\
\hline 11 & 1 & & CIRCUIT BREAKER 3 PHASE 15 AMP. $480 \mathrm{~V}$ & & 33.00 & SQUARE D & \\
\hline 12 & & & & & & & ' \\
\hline 13] & $156^{\prime \prime}$ & $13^{\prime}$ & STANDARD POWER CABLE $(600 \mathrm{~V}) \mathrm{CU}$ & & 1.65 & ALFA WIRE $.126 / F T$ & \\
\hline 14 & & & THREE WIRE CONDUCTOR 20 GAGE & & & & \\
\hline 13) & 312" & $26^{\prime}$ & STANDARD CONTROL CABLE $(600$ V) CU 24 GAGE & & 3.30 & BELDEN WIRE $.126 / F T$ & \\
\hline 16 & & & & & & & \\
\hline 17) & $108^{\prime \prime}$ & $9^{\prime}$ & FIBER OPTIC CABLE & & 2.97 & GRIOT . .33/FT & \\
\hline 10 & & & GALLITE 2000 TYPE $200 \mathrm{P}$ & & & & \\
\hline 18 & 4 & & FIBER OPTIC TERMINATORS & & 6.40 & & \\
\hline 20 & & & . & & & & \\
\hline 21 & 1 & & 25 PIN CONNECTOR, MALE \& FEMALE & & .48 & & \\
\hline 22 & & & & & & & \\
\hline 23 & 3 & & 10 PIN CONNECTOR, MALE \& FEMALE & & 6.75 & & \\
\hline 24 & & & & & & & \\
\hline
\end{tabular}




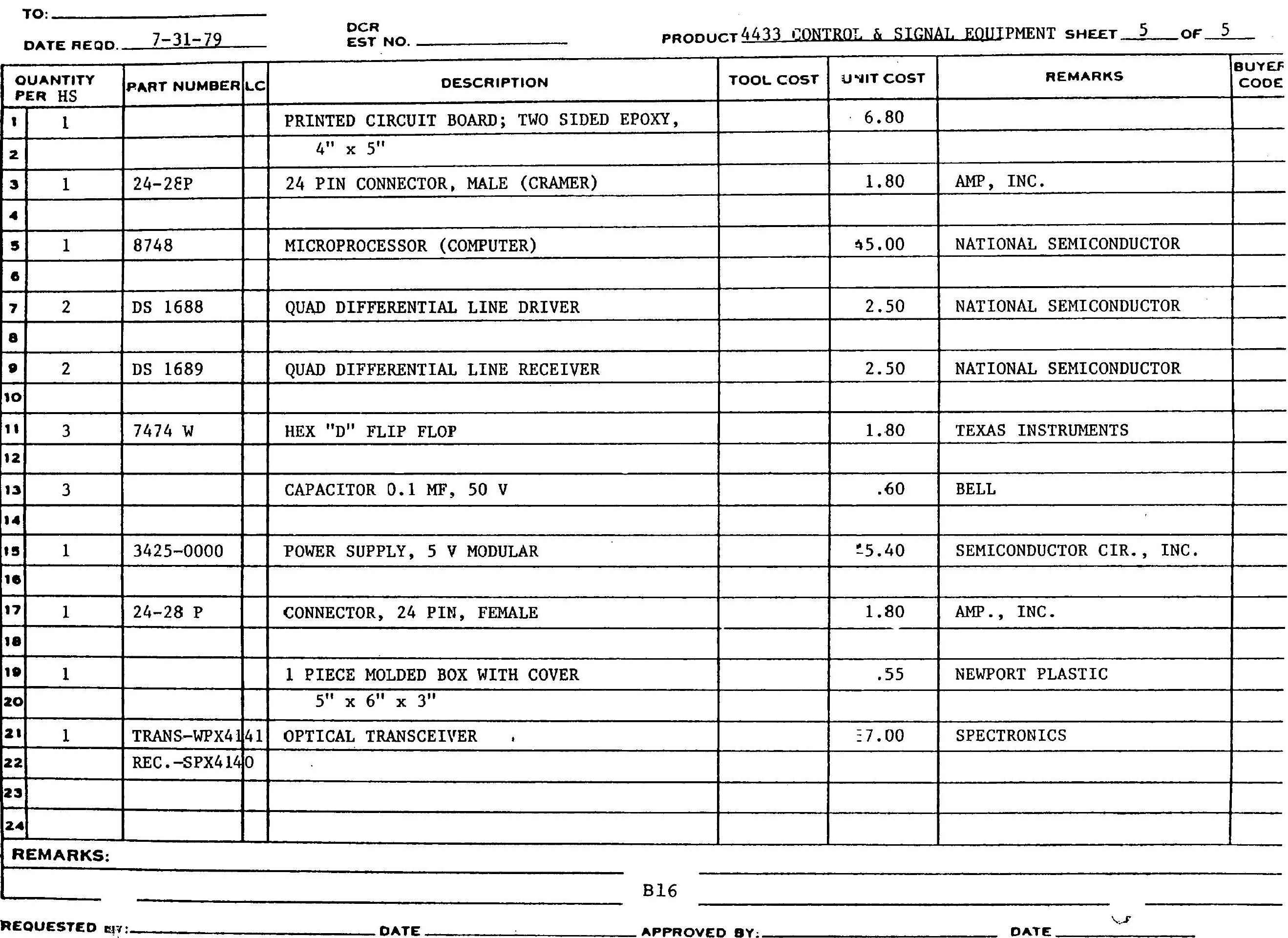


MATERIAL PRICE REQUEST - 25,000 ANNUAL VOLUME HELIOSTAT

\begin{tabular}{|c|c|c|c|c|c|c|c|c|}
\hline \multicolumn{3}{|c|}{ DATE REOD. $7-31-79$} & \multicolumn{2}{|r|}{$\begin{array}{l}\text { DCR } \\
\text { EST NO. }\end{array}$} & \multicolumn{4}{|c|}{ PRODUCT 4451 SUPPORT STRUCTURE } \\
\hline \multicolumn{2}{|c|}{$\begin{array}{l}\text { OUANTITY } \\
\text { PER HS }\end{array}$} & \multirow{2}{*}{\begin{tabular}{|l|} 
PAAT NUMBER \\
$1 D 44046$ \\
\end{tabular}} & \multirow{2}{*}{\begin{tabular}{|c}
$\begin{array}{c}\text { ERD } \\
\text { CODE }\end{array}$ \\
.112 \\
\end{tabular}} & \multirow{2}{*}{$\begin{array}{l}\text { DESCRIPTION } \\
\text { PEDESTAL }\end{array}$} & \multirow{2}{*}{$\frac{\text { TOOL COST }}{7}$} & \multirow{2}{*}{$\frac{\text { UNIT COST }}{260.00}$} & \multirow{2}{*}{ 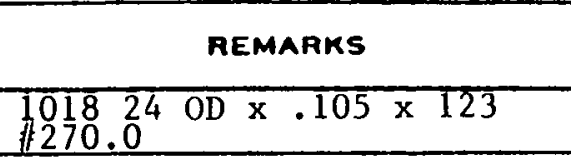 } & \multirow[t]{2}{*}{$\begin{array}{l}\text { BUYES } \\
\text { COOE }\end{array}$} \\
\hline 1 & 1 & & & & & & & \\
\hline 2 & & & & & & & & \\
\hline 3 & 1 & 1022711 & .099 & $\mathrm{CAP}$ & & & $\begin{array}{lllllll}010 & 18 & 23.8 & 00 & \times & 11.00 & 10 \times 25\end{array}$ & \\
\hline 4 & & & & & & & & \\
\hline 5 & 1 & 1D40046-7 & .068 & COVER & & & $1018.03 \times 1$ OD $\# 4$ & \\
\hline 6 & & & & & & & & \\
\hline 7 & 1 & & .175 & TAPERED PIPE & & 98.00 & $\begin{array}{l}101824^{\prime \prime} \mathrm{D} \times 46 \times 7 \mathrm{GA} \\
1175.5\end{array}$ & \\
\hline • & & & & & & & & \\
\hline$\bullet$ & & & & & & & & \\
\hline 10 & & & & & & & & \\
\hline 11 & & & & & & & & \\
\hline 12 & & & & & & & & \\
\hline 13 & & & & & & & & \\
\hline 14 & & & & & & & & \\
\hline 19 & & & & & & & & \\
\hline 10 & & & & & & & & \\
\hline 17 & & & & & & & & \\
\hline 10 & & & & & & & & \\
\hline 10 & & & & & & & & \\
\hline 20 & & & & & & & & \\
\hline 21 & & & & & & & & \\
\hline 22 & & & & & & & & \\
\hline 23 & & & & & & & & \\
\hline 24 & & & & & & & & \\
\hline
\end{tabular}


MATERIAL PRICE REQUEST - 250,000 ANNUAL VOLUME HELIOSTAT

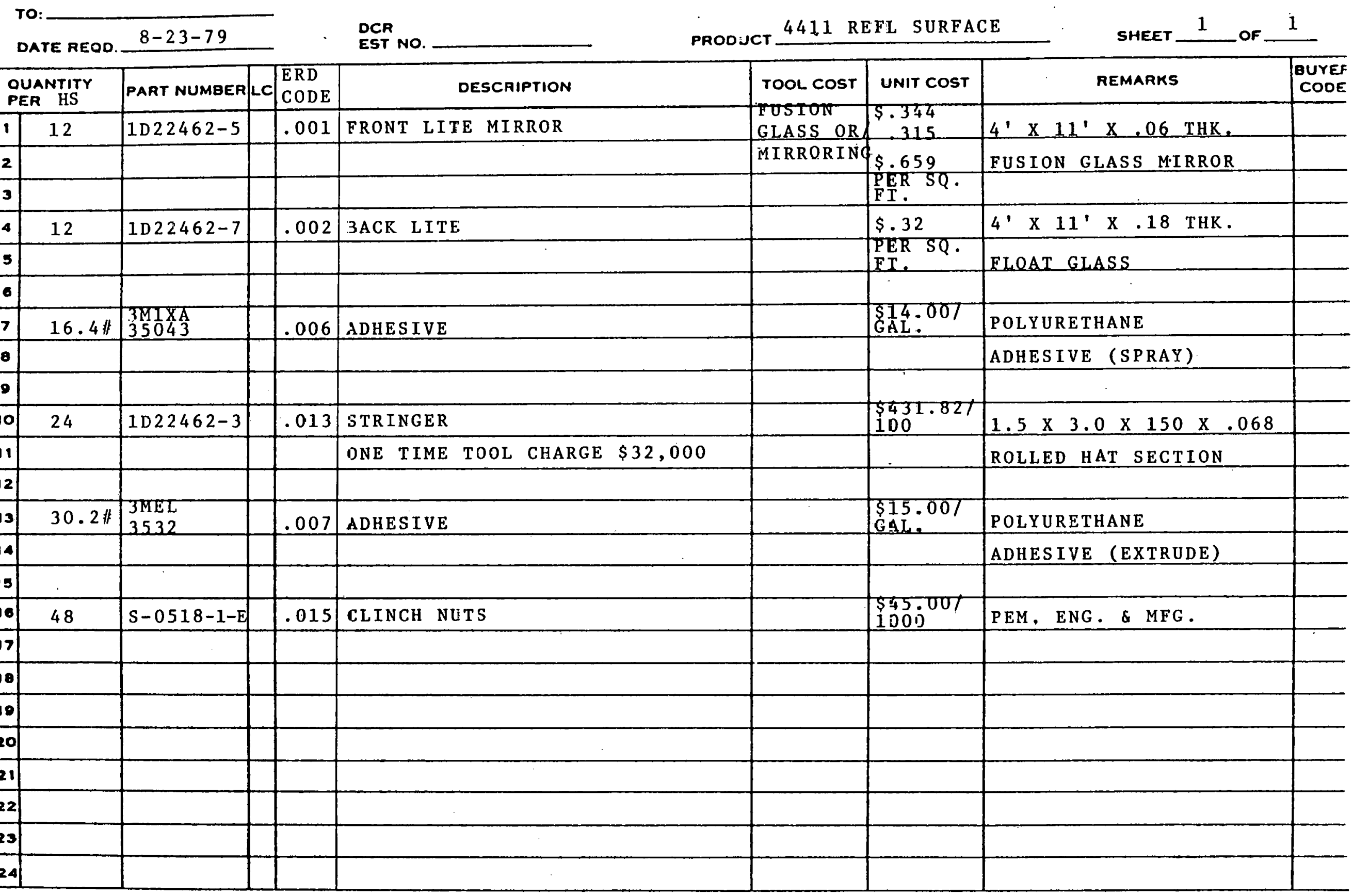

REMARKS: 
MATERIAL PRICE REQUEST - 250,000 ANNUAL VOLUME HEI,IOSTAT

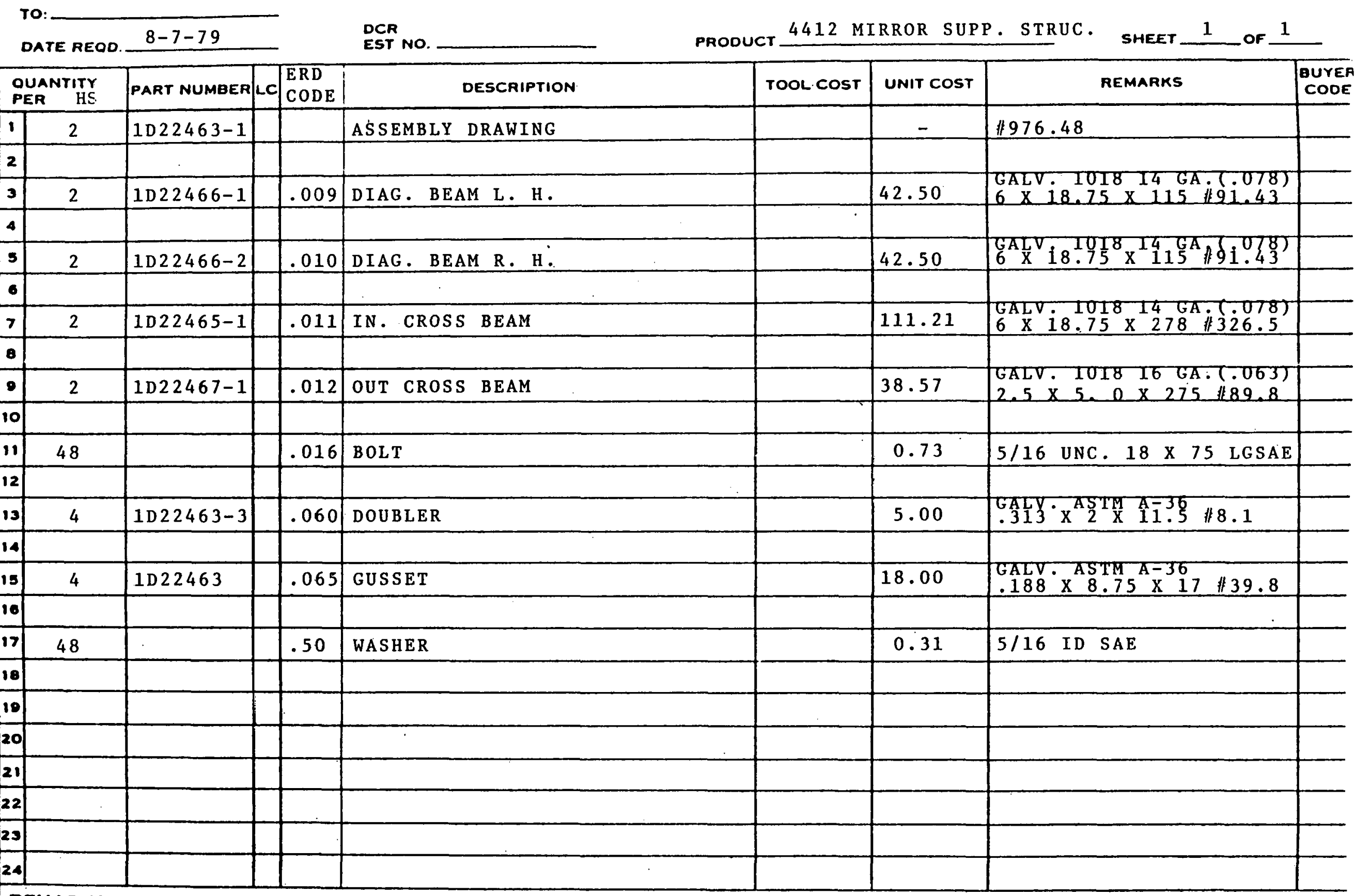

REMARKS: 
MATERIAL PRICE REQUEST - 250,000 ANNUAL VJLUME HELIOSTAT

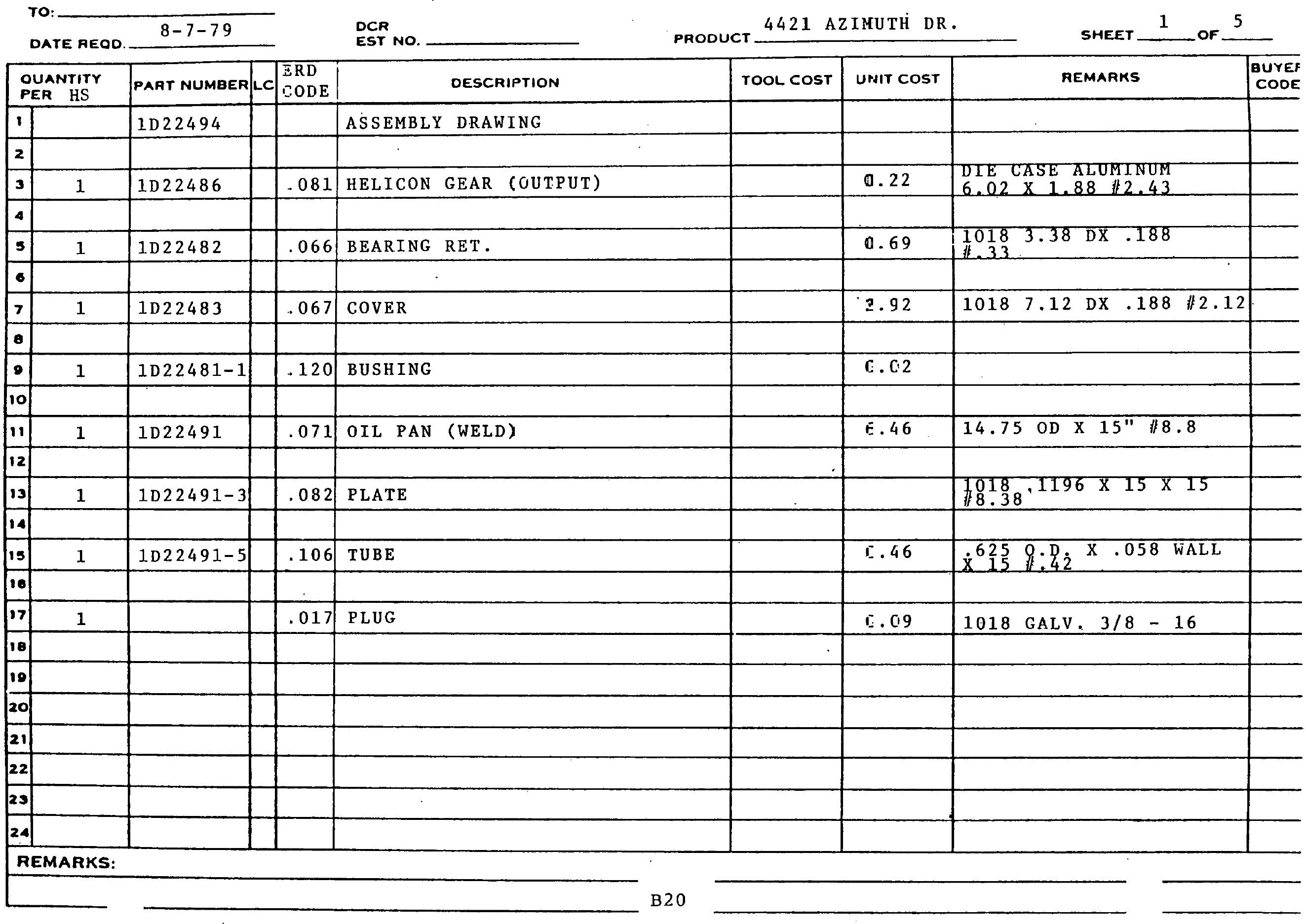


MATERIAL PRICE REQUEST - 250,000 ANNUAL VOLUME HEI.IOSTAT

TO:

$\underset{\text { ECR NO. }}{\text { PCRODUCT } 4421 \text { AZMUTH DR. }} \quad$ SHEET $2 \quad 5$

\begin{tabular}{|c|c|c|c|c|c|c|c|c|}
\hline \multicolumn{2}{|c|}{$\begin{array}{l}\text { OUANTITY } \\
\text { PER HS }\end{array}$} & \multirow{2}{*}{\begin{tabular}{|l} 
PART NUMBER \\
2466 N3987
\end{tabular}} & \multirow{2}{*}{\begin{tabular}{c|c} 
LC & $\begin{array}{l}\text { RD } \\
\text { CODE }\end{array}$ \\
.146
\end{tabular}} & \multirow[t]{2}{*}{ DESCRIPTION } & \multirow{2}{*}{ TOOL COST } & \multirow{2}{*}{$\begin{array}{c}\text { UNIT COST } \\
3.23 \\
\end{array}$} & \multirow[t]{2}{*}{ REMARKS } & \multirow{2}{*}{\begin{tabular}{|l}
$\begin{array}{c}\text { BUYES } \\
\text { CODE }\end{array}$ \\
\end{tabular}} \\
\hline 1 & 1 & & & & & & & \\
\hline \multicolumn{9}{|l|}{2} \\
\hline 3 & 4 & $1 \mathrm{D} 22485$ & .136 & SHIM (GEAR) & & 0.16 & $1.500 . \mathrm{D} . \mathrm{X} 1.125 \mathrm{I} . \mathrm{D}$. & \\
\hline \multicolumn{9}{|l|}{4} \\
\hline 5 & 1 & $N-08$ & .022 & LOCKNUT (WAVE GENERATOR) & & 0.65 & & \\
\hline \multicolumn{9}{|l|}{6} \\
\hline 7 & $\underline{1}$ & $w-08$ & .052 & WASHER (WAVE GENERATOR) & & 0.12 & & \\
\hline \multicolumn{9}{|l|}{$\theta$} \\
\hline 9 & 1 & 2459 N2568 & .145 & PACKING & & 2.77 & & \\
\hline \multicolumn{9}{|l|}{10} \\
\hline 11 & 1 & ALVANIAEP & .140 & GREASE & & 0.37 & 1 PINT (SHELL) & \\
\hline \multicolumn{9}{|l|}{12} \\
\hline 13 & $\mathbb{1}$ & $10 \mathrm{~W} 40$ & .141 & OIL & & 1.01 & (SHELL) & \\
\hline \multicolumn{9}{|l|}{14} \\
\hline is & 1 & $M F-075$ & .023 & PULL COR ELBOW & & 1.44 & & \\
\hline \multicolumn{9}{|l|}{10} \\
\hline 17 & 8 & $1 / 4-20 \times .6$ & .024 & SCREW-FLT. HD. & & 0.045 & & \\
\hline \multicolumn{9}{|l|}{18} \\
\hline 10 & 8 & $\# 8-32 \times .56$ & .025 & BOLT L' WASHER & & 0.047 & & \\
\hline \multicolumn{9}{|l|}{20} \\
\hline 21 & 4 & $\# 10-24 x .6$ & .026 & BOLT $L^{\prime}$ WASHER & & 0.019 & & \\
\hline \multicolumn{9}{|l|}{22} \\
\hline 23 & 1.6 & $3 / 8-16-2$ & .027 & BOLT $\mathrm{L}^{\prime}$ WASHER & & 0.725 & & \\
\hline 24 & 8 & $5 / 8-11 \times 4$ & .028 & BOLT L' WASHER & & 2.38 & & \\
\hline
\end{tabular}


MATERIAL PRICE REQUEST - 250,000 ANNUA VOLUME HEI.IOSTAT

\begin{tabular}{|c|c|c|c|c|c|c|c|c|c|}
\hline \multicolumn{3}{|c|}{ DATE REOD. $8-7-79$} & \multicolumn{2}{|r|}{$\begin{array}{l}\text { DCR } \\
\text { EST NO. }\end{array}$} & \multicolumn{3}{|c|}{ PRODUCT 4421 AZIMUTH DR. } & \multicolumn{2}{|c|}{ SHEET 3 OF 5} \\
\hline \multicolumn{2}{|c|}{$\begin{array}{l}\text { OUANTITY } \\
\text { PER HS } \\
\end{array}$} & PART NUMBER & \begin{tabular}{ll|} 
CRD \\
CODE
\end{tabular} & DESCRIPTION & & TOOL COST & UNIT COST & REMARKS & $\begin{array}{l}\text { BUYEF } \\
\text { CODE }\end{array}$ \\
\hline 1 & & & & . & & & & & \\
\hline \multicolumn{10}{|l|}{2} \\
\hline 3 & 1 & & .061 & KEY & & & 0.02 & $3 / 8 \mathrm{SQ} . \times 3 / 4 \mathrm{LG}$. & \\
\hline \multicolumn{10}{|c|}{$750=1700$} \\
\hline 5 & 1 & & .130 & WAVE GEY, BEAR & & & 70.70 & $\begin{array}{l}9.5 \text { OD X } 7.250 \\
1.5 \text { L. }\end{array}$ & \\
\hline \multicolumn{10}{|c|}{ 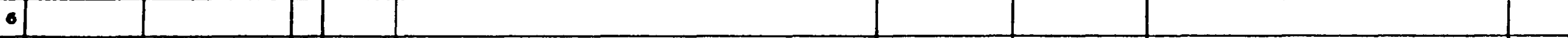 } \\
\hline 7 & 1 & & .62 & KEY (GEFR) & & & .008 & $3 / 16$ SQ. X $11 / 8^{\prime} \mathrm{LG}$. & \\
\hline \multicolumn{10}{|l|}{ - } \\
\hline 9 & 1 & $\mathrm{~N}-06$ & .018 & $\mathrm{NUT}$ (GEAR) & & & 0.44 & . & \\
\hline \multicolumn{10}{|c|}{10} \\
\hline 11 & 1 & $\mathrm{~N}-06$ & .051 & WASHER (GEAR) & & & 0,10 & & \\
\hline \multicolumn{10}{|l|}{12} \\
\hline 13 & 1 & $\mathrm{BL}-75$ & .019 & LOCKNUT & & & 0.0 .6 & & \\
\hline \multicolumn{10}{|c|}{14} \\
\hline 15 & 12 & $\mathrm{HL}-20-30$ & .020 & BOLTS ( & & & 31.80 & $5 / 8$ NOM & \\
\hline \multicolumn{10}{|l|}{10} \\
\hline 27 & 12 & $\mathrm{HL}-86-20$ & .021 & NUTS (SFEC.) & & & 21.57 & $5 / 8$ NOM & \\
\hline \multicolumn{10}{|c|}{18} \\
\hline 10 & 1 & $1 \mathrm{D}-22499$ & & HARMONIC DRIVE ASSEMBLY & & & & & \\
\hline \multicolumn{10}{|c|}{20} \\
\hline 21) & 1 & $106 \times 5 \mathrm{ZZ}$ & .131 & BEARING (DRIVE SHAFT) & & & 3.31 & & \\
\hline \multicolumn{10}{|c|}{22} \\
\hline 23) & 1 & $1 D-22490$ & .132 & BEARING KIT & & & 20.78 & & \\
\hline 24 & & $\dot{.}$ & & & & & & & \\
\hline \multicolumn{10}{|c|}{ REMARKS: } \\
\hline & & & & & B22 & & & & \\
\hline
\end{tabular}


MATERIAL PRICE REQUEST - 250,000 ANNUAL VOLUME HELIOSTAT

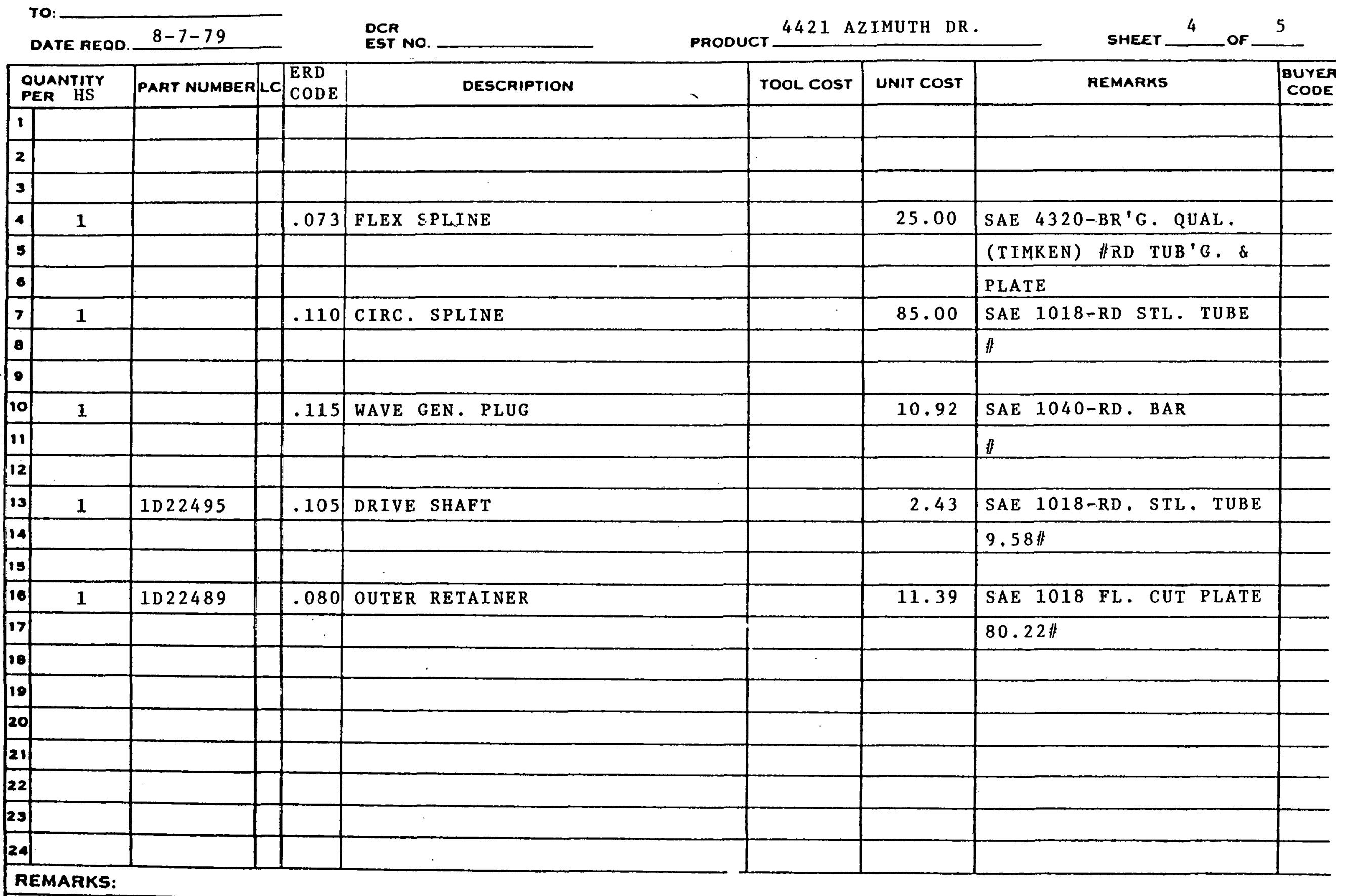


MATERIAL PRICE REQUEST - 250,000 ANNUAL VOLUME HELIOSTAT

\begin{tabular}{|c|c|c|c|c|c|c|c|c|c|}
\hline s & DATE REOD & $8-7-79$ & & $\begin{array}{l}\text { DCR } \\
\text { EST NO. }\end{array}$ & & CT $4421 \mathrm{~A}$ & IMUTH DR & 5 of & 5 \\
\hline & $\begin{array}{l}\text { UANTITY } \\
\text { ER HS }\end{array}$ & PART NUMBER & \begin{tabular}{l|l} 
ERD \\
CODE
\end{tabular} & DESCRIPTION & & TOOL COST & IJNIT COST & REMARKS & $\begin{array}{l}\text { BUYE } \\
\text { CODI }\end{array}$ \\
\hline 1 & 1 & $1 \mathrm{D} 22493$ & .072 & HOUSING (WELD) & & & & & \\
\hline 2 & & & & & & & & & \\
\hline 3 & 1 & $1 \mathrm{D} 22493-3$ & .083 & RETAINER & & & 60.00 & $19.50 \times 1.62 \quad 1018 \quad 42$ 非 & \\
\hline 4 & & & & & & & & & \\
\hline $\mathbf{s}$ & 1 & $1 \mathrm{D} 22493-5$ & .107 & TUBE & & & 33.00 & $1018 \quad 17 \mathrm{D} \times 5.82 \quad 36.48$ 非 & \\
\hline 6 & & & & & & & & & \\
\hline 7 & 1 & 1D22493-7 & .084 & PLATE & & & 18.06 & $101817 \mathrm{D} \times .5030 .8 \#$ & \\
\hline $\mathbf{8}$ & & & & & & & & & \\
\hline 9 & 1 & $1 D 22493-9$ & .108 & TUBE & & & 4.00 & $10183.38 \mathrm{D} \times 2.5 \quad 5.97 \#$ & \\
\hline 10 & & & & & & & & & \\
\hline 11 & 1 & 1D22493-2p & .109 & TUBE & & & 9.00 & $10187 \mathrm{D} \mathrm{X} \mathrm{4.50} \mathrm{10.3 \#}$ & \\
\hline 12 & & & & & & & & & \\
\hline 13 & 2 & $1 D 22493-1 \beta$ & .085 & LUG & & & 37.35 & $101823 \times 8 \times 1.3888$ \# & \\
\hline 14 & & & & & & & & & \\
\hline 15 & 1 & 1D 22495-11 & .113 & TUBE & & & 0.55 & $2.7 \#$ & \\
\hline 16 & & & & & & & & & \\
\hline 17 & 1 & $1 D 22493-1$ & .086 & LUG & & & 6.64 & $101899 \times 7 \times 1.38 \quad 9.7$ 非 & \\
\hline 18 & & & & & & & & & \\
\hline 19 & 1 & $1 \mathrm{D} 22493-1$ & .087 & LUG & & & 6.64 & $1018 \quad 9 \times 7 \quad 7 \times 1.38 \quad 9.7$ 非 & \\
\hline 20 & & & & & & & & & \\
\hline 21 & 1 & $1 \mathrm{D} 22493-2$ & .088 & MOUNT & & & 1.25 & $10185.5 \times 5.5 \times .38 \quad 2.7$ & \\
\hline 22 & & & & & & & & & \\
\hline 23 & 1 & $1022493-21$ & .089 & WE B & & & 9.13 & $101817 \times 8.5 \times .517 .3 \#$ & \\
\hline 24 & 1 & $1022497-21$ & .090 & PLATE & & & 4.00 & $10186.50, D . X .5 \quad 5.3 \#$ & \\
\hline $\mathbf{R}$ & EMARKS: & & & & & & & & \\
\hline & & & & & B24 & & & & \\
\hline
\end{tabular}


MATERIAL PRICE REQUEST - 250,000 ANNUAL VOLUME HELIOSTAT

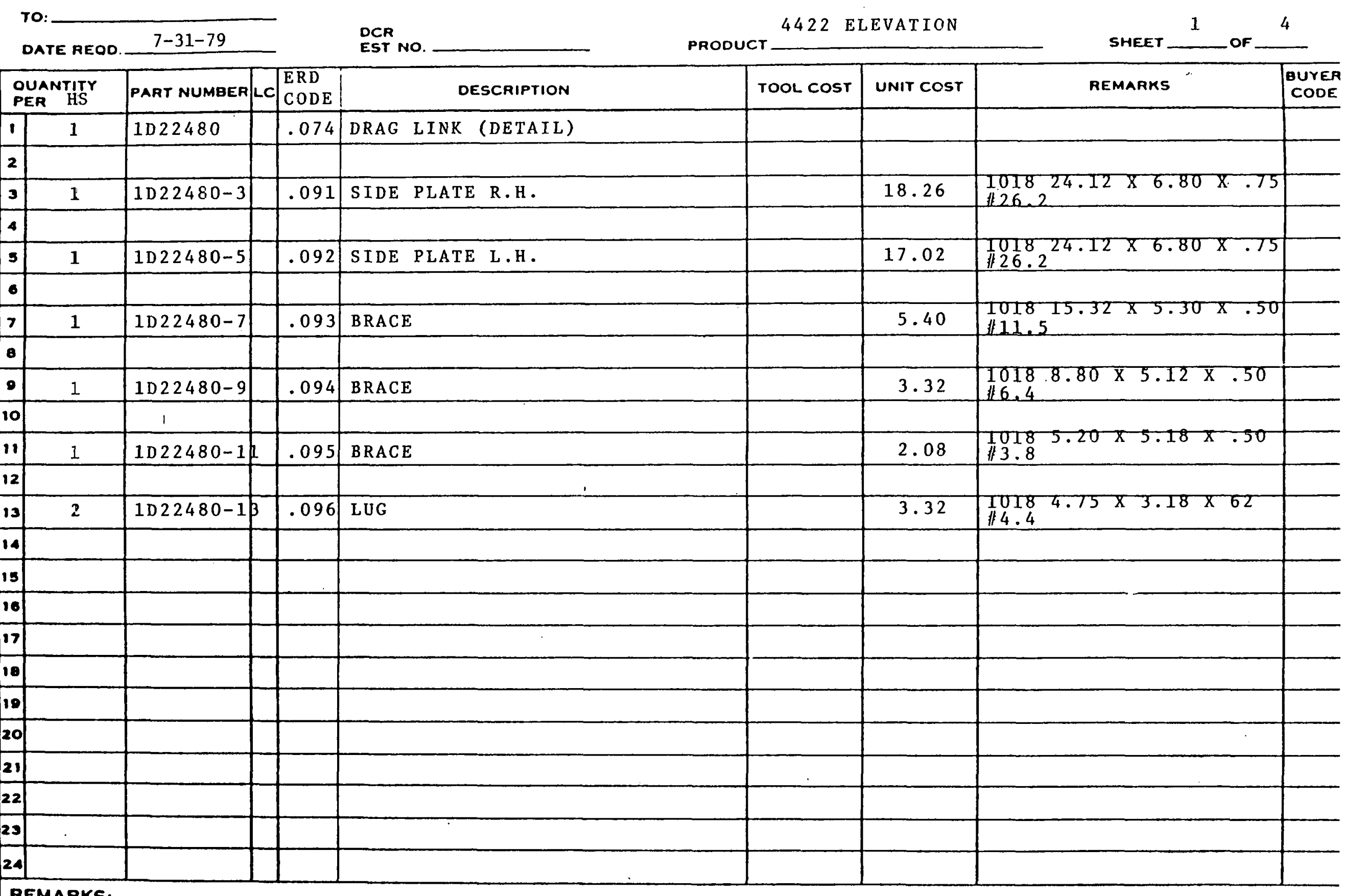

REMARKS: 
MATERIAL PRECE REQUEST - 250,000 ANNUAL VOLUME HELIOSTAT

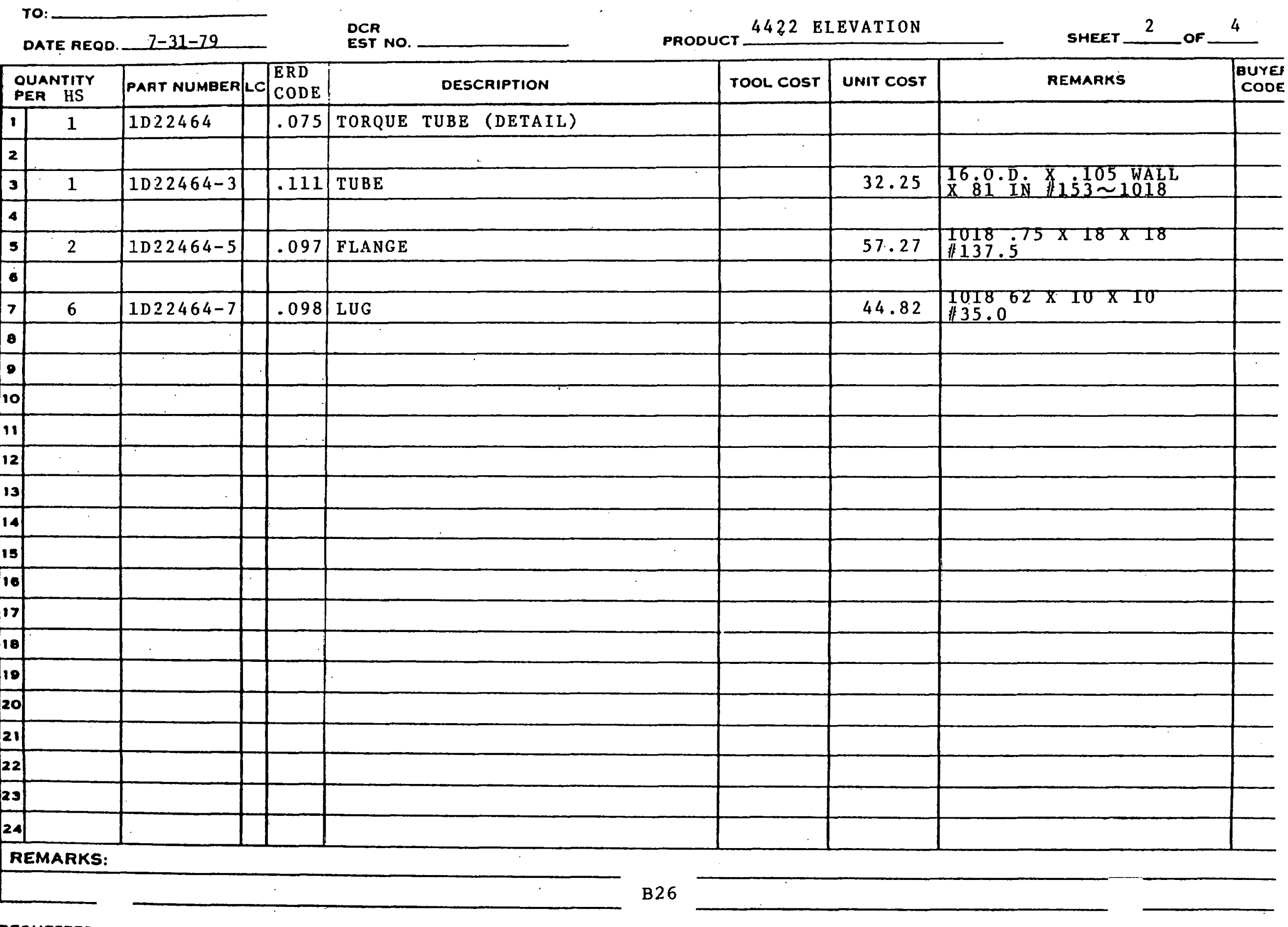

REOUESTED BY: 
MATERIAL PRICE REQUEST - 250,000 ANNUAL VOLUME HELIOSTAT

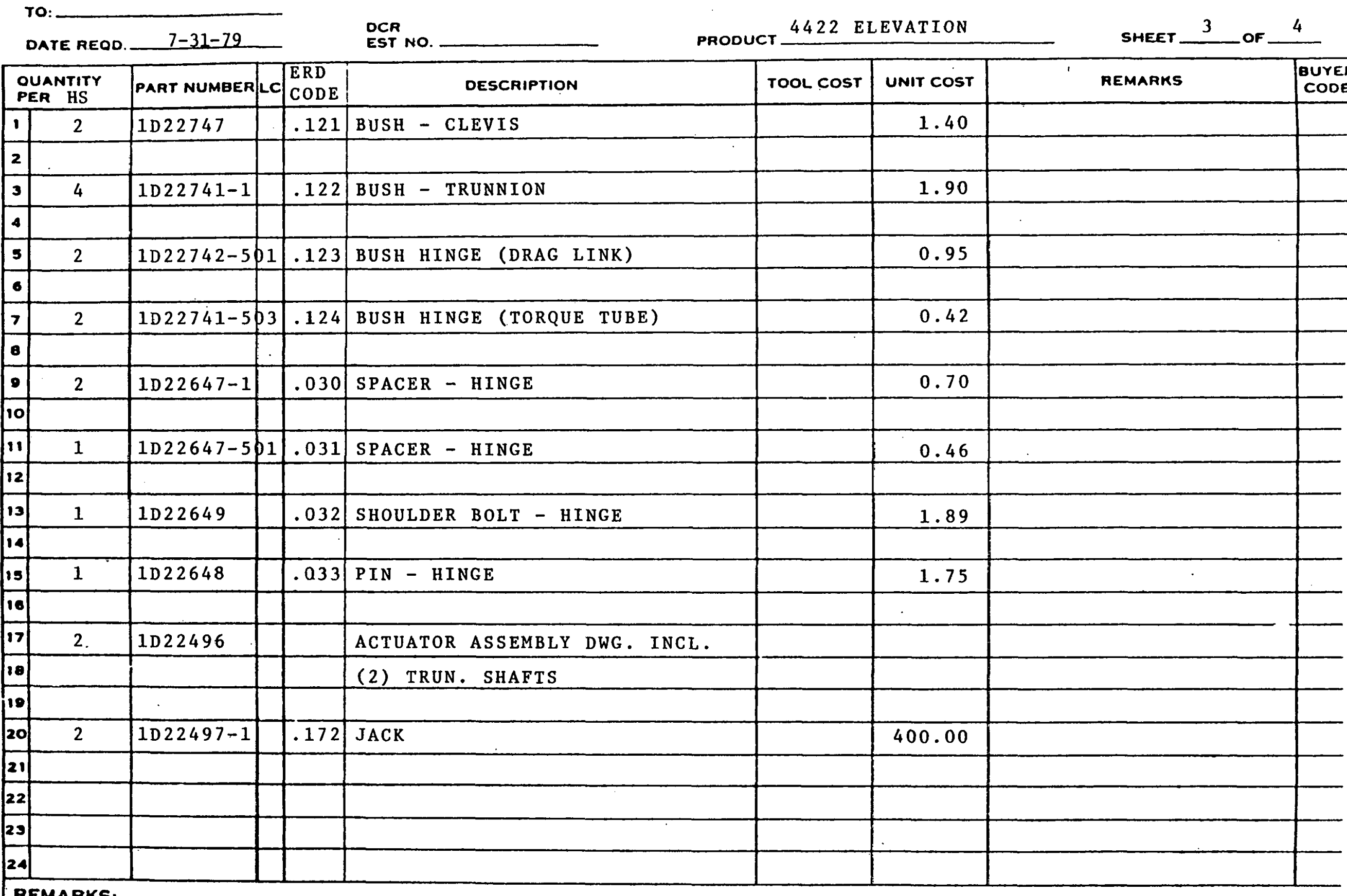


MATERIAL PRICE REQUEST - 250,000 ANNUAL VOLUME HELIOSTAT

\begin{tabular}{|c|c|c|c|c|c|c|c|c|c|c|}
\hline \multicolumn{4}{|c|}{ DATE REOD. $7-31-72$} & \multicolumn{2}{|r|}{$\begin{array}{l}\text { OCR } \\
\text { EST NO. }\end{array}$} & \multicolumn{3}{|c|}{ PRODUCT 4422 ELEVATION } & \multicolumn{2}{|c|}{ SHEET 4 OF 4} \\
\hline \multicolumn{2}{|c|}{$\begin{array}{l}\text { OUANTITY } \\
\text { PER HS }\end{array}$} & \multirow{2}{*}{\begin{tabular}{|l} 
PART NUMBER \\
1D $22749-5$
\end{tabular}} & \multirow{2}{*}{\begin{tabular}{|l|}
$C$ \\
1
\end{tabular}} & \multirow{2}{*}{\begin{tabular}{|l|} 
ERD \\
CODE \\
.133 \\
\end{tabular}} & \multicolumn{2}{|l|}{ DESCRIPTION } & \multirow[t]{2}{*}{ TOOL COST } & \multirow{2}{*}{$\frac{\text { UNIT Cost }}{0.40}$} & \multirow[t]{2}{*}{ REMARKS } & \multirow[t]{2}{*}{$\begin{array}{l}\text { BUYER } \\
\text { COOE }\end{array}$} \\
\hline $\mathbf{1}$ & 4 & & & & THRUST BEAR - CLEVIS & & & & & \\
\hline \multicolumn{11}{|c|}{2} \\
\hline 3 & 4 & $1 \mathrm{D} 22727-5 p$ & 1 & .137 & SHIM - CLEVIS & & & 0.69 & & \\
\hline \multicolumn{11}{|l|}{4} \\
\hline s & 2 & $1 D 22735-5 p$ & 1 & .029 & PIN - CLEVIS & & & 2.49 & & \\
\hline \multicolumn{11}{|c|}{6} \\
\hline 7 & 4 & $1 \mathrm{D} 22727-1$ & & .138 & SHIM - TRUNNION & & & 0.20 & & \\
\hline \multicolumn{11}{|c|}{8} \\
\hline 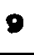 & 4 & $1022749-1$ & & .134 & THRUST BRG. - TRUNNION & & & 0.693 & & \\
\hline \multicolumn{11}{|c|}{10} \\
\hline \multicolumn{11}{|c|}{11} \\
\hline \multicolumn{11}{|c|}{12} \\
\hline \multicolumn{11}{|c|}{13} \\
\hline \multicolumn{11}{|c|}{14} \\
\hline \multicolumn{11}{|c|}{15} \\
\hline \multicolumn{11}{|c|}{16} \\
\hline \multicolumn{11}{|c|}{17} \\
\hline \multicolumn{11}{|c|}{10} \\
\hline \multicolumn{11}{|c|}{10} \\
\hline \multicolumn{11}{|c|}{20} \\
\hline \multicolumn{11}{|c|}{21} \\
\hline \multicolumn{11}{|c|}{22} \\
\hline 23 & & & & & & & & & & \\
\hline 24 & & & & & & & & & & \\
\hline & & & & & & & & & & \\
\hline & . & & & & & B28 & & & & \\
\hline
\end{tabular}


MATERIAL PRICE REQUEST - 250,000 ANNUAL VOLUME HEI,IOSTAT

To:

DATE REOO. 11-26-79

\begin{tabular}{|l|l|l|l|}
\hline $\begin{array}{l}\text { OUANTITY } \\
\text { PER HS }\end{array}$ & PART NUMBER & LC & $\begin{array}{l}\text { ERD } \\
\text { CODE }\end{array}$ \\
\hline
\end{tabular}

DCR

EST NO.

PER HS

\begin{tabular}{l|l|}
\hline & 1 \\
\hline 2 &
\end{tabular}

3

\begin{tabular}{|l|l|}
\hline 5 & 1 \\
\hline
\end{tabular}

(6)

\begin{tabular}{l}
\hline \\
\hline 8 \\
\hline
\end{tabular}

9

10

11

12

13

14

15

10

17

18

10

20

21

\begin{tabular}{|l|}
22 \\
23 \\
24
\end{tabular}

REMARKS:

\begin{tabular}{|l|l|l|}
\hline $1 D 44046$ & .112 & PEDESTAL \\
\hline
\end{tabular}

1022711

1

$1040046-7$

\begin{tabular}{l|l|l|l}
\hline 1. & & .175 & TAPERED PIPE \\
\hline
\end{tabular}

DESCRIPTION

\begin{tabular}{|l|l|l|}
\hline & .099 & CAP \\
\hline & & \\
\hline
\end{tabular}

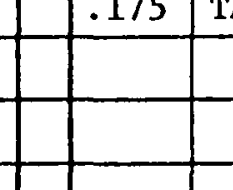

REMARKS:
PROOUCT 4451 HELIOSTAT SUPP. STRUCT. SHEET 1 OF 1

\begin{tabular}{|c|c|c|c|}
\hline TOOL COST & UNIT COST & REMARKS & $\begin{array}{l}\text { DUYER } \\
\text { COOE }\end{array}$ \\
\hline & 60.34 & $\begin{array}{l}101824 \text { OD } \times .105 \times 123 \\
3270.0\end{array}$ & . \\
\hline & 46.87 & $\begin{array}{l}101823.8 \text { OD } \times 11.010 \times 25 \\
1 \$ 75\end{array}$ & \\
\hline & 1.20 & $1018.03 \times 10 D \# 4$ & \\
\hline & 39.22 & $\begin{array}{l}101824^{4} \text { D } \times 46 \times 7 G A \\
135.5\end{array}$ & \\
\hline & . & & \\
\hline & & & \\
\hline & & & \\
\hline & & & \\
\hline & & & \\
\hline & & & \\
\hline & & & \\
\hline & & & \\
\hline & & & \\
\hline & & & \\
\hline & & & \\
\hline & & & \\
\hline & & & \\
\hline & & & \\
\hline & & & \\
\hline & & & \\
\hline & & & \\
\hline
\end{tabular}


MATERIAL PRICE REQUEST - 250,000 ANNUAL VOLUME HELIOSTAT

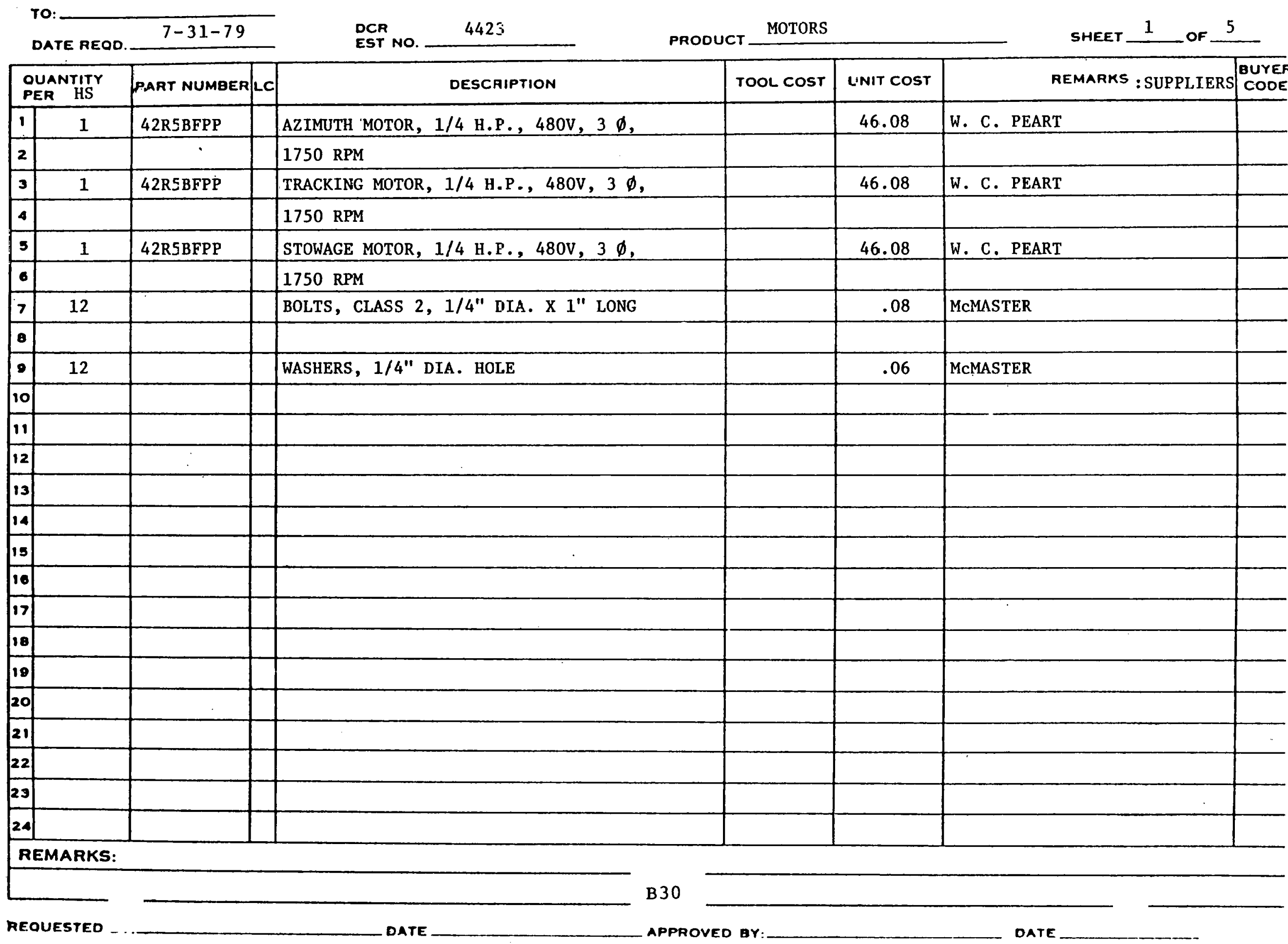


MATERIAL PRICE REQUEST - 250,000 ANNUAL VOLUME HELIOSTAT

$$
\text { TO: }
$$

DATE REOD. 7-31-79

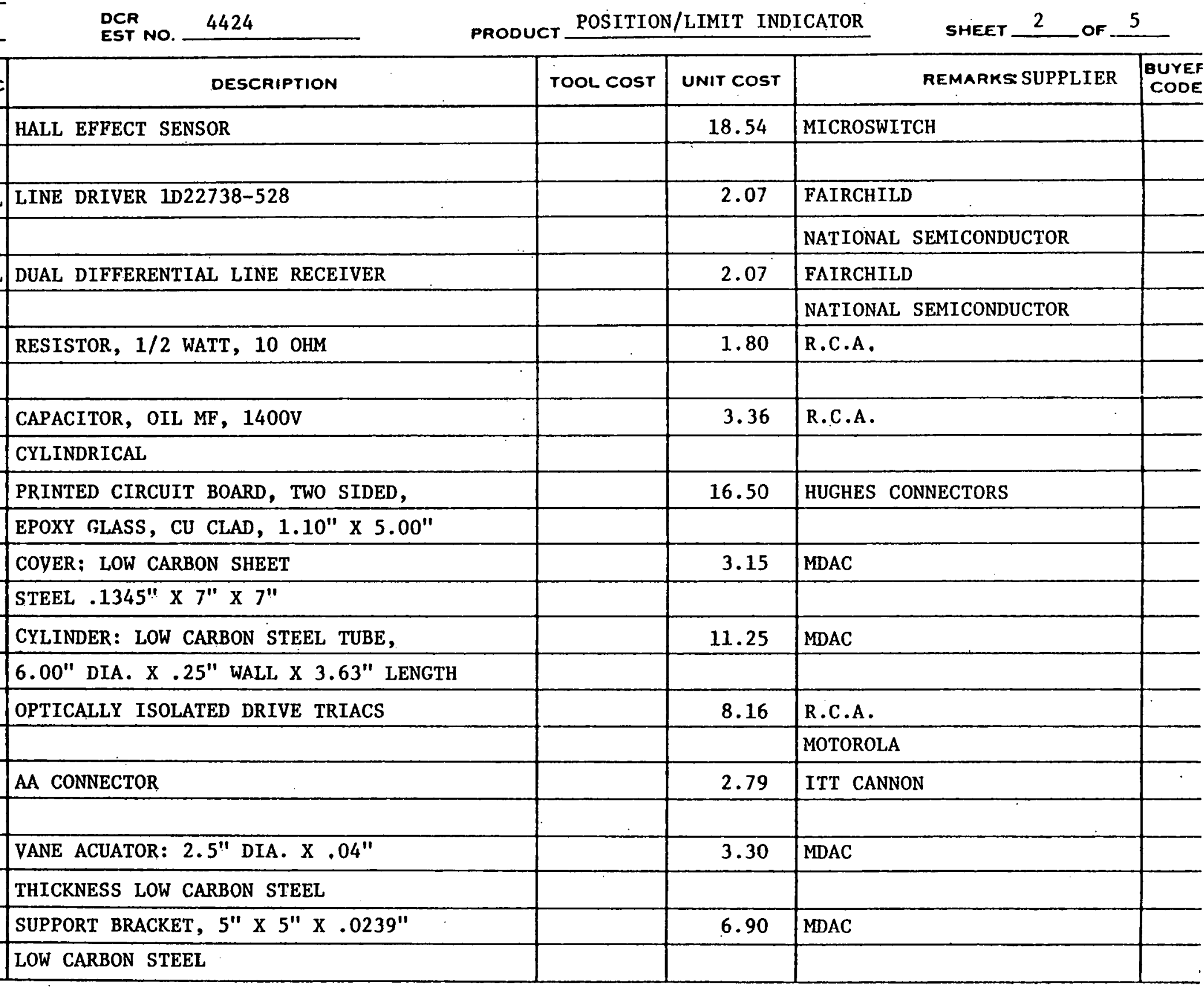

\section{REMARKS:}


MATERIAL PRICE REQUEST - 250,000 ANNUAL VOLUME HELIOSTAT

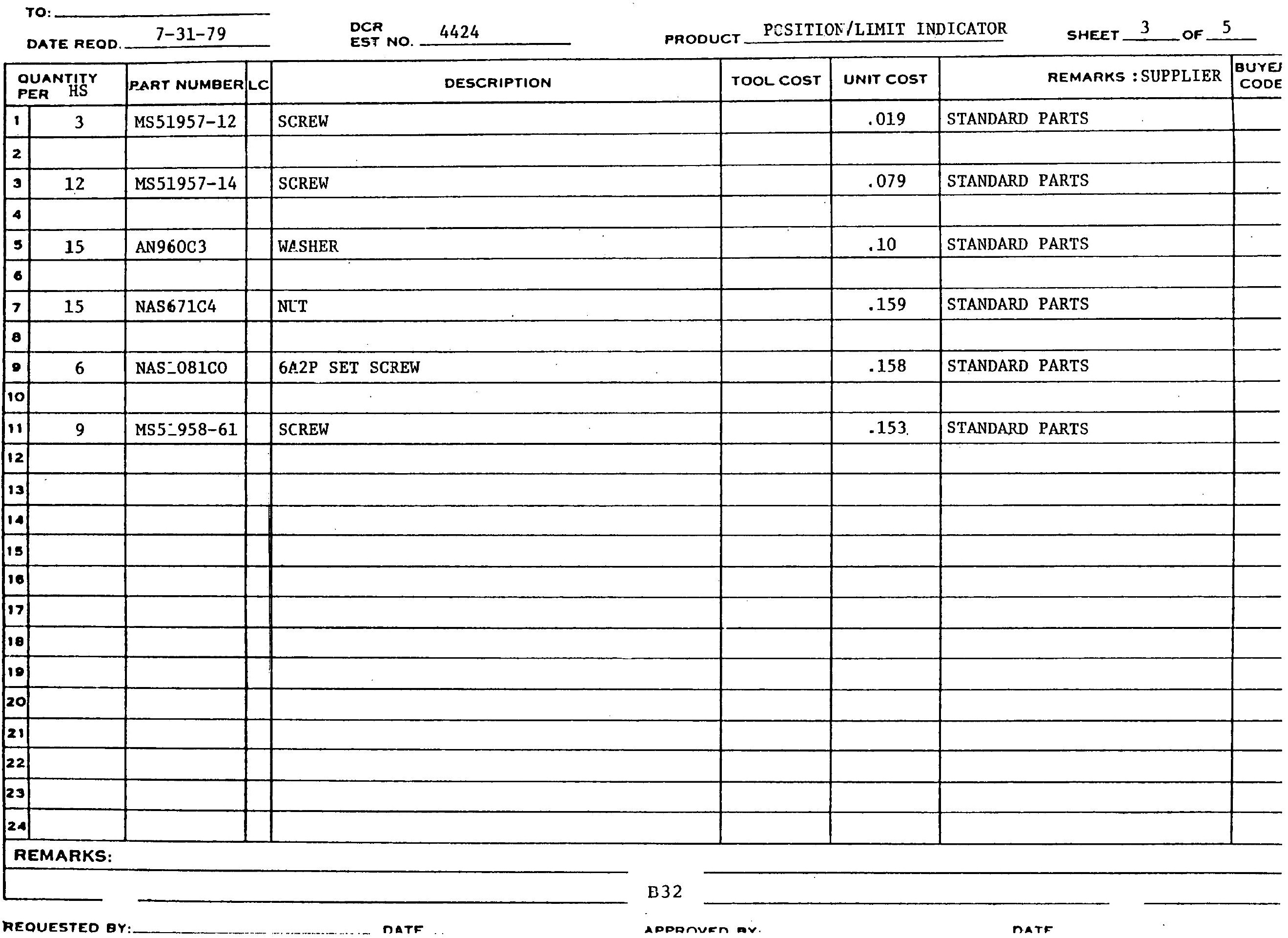


MATERIAL PRICE REQUEST - 250,000 ANNUAL VOLUME HELIOSTAT

TO:

OUANTITY

PER HS

\begin{tabular}{|c|c|c|c|}
\hline & PART NUMBER & LC \\
\hline 1 & 1 &
\end{tabular}$$
\begin{array}{|l|l|}
\hline 7 & 4 \\
\hline
\end{array}
$$$$
10
$$$$
\begin{array}{|l|l|}
\hline 10 & \\
\hline 11 & 1 \\
\hline
\end{array}
$$

\begin{tabular}{|c|c|c|}
\hline 13 & $156^{\prime \prime}$ & \\
\hline 14 & & \\
\hline 15 & $312^{\prime \prime}$ & \\
\hline
\end{tabular}

\begin{tabular}{|c|c|}
\hline 16 & $312^{\prime \prime}$ \\
\hline 17 & $108^{\prime \prime}$ \\
\hline 18 & \\
\hline 19 & 4 \\
\hline 20 & \\
\hline 21 & 1 \\
\hline 22 & \\
\hline 23 & 3 \\
\hline 24 & \\
\hline
\end{tabular}

REMARKS:

DCR $\quad 4425$

PRODUCT POWER SUPPLY/DISTRIBUTION

SHEET 4 OF 5

\begin{tabular}{|c|c|c|c|c|}
\hline DESCRIPTION & TOOL COST & UNIT COST & REMARKS : SUPPLIER & $\begin{array}{l}\text { BUYER } \\
\text { CODE }\end{array}$ \\
\hline JUNCTION BOX $6^{\prime \prime} \times 6^{\prime \prime} \times 3^{\prime \prime}$ & & 14.14 & & \\
\hline \multicolumn{5}{|l|}{ (DUST \& WATER PROOF) } \\
\hline TERMINAL STRIP & & .38 & & \\
\hline MOUNTING PANEL $5^{\prime \prime} \times 5^{\prime \prime} \times 3 / 16^{\prime \prime}$ & & 2.00 & & \\
\hline TERMINATOR & & 19.08 & CROUSE \& HINDS & \\
\hline CABLE FITINGS & & 71.30 & CROUSTE \& HINDS & \\
\hline CIRCUIT BREAKER, $3 \emptyset, 15$ AMP, $480 \mathrm{~V}$ & & 28.00 & SQUARE D & \\
\hline STANDARD POWER CABLE(600V), COPPER THREE & & 1.65 & ALFA WIRE . 126/FT, & \\
\hline \multicolumn{5}{|l|}{ WIRE CONDUCTOR, 20 GAGE } \\
\hline STANDARD CONTROL CABLE (600V), COPPER & & 3.30 & BELDEN WIRE . 126/FT. & \\
\hline \multicolumn{5}{|l|}{24 GAGE } \\
\hline FIBER OPTIC CABLE, GALLITE 2000 TYPE & & 2.97 & GRIOT & \\
\hline \multicolumn{5}{|l|}{$200 \mathrm{P} ; 2$ ONE MM } \\
\hline FIBER OPTIC TERMINATORS & & 5.80 & & \\
\hline 25 PIN CONNECTOR: MALE AND FEMALE & & .47 & & \\
\hline 10 PIN CONNECTOR: MALE AND FEMALE & & 6.45 & & \\
\hline & & & & \\
\hline
\end{tabular}


MATERIAL PRICE REQLEST - 250,000 ANNUAL VOLUME HELIOSTAT

\begin{tabular}{|c|c|c|c|c|c|c|c|c|}
\hline \multicolumn{4}{|c|}{ DATE REOD. $7-31-79$} & \multirow[b]{2}{*}{ DESCPIPTION } & CT CONTROL & $\because$ SIGNAL E & \multicolumn{2}{|l|}{ SHEET 5 OF 5} \\
\hline \multicolumn{2}{|c|}{$\begin{array}{l}\text { OUANTITY } \\
\text { PER HS }\end{array}$} & \multirow[t]{2}{*}{ PART NUMBEF } & \multirow[t]{2}{*}{ LCC } & & \multirow[t]{2}{*}{ TOOL COST } & \multirow{2}{*}{$\begin{array}{c}\text { UNIT COST } \\
5.60 \\
\end{array}$} & \multirow[t]{2}{*}{ REMARKS : SUPPLIER } & \multirow[t]{2}{*}{$\begin{array}{l}\text { BUYEF } \\
\text { CODE }\end{array}$} \\
\hline 1 & 1 & & & PRINTED CIRCUIT BOARD: TWO SIDED EPOXY, & & & & \\
\hline 2 & & & & $4^{\prime \prime} \times 5^{\prime \prime}$ & & & & \\
\hline 3 & 1 & $24-28 P$ & & 24 PIN CONNECTOR, MALE & & 1.65 & AMP, INC. & \\
\hline \multicolumn{9}{|l|}{4} \\
\hline 5 & 1 & 8748 & & MICROPROCESSOR & & 42.00 & NATIONAL SEMICONDUCTOR & \\
\hline \multicolumn{9}{|l|}{6} \\
\hline 7 & 2 & DS1688 & & QUAD. DIFFERENTIAL LINE DRIVER & & 2.40 & NATIONAL SEMICONDUCTOR & \\
\hline \multicolumn{9}{|l|}{8} \\
\hline 9 & 2 & DS1689 & & QUAD. DIFFERENTIAL LIWE RECEIVER & & 2.40 & NATIONAL SEMICONDUCTOR & \\
\hline \multicolumn{9}{|l|}{10} \\
\hline 11 & 3 & $7474 \mathrm{~W}$ & & HEX "D" FLIP FLOP & & 1.62 & TEXAS INSTRUMENT & \\
\hline \multicolumn{9}{|l|}{12} \\
\hline 13 & 3 & & & CAPACITOR, $0.1 \mathrm{MF}, 50 \mathrm{~V}$ & & .57 & BELL & \\
\hline \multicolumn{9}{|l|}{14} \\
\hline 15 & 1 & $3425-0000$ & & POWER SUPPLY, 5V MODULAR & & 34.39 & SEMICONDUCTOR CIR. INC. & \\
\hline \multicolumn{9}{|l|}{10} \\
\hline 17 & 1 & $24-28 P$ & & CONNECTOR, 24 PIN, FEMALE & & 1.65 & AMP, INC. & \\
\hline \multicolumn{9}{|l|}{18} \\
\hline 18 & 1 & & & 1 PIECE MOLDED 6 OZ, WIRE & & .50 & NEWPORT PLASIC & \\
\hline 20 & & & & COVER, $5 " \times 6 " \times 3 "$ & & & & \\
\hline 21 & 1 & TRANS-WPX-4 & 14. & OPTICAL TRANSCENER & & 30.00 & SPECTRONICS & \\
\hline 22 & & REC-SPX-414 & 0 & & & & - & \\
\hline 23 & & & & & & & & \\
\hline 24 & & & & & & & & \\
\hline
\end{tabular}


APPENDIX C

TOOL AND LABOR ROUTING 
THIS PAGE WAS INTENTIONALLY

\section{LEFT BLANK}


25,000 ANNUAL VOLUME 
THIS PAGE

WAS INTENTIONALLY

LEFT BLANK 


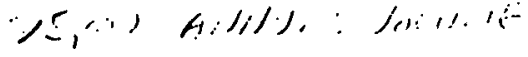

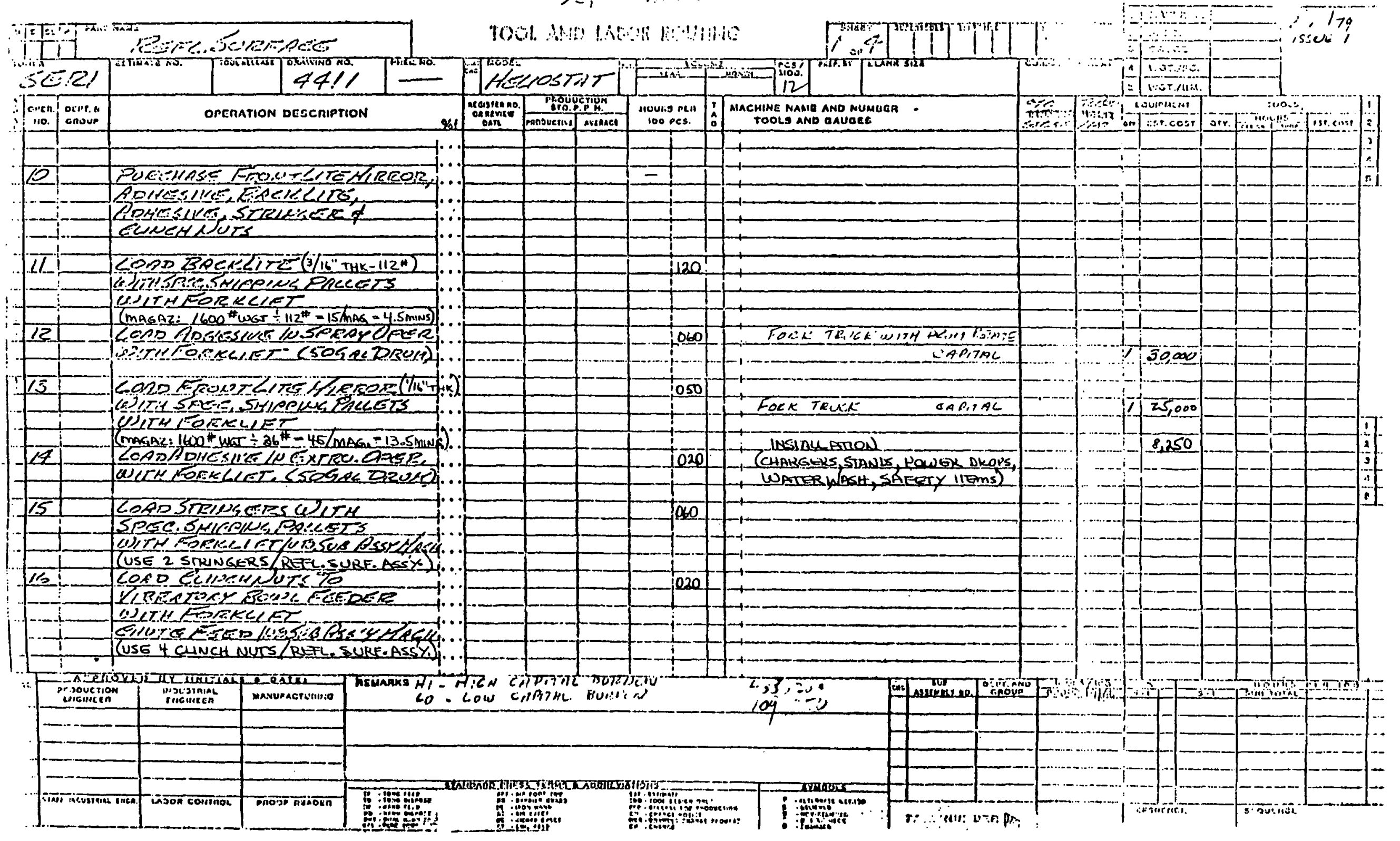




$$
\text { 2. }
$$

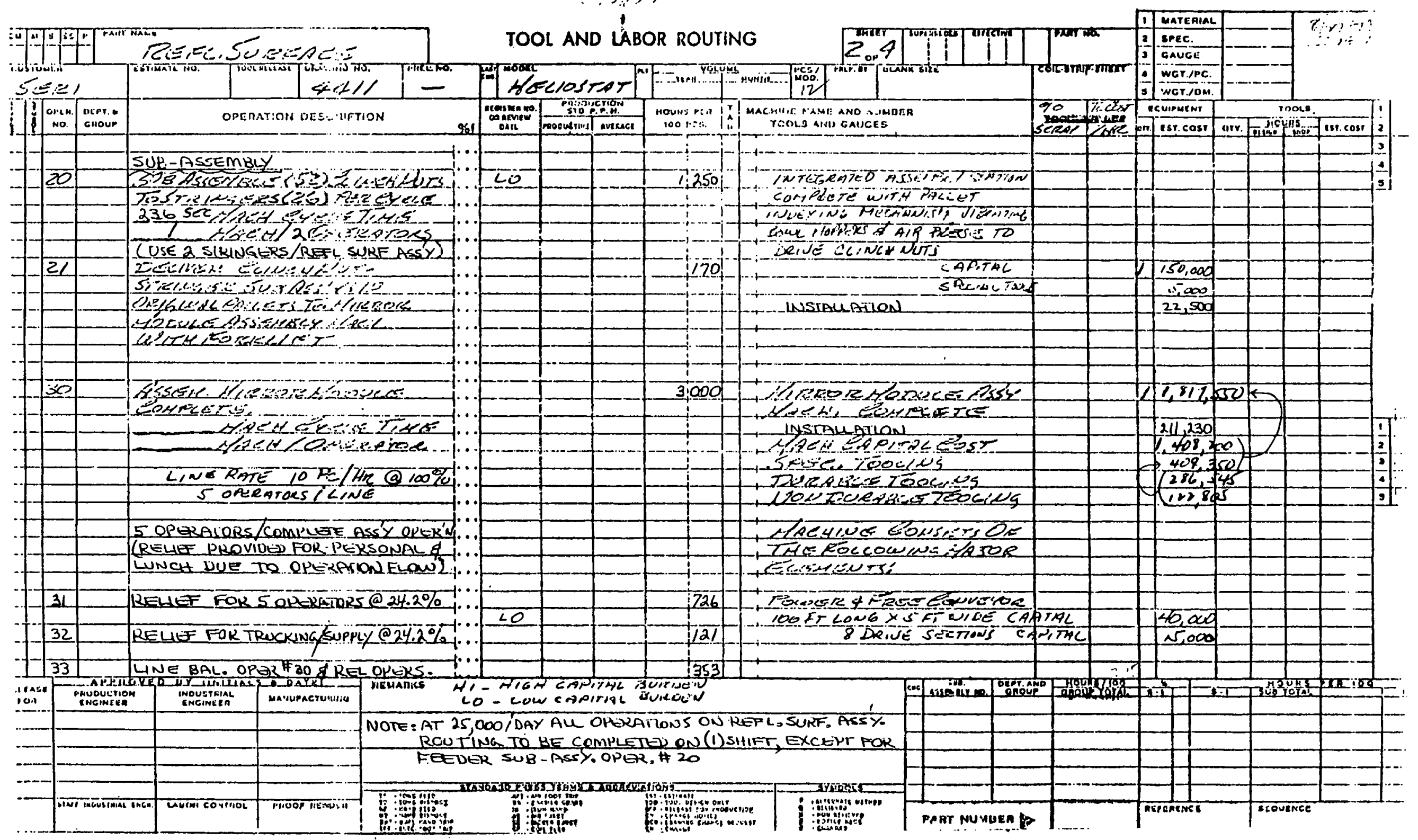


., 01,

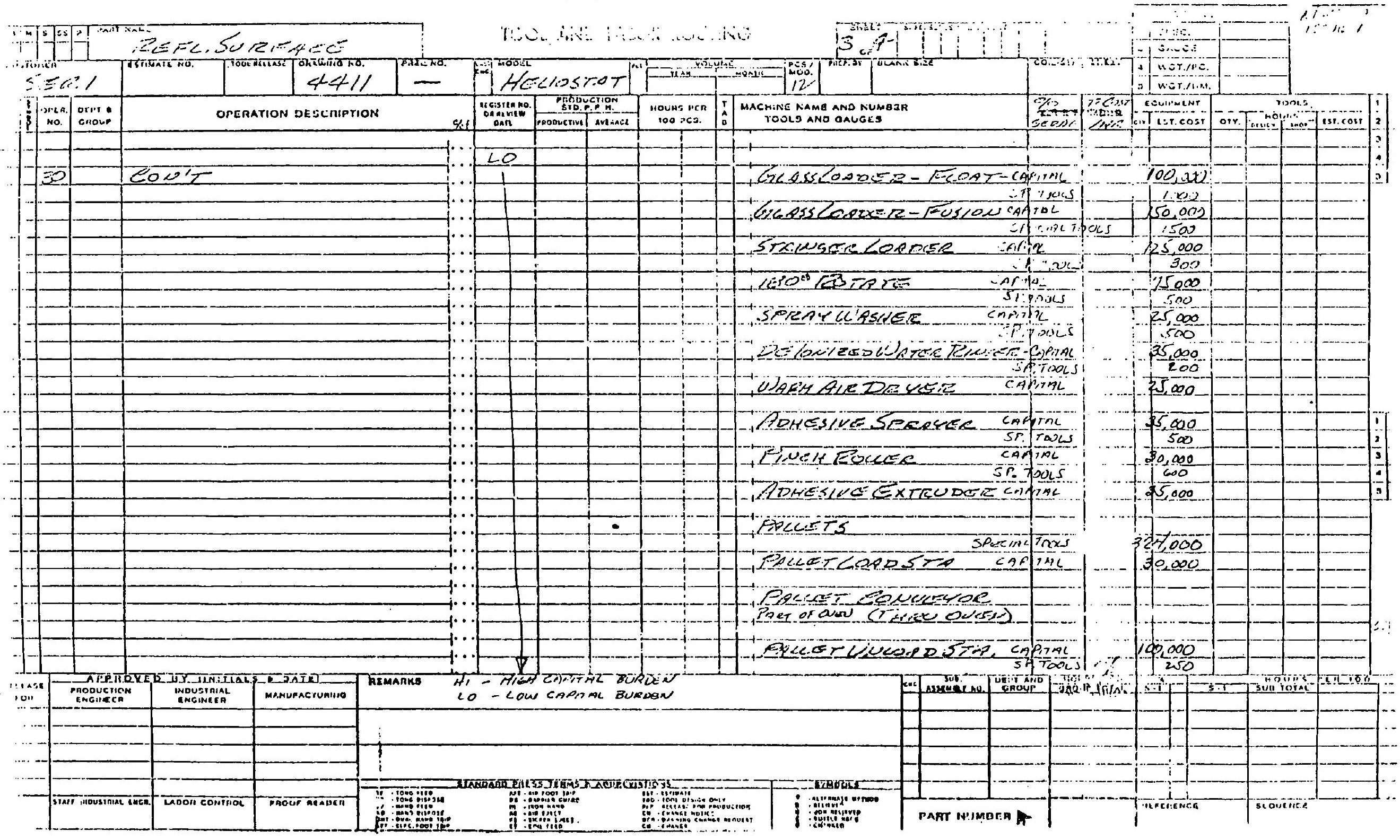




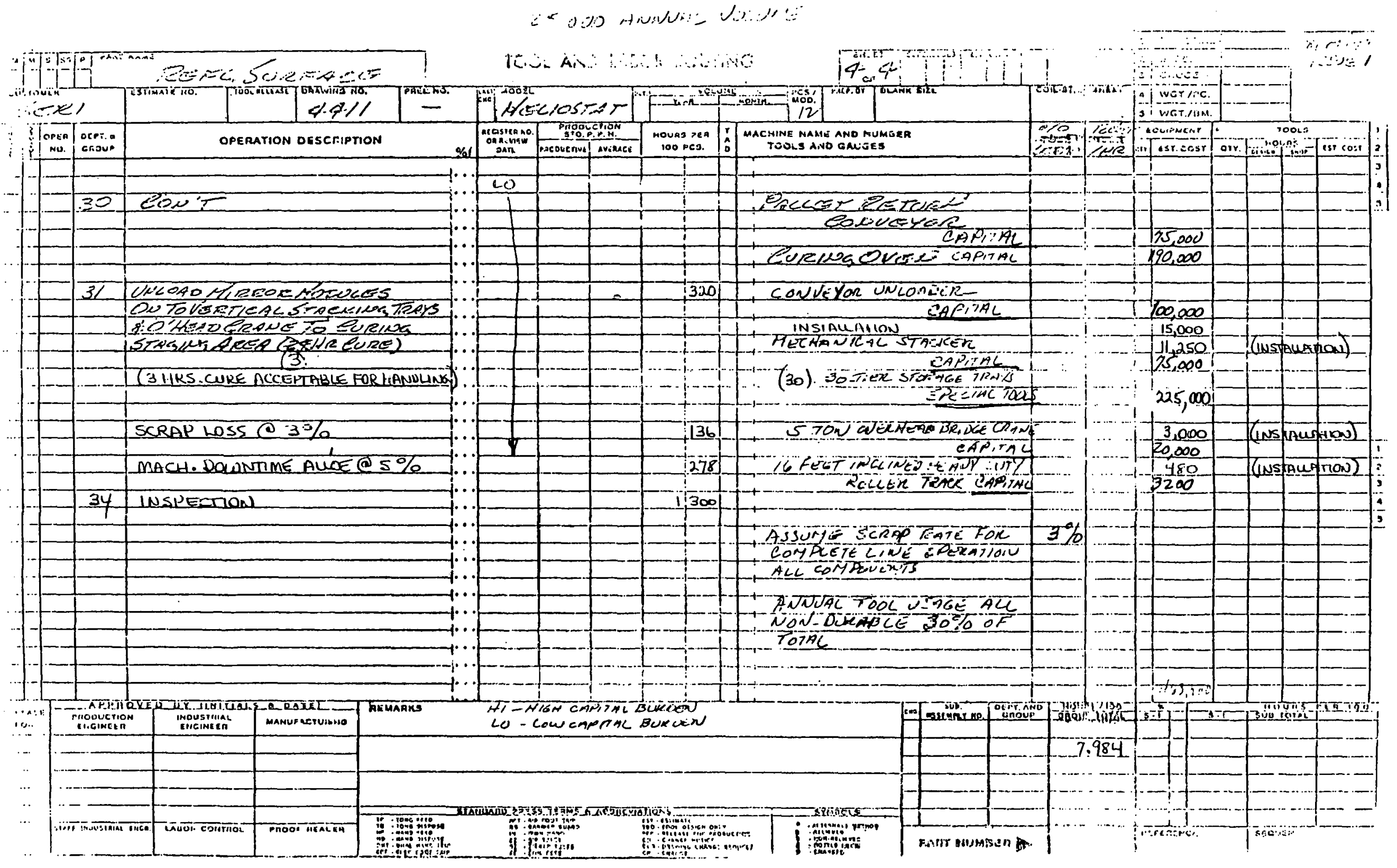




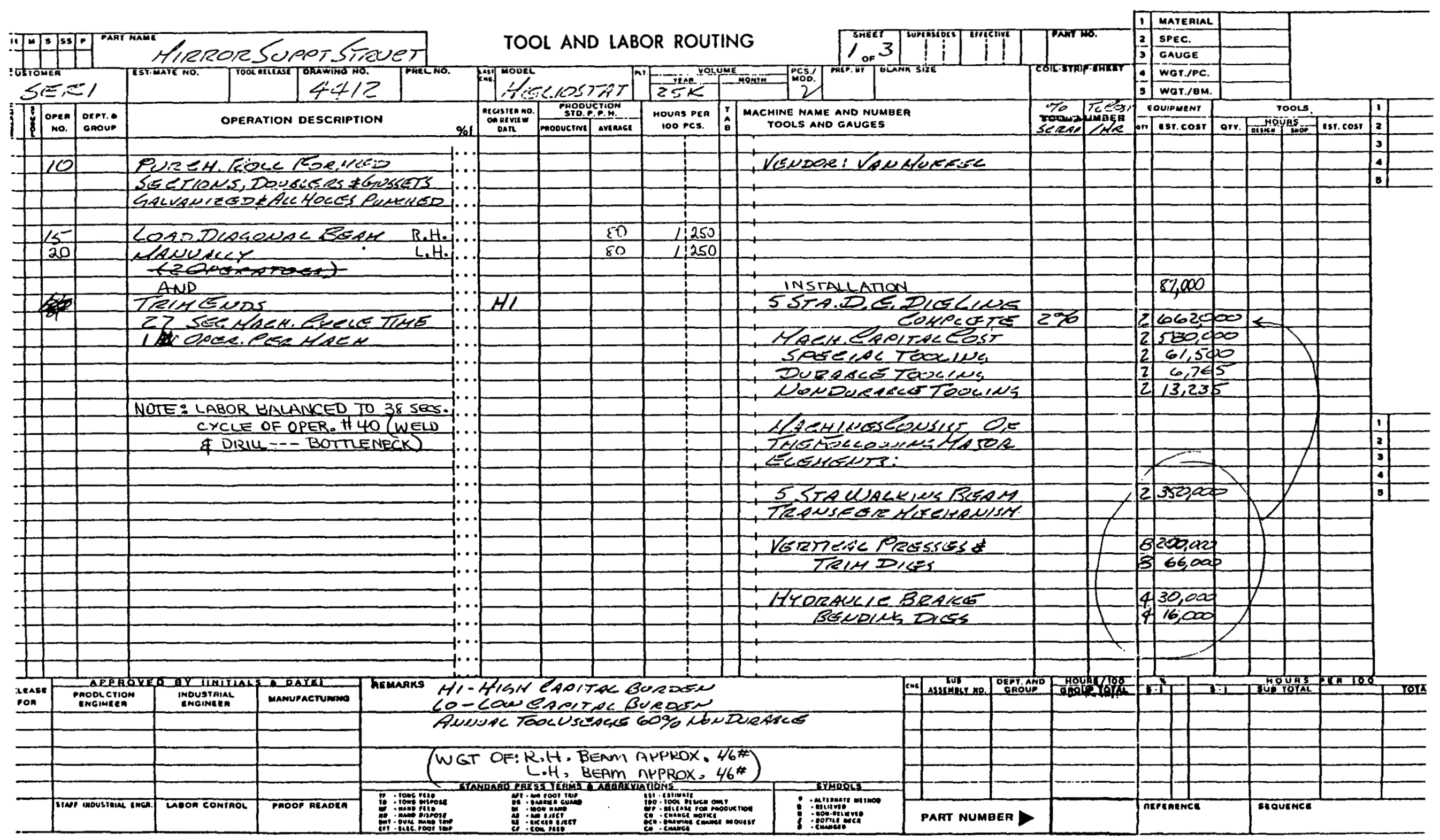




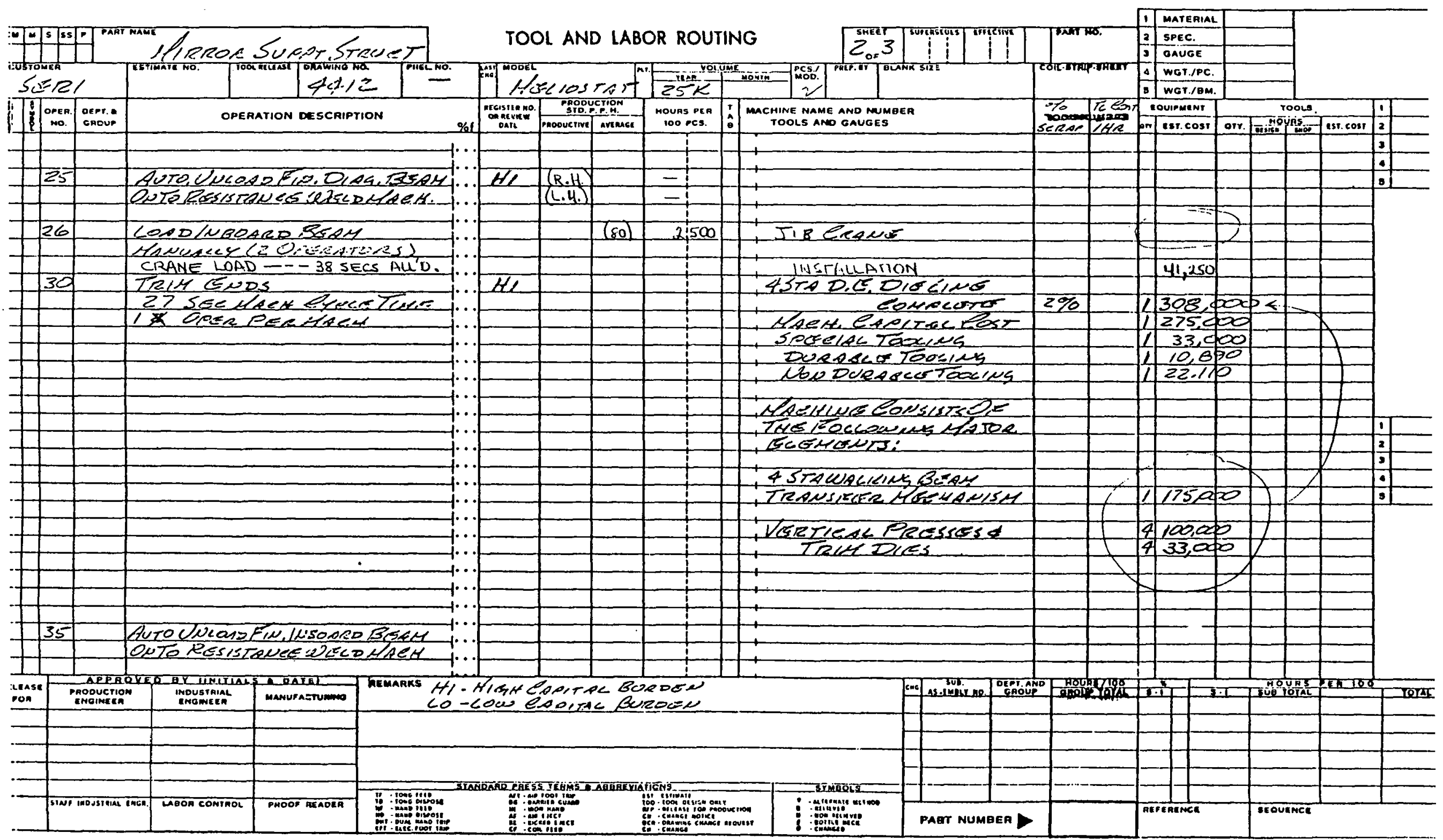




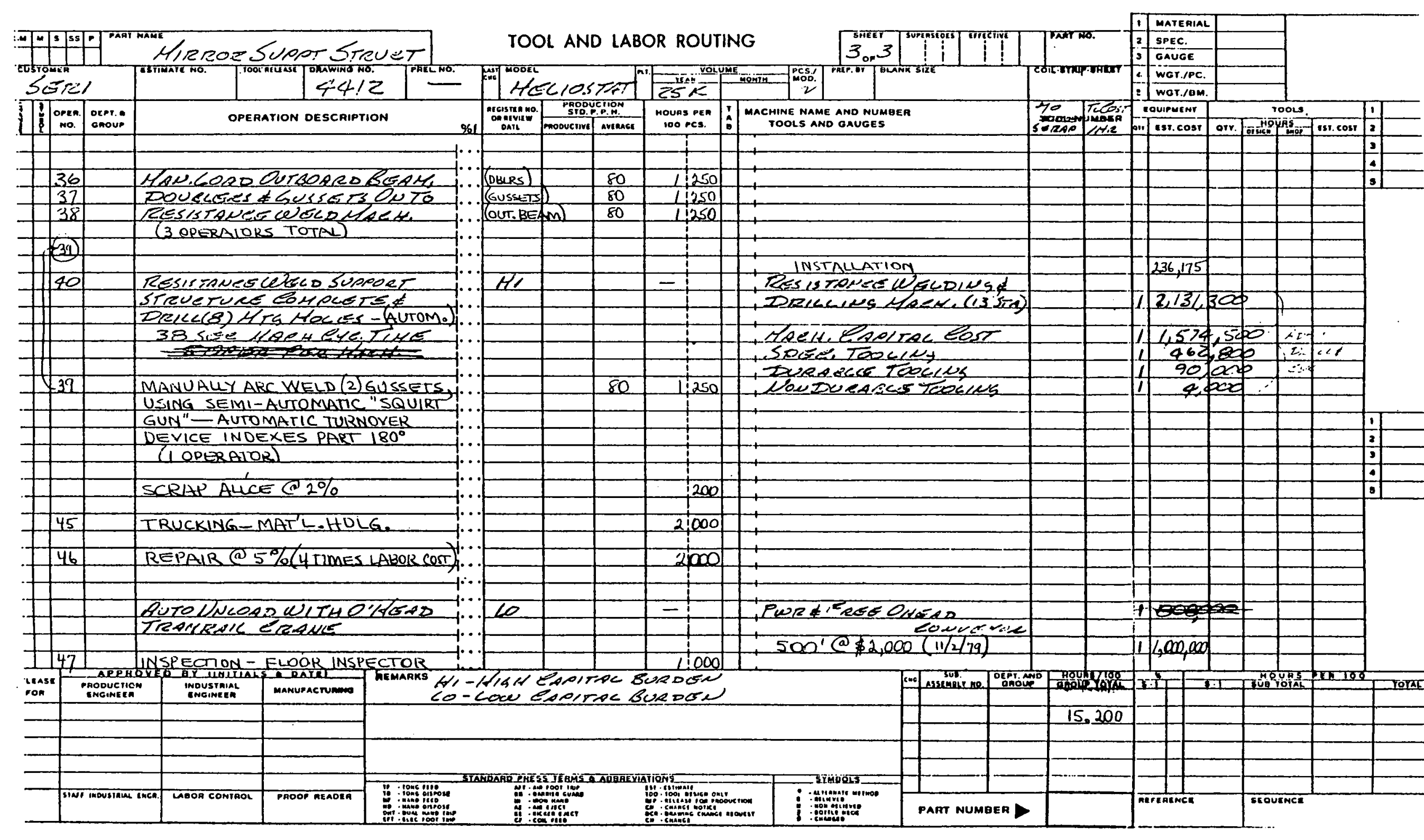




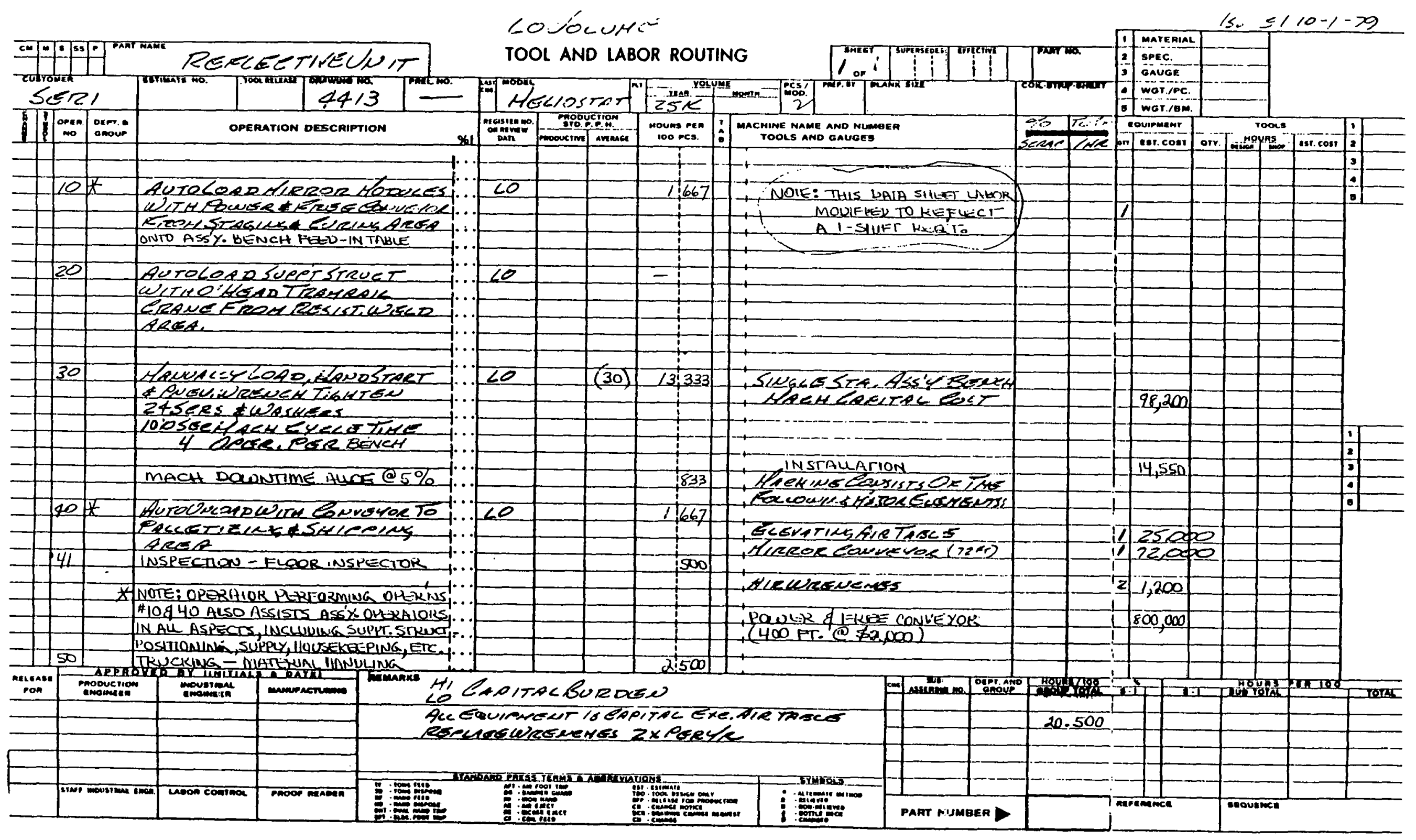

$\mathrm{Cl} 2$ 


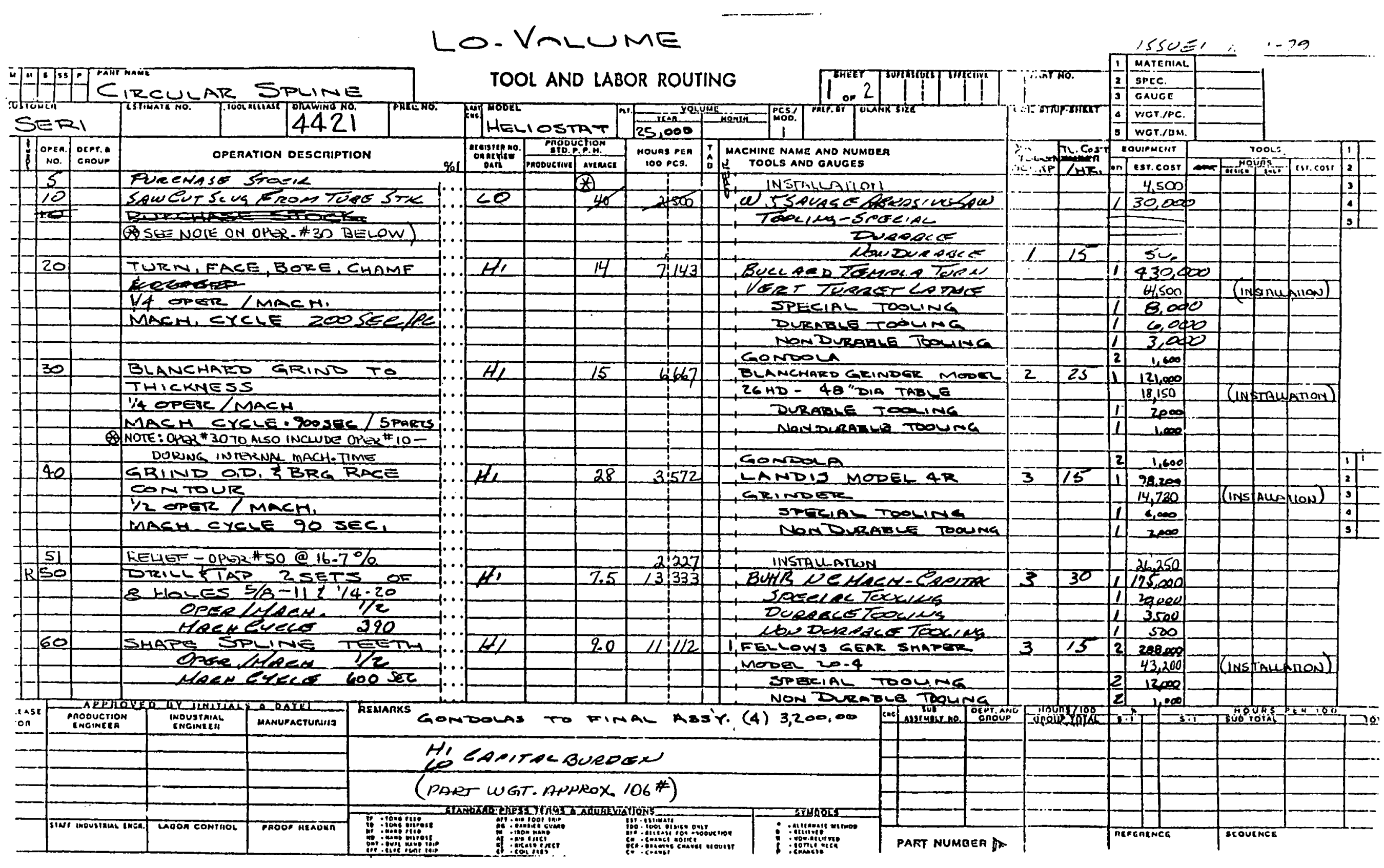




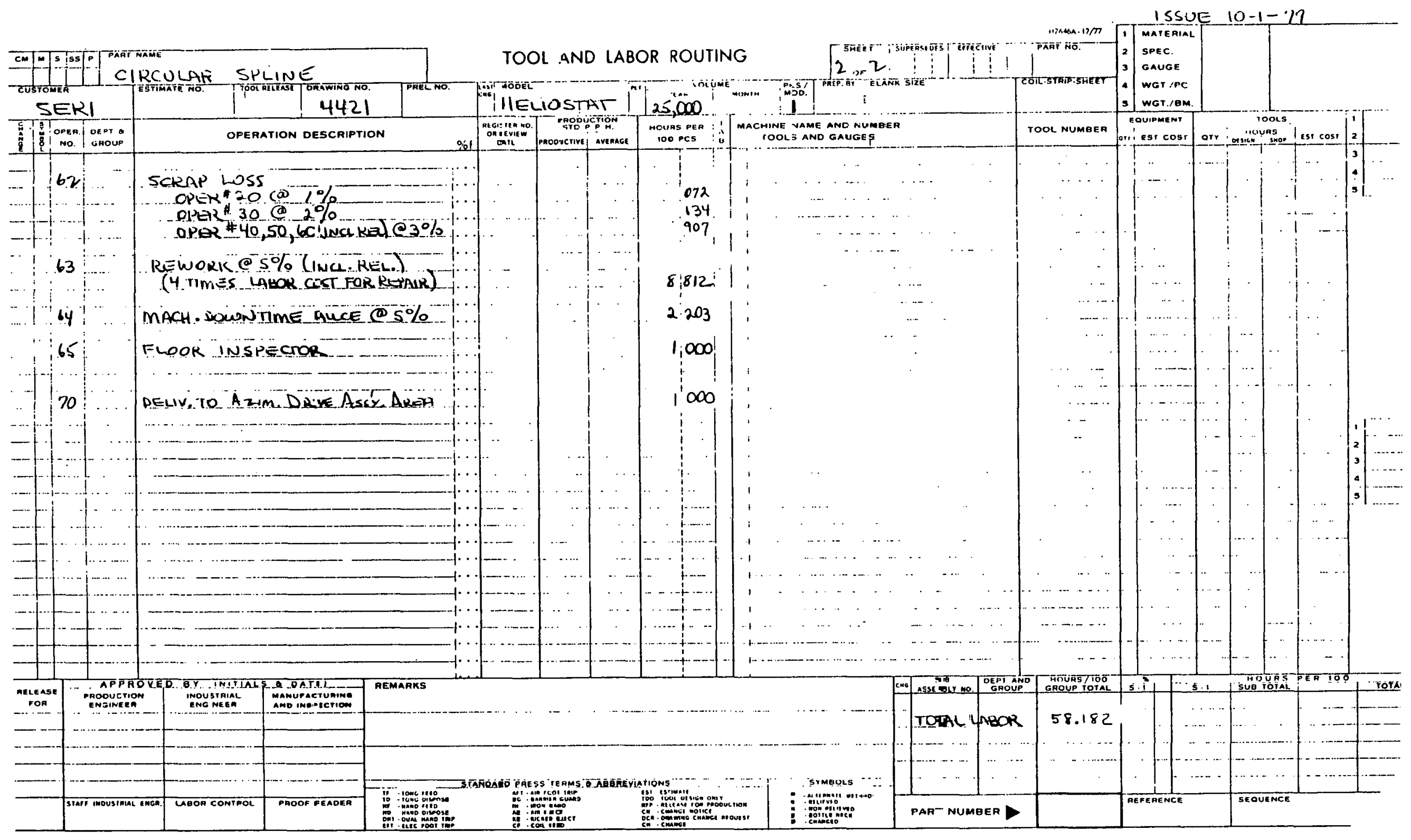




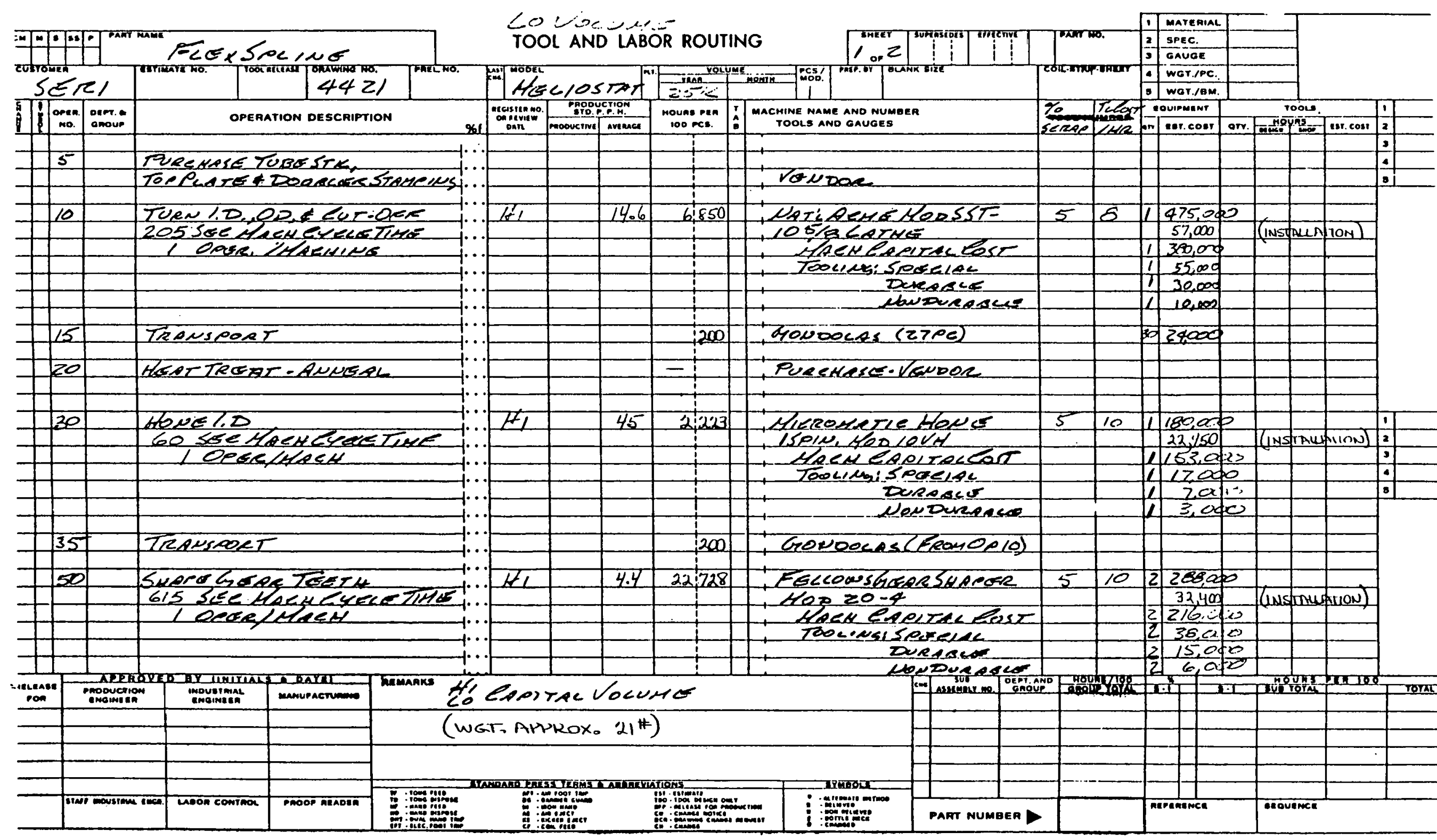

C15 


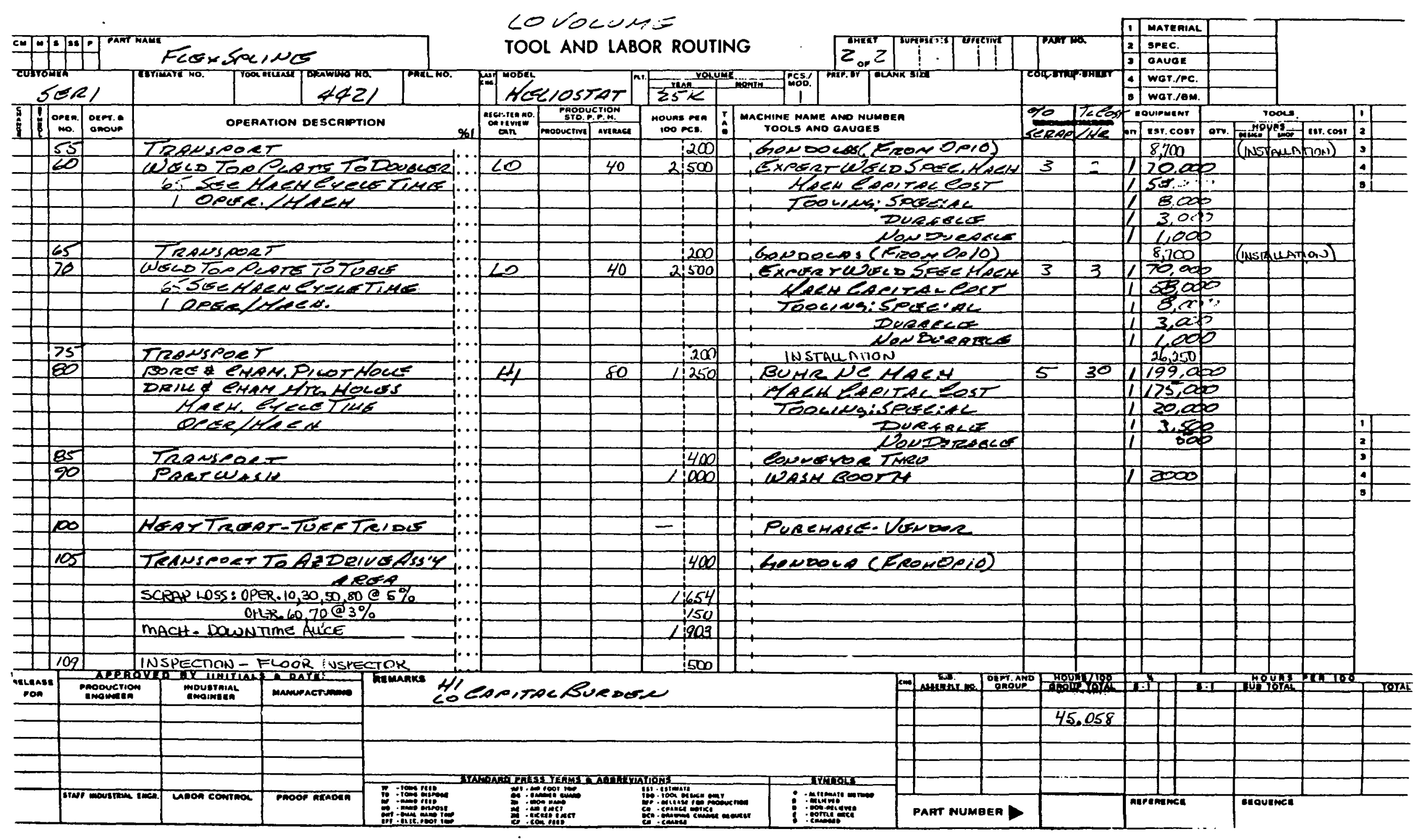




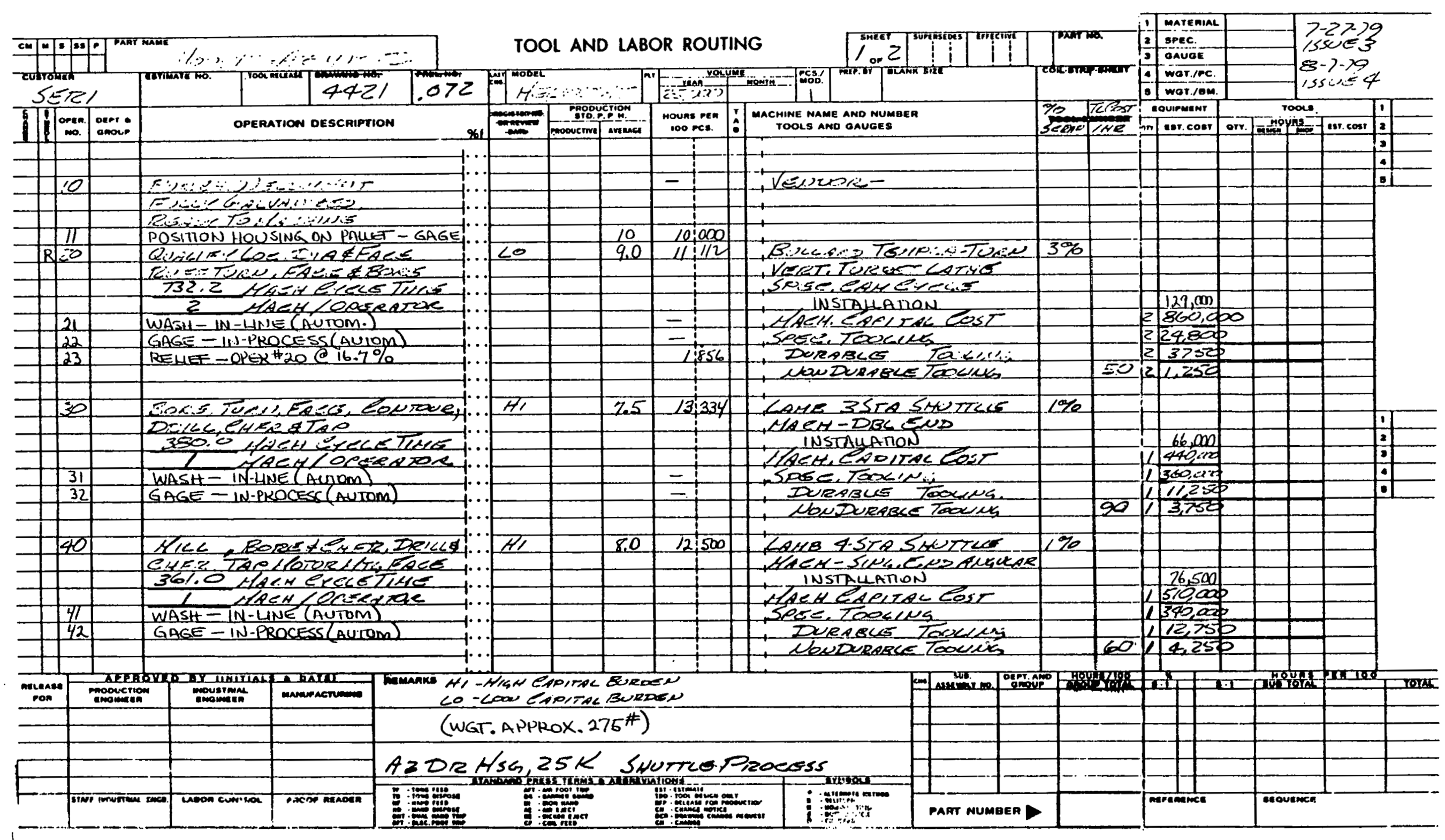




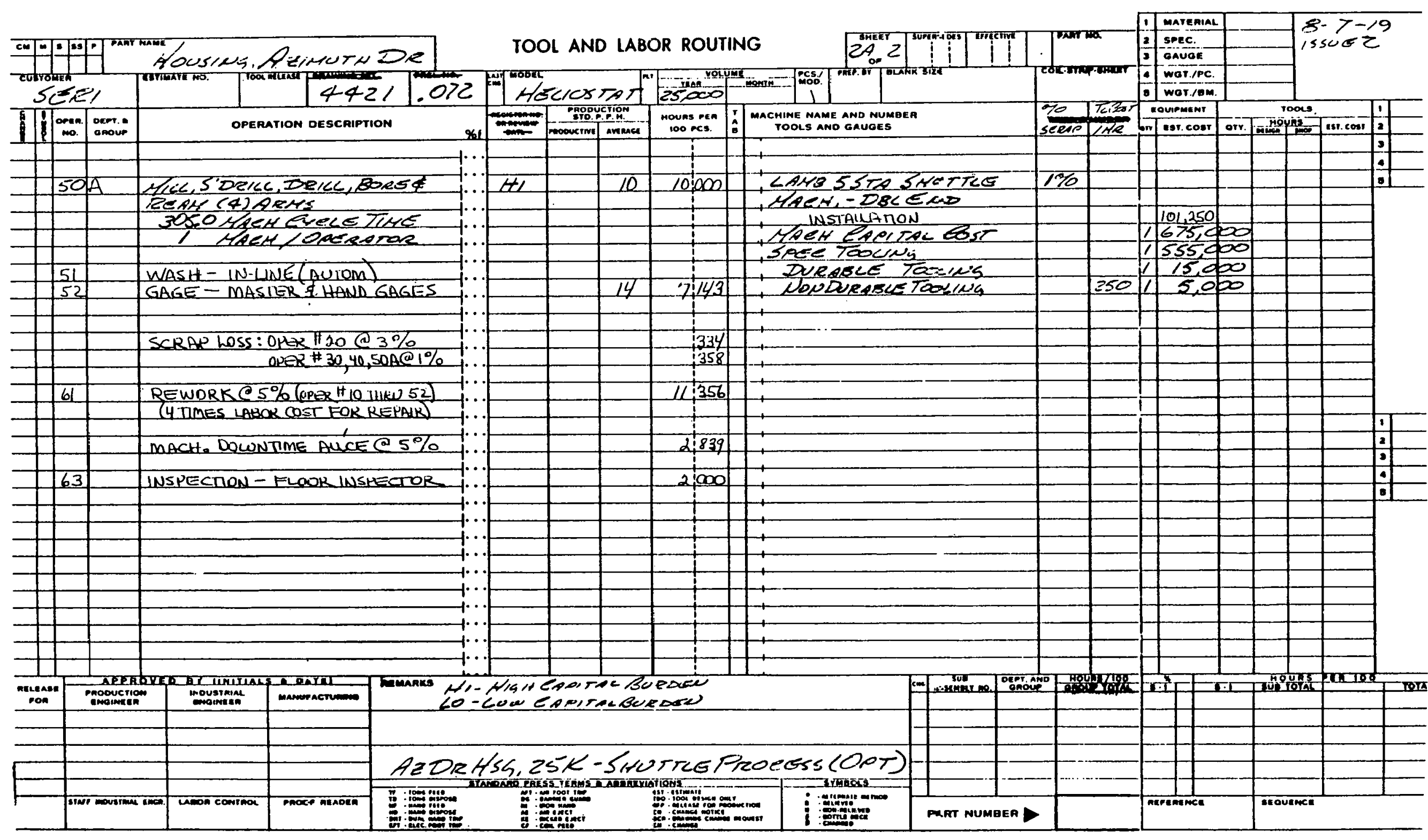




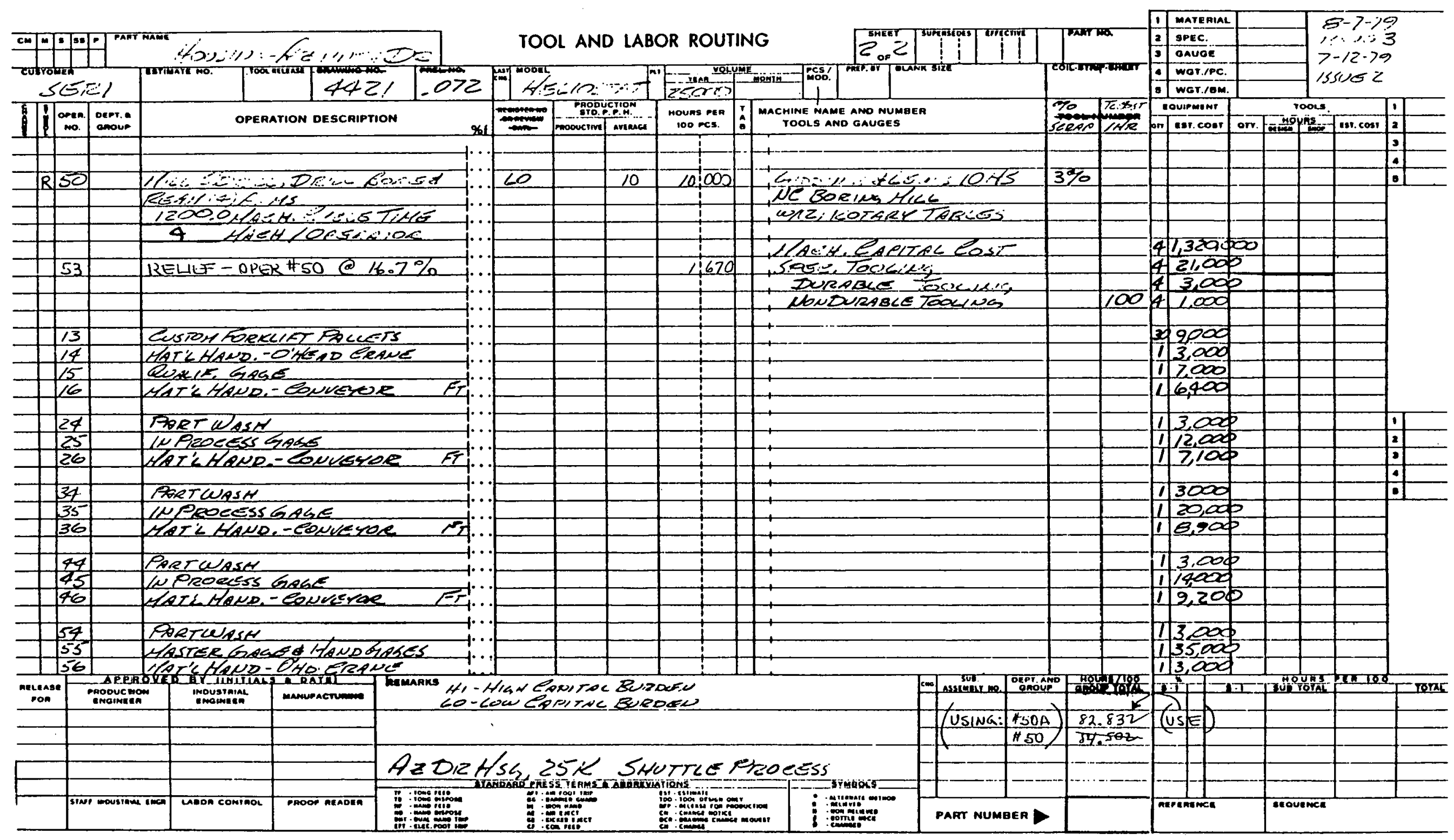

C19 


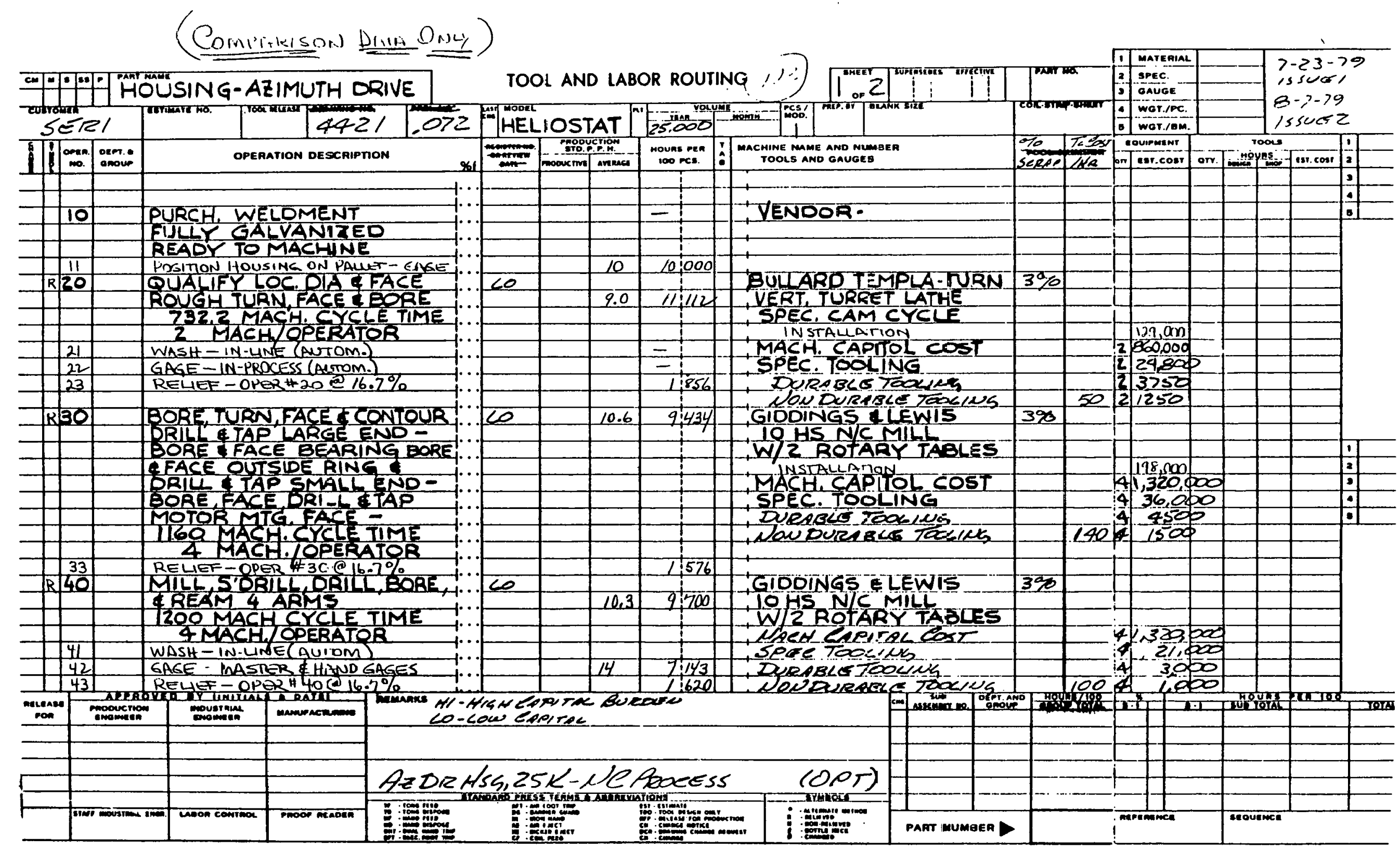




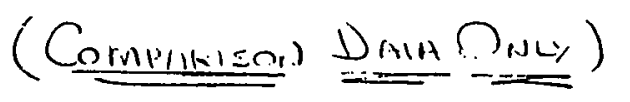

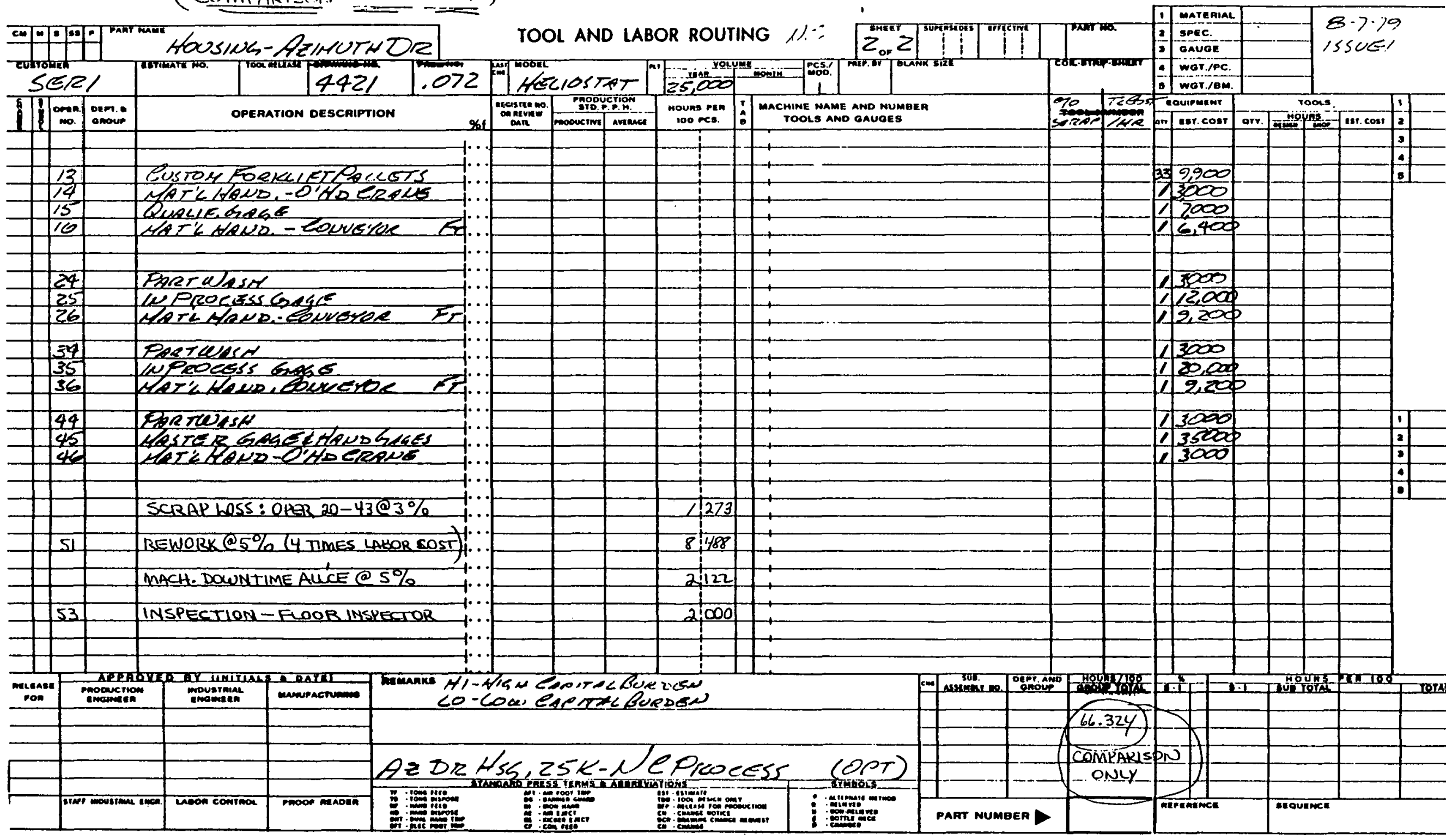


LO-V.LUME

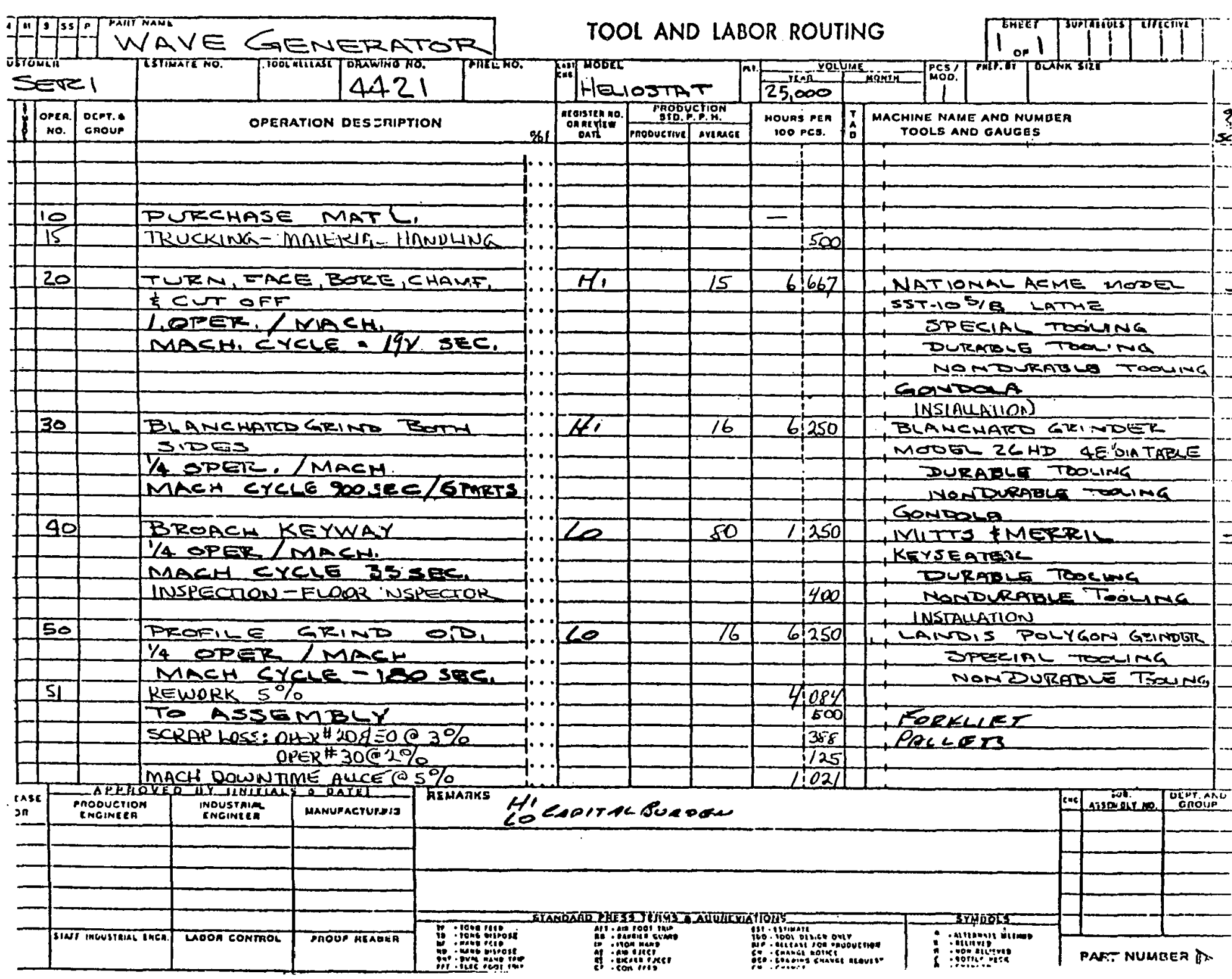

ISSCEI

1 Matenial

$\frac{1}{2} \frac{M A}{S R E}$

Grec.

4 wGT.jPC.

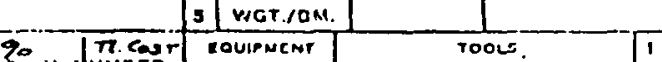

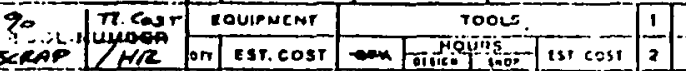

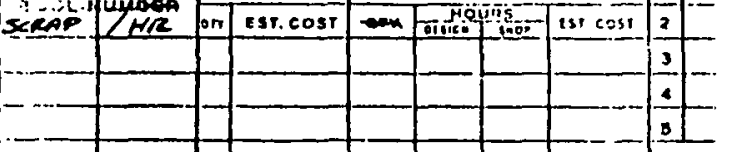

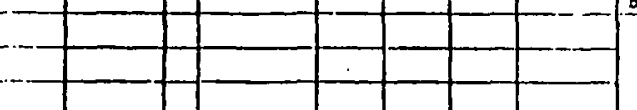

$2 0 \longdiv { 1 1 } 4 7 5,000$
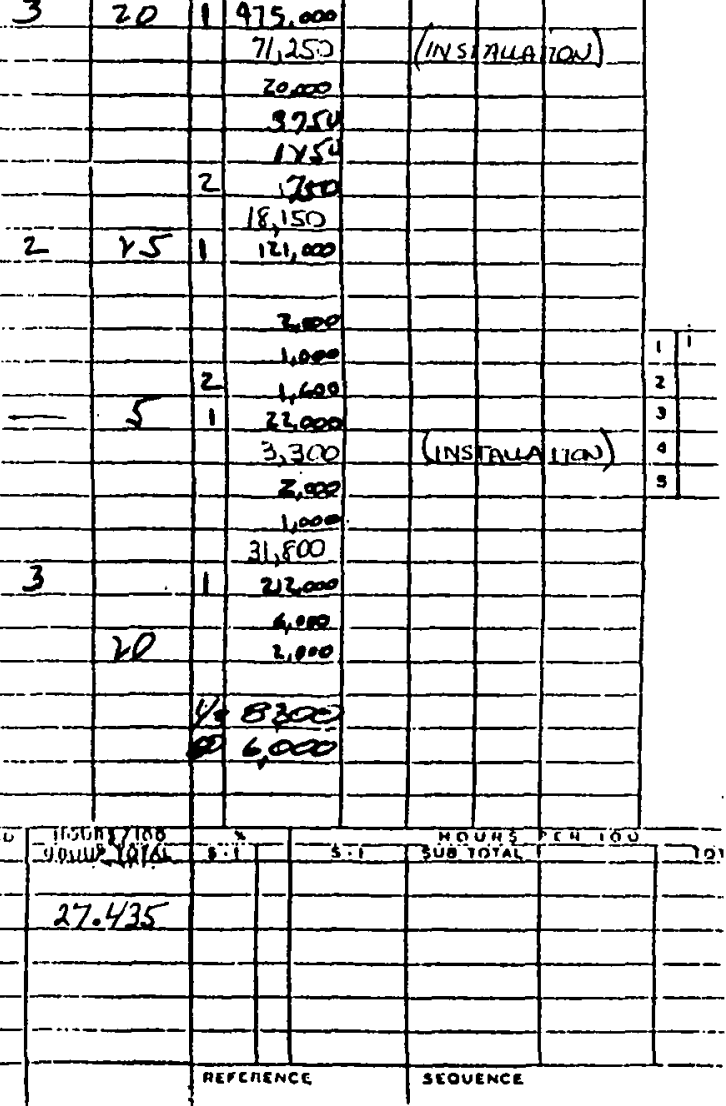

C22 


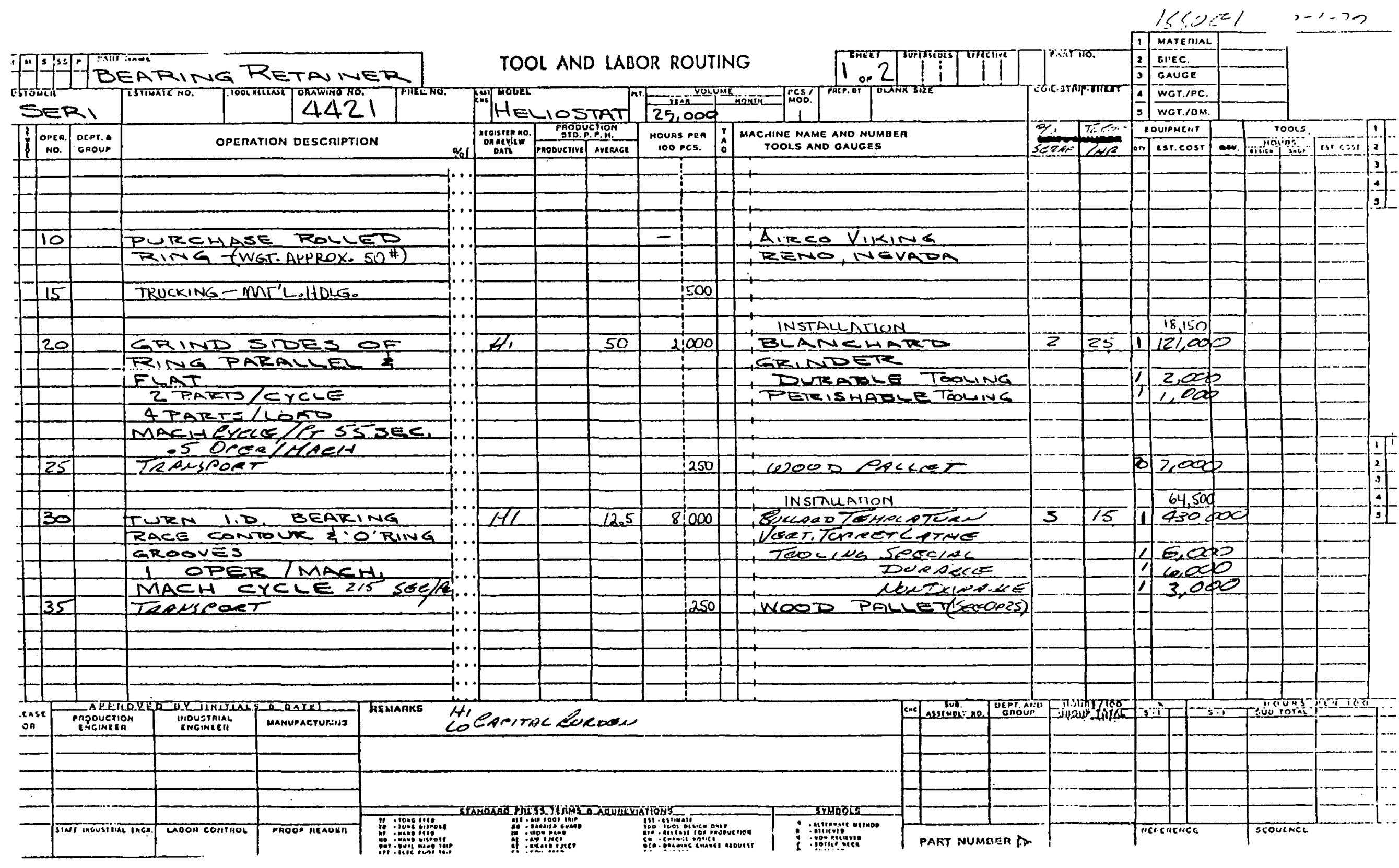




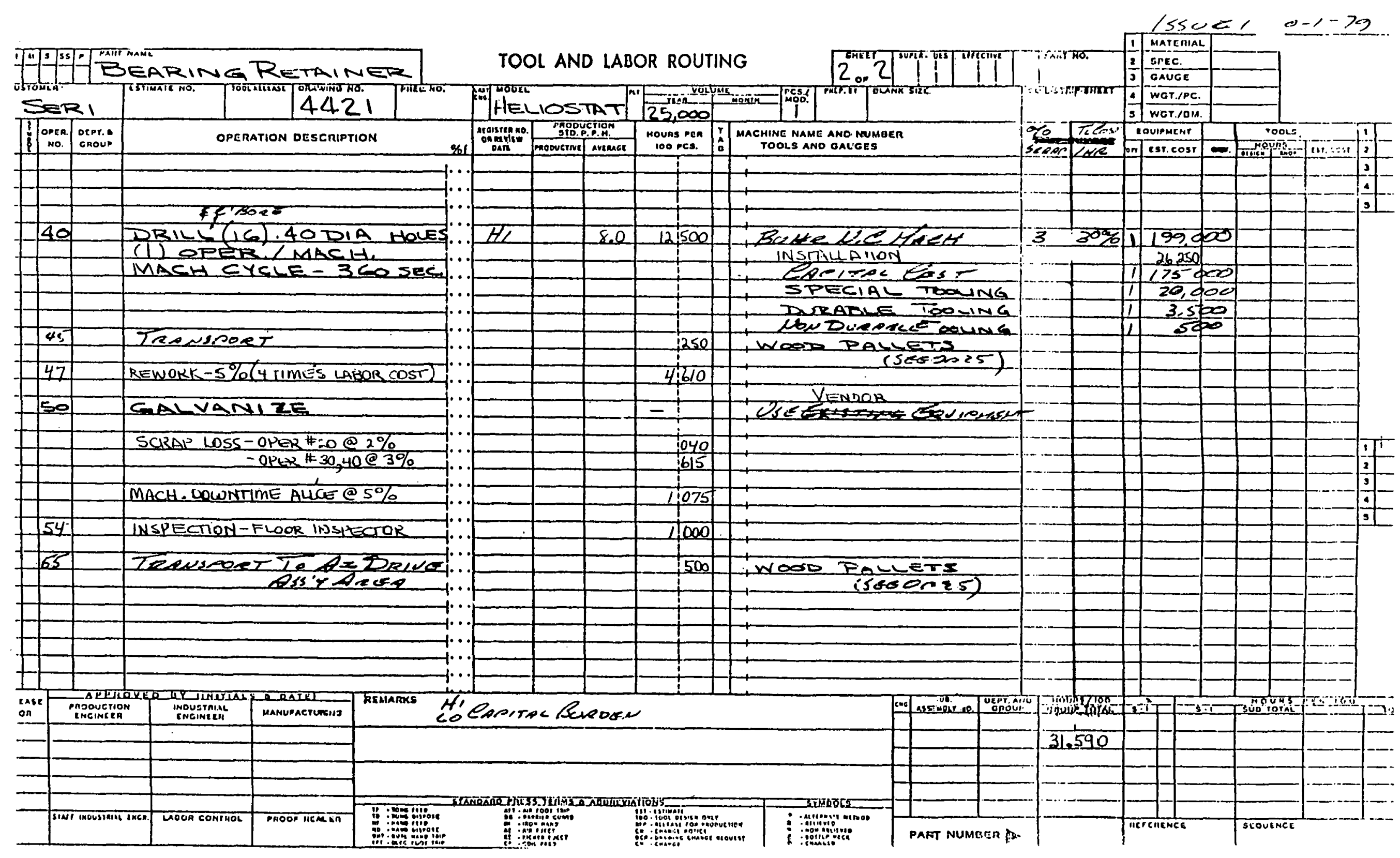


Low. $V_{n} \cdot \ldots \ldots+1,0$

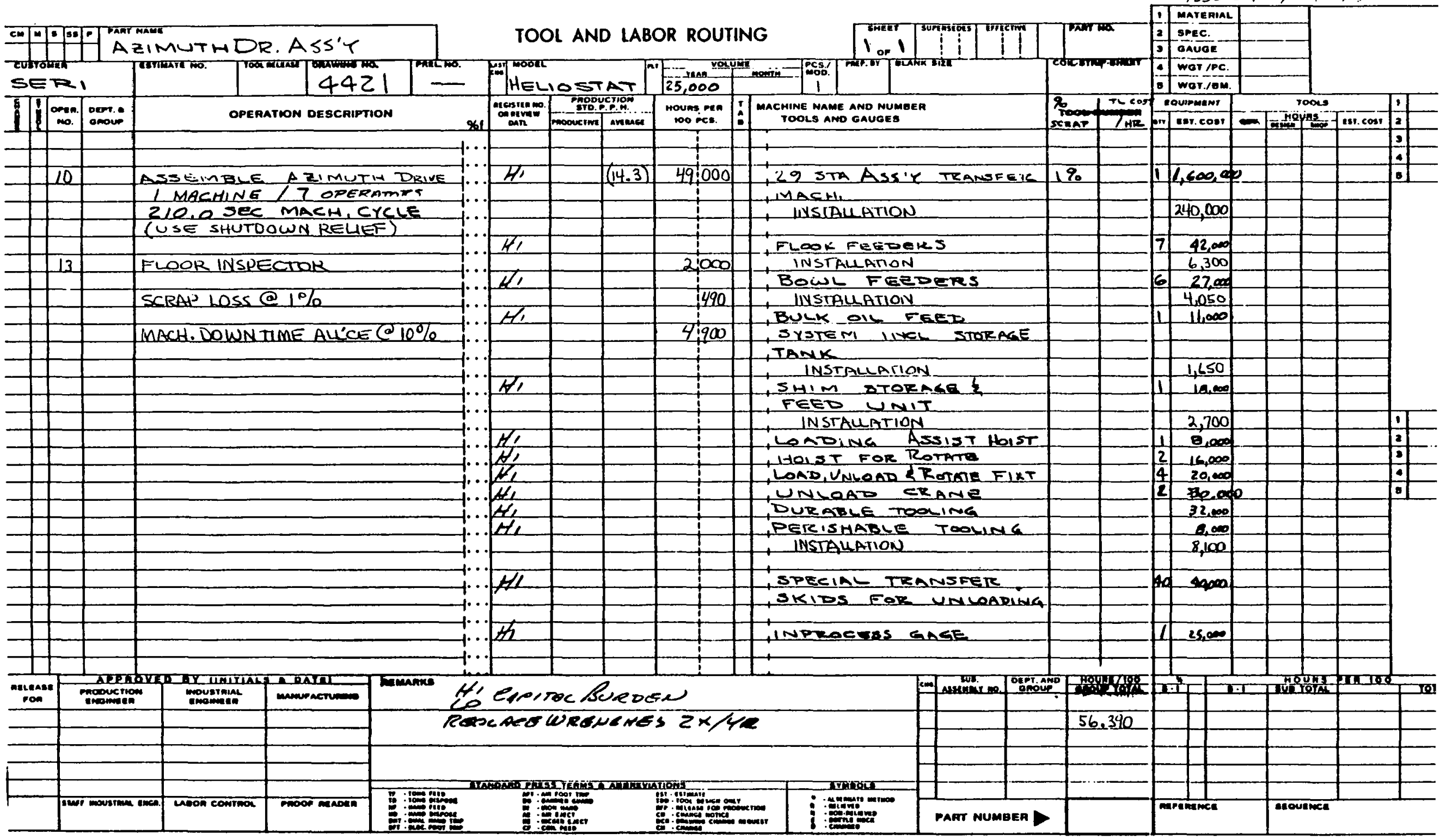




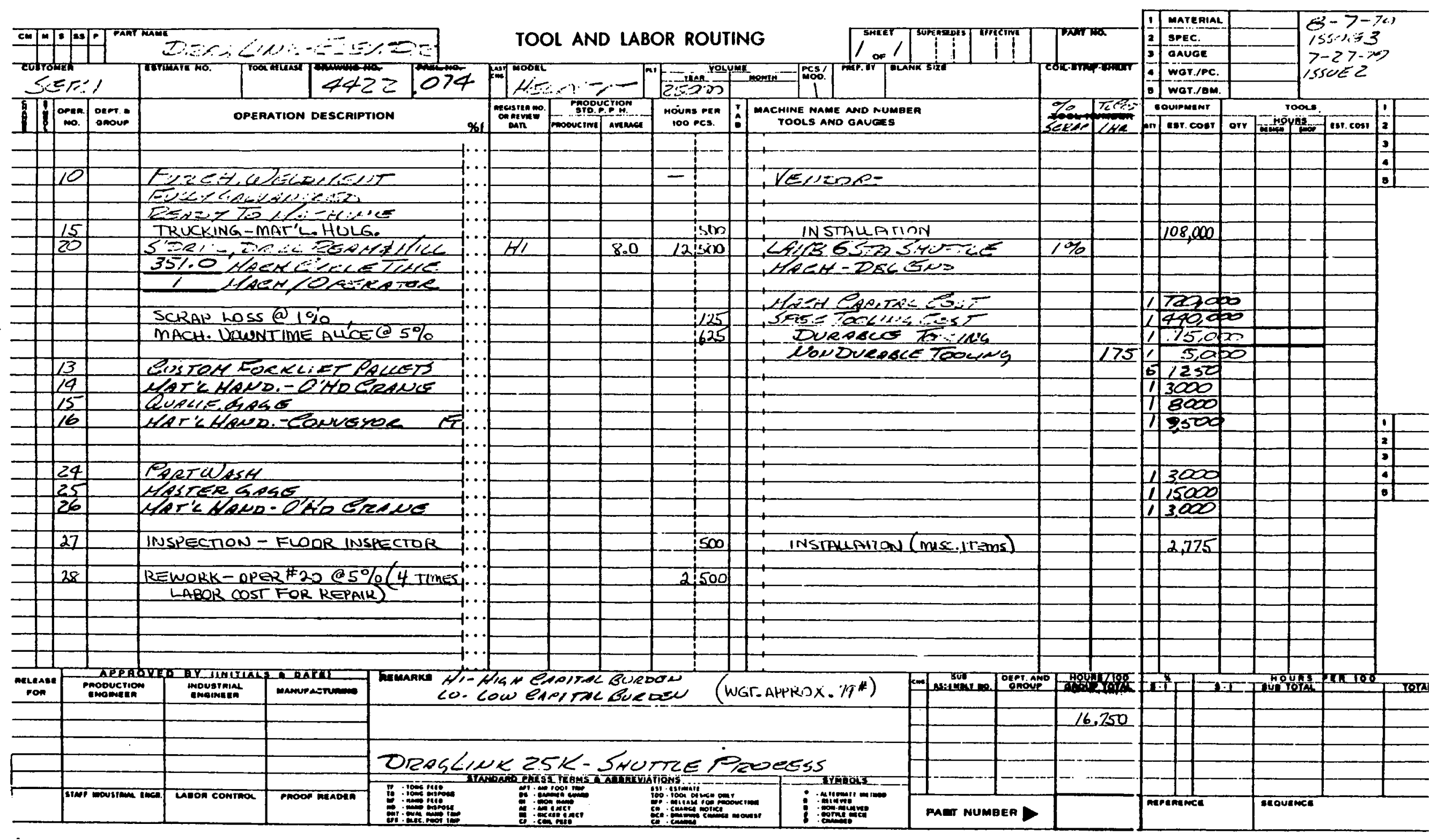

C26 


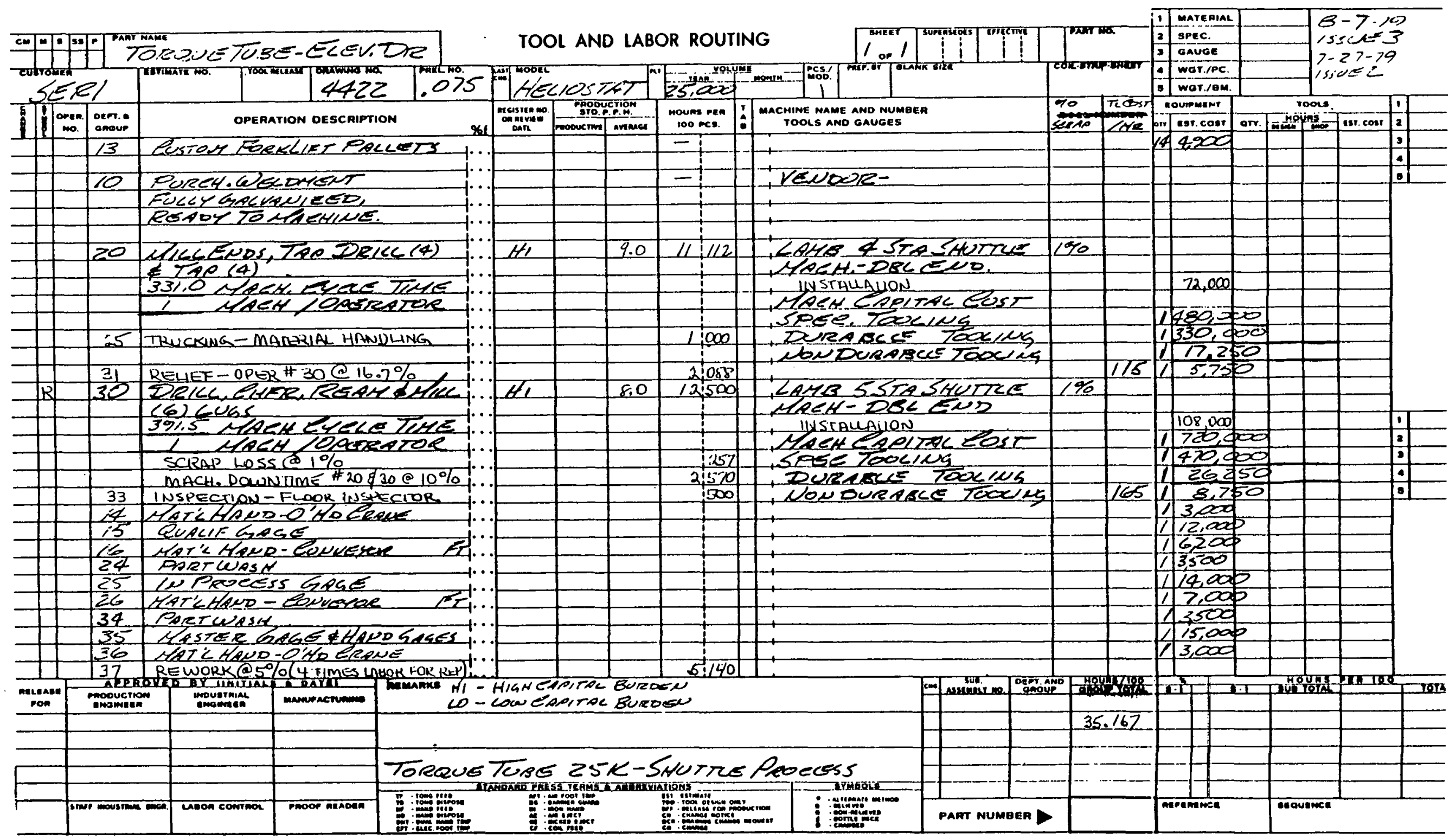


Lo. $V^{-w \cdot A=}$

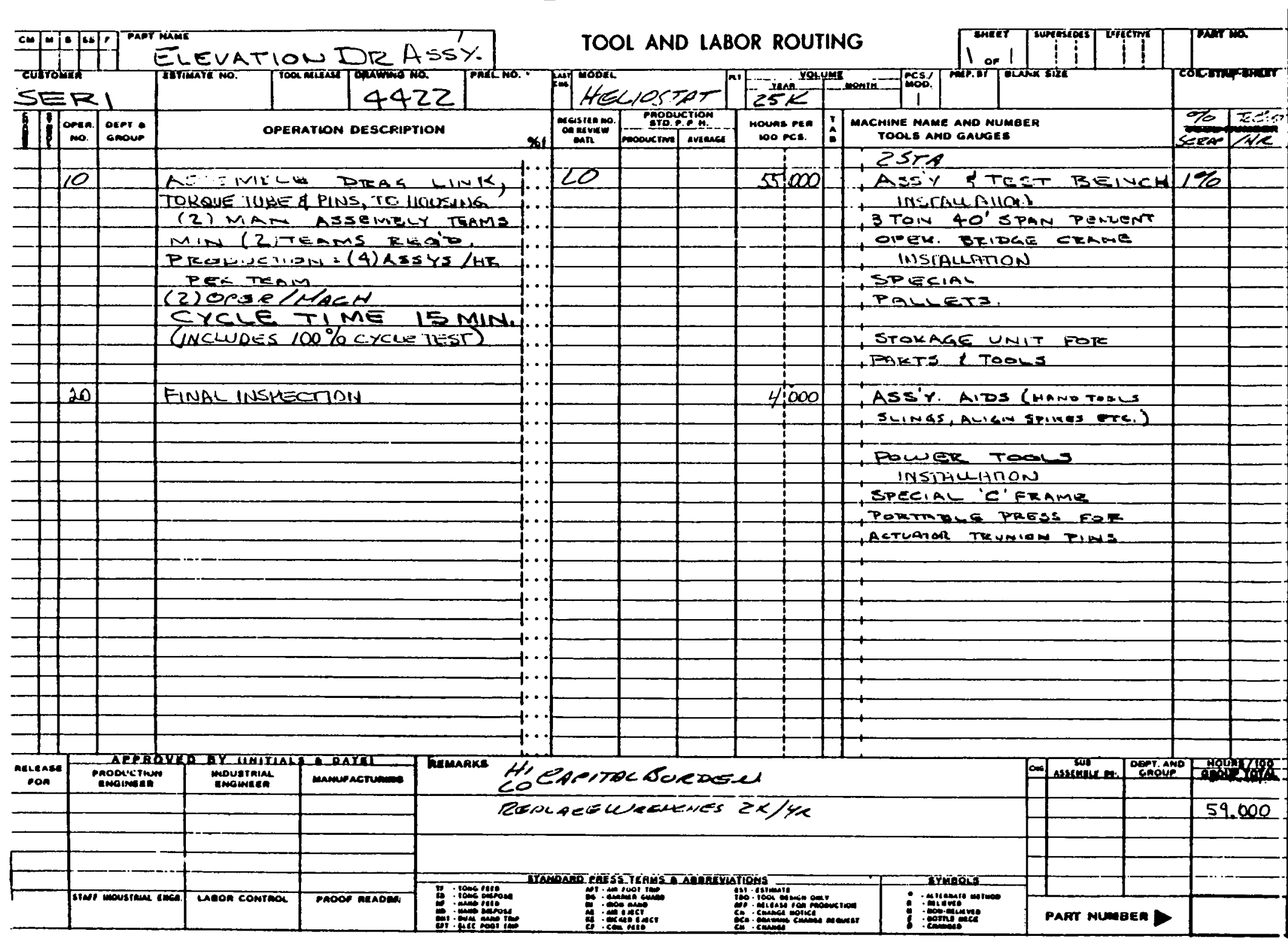

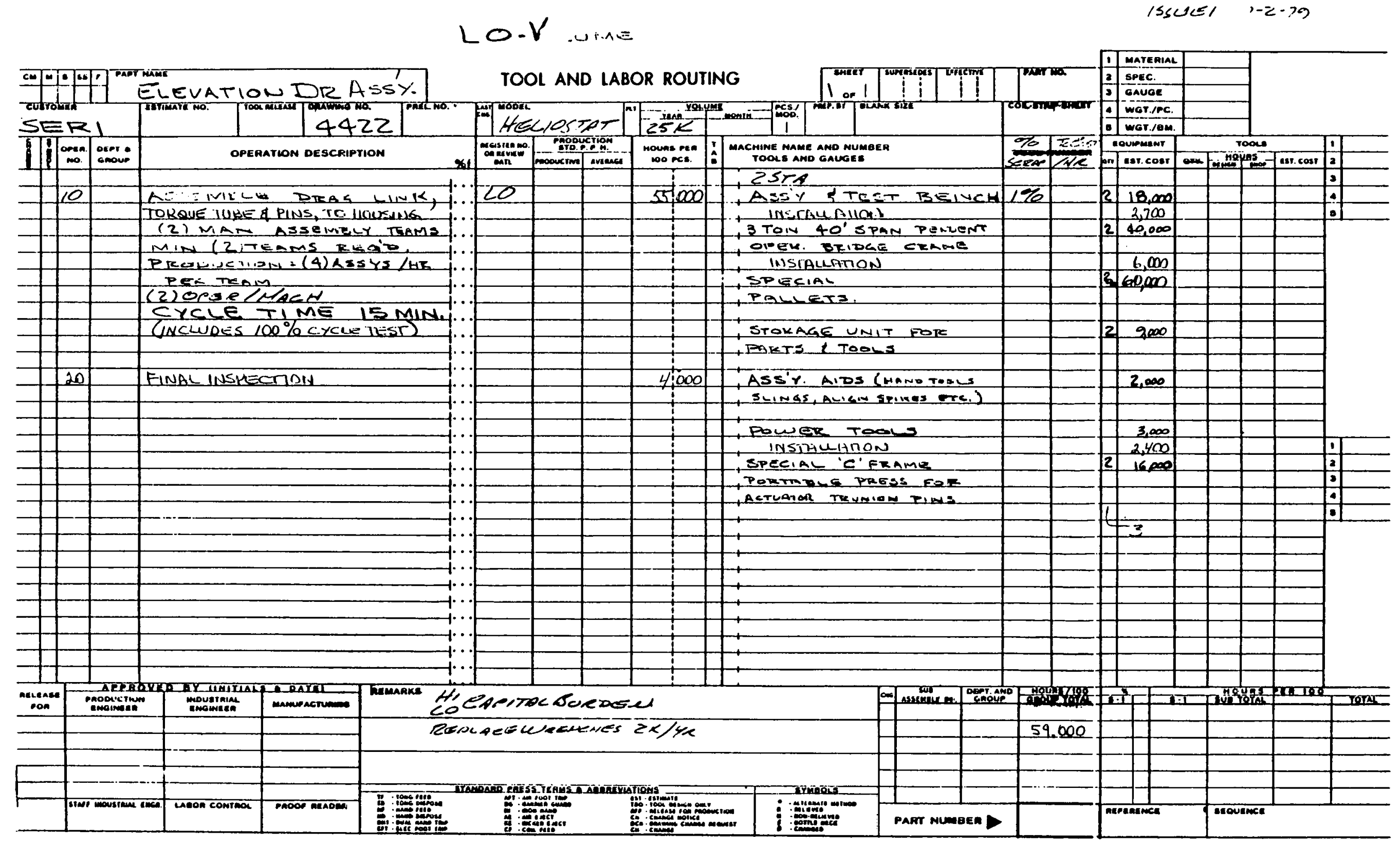




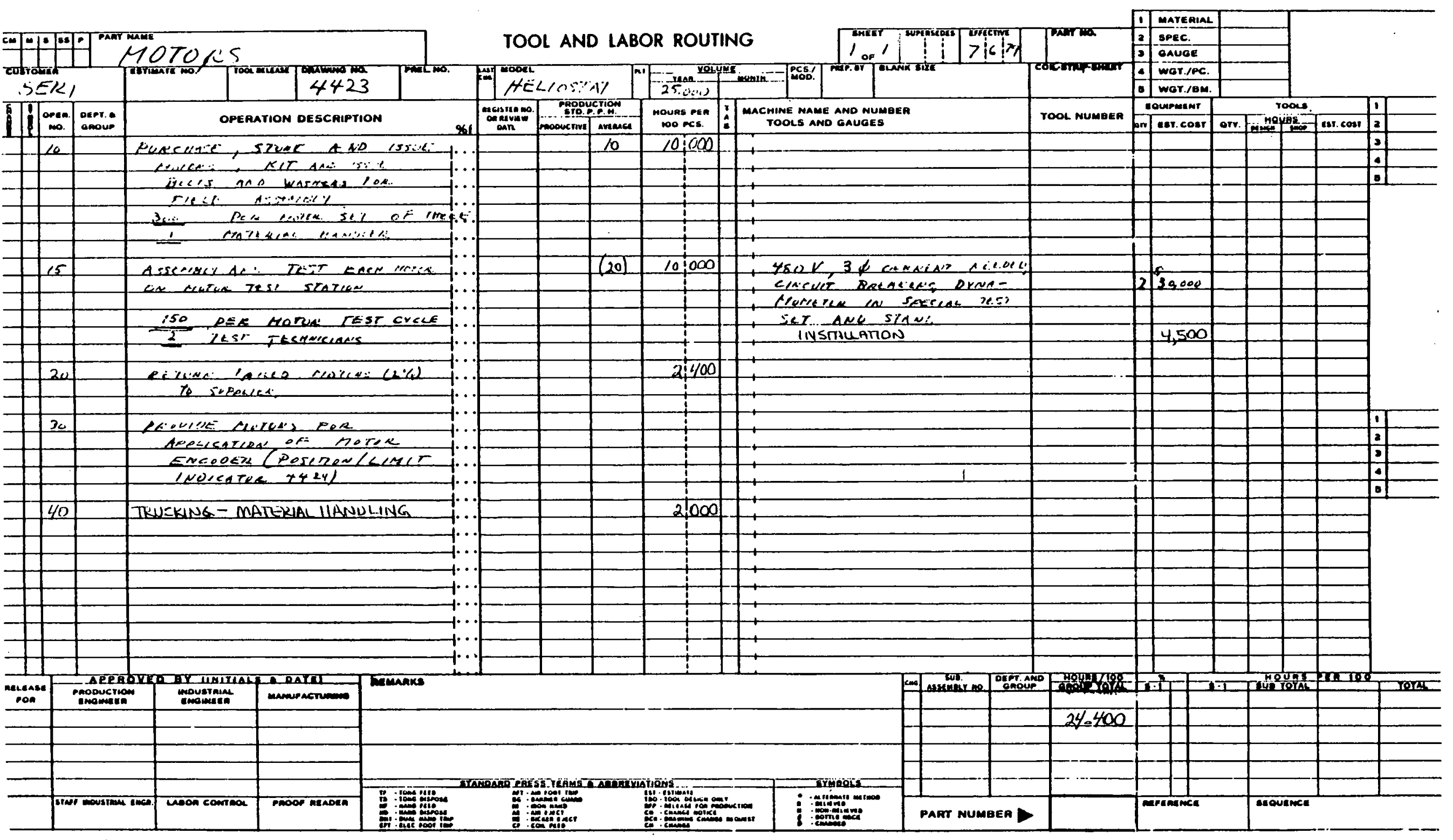




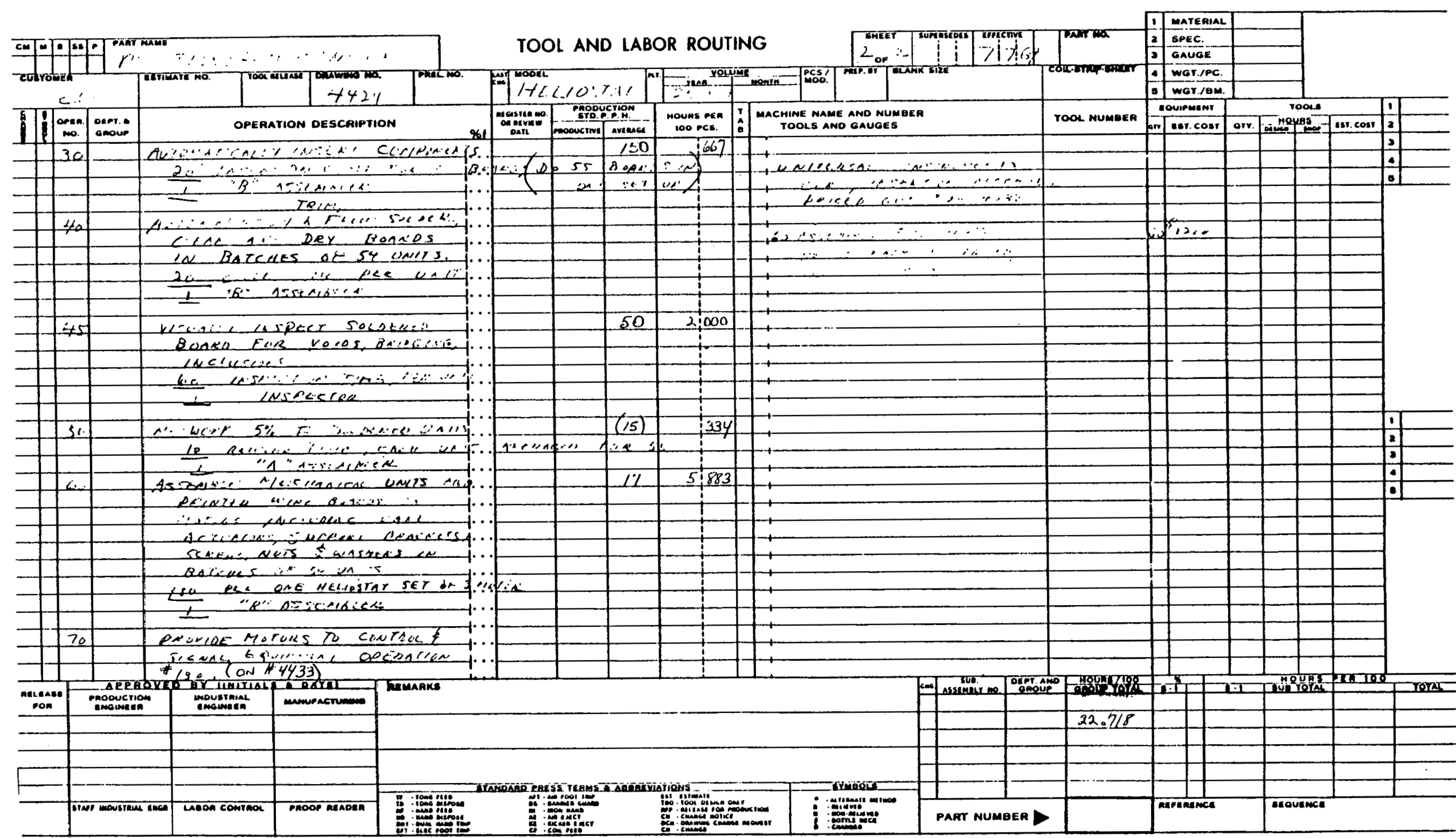




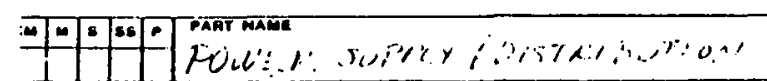

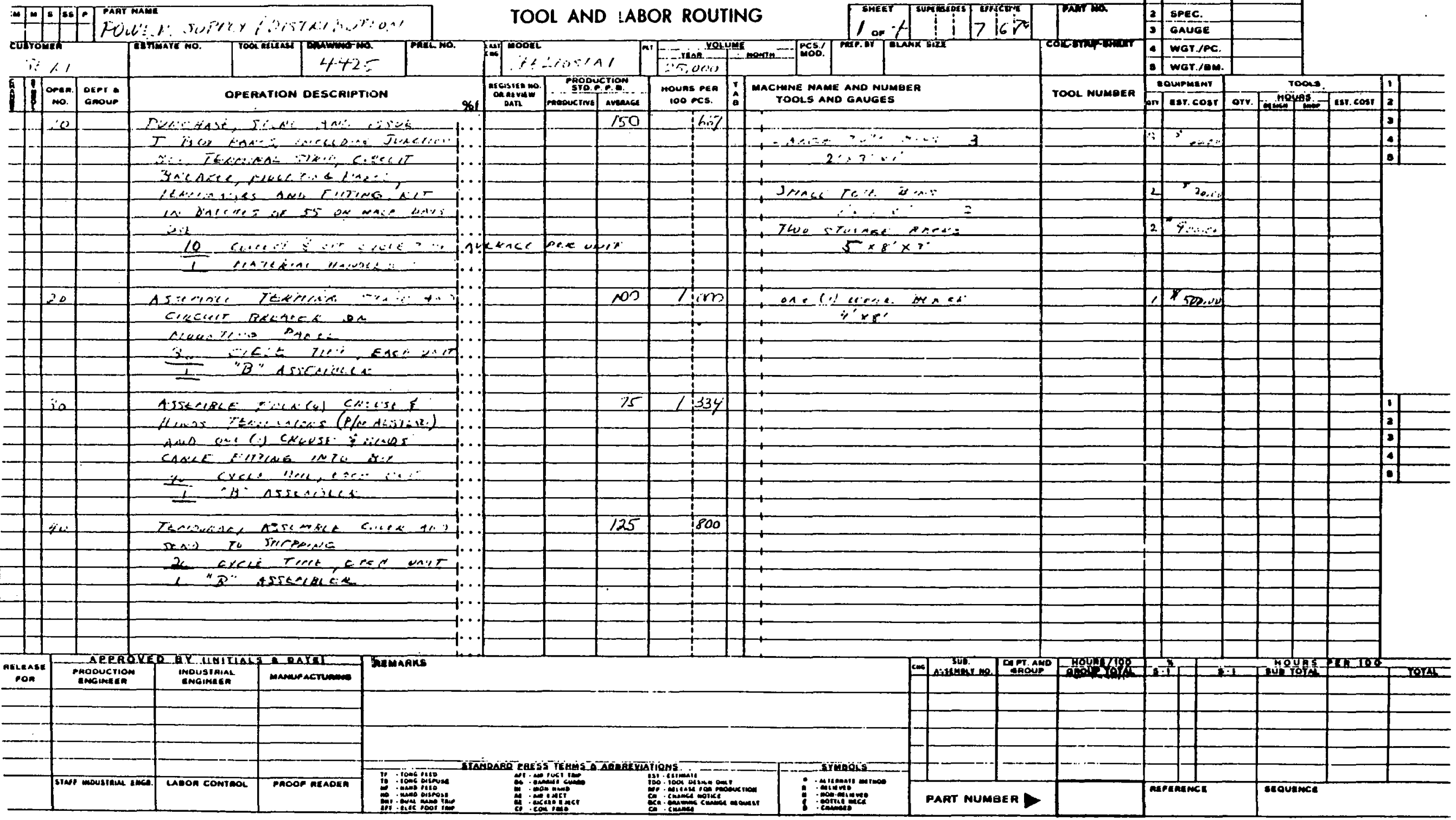




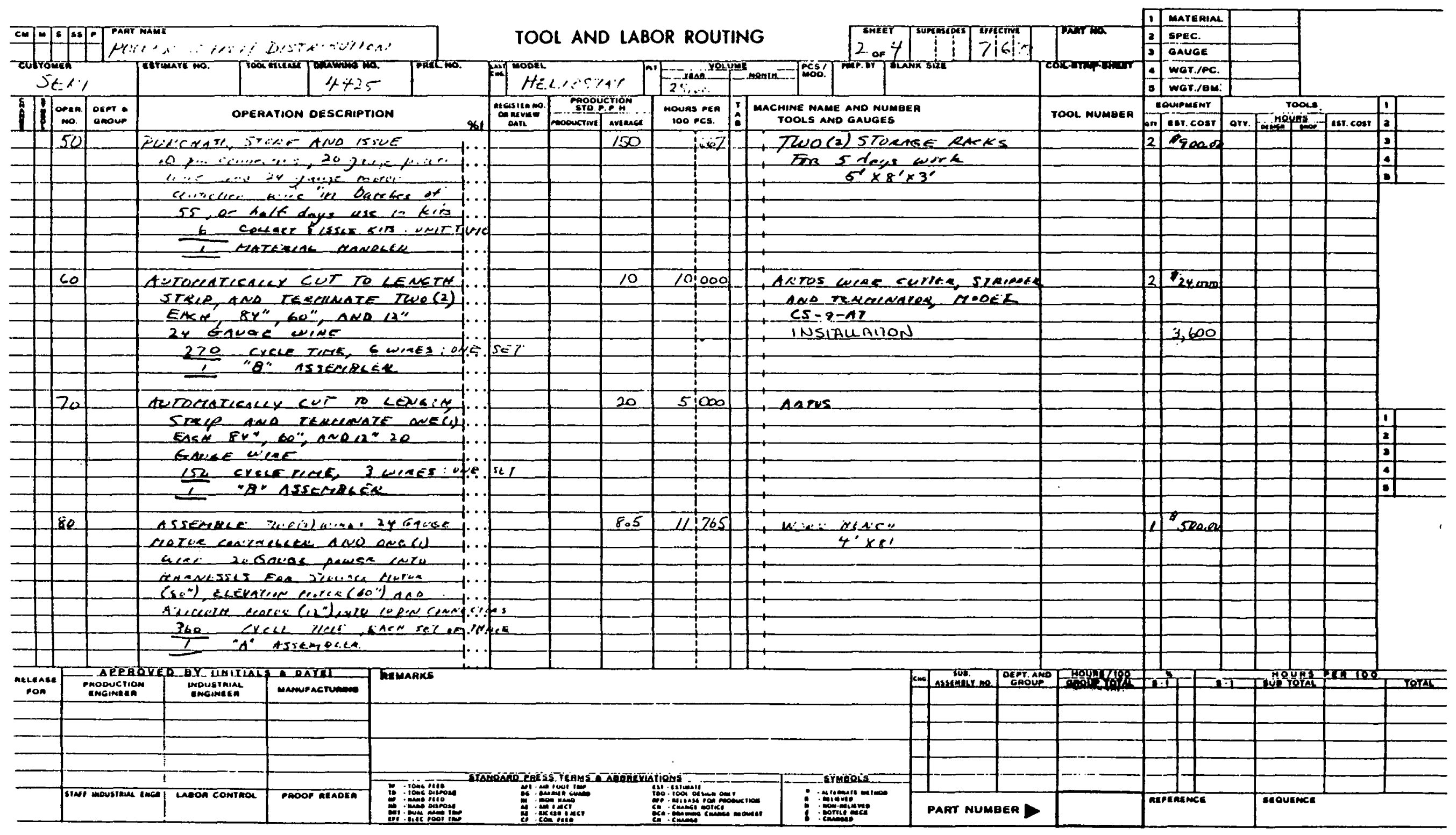




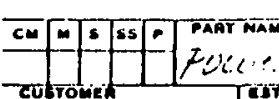

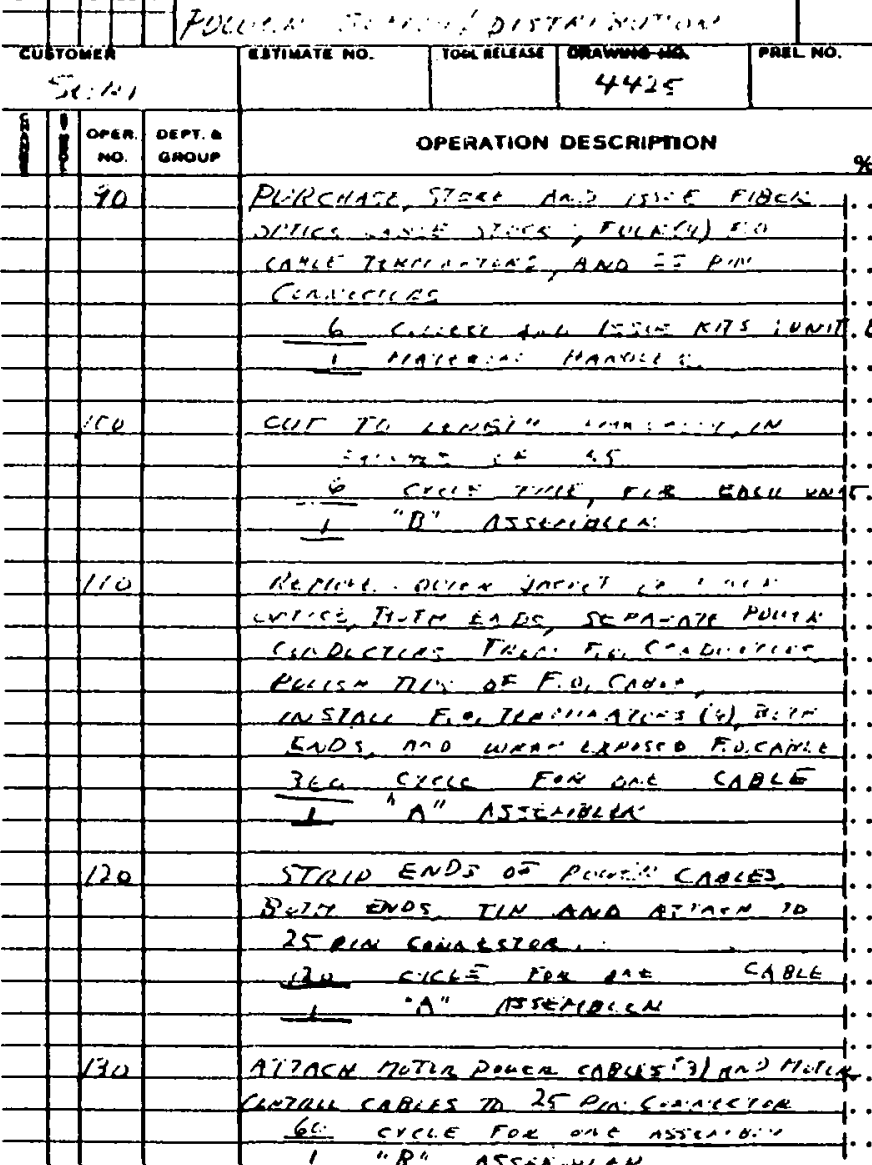

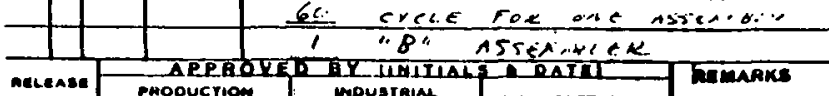

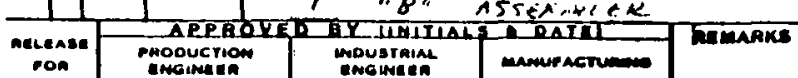
encimant

mowaren

\begin{tabular}{|c|}
\hline \\
\hline \\
\hline 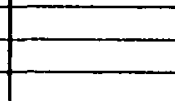 \\
\hline
\end{tabular}

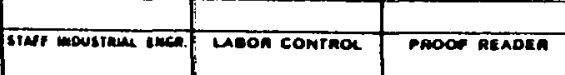

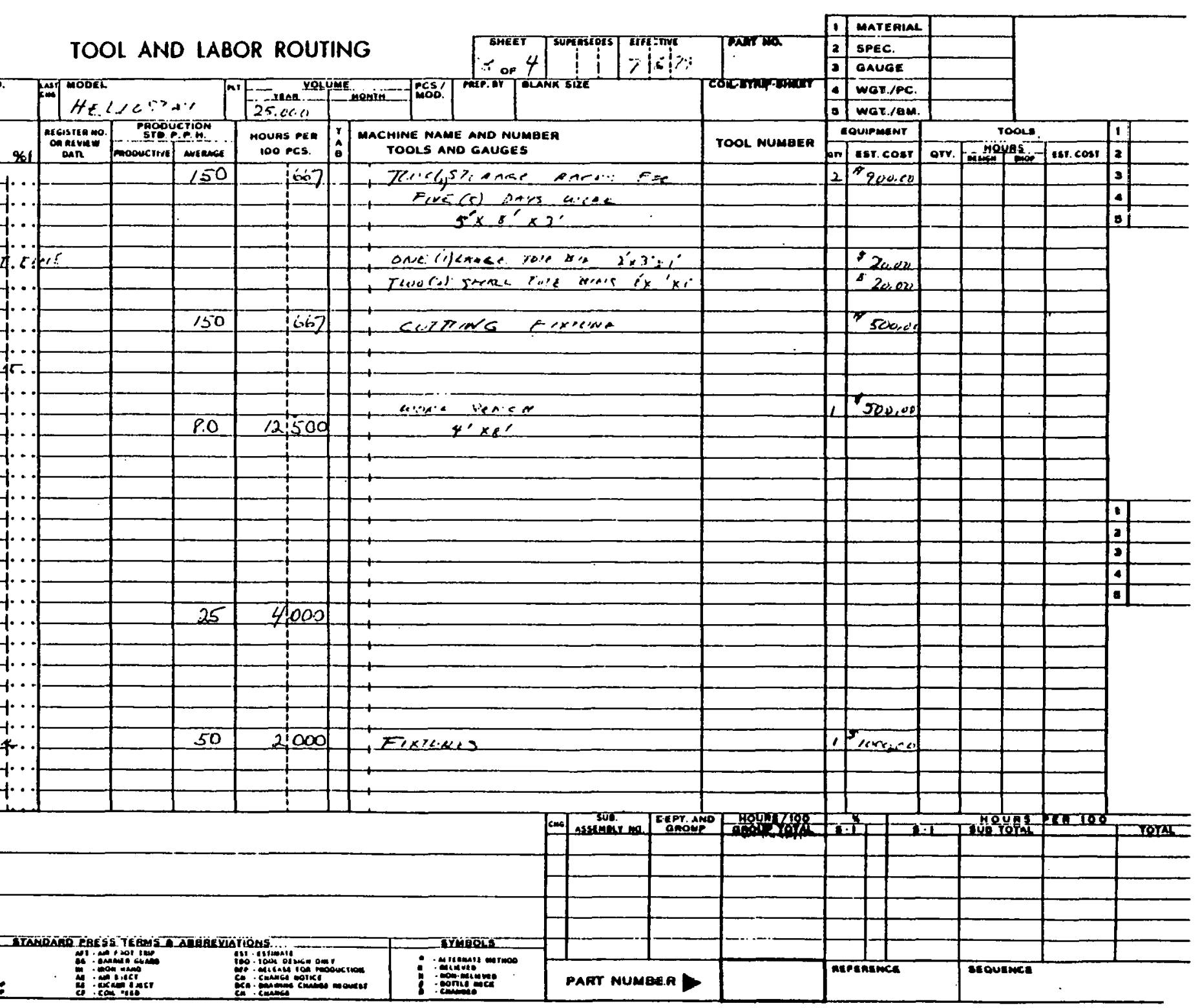




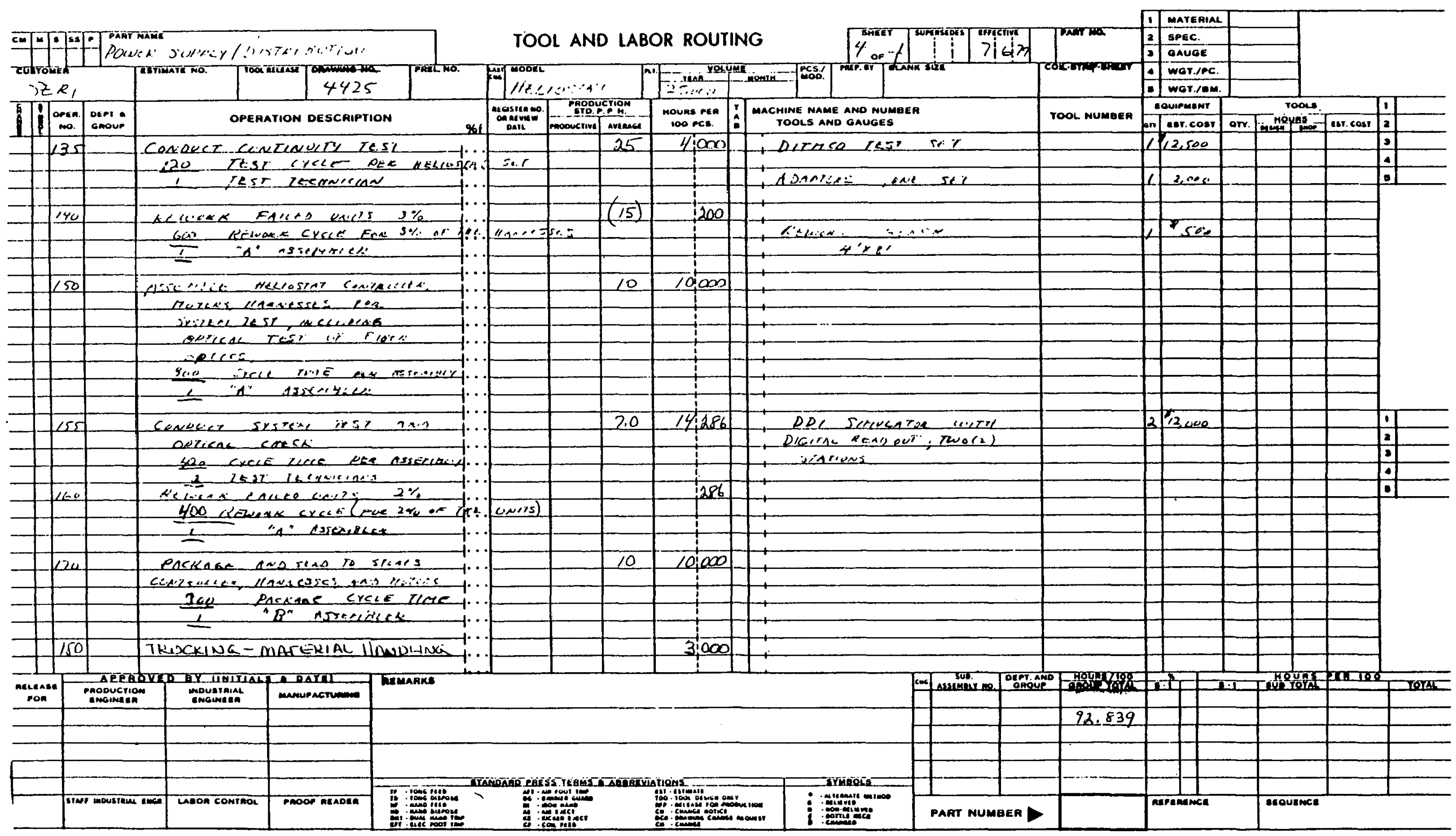




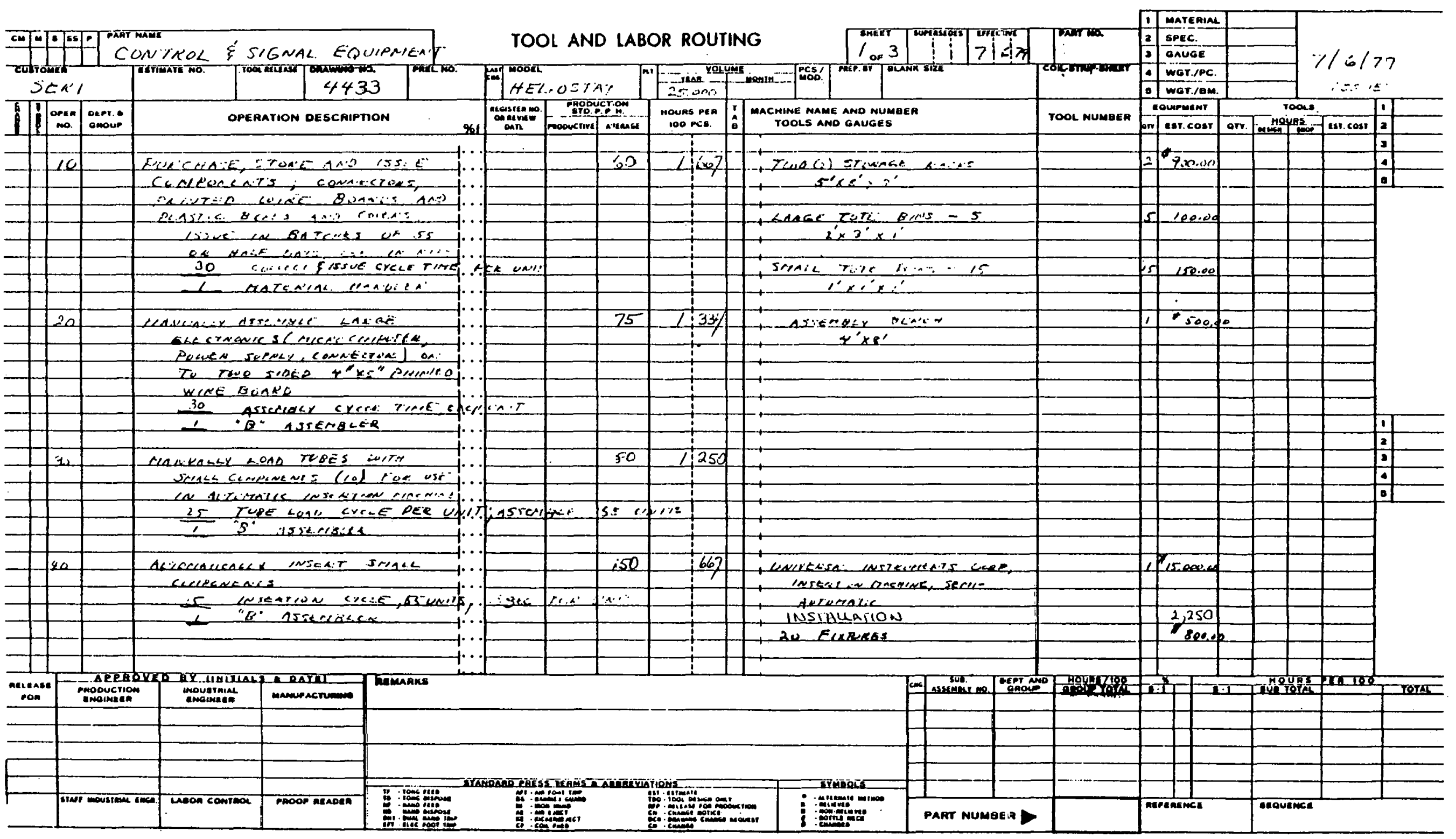




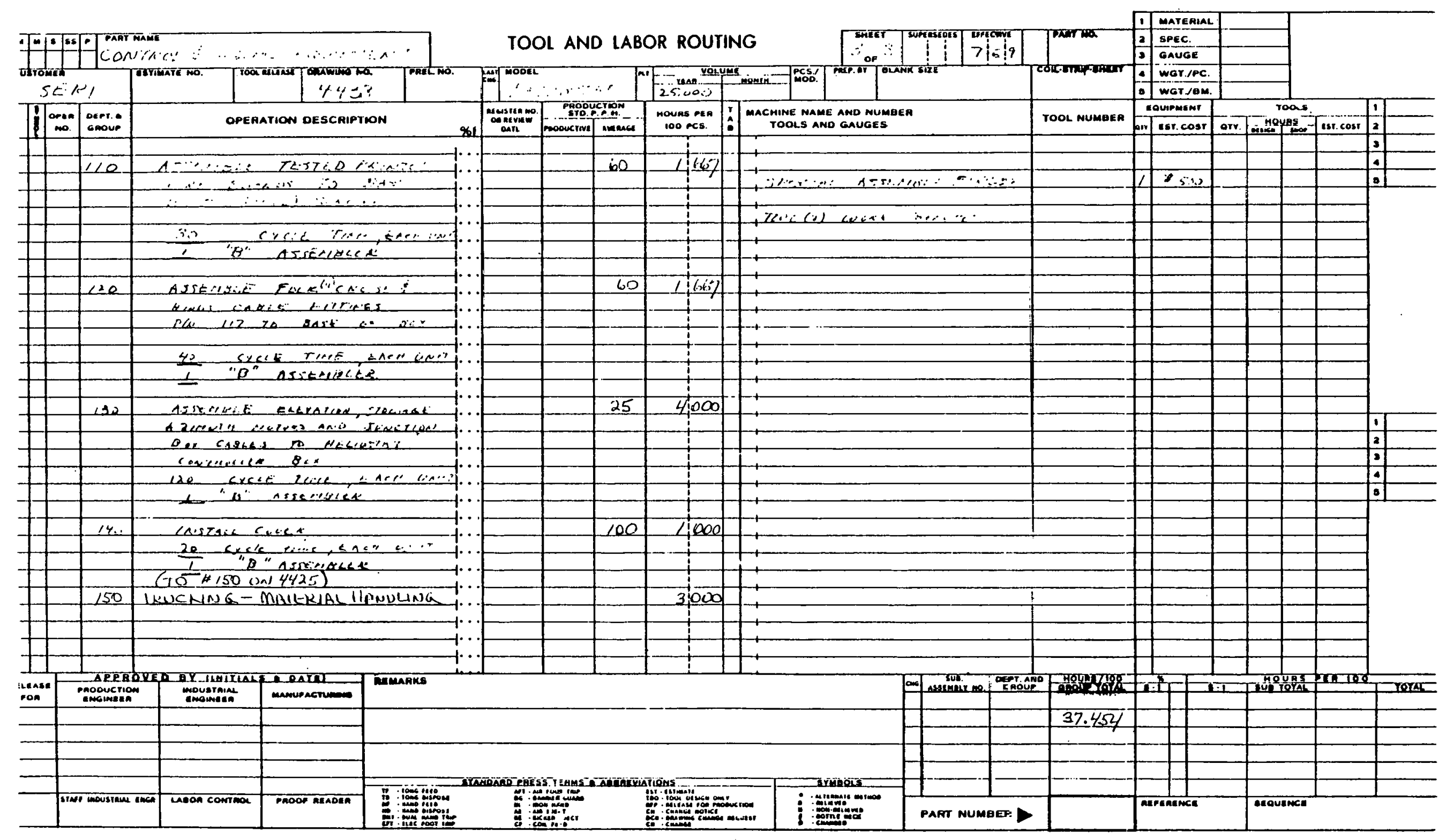




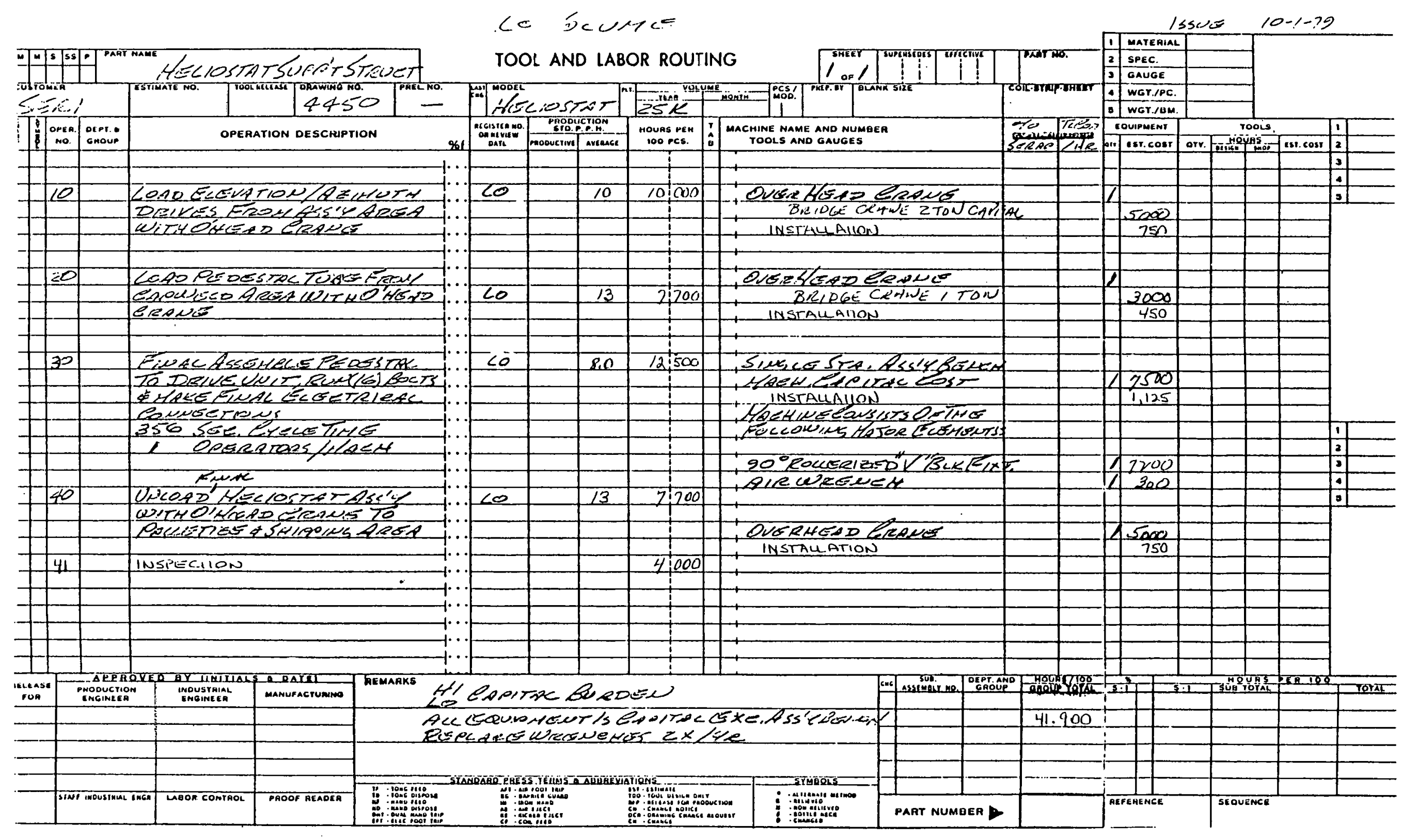




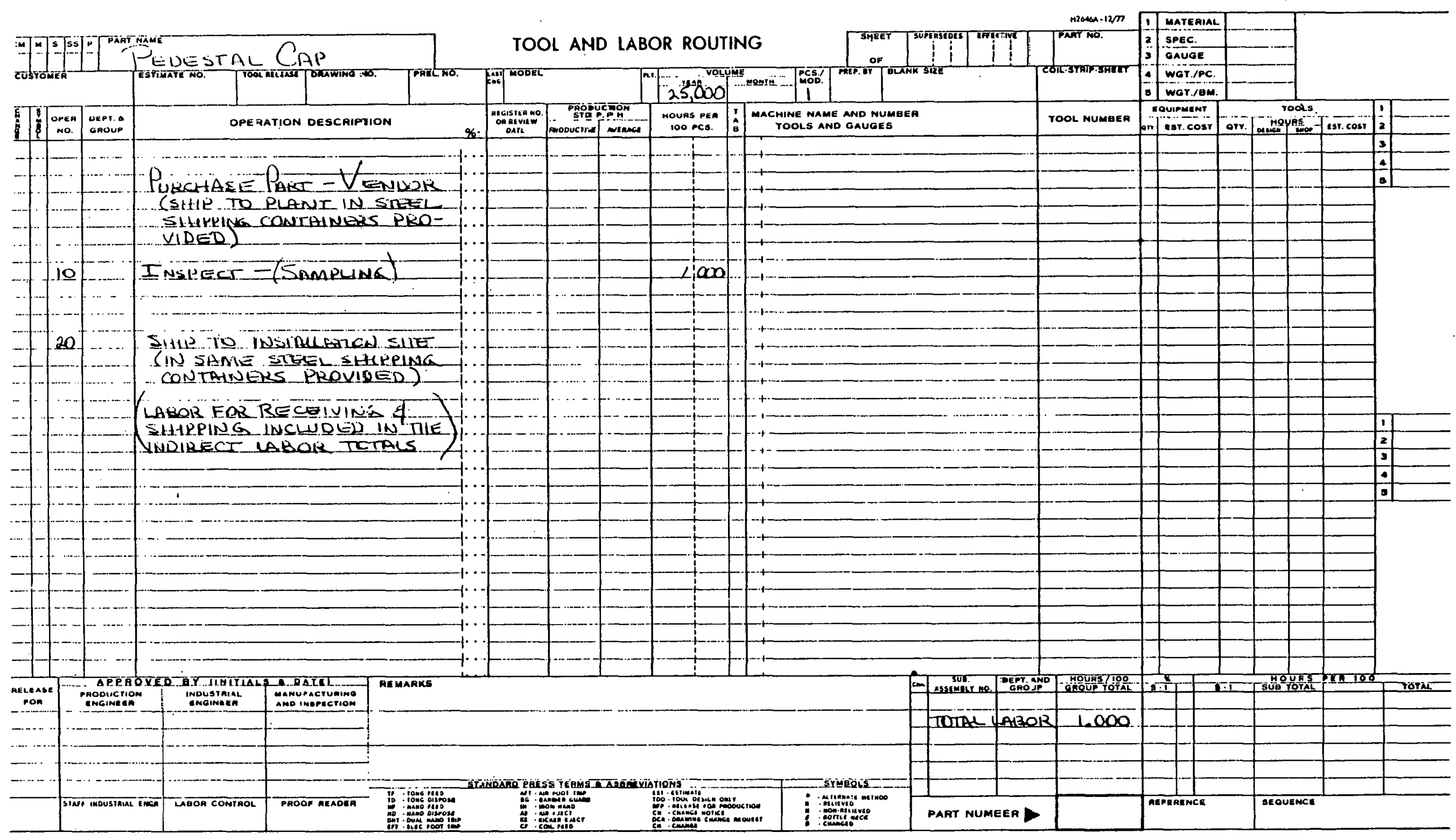


250,000 ANNUAL VOLUME

$C A 1$ 


\section{THIS PAGE WAS INTENTIONALLY \\ LEFT BLANK}


$350, K_{A}$ wNUAC JoLUATÉ

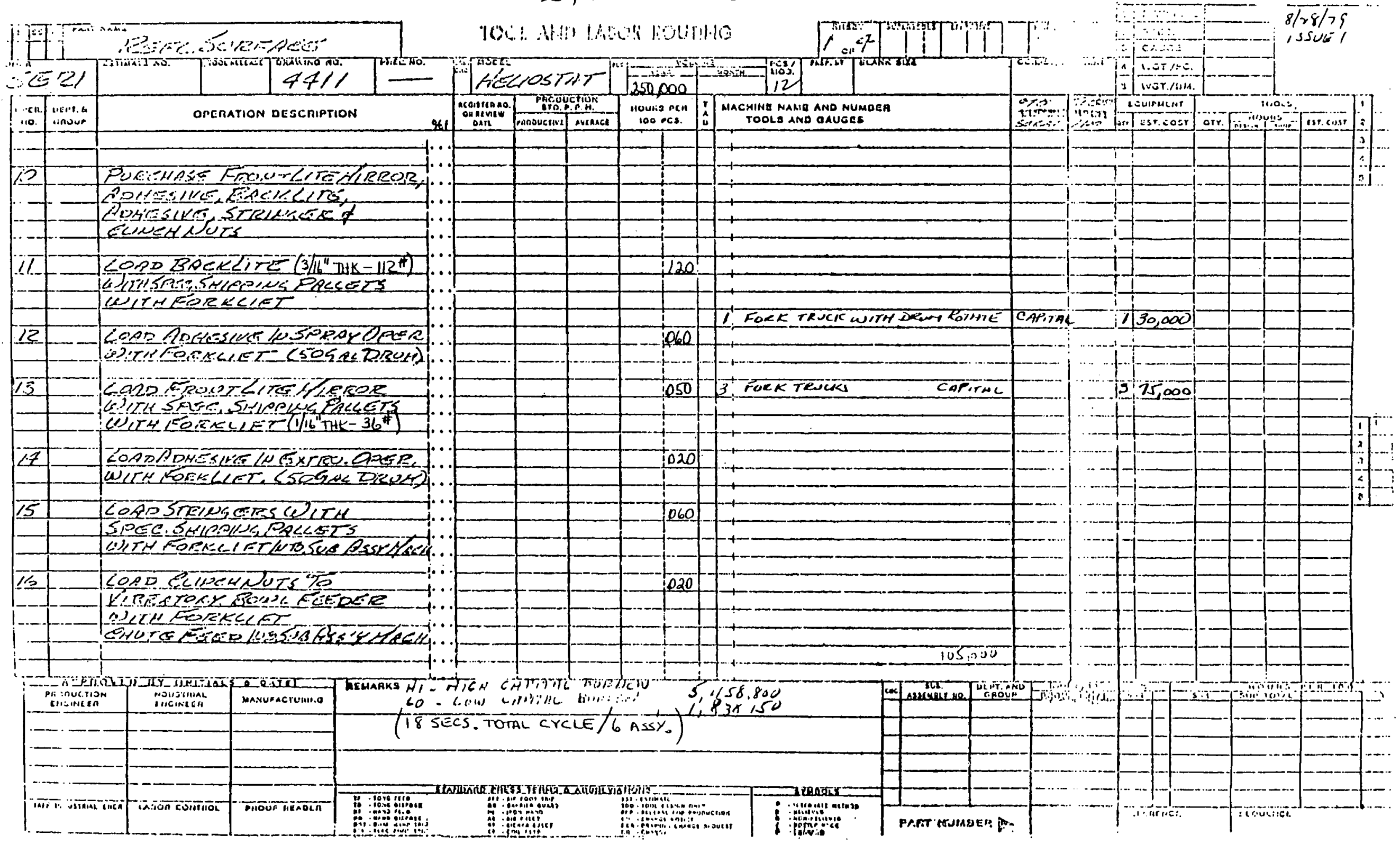


$2 \leq 0,000 A$ INAC VOCUME

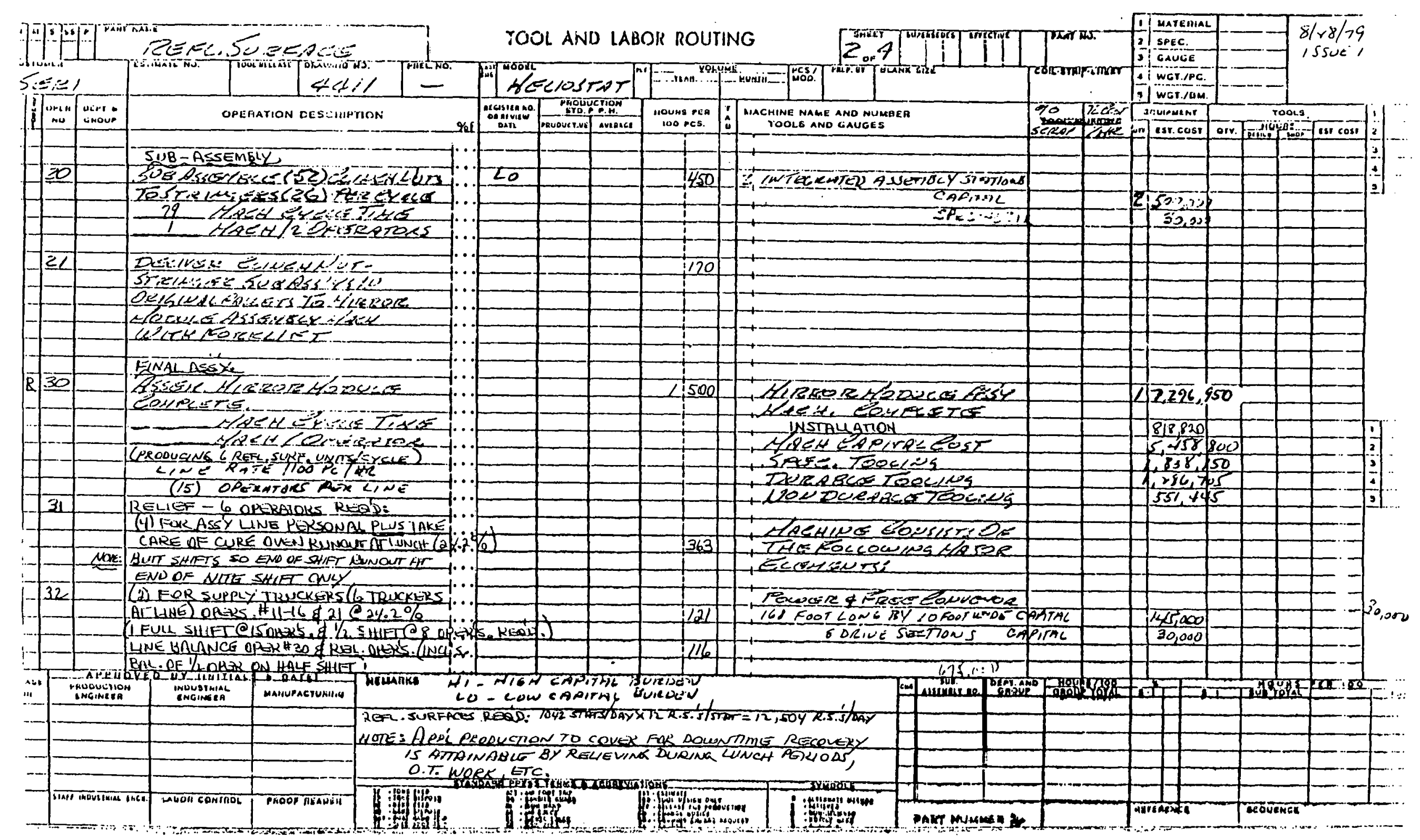


250,000 A NAUHC NOCUNAE

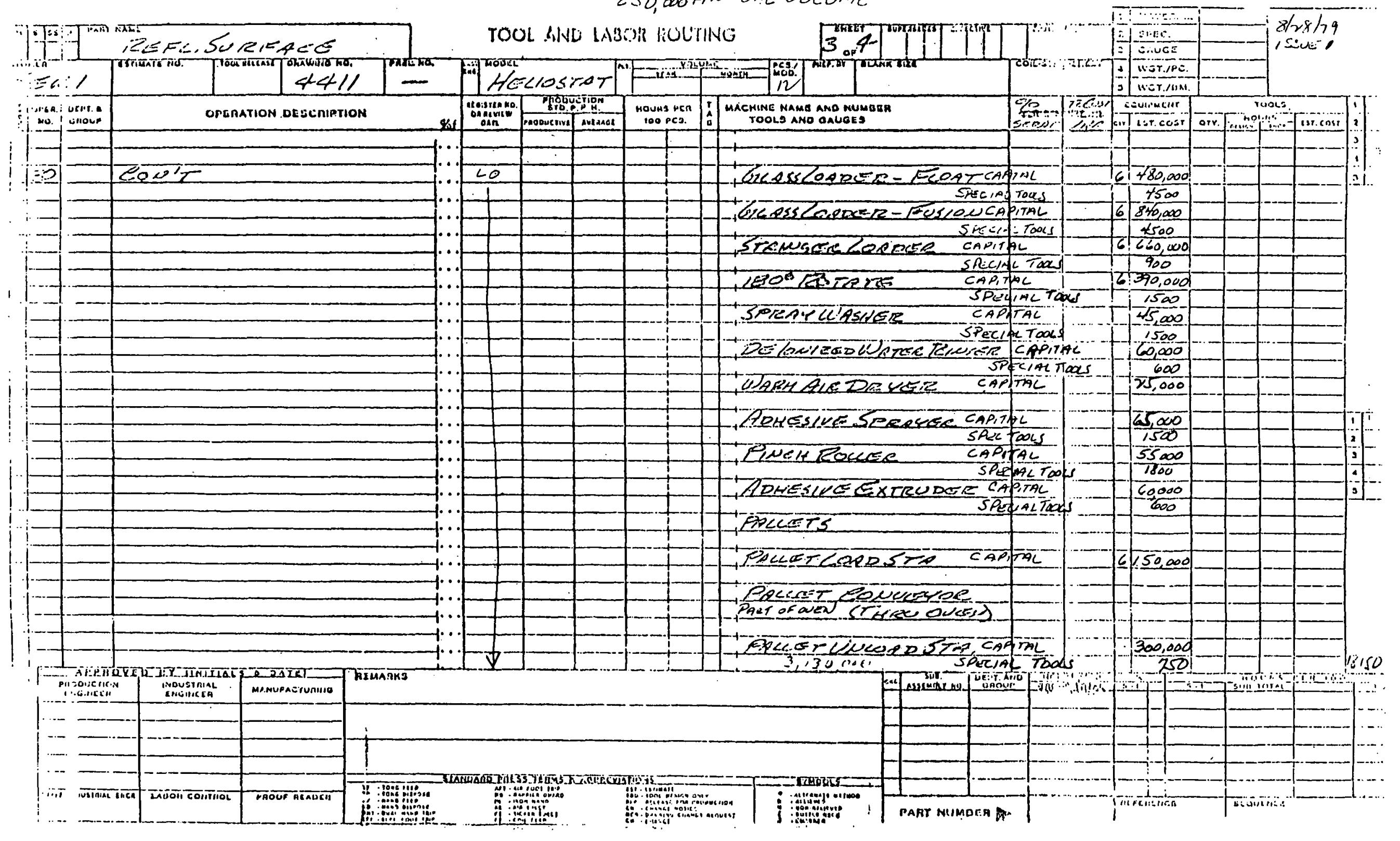


US, 000 ANNUAL VOCUME

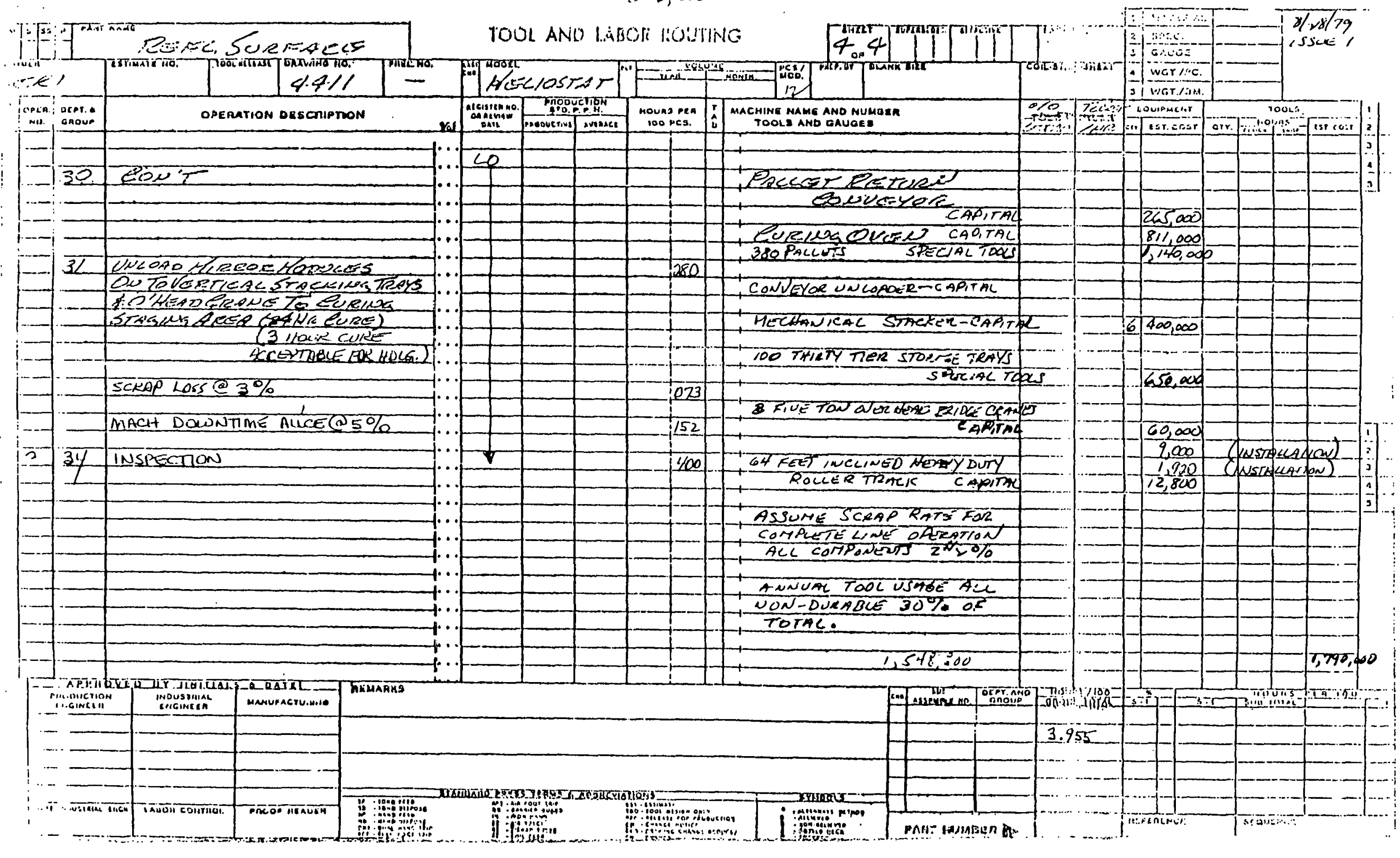




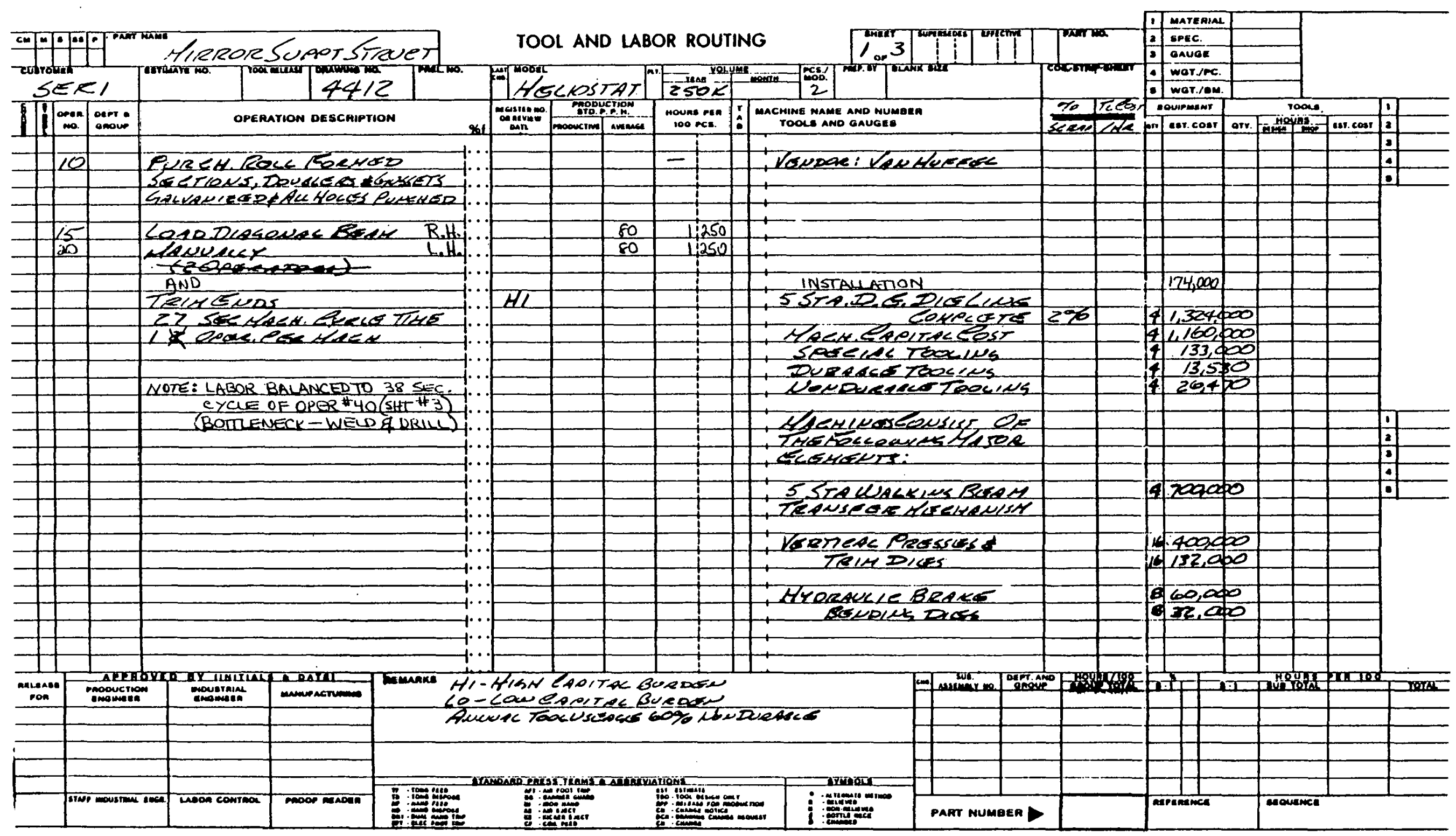




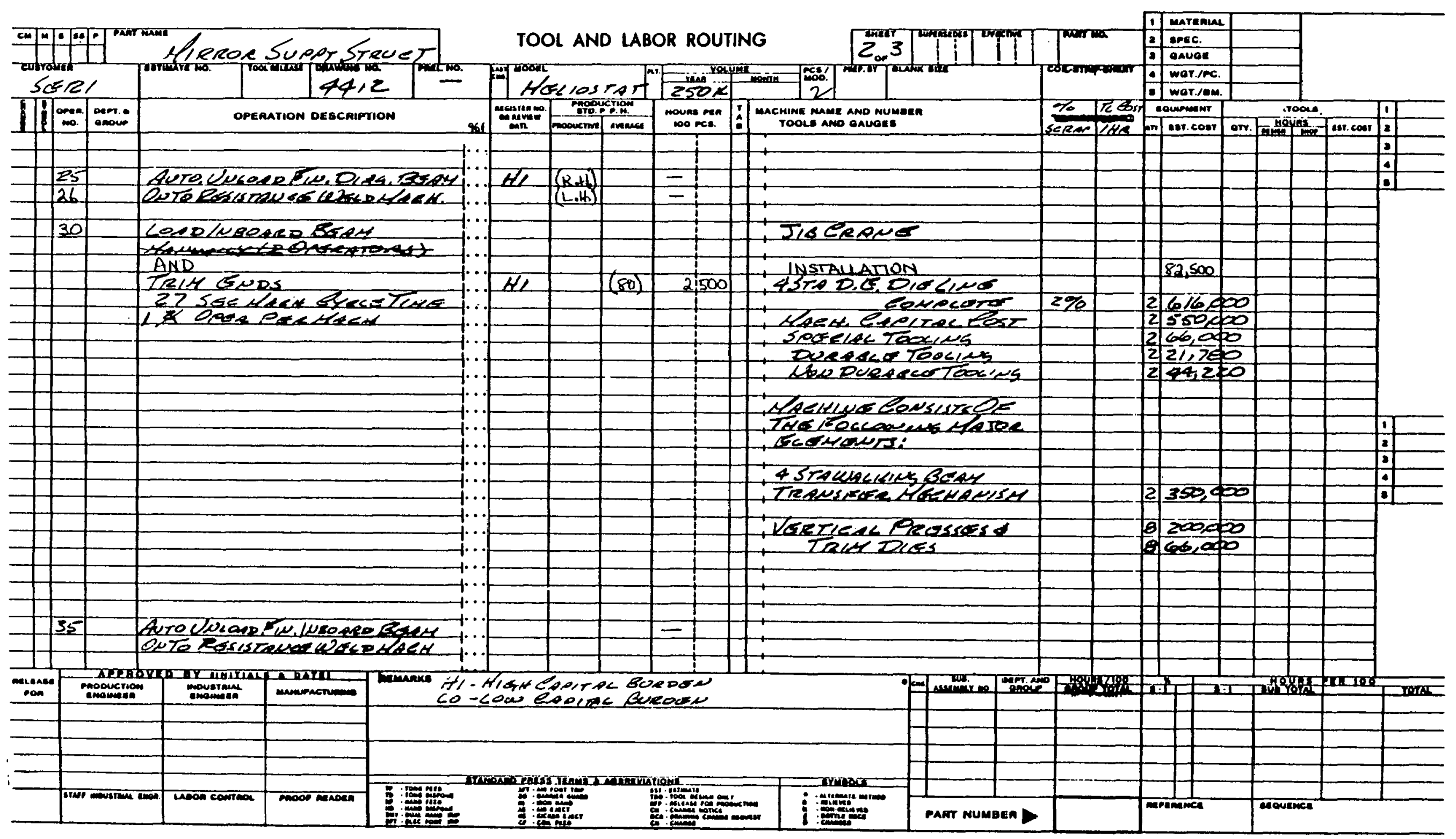


li-Volume

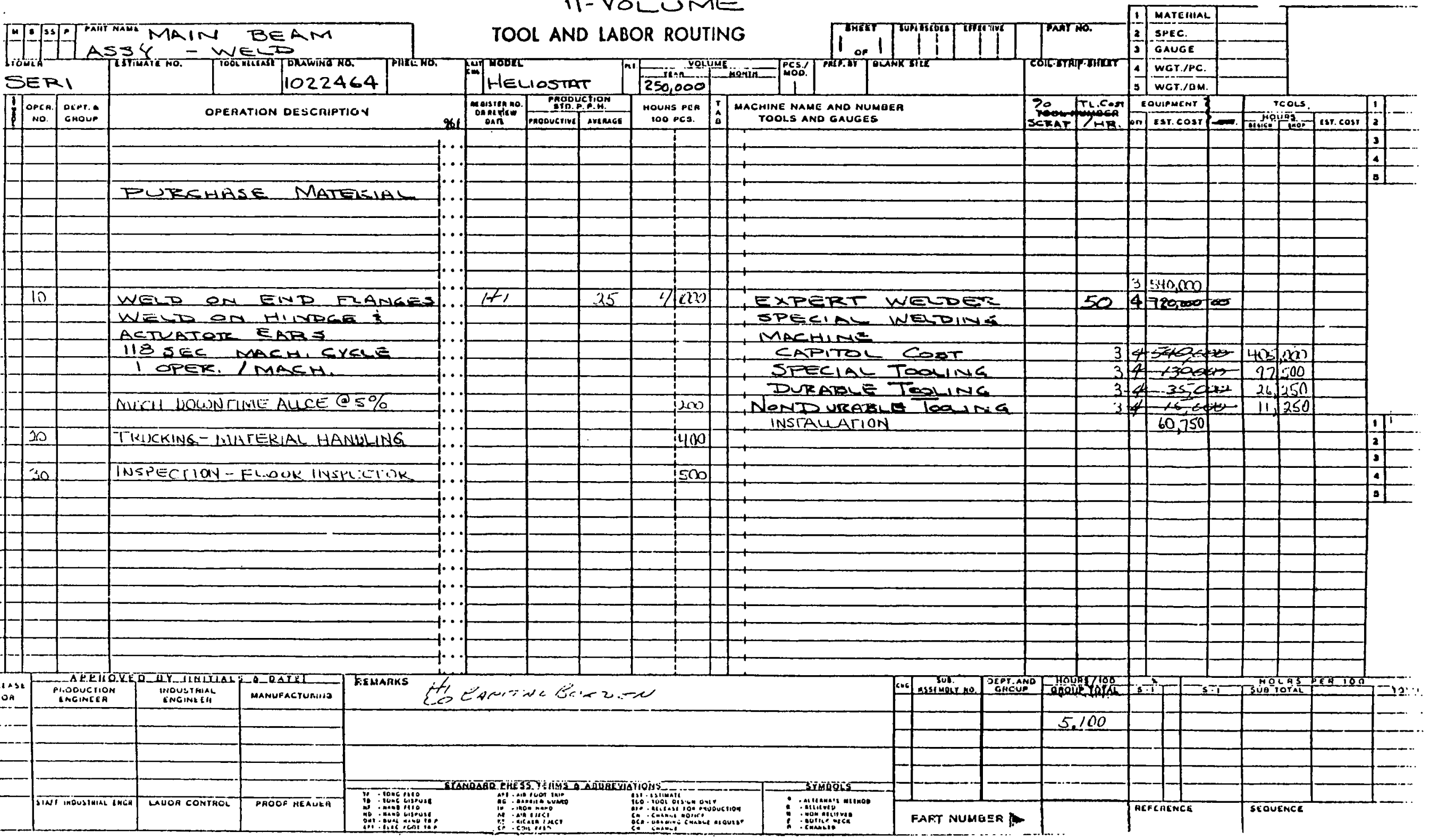




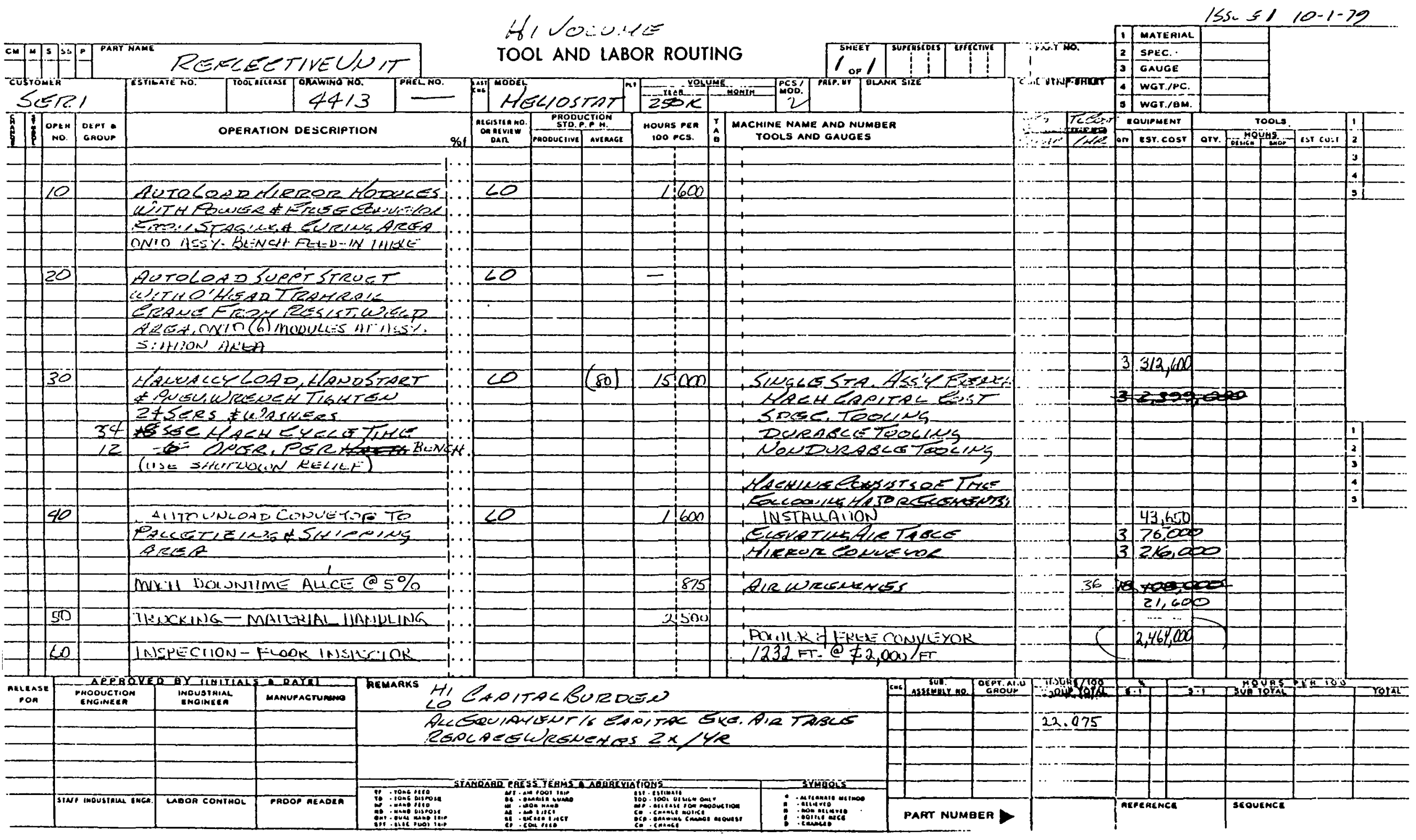

C51 


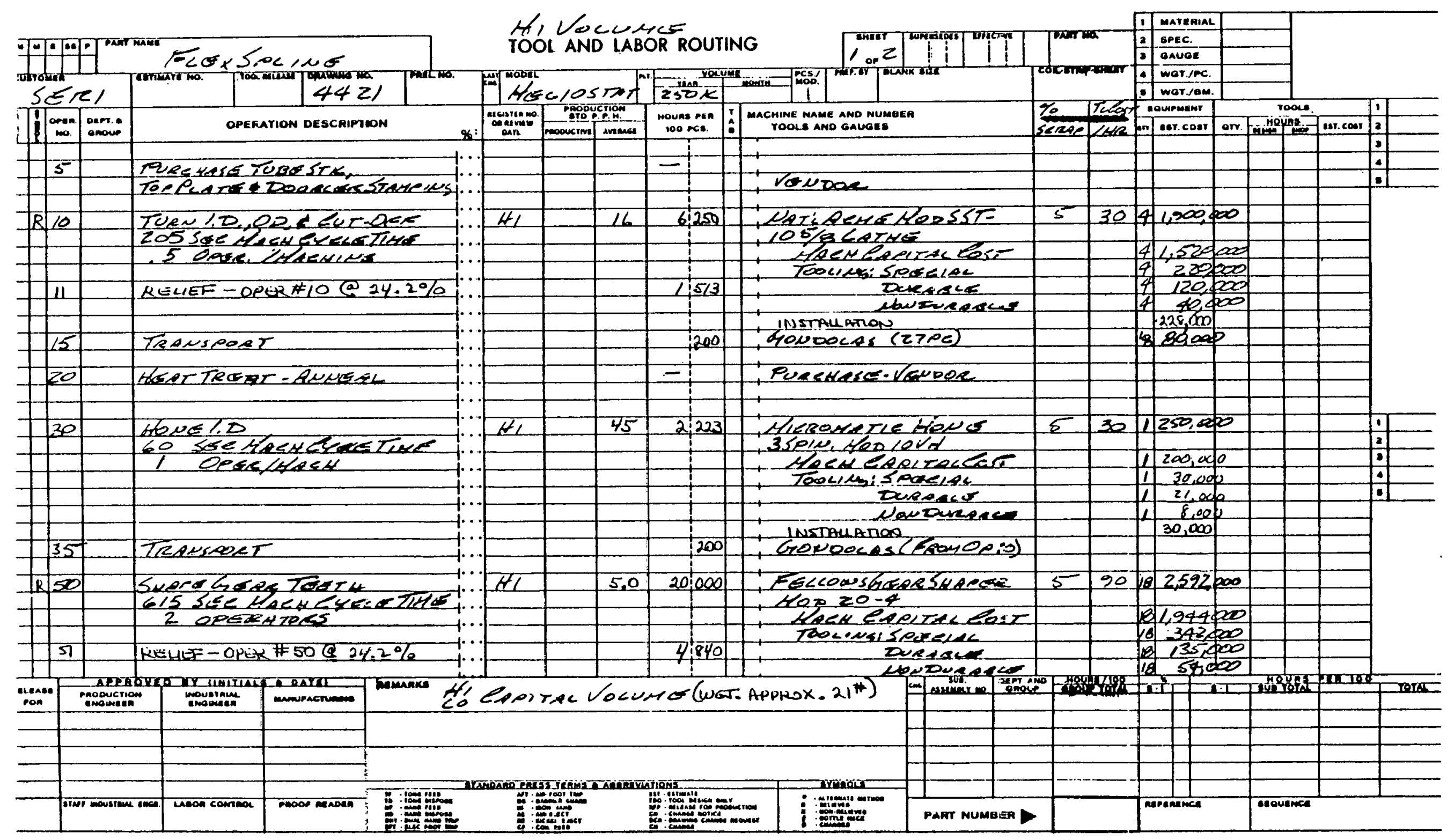




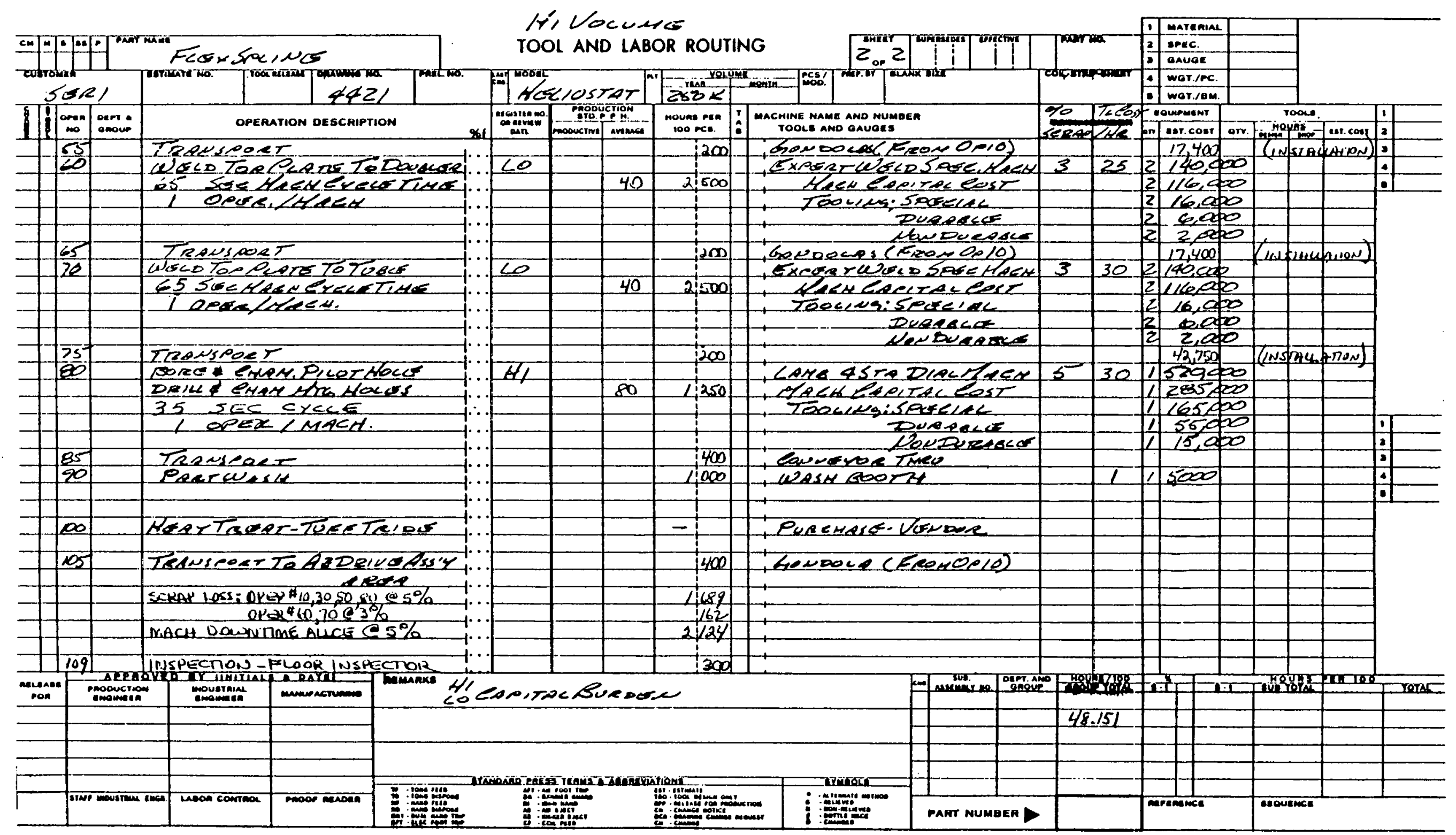




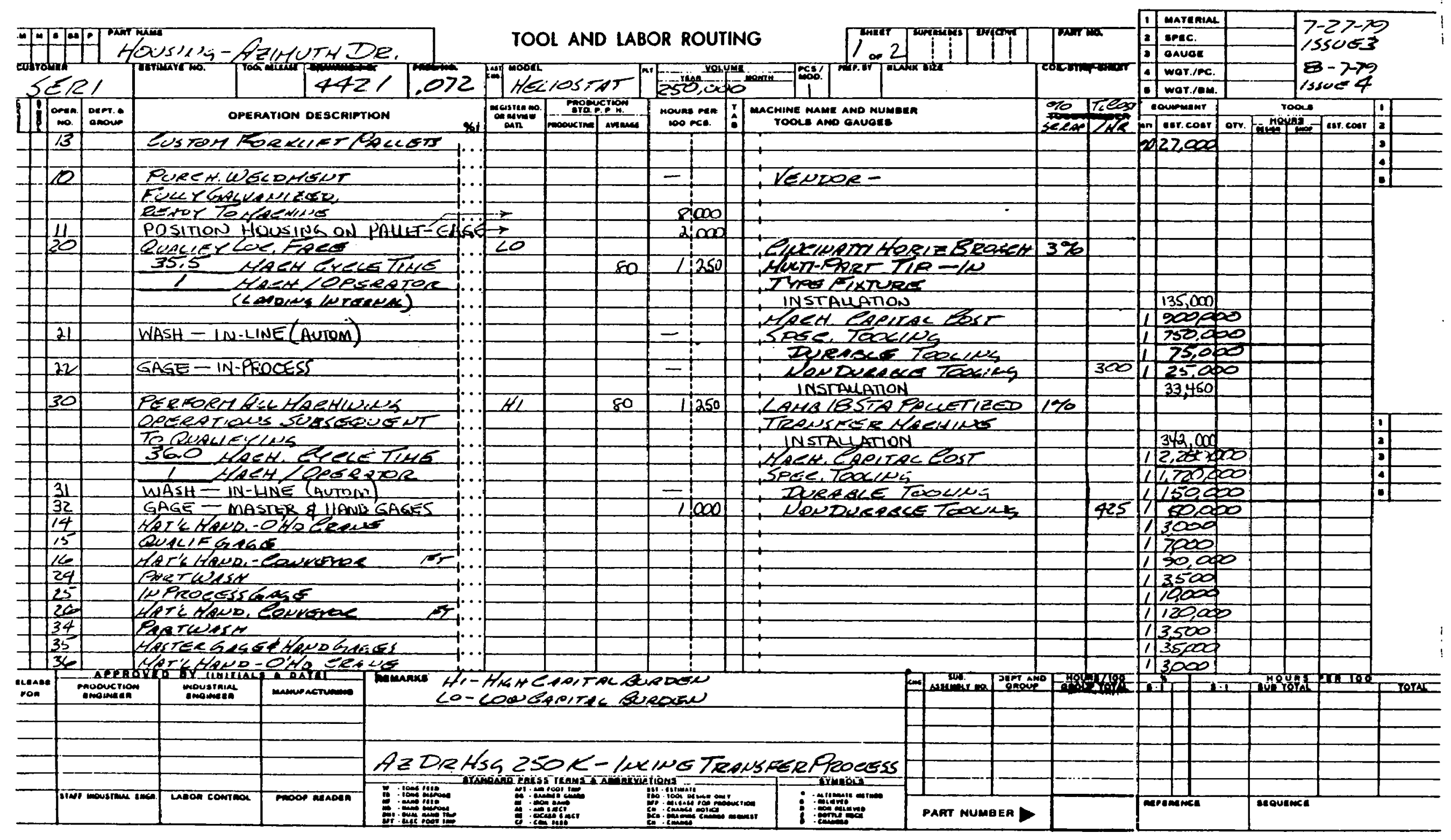




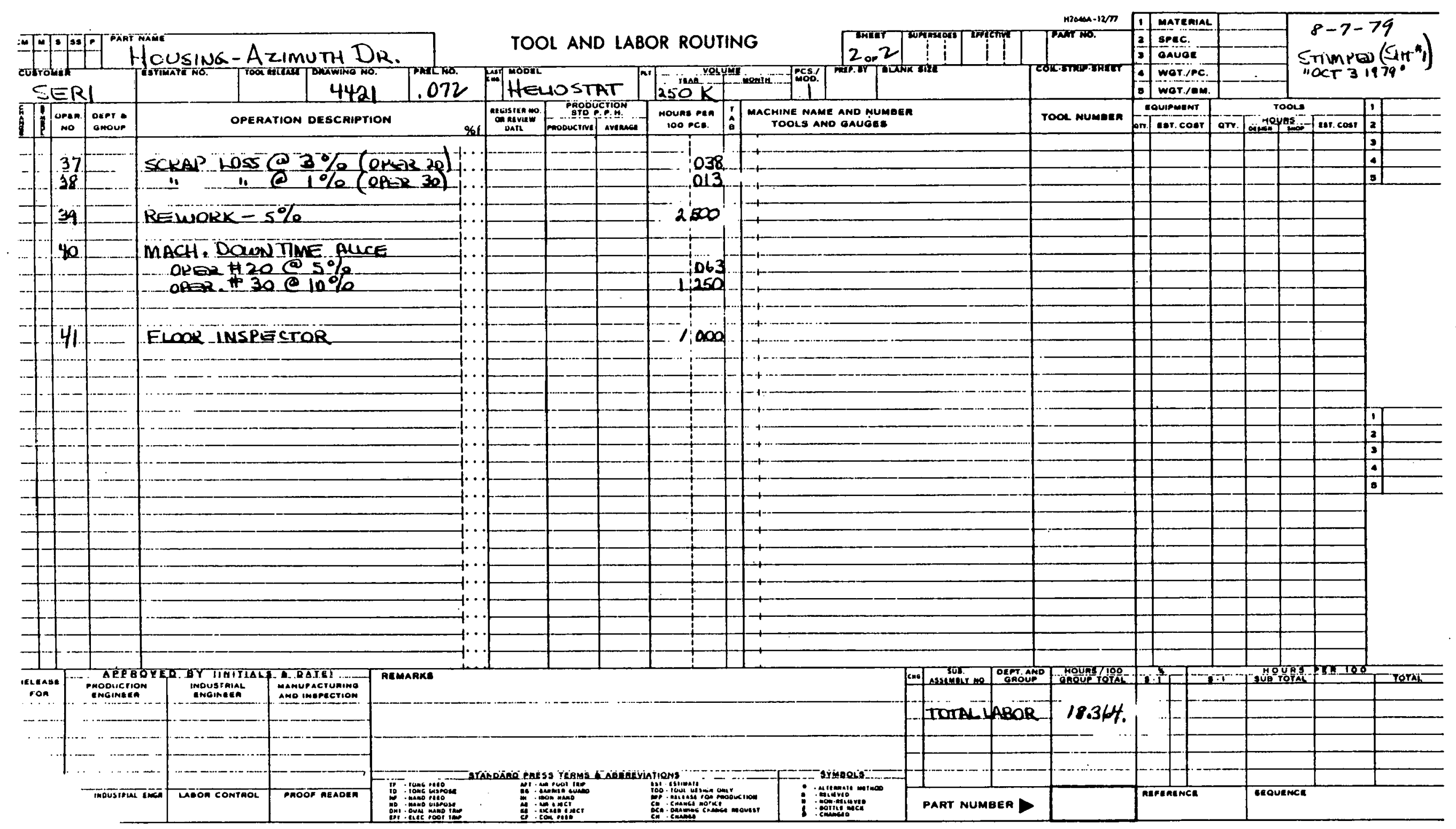




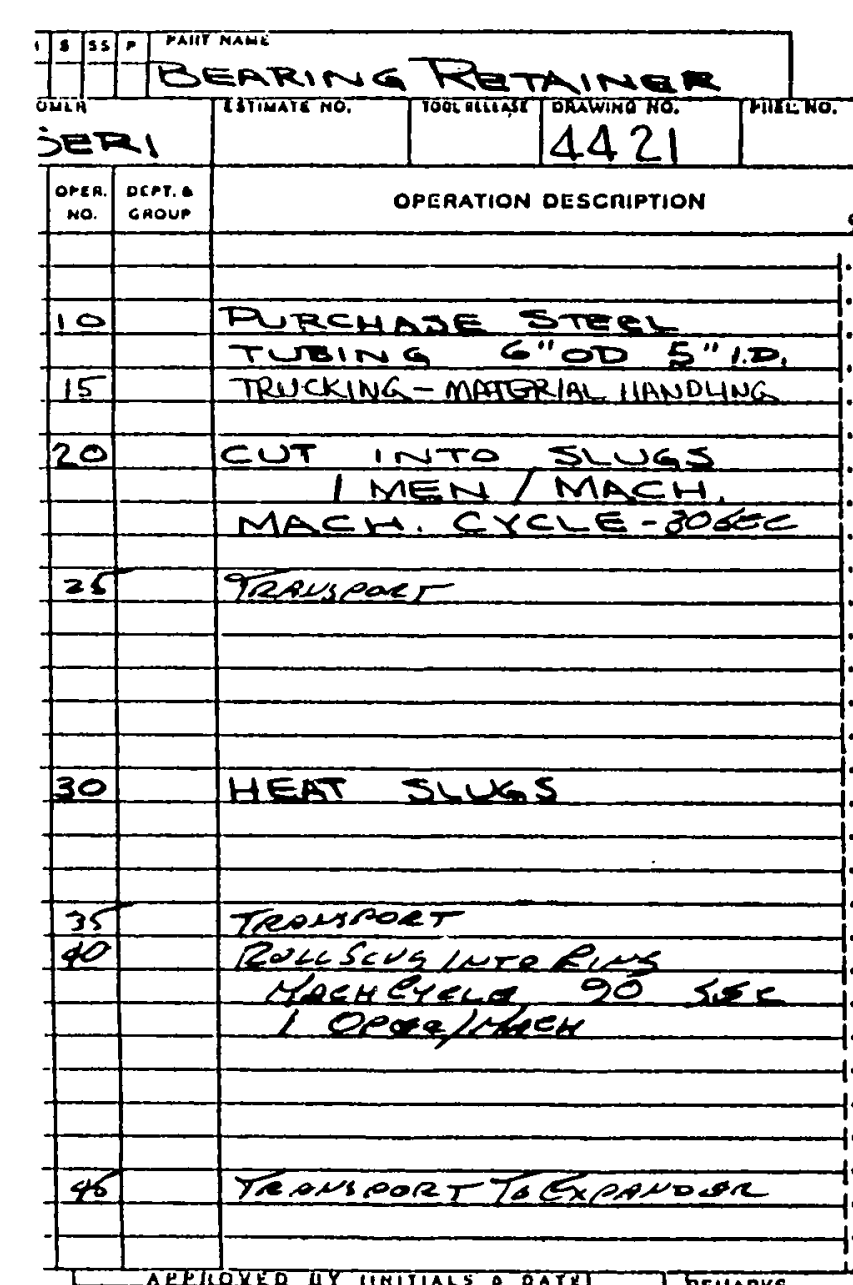

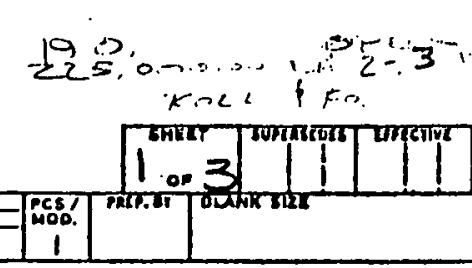

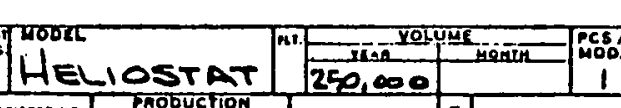

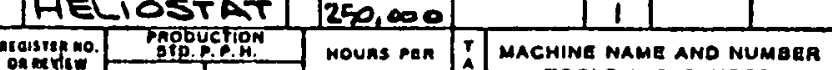

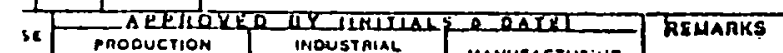

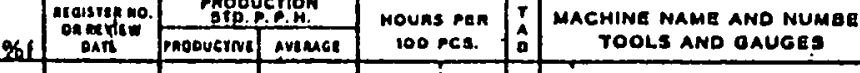

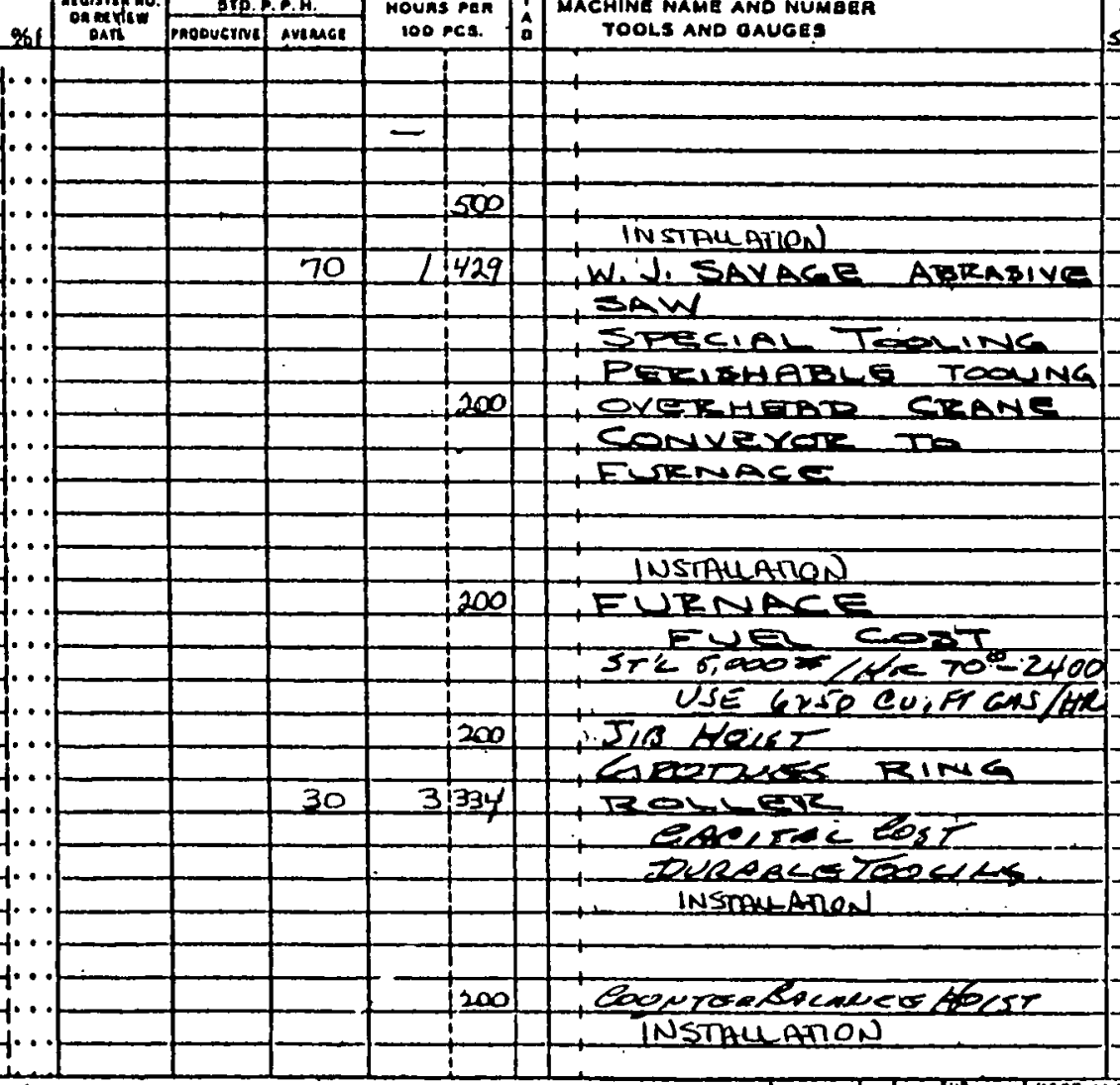

पहEम-

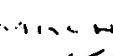

-

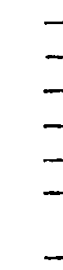

7

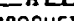

\begin{tabular}{|c|c|}
\hline 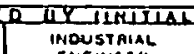 & R 0 ental \\
\hline & \\
\hline & \\
\hline & \\
\hline & \\
\hline WDON CONTHOL & TROOO MEAUER \\
\hline & \\
\hline
\end{tabular}

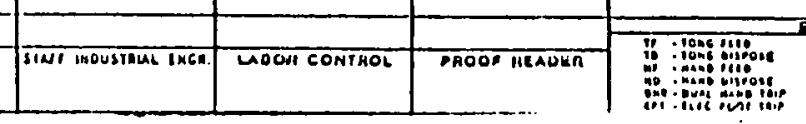

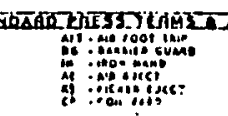

\begin{tabular}{|c|c|c|c|}
\hline - SE (WGT. AP & $x .50^{4)}$ & 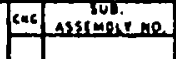 & 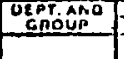 \\
\hline & & & \\
\hline & & & \\
\hline & & 1 & \\
\hline 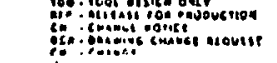 & a : & PART N & $=R$ \\
\hline
\end{tabular}

carrompram

MSUCE/

$-1-29$

$\frac{1}{2}$ MATER.

3 Gauce

4 WCT.jPC.

5 WaT.jom.

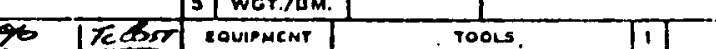

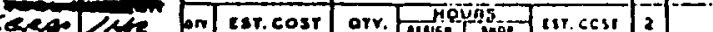
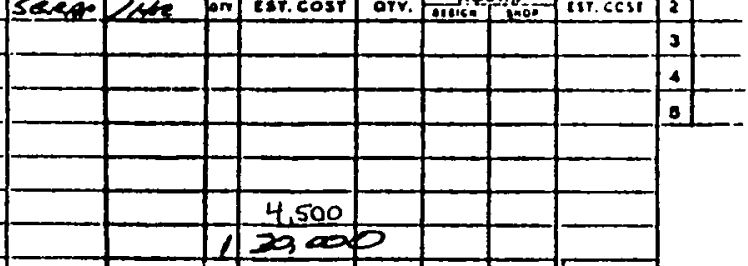

\begin{tabular}{l|l|l}
-1 & \\
\hline
\end{tabular}

| 


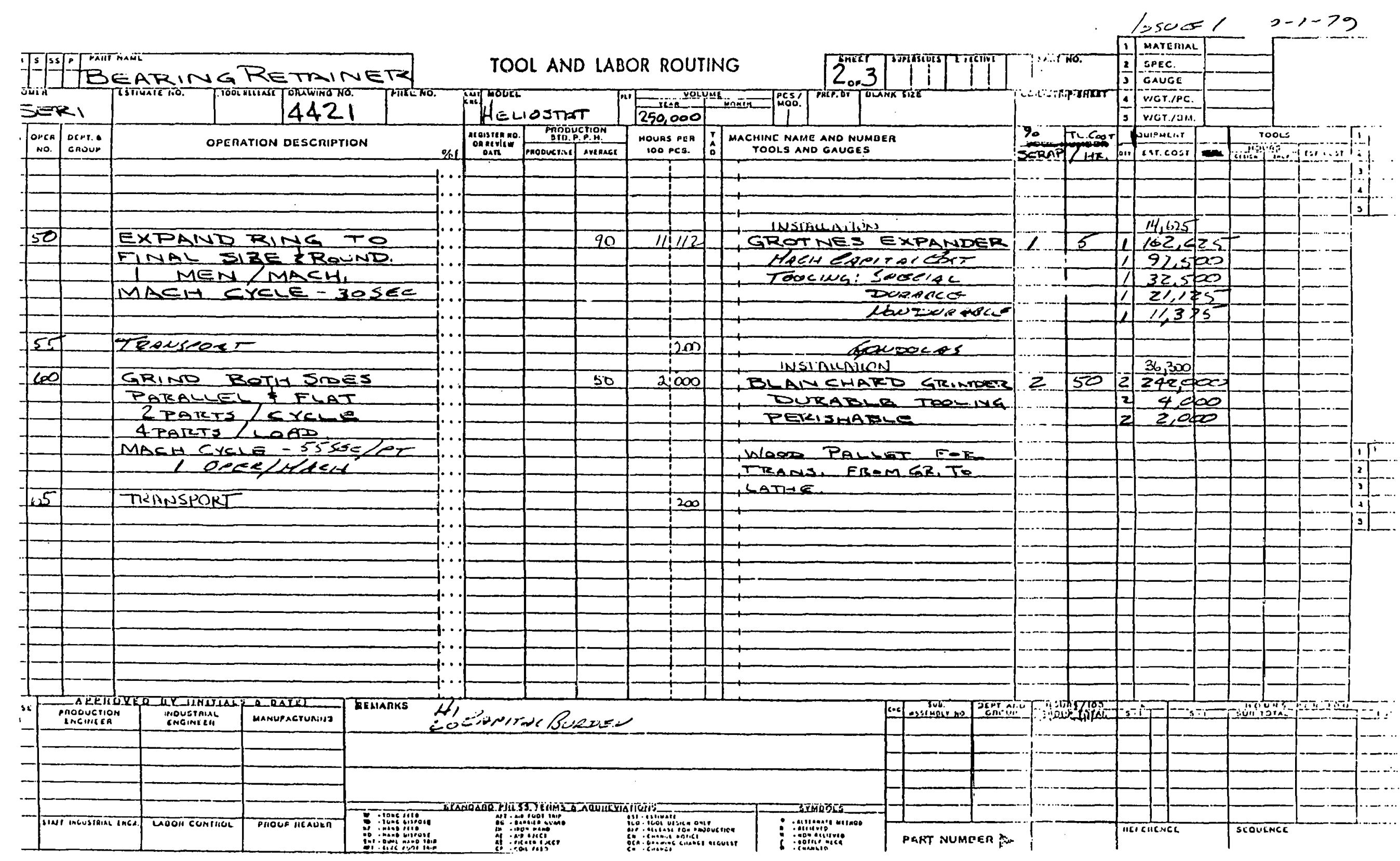




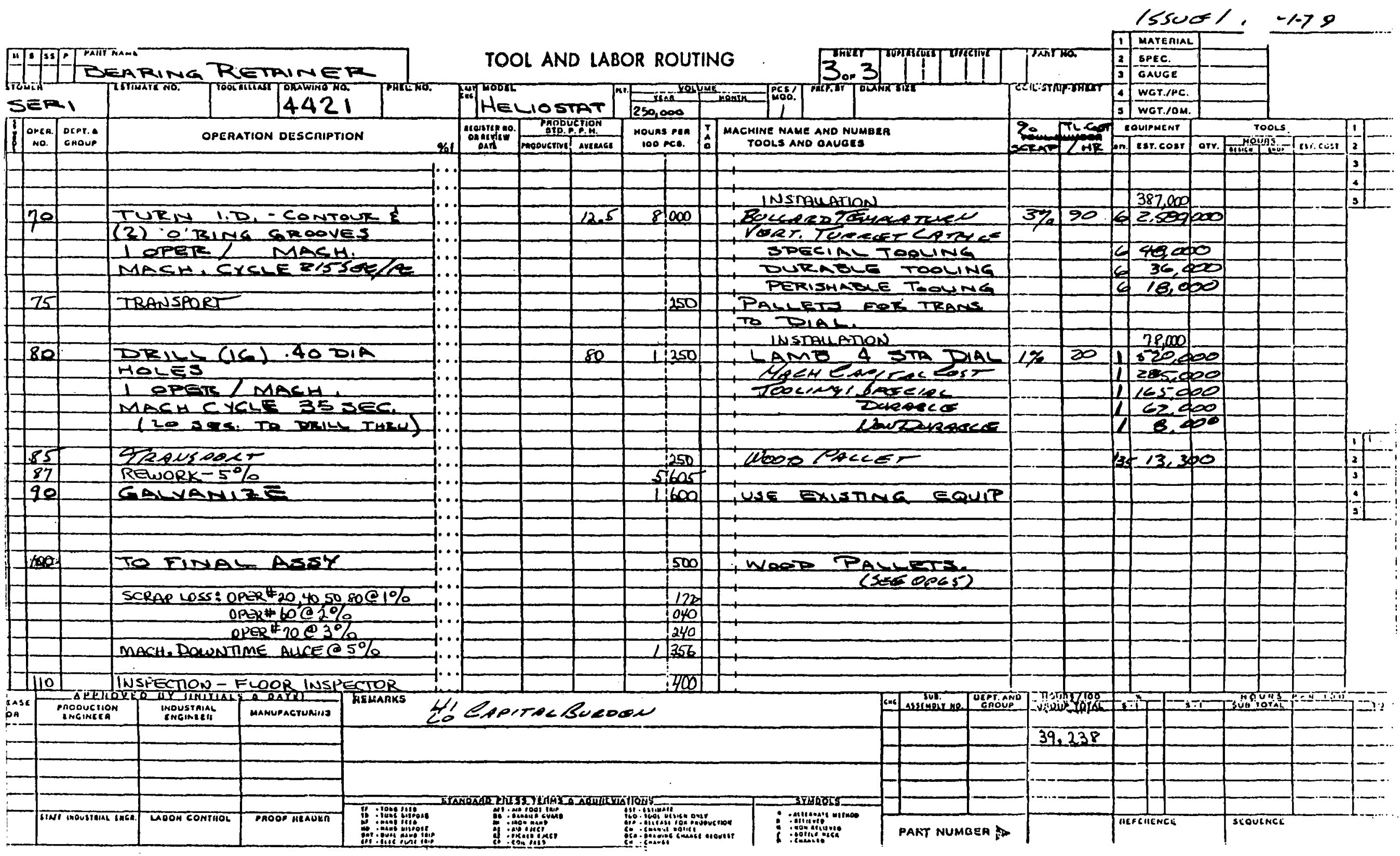




\section{1-Volume}

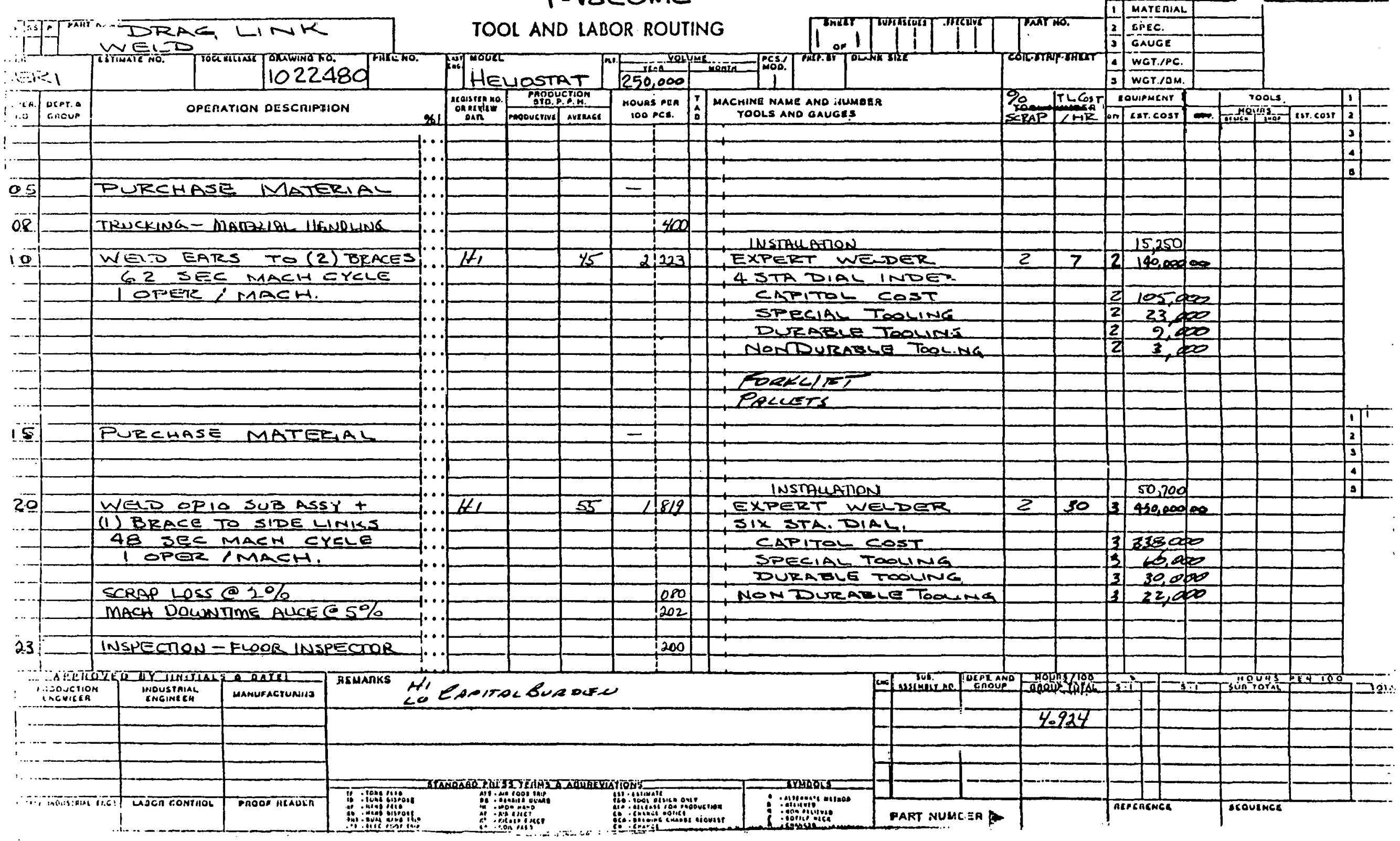




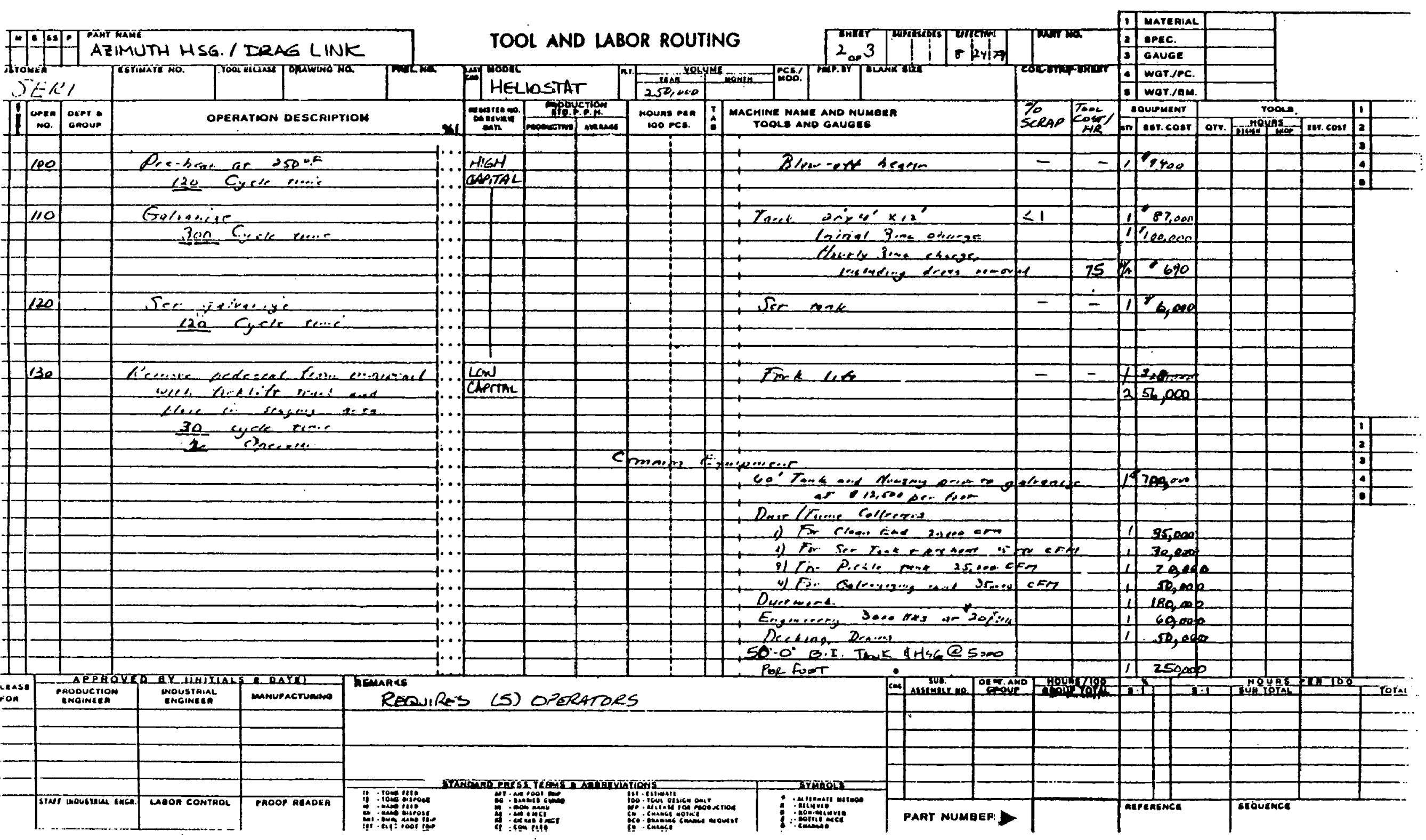




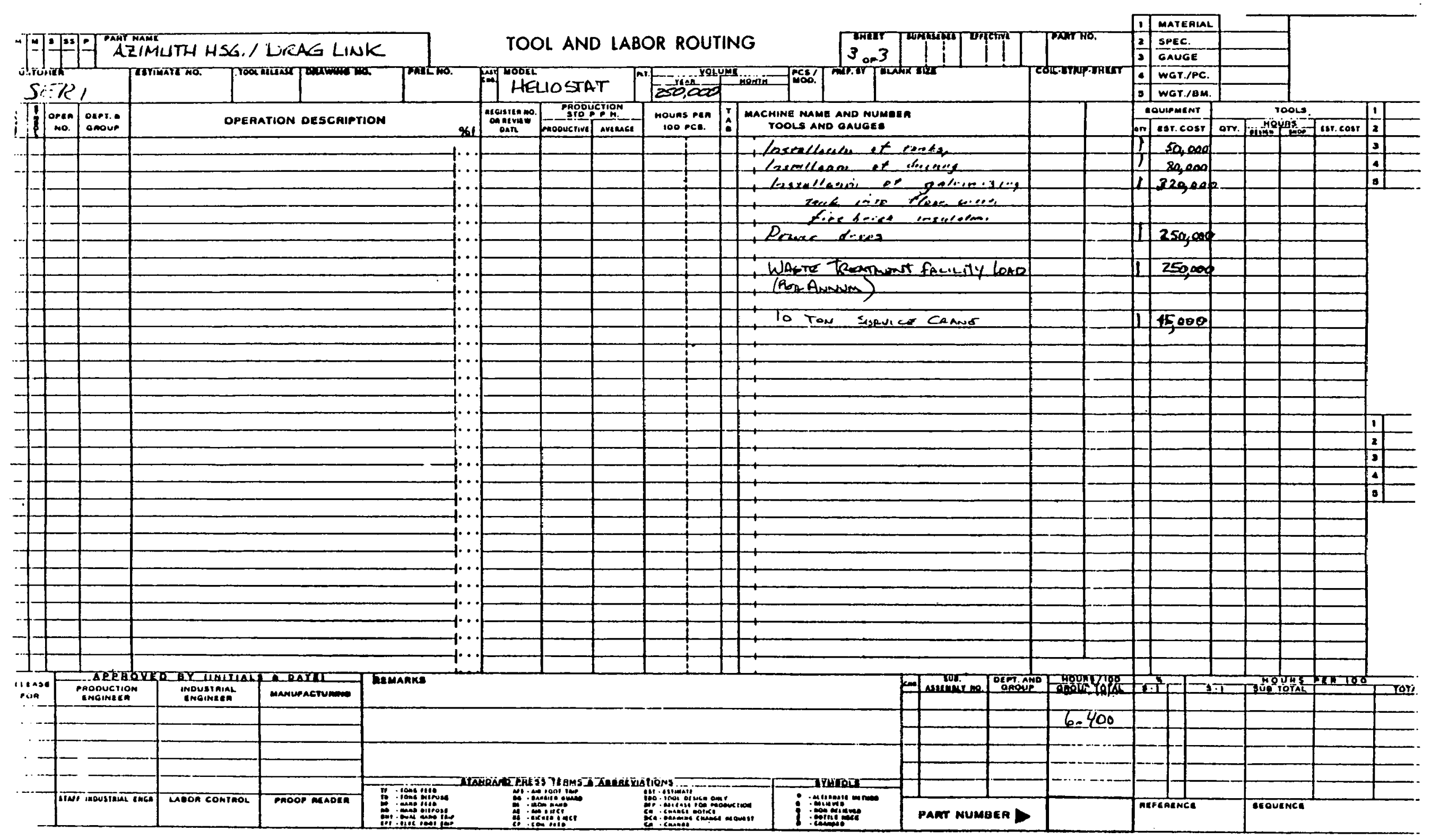




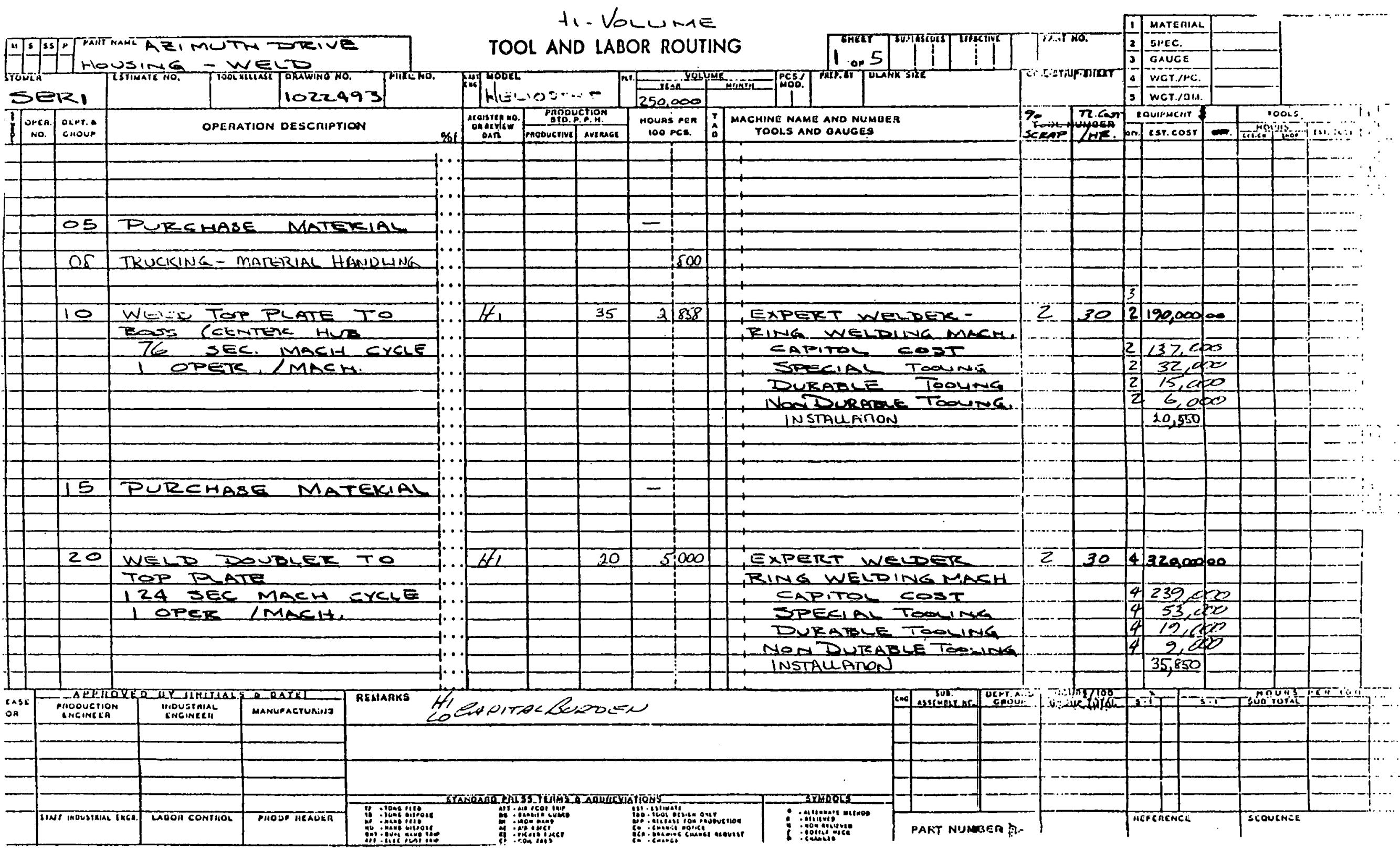




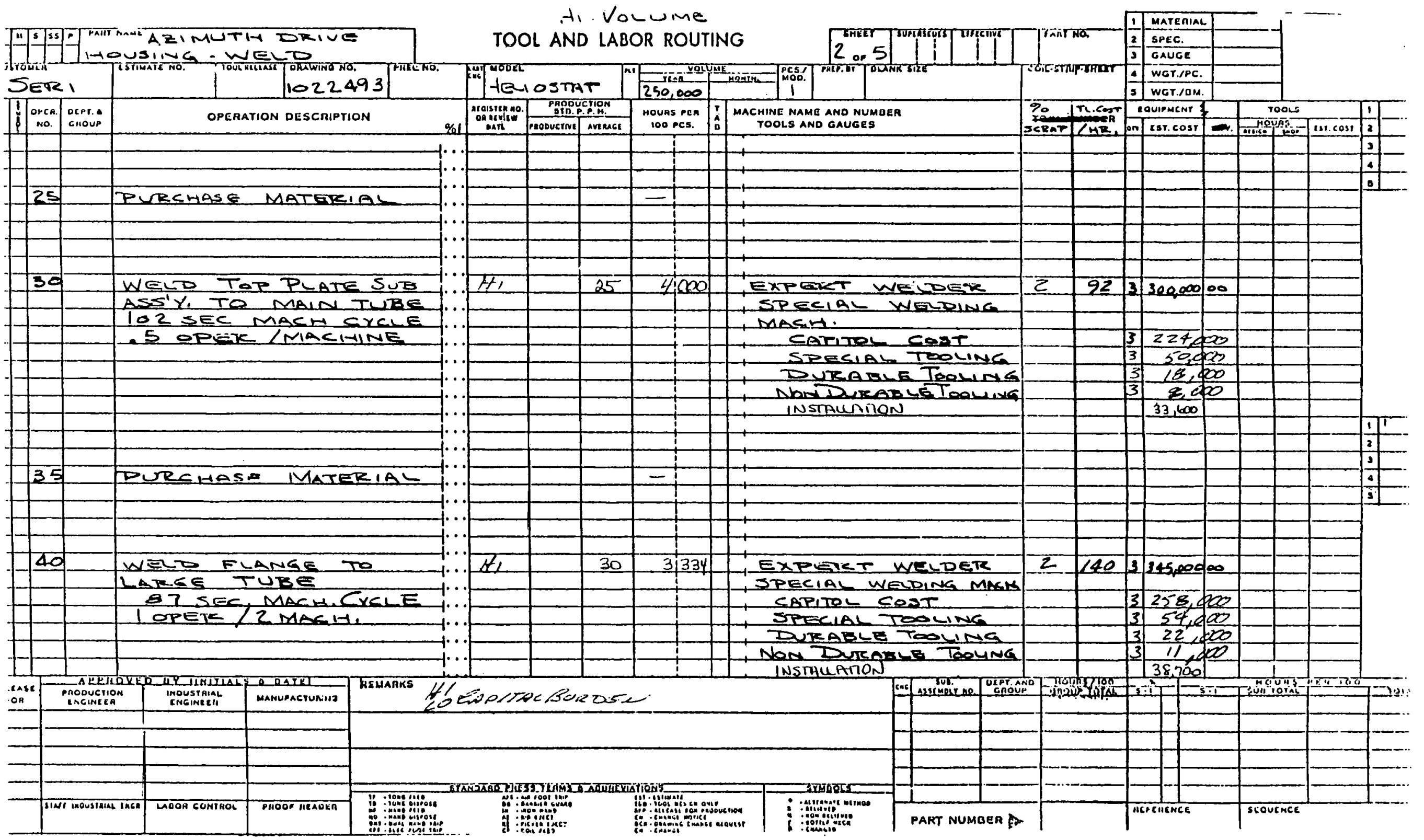




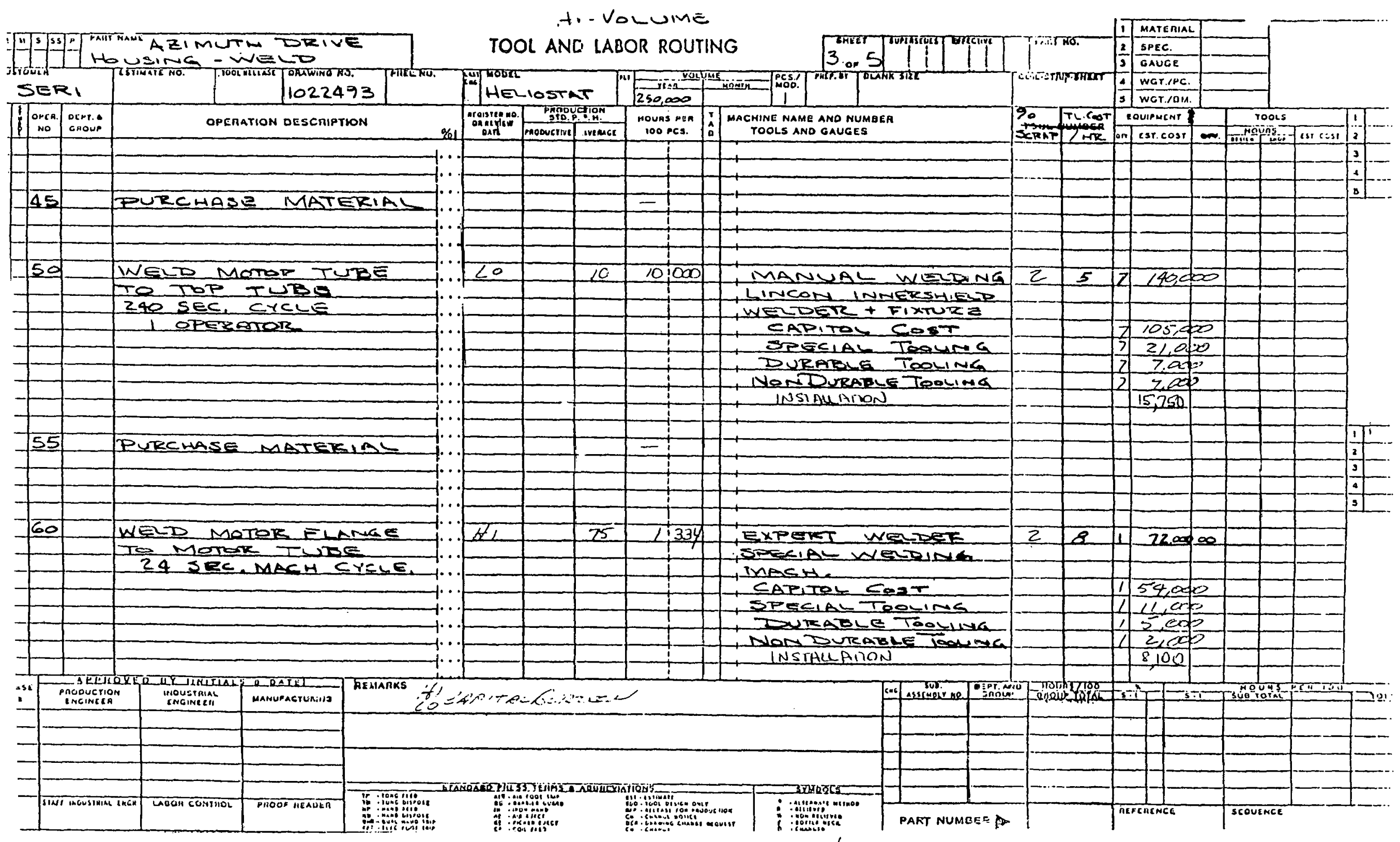


HI VOL LNME

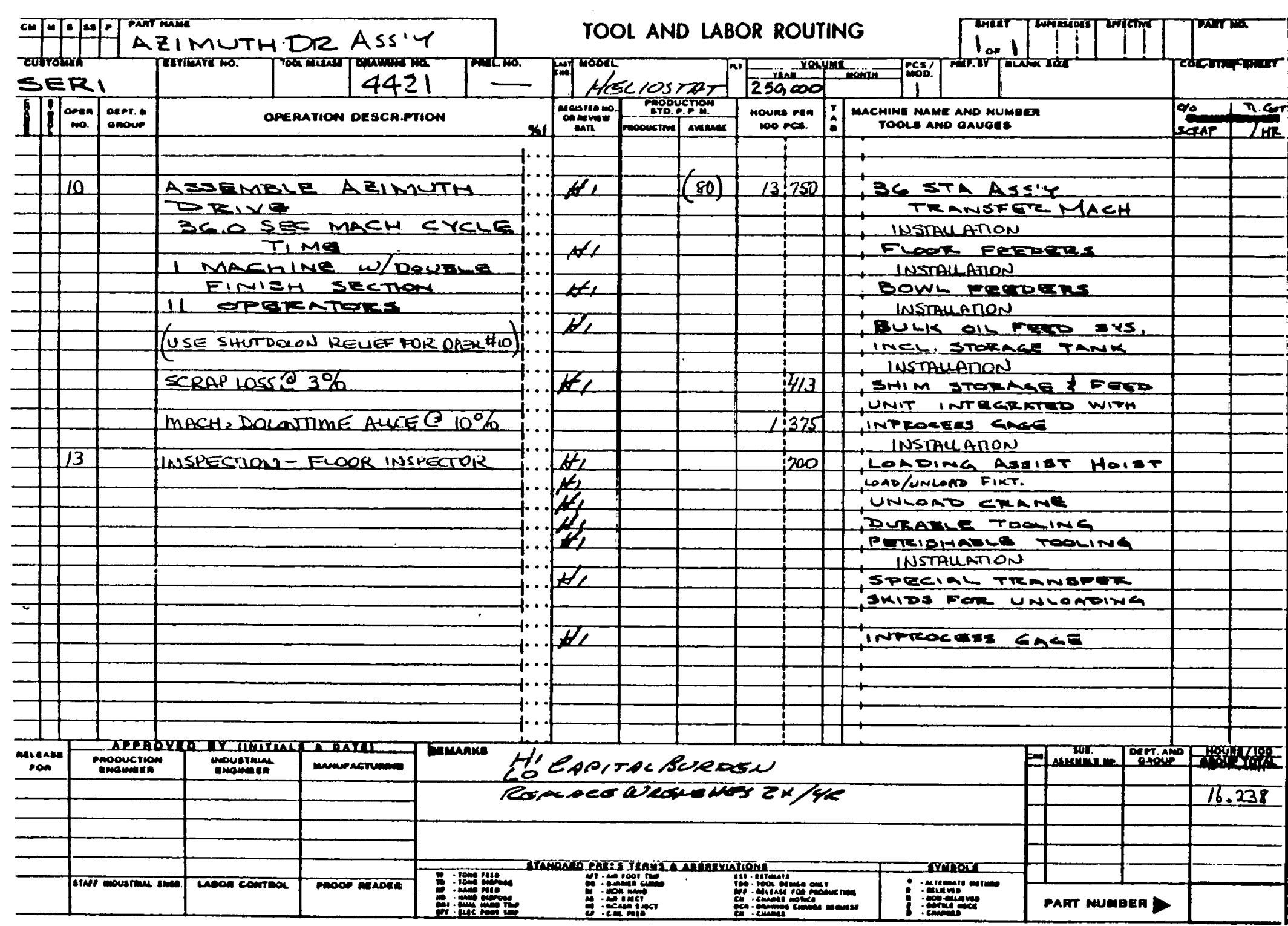

155007 \begin{tabular}{|l|l|l|}
\hline MaTERIAL & | \\
\hline & Sré & \\
\hline
\end{tabular} \begin{tabular}{|l|l|}
\hline 3 & spec. \\
\hline & gaver \\
\hline
\end{tabular}

- anver

4 wor./pc.

- war.am.

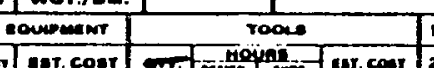

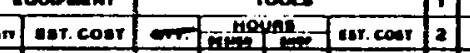

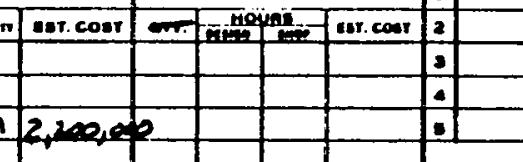

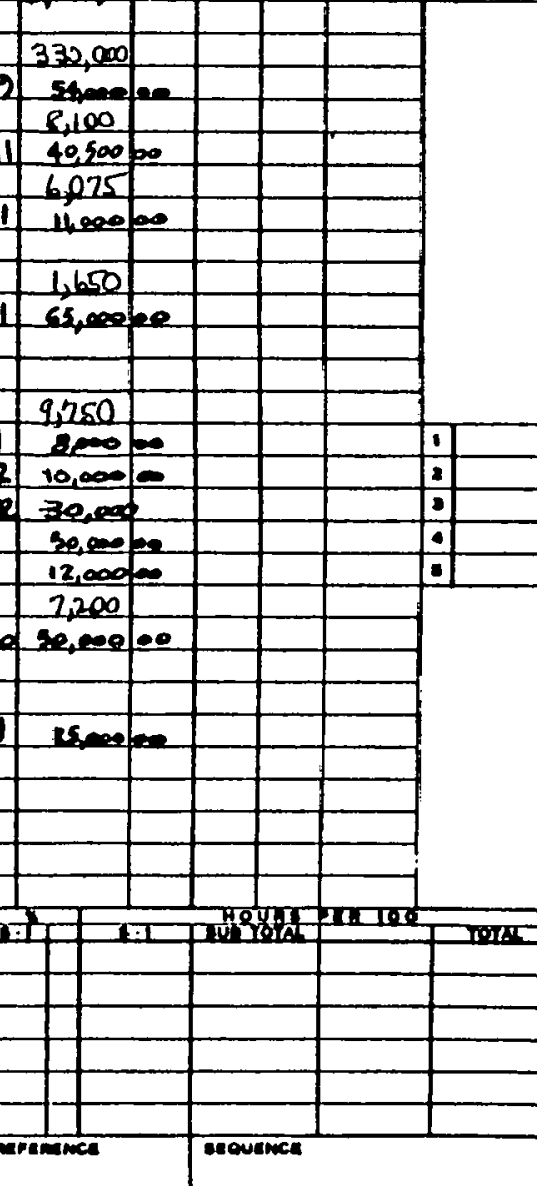




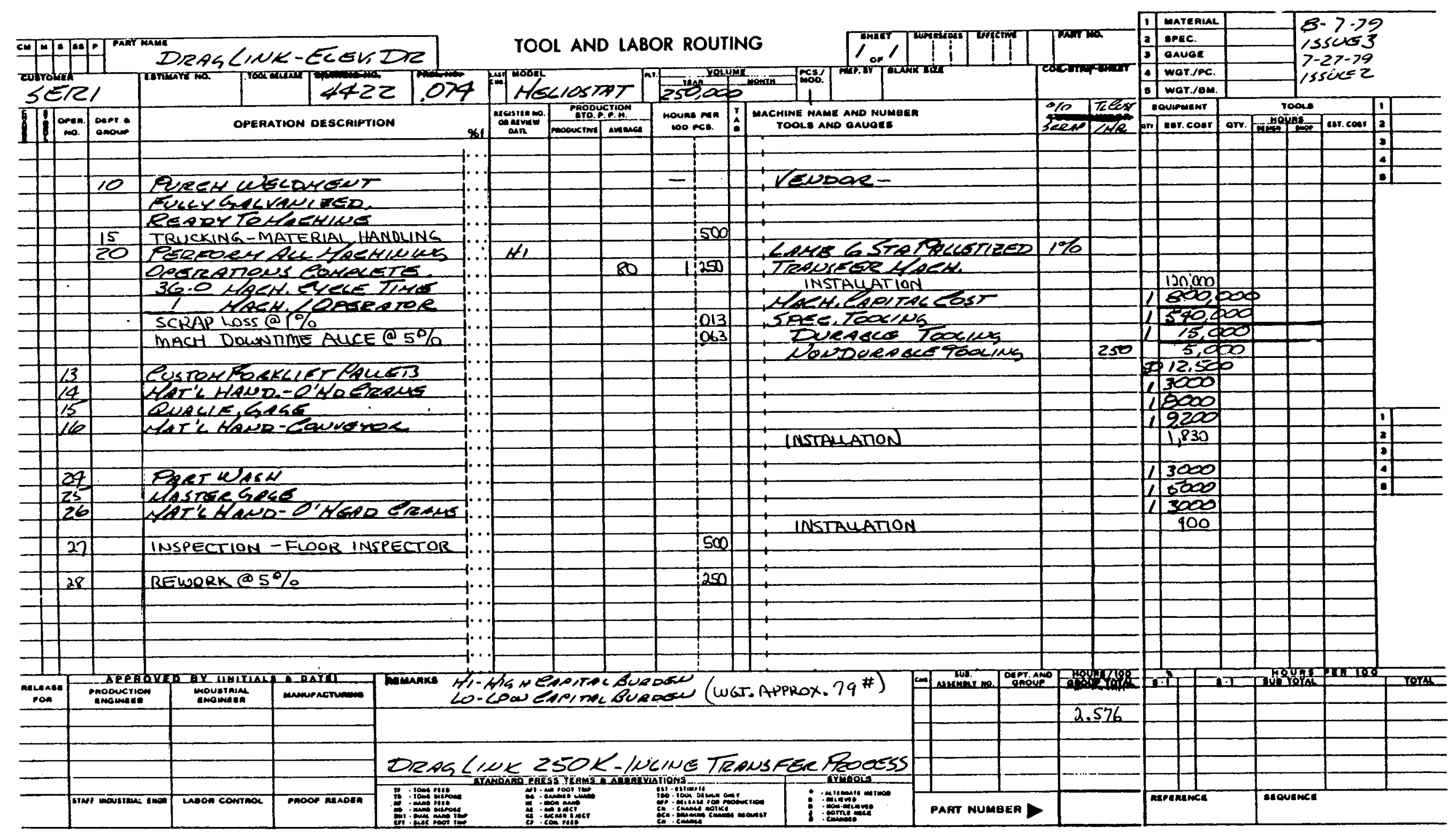




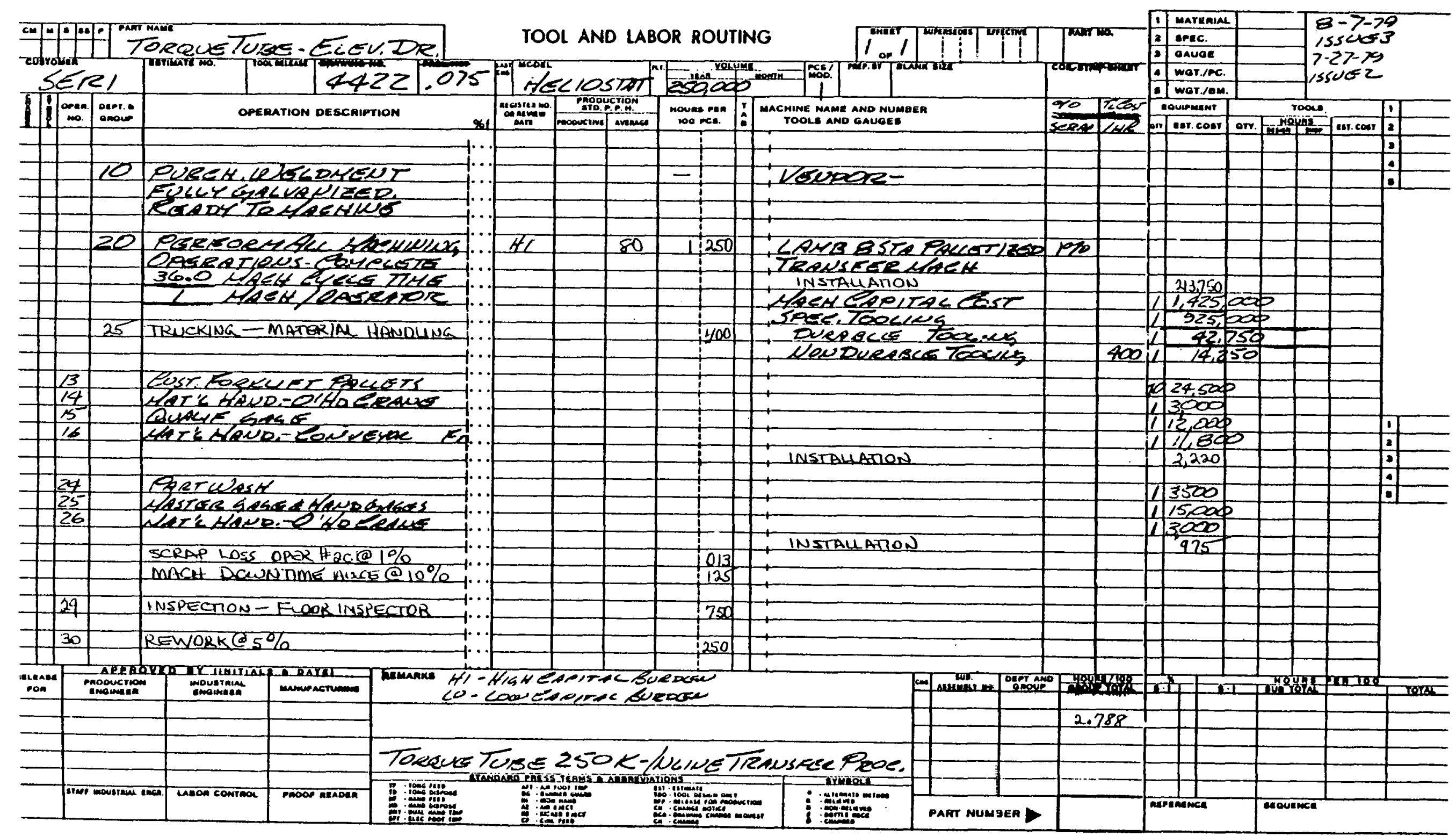




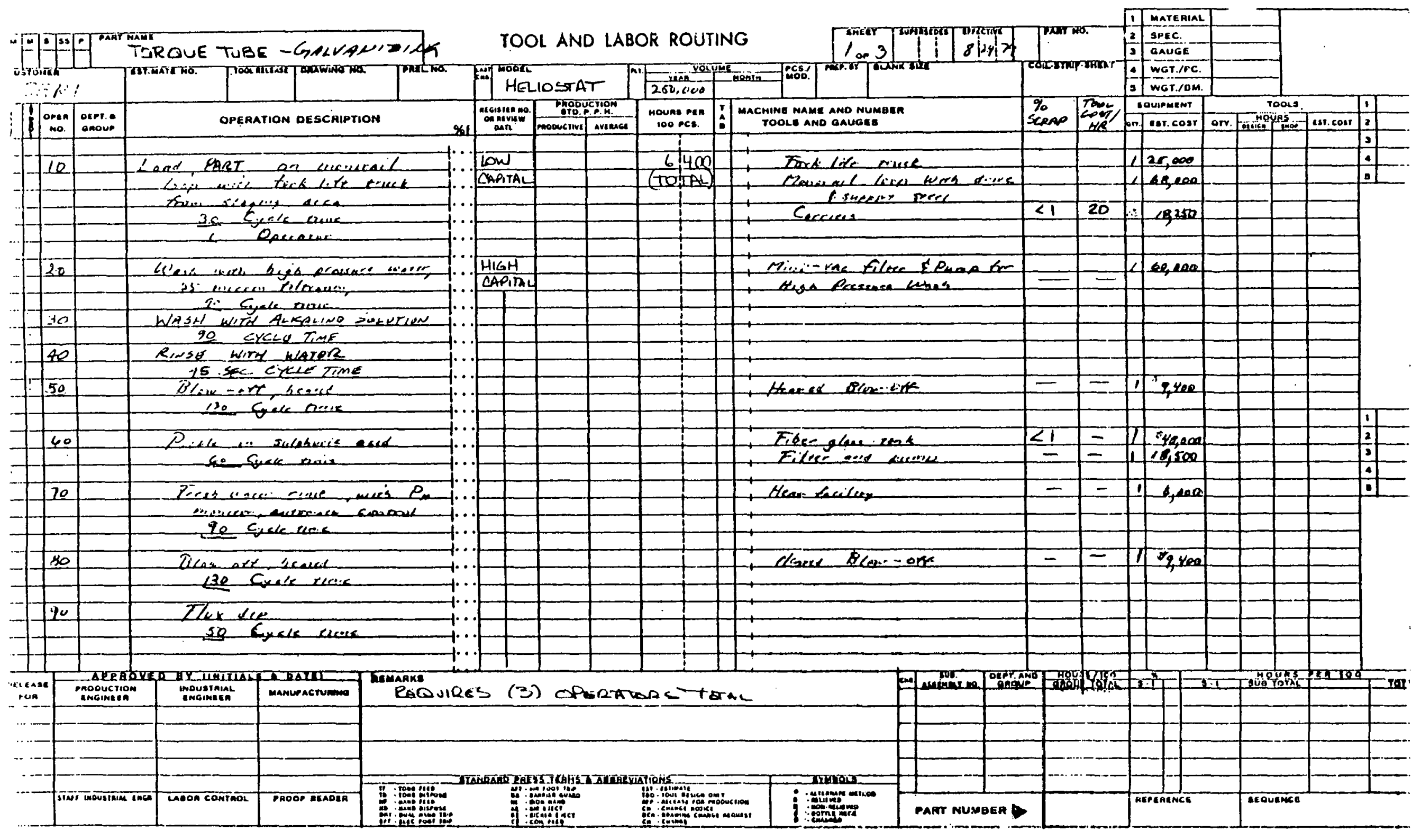




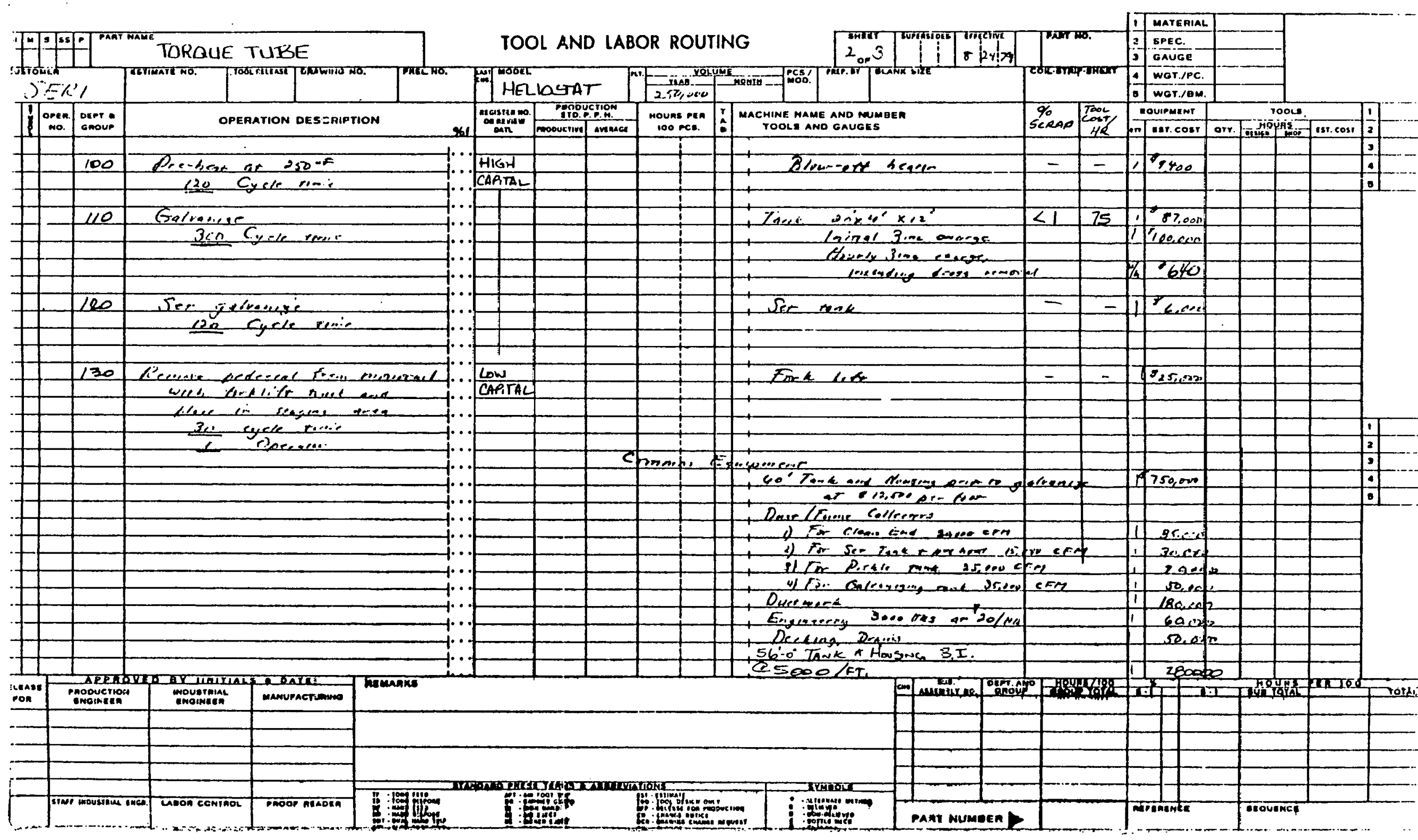




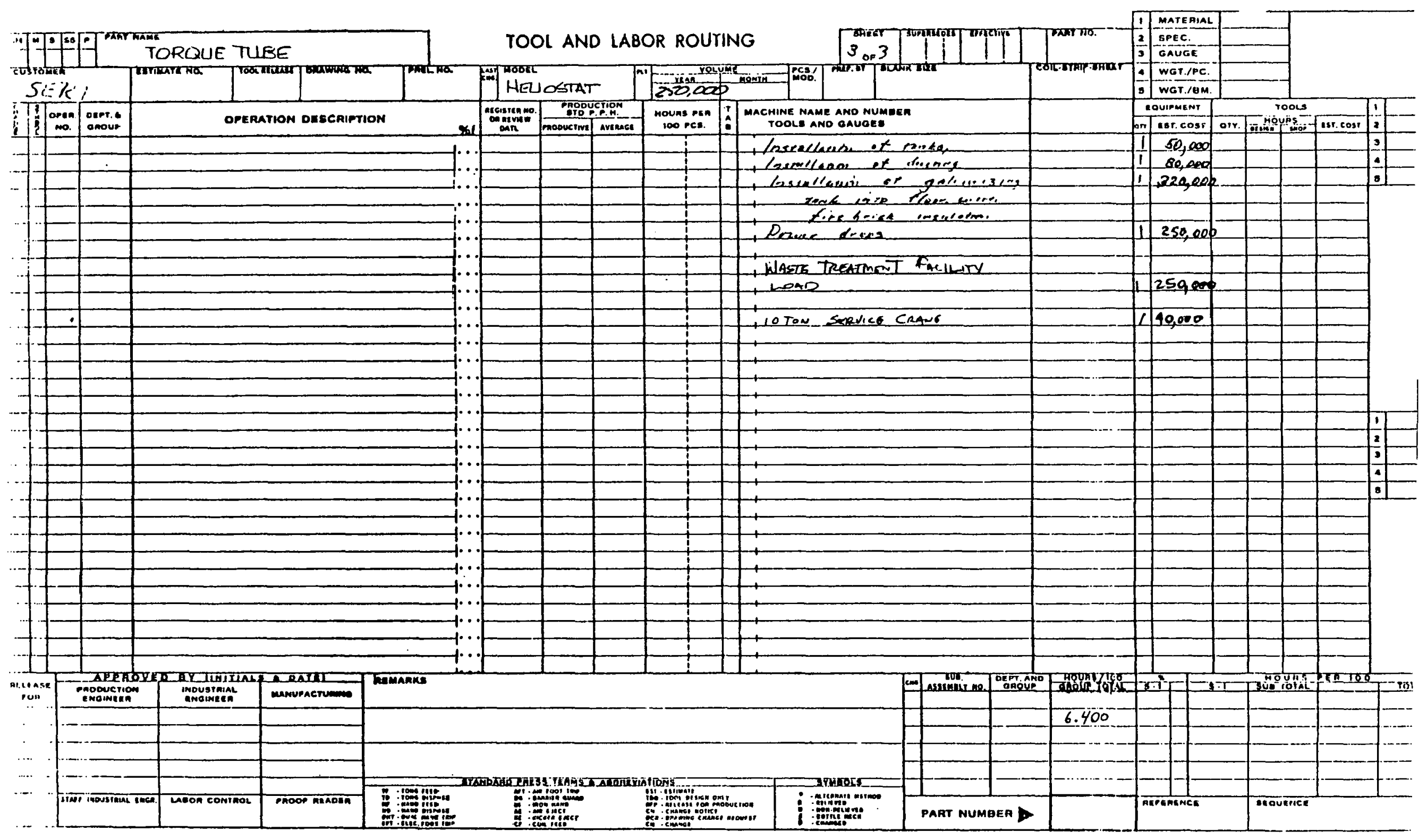




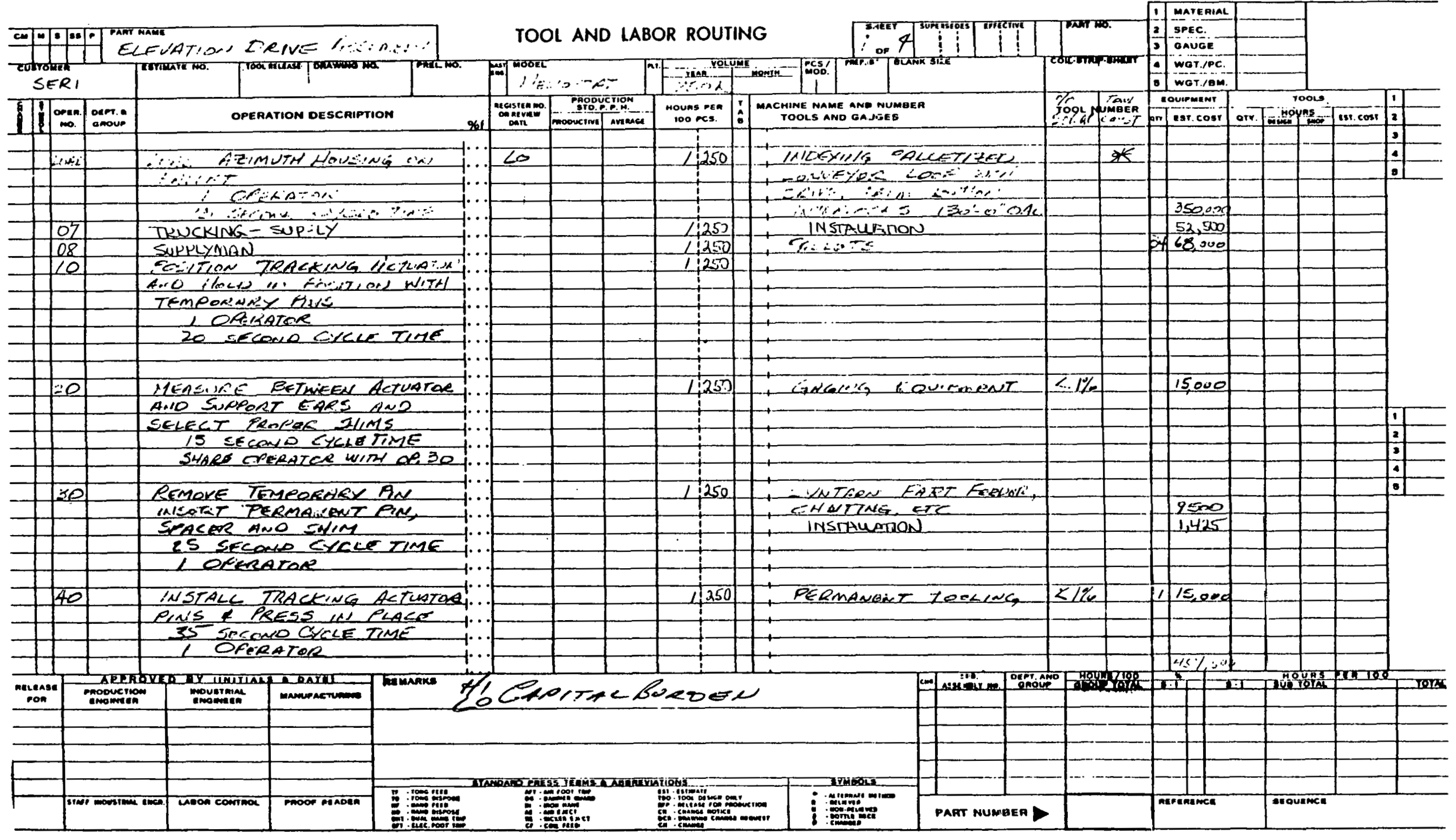




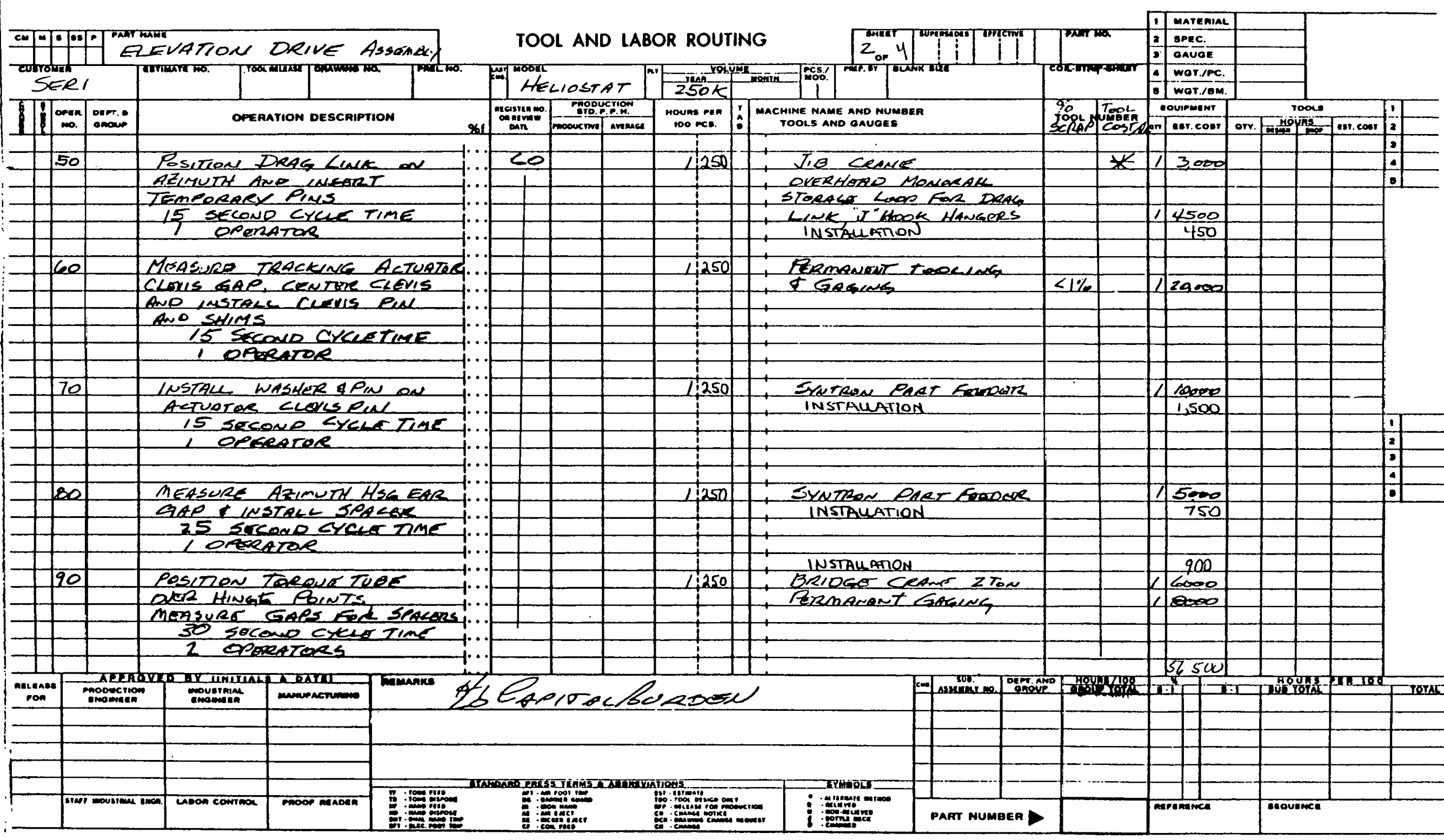




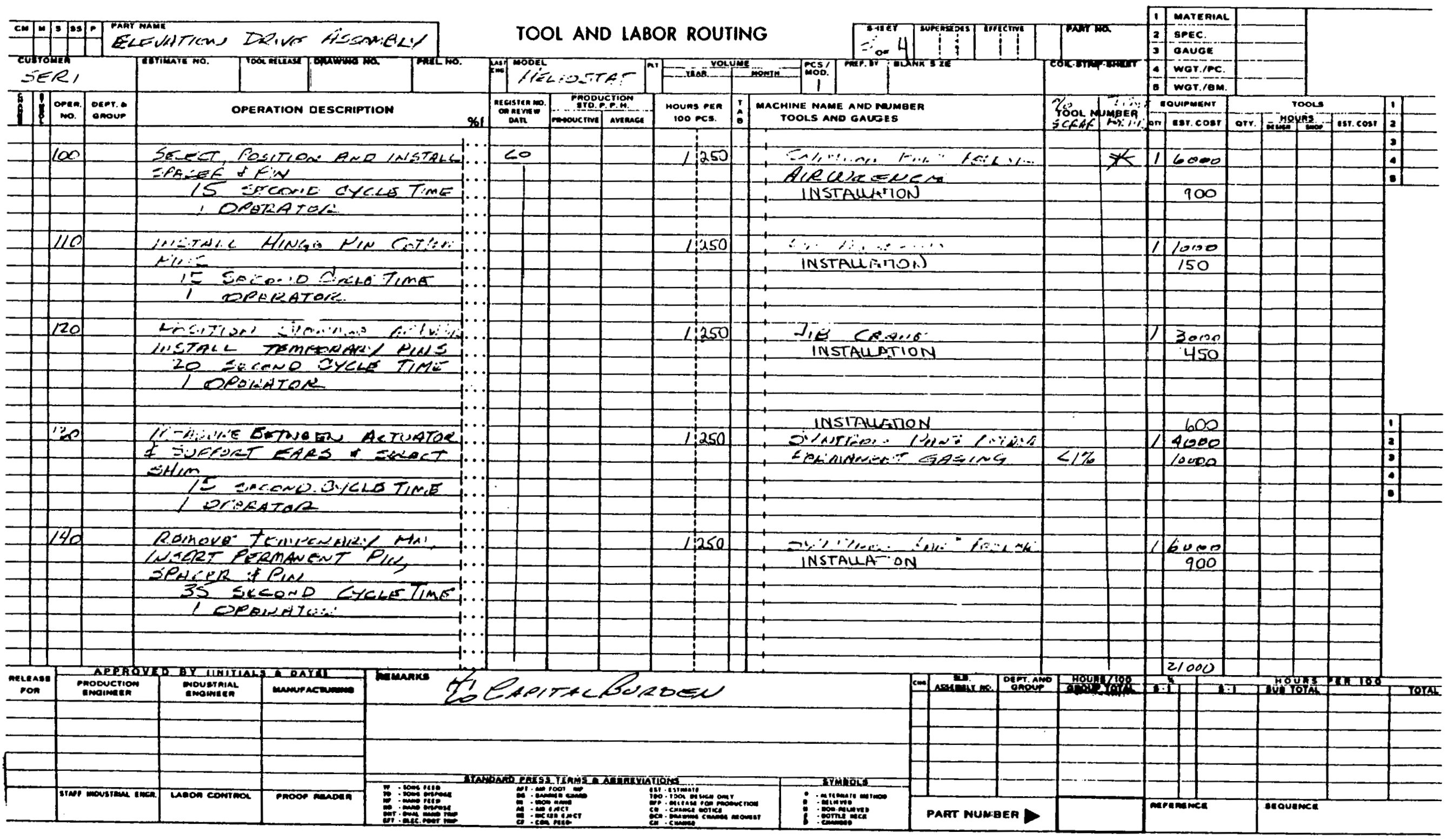




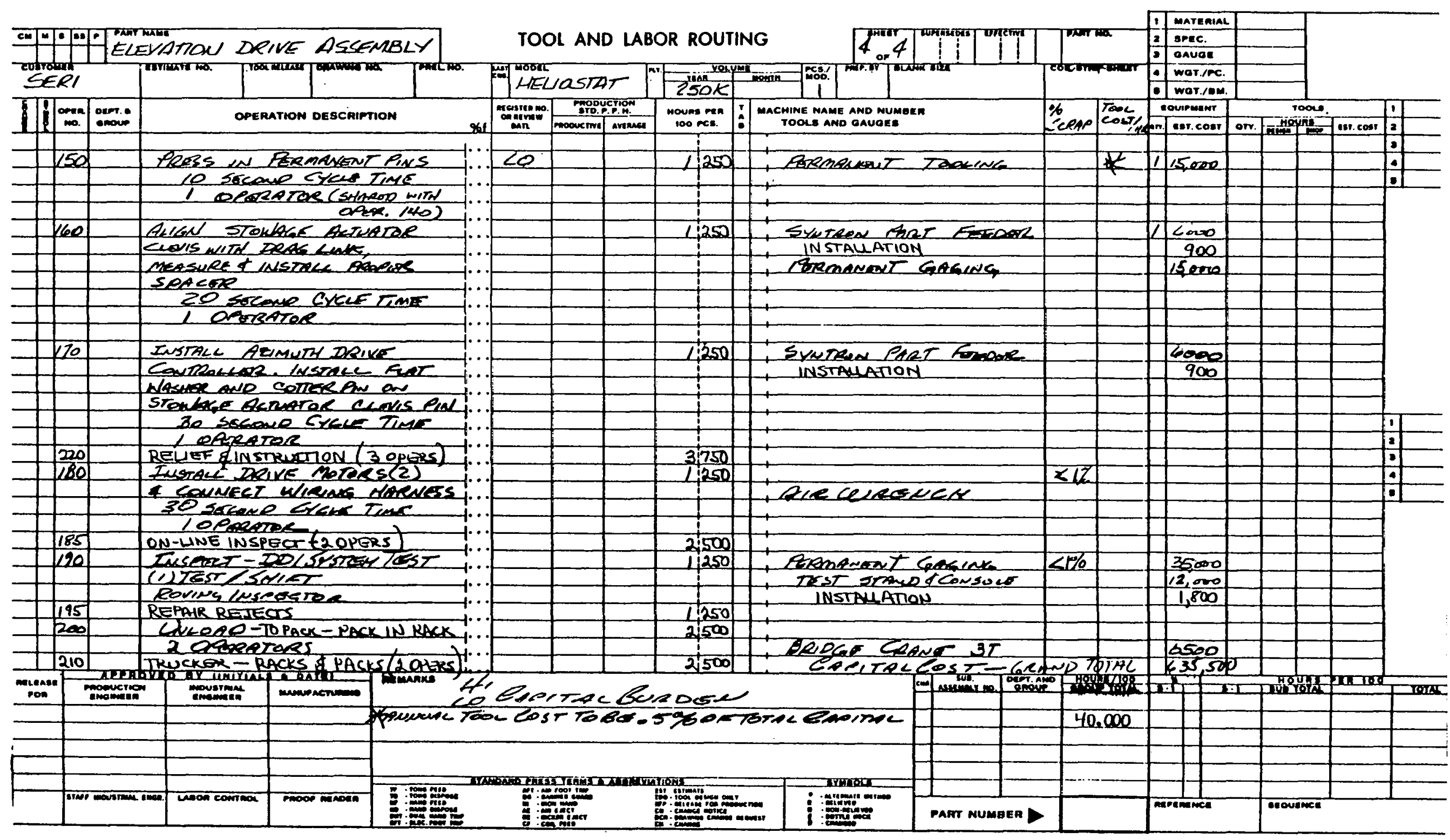


HIGH K. UME

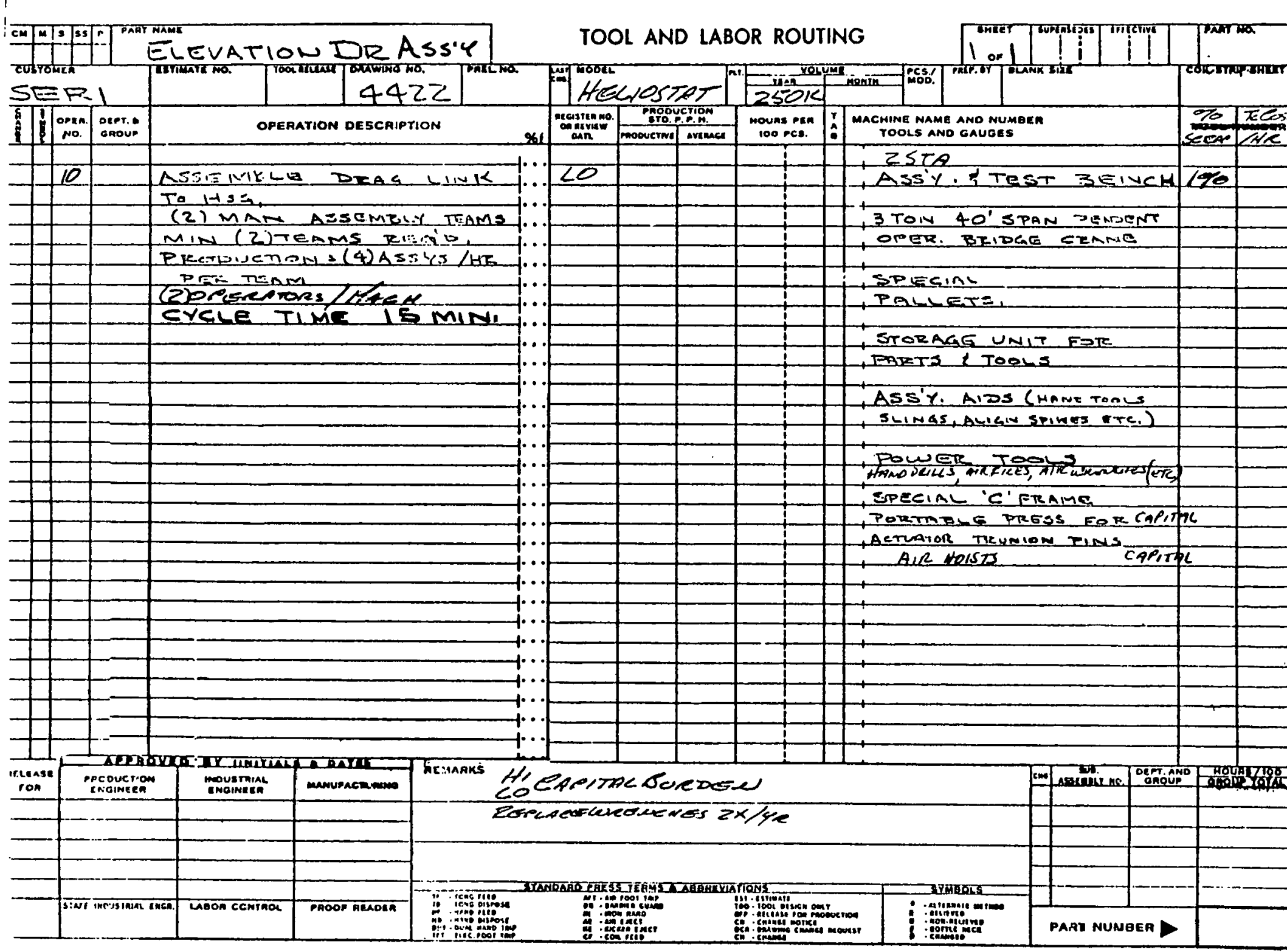

15suce 1. 2-79

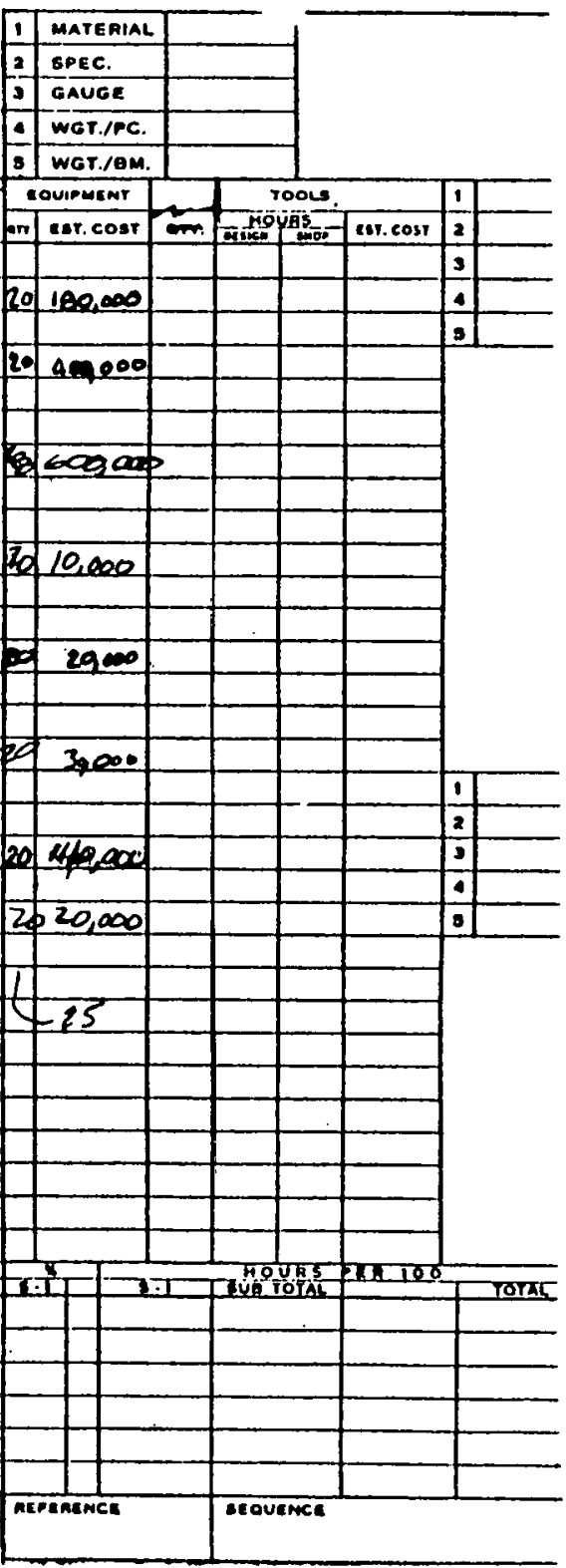




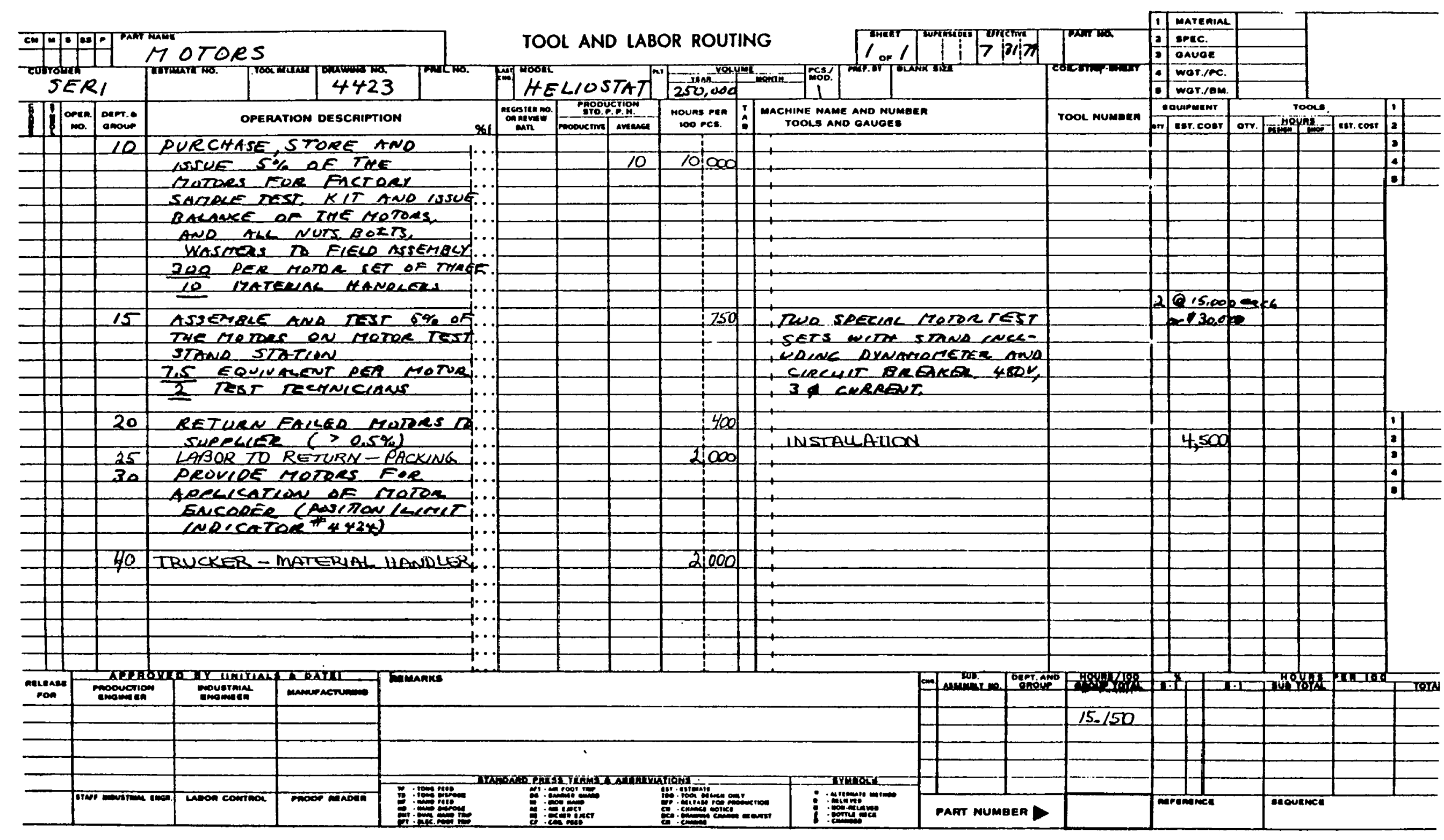




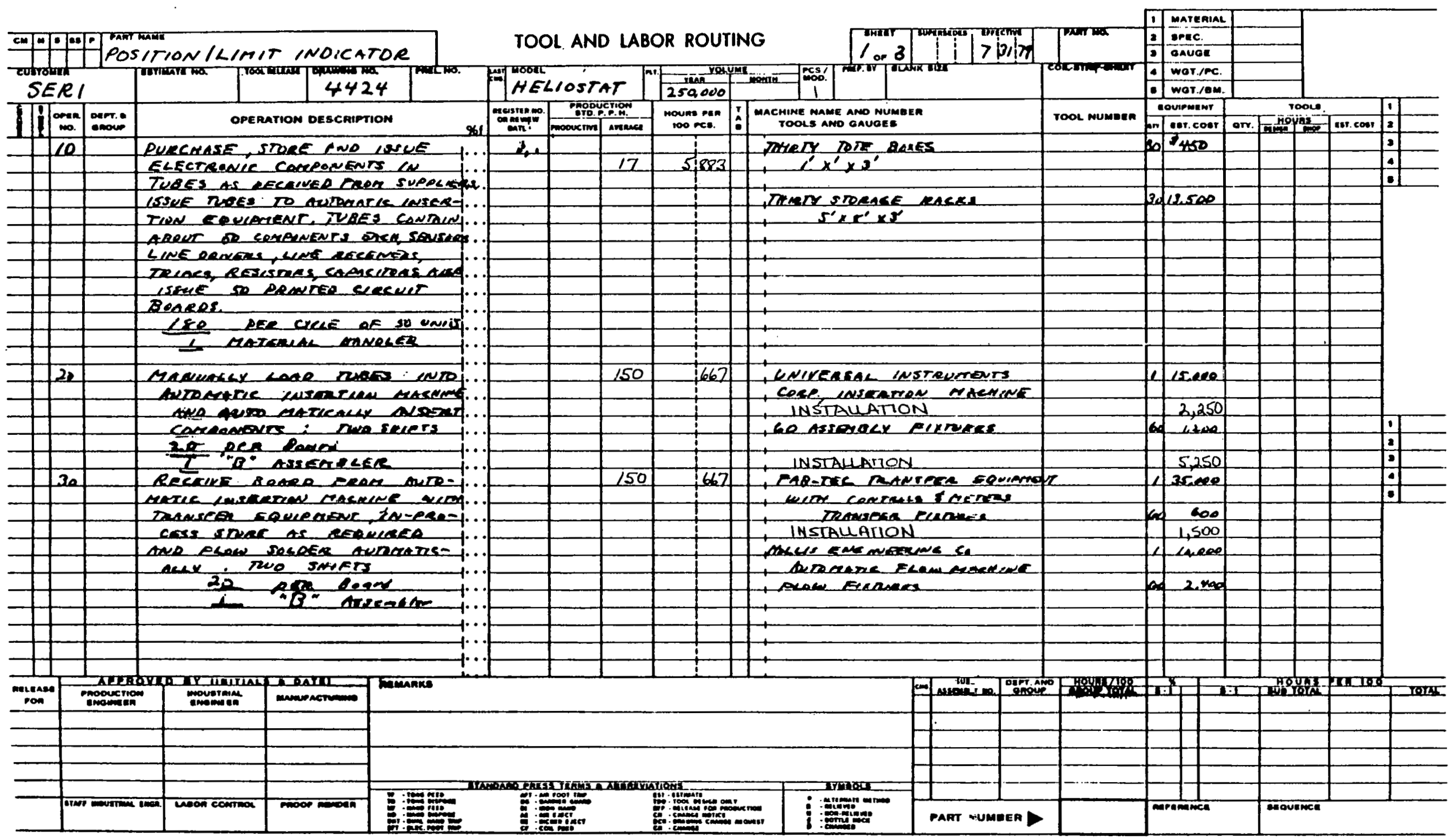




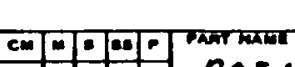

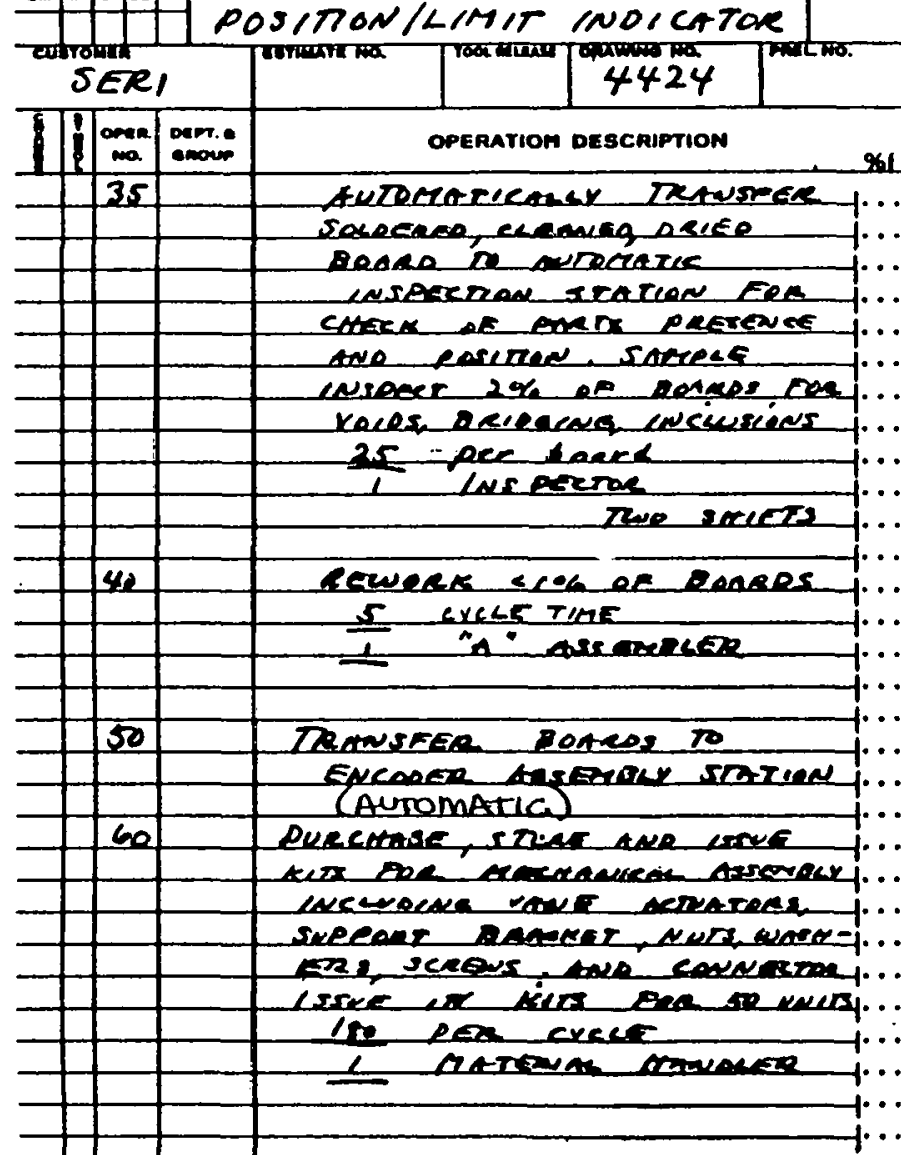

TOOL AND LABOR ROUTING

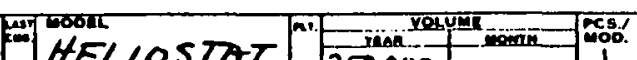
HELIOSTAT

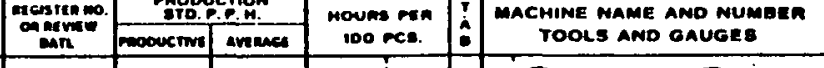

$\sqrt{0}$ \begin{tabular}{|l|l|l|}
\hline 2 & Matefial & \\
\hline 2 & BpeC. & \\
\hline Gauge & \\
\hline & WOT.FC. & \\
\hline & WOT./OM. & \\
\hline
\end{tabular} Wot./0m.

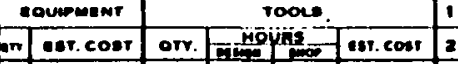

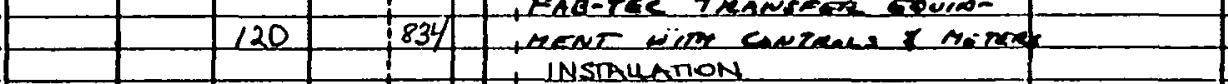

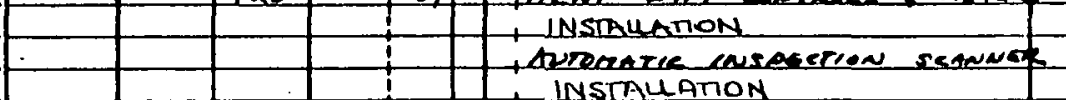
- Installation

\begin{tabular}{|c|c|c|c|c|c|c|c|}
\hline $\begin{array}{ll}\text { mereage } \\
\text { non }\end{array}$ & 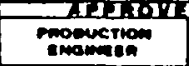 & 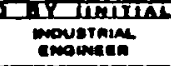 & RDATA & 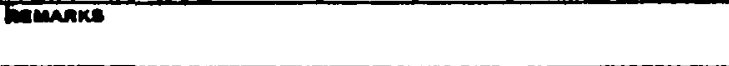 & of axming & Ond & \\
\hline & & & & & & & \\
\hline & & & & & & & \\
\hline & & & & & & & \\
\hline & & & & T. & & & \\
\hline & 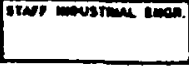 & noon conthor & niboor minath & 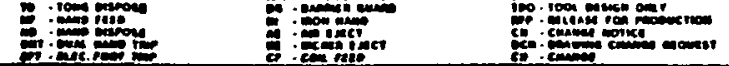 & PAAT NU & ER & \\
\hline
\end{tabular}




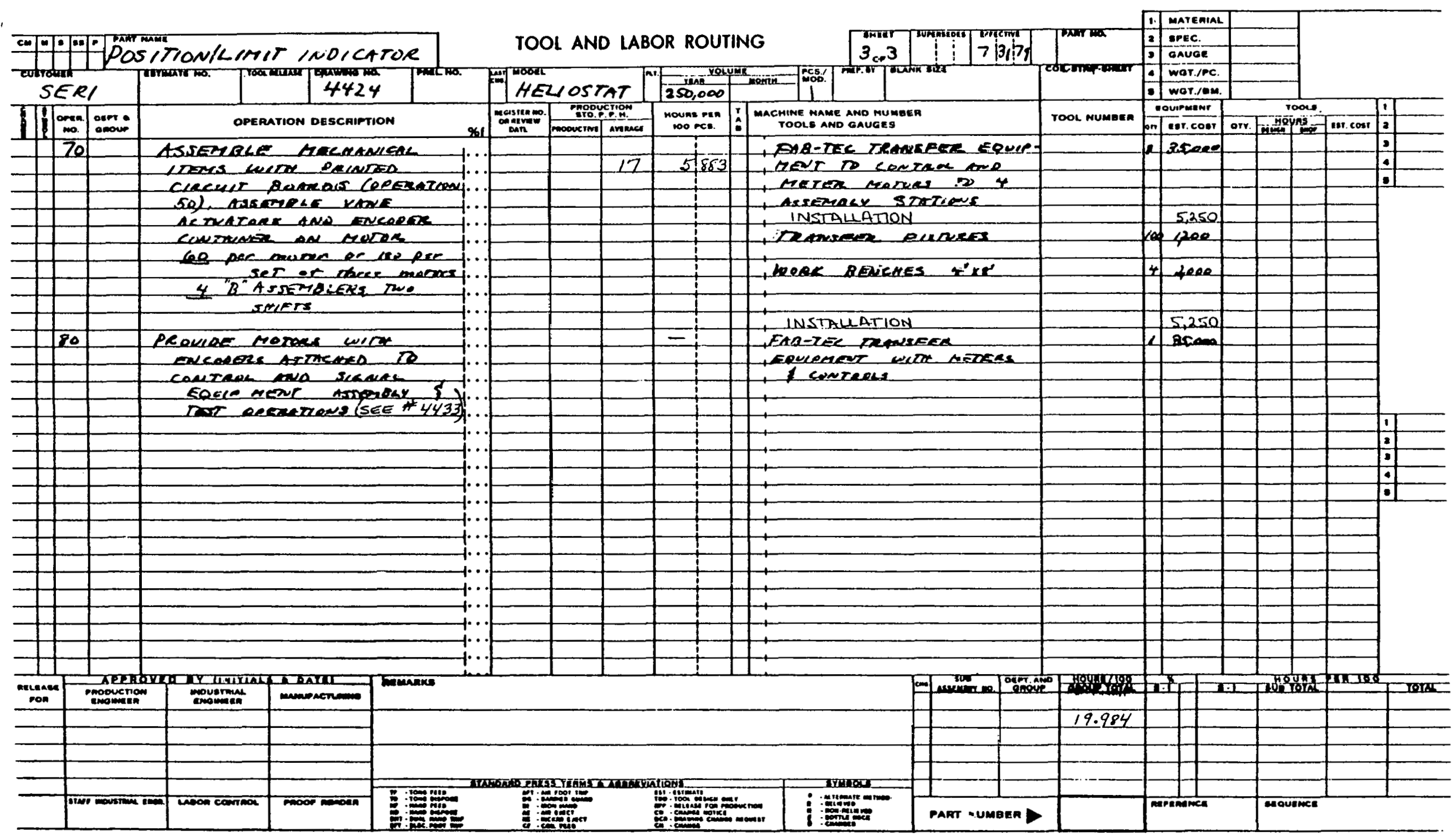




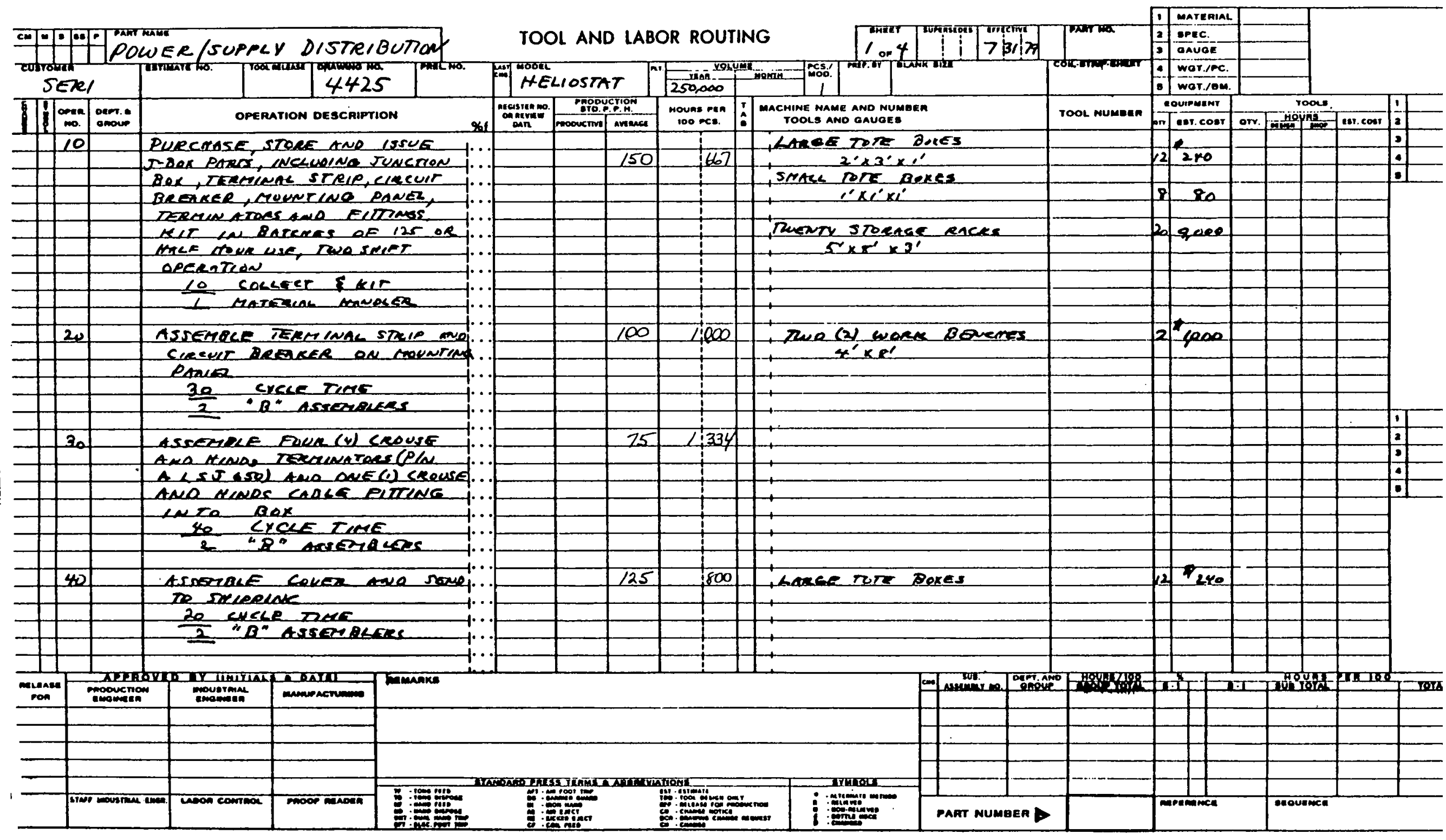




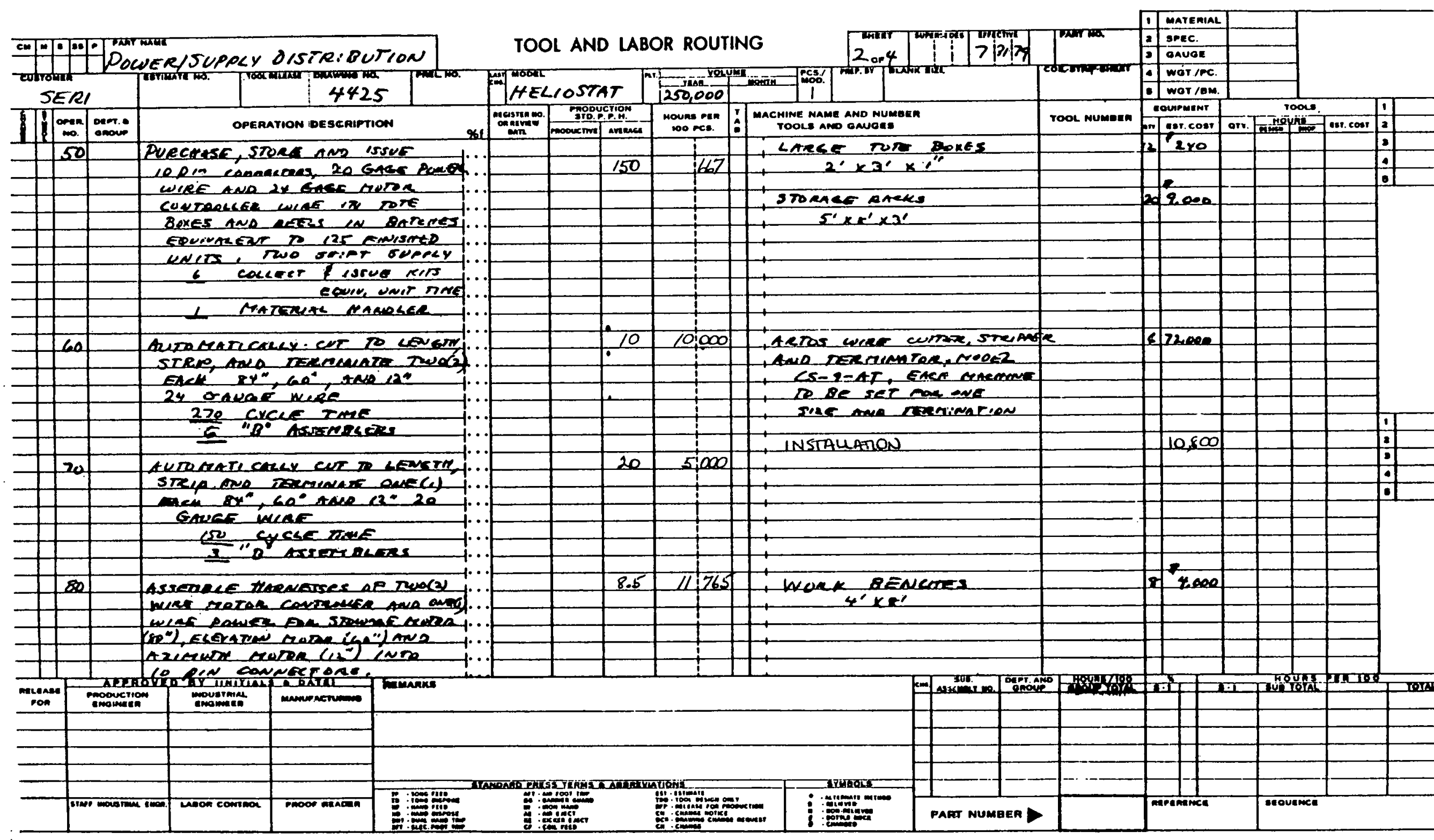




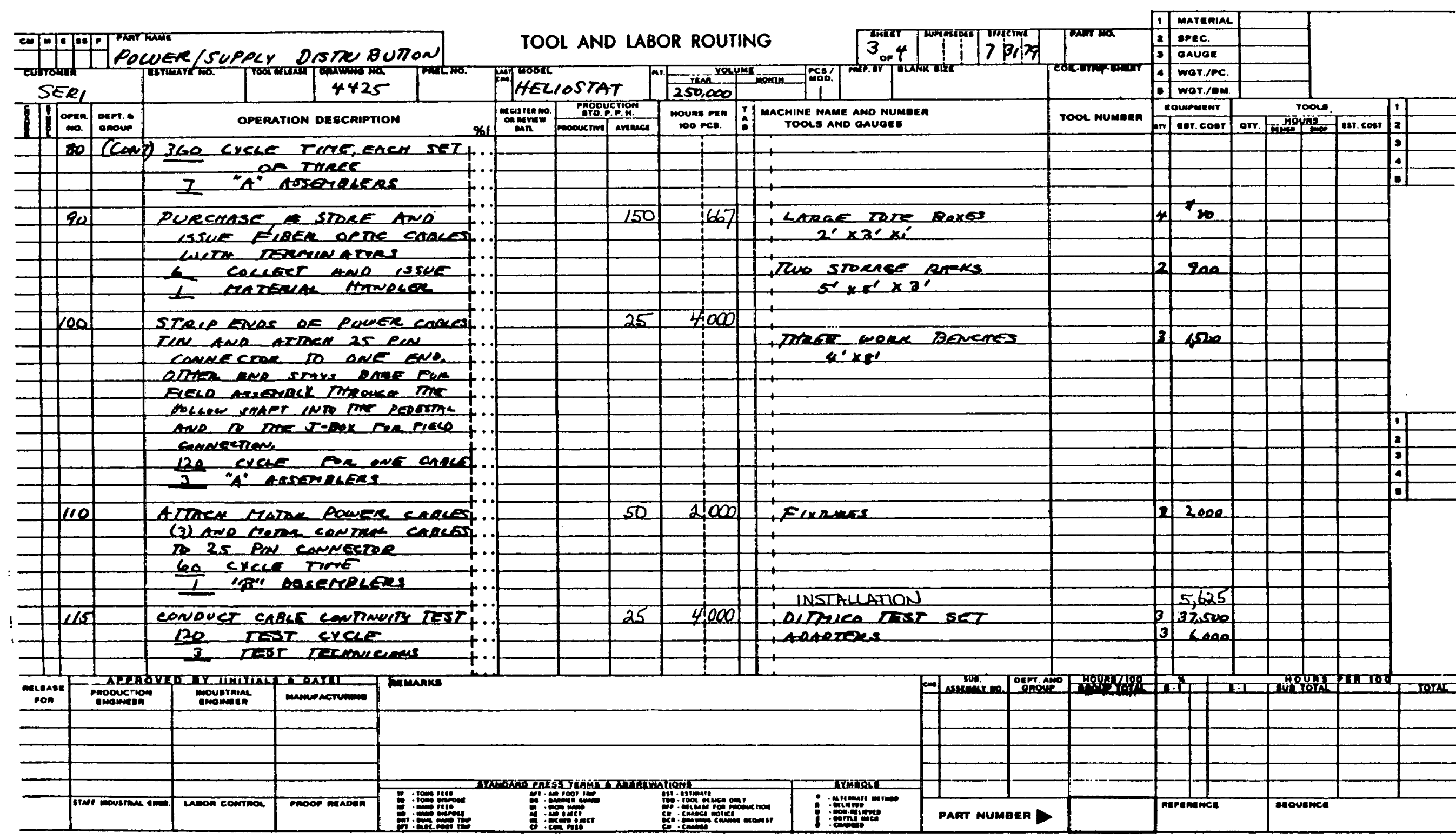




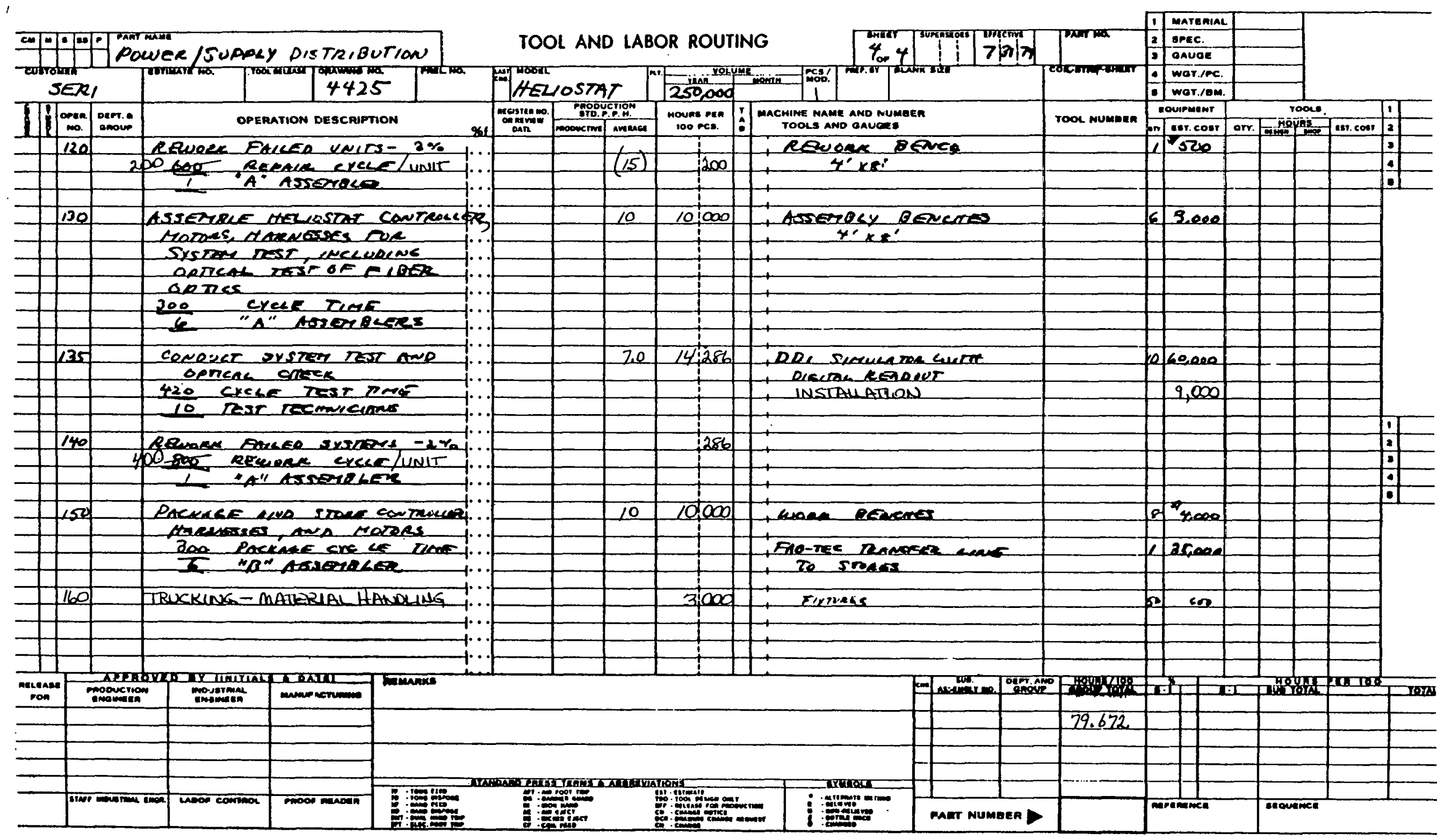




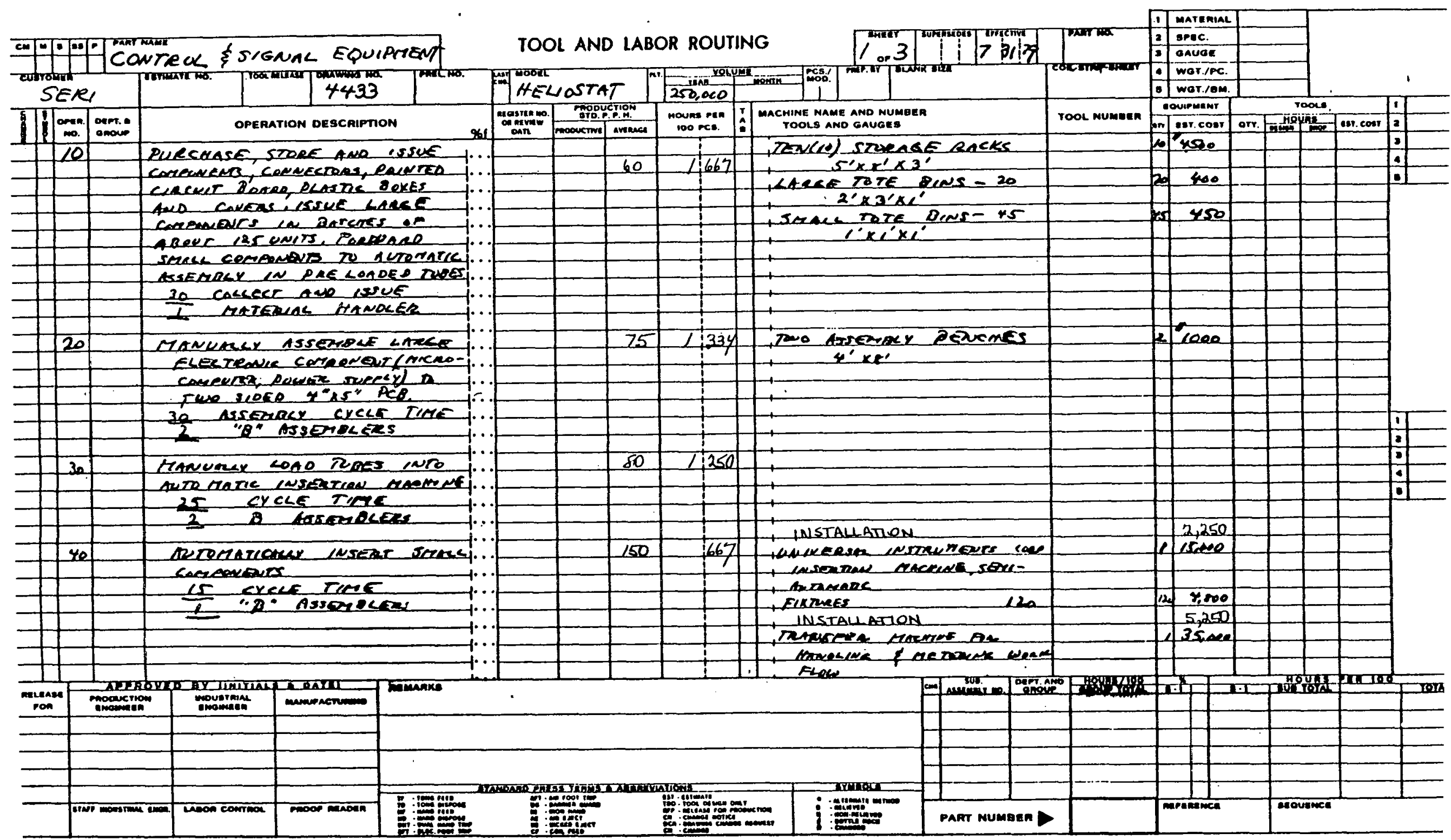

C91 


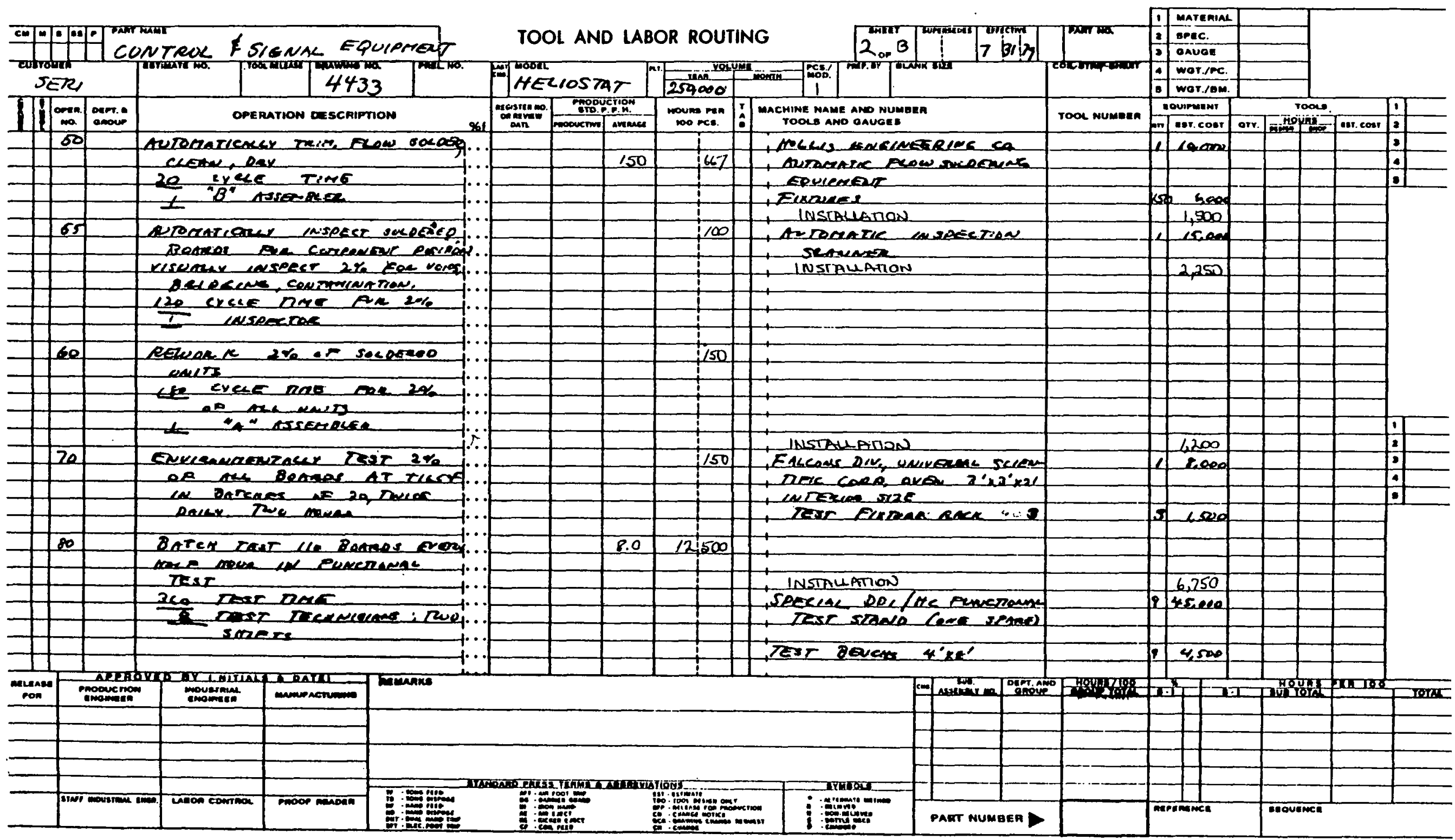




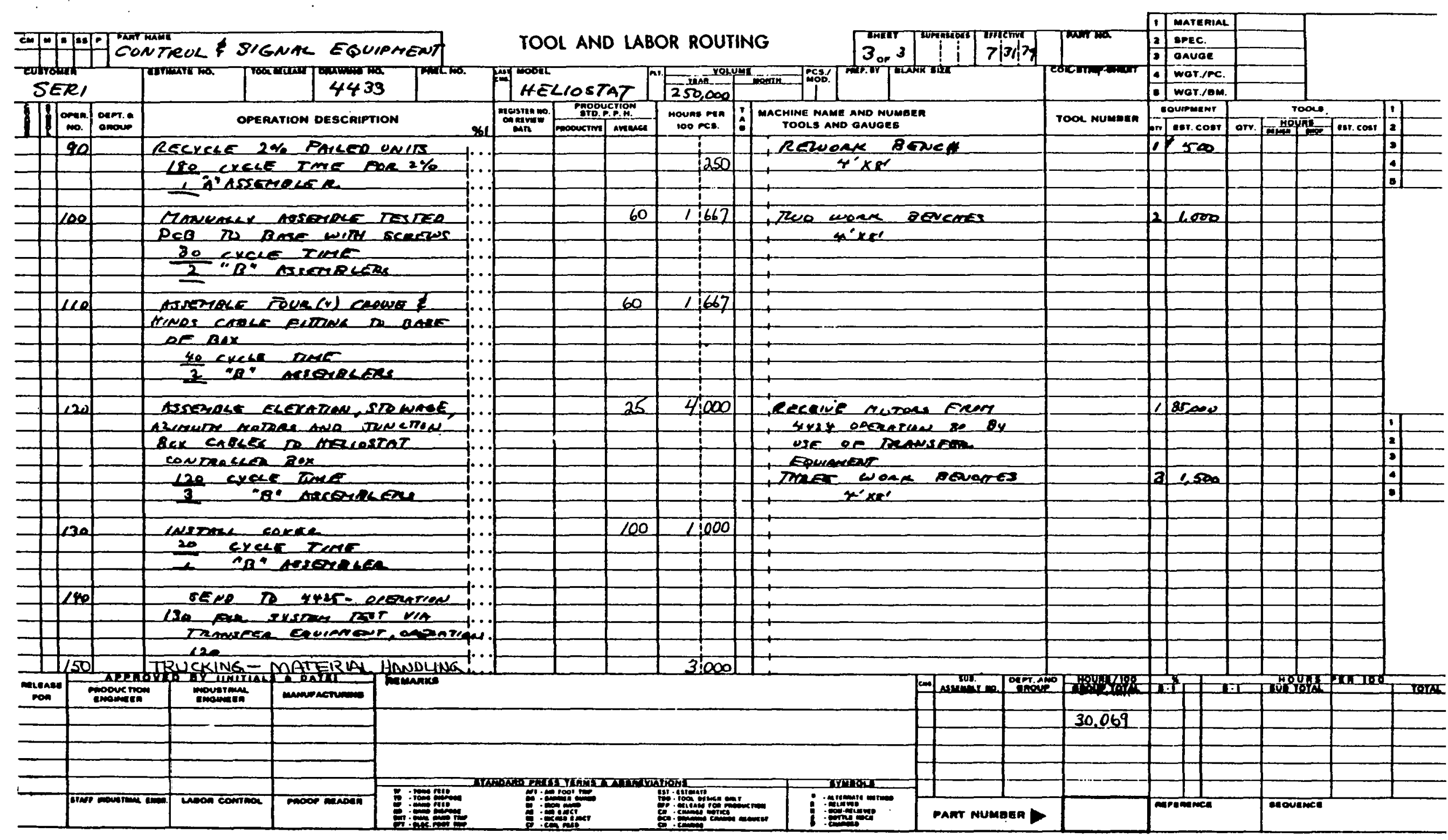

C93. 


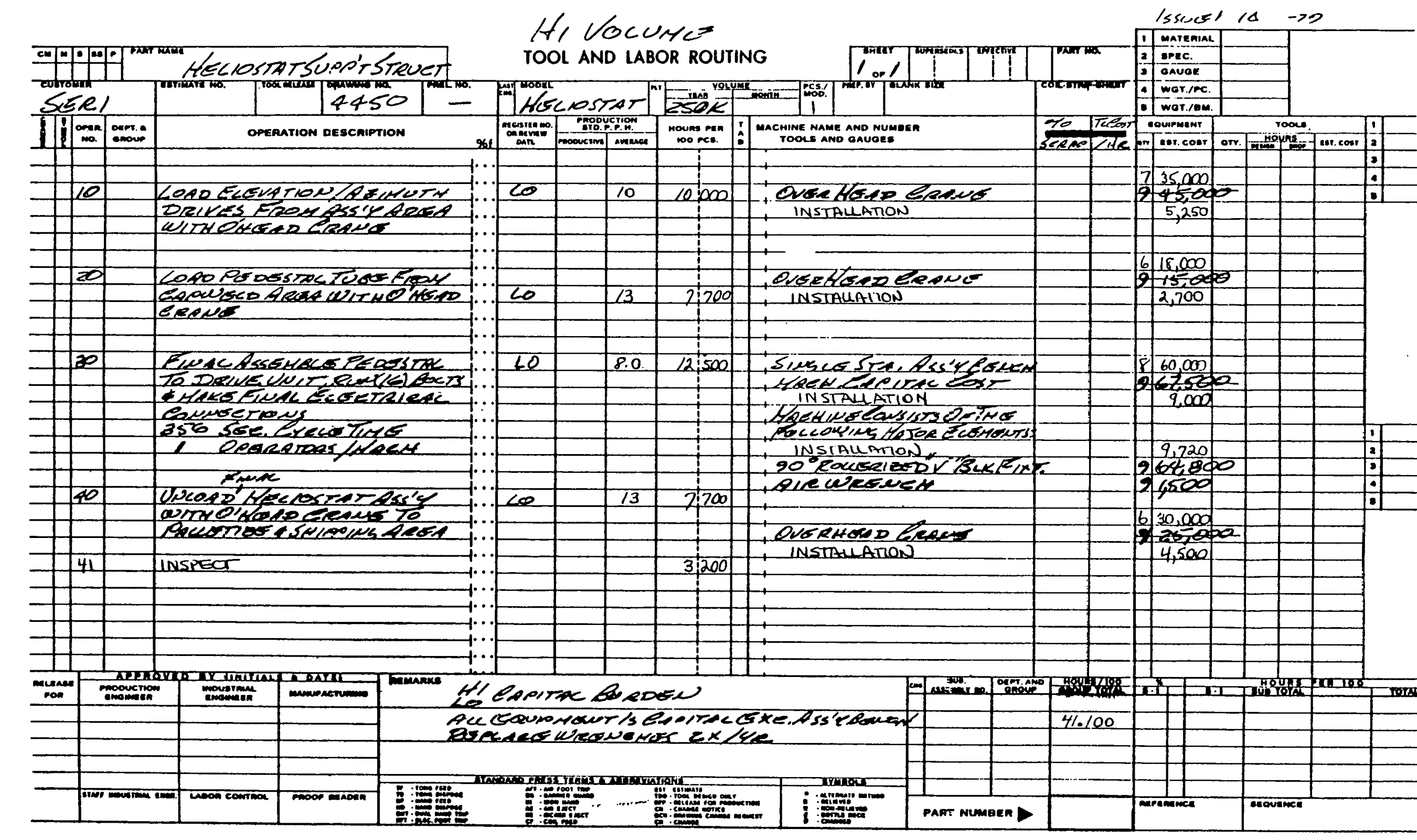




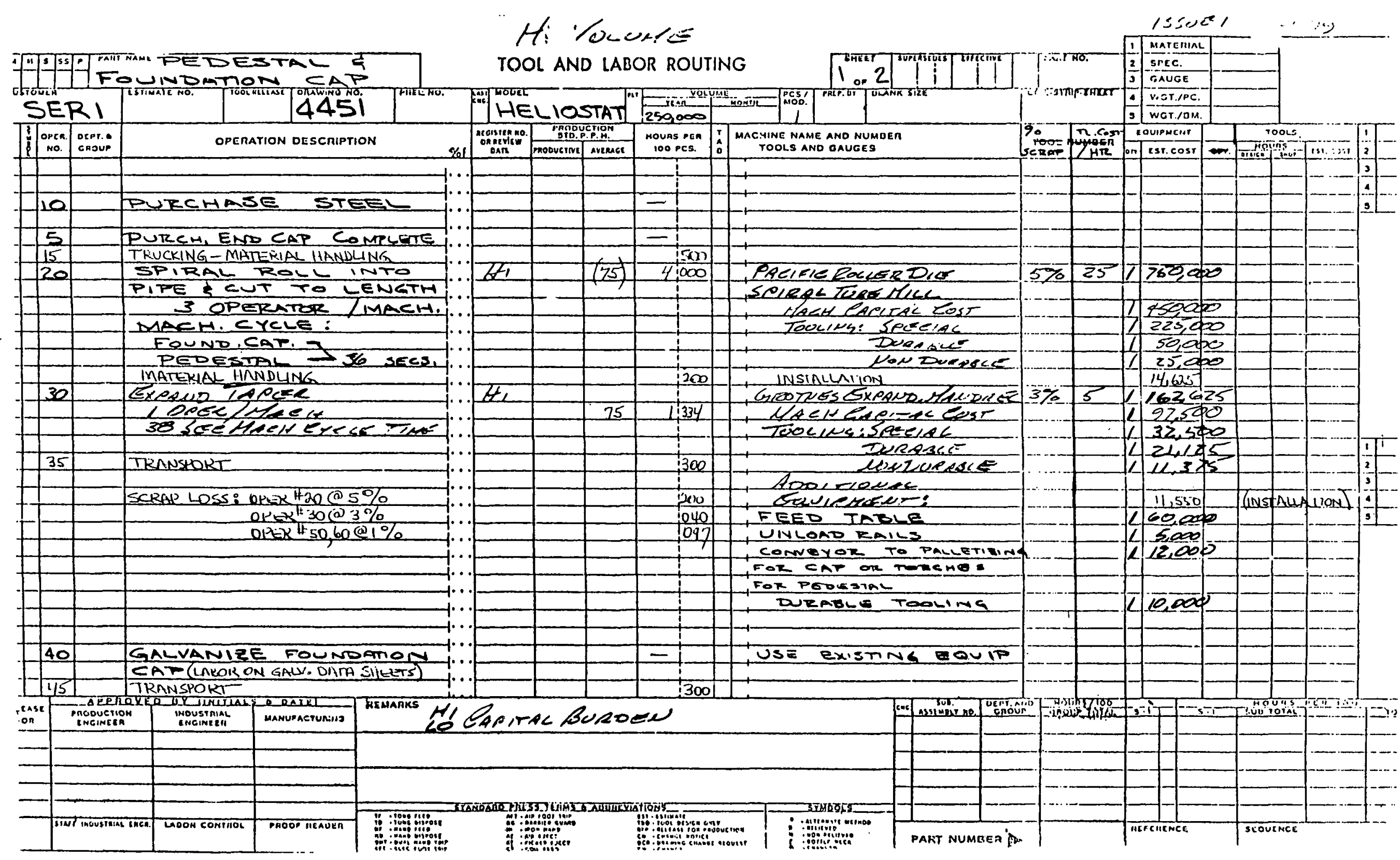




\section{"Nocures}

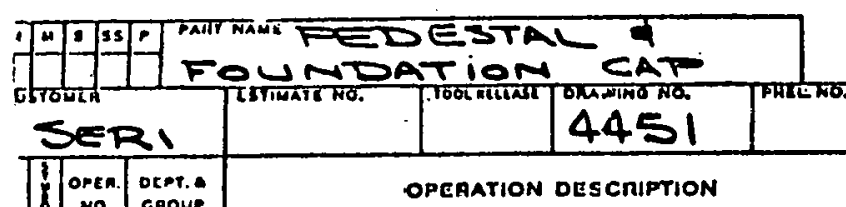
प्रण0खा
TOOL AND LABOR ROUTING

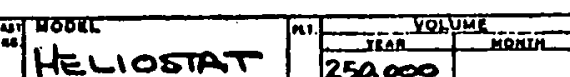

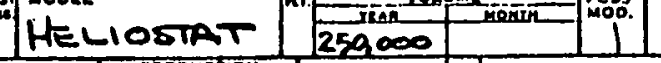

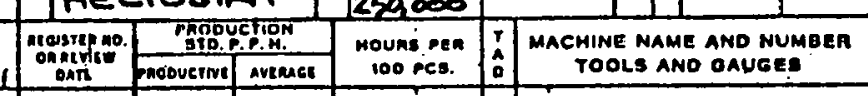

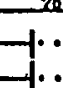

.
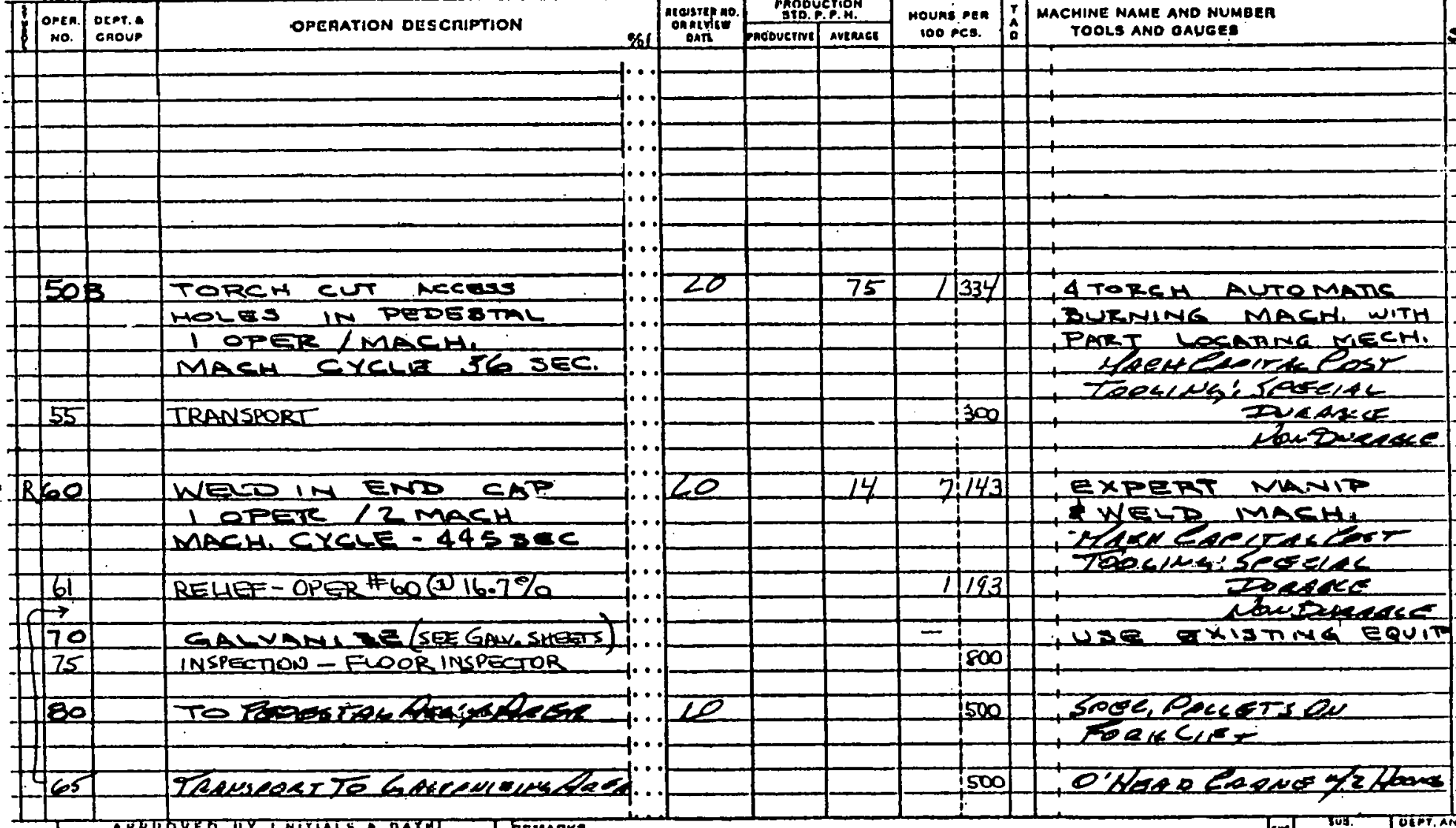

\begin{tabular}{|c|c|c|c|}
\hline 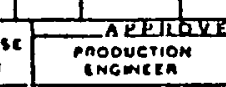 & 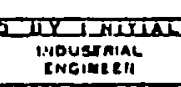 & manuaretunima & 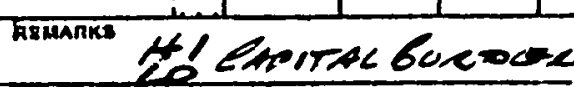 \\
\hline & & & \\
\hline & - & & \\
\hline Sint inousthat Inct & 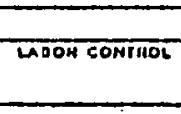 & 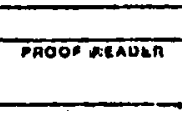 & E: \\
\hline
\end{tabular}
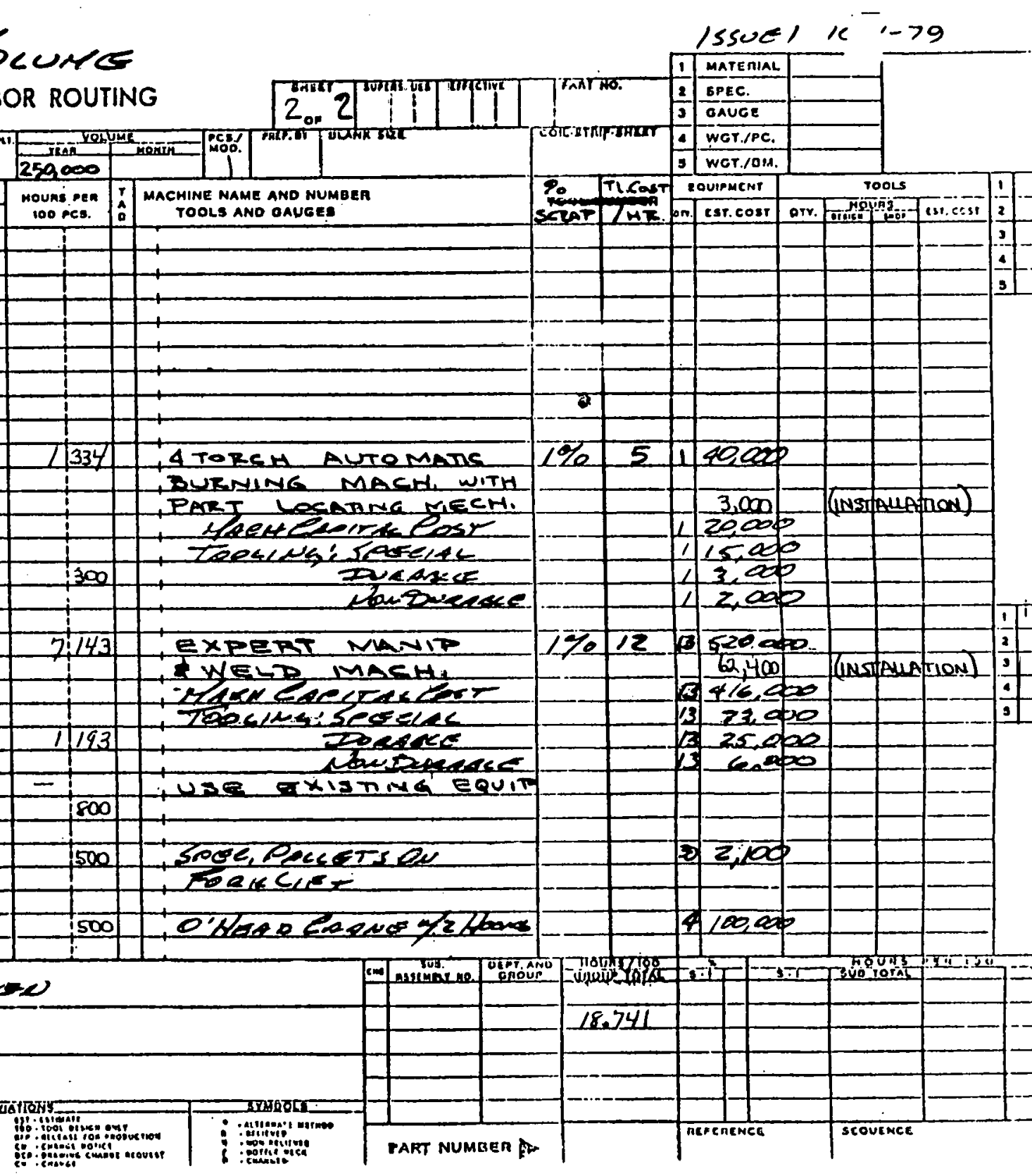


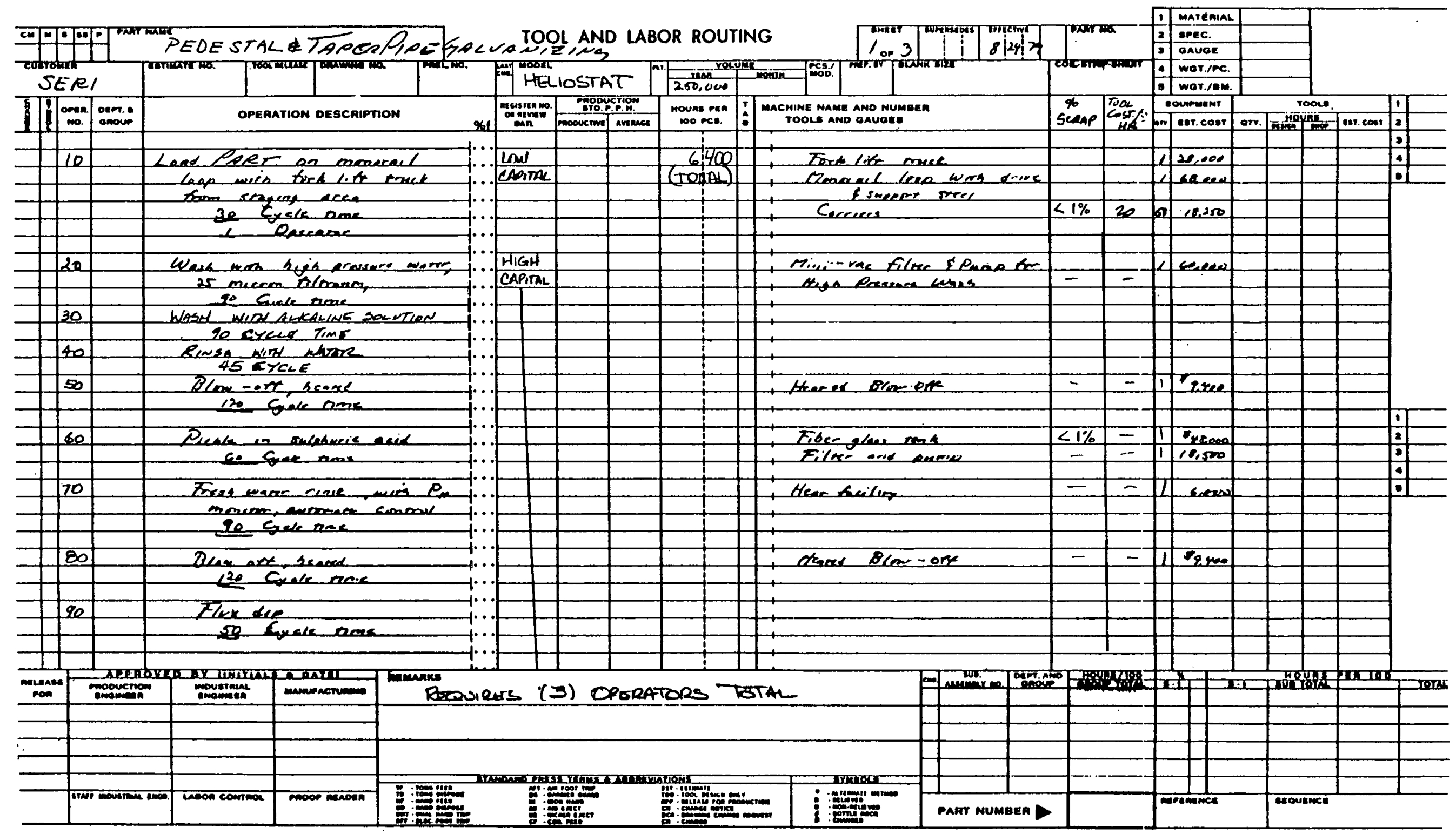




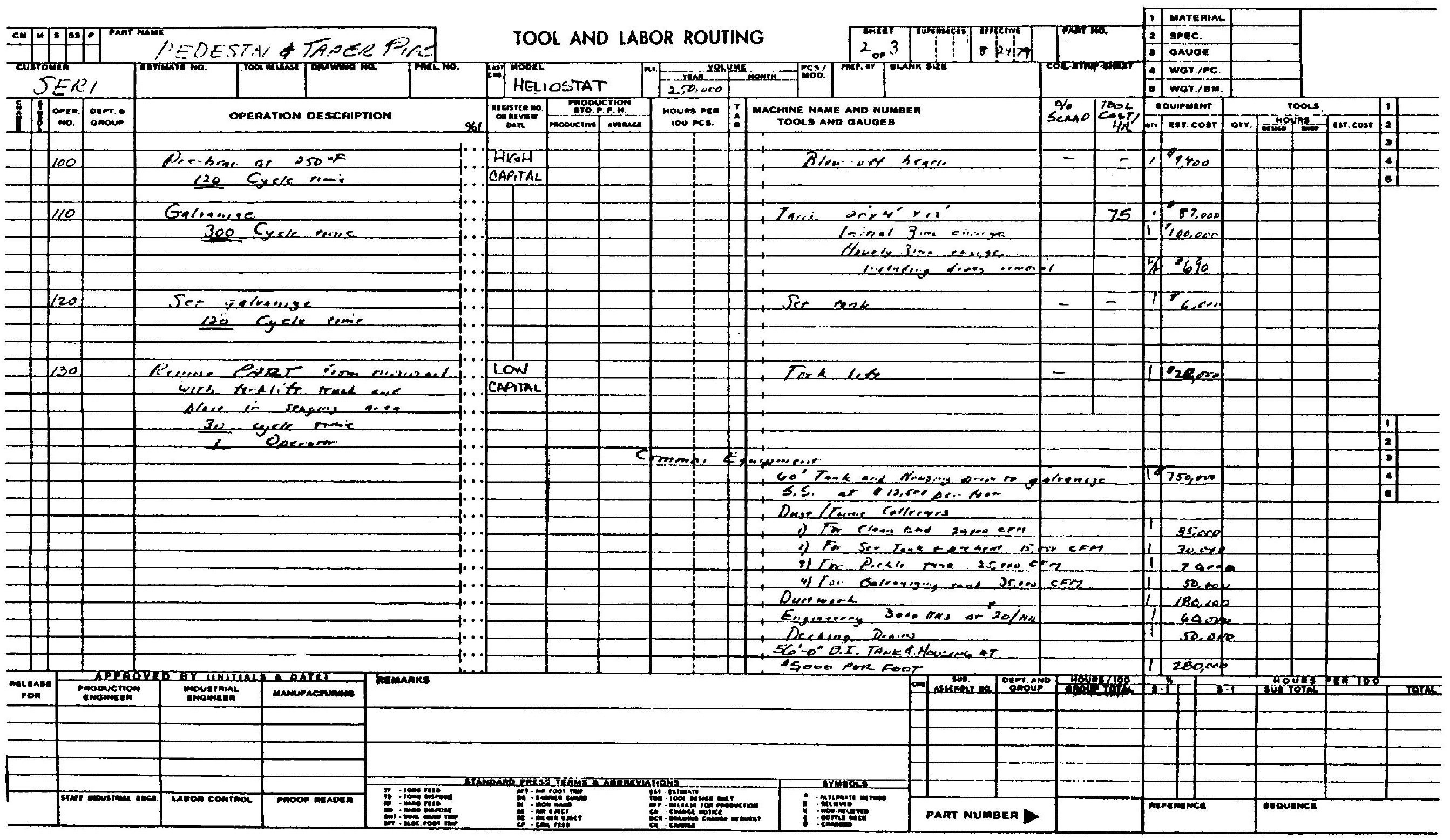




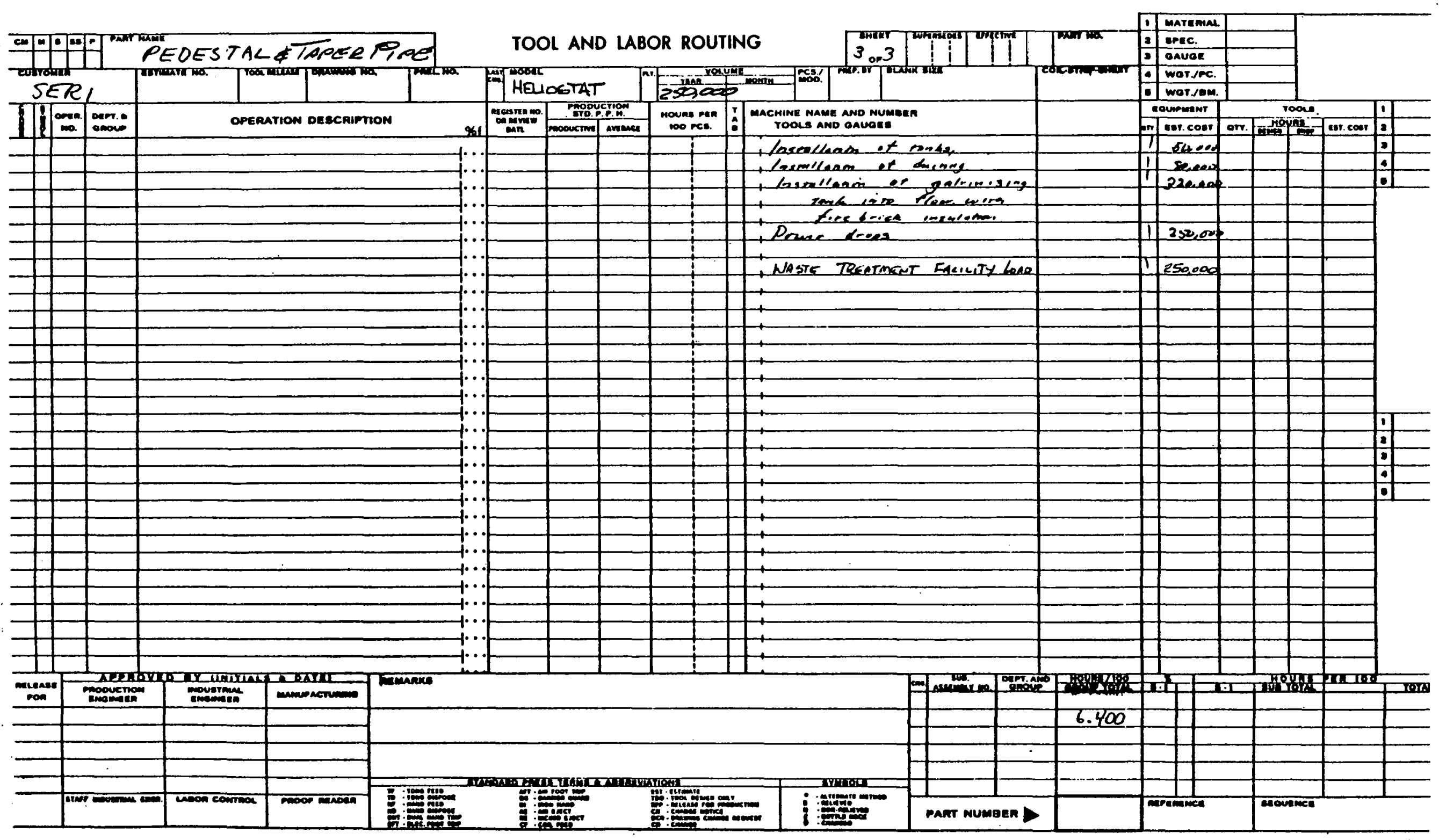


APPENDIX D

PRODUCT COST ESTIMATE 


\section{THIS PAGE WAS INTENTIONALLY \\ LEFT BLANK}


PRODUCT COST ESTIMATE - 25,000 ANNUAL VOLUME HELIOSTAT REFLECTIVE UNIT
מАT. 11-26-79

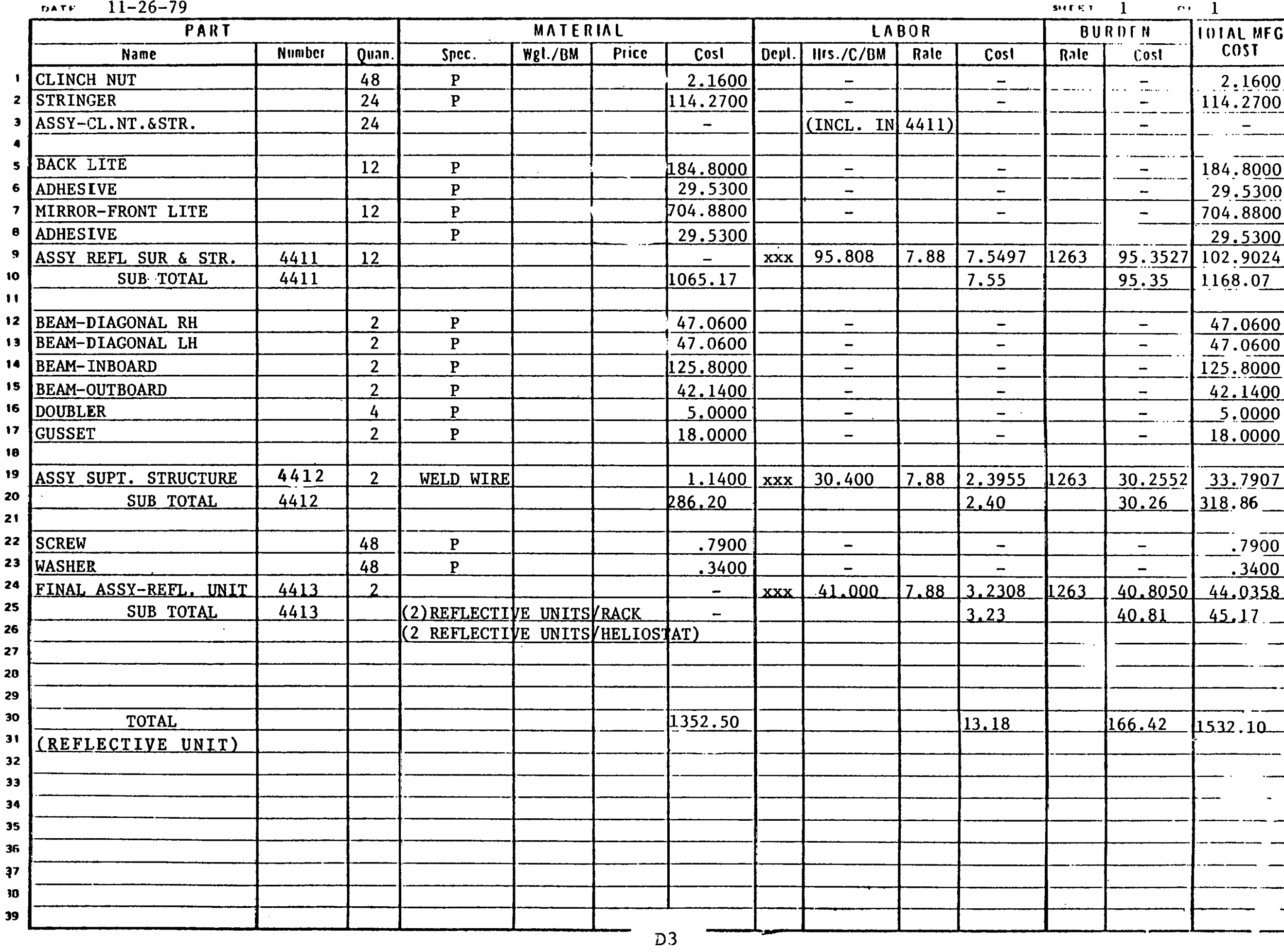


PRODUCT COST ESTIMATE - 25,000 ANNUAL VOLUME HELIOSTAT

DRIVE UNIT \& ELECTRONICS

No. 936

מin, $1 \quad \ldots 6$

\begin{tabular}{|c|c|c|c|c|c|c|c|c|c|c|c|c|c|}
\hline \multicolumn{3}{|l|}{ PART } & \multicolumn{4}{|c|}{ MATERIAL } & \multicolumn{4}{|c|}{ LABOR } & \multicolumn{2}{|c|}{ BURITN } & \multirow{2}{*}{$\begin{array}{c}\text { I1)INL MFC } \\
\text { COST }\end{array}$} \\
\hline Name & Muniber & Quan. & Spec. & $\mathrm{HB}_{\mathrm{B}} / \mathrm{BM}$ & Price & $\cos 1$ & $0<\mu 1$. & $\mathrm{HIS./C/BM}$ & Ralc & $\cos 1$ & Raic & Cosi & \\
\hline & & & & & & & & & & & $-\cdots$ & $\ldots$. & $\ldots \ldots \ldots$ \\
\hline HOUSING-AZIMUTH DR. & 4421 & 1 & $\mathbf{P}$ & & & 370.0000 & & - & & - & & $=$ & 370.0000 \\
\hline MACHINE_HOUSING & $\dot{4} 421$ & 1 & & & & - & $\mathrm{xxx}$ & 82.832 & 7.88 & 6.5272 & 1263 & 82.4385 & -88.9657 \\
\hline DRIVE SHAFT & $\$ 421$ & 1 & $\mathbf{P}$ & & & 20.0000 & & - & & - & & $=$ & -20.0000 \\
\hline & & & & & & & & & & & & 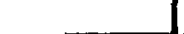 & \\
\hline & & & & & & & & & & & & $\ldots$ & \\
\hline RETAINING OUTER & 4421 & 1 & $\mathbf{P}$ & & & 77.0000 & & - & & - & & $\ldots$ & 77.0000 \\
\hline HELICON GEAR (OUTPUT) & 4421 & 1 & $P$ & & & .3528 & & _ & & - & & $=$ &.$\quad .3528$ \\
\hline RETATNFR BFARTNG & $\$ 421$ & 1 & & & & 6900 & & - & & - & & - & 6000 \\
\hline MACHINE-RET. BEARING & 4421 & 1 & & & & - & $\mathrm{xxx}$ & 33.3500 & 7.88 & 2.6300 & 1263 & 33.1900 & $\frac{.6900}{35.8200}$ \\
\hline & & & & & & & & & & - & & - $\cdots$ & \\
\hline COVER \& HUB & 4421 & 1 & $\underline{\mathbf{P}}$ & & & 2.9200 & & - & & - & & - & 2.9200 \\
\hline BUSHING & 4421 & 1 & $\mathbf{P}$ & & & .0264 & & - & & - & & - & .0264 \\
\hline OIL PAN (WELD) & 4421 & 1 & $\mathbf{P}$ & & & 6.4600 & & $=$ & & - & & - & $6 . \overline{4600}$ \\
\hline PLATE & 4421 & 1 & $\mathbf{P}$ & 2 & & & & - & & - & & - & \\
\hline TUBE & 4421 & 1 & $P$ & tr & & .4741 & & $=$ & & - & & - &. .4741 \\
\hline PLUG & 4421 & 1 & $\mathbf{P}$ & & & .0984 & & - & & - & & - & .0984 \\
\hline & & & & & & & & & & & & & L. \\
\hline & & & & & & & & & & & & & -1 \\
\hline & & & & & & & & & & & & & \\
\hline & & & & & & & & & & & & & \\
\hline & & & & & & & & & & & & & \\
\hline & & & & & & & & & & & & & 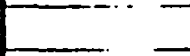 \\
\hline & & & & & & & & & & & & & \\
\hline & & & & & & & & & & & & & \\
\hline & & & & & & & & & & & & & $\ldots$ \\
\hline & & & & & & & & & & & & & \\
\hline & & & & & & & & & & & & & $\ldots$ \\
\hline & & & & & & & & & & & & & \\
\hline TUBING-SEAMLESS & 4421 & 1 & & & & & & & & & & & - \\
\hline DIAPHRAGM & 4421 & 1 & & & & & & & & & & & \\
\hline SUPPORT DOUBLER & 4421 & 1 & $\bar{P}$ & & & 25.0000 & & - & & - & & - & 25.0002 \\
\hline HEAT TREAT, WELD MACH, & 4421 & 1 & & & & - & $x x x$ & 45.058 & 7.88 & 3.5506 & 1263 & 44.8441 & .48 .3942 \\
\hline ASSY FLEXIBLE SPLINE & & & & & & & & & & & & & \\
\hline L_ & & & & & & & & & & & & & \\
\hline TOTAL P1 & 4421 & & & & $D 4$ & 503.02 & & & & 12.71 & & 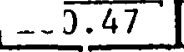 & 676.70 \\
\hline
\end{tabular}


PRODUCT COST ESTIMATE - 25,000 ANNUAL VOLUME HELIOSTAT DRIVE UNIT \& ELECTRONICS

\begin{tabular}{|c|c|c|c|}
\hline & \multicolumn{3}{|l|}{ PAII T } \\
\hline & Name & Nuraber & Quan \\
\hline 1 & KEY & 4421 & 1 \\
\hline 2 & & & \\
\hline 3 & SPLINE-CIRCULAR & 4421 & 1 \\
\hline 4 & MACH. CIRC. SPLINE & 4421 & 1 \\
\hline & & & \\
\hline 6 & BEAFING-WAVE GENERATO & 4421 & 1 \\
\hline 7 & KEY (GEAR) & 4421 & 1 \\
\hline 日 & NUT (GEAR) & 4421 & 1 \\
\hline 9 & WASHER (GEAR) & 4421 & 1 \\
\hline 10 & LOCENUT & 4421 & 12 \\
\hline 1 & BOLT (SPECIAL) & 4421 & 12 \\
\hline 12 & NUT (SPECIAL) & 4421 & 1 \\
\hline 13 & ASSY. HARMONIC DR, & 4421 & 1 \\
\hline 14 & & & \\
\hline 15 & & & \\
\hline 16 & WAVE GENERATOR PLUG & 4421 & 1 \\
\hline 17 & MACH. WAVE GEN. PLUG & 4421 & 1 \\
\hline 18 & & & \\
\hline 19 & BEARING (DR. SHAFT) & 4421 & 1 \\
\hline 20 & TURRET BEARING & 4421 & 1 \\
\hline 21 & PACXING & 4421 & 1 \\
\hline 22 & SHIM (GEAR) & 4421 & 4 \\
\hline 23 & LOCKNUT (WAVE GEN) & 4421 & 1 \\
\hline 24 & WASHER (WAVE GEN) & 4421 & 1 \\
\hline 25 & PACKING & 4421 & 1 \\
\hline 26 & GREASE & 4421 & 1 \\
\hline 27 & ـــــ & 4421 & 1 \\
\hline 20 & ELBaW & 4421 & 1 \\
\hline 29 & SCREW & 4421 & 8 \\
\hline 30 & BOLT & 4421 & 8 \\
\hline 31 & BOLT & 4421 & 4 \\
\hline 32 & BOLT & 4421 & 16 \\
\hline 33 & BOLT & 4421 & 8 \\
\hline 34 & & & \\
\hline 35 & ASSY-AZIMUTH DR. & 4421 & 1 \\
\hline 36 & & & \\
\hline 37 & SUE TOTAL (P1) & 4421 & \\
\hline 30 & SUE TOTAL (P2) & 4421 & \\
\hline 39 & SUB TOTAL & 4421 & \\
\hline
\end{tabular}

\section{MATERIAL}

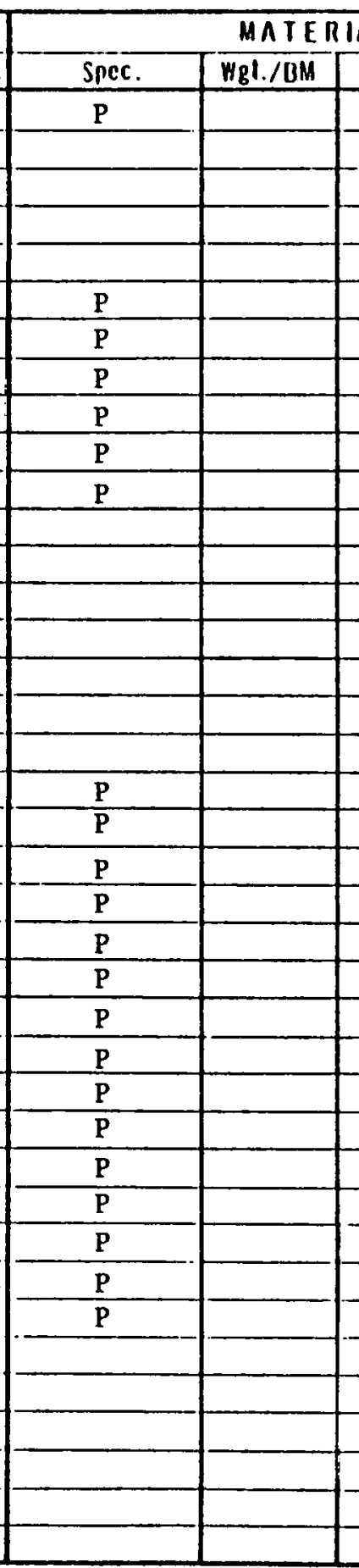

No. 936

s... 2

BURIIII

\begin{tabular}{|c|c|c|c|c|c|c|c|}
\hline & \multicolumn{4}{|c|}{$\angle A B O R$} & \multicolumn{2}{|c|}{ BURIIN } & \multirow{2}{*}{$\begin{array}{c}\text { I1)IAL MFG. } \\
\text { COST }\end{array}$} \\
\hline $\cos 1$ & Dept. & His./C/BM & Rale & $\cos 1$ & Role & c.0.51 & \\
\hline .0227 & & - & & - & & - & .0227 \\
\hline & & & & & & $\cdots$ & \\
\hline 85.0000 & & - & & - & & - & 85.0000 \\
\hline- & $x x x$ & 58.182 & 7.88 & 4.5847 & 1263 & 57.9048 & $62.48 \overline{95}$ \\
\hline & & & & & & - & \\
\hline 75.6200 & & - & & - & & - & $7 \overline{5} . \overline{6} \overline{200}$ \\
\hline .0106 & & - & & - & & - & .0106 \\
\hline .4400 & & $=$ & & - & & $\overline{-}$ & .4400 \\
\hline .1000 & & - & & - & & - & .1000 \\
\hline .0600 & & - & & $5-$ & & - & .0600 \\
\hline 31.8000 & & - & & - & & - & 31.8000 \\
\hline 21.5700 & & - & & - & & - & 21.5700 \\
\hline- & $x \times x$ & (INCL. IN & MACH. & OPER \& \& & AZIM. & - & - \\
\hline & & DR. ASS & ) & & & & + \\
\hline & & & & & & & To omn \\
\hline$\frac{10.9200}{-}$ & $x \times x$ & $\frac{-}{27.435}$ & $7.8 \overline{8}$ & - & 1263 & $\frac{-}{27.3048}$ & 10.9200 \\
\hline - & $x x x$ & 27.435 & & & & 21.3040 & 29.4661 \\
\hline 3.3100 & & - & & - & & - & 3.3100 \\
\hline 20.7800 & & - & & - & & - & 20.7800 \\
\hline 3.4861 & & - & & - & & - & $3.4 \overline{861}$ \\
\hline .1557 & & - & & - & & - & .1557 \\
\hline .6500 & & - & & - & & $\overline{-}$ & .6500 \\
\hline .1200 & & $\overline{-}$ & & - & & 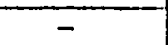 & .1200 \\
\hline 3.0252 & & - & & - & & - & 3.0252 \\
\hline .3700 & & - & & - & & - & .3700 \\
\hline 1.0100 & & - & & - & & - & 1.0100 \\
\hline 1.4400 & & - & & - & & - & 1.4400 \\
\hline .0600 & & - & & - & & - & .0600 \\
\hline .0500 & & - & & - & & - & .0500 \\
\hline .0200 & & - & & - & & - & .0200 \\
\hline .7800 & & - & & - & & - & .7800 \\
\hline 2.5640 & & & & & & & 2.5640 \\
\hline - & $x \times x$ & 56.390 & 7.88 & 4.4435 & 1263 & 56.1214 & 60.5649 \\
\hline & & & & & & & \\
\hline 263.36 & & & & 11.19 & & 141.33 & 415.88 \\
\hline 503.02 & & & & 12.71 & & 160.47 & 676.20 \\
\hline 766.38 & & & & 23.90 & & 301.80 & 1092.08 \\
\hline
\end{tabular}


PRODUCT COST ESTIMATE - 25,000 ANNUAL VOLUME HELIOSTAT DRIVE UNIT \& ELECTRONICS

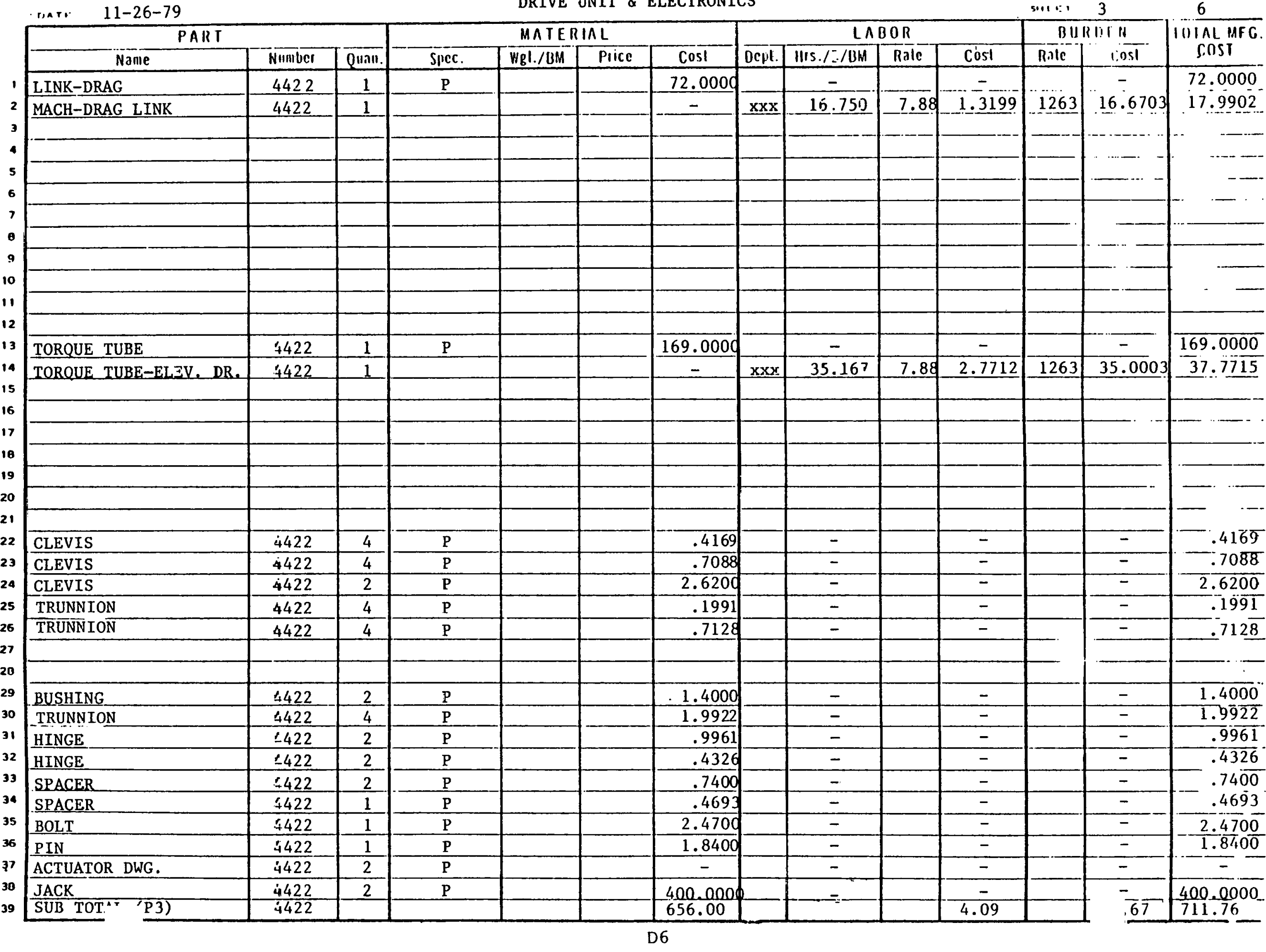


PRODUCT COST ESTIMATE - 25,000 ANNUAL VOLUME HELIOSTAT DRIVE UNIT \& ELECTRONICS

MA TERIAL

\begin{tabular}{|c|c|c|}
\hline \multicolumn{3}{|l|}{ PAIR T } \\
\hline Name & Number & Quan. \\
\hline ASSY. ELEVATION DR. & 4422 & 1 \\
\hline SUB TOTAL (P3) & 4422 & \\
\hline SUB TOTAL & 4422 & \\
\hline BOLT & 4423 & 4 \\
\hline WASHER & 4423 & 4 \\
\hline MOTOR & 4423 & 1 \\
\hline BOLT & 4423 & 4 \\
\hline WASHER & 4423 & 4 \\
\hline MOTOR & 4423 & 1 \\
\hline BOLT & 4423 & 4 \\
\hline WASHER & 4423 & 4 \\
\hline MOTOR & 4423 & 1 \\
\hline MOTORS & 4423 & 1 \\
\hline SUB TOTAL & 4423 & \\
\hline SENSOR-HALL EFFECT & 4424 & 6 \\
\hline DRIVER - LINE & 4424 & 3 \\
\hline DUAL DIFF . LINE REC. & 4424 & 3 \\
\hline ACTUATOR & 4424 & 3 \\
\hline RESISTOR & 4424 & 12 \\
\hline CAPACITOR & 4424 & 12 \\
\hline CONN. & 4424 & 3 \\
\hline PRINTED CIRCUIT BOARD & 4424 & 3 \\
\hline TRIACS - OPT. ISOL. & 4424 & 12 \\
\hline SCREW & 4424 & 3 \\
\hline SCREW & 4424 & 12 \\
\hline WASHER & 4424 & 15 \\
\hline NUT & 4424 & 15 \\
\hline SCREW & 4424 & 6 \\
\hline SCREW & 4424 & 9 \\
\hline CYLINDER & 4424 & 3 \\
\hline COVER & 4424 & 3 \\
\hline BRACKET & 4424 & 3 \\
\hline POSITION/LIMIT/IND. & 4424 & 1 \\
\hline SUB TOTAL & 4424 & \\
\hline
\end{tabular}

\begin{tabular}{|c|c|}
\hline \multicolumn{2}{|r|}{ MATE } \\
\hline Spec. & $\mathrm{Wgt} . / \mathrm{BM}$ \\
\hline & \\
\hline & \\
\hline & \\
\hline & \\
\hline $\mathbf{P}$ & \\
\hline $\mathbf{P}$ & \\
\hline$P$ & \\
\hline $\mathbf{P}$ & \\
\hline $\mathbf{P}$ & \\
\hline $\mathbf{P}$ & \\
\hline $\mathbf{p}$ & \\
\hline$P$ & \\
\hline $\mathbf{P}$ & \\
\hline & \\
\hline & \\
\hline & \\
\hline $\mathrm{P}$ & \\
\hline $\mathbf{P}$ & \\
\hline $\mathrm{P}$ & \\
\hline$P$ & \\
\hline $\mathrm{P}$ & \\
\hline$P$ & \\
\hline $\mathrm{P}$ & \\
\hline $\mathrm{P}$ & \\
\hline $\mathrm{p}$ & \\
\hline $\mathbf{P}$ & \\
\hline $\mathrm{P}$ & \\
\hline $\mathrm{P}$ & \\
\hline $\mathrm{P}$ & \\
\hline $\mathbf{P}$ & \\
\hline $\mathbf{P}$ & \\
\hline $\mathbf{P}$ & \\
\hline $\mathbf{P}$ & \\
\hline $\mathbf{P}$ & \\
\hline & \\
\hline & \\
\hline & \\
\hline
\end{tabular}

SN1 :

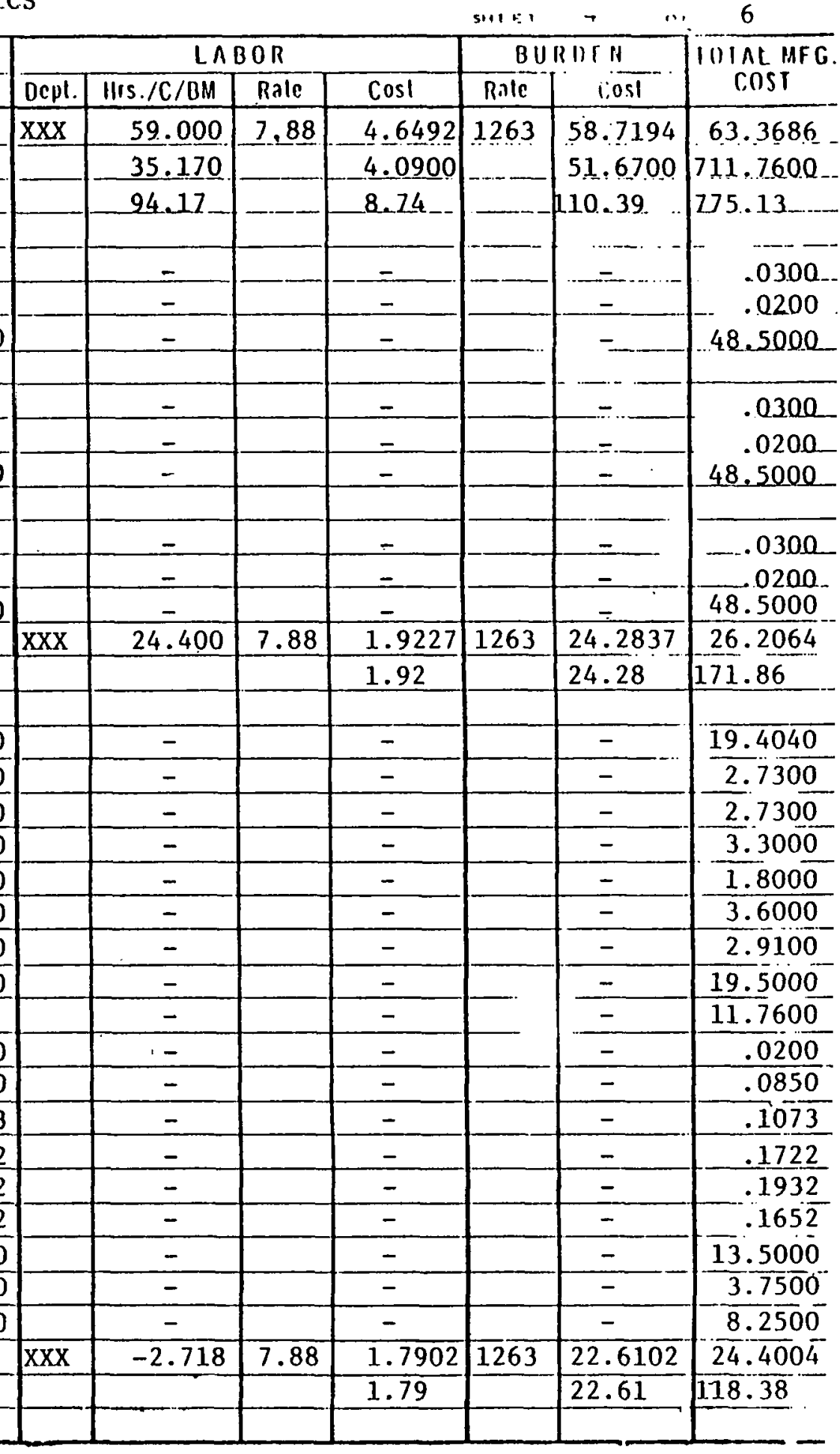


PRODUCT COST ESTIMATE - 25,000 ANNUAL VOLUME HELIOSTAT

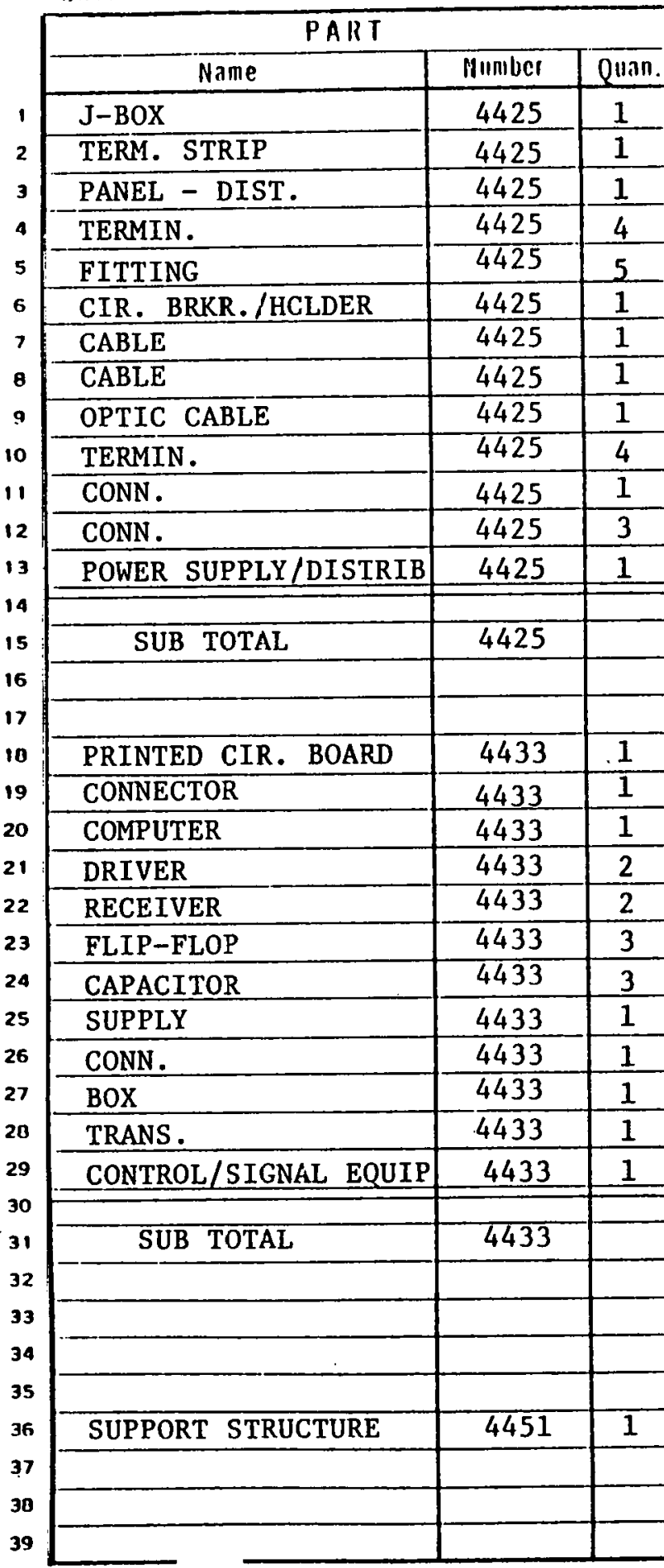
DRIVE UNIT AND ELECTRONICS

MATERIAL

No. 936

sin: $\quad 5 \quad \cdots \quad 6$

BURIT H

LABOR Wgl./BM Price

\begin{tabular}{|r|}
\hline \multicolumn{1}{c}{ Cos 1} \\
\hline 14.9700 \\
.6500 \\
\hline 2.0000 \\
19.0800 \\
71.3000 \\
\hline 33.0000 \\
\hline 1.6467 \\
\hline 3.3134 \\
\hline 2.9700 \\
\hline 6.4000 \\
\hline .4800 \\
\hline 6.7500 \\
\hline- \\
\hline
\end{tabular}

Dcpt

\begin{tabular}{|c|c|c|c|c|c|}
\hline \multicolumn{3}{c|}{ LABOR } & \multicolumn{2}{c|}{ BUR RI I } \\
\hline Dcpt. & IIIS./C/BM & Rale & Cost & Rnic & Cost \\
\hline & - & & - & & -
\end{tabular}

00

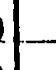

$=-$

(

$+\infty \quad-162.56$

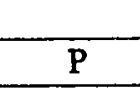

P

\begin{tabular}{|}
\hline \\
\hline
\end{tabular}

-..

-....

$\cdots=$

$-$

$-$

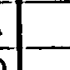

\begin{tabular}{|c|c|c|c}
\hline & - & & - \\
\hline & - & & - \\
\hline- & & - \\
\hline
\end{tabular}

7.3157
162.56

6.7500

1.8000

45.0000

2.5000

2.5000

1.8000
.6000

$\frac{45.4000}{1.8000}$

1.8000
.5500

37.0000

\begin{tabular}{|c|c|c|c|}
\hline- & $\mathrm{XXX}$ & 37.454 & 7.88 \\
\hline 145.70 & & & \\
\hline & & & \\
\hline & & \\
\hline & & & \\
\hline 260.00 & & - & \\
\hline & & & \\
\hline & & & \\
\hline
\end{tabular}

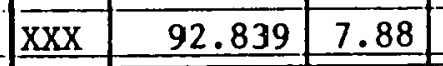

7.32

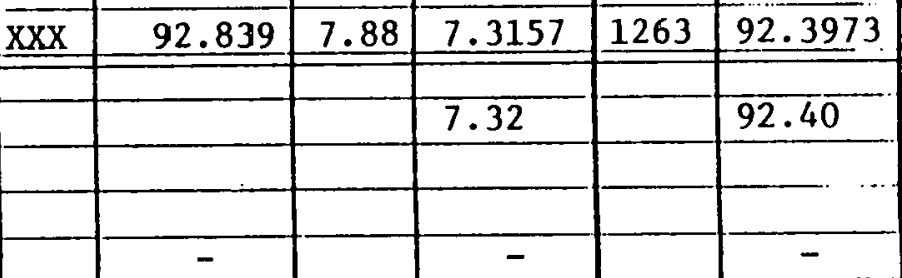

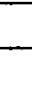

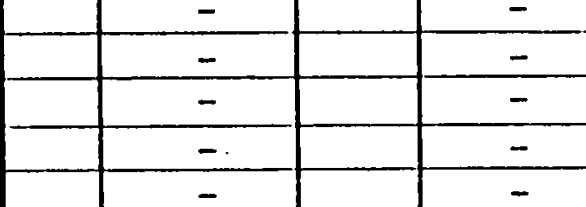

-

$+$

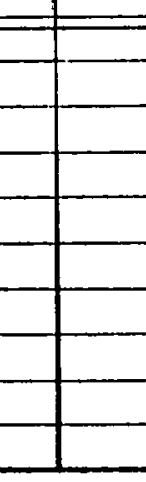


PRODUCT COST ESTIMATE - 25,000 ANNUAL VOLUME HELIOSTAT DRIVE UNIT AND ELECTRONICS

MATERIAL

Sint

6

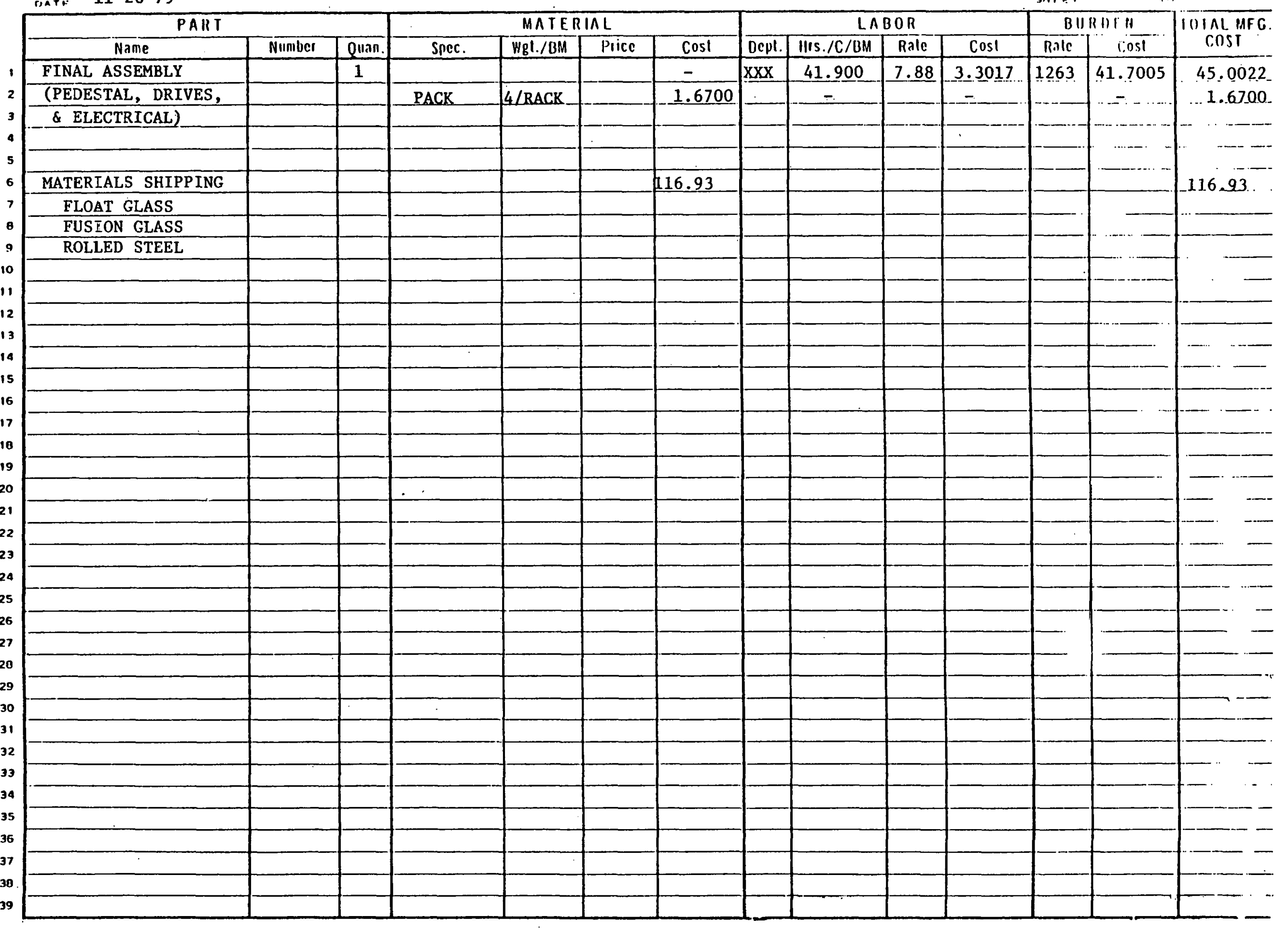


PRODUCT COST ESTIMATE - 25,000 ANNUAL VOLUME HELIOSTAT FOUNDATION CAP

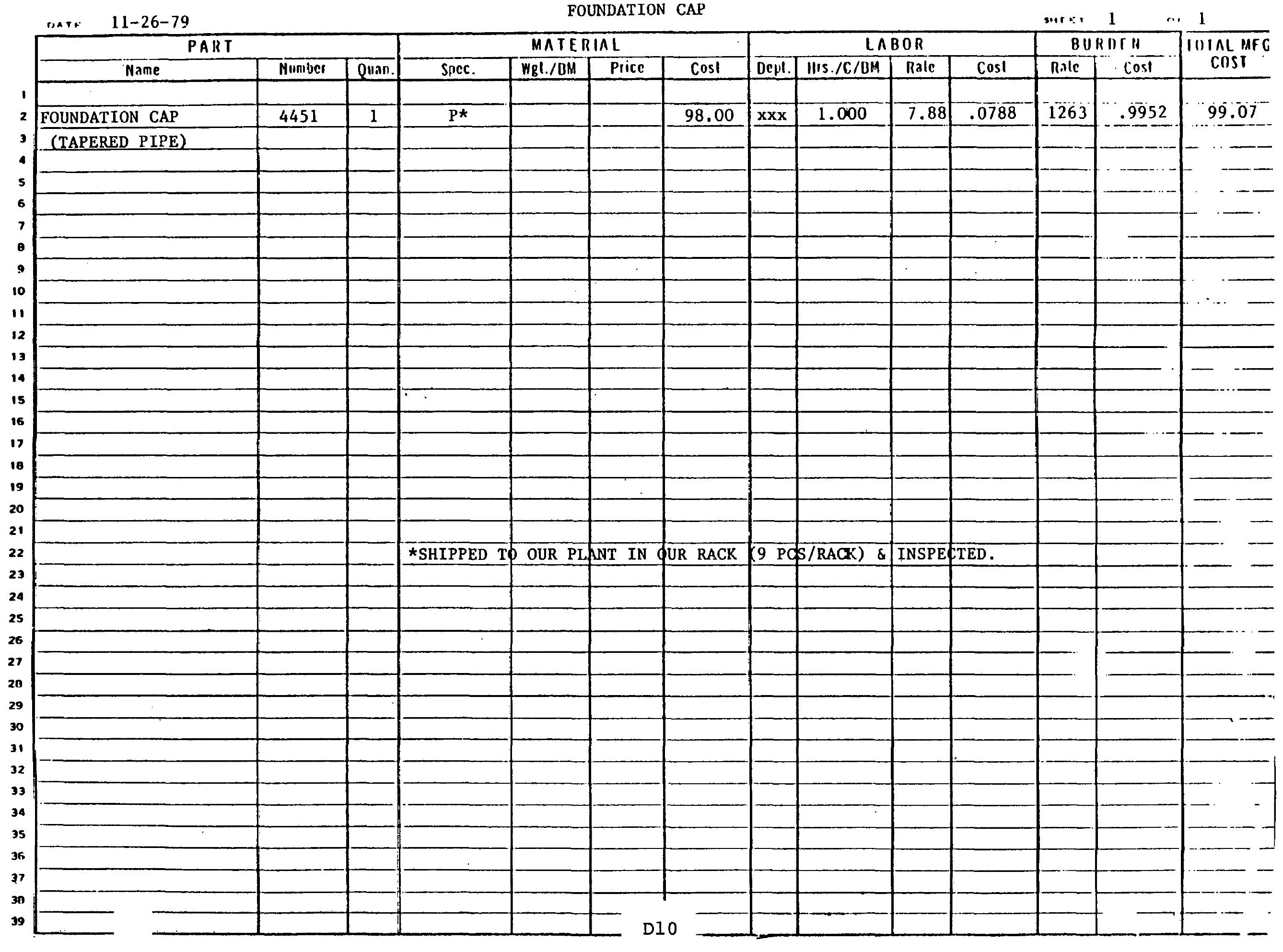




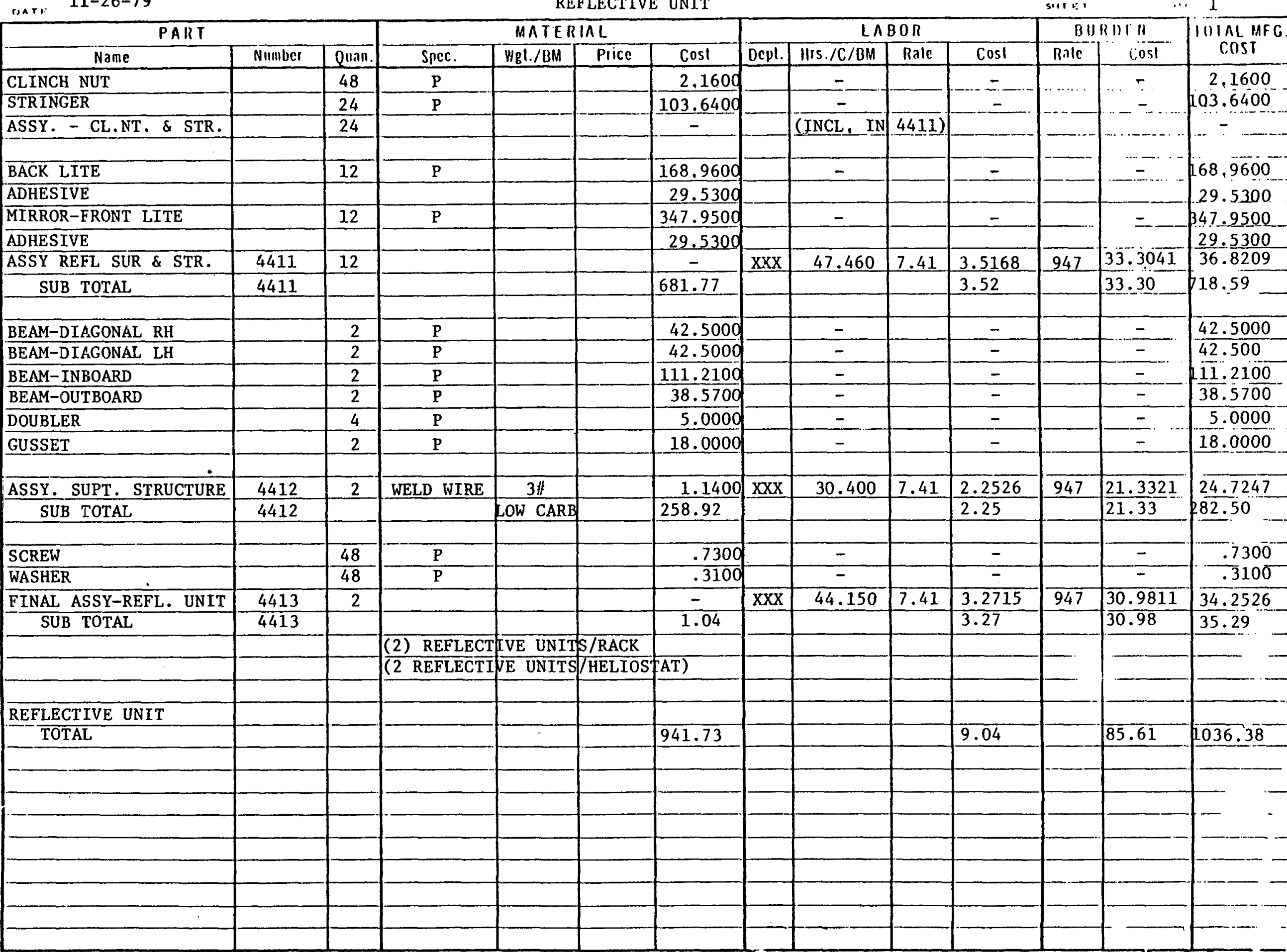


PRODUCT CCST ESTIMATE - 250,000 ANNUAL VOLUME HEL, 30 OSTAT DRIVE UNIT \& ELECTRONICS

\begin{tabular}{|c|c|c|c|c|c|c|c|c|c|c|c|c|c|c|}
\hline & $11-26-79$ & & & 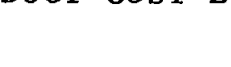 & DRIVE U & NIT \& EL & LECTRONICS & $S$ & & & & \multirow{2}{*}{\multicolumn{2}{|c|}{$\frac{\sin \theta, \quad 1}{B(|R|) \Gamma}$}} & \multirow{3}{*}{$\underbrace{6}_{\substack{10 \mathrm{IML} \mathrm{MFC} \\
\mathrm{COST}}}$} \\
\hline & \multicolumn{3}{|l|}{ P.ART } & \multicolumn{4}{|c|}{ MATERIAL } & \multicolumn{4}{|c|}{$\angle \wedge B O R$} & & & \\
\hline & Name & Nuriber & Quan. & Spec. & $\mathrm{HgI} / \mathrm{BM}$ & Price & $\cos 1$ & Dcpt. & $1115 . / C / B M$ & Rale & $\operatorname{Cos} 1$ & Rilc & $1: 051$ & \\
\hline 1 & GALV. HOUSING & & 1 & & & + & - & $\mathrm{XxX}$ & $3.20 !$ & 7.41 & .2371 & 947 & 2.2453 & 2.4824 \\
\hline 2 & & & & & & & & & & & & & ....... & $\ldots \quad \ldots \ldots \ldots$ \\
\hline 3 & & & & & & & & & - & & - & & $-\ldots$ & \\
\hline 4 & MACHINE HOUSING & 4421 & 1 & & & & - & $\mathrm{xxx}$ & $18.36^{\prime}$ & 7.41 & 1.3608 & 947 & 12.8868 & 14.2476 \\
\hline 5 & & & & & & & & & & & & & & \\
\hline 6 & DRIVE SHAFT & 4421 & 1 & $\mathrm{P}$ & & & 2.4300 & & - & & - & & - & 2.4300 \\
\hline $\mathbf{8}$ & & & & & & & & & & & & & & \\
\hline 9 & RETAINER, OUTER & 4421 & 1 & $\underline{P}$ & & & 11.3900 & & - & & - & & - & 11.3900 \\
\hline 10 & HELICON GEAR (OLTPUT) & 4421 & 1 & $\mathrm{P}$ & & & .2205 & & - & & - & & - & .2205 \\
\hline 11 & & & & & & & & & & & & & & \\
\hline 12 & RETAINER, BEARING & 4421 & 1 & $\underline{P}$ & & & .6900 & & - & & - & & - & .6900 \\
\hline 13 & MACHINE-RET , BEARING & 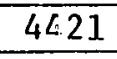 & 1 & & & & - & $\mathrm{xxX}$ & 39.238 & 7.41 & 2.9075 & 947 & 27.5340 & 30.4415 \\
\hline 14 & & & & & & & & & & & & & & \\
\hline 15 & COVER & $4<21$ & 1 & $\mathbf{p}$ & & & 2.9200 & & - & & - & & - & 2.9200 \\
\hline 16 & BUSHING & $4<21$ & 1 & $\mathrm{P}$ & & & .0264 & & - & & - & & - & .0264 \\
\hline 10 & PLATE & 4421 & 1 & $P$ & & & - & & - & & $=$ & & - & $\cdot-$ \\
\hline 19 & TUBE & 4421 & 1 & $\underline{P}$ & & & .4552 & & - & & - & & - & .4552 \\
\hline 20 & PLUG & 4421 & 1 & $P$ & & & .0915 & & - & & - & & - & .0915 \\
\hline 21 & & & & & & & & & & & & & & \\
\hline 22 & HOUSING (WELD) & 4421 & 1 & & & & - & $\mathrm{XxX}$ & 40.527 & 7.41 & 3.0031 & 947 & 28.4394 & 31.4425 \\
\hline 23 & & & & & & & & & & & & & & \\
\hline 24 & RETAINER & 4421 & 1 & $\mathbf{P}$ & & & 60.0000 & & - & & $=$ & & - & 60.0000 \\
\hline 25 & TUBE & 4421 & 1 & $\mathbf{P}$ & & & 33.0000 & & - & & - & & - & 33.0000 \\
\hline 26 & PLATE & 4421 & 1 & $\mathbf{P}$ & & & 18.0600 & & - & & - & & - & 18.0600 \\
\hline 27 & TUBE & 4421 & 1 & $\mathbf{P}$ & & & 4.0000 & & - & & - & & - & 4.0000 \\
\hline 20 & TUBE & 4421 & 1 & $\mathbf{p}$ & & & 9.0000 & & - & & - & & - & 9.0000 \\
\hline 29 & LUG & 4421 & 2 & $\mathbf{P}$ & & & 37.3500 & & - & & - & & $=$ & 37.3500 \\
\hline 30 & TUBE & 4421 & 1 & $\mathbf{P}$ & & & .5459 & & - & & $=$ & & - & .5459 \\
\hline 31 & LUG & 4421 & 1 & $P$ & & & 6.6400 & & - & & - & & - & 6.6400 \\
\hline 32 & LUG & 4421 & 1 & $\mathrm{P}$ & & & 6.6400 & & - & & - & & - & 6.6400 \\
\hline 33 & MOUNT & 4421 & 1 & $P$ & & & 1.2450 & & - & & - & & - & 1.2450 \\
\hline 34 & WE B & 4421 & 1 & $\mathbf{P}$ & & & 9.1300 & & - & & - & & - & 9.1300 \\
\hline 35 & PLATE & 4421 & 1 & P & & & 4.0000 & & - & & - & & - & 4.0000 \\
\hline 39 & P1 SU ${ }^{\text {Tก TAL }}$ & 4421 & & & & & 239.30 & & & & 11.65 & & & 361.31 \\
\hline
\end{tabular}


PRODUCT COST ESTIMATE - 250,000 ANNUAL VOLUME HELIOSTAT

DRIVE UNIT \& ELECTRONICS

No. 936

sil : : त. 6

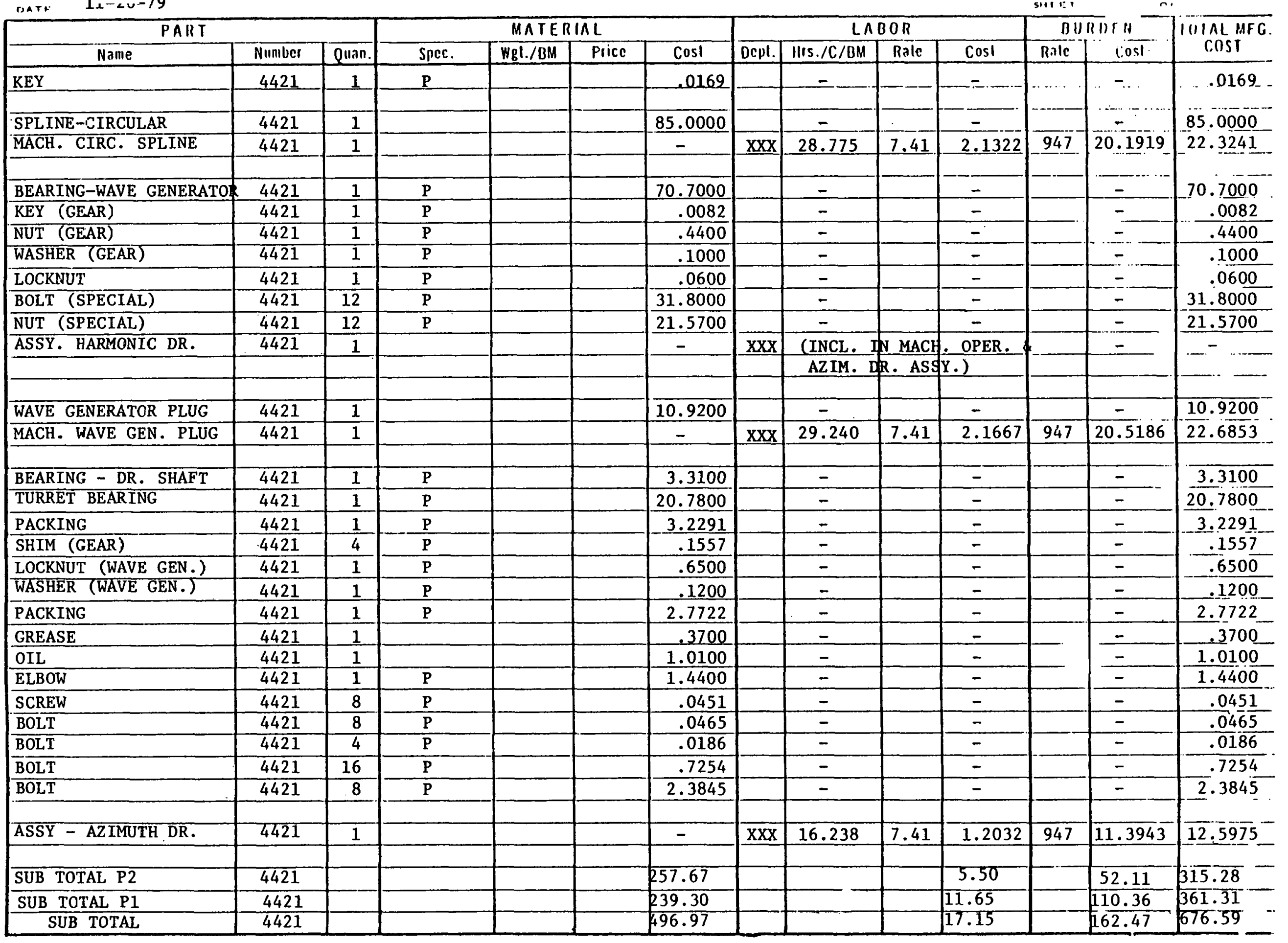




\section{MATERIAL}

1 GALV. DRAG LINK

MACH. - DRAG LINK

3

4 PLATE - SIDE RH

5 PLATE - SIDE LH

BRACE

BRACE

BRACE

LUG

10

WE

12$$
14
$$

15

16

17

10

19

20

22

23

24

26

20

29

30$$
3
$$$$
32
$$

\section{4}

SPACER

35 BOLT

36 PIN

37 ACT. DWG.

30 JACK

39 SUBTOTAL

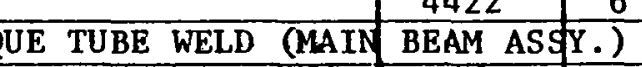

CLEVIS

CLEVIS

TRUNNION

TRUNNION

BUSHING

RUNNION

INGE

ACER

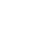

G.

PAIRT

N.Imber Quan.

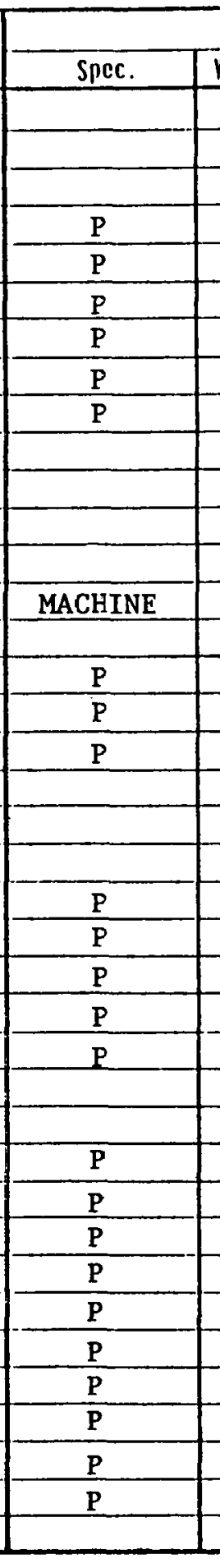

\begin{tabular}{|l|l|}
\hline 4422 & 1 \\
\hline 4422 & 1 \\
\hline & \\
\hline 4422 & 1 \\
\hline 4422 & 1 \\
\hline 4422 & 1 \\
\hline 4422 & 1 \\
\hline 4422 & 1 \\
\hline 4422 & 2 \\
\hline 4422 & 1 \\
\hline & \\
\hline & \\
\hline 4422 & 1 \\
\hline 4422 & 1 \\
\hline 4422 & 2 \\
\hline 4422 & 6 \\
\hline
\end{tabular}

\begin{tabular}{|l|l|l}
$\mathrm{Hgl} / \mathrm{B} \mathrm{BM}$ & Price & Cosl \\
\hline
\end{tabular}

L

\begin{tabular}{|l|l|l|}
\hline & & \\
\hline & 4422 & 4 \\
\hline & 4422 & 4 \\
\hline & 4422 & 2 \\
\hline & 4422 & 4 \\
\hline & 4 & \\
& 4422 & 2 \\
\hline & 4422 & 4 \\
\hline & 4422 & 2 \\
\hline & 4422 & 2 \\
\hline & 4422 & 1 \\
\hline & 4422 & 1 \\
\hline & 4422 & 1 \\
\hline & 4422 & 2 \\
\hline & 4422 & 2 \\
\hline & 4422 & \\
\hline
\end{tabular}

LABOR

\begin{tabular}{|c|c|c|c|c|c|c|}
\hline \multicolumn{4}{|c|}{ LABOR } & \multicolumn{2}{|c|}{ BURDCH } & \multirow{2}{*}{$\begin{array}{c}\text { IUIAL MFG. } \\
\text { COST }\end{array}$} \\
\hline Dcpl. & $\mathrm{HIS./C} / \mathrm{BM}$ & Rale & $\operatorname{Cos} 1$ & Rolc & $\quad \overline{0.051}$ & \\
\hline $\mathrm{XXX}$ & 3.200 & 7.41 & .2371 & 947 & .2 .2453 & 2.4824 \\
\hline \multirow[t]{7}{*}{$\mathrm{XXX}$} & 2.576 & 7.41 & .1909 & 947 & 1.8078 & 1.9987 \\
\hline & - & & - & & - & 18.2600 \\
\hline & - & & - & & - & 17.0200 \\
\hline & - & & - & & - & -5.4000 \\
\hline & - & & - & & $=$ & 3.3200 \\
\hline & - & & - & & $=$ & 2.0800 \\
\hline & - & & - & & - & 3.3200 \\
\hline \multirow[t]{2}{*}{$\mathrm{XXX}$} & 4.924 & 7.41 & .3649 & 947 & 3.4556 & 3.8205 \\
\hline & & & & & & \\
\hline $\mathrm{XXX}$ & 6.400 & 7.41 & .4742 & 947 & 4.4907 & 4.9649 \\
\hline \multirow[t]{4}{*}{$\mathrm{XXX}$} & 2.788 & 7.41 & .2066 & 947 & 1.9565 & 2.1631 \\
\hline & . & & . & & 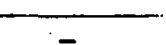 & 32.2549 \\
\hline & - & & - & & - & 57.2700 \\
\hline & - & & - & & - & 44.8200 \\
\hline \multirow[t]{7}{*}{$\mathrm{XXX}$} & $5 .-00$ & 7.41 & .3779 & 947 & 3.5787 & 3.9566 \\
\hline & & & & & & $-1-$ \\
\hline & - & & - & & - & .4049 \\
\hline & - & & - & & - & .6900 \\
\hline & - & & - & & - & 2.4890 \\
\hline & - & & - & & - & .1960 \\
\hline & - & & - & & - & .6930 \\
\hline & & & & & & \\
\hline & & & & & & \\
\hline & - & & - & & - & 1.4000 \\
\hline & - & & - & & - & 1.9045 \\
\hline & - & & - & & - & .9522 \\
\hline & - & & - & & - & .4207 \\
\hline & - & & - & & $=$ & .7000 \\
\hline & - & & - & & - & .4567 \\
\hline & - & & - & & - & 1.8900 \\
\hline & - & & - & & - & 1.7480 \\
\hline & - & & $=$ & & $=$ & - \\
\hline & $=$ & & - & & - & $400,0000_{-}$ \\
\hline & & & 1.85 & & 53 & 617.07 \\
\hline
\end{tabular}


PRODUCT COST ESTIMATE - 250,000 ANNUAL VOLUME HELIOSTAT DRIVE UNIT \& ELECTRONICS

MATERIAL

\begin{tabular}{|c|c|c|}
\hline \multicolumn{3}{|l|}{ PART } \\
\hline Name & Number & Qแan. \\
\hline ASSY. ELEVATION DR. & 4422 & 1 \\
\hline SUB TOTAL (P3) & 4422 & \\
\hline SUB TOTAL & 4422 & \\
\hline BOLT & 4423 & 4 \\
\hline WASHER & 4423 & 4 \\
\hline MOTOR & 4423 & 1 \\
\hline BOLT & 4423 & 4 \\
\hline WASHER & 4423 & 4 \\
\hline MOTOR & 4423 & 1 \\
\hline BOLT & 4423 & 4 \\
\hline WASHER. & 4423 & 4 \\
\hline MOTOR & 4423 & 1 \\
\hline MOTORS & 4423 & 1 \\
\hline SUE TOTAL & 4423 & \\
\hline SENSOK & 4424 & 6 \\
\hline DRIVER & 4424 & 3 \\
\hline LINE REC. & 4424 & 3 \\
\hline ACTUATOR & 4424 & 3 \\
\hline RESISTOR & 4424 & 12 \\
\hline CAPACITOR & 4424 & 12 \\
\hline CONN. & 4424 & 3 \\
\hline CIRCUIT & 4424 & 3 \\
\hline TRIACS & 4424 & 12 \\
\hline SCREW & 4424 & 3 \\
\hline SCREW & 4424 & 12 \\
\hline WASHER & 4424 & 15 \\
\hline NUT & 4424 & 15 \\
\hline SCREW & 4424 & 6 \\
\hline SCREW & 4424 & 9 \\
\hline CYLINDER & 4424 & 3 \\
\hline COVER & 4424 & 3 \\
\hline BRACKET & 4424 & 3 \\
\hline POSITION/LIMIT/IND. & 4424 & 1 \\
\hline SUB TOTAL & 4424 & \\
\hline
\end{tabular}

\begin{tabular}{|l}
\hline Spec. \\
\hline \\
\hline \\
\hline$P$ \\
\hline$P$ \\
\hline$P$ \\
\hline$P$ \\
\hline$P$ \\
\hline$P$ \\
\hline$P$ \\
\hline$P$ \\
\hline$P$ \\
\hline$P$ \\
\hline$P$ \\
\hline$P$ \\
\hline$P$ \\
\hline$P$ \\
\hline$P$ \\
\hline$P$ \\
\hline$P$ \\
\hline$P$ \\
\hline$P$ \\
\hline$P$ \\
\hline$P$ \\
\hline$P$ \\
\hline$P$ \\
\hline$P$ \\
\hline$P$
\end{tabular}

${ }^{W}$

$\sin \operatorname{sen}$

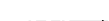

LABOR

\begin{tabular}{|l|l|l|}
$\mathrm{Mgl}$ I./BM & Price & Cost \\
\hline
\end{tabular}


PRODUCT COST ESTIMATE - 250,000 ANNUAL VOLUME HELIOSTAT DRIVE UNIT \& ELECTRONICS
No. 936

S11:. 5

\begin{tabular}{|c|c|c|}
\hline \multicolumn{3}{|l|}{ PART } \\
\hline Name & Number & Quan. \\
\hline $\mathrm{J}-\mathrm{BOX}$ & 4425 & 1 \\
\hline TERM. STRIP & 4425 & 1 \\
\hline PANEL & 4425 & 1 \\
\hline TERMIN. & 4425 & 4 \\
\hline FITTING & 4425 & 5 \\
\hline CIR. BRKR. & 4425 & \\
\hline CABLE & 4425 & 1 \\
\hline CABLE & 4425 & 1 \\
\hline OPTIC CABLE & 4425 & 1 \\
\hline TERMIN. & 4425 & 4 \\
\hline CONN. & 4425 & 1 \\
\hline CONN. & 4425 & 3 \\
\hline POWER SUPPLY/DISTRIB. & 4425 & 1 \\
\hline SUB TOTAL & 4425 & \\
\hline PRINTED CIR. BOARD & 4433 & 1 \\
\hline CONNECTOR & 4433 & 1 \\
\hline COMPUTER & 4433 & 1 \\
\hline DRIVER & 4433 & 2 \\
\hline RECEIVER & 4433 & 2 \\
\hline FLIP-FLOP & 4433 & 3 \\
\hline CAPACITOR & 4433 & 3 \\
\hline SUPPLY & 4433 & 1 \\
\hline CONN . & 4433 & 1 \\
\hline BOX & 4433 & 1 \\
\hline TRANS. & 4433 & 1 \\
\hline CONTROL/SIGNAL EQUIP. & 4433 & 1 \\
\hline SUB TOTAL & 4433 & \\
\hline PEDESTAL & 4451 & 1 \\
\hline CAP - END & 4451 & 1 \\
\hline COVER & 4451 & 1 \\
\hline SUPPORT STRUCTURE & 4451 & 1 \\
\hline GALV. PEDESTAL $\bar{\alpha}$ & & \\
\hline FOUNDATION CAP & & \\
\hline SUB TOTAL (P5) & 4451 & \\
\hline FOUNDATION CAP & 4451 & \\
\hline SUB T & 4451 & \\
\hline
\end{tabular}

\begin{tabular}{|c|c|c|c|c|c|c|c|c|c|c|}
\hline \multicolumn{4}{|c|}{ MATERIAL } & \multicolumn{4}{|c|}{ LABOR } & \multicolumn{2}{|c|}{ BURDC I } & \multirow{2}{*}{$\begin{array}{c}\text { COAL MFG. } \\
\text { COST }\end{array}$} \\
\hline Spec. & $\mathrm{HgI} / \mathrm{BM}$ & Price & $\cos 1$ & Depl. & IIIS./C.,BM & Ralc & CosI & Rate & 0.051 & \\
\hline $\mathbf{P}$ & & & 14.1400 & & $=$ & & $-=\ldots$ & & $-\ldots$ & 14.1400 \\
\hline $\mathbf{P}$ & & & .3800 & & $=$ & & - & & $\ldots$ & .3800 \\
\hline $\mathbf{P}$ & & & 2.0000 & & - & & $=-$ & {$[\cdots$} & $\ldots=\ldots$ & $-2.0000_{-}$ \\
\hline $\mathbf{P}$ & & & 19.0800 & & - & & $工$ & & $=\ldots$ & 19.0800 \\
\hline $\mathbf{P}$ & & & 71.3000 & & $=$ & & 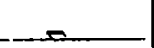 & & $\ldots \ldots \ldots$ & 71.3000 \\
\hline $\mathbf{P}$ & & & 28.000 & & - & & - & & - & 28.000 \\
\hline $\mathbf{P}$ & & & 1.6467 & & - & & - & & - & 1.6467 \\
\hline $\mathrm{P}$ & & & 1.6467 & & - & & - & & - & 1.6467 \\
\hline $\mathbf{P}$ & & & 2.9700 & & - & & - & & $-\therefore$ & 2.9700 \\
\hline$P$ & & & 5.8000 & & $=$ & & - & & $=$ & 5.8000 \\
\hline $\mathbf{P}$ & & & .4700 & & - & & $=$ & & - & .4700 \\
\hline \multirow[t]{3}{*}{$\mathbf{P}$} & & & 6.4500 & & & & & & & 6.4500 \\
\hline & & & - & $\mathrm{XXX}$ & 79.8003 & 7.41 & 5.9132 & 947 & 55.9980 & 61.9112 \\
\hline & & & 153.89 & & & & 5.91 & & 56.00 & 215.80 \\
\hline & & & & & & & & & & \\
\hline $\mathbf{P}$ & & & 5.6000 & & $=$ & & $=$ & & - & 5.6000 \\
\hline $\mathbf{P}$ & & & 1.6500 & & - & & $=$ & & $=$ & $1-6500$ \\
\hline $\mathbf{P}$ & & & 42.0000 & & - & & $=$ & & $r$ & .42 .0000 \\
\hline$P$ & & & 2.4000 & & $=$ & & $=$ & & 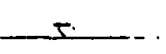 & 2.4000 \\
\hline P & & & 2.4000 & & - & & $=$ & & - & 2.4000 \\
\hline $\mathbf{P}$ & & & -1.6200 & & - & & $=$ & & - & 1.6200 \\
\hline $\mathbf{P}$ & & & .5700 & & $\tau$ & & $=$ & & $=$ & .5700 \\
\hline $\mathrm{P}$ & & & 34.3900 & & 5. & & - & & $=$ & 34.3900 \\
\hline $\mathbf{P}$ & & & 1.6500 & & $\mp$ & & - & & $=$ & 1.6500 \\
\hline$\underline{\mathbf{p}}$ & & & .5000 & & $\tau$ & & $=$ & & - & .5000 \\
\hline \multirow[t]{4}{*}{ P } & & & 30.000 & & - & & $=$ & & 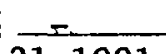 & 30.0000 \\
\hline & & & - & $\mathrm{XXX}$ & 30.6 .69 & 7.41 & 2.2281 & 947 & 21.1001 & 23.3282 \\
\hline & & & 122.78 & & & & 2.23 & & 21.10 & 146.11 \\
\hline & & & 6034001 & & - & & & & & $60.3 \overline{4007}$ \\
\hline \multirow{8}{*}{ p } & & & 46.8700 & & - & & $=$ & & $=$ & 168700 \\
\hline & & & 1.2000 & & - & & $r$ & & & 12000 \\
\hline & & & - & $\mathrm{XXX}$ & 18.741 & 7.41 & 1.3887 & 947 & 13.1510 & 14.5397 \\
\hline & & & & & & & & & & \\
\hline & - & & - & $X X X$ & 6.400 & 7.41 & .4742 & 947 & 4.4907 & 4.9649 \\
\hline & & & 108.41 & & & & 1.86 & & 17.64 & 127.91 \\
\hline & & & 39.66 & & & & & & & 39.66 \\
\hline & & & 148.07 & & & & 1.86 & & 5 & 167.57 \\
\hline
\end{tabular}

D16 
MATERIAL

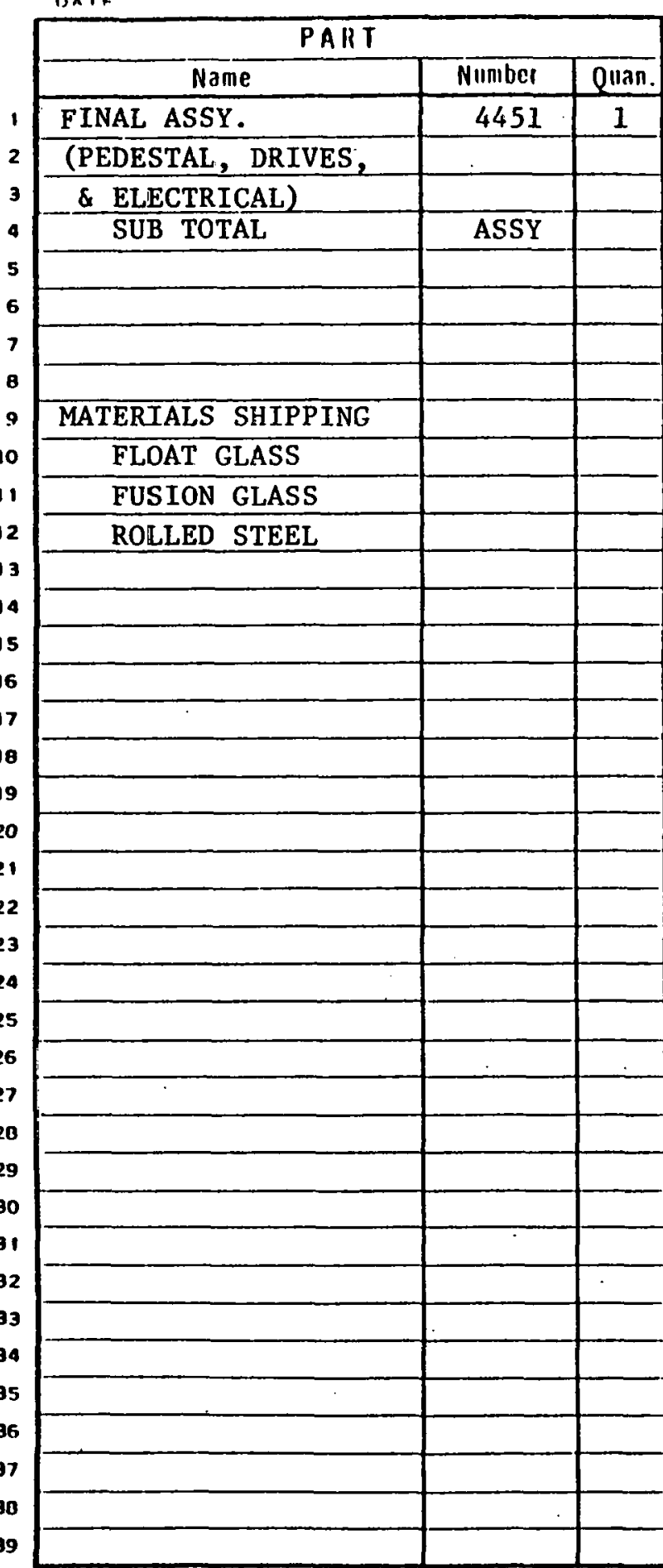

SwI t

‥ 6

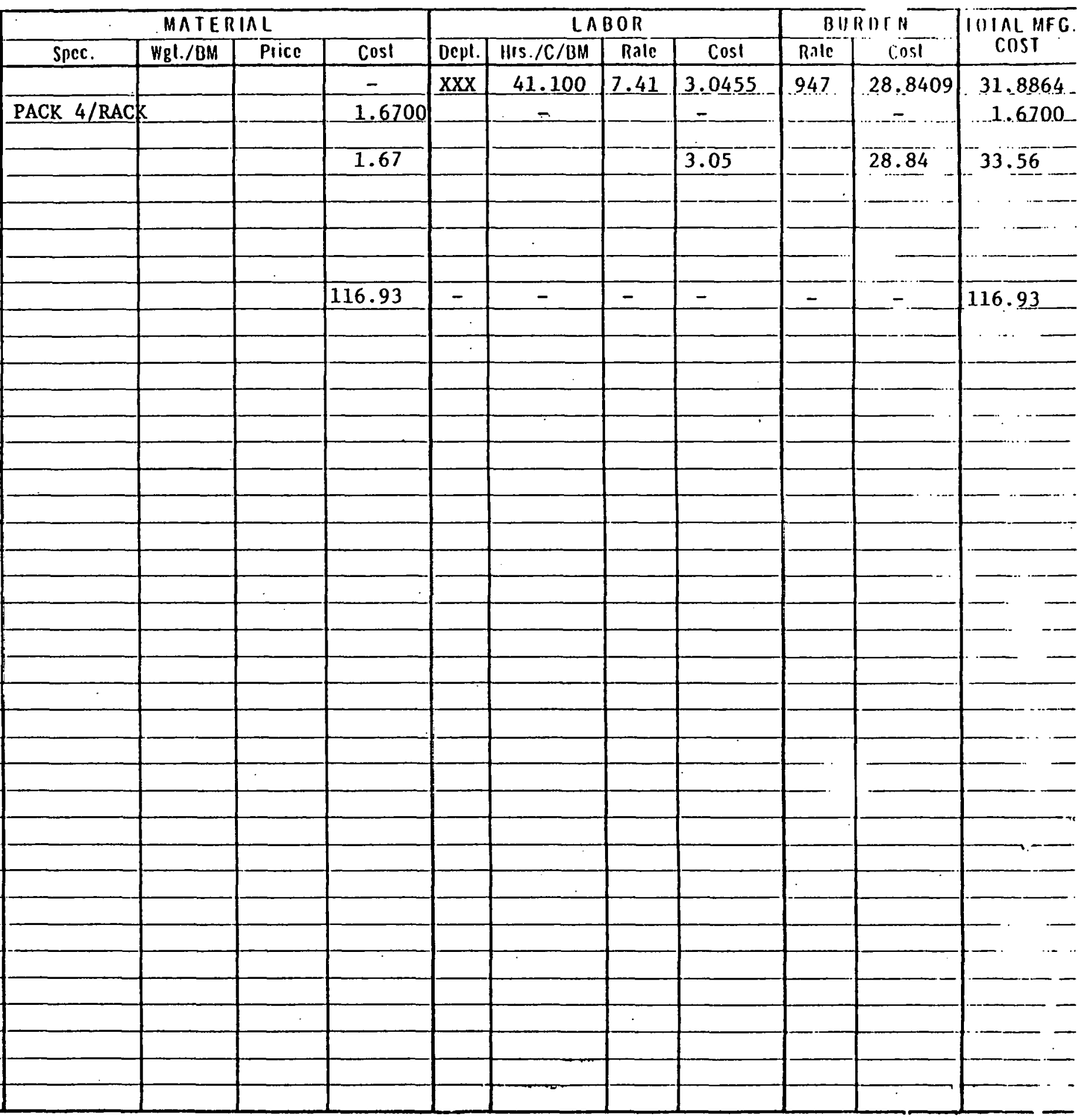


PRODUCT COST ESTIMATE - 250,000 ANNUAL VOLUME HELIOSTAT FOUNDATION CAP
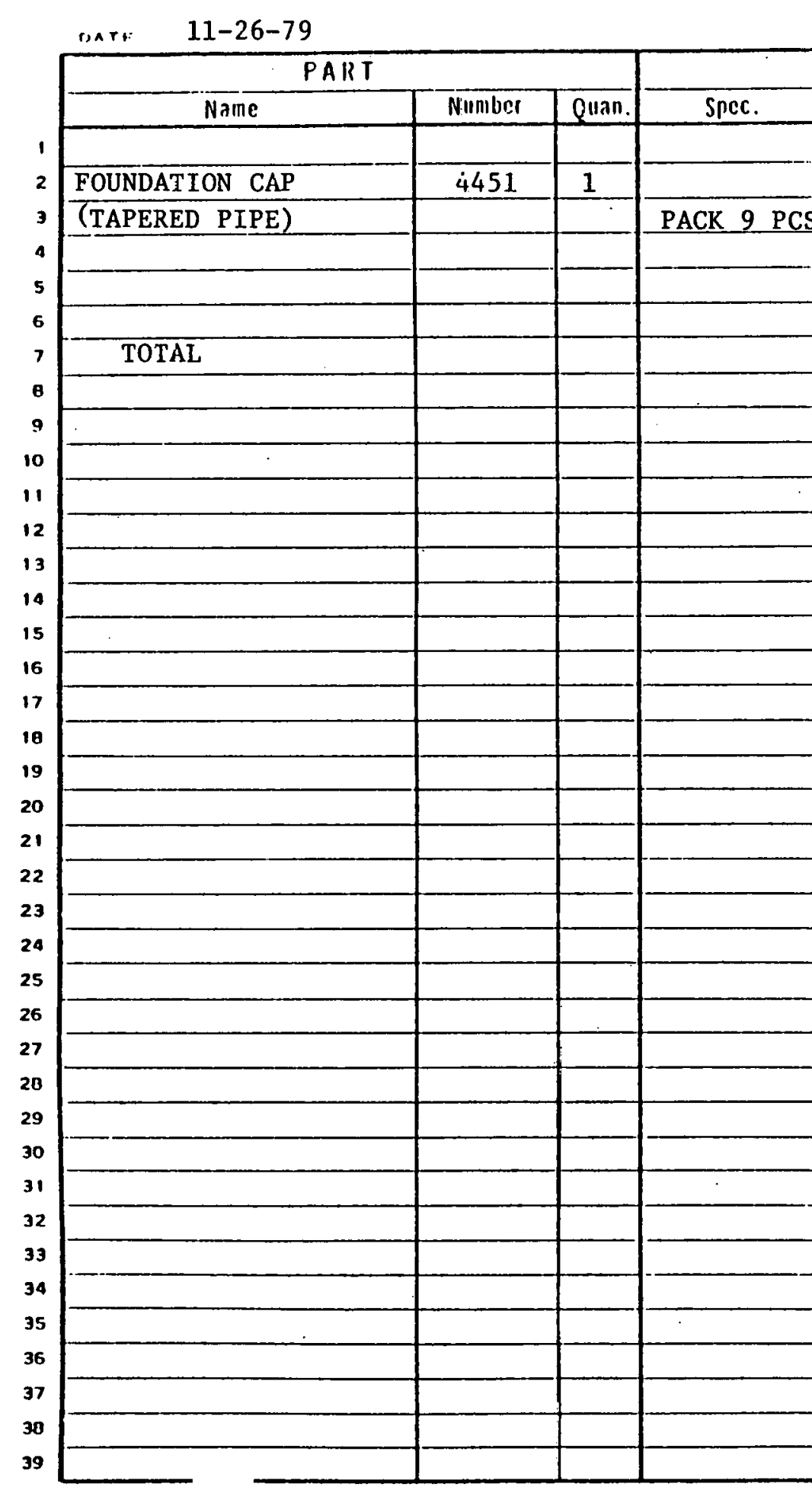

\section{MATERINL}

\section{LA.80R} \begin{tabular}{|l|l|}
\hline Mgl./BM & Price \\
\hline
\end{tabular}

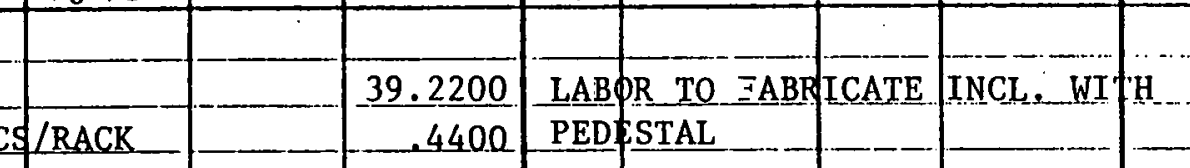

39.66

\begin{tabular}{l|l|l|l|}
\hline & & & \\
\hline & & 39.66 \\
\hline
\end{tabular}




\section{APPENDIX E \\ LABOR DEVELOPMENT}

This appendix is provided as an example so the reader can see the methodology by which the labor data was developed for the tool and labor routing sheets. 


\section{THIS PAGE}

\section{WAS INTENTIONALLY LEFT BLANK}


HOUSING - AZIMUTH DRIVE - (25,000\%YR)

\section{SUMMARY DATA}

\begin{tabular}{|c|c|c|c|c|c|c|}
\hline Oper.非 & Equip't. & $\begin{array}{l}\text { Shift } \\
\underline{0100 \%}\end{array}$ & $\begin{array}{c}\text { Day } \\
@ 100 \%\end{array}$ & $\begin{array}{ll} & \text { Day } \\
\text { Less } & \text { Downtime } \\
\end{array}$ & $\begin{array}{c}\text { Day } \\
\text { Less } \\
\text { Scrap @3\% } \\
\end{array}$ & Relief \\
\hline $20^{\circ}$ & 2. Mach's. & 80.15 & 160.30 & $152.29(@ 5 \%)$ & $147.72^{\circ}$ & $\begin{array}{l}\text { Personal, wash- } \\
\text { up \& lunch }\end{array}$ \\
\hline 30 & 3-Sta.in-1ine & 71.69 & 143.38 & $129.04(@ 10 \%)$ & $\cdot 125.17$ & Personal \\
\hline 40 & 4-Stá.in-line & 75.67 & 151.34 & $136.20(@ 10 \%)$ & 132.11 & Personal \\
\hline 50 & 4 Mach's. & 82.50 & 165.00 & $156.75(@ 5 \%)$ & $152.05^{*}$ & Personal \\
\hline OR & & & & & & \\
\hline $50 \mathrm{~A}$ & 5-Sta.in-1ine & 88.53 & 177.06 & $159.35(@ 10 \%)$ & 154.57 & Personal \\
\hline
\end{tabular}

* Recommend reduction of equipment from (4) to (3) machines, and fully relieve, including wash-up and lunch periods. This would provide a daily (less downtime and scrap) average output of $130 /$ day (da1ly average production volume for $25,000 / y r$. @ 104/day). 
HOUSING - AZIMUTH DRIVE - (25,000/YR)

OPERATION \#20 1 Operator/2 Machines (@ 732.2 Secs./Cycle Time at Machine)

Operation to be relieved for all personal, wash-up and lunch periods. This due to two princlpal reasons: (1) Long cycle time of operation;

(2) To bring production volume level up closer

to other operations on this part.

Additionally, if tool changes should be necessary the total output (with one mach. down per time) would not be reduced too drastically. Planned tool changes should be made at end of shift, through the period between shifts, and at the beginning of the 2nd shift (also at end of 2nd shift, when necessary).

AVAILABLE MACHINE OPERATING TIME/SHIFT (2 MACHS.)

Plus: Lunch Period of 30 Mins ( $x$ 2 Machs.)

Total Available Production Time

Less: Check Station for Tools, etc. at Startup ( $2 \times 5) 10$ Mins

Startup Mach. 非. (非 Down x 6.1)

Shutdown Mach. \#2 (非 Down $\times$ 6.1)

6.1 Mins

Cleanup at End of Shift (2 $\times 10$ Mins)

Available Machine Operating Time/Shift

6.1 Mins

20 Mins

42.2 Mins

\begin{tabular}{rr}
960 & Mins \\
60 & Mins \\
\hline 1,020 & Mins
\end{tabular}

SHIFT PRODUCTION ( $8 \mathrm{Hrs.} \mathrm{+} 30$ Mins Lunch)

$977.8 \mathrm{Mins} / \mathrm{Sh1ft} \div \frac{732.2 \mathrm{Secs} / \text { Cycle }}{60 \mathrm{Secs} / \mathrm{Min}}=80.15 \mathrm{PCS} /$ Shift

DAILY PRODUCTION ( $16 \mathrm{Hrs.}+2 \times 30$ Mins Lunch)
80.15 PCS/Shift $\times 2$ Shifts
$=160.30$ PCS $/ 2$ Shifts
Less: $5 \%$ Machine Downtime
$=152.29$
$3 \%$ Scrap Loss
$=147.72$ 
OPERATION \#30 1 Operator/3-Sta. Machine (@ 380 Secs./Machine Cycle)

Operation to be relieved for all personal time only. Normally this operation to be shut down for the washup-lunch period. During this shutdown and between shifts the equipment should be checked for tools quality, etc. to minimize downtime during planned operating time.

AVAILABLE MACHINE OPERATING TIME/SHIFT

Less: Check Station for Tools, etc. at Startup

480 Mins

1/2-Cycle Loss (Avg.) for. Lunch Shutdown

Mins Wash-up Before Lunch

1/2-Cycle Loss (Avg.) for End of Shift Shutdown Cleanup Work Area, Machine, etc. End of Shift Available Machine Operating Time/Shift

\begin{tabular}{rlr}
5 & Mins & \\
3 Mins & \\
5 Mins & \\
3 Mins & \\
10 Mins & 26 Mins \\
\hline
\end{tabular}

SHIFT PRODUCTION ( 8 Hrs.)

454 Mins/Shift $\div \frac{380 \text { Secs/Cycle }}{60 \text { Secs/Min }}=71.69$ PCS/Shift (8.96 PPH Avg.)

DAILY PRODUCTION (16 Hrs.)

$71.69 \mathrm{PCS} /$ Shift $\times 2$ Shifts

$=143.38$ PCS $/ 2$ Shifts

Less: $10 \%$ * Machine Downtime

$=129.04$

3\% Scrap Loss

$=125.17$

*In-LIne Machines Projected Downtime @ 10\% 
OPERATION \#40 1 Operator/4-Sta. Machine (@ 361 Secs./Machine Cycle).

Operation to be relleved for all personal time only. Normally this operation to be shut down for the washup-lunch period. During this shutdown and between shifts the equipment should be checked for tools quality, etc. to minimize downtime during planned operating time.

AVAILABLE MACHINE OPERATING TIME/SHIFT

Less: Check Station for Tools, etc. at Startup 1/2-Cycle Loss (Avg.) for Lunch Shutdown Wash-up Before Lunch

1/2-Cycle Loss (Avg.) at End of Shift -

Cleanup Work Area, Machine, etc. End of ShIft Available Machine Operating Time/Shift
5 Mins

3 Mins

5 Mins

3 Mins

480 Mins

10 Mins

26 Mins

SHIFT PRODUCTION (8.Hrs.)

$454 \mathrm{Mins} /$ Shift $\div \frac{360 \text { Secs/Cycle }}{60 \text { Secs/Min }}=75.67 \mathrm{PCS} /$ Shift (9.46 PPH Avg.)

DAILY PRODUCTION (16 Hrs.)

75.67 PCS/Shift $\times 2$ Shifts

$=151.34$ PCS $/ 2$ Shifts

Less: $10 \%$ * Machine Downtime

$=136.20$

3\% Serap Loss

a 132.11

*In-Line Machines Projected Machine Downtime e $10 \%$ 
HOUSING - AZIMUTH DRIVE - $(25,000 / Y R)$

OPERATION \#50 1 Operator/4 Machines - (1200 Secs. Cycle Time/Machine).

Operation to be relieved for all personal time only. Normally this operation to be shut down for the washup-lunch period. During this shutdown and between shifts the equipment should be checked for tools quality, etc. to minimize downtime during planned operating time.

AVAILABLE MACHINE OPERATING TIME/SHIFT ( $4 \times 480)$

Less: Check for Tools, etc. ( $4 \times 10 \mathrm{Mins})$

Startup \#1 Machine $(2,3 \& 4$ Down $x 5$ Mins)* 15 Mins

Startup \#2 Machine ( $3 \& 4$ Down x 5 Mins)* 10 Mins

Startup \#3 Machine ( 4 Down x 5 Mins)* 5 Mins

Shutdown for Washup-Lunch 30 Mins

I/2 of Machine Cycle Times Loss**(Average) 15 Mins

Washup ( $4 \times 5$ Mins) . 20 Mins

Startup After Lunch 30 Mins

Shutdown for End of Shift 30 Mins

$1 / 2$ of Machine Cycle Times Loss**(Average) 15 Mins

Cleanup ( $4 \times 15$ Mins) 60 Mins

Available Machine Operating Time/Shift $\quad 1650$ Mins

SHIFT PRODUCTION ( 8 Hrs.).

1650 Mins/Shift $\div \frac{1200 \text { Secs } / \text { Cycle }}{60 \text { Secs } / \text { Min }}=82.50 \mathrm{PCS} /$ Shift $(10.31 \mathrm{PPH})$

DAILY RRODUCTION ( 16 Hrs.)

82.50 PCS/Shift $\times 2$ Shifts

$=165.00 \mathrm{PCS} / 2$ Shifts

Less: 5\%** Machine Downtime

(Individusl Machines).

$=156.75$

$3 \% \quad$ Scrap Loss

$=152.05$

*Loss Due to Each Startup and Shutdown

**Individual Machinee Downtime Projected (f) 5\% 
HOUSING - AZIMUTH DRIVE - $(25,000 /$ YR $)$

OPERATION 50A 1 Operator/5-Sta. Machine (@ 305 Secs./Machine Cycle).

Operation to be relieved for all personal time only. Normally this operation to be shut down for the washup-lunch period. During this shutdown and between shifts the equipment should be checked for tools quality, etc. to minimize downtime during planned operating time.

AVAILABLE MACHINE OPERATING TIME/SHIFT

Less: C.heck Station for Tools, etc. at Starcup 1/2-Cycle Loss (Avg.) for Lunch Shutdown Washup Before Lunch

1/2-Cycle Loss (Avg.) for End of Shift Cleanup Work Area, Machines, etc. Available Machine Operating Time/Shift

480 Mins

5 . Mins

2.5 Mins

5 Mins

2.5 Mins

15 Mins

SHIFT PRODUCTION ( 8 Hrs.)

$450 \mathrm{Mins} /$ Shift $\div \frac{305 \mathrm{Secs} / \text { Cycle }}{60 \mathrm{Secs} / \mathrm{Min}}=88.53 \mathrm{PCS} /$ Shift (11.07)

DAILY PRODUCTION ( 8 HrS.)

88.53 PCS/Shift $\times 2$ Shifts

$=177.06$ PCS $/ 2$ Shifts

Less: $10 \%$ * Machine Downtime

$=159.35$

3\% Scrap Loss

$=154.37$

*In-Line Mạchines 10\% Downtime 
TAG RELIEF - For Continuous Operation - Lunch Shutdown

(2) Shutdown Relief @ 10 Mins

(3) Personal Reliefs $(9+9+8)$

Total Relief Operator for Personal

(5) Allowance for Walk to Relief Station @ 3 Mins

Total Relief Operator Time/Operator Relieved

20 Mins

26 Mins

46 Mins

15 Mins

61 Mins

Therefore:

Rellef operator can take own personal relief (46 minutes + washup) plus relieve total of (6) machine operators ( 7 hours only available due to policy of no relief 15 minutes after startup of shift, 15 minutes before and 15 minutes after lunch, and 15 minutes before shift end).

Relief calculated thus at $\frac{100 \%}{6 \text { oper. }}=16.7 \%$ Relief Allowance/Oper. Relieved (6 oper. @ 61 mins +51 mins for self +60 mins no relieve $=477$ mins $/$ shift)

TAG RELIEF - For Continuous Operation, Including Washup and Lunch

(2) Shutdown Relief (c 10 Mins

(3) Personal Relief $(9+9+8)$ Total Relief/Operator for Personal

(I) Relieve for Washup Before Lunch

(1) Relleve for Lunch Period

(6) Allowance for Walk to Relief Station @ 3 Mins Total Relief Operator Time/Operator Relieved
20 Mins

26 Mins

$\begin{array}{r}46 \text { Mins } \\ 5 \text { Mins } \\ 30 \text { Mins } \\ 18 \text { Mins } \\ \hline 99 \text { Mins }\end{array}$

Therefore:

Relief operator can take own personal relief (46 minutes +5 minutes washup) plus relieve maximum of (3) machine operators ( 7 hours only available - see above note). As this leaves a fair amount of time for "other" work relief calculation based on 3 operators a 99 minutes +51 minutes for self $=348$ mins. $\frac{348 \text { Mins. Rel. Time }}{480 \text { Mins. Avail. Time }}=72.5 \%$ Rel. $\div 3$ Operators Rel'd. $=24.2 \% /$ pperator. (480 Mins./Shift - 348 Mins. Relief Time = 132 Mins. Available for "other" work) 
EXPAND TIME INDICATED AT 45 SECOndS (of Total 120 Second Cycle)

Secs.

$0440 \quad 80120160260240280320360400440 \quad 480520560600$

MULTIPLE

MACHINE (2)

SETUP

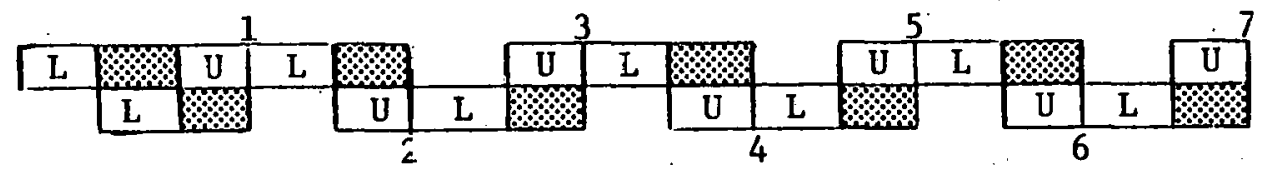

$$
\left.\begin{array}{l}
1 \& 2=\$ 1 \text { PCS } \\
72
\end{array}\right\} 1 \frac{1}{3} \text { mi }
$$

$$
\mathrm{L}=\text { Load } \quad \mathrm{U}=\text { Unload } \quad \text { Mach. Oper. T1me }
$$

$$
\begin{array}{ll}
\text { Startup } & 2 \times 5 \text { Mins: }=10 \\
\text { Washup } & 2 \times 5 \text { Mins. }=10
\end{array}
$$

$8 \mathrm{Hr} \cdot \operatorname{Sh} 1 \mathrm{ft}$

2 Mach. $x 480$ Mins. $=960$ Mins. Avail. $/ 2$ Mach.

-30 Mins.*

$=\underline{930 \text { Mins. }}=620 \div 8=77.5 \times 2$ Setups $=155$ Avallable/Haur Avg. (Req'd: 130/Hour Avg.)

$90 \mathrm{secs} / \mathrm{icycle}$

$60 \mathrm{secs} / \mathrm{min}$.

RECOMMEND

(2) Operators on (4) Vachines - (2 Bridge Cranes to Service Setups)

(1) Operator fcr Truck-Moving of Containers (Supply \& Fin'd. Parts), Relief, Trouble Shooter, Machines, $\in t c$.

( 3 Operators to Wc.rk as a Team)

Therefore: (4) Machires Required Instead of Indicated (5) Machines $(-\$ 80,000)$.

(2) Overhead Crane Monoralls Instead of (3) Indicated $(-\$ 20,000)$

RATE INFORMATION

155/Hours Available from (2) Operators Plus (1) Supply, Relief Operator (3 Operator Team)

Therefore: $\frac{155 \mathrm{PPH} \times 8 \mathrm{Hrs} / \mathrm{Sh1ft}}{3 \text { oper. } \times 8 \mathrm{Hrs} / \text { Sh1ft }}=51.67 \mathrm{PPH} /$ Operator

Due to Sone Time Losses Inherent in an Overlapping Cycle Operation Use: 50 PPH for Est. 
MANPOWER REQUIREMENTS @ 250,000/YEAR

\begin{tabular}{|l|c|l|l|l|l|}
\hline ZINC GALVANIZING (3 Systems) & OPERATORS & MAINTEN. & SWEEPERS & MAT'L. HDLRS. & TOTALS \\
\hline Azim. Hsg./Drag Link & $3+3=6$ & & $1+1=2$ & $1+1=2$ & $3+3=6$ \\
\hline Pedestal & $3+3=6$ & & & & $3+3=6$ \\
\hline Torque Tube Ass'y. & $3+3=6$ & & & & $3+3=6$ \\
\hline Gen'l. Area & $9+9=18$ & $\frac{1+1=2}{1+1=2}$ & $\frac{1+1=2}{1+1=2}$ & $\frac{1+1=2}{1+1=2}$ & $\frac{3+3=6}{12+12=24}$ \\
\hline
\end{tabular}


TOTAL HELIOSTAT

\begin{tabular}{|c|c|c|}
\hline $\begin{array}{l}\text { B/M } \\
4418 \text { ReflectIve Unit } \\
\quad \text { (\$4418 Not in } B / M)\end{array}$ & $\begin{array}{c}\frac{25 \mathrm{~K}}{(\mathrm{SH} / 100)} \\
-\end{array}$ & $\frac{250 \mathrm{~K}}{\frac{(\mathrm{SH} / 100)}{-}}$ \\
\hline 4411 Reflective Surface (Total for 12) & 95.808 & 47.460 \\
\hline 4412 M1rror Back Structure (Total for 2) & 30.400 & 30.400 \\
\hline 4413 Assembly \& Bond (Refl. Unit) (Total for 2) & 41.000 & 44.150 \\
\hline $\begin{array}{l}4420 \text { Drive Unit } \\
\text { (非420 Not in } B / M)\end{array}$ & - & - \\
\hline $\begin{aligned} & 44.21 \text { Azimuth } \text { (Azim. Dr. Ass'y.) } \\
& \text { (Azim. Hsg.-Galv.) } \\
& \text { (Bearing Retainer) } \\
& \text { (Clrcular Spline) } \\
& \text { (Drive Shaft) } \\
& \text { (Flex Spline) } \\
& \text { (Housing-Azim. Dr.) } \\
& \text { (Housing-Azim. Dr.-Weld) } \\
& \text { (Wave Generator) } \\
& \text { (Sub-total) }\end{aligned}$ & $\begin{array}{l}56.390 \\
- \\
31.590 \\
58.182 \\
\text { (Purch) } \\
45.058 \\
82.832 \\
\text { (Purch) } \\
27.435 \\
(301.487)\end{array}$ & $\begin{array}{r}16.238 \\
3.200 \\
39.238 \\
28.775 \\
7.787 \\
48.151 \\
18.364 \\
40.527 \\
29.240 \\
(231.520)\end{array}$ \\
\hline $\begin{aligned} 4422 \text { Elevation } & (\text { Drag Link-Elev. Dr.) } \\
& \text { (Elev.-Dr. Ass'y.) } \\
& \text { (Drag Link-Weld) } \\
& \text { (Drag Link-Galv.) } \\
& \text { (Main Beam Ass'y.) } \\
& \text { (Torque Tube-Elev. Dr.) } \\
& \text { (Torque Tube-Galv.) } \\
\text { (Sub-total) } & \end{aligned}$ & $\begin{array}{c}16.750 \\
59.000 \\
\text { (Purch) } \\
- \\
\text { (Purch) } \\
35.167 \\
- \\
(110.917)\end{array}$ & $\begin{array}{r}2.576 \\
40.000 \\
4.924 \\
3.200 \\
5.100 \\
2.788 \\
6.400 \\
(64.988)\end{array}$ \\
\hline 4423 Motor Total & 24.400 & 15.150 \\
\hline 4424 Position/Limlt Indicator & 22.718 & 19.984 \\
\hline 4425 Power Supply/Distribution & 92.839 & 79.672 \\
\hline $\begin{array}{l}4426 \text { Ass'y. Dr. / Pedestal/Electr. } \\
(\$ 4426 \text { Not in B/M) }\end{array}$ & - & - \\
\hline 4433 Control/Signal Eq't. & 37.454 & 30.069 \\
\hline $\begin{array}{l}4451 \text { Heliostat } \\
\text { Support Structure } \\
\text { (Pedestal \& Found. Cap.) } \\
\text { (Pedestal \& Taper Pipe-Galv.) } \\
\text { (Support Structure-Final) } \\
\text { (Sub-total) }\end{array}$ & $\begin{array}{l}\text { (Purch) } \\
- \\
\frac{41.900}{(41.900)}\end{array}$ & $\begin{array}{r}18.741 \\
6.400 \\
41.100 \\
(66.241)\end{array}$ \\
\hline TOTAL (Std. Hrs./100 Units) & 798.923 & 629.634 \\
\hline
\end{tabular}




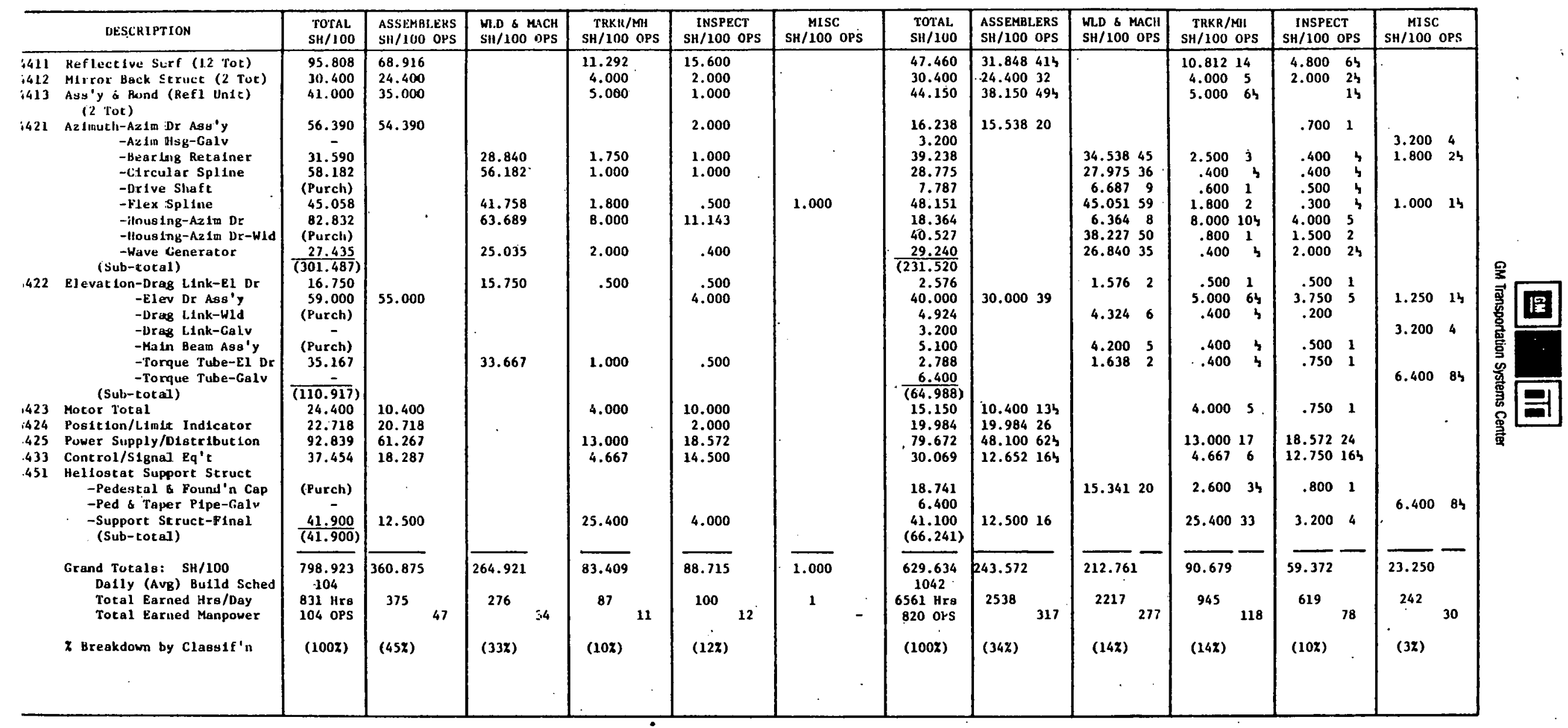




\begin{tabular}{|c|c|}
\hline \begin{tabular}{c|l|l}
$\begin{array}{c}\text { Document Control } \\
\text { Page }\end{array}$ & $\begin{array}{l}\text { 1. SERI Report No. } \\
\text { TR-8052-1 TR-8052-2 }\end{array}$ & 2. NTIS Accession No.
\end{tabular} & 3. Recipient's Accession No. \\
\hline 4. Title and Subtitle & $\begin{array}{l}\text { 5. Publication Date } \\
\text { December } 1979 \\
\end{array}$ \\
\hline \multicolumn{2}{|l|}{$\begin{array}{l}\text { TR-8052-1: Report } \\
\text { TR-8052-2: Executive Summary }\end{array}$} \\
\hline $\begin{array}{l}\text { 7. Author(s) J. F. Britt, C. W. Shulte: General Motors } \\
\text { H. L. Davey: F. Jos. Lamb Co. }\end{array}$ & $\begin{array}{l}\text { 8. Performing Organization Rept. No. } \\
\text { EP-79134 }\end{array}$ \\
\hline 9. Performing Organization Name and Address & 10. Project/Task/Work Unit No. \\
\hline $\begin{array}{l}\text { Transportation Systems Center } \\
\text { General Motors Corporation } \\
\text { Warren, Michigan } 48090\end{array}$ & $\begin{array}{l}\text { 11. Contract (C) or Grant (G) No. } \\
\text { (C) XL-9-8052--1 } \\
\text { (G) }\end{array}$ \\
\hline \multirow{2}{*}{$\begin{array}{l}\text { 12. Sponsoring Organization Name and Address } \\
\text { Solar Energy Research Institute } \\
1617 \text { Cole Blvd } \\
\text { Golden, Colorado } 80401\end{array}$} & $\begin{array}{l}\text { 13. Type of Report \& Period Covered } \\
\text { Final Technical Report }\end{array}$ \\
\hline & 14. \\
\hline \multicolumn{2}{|l|}{ 15. Supplementary Notes. } \\
\hline \multicolumn{2}{|l|}{ Project Manäger: Dennis Horgan } \\
\hline \multicolumn{2}{|c|}{$\begin{array}{l}\text { 16. Abstract (Limit: } 200 \text { words) } \\
\text { The primary objective of this study is to provide a factory cost for the production } \\
\text { of heliostats in terms of } 1979 \text { dollars. Factory cost is defined as the sum of all } \\
\text { direct labor, direct material and burden expenses that are incurred in the manufacture } \\
\text { of a heliostat, and its packaging for shipment. Transportation, installation, taxes } \\
\text { other than plant real taxes, profit, selling expenses, and all other profit and loss } \\
\text { items are not included. Two production volumes are considered, } 25,000 \text { heliostat units } \\
\text { per year and } 250,000 \text { heliostat units per year. } \\
\text { The s sudy concluded that the factoyy cost to manufacture heliostats is } \$ 95.99 / \mathrm{m}^{2} \text { at } \\
25,0 \text { units per year and } \$ 67.95 / \mathrm{m}^{2} \text { at } 250,000 \text { units per year. The Policy Analysis } \\
\text { Branch of, the } S o l a r \text { Energy Research Institute estimates that this implies an installed } \\
\text { price of } \$ 122.12 / \mathrm{m}^{2} \text { at the } 25,000 \text { unit-per-year volume. }\end{array}$} \\
\hline
\end{tabular}

\section{Document Analysis}

a. Descriptors Heliostats; Cost; Design; Specifications; Production; Components; Technolog Assessment; Mirrors; Reflective Surfaces; Manufacturing; Solar Tracking; Control Equipf ment; Industrial Plants; Site Selection

b. Identifiers/Open-Ended Terms

\section{c. UC Categorles}

$$
62 c, 64 c
$$

18. Availability Statement

National Technical Information Service (NTIS)

U. S. Department of Commerce

5285 Port Royal Road

Springfield, Virginia 22161 